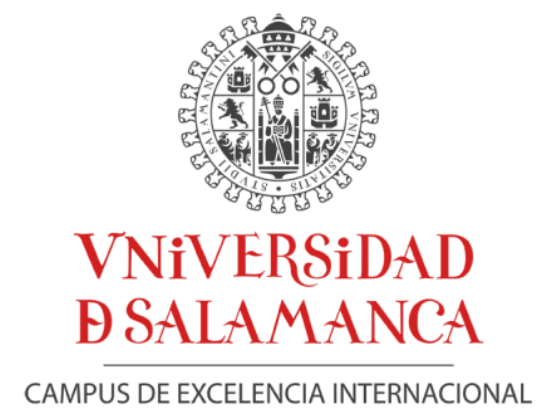
INSTITUTO UNIVERSITARIO DE CIENCIAS DE LA EDUCACIÓN PROGRAMA DE DOCTORADO FORMACIÓN EN LA SOCIEDAD DEL CONOCIMIENTO
(RD 99/2011)

TESIS DOCTORAL

\title{
MODELO DE REALIDAD AUMENTADA Y NAVEGACIÓN PEATONAL DEL PATRIMONIO TERRITORIAL: DISEÑO, IMPLEMENTACIÓN Y EVALUACIÓN EDUCATIVA
}

Autor: Jorge Cristián Joo Nagata

Directores: Dr. José Rafael García-Bermejo Giner

Dr. Fernando Martínez Abad

Salamanca, 2016 

INSTITUTO UNIVERSITARIO DE CIENCIAS DE LA EDUCACIÓN PROGRAMA DE DOCTORADO: FORMACIÓN EN LA SOCIEDAD DEL CONOCIMIENTO (RD 99/2011) Área de Métodos de Investigación y Diagnóstico en Educación

Dr. José Rafael García-Bermejo Giner, Profesor Titular de Universidad, en el Departamento de Informática y Automática de la Universidad de Salamanca, y Dr. Fernando Martínez Abad, Profesor Ayudante en el Departamento de Métodos de Investigación y Diagnóstico en Educación de la Universidad de Salamanca, en calidad de directores del trabajo de Tesis Doctoral titulado: "Modelo de Realidad Aumentada y Navegación Peatonal del Patrimonio Territorial: diseño, implementación y evaluación educativa", realizada por Don Jorge Cristián Joo Nagata,

HACEN CONSTAR que dicho trabajo alcanza, bajo nuestro punto de vista, todos los requisitos científicos y formales para ser presentado y defendido públicamente. La investigación indaga sobre un problema relevante en investigación educativa y presenta un grado alto de innovación. El proceso metodológico seleccionado resulta adecuado a los objetivos e hipótesis planteadas y la discusión es completa y relacionada con una actualizada fundamentación teórica. Presenta una contextualización adecuada, un riguroso procedimiento de obtención y análisis de datos y una extracción de conclusiones valiosas para el área de conocimiento en el que está inmerso.

Por todo ello, manifestamos nuestro acuerdo para que sea autorizada la presentación y defensa del trabajo referido

En Salamanca, a 25 de Mayo de 2016
Dr. José Rafael García-Bermejo Giner
Dr. Fernando Martínez Abad 



\section{AGRADECIMIENTOS}

Tanto tiempo de trabajo, de estudio, de aprendizajes y de búsqueda de saberes, se sintetizan en esta Tesis Doctoral, la que ha tenido el apoyo de muchas personas, que, a lo largo de este tiempo, me han otorgado su ayuda para que esta tarea pueda salir adelante. Es difícil poder mencionar en tan pocas líneas a todas las personas que han estado conmigo en este proceso. Espero no olvidar a nadie, situación que suele ocurrir en estas etapas finales, en los que uno quiere dar la importancia debida a todos los que ha sido parte de proceso de crecimiento personal. Los tengo a todos en mente, pero sepan que si hago una omisión involuntaria, va para ustedes, mi gran y sincero agradecimiento.

En un primer lugar, quisiera agradecer a los Directores de esta Tesis Doctoral, el Dr. José Rafael García-Bermejo Giner y el Dr. Fernando Martínez Abad quienes creyeron en mí y en la posibilidad de que esta idea extraña pudiera llegar a buen puerto, aportando cada uno desde su especialidad, importantes elementos para descubrir cosas nuevas. Con ambos aprendí que el conocimiento es algo muy complejo e infinito, pero cuando te guían y apoyan, los caminos se clarifican.

Mis agradecimientos a mi familia: mis padres Jorge y María, mi tía Sumires, mis hermanos y sus familias por su constante interés y cariño. De manera particular, va el agradecimiento a mi hermano Davis que ha sido un apoyo desde el rigor que impone la lejanía.

También, muchos amigos se han hecho presentes de manera incondicional, con sus consejos, conversaciones o el simplemente compartir una conversación con un café:

A mis amigos Patricio Cabrera y Carmen Salas que han sido parte de este proceso y han podido participar en él. A Voltaire Alvarado P., quien el destino le está guiando por un camino similar al que yo he realizado, en donde el destino parece ser la complejidad de las cosas.

A la gente de la UAHC, particularmente a Marcelo Garrido y Ulises Sepúlveda, con sus importantes apoyos y concejos en un ámbito que ha estado caracterizado por el descubrimiento constante y las nuevas formas de ver la realidad. 
A la gente del CFV de la Universidad Metropolitana de Ciencias de la Educación, especialmente Karina Guerra, quienes siempre me han acogido en este pequeño universo que significa la educación en estos contextos de tecnología.

A la gente de Salamanca, ciudad que es ahora parte de mi historia de vida, y que con estas personas, sentí como si fuera mi hogar: Paloma No Gutiérrez, Charo de Castro, Charo Peralta, Azucena Peláez, Jessica Venegas, Fermín González y María Paz. Su amistad y generosidad hicieron mucho más fácil mi estadía en esta nueva ciudad.

A los Profesores Dr. Francisco García-Peñalvo y Dra. María Jesús Rodríguez quienes desde el periodo de Máster TIC me han ayudado en diversos puntos del ámbito académico.

Finalmente quiero hacer un especial agradecimiento a la Facultad de Historia, Geografía y Letras de la Universidad Metropolitana de Ciencias de la Educación, que con su proyecto MECESUP UMC0803 "Mejoramiento de la docencia y el aprendizaje a través de la incorporación de estrategias metodológicas TIC, con el fin de fortalecer el currículum en la formación inicial docente en la Universidad Metropolitana de Ciencias de la Educación (FID-UMCE, Chile)", me entregaron su apoyo económico para poder realizar la presente investigación.

Mi profundo agradecimiento se encuentra con Ustedes. 




\section{Índice de contenidos}

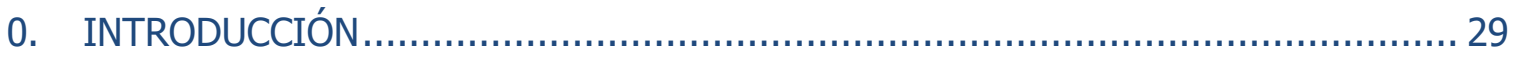

1. REALIDAD AUMENTADA EN EDUCACIÓN: UN ESCENARIO ILUSTRATIVO ...............35

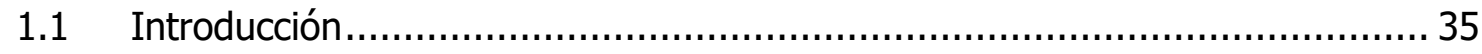

1.2 Marco conceptual de la Realidad Aumentada............................................. 35

$1.3 \quad$ Historia del concepto y su desarrollo tecnológico …...................................... 36

1.4 De la Realidad Combinada a la Realidad Virtual ........................................4 43

$1.5 \quad$ Funcionamiento de un sistema de RA .................................................... 44

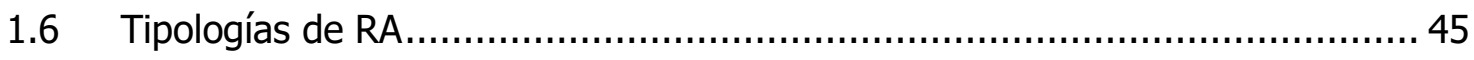

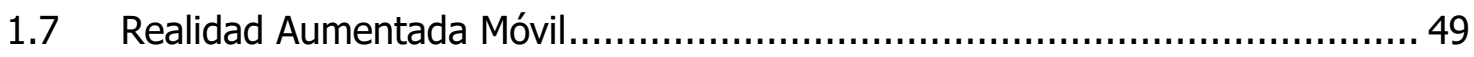

1.8 Educación y Realidad Aumentada ....................................................... 52

1.8.1 Aprendizaje móvil (m-learning) y RA...........................................5 53

1.8.2 Aprendizaje Situado (u-learning) y RA.............................................5 54

1.8.3 Elementos que deben estar presentes en el diseño de actividades de

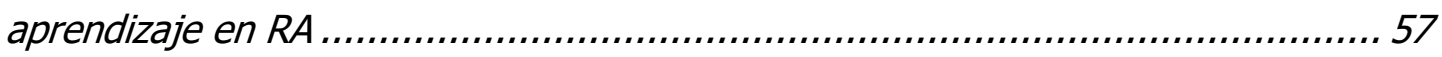

1.8.4 Experiencias sobre RA y Educación..............................................5 58

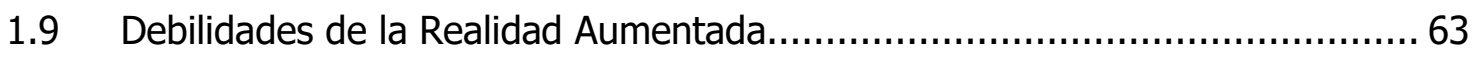

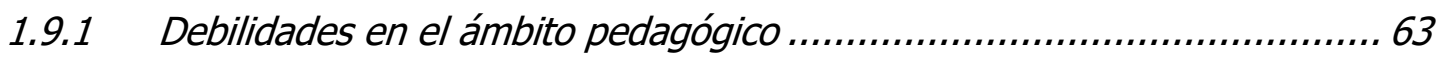

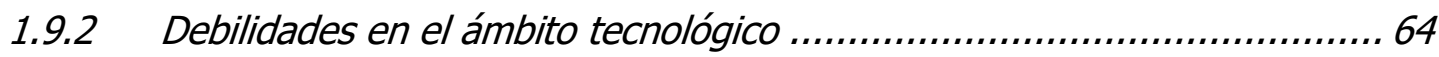

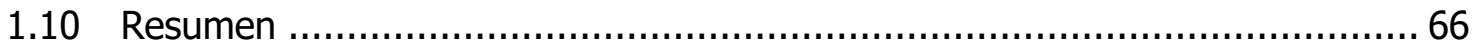

2. APLICACIÓN DE LOS DISPOSITIVOS MÓVILES A LA NAVEGACIÓN PEATONAL, GEOTECNOLOGÍA, REPRESENTACIÓN TERRITORIAL Y CONTEXTOS EDUCATIVOS ..... 69

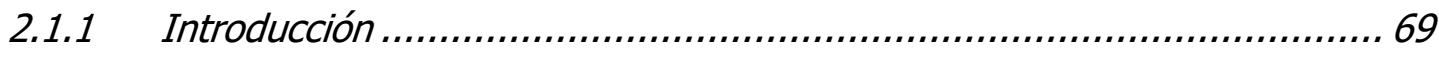


2.2 Modelamiento y análisis del territorio a través de diferentes técnicas de representación y abstracción ................................................................. 72

2.2.1 Mapas, cartas y planos .......................................................... 73

2.2.2 Otras formas de representación y observación de la superficie terrestre.. 77

2.2.3 Elementos relativos a la representación.............................................83 83

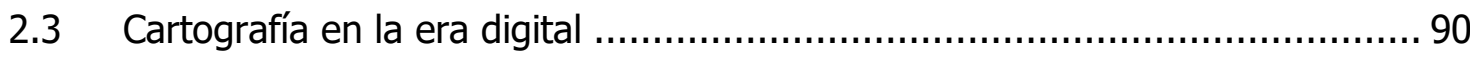

2.4 El contexto de las geotecnologías............................................... 92

2.5 Los mapas en un contexto de movilidad ............................................. 94

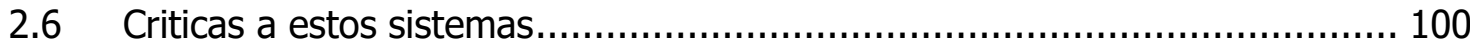

2.7 La representación de la Tierra como elemento didáctico en la enseñanza .... 101

2.7.1 Inteligencia espacial .......................................................... 102

2.7.2 Aprendizaje con aplicaciones geotecnológicas................................. 104

2.7.3 Experiencias sobre Geotecnologías y Educación ............................... 107

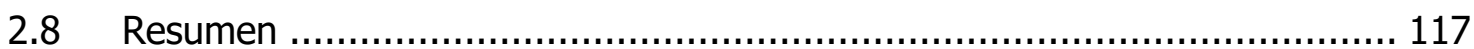

3. CONTEXTO SOCIAL DE LA TECNOLOGÍA EN LOS PROCESOS EDUCATIVOS ........ 121

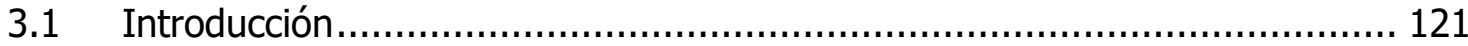

3.2 Sociedad, complejidad y TIC: estableciendo un escenario....................... 123

3.2.1 Sociedad del Conocimiento frente a una Sociedad de la Información .... 123

3.2.2 Precauciones en torno a esta Sociedad del Conocimiento, en un contexto de aprendizaje..... 124

3.2.3 Cuando la información se convierte en saber 126

3.2.4 La apuesta de la educación en la Sociedad del Conocimiento. De la implementación de los datos al creación de políticas del saber 126 
3.2.6 Situación en España

3.3 Difusión de las innovaciones, adopción de tecnologías y su impacto en los recursos dirigidos a la educación

3.3.1 La Sociedad del Conocimiento tiene como base la modernidad líquida .. 133

3.3.2 Difusión de las innovaciones.................................................. 134

3.3.3 Los Ciclos de Exceso de Expectativas (overexpectation)...................... 138

3.4 Modernidad líquida en la educación. Contexto teórico de la tecnología en la enseñanza

3.4.1 Comprendiendo e implementando la complejidad de un proceso: Modelo Technological PedAgogical Content Knowledge

3.4.2 Un modelo que se surge de la Informática y que se transfiere a la Educación: los Objetos de Aprendizaje. 151

3.5 Resumen 156

4. MARCO METODOLÓGICO Y DISEÑO DE LA INVESTIGACIÓN. 161

4.1 Introducción 161

4.2 Objetivos e hipótesis de la investigación 162

4.3 Delimitación de los contextos territoriales mediante el patrimonio. 165

4.3.1 Obtención de datos base para la delimitación territorial-patrimonial...... 165

4.3.2 Metodología de análisis espacial utilizadas 171

4.4 Fase de desarrollo e implementación de software NPM-RA 181

4.4.1 Elicitación de requisitos para el desarrollo de la investigación 183

4.4.2 Análisis de requisitos o especificación de requisitos de software 187

4.4.3 Diseño del software. 194 
4.4.4 Implementación

4.4.5 Verificación ....................................................................... 197

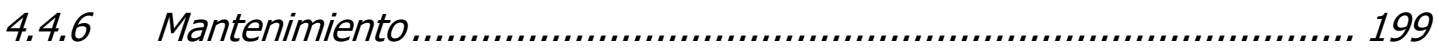

4.5 Marco metodológico de la experiencia educativa: fase cuantitativa.............. 199

4.5.1 Diseño de la investigación. Estudio Experimental ............................... 199

4.5.2 Variables e instrumentos......................................................... 201

4.5.3 Descripción del tratamiento...................................................... 207

4.5.3.1 Utilización de tablets en el trabajo de campo (m-learning/u-learning). 208

4.5.3.2 Utilización de ordenadores con enseñanza tradicional (e-learning). 211

4.5.4 Fiabilidad y validez de los instrumentos de medición ........................... 214

4.5.4.1 Diseño del instrumento ................................................... 215

4.5.4.2 Validez de las escalas........................................................... 216

4.5.4.3 Análisis de ítems............................................................. 221

4.5.5 Población y muestra. Estudio cuasiexperimental............................. 231

4.5.6 Análisis de los datos ............................................................. 234

4.6 Marco metodológico de la experiencia educativa: fase cualitativa ............... 236

4.6.1 Contexto metodológico cualitativo de la entrevista ............................. 238

4.6.2 Grado de estructuración y finalidad de la entrevista aplicada................ 239

4.6.3 Número de participantes en el proceso de entrevistas ....................... 243

4.6.4 Técnicas de análisis de los datos obtenidos ................................... 244

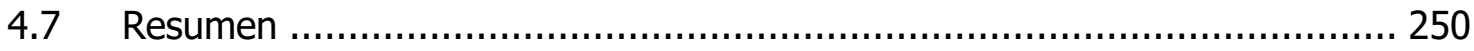

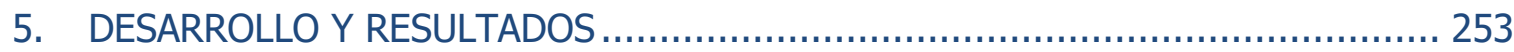

$5.1 \quad$ Modelos de desplazamiento territorial ............................................... 253 
5.1.2 Determinación de áreas de servicios en función del tiempo. 257

5.2 Software NPM-RA 265

5.2.1 Aplicación Santiago Patrimonial (AR-NPM 1.0) ............................... 268

5.2.2 Aplicación Salamanca Patrimonial (AR-NPM 2.0) ............................. 274

5.3 Resultados de la fase cuantitativa de la experiencia educativa .................. 279

5.3.1 Estudio exploratorio de las variables .......................................... 279

5.3.1.1 Pre-Test: Análisis gráfico con los constructos totales de cada experiencia 279

5.3.1.2 Pre-Test: Análisis estadístico básico y contrastes de normalidad según

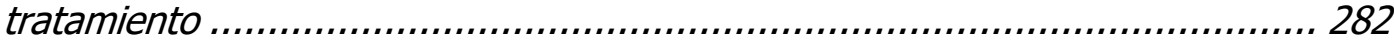

5.3.1.3 Post-Test: Análisis gráfico con los constructos totales de cada experiencia 285

5.3.1.4 Post-Test: Análisis estadístico básico y contrastes de normalidad según

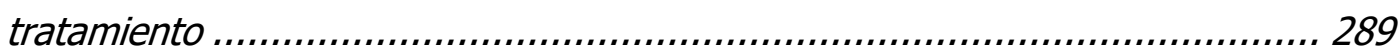

5.3.1.5 Pre-Test: Análisis gráfico de las distribuciones por ítem................. 292

5.3.1.6 Pre-Test: Análisis estadístico básico y contrastes de normalidad según ítem $\quad 300$

5.3.1.7 Post-Test: Análisis gráfico de las distribuciones por ítem .............. 307

5.3.1.8 Post-Test: Análisis estadístico básico y contrastes de normalidad según ítem 314

5.3.2 Diferencias Pre-Test y Post-Test. Aplicación de los contrastes de hipótesis 322

5.3.2.1 Resultados de los contrastes de hipótesis para Chile .................... 327

5.3.2.2 Resultados de los contrastes de hipótesis para España................. 336

5.3.2.3 Diferencias Pre-Test/Post. Análisis gráfico................................ 343

5.3.3 Escala de satisfacción de las experiencias educativas......................... 354 
5.4 Contexto cualitativo de las experiencias educativas realizadas 359

5.4.1 Análisis de los datos obtenidos de los docentes................................. 359

5.4.2 Análisis de los datos obtenidos de los alumnos ............................... 372

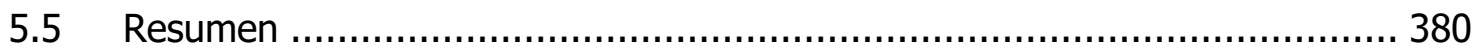

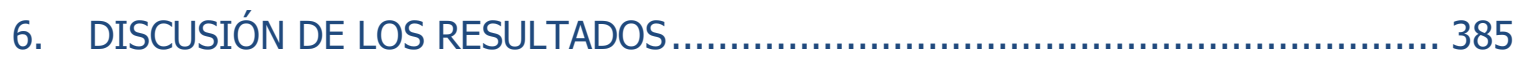

6.1 Discusión en torno al marco teórico.............................................. 385

6.1.1 Realidad aumentada: más que una extensión visual de la realidad ....... 386

6.1.2 Geotecnología en la escala local con contenidos personalizables........... 389

6.1.3 Dimensión social y educativa en torno a estas herramientas ............... 392

6.2 Discusión de los resultados ................................................... 396

6.2.1 Contexto patrimonial y territorial ............................................. 396

6.2.2 Desarrollo informático......................................................... 398

6.2.3 Dimensión Cuantitativa ............................................................... 399

6.2.4 Dimensión cualitativa............................................................ 402

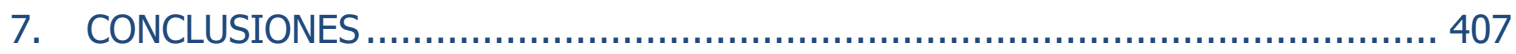

7.1 Conclusiones desde los aspectos teóricos y empíricos .......................... 407

7.2 Aspectos perfectibles de la investigación...................................... 414

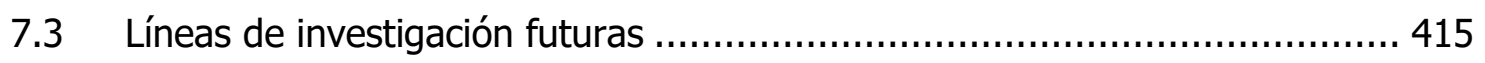

7.4 Publicaciones vinculadas a la Tesis Doctoral ..................................... 416

7.4.1 Artículos en revistas científicas ................................................. 416

7.4.2 Capítulo de libro en obras colectivas .......................................... 417

7.4.3 Contribuciones en congresos................................................4 417 


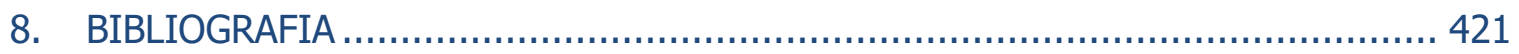

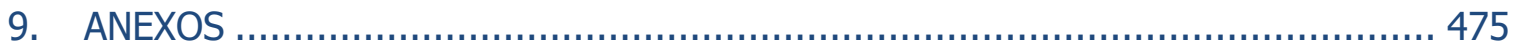




\section{Índice de tablas}

Tabla 1.1 Comparación de contextos de aprendizaje m-learning y u-learning (Hwang et

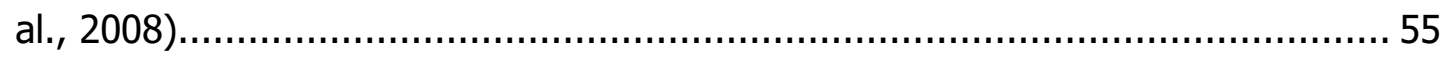

Tabla 1.2: Taxonomía inicial de RA aplicada a la Educación en experiencias españolas

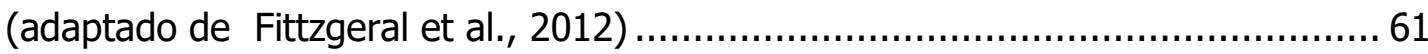

Tabla 1.3: Taxonomía inicial de RA aplicada a la Educación en experiencias latinoamericanas (adaptado de FitzGerald et al., 2012).................................62 62

Tabla 2.1 Globos Terráqueos Virtuales y sus características ............................... 78

Tabla 2.2 Propiedades y representaciones de los elementos geométricos.................. 87

Tabla 2.3 Escalas tempo-espaciales (Joly, 1982).............................................. 89

Tabla 2.4 Tipos de datos y ejemplos con información geoespacial ............................ 93

Tabla 2.5 Acciones básicas espaciales utilizadas en contexto de movilidad (Reichenbacher,

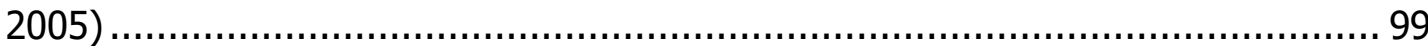

Tabla 2.6 Competencias planteadas en la utilización de TIC para el estudio del territorio. Basado en Ehlers (2008); Boix y Olivella (2007); Rød, Larsen, y Nilsen (2010); De Miguel González (2014) . ............................................................. 106

Tabla 2.7 Taxonomía inicial de geotecnologías aplicadas a la Educación: experiencias españolas 109

Tabla 2.8 Taxonomía inicial de geotecnologías aplicada a la Educación: experiencias latinoamericanas 110

Tabla 4.1 Datos territoriales para Santiago de Chile .......................................... 166

Tabla 4.2 Datos territoriales para Salamanca (España) ...................................... 166

Tabla 4.3 Elementos utilizados para la selección de elementos patrimoniales ............ 168

Tabla 4.4 Variables utilizadas en la evaluación EMC .......................................... 172

Tabla 4.5 Resumen de los valores ECM por ruta. Santiago de Chile ......................... 176

Tabla 4.6 Resumen de los valores ECM por ruta. Salamanca (España).................... 176

Tabla 4.7 Comparación de SDK de Realidad Aumentada.................................... 188

Tabla 4.8 Comparación de servicios de mapas en línea ...................................... 192

Tabla 4.9 Frameworks para la implementación de la aplicación NPM-RA ................... 194

Tabla 4.10 Diseño cuasiexperimental pre-test/post-test con grupo experimental (Aplicación móvil) y grupo control (Ordenador de escritorio) ........................... 200

Tabla 4.11 Especificaciones para el instrumento de evaluación. Experiencia de Santiago de Chile 204 
Tabla 4.12 Especificaciones para el instrumento de evaluación. Experiencia de Salamanca 205

Tabla 4.13 Especificaciones para la encuesta de satisfacción ................................ 207

Tabla 4.14 Contenidos para cada intervención educativa ..................................... 209

Tabla 4.15 Clasificación dificultad de ítems (Pomés \& Argüelles, 1991) .................... 221

Tabla 4.16 Índice de dificultad para la intervención educativa en Chile $(n=145)$...... 222

Tabla 4.17 Índice de dificultad para la intervención educativa en España $(n=33) \ldots 223$

Tabla 4.18 Clasificación de discriminación de ítems (Pomés \& Argüelles, 1991) ......... 224

Tabla 4.19 Índice de discriminación prueba objetiva aplicada en Chile..................... 225

Tabla 4.20 Índice de discriminación prueba aplicada en España ............................. 227

Tabla 4.21 Correlación biserial puntual para la prueba objetiva aplicada en Chile....... 229

Tabla 4.22 Correlación biserial puntual para la prueba objetiva aplicada en España ... 230

Tabla 4.23 Distribución de población y muestra de alumnos de 70 EGB Chile. ........... 232

Tabla 4.24 Distribución de población y muestra de alumnos de $8^{\circ}$ EGB Chile ............ 232

Tabla 4.25 Distribución de población y muestra de alumnos de $1^{\circ}$ y $2^{\circ}$ de ESO España

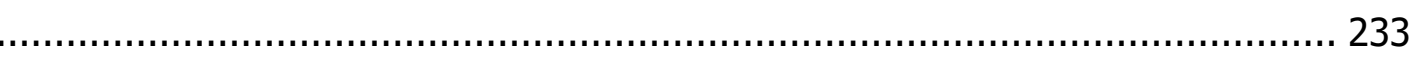

Tabla 4.26 Las siete etapas de la investigación con entrevistas ........................... 239

Tabla 4.27 Preguntas realizadas a los profesores/docentes.............................. 240

Tabla 4.28 Preguntas realizadas a los alumnos .............................................. 241

Tabla 4.29 Sistema de categorías utilizadas en la entrevista para los docentes .......... 246

Tabla 4.30 Sistema de categorías utilizadas en la entrevista para los alumnos ........... 248

Tabla 5.1 Magnitudes de los modelos de desplazamiento peatonal y patrimonial ....... 257

Tabla 5.2 Cantidad de registros (puntos) por experiencia desarrollada con iPad ......... 260

Tabla 5.3 Tiempo modelado y observado para las rutas definidas .......................... 264

Tabla 5.4 Elementos del proyecto para cada aplicación ...................................... 268

Tabla 5.5 Escenas de la aplicación Santiago Patrimonial (AR-NPM 1.0) .................... 269

Tabla 5.6 Escenas de la aplicación Salamanca Patrimonial (AR-NPM 2.0) ................. 274

Tabla 5.7 Pre-Test. Exploración de estadísticos básicos ...................................... 283

Tabla 5.8 Test de normalidad de Kolmogorov-Smirnov Pre-Test............................. 285

Tabla 5.9 Post-Test. Exploración de estadísticos básicos.................................... 290

Tabla 5.10 Test de normalidad de Kolmogorov-Smirnov Post-Test........................... 292

Tabla 5.11 Pre-test Chile. Exploración de estadísticos básicos para las puntuaciones T

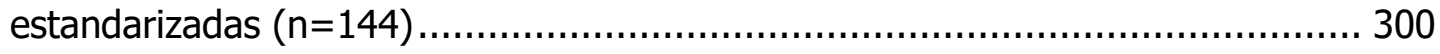

Tabla 5.12 Pre-test Chile. Exploración de estadísticos básicos para las puntuaciones $\mathrm{T}$

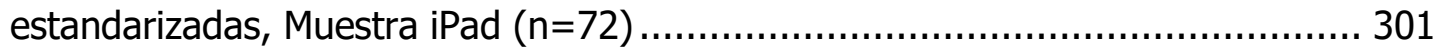


Tabla 5.13 Pre-test Chile. Exploración de estadísticos básicos para las puntuaciones T

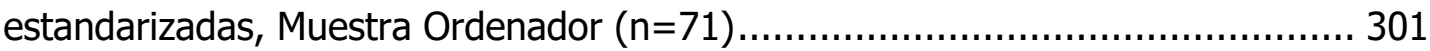

Tabla 5.14 Test de normalidad de Kolmogorov-Smirnov Pre-Test. Caso de Chile $(n=144)$ 305

Tabla 5.15 Test de normalidad de Kolmogorov-Smirnov Pre-Test. Caso de Chile, iPad $(n=72)$ 306

Tabla 5.16 Test de normalidad de Kolmogorov-Smirnov Pre-Test. Caso de Chile, Ordenador $(n=71)$ 306

Tabla 5.17 Post-Test Chile. Exploración de estadísticos básicos para las puntuaciones T estandarizadas $(n=144)$ 314

Tabla 5.18 Post-Test Chile. Exploración de estadísticos básicos para las puntuaciones T

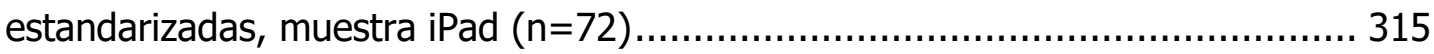

Tabla 5.19 Post-Test Chile. Exposición de resultados estadísticos básicos para las puntuaciones T estandarizadas, muestra Ordenador $(n=71) \ldots \ldots \ldots \ldots \ldots \ldots \ldots \ldots . \ldots \ldots \ldots$

Tabla 5.20 Test de normalidad de Kolmogorov-Smirnov Post-Test. Caso de Chile $(n=144)$ 320

Tabla 5.21 Test de normalidad de Kolmogorov-Smirnov Post-Test. Caso de Chile,

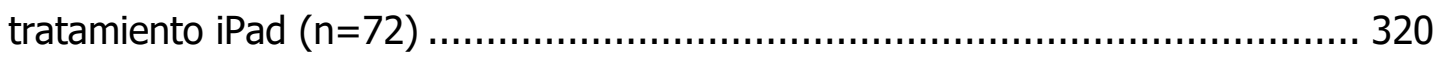

Tabla 5.22 Test de normalidad de Kolmogorov-Smirnov Post-Test. Caso de Chile, tratamiento Ordenador $(n=71)$

Tabla 5.23 Estadísticos básicos y diferencia de medias Pre-Test - Post-Test, constructos totales.

Tabla 5.24 Estadísticos básicos y diferencia de medias Pre-Test - Post-Test. Caso de Chile 323

Tabla 5.25 Estadísticos básicos y diferencia de medias Pre-Test - Post-Test. Caso de Chile, tratamiento iPad. 324

Tabla 5.26 Estadísticos básicos y diferencia de medias Pre-Test - Post-Test. Caso de Chile, tratamiento Ordenador. 324

Tabla 5.27 Estadísticos básicos y diferencia de medias Pre-Test - Post-Test. Caso de España 325

Tabla 5.28 Estadísticos básicos y diferencia de medias Pre-Test - Post-Test. Caso de España, tratamiento iPad 326

Tabla 5.29 Estadísticos básicos y diferencia de medias Pre-Test - Post-Test. Caso de España, tratamiento Ordenador 326 
Tabla 5.30 Contraste de hipótesis. Diferencia de medias-medianas Pre-Test/Post-Test para Chile

Tabla 5.31 Prueba de Wilcoxon. Diferencia de medianas Pre-Test/Post-Test según elementos y procesos para Chile.

Tabla 5.32 Prueba W-Wilcoxon. Diferencia de medianas Pre-Test/Post-Test según tratamiento para Chile

Tabla 5.33 Prueba U de Mann-Whitney, contenidos y procesos en Pre-Test, Chile ..... 334

Tabla 5.34 Prueba U de Mann-Whitney, contenidos y procesos en Post-Test, Chile.... 335

Tabla 5.35 Rangos con signo de Wilcoxon. Diferencia de medianas Pre-Test/Post-Test para España

Tabla 5.36 Rangos con signo de Wilcoxon. Diferencia de medianas Pre-Test/Post-Test según tratamiento para España 340

Tabla 5.37 Prueba U de Mann-Whitney en contenidos y procesos en Pre-Test, España 341

Tabla 5.38 Prueba U de Mann-Whitney en contenidos y procesos en Post-Test, España

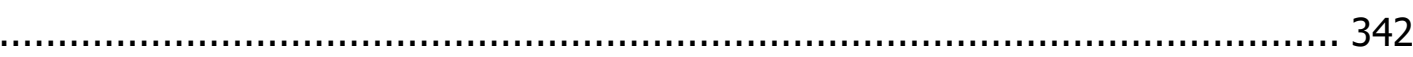

Tabla 5.39 Descriptivos básicos ítems de satisfacción experiencia con iPads.............. 355 Tabla 5.40 Descriptivos básicos ítems de satisfacción experiencia con Ordenadores... 356 Tabla 5.41 Antecedentes sociodemográficos de los docentes 359

Tabla 5.42 Dimensiones, variables y episodio narrativo representativo de los docentes: antecedentes generales en el uso de las TIC 360

Tabla 5.43 Dimensión Evaluación de la Experiencia: variables y episodio narrativo representativo de los docentes 361

Tabla 5.44 Dimensión Uso de la tecnología en el contexto educativo, variables y episodio narrativo representativo de los docentes 364

Tabla 5.45 Dimensión Uso personal de la tecnología, variables y episodio narrativo representativo de los docentes 365

Tabla 5.46 Dimensión Significado, variables y episodio narrativo representativo de los docentes 366

Tabla 5.47 Forma de realización del aprendizaje con la actividad TIC 370

Tabla 5.48 Percepción sobre los recursos de RA-NPM en e-learning y m-learning ...... 371

Tabla 5.49 Antecedentes sociodemográficos de los alumnos. 372

Tabla 5.50 Dimensiones, variables y episodio narrativo representativo de los alumnos: antecedentes generales en el uso de las TIC 373

Tabla 5.51 Dimensión uso personal de la tecnología por parte de los alumnos 374 
Tabla 5.52 Dimensión uso personal de la tecnología por parte de los alumnos .......... 375

Tabla 5.53 Dimensión evaluación de la experiencia RA-NPM por parte de los alumnos 377 


\section{Índice de gráficos}

Gráfico 5.1 Función de densidad Pre-Test según tratamiento, experiencia de Chile .... 279 Gráfico 5.2 Diagramas de cajas Pre-Test según tratamiento, experiencia de Chile ..... 280 Gráfico 5.3 Función de densidad Pre-Test según tratamiento, experiencia de España. 281 Gráfico 5.4 Diagramas de cajas Pre-Test según tratamiento, experiencia de España .. 282 Gráfico 5.5 Q-Q normales Pre-Test según tratamiento, experiencia de Chile. 283

Gráfico 5.6 Q-Q normales Pre-Test según tratamiento, experiencia de España . 284 Gráfico 5.7 Función de densidad Post-Test según tratamiento, experiencia de Chile... 286 Gráfico 5.8 Diagramas de cajas Post-Test según tratamiento, experiencia de Chile.... 287 Gráfico 5.9 Función de densidad Post-Test según tratamiento, experiencia de España 288 Gráfico 5.10 Diagramas de cajas Post-Test según tratamiento, experiencia de España289 Gráfico 5.11 Q-Q normales Post-Test según tratamiento, experiencia de Chile .... 290 Gráfico 5.12 Q-Q normales Post-Test según tratamiento, experiencia de España 291 Gráfico 5.13 Función de densidad Pre-Test. Elementos de contenido, experiencia de Chile

Gráfico 5.14 Diagramas de cajas Pre-Test. Elementos de contenidos, experiencia de Chile 294

Gráfico 5.15 Función de densidad Pre-Test. Elementos de contenido, experiencia de Chile, iPad

Gráfico 5.16 Diagramas de cajas Pre-Test. Elementos de contenidos, experiencia de Chile, iPad 295

Gráfico 5.17 Función de densidad Pre-Test. Elementos de contenido, experiencia de Chile, Ordenador . 295

Gráfico 5.18 Diagramas de cajas Pre-Test. Elementos de contenidos, experiencia de Chile, Ordenador . 296

Gráfico 5.19 Función de densidad Pre-Test. Procesos, experiencia de Chile. 297

Gráfico 5.20 Diagramas de cajas Pre-Test. Procesos, experiencia de Chile ..... 297

Gráfico 5.21 Función de densidad Pre-Test. Procesos, experiencia de Chile, iPad....... 298 Gráfico 5.22 Diagramas de cajas Pre-Test. Procesos, experiencia de Chile, iPad ........ 298 Gráfico 5.23 Función de densidad Pre-Test. Procesos, experiencia de Chile, Ordenador

Gráfico 5.24 Diagramas de cajas Pre-Test. Procesos, experiencia de Chile, Ordenador 299 Gráfico 5.25 Q-Q normales Pre-Test Chile. Contenidos.... 302

Gráfico 5.26 Q-Q normales Pre-Test Chile iPad. Contenidos 302 
Gráfico 5.27 Q-Q normales Pre-Test Chile Ordenador. Contenidos.......................... 303

Gráfico 5.28 Q-Q normales Pre-Test Chile. Procesos ........................................ 304

Gráfico 5.29 Q-Q normales Pre-Test Chile iPad. Procesos .................................. 304

Gráfico 5.30 Q-Q normales Pre-Test Chile Ordenador. Procesos ............................ 305

Gráfico 5.31 Función de densidad Post-Test. Elementos de contenido, experiencia de Chile 307

Gráfico 5.32 Diagramas de cajas Post-Test. Elementos de contenidos, experiencia de Chile 308

Gráfico 5.33 Función de densidad Post-Test. Elementos de contenido, experiencia de Chile, iPad 308

Gráfico 5.34 Diagramas de cajas Post-Test. Elementos de contenidos, experiencia de Chile, iPad 309

Gráfico 5.35 Función de densidad Post-Test. Elementos de contenido, experiencia de Chile, Ordenador 309

Gráfico 5.36 Diagramas de cajas Post-Test. Elementos de contenidos, experiencia de Chile,

Ordenador 310

Gráfico 5.37 Función de densidad Post-Test. Procesos, experiencia de Chile ............. 310

Gráfico 5.38 Diagramas de cajas Post-Test. Procesos, experiencia de Chile............... 311

Gráfico 5.39 Función de densidad Post-Test. Procesos, experiencia de Chile, iPad ..... 312

Gráfico 5.40 Diagramas de cajas Post-Test. Procesos, experiencia de Chile, iPad ....... 312 Gráfico 5.41 Función de densidad Post-Test. Procesos, experiencia de Chile, Ordenador 313

Gráfico 5.42 Diagramas de cajas Post-Test. Procesos, experiencia de Chile, Ordenador 313

Gráfico 5.43 Q-Q normales Post-Test Chile. Contenidos..................................... 316

Gráfico 5.44 Q-Q normales Post-Test Chile. Contenidos, iPad.............................. 316

Gráfico 5.45 Q-Q normales Post-Test Chile. Contenidos, Ordenador ........................ 317

Gráfico 5.46 Q-Q normales Post-Test Chile. Procesos ........................................ 318

Gráfico 5.47 Q-Q normales Post-Test Chile. Procesos, iPad ................................. 318

Gráfico 5.48 Q-Q normales Post-Test Chile. Procesos, Ordenador.......................... 319

Gráfico 5.49 Diferencias Pre-Test/Post-Test según tratamiento. Caso de Chile........... 329 Gráfico 5.50 Diferencias Pre-Test/Post-Test según contenido y proceso. Caso de Chile 331

Gráfico 5.51 Diferencias Pre-Test/Post-Test según tratamiento. Caso de España ....... 336 
Gráfico 5.52 Diferencias Pre-Test/Post-Test según contenido y proceso. Caso de España

Gráfico 5.53 Resultados Pre-Test/Post-Test, tratamiento iPad Chile ........................ 343

Gráfico 5.54 Funciones de densidad conjuntas, ítems de contenidos iPad Chile ......... 344

Gráfico 5.55 Diagramas de dispersión e histograma de variables bidimensionales, ítems de contenidos iPad Chile..................................................................... 344

Gráfico 5.56 Funciones de densidad conjuntas, ítems de procesos iPad Chile ............. 345

Gráfico 5.57 Diagramas de dispersión e histograma de variables bidimensionales, ítems de procesos iPad Chile.......................................................................... 345

Gráfico 5.58 Resultados Pre-Test/Post-Test, tratamiento Ordenador Chile.................. 346

Gráfico 5.59 Funciones de densidad conjuntas, ítems de contenidos Ordenador Chile 347

Gráfico 5.60 Diagramas de dispersión e histograma de variables bidimensionales, ítems de contenidos Ordenador Chile ................................................................ 347

Gráfico 5.61 Funciones de densidad conjuntas, ítems de procesos Ordenador Chile ... 348

Gráfico 5.62 Diagramas de dispersión e histograma de variables bidimensionales, ítems de procesos Ordenador Chile .............................................................. 348

Gráfico 5.63 Resultados Pre-Test/Post-Test, tratamiento Ordenador España ............. 349

Gráfico 5.64 Resultados Pre-Test/Post-Test, tratamiento iPad España...................... 350

Gráfico 5.65 Funciones de densidad conjuntas, ítems de contenidos iPad España ...... 350

Gráfico 5.66 Diagramas de dispersión e histograma de variables bidimensionales, ítems de contenidos iPad España .................................................................. 351

Gráfico 5.67 Funciones de densidad conjuntas, ítems de procesos iPad España ......... 351

Gráfico 5.68 Diagramas de dispersión e histograma de variables bidimensionales, ítems de

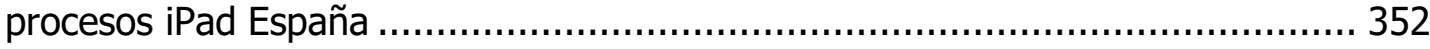

Gráfico 5.69 Funciones de densidad conjuntas, ítems de contenidos iPad España ...... 352

Gráfico 5.70 Diagramas de dispersión e histograma de variables bidimensionales, ítems de contenidos Ordenador España 353

Gráfico 5.71 Funciones de densidad conjuntas, ítems de procesos Ordenador España 353

Gráfico 5.72 Diagramas de dispersión e histograma de variables bidimensionales, ítems de procesos Ordenador España ......................................................... 354

Gráfico 5.73 Resultados encuesta de satisfacción según tratamiento ....................... 357

Gráfico 5.74 Resultados encuesta de satisfacción según país ................................. 357 


\section{Índice de figuras}

Figura 1.1 Evolución de los conceptos "Realidad Aumentada" y "Educación" en Google Scholar ................................................................................ 41

Figura 1.2 Evolución de los conceptos de "Realidad Aumentada" y "Educación" en diferentes bases de datos científicas ...................................................... 42

Figura 1.3 Continuo de la virtualidad (Milgran y Kishino, 1994) ............................. 43

Figura 1.4: Estructura de construcción para RA. .......................................... 45

Figura 1.5: Marcador QR .................................................................. 46

Figura 1.6: Markeless presente en una caja de medicamentos ............................ 46

Figura 1.7: Objeto tridimensional como marcador para RA. ................................ 47

Figura 1.8: Implementación de Realidad Aumentad Móvil en un contexto de navegación.

51

Figura 1.9: diferentes dominios en e-learning y u-learning.................................. 54

Figura 2.1 Clasificación de las aplicaciones sociales con localización por modo y grado de prosumición(basado en Fischer, 2014) .................................................. 72

Figura 2.2 Fotografía aérea de Salamanca. Vuelo Americano Serie A 1945-1946 (Instituto Geográfico Nacional, 1946) ....................................................... 80

Figura 2.3 Modelo Digital de Elevaciones y Banda Infrarroja de datos del satélite Landsat

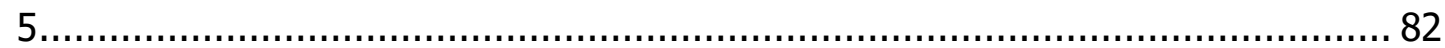

Figura 2.4 Elementos de abstracción geométrica utilizados en cartografía................... 84

Figura 2.5 Dimensión de la longitud en función de la latitud ................................. 86

Figura 2.6 Proyecciones de Mercator (en gris), Mollweide (rojo) y Plate Carrée (naranja) 90

Figura 2.7 Etapas del proceso de observación de los fenómenos del mundo real convertidos en modelos de datos estandarizados (Burrough y McDonnell, 1998)... 92

Figura 2.8 Esquema topológico de la red metro de Santiago de Chile, en una interfaz móvil (Empresa de Transporte de Pasajeros Metro S.A., 2015)................................ 95

Figura 3.1 Políticas nacionales de TIC en América Latina y el Caribe......................... 129 Figura 3.2 Porcentaje de familias con acceso a un ordenador desde casa, año 2011 países OCDE ..................................................................................... 132

Figura 3.3 Proceso de difusión de innovaciones (Rogers, 2003) ............................ 135

Figura 3.4 Categorización de adoptadores tomando como base la tecnología de innovación utilizada. Adaptado de Rogers (2003).............................................. 137

Figura 3.5 Ciclos de Exceso de expectativas (Gartner, 2015)........................... 140 
Figura 3.6 Evolución de la RA en los Ciclos de Exceso de Expectativas. 141

Figura 3.7 Estructura del modelo TPACK ................................................... 148

Figura 3.8 Estructura del modelo G-TPACK................................................ 150

Figura 3.9 Modelo de la investigación desde la estructura TPACK ........................ 151

Figura 3.10 Modelo de Objeto de Aprendizaje del Proyecto MIH........................... 153

Figura 3.11 Objeto de Aprendizaje planteado en un contexto móvil ........................ 155

Figura 4.1: Especialistas que participaron en la evaluación del instrumento de patrimonio

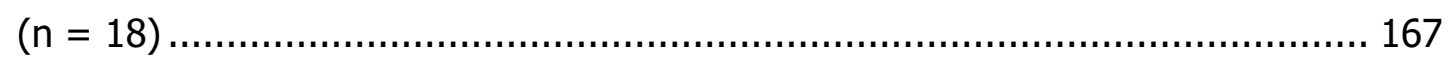

Figura 4.2 Santiago de Chile y edificaciones patrimoniales consideradas .................. 170

Figura 4.3 Salamanca (España) y edificaciones patrimoniales............................. 171

Figura 4.4 Modelo de datos territoriales utilizados....................................... 173

Figura 4.5 Valor multicriterio de aptitud patrimonial-peatonal. Santiago de Chile. ...... 174 Figura 4.6 Valor multicriterio de aptitud patrimonial-peatonal. Salamanca (España) ... 175 Figura 4.7 Polígonos de Thiessen en función del EMC sin ajuste de ejes. Santiago de Chile 178

Figura 4.8 Polígono de Thiessen en función del EMC sin ajuste de ejes. Salamanca

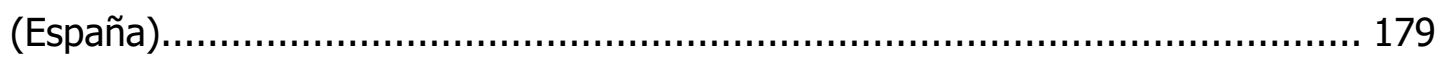

Figura 4.9 Rutas patrimoniales para Santiago de Chile ................................... 180

Figura 4.10 Rutas patrimoniales, Salamanca (España)..................................... 181

Figura 4.11 Etapas del ciclo de vida del software (Joyanes Aguilar, 2008)................ 182

Figura 4.12 Modelo de RA Palacio de la Moneda, Santiago de Chile ........................ 191

Figura 4.13 Modelo en RA Catedral Nueva de Salamanca ................................... 191

Figura 4.14 Diagrama de la aplicación móvil en donde se despliegan el Sistema de Navegación Peatonal, Realidad Aumentada y la información almacenada ............ 196

Figura 4.15 Estructura de la sección cuantitativa de la investigación....................... 201

Figura 4.16 Escena de la Aplicación "Santiago Patrimonial" (versión 1.0 aplicación RA-

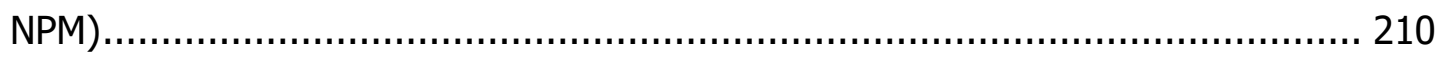

Figura 4.17 Escena de la Aplicación "Salamanca Patrimonial" (versión 1.1 aplicación RA-

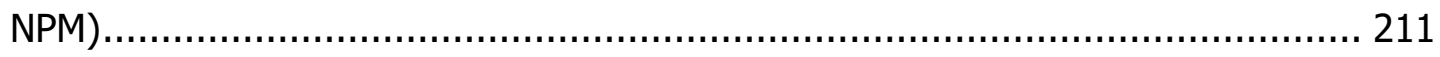

Figura 4.18 eXeLearning implementado para la experiencia educativa en aula (ordenador

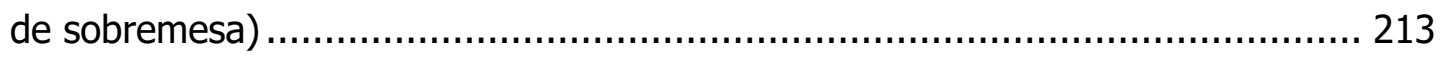

Figura 4.19 Modelo digital de terreno sobre la ciudad de Salamanca ..................... 214

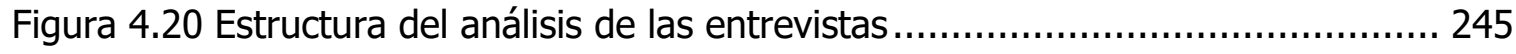

Figura 5.1 Modelo de desplazamiento peatonal, zona E Santiago de Chile................ 255

Figura 5.2 Modelo de desplazamiento peatonal, zona A Salamanca, España ............... 256 
Figura 5.3 Tiempos de desplazamientos, zona E Santiago de Chile ......................... 258

Figura 5.4 Tiempos de desplazamientos, zona A Salamanca, España ...................... 259

Figura 5.5 Localización de los puntos de ruta, Santiago de Chile ............................. 262

Figura 5.6 Localización de los puntos de ruta, Salamanca, España .......................... 263

Figura 5.7 Diagrama de Casos de Uso de la Aplicación RA-NPM ............................. 265

Figura 5.8 Estructura de las aplicaciones móviles de Santiago y Salamanca en el proyecto

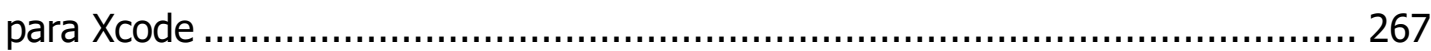

Figura 5.9 Diagrama de clases simplificado para la aplicación Santiago Patrimonial (AR-

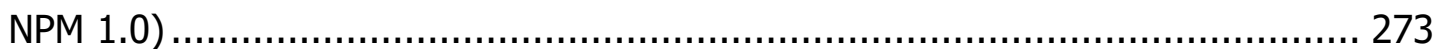

Figura 5.10 Diagrama de clases aplicación Salamanca Patrimonial (AR-NPM 2.0)....... 278

Figura 5.11 Relaciones entre categorías y códigos. Docentes .............................. 367

Figura 5.12 Nube de palabras, entrevistas con los docentes................................ 369

Figura 5.13 Relaciones entre categorías y códigos. Alumnos .............................. 378

Figura 5.14 Nube de palabras, entrevistas con los alumnos ............................... 379 
INTRODUCCIÓN 



\section{INTRODUCCIÓN}

El rápido desarrollo de la tecnología que se ha producido en las últimas décadas a nivel global, está generando modificaciones en las condiciones sociales con la incorporación de los nuevos avances en la ciencia y las técnicas, lo que está afectando a la vida cotidiana de las personas (Innerarity, 2016). En estos numerosos progresos tecnológicos se encuentra la incorporación de los dispositivos móviles, con una alta capacidad de procesamiento y almacenamiento de datos, sensores de datos específicos y vías de despliegue grafico que permiten nuevas formas de representación de la realidad con la transformación de los datos en información con valor añadido. En este sentido, técnicas como la Realidad Aumentada, la Cartografía Móvil y la Navegación Asistida, han aportado, desde sus vertientes, la configuración de una forma de entender y modelar la realidad sobre los lugares y los territorios (Shekhar, Feiner, \& Aref, 2016). De esta manera, casi todos los fenómenos que se producen en un contexto de espacio físico, se ven influenciados por el marco que establecen las Tecnologías de la Información y la Comunicación (TIC), abarcando desde la simple representación o modelación de los escenarios espaciales, hasta la posibilidad de generar y estructurar lugares desde nuevas y complejas estructuras de datos (Realidad Virtual), con el desarrollo de técnicas de procesamiento y metodologías de despliegue gráfico.

Con la aparición del ser humano y del establecimiento de las estructuras sociales, el territorio, los paisajes, las regiones y los lugares han sido unos componentes importantes, desarrollando diversas herramientas condicionadas a su contexto histórico para el entendimiento de estos sistemas: desde la simple representación gráfica en papel (mapa), pasando a la brújula, el astrolabio y los sistemas de coordenadas (latitud y longitud), hasta la complejidad digital actual con la implementación de servidores de mapas, los sistemas globales de navegación por satélite y la información colaborativa sobre estas herramientas, elementos propios de la Web 2.0 y 3.0 (De Jong, 2015; Gonzálvez Vallés, 2011).

Desde una dimensión educativa, este desarrollo también ha sido vertiginoso, siendo fuertemente condicionado con la implementación de nuevas metodologías, instrumentos de difusión, y la creación de conocimiento. Con el inicial Aprendizaje Electrónico-e-learning-, se han generado nuevos lineamientos pedagógicos, relacionados directamente con los procesos de innovación y adopción de la tecnología digital siendo el Aprendizaje Móvil -m-learning-, etapa marcada por la portabilidad y la distancia del 
proceso de enseñanza-aprendizaje, deviniendo en un nuevo estadio, el Aprendizaje Situado -u-learning-, en donde la información aparece en cualquier momento y lugar que se requiere, confluyendo campos del conocimiento en donde existe una clara complementariedad de contenidos, métodos y objetivos (Sánchez Prieto, Olmos Migueláñez, \& García Peñalvo, 2014).

En función de la dimensión tecnológica, herramientas como la Realidad Aumentada (RA) -la cual lleva en desarrollo durante en los últimos 25 años-, ha sido fuertemente complementada con el aumento exponencial de las capacidades del hardware, tanto en dispositivos estacionarios como en los móviles, alcanzando la masificación y permitiendo su accesible implementación (Roopesh, Sunkur, Panchoo, \& Kirtee, 2016; Schmalstieg, Langlotz, \& Billinghurst, 2011). Es así que con la incorporación de nuevas funcionalidades, se ha logrado incrementar el número de interacciones y actividades relacionadas a la generación de contenidos para RA. Esta herramienta se ha visto potenciada con la implementación de este tipo de tecnología en diversos campos del saber, de los cuales destacan la educación y el patrimonio territorial, en donde se han desarrollado importantes contenidos temáticos generando una nueva forma de presentar y difundir temáticas presentes en el espacio físico. Otra de las tecnologías que se ha visto fortalecida por los avances en la portabilidad que otorgan estos dispositivos, ha sido la Navegación Peatonal Móvil (NPM), permitiendo el desarrollo de diversos contenidos, situándolos en un contexto de desplazamiento automatizado y personalizable a los requerimientos particulares, y, con ello, establecerlo dentro de las dinámicas educativas (Bienk, Kattenbeck, Ludwig, Müller, \& Ohm, 2013; Rovelo, Abad, Juan, \& Camahort, 2015).

Es desde estas dimensiones donde se establece la presente Tesis Doctoral, en la cual se pretendió la construcción de una aplicación móvil ligado a recursos informáticos como son la RA y la NPM enmarcado dentro de un proceso de formación educativa, en lo referido a contextos e-learningy m-learning) en el marco de la información territorial sobre el patrimonio histórico y cultural correspondiente a las ciudades de Santiago de Chile y Salamanca en España. De esta manera, la Tesis se desarrolla en el contexto de cuatro grandes dimensiones:

- En la contextualización de la información patrimonial sobre el territorio, teniendo en cuenta sus características y su funcionalidad en un contexto de implementación informática. 
- En el diseño y desarrollo de una plataforma móvil de RA-NPM, definiendo su arquitectura, funcionalidad, interface e implementación;

- En la evaluación cuantitativa de la comprensión y efectividad educativa del sistema informático móvil desarrollado (m-learning), en comparación con otros sistemas de aprendizaje mediado por la tecnología (e-learning)

- En la determinación de las percepciones y actitudes presentes en alumnos y profesores hacia esta forma de implementación educativa, obteniendo los testimonios particulares de los participantes.

De esta manera, estas dimensiones se estructuran en torno a 3 grandes unidades de contenidos bien definidos:

En la primera unidad se desarrolla el marco teórico que delimita los aspectos fundamentales de la investigación, planteándose un estudio profundo sobre cada uno de los aspectos involucrados. Así, se comienza con la contextualización de la RA como herramienta informática, su evolución histórica y el rol que toma en los procesos educativos (Capitulo 1). Estos mismos elementos se abordan en el planteamiento de las herramientas informáticas sobre el territorio, haciendo hincapié en los contextos sociales en que se derivan de su utilización y evolución a los largo del tiempo (Capitulo 2). También se realiza un estudio profundo del estado de la cuestión desde el contexto social, presentando las bases epistemológicas generales, algunos de los paradigmas presentes en la Sociedad de la Información y su evolución en un contexto dinámico. Particularmente, se hace referencia a los procesos educativos y cómo estos se han visto fuertemente influenciados por el desarrollo tecnológico, poniendo como ejemplo algunas implementaciones de ambos elementos en su conjunto (Capitulo 3).

La segunda unidad de esta Tesis se encuentra referida al estudio empírico y a los resultados obtenidos desde los planteamientos iniciales mediante la evaluación de una intervención educativa práctica. Mediante un proceso holístico, que involucra desde aspectos informáticos hasta los educativos, se pretende realizar una investigación sistemática, controlada, empírica y objetiva, con el fin de obtener y desarrollar una estructura de conocimientos sobre el e-learning y de manera particular el $m$-learning. Esta unidad comienza con la delimitación territorial de las áreas que fueron implementadas para el contexto educativo. Para este proceso se utilizaron una serie de modelos informáticos, en donde la principal variable a utilizar correspondió a los elementos 
patrimoniales presentes en cada ciudad. Éstos sirvieron de contexto temático y físicoespacial para su desarrollo informático. Así, se generó la generación de una aplicación móvil NPM-RA teniendo en cuenta el uso de una arquitectura orientada a la encapsulación y la herencia del código, determinando las fortalezas y oportunidades en un ambiente altamente dinámico y cambiante. Teniendo estos resultados, se comienza la realización del estudio empírico enmarcado desde un contexto cuasiexperimental, evaluando la efectividad de estas herramientas tanto en lo que respecta a contextos de e-learning como de m-learning, así como para los casos de Chile y España. El análisis de los datos muestra la efectividad de estas herramienta, particularmente la referida a m-learning, aunque con la presencia de matices y variaciones en dimensiones, procesos y contenidos (Capítulos

\section{4 y 5$)$.}

La última unidad se presenta como un bloque de discusión y conclusiones derivadas de las etapas anteriores, que intenta sintetizar los principales aspectos, ideas, resultados e inconvenientes que han surgido durante el desarrollo de este gran ejercicio académico. De esta manera, se incluye una discusión de la información obtenida, desde el marco teórico, los aspectos informáticos y educativos. Mediante estos apartados se exponen las principales conclusiones de la investigación desde el punto de vista teórico y empírico (Capítulos 6 y 7).

Debido a la importancia de los hallazgos y logros alcanzados en esta investigación, los cuales, desde una perspectiva multidimensional, fueron abordados por un conjunto de saberes, medios y técnicas, tratando de confluirlos en un ejercicio complejo pero sinérgico, se realiza esta síntesis, con el fin de facilitar su lectura, y ayudando a toda persona interesada en el tema a comprender los aspectos abordados en los diversos campos del conocimiento en que la investigación se encuentra inmersa.

Finalmente, parte importante de la información y los datos que se han generado en una investigación de esta naturaleza, se han puesto a disposición de los lectores en la sección de los anexos de esta Tesis. Debido al volumen de datos generados, y a pesar de su relevancia para la comprensión de algunos elementos y procedimientos utilizados a los largo de la investigación, se han incluido como información digital presente en un DVDROM, situándose al final de este escrito. 
Capítulo I

Realidad Aumentada en Educación: Un escenario ilustrativo 



\section{REALIDAD AUMENTADA EN EDUCACIÓN: UN ESCENARIO ILUSTRATIVO}

\subsection{Introducción}

Las técnicas de Realidad Aumentada (RA), nacidas hace aproximadamente 25 años, han experimentado un rápido crecimiento como consecuencia aumento exponencial de las capacidades de hardware, tanto en dispositivos estacionarios como en los móviles. Es en este último caso donde se aprecian importantes funcionalidades emergentes, que hacen posible un mayor número de actividades relacionadas con la generación de contenidos para RA. Lo anterior se ha visto incrementado con la aplicación de este tipo de técnicas en diversos campos del saber, entre los cuales destacan la educación y el patrimonio territorial. En estos campos se han desarrollado importantes contenidos temáticos, generando una nueva forma de presentar y difundir informaciones presentes en nuestro espacio cultural.

La RA, como herramienta derivada de la informática, presenta una gran adaptabilidad de contenidos y métodos, lo que ha facilitado la inclusión de diversas disciplinas y áreas en su utilización, las que van desde la visualización de los procesos industriales hasta la medicina, pasando por la publicidad y la astronomía. De esta manera, el usuario final obtiene la información digital de una manera fluida, en donde los contenidos se presentan con una facilidad didáctica que contribuye en la mejora de la experiencia de la comprensión de los fenómenos visualizados. La utilización de la RA en Educación, siempre se ha enmarcado en contextos de enseñanza-aprendizaje similares a los que se sitúan las metodologías de e-learning, en donde el estudiante recibe información complementaria -contenidos- a través de la pantalla del ordenador y/o dispositivo con una interfaz de usuario -GUI- particular (Goel \& Bhardawaj, 2014). Es en estos casos donde existe una permanente interacción con el contenido de aprendizaje y un escenario real.

\subsection{Marco conceptual de la Realidad Aumentada}

La Realidad Aumentada (RA) como concepto y herramienta no tiene una reciente aparición, enmarcándose dentro de una gran estructura de técnicas que relacionan realidad y representación digital. En una definición inicial, la RA se establece como la 
combinación de información real y virtualizada por un ordenador, efectuando una fusión en tres dimensiones con el fin de generar un modelo digital observable (Azuma, 1997; Azuma et al., 2001; Billinghurst, Kato, \& Poupyrev, 2001; C. González, Martín-Gutiérrez, \& Domínguez, 2013; Martín Gutiérrez et al., 2010; Milgram \& Kishino, 1994; Milgram, Takemura, Utsumi, \& Kishino, 1995; Ruiz Torres, 2013). En la tecnología de RA el mundo real es el soporte y contexto de la información digitalizada, formada por elementos presentados en una única interfaz de salida que se visualiza mediante un dispositivo. En esta técnica de representación de la información, existe una complementariedad constante de los datos digitales-virtuales, en donde la realidad, unida con los datos digitales, permite una experiencia compleja, visualizando información que el usuario no puede captar por las limitaciones propias de la naturaleza

\subsection{Historia del concepto y su desarrollo tecnológico}

Los primeros antecedentes sobre RA se dan en la obra de L. Frank Baurn "La llave maestra" de 1901, en donde se plantea la existencia de un aparato electrónico que permite visualizar información sobre datos reales. En la obra, esta tecnología se utilizaba para mostrar información relativa a los personajes (J. Johnson, 2012). Posteriormente, entre los años 1952 a 1962, el cineasta Morton Heilig crea y patenta un aparato simulador que llama "Sensorama" en donde se entremezclan visualizaciones, sonidos, vibraciones y olores, aunque sin la posibilidad de interacción con la información recibida. No fue hasta mediados de la década de los 60 del siglo XX, cuando el trabajo de Ivan Sutherland hace realidad un aparato denominado "The Ultimate Display' en donde existía un sistema que hacía posible la interacción con elementos en un ambiente especial, diferente al existente en la realidad, en el cual se respetan las leyes de la física. Después de una serie de ensayos, Sutherland crea el "Head-mounted display", dispositivo con el cual el usuario visualizaba una imagen en perspectiva que cambiaba en función de los movimientos realizados por su cabeza (Sutherland, 1968). Ya en el año 1975, el ingeniero Myron Krueger diseña el "Videoplace", aparato que permitía a los usuarios interactuar con objetos generados por ordenador, siendo esta la primera vez en que se presenta una interacción real entre usuario y tecnología (Ruiz Torres, 2013; Sherman \& Craig, 2002). 
Ya en el año 1980 Steve Mann, del Departamento de Ingeniería Eléctrica y Computacional de la Universidad de Toronto, desarrolla el primer dispositivo "wearable"1 consistente en un ordenador con un sistema visual en donde se generaban superposiciones de texto e imágenes que constituían una primera versión de realidad aumentada. Dicho aparato se conoció como "EyeTap" y fue el precursor del actual Google Glass, que se encuentra aún en estado de prototipo (Mann, 2012). En el año siguiente 1981-, se crean dos importantes sistemas relacionados con la RA: el primero es la incorporación de información digital a los mapas sinópticos del tiempo, lo cual, mediante cámaras de TV, permitía la observación de símbolos abstractos para los pronósticos del tiempo en televisión. Paralelamente, se desarrollaba el sistema "Super Cockpit", consistente en un casco con una pantalla de visualización de información para el piloto, y que ofrecía datos relativos al aparato o a la ruta durante el vuelo (Sherman \& Craig, 2002). Con la entrada a la década de los 90, comienza la generalización del concepto "Realidad Aumentada", atribuido al investigador de Boeing Tom Caudell, que en conjunto con David Mizell, hacen referencia a una nueva tecnología que permite aumentar el campo visual informativo del usuario, con datos de un determinado espacio de observación (K. Lee, 2012; Ruiz Torres, 2013). De la misma manera, estos autores describen las posibles ventajas que ofrece la RA respecto a la tecnología de Realidad Virtual, particularmente en torno a lo referido a la capacidad de procesamiento y el despliegue de información gráfica.

El año 1992 fue especialmente productivo para el desarrollo de esta tecnología; se pueden mencionar dos grandes hitos: por una parte Louis Rosenberg desarrolla uno de los primeros sistemas funcionales de RA llamado "Virtual Fixture" en conjunto con el laboratorio de investigación de la Fuerza Área de Estados Unidos (Rosenberg, 1993); paralelamente, Steven Feiner, Balir Macintyre y Doree Seligman presentan la primera aplicación compleja de RA, un prototipo bautizado con el nombre de "Karma" (Azuma et al., 2001).

Pero no fue hasta el año 1994, cuando Paul Milgram y Fumio Kishino presentan el artículo " $A$ taxonomy of mixed reality visual displays", en donde plantean un marco definitorio entre los que son los entornos reales y los entornos virtuales dentro de un contexto conocido como "virtuality continuum". Tomando como base la cantidad de

\footnotetext{
${ }^{1}$ El término inglés wearable denota aquellos dispositivos que se pueden llevar encima, como si de una prenda de vestir se tratase.
} 
información generada por el ordenador en un entorno determinado, es posible clasificar la tecnología en función de la cantidad de información real y virtual que se mezcla para construir el producto final, obteniendo modelos de virtualidad aumentada, realidad aumentad o entornos mixtos o híbridos (Milgram \& Kishino, 1994). De manera paralela, en el trabajo de Milgram, Takemura, Utsumi y Kishino "Augmented Reality: a class of displays on the reality-virtuality continuum" se describían y clasificaban los entornos virtuales generados por ordenador en función de la cantidad de información real y virtualizada utilizada (1995).

La utilización definitiva del termino de Realidad Aumentada se encuentra en un artículo publicado por Ronald Azuma en 1997, y titulado " $A$ survey of augmented reality", en donde se plantean las características que tiene esta tecnología.

Para 1998, Hirokazu Kato y Mark Billinghurst dan otro paso importante en el desarrollo tecnológico de la Realidad Aumentada, que es la creación del framework ARToolKit, software que permite el desarrollo de contenidos y aplicaciones en Realidad Aumentada, que se distribuía con licencia GPL (General Public License), y multiplataforma. Escrito originalmente en el Instituto de Ciencia y Tecnología de Nara, Kioto, Japón, fue lanzado por la Universidad de Washington junto con el departamento HIT Lab de dicha institución (Sherman \& Craig, 2002). En este mismo año se introducen los trabajos sobre Realidad Espacial Aumentada (Spatial Reality Augmented) de Ramesh Raskar, Greg Welch y Henry Fuchs, en donde los elementos presentes en el ambiente físico se complementa con imágenes que se integran en la visualización de datos que tiene el usuario mediante una interfaz de visualización (1998).

Ya hacia el final de la década, comienza el desarrollo en profundidad de los sistemas de RA por la comunidad científica, a través de congresos sobre el tema, presentando los avances y direcciones que está tomando esta nueva tecnología. Entre las reuniones más destacadas cabe mencionar: el IEEE International Workshop on Augmented Reality (IWAR) realizado en San Francisco en 1998; International Symposium on Mixed Reality (ISMR) en 1999 realizado en Yokohama; el 2000 el IEEE, ACM y Eurographics International Symposium on Augmented Reality (ISMAR) realizado en Múnich. 
Con la entrada del siglo XXI aparece el primer juego de RA con el nombre de $A R Q u a k e^{2}$, desarrollado por Bruce Thomas y otros, en el cual los usuarios utilizaban un sistema GPS con brújula digital que hacía posible detectar la ubicación de elementos y otros jugadores. El sistema completo permitía el reconocimiento de marcas o puntos de interés dentro de un contexto de ambiente real, facilitando al usuario su interacción con la información. Este desarrollo fue presentado en el congreso International on Wearable Computers del año 2000 (Thomas et al., 2000).

Con la aparición de los Personal Digital Assistant (PDA) comienzan a crearse los primeros sistemas de realidad aumentada, destacando el sistema AR-PDA desarrollado por Jürgen Freund, que mediante un sistema inalámbrico incluido en un sistema de hardware permitía la visualización de datos de realidad aumentada. El sistema básico mostraba una imagen real capturada con la cámara del dispositivo complementado con información virtual digitalizada (Freund, Geiger, Grafe, \& Kleinjohann, 2001). En el año 2002 se desarrolla un sistema de realidad aumentada móvil por el equipo de Micheal Kalkush (Kalkush et al., 2002) que permitía al usuario, mediante un sistema informático móvil de realidad amentada, el desplazamiento guiado. El sistema estaba desarrollado en ARToolkit, con marcadores visuales presentes en el ambiente físico en donde se encontraba el usuario. Posteriormente, se desarrollaron programas que incorporaron elementos de multimedia en 3D y narrativas hipermedia como el "mobile AR Authoring System" creado por Guven y Feiner (2003), en donde mediante un sistema "portable" (wearable) el usuario se sumergía en la información que ofrecía el entorno 3D.

Con el desarrollo de los dispositivos móviles de última generación, en los cuales la capacidad de almacenamiento y procesamiento de información se incrementan notoriamente, la realidad aumentada comienza a tener un importante auge, con el desarrollo de aplicaciones y nuevas formas de distribución y mercados de difusión de este tipo de información. En este aspecto destaca el trabajo de Mathias Möhring, quien desarrolla un reconocimiento de marcas 3D para la telefonía móvil, convirtiéndose en la primera aplicación masiva de realidad aumentada. El software creado permitía el reconocimiento de diversas marcas creadas en 3D, facilitando el adecuado renderizado

\footnotetext{
${ }^{2}$ Correspondería a una versión en realidad aumentada del juego Quake de la empresa ID Software.
} 
gráfico de información y datos en el dispositivo móvil en tiempo real (Möhring, Lessig, \& Bimber, 2004).

Para el año 2009 comienza el desarrollo de las primera aplicaciones masivas de RA con empresas que se dedican a la creación de contenidos y plataformas con este tipo de tecnología. Destacan programas como Wikitude y Metaio, en donde se introducen las primeras aplicaciones móviles para dispositivos inteligentes (Jamali, Shiratuddin, \& Wong, 2014). Esto se condice con la masificación en el mercado de las tabletas y teléfonos inteligentes, a partir de la consolidación de los sistemas operativos para móviles iOS de Apple y Android 3 .

A comienzos de 2015 la RA ya cuenta con la existencia de más de 70 kits de desarrollo de software (SDK por sus siglas en inglés), de los cuales 14 funcionan con tecnología que se complementa a los sistemas de geolocalización y portabilidad (N. Davis, 2016). En las tiendas especializadas como Google Play o iTunes es posible encontrar más 500 aplicaciones $^{4}$ que incorporan la RA para el despliegue de información temática, las cuales se presentan en categorías como la entretención, publicidad, referencia, productividad, negocios, entre otros (Joo Nagata, García-Bermejo Giner, \& Martínez Abad, 2015).

De manera paralela, en el ámbito de la investigación científica es posible ver un incremento constante en los resultados de las palabras clave conjuntas "Realidad Aumentada" y "Educación" en las diferentes bases de datos actuales para la consulta y difusión científica. Particularmente se destaca Google Scholar que en el año 2014 ya presentaba 4940 referencias en torno a estos términos ${ }^{5}$ (Figura 1.1).

\footnotetext{
${ }^{3}$ La aparición del sistema operativo iOS (2007) y de Android (2008) marcan puntos de inflexión en la portabilidad y potencialidad de estos dispositivos, aportando capacidades importantes para los usuarios y permitiendo llevar la potencia de ordenadores en teléfonos móviles (Honan, 2007; Mahapatra, 2013).

${ }^{4}$ Se contabilizaron las aplicaciones para móviles y tabletas presentes hasta el mes de enero de 2015.

${ }^{5}$ Google Scholar (o Académico) es la sección especializada en artículos de revistas científicas del buscador de Mountain View (en http://scholar.google.com/).
} 
Figura 1.1 Evolución de los conceptos "Realidad Aumentada" y "Educación" en Google Scholar ${ }^{6}$

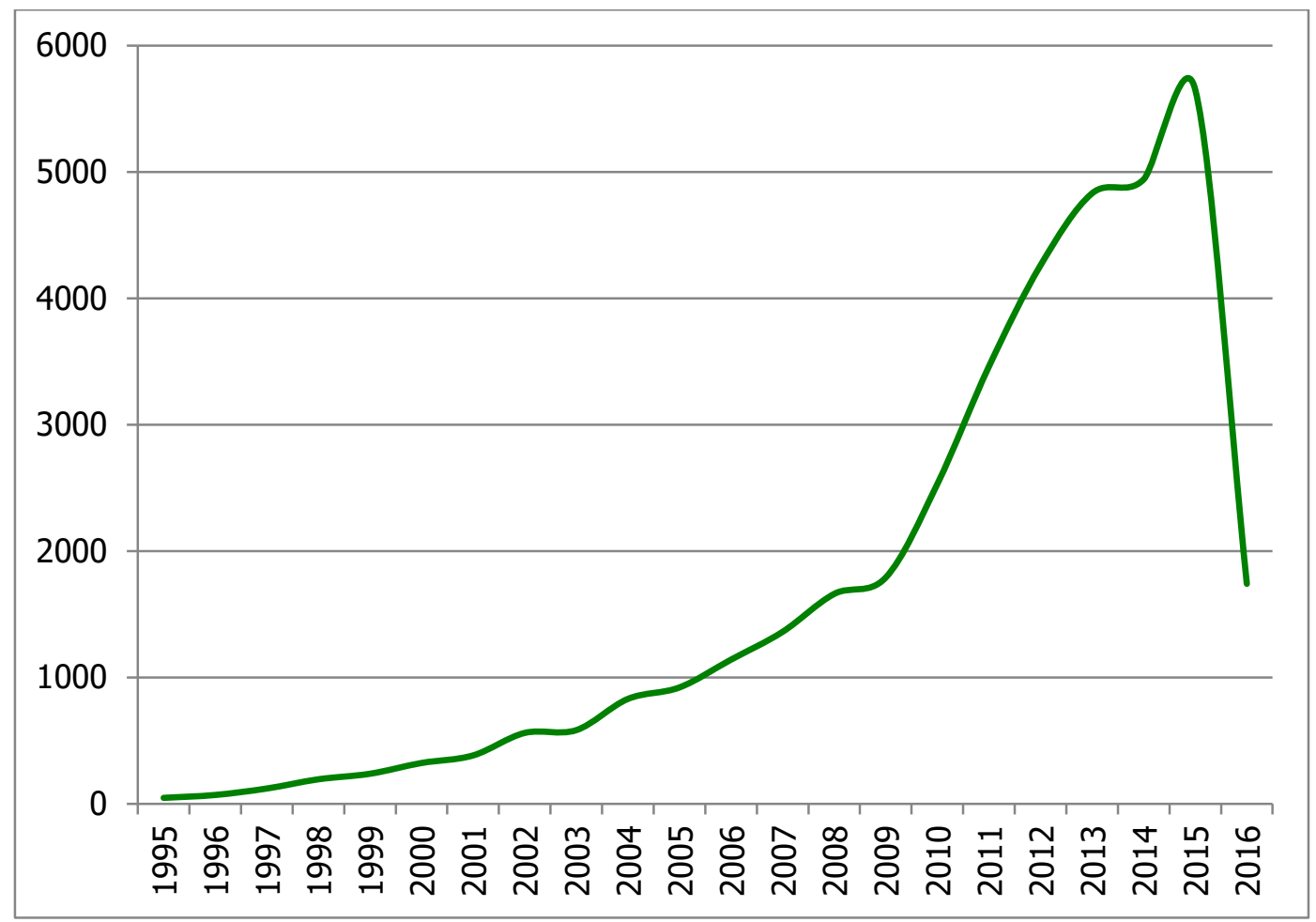

Fuente: Elaboración propia.

Otro elemento importante a considerar es la cantidad limitada de investigaciones (artículos en Dialnet y Scielo) y de tesis doctorales realizadas en el idioma español (Teseo). Sin embargo, y de la misma manera que en gráfico anterior, se presenta un aumento constante de temas desarrollados en torno a la RA (Figura 1.2).

${ }^{6}$ Datos recopilados hasta el día 20 de mayo de 2016. 
Figura 1.2 Evolución de los conceptos de "Realidad Aumentada" y "Educación" en diferentes bases de datos científicas ${ }^{7}$

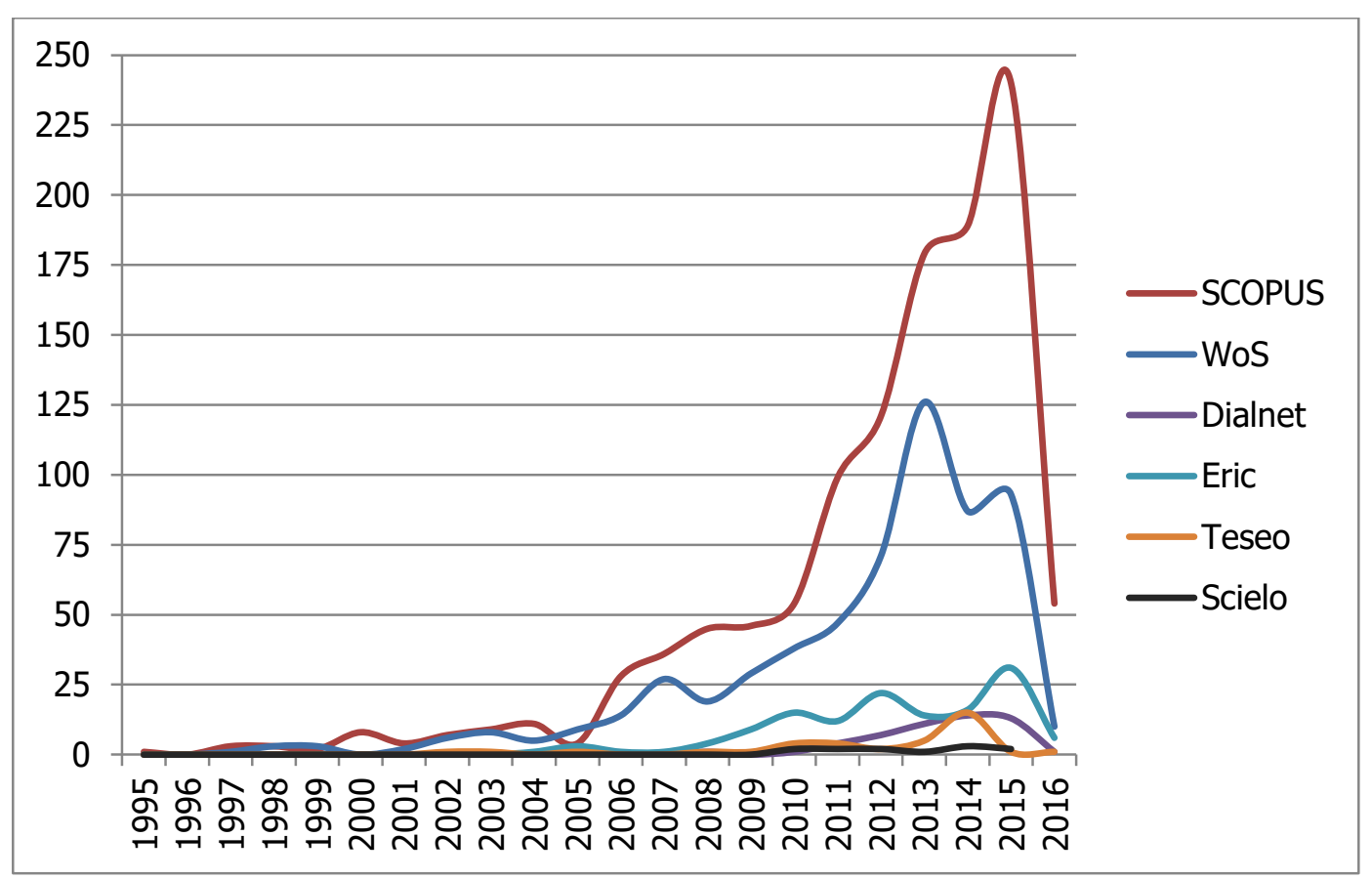

Fuente: Elaboración propia.

Las bases de datos Scopus y WoS tienen un alcance mundial, mientras que Dialnet y SciELO ofrecen una cobertura regional, particularmente para la región de Iberoamérica. Por otro lado Teseo y Eric son bases de datos de carácter nacional-local (España y Estados Unidos respectivamente). Todos los valores encontrados en estas fuentes referenciales de datos, a pesar de sus diferentes magnitudes, muestran en un contexto general un constante incremento de la utilización de la RA en estudios en el campo de la educación,

7 Scopus es una base de datos bibliográfica de revistas científicas que en la actualidad abarca aproximadamente 18.000 títulos de 5000 editores internacionales e incluye la cobertura de 16.500 revistas de diferentes áreas de las ciencias (en http://www.scopus.com). World of Science-WoS- es una plataforma de la empresa Thompson Reuters que reúne las referencias de las principales publicaciones científicas existentes en este momento (en http://apps.webofknowledge.com/). Dialnet es una base de datos de libre acceso creada por la Universidad de La Rioja y constituye un índice de revistas científicas y humanísticas, libros (monografías) y tesis doctorales de España, Latinoamérica y Portugal (en http://dialnet.unirioja.es/). Eric (Educational Resources Information Center) es una base de datos patrocinada por el Departamento de Educación de Estados Unidos y cuenta con aproximadamente 1,2 millones de registros (en http://www.eric.ed.gov/). Teseo es una base de datos implementada por el Ministerio de Educación, Cultura y Deporte de España, y cuenta con la información de las tesis doctorales realizadas desde el año 1976 (en https://www.educacion.gob.es/teseo/login.jsp). SciELO es un proyecto de biblioteca electrónica creada por la Fundación para el Apoyo a la Investigación de Estado de Sao Paulo y el Centro Latinoamericano y del Caribe de Información en Ciencias de la Salud, que permite la publicación electrónica de diversas revistas científicas de Latinoamérica (en http://www.scielo.org/). Datos recopilados hasta el día 20 de mayo de 2016. 
correlacionándose con el modelo de evolución presentado por los ciclos de exceso de expectativas que se analizará en el Capítulo 3.

\subsection{De la Realidad Combinada a la Realidad Virtual}

En el contexto actual de las telecomunicaciones, con avances significativos en materia de hardware y flujos de datos, se hace posible generar una nueva dimensión virtual, en donde la realidad sea el soporte significativo de la expresión de la información digitalizada. Ambos elementos, realidad e información, confluyen en un dispositivo en común el cual se encuentra en constante interacción con el usuario. El desarrollo teórico de esta técnica está basado en los trabajos de Milgram y Kishino (Milgram \& Kishino, 1994; Milgram et al., 1995) quienes han definido una taxonomía basada en el "continuo de la virtualidad" ( virtuality continuum) y que tiene como parámetro base la representación digital de los datos mediante un dispositivo (pantalla o display) de interface. De esta manera, se pueden apreciar dos extremos en esta clasificación: un entorno real y un entorno virtual y sus correspondientes transiciones según el grado de dominancia de la tecnología (Figura 1.3).

Figura 1.3 Continuo de la virtualidad (Milgran y Kishino, 1994)

\section{Realidad Mezclada}
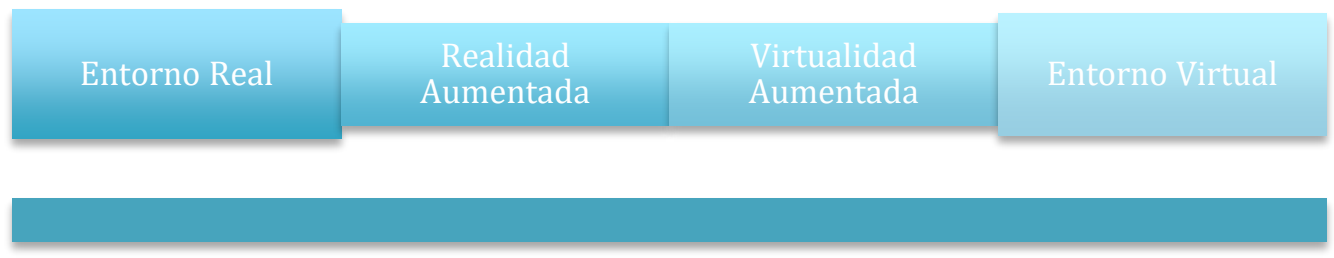

Este continuo virtual posee en un extremo una serie de elementos de objetos que son presentados y desplegados con una situación real determinada. En el segundo extremo se encuentran los "Entornos Reales" constituidos sólo por objetos y fenómenos presentes en la realidad. Aquí se incluyen las observaciones directas realizadas mediante videos de escenarios del mundo real. Por contraposición, los entornos virtuales son solamente generados por ordenador con elementos y fenómenos digitales, lo que sería cualquier representación computacional en un entorno gráfico. 
En un comienzo, la mayoría de las aplicaciones de RA fueron realizadas para

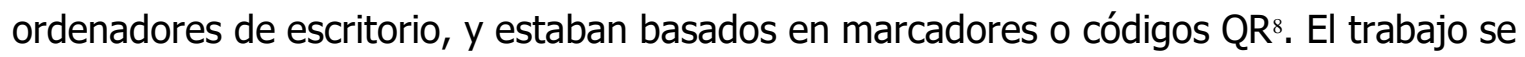
hace mediante la creación de la aplicación de AR en un entorno funcional, en donde la visualización de los datos se basa en apoyos físico-gráficos, representando los elementos de contenido definidos mediante objetos 3D en la interfaz de usuario (Nelles, Lee, Billinghurst, \& Kim, 2004). El usuario puede interactuar con una dimensión virtual y digital, usando marcadores tangibles que pueden estar impresos, o definidos en texturas o imágenes.

\subsection{Funcionamiento de un sistema de RA}

Cuando se habla de un sistema de RA, se establece la conjunción de una serie de elementos, tanto de hardware y de software, que se relacionan entre si, permitiendo la creación, visualización y consulta de datos digitales en este contexto de funcionamiento. De esta manera los componentes básicos del sistema son (Kipper \& Rampolla, 2012; Rohs, 2012):

- Hardware:

○ Un ordenador, el cual puede ser un PC o un dispositivo móvil (tableta, teléfono inteligente o gafas).

- Un monitor o dispositivo de visualización de los datos.

- Una cámara para la captura de los datos del entorno y que actúa como rastreador.

- Conectividad a redes (3G, $4 \mathrm{G}$ o $\mathrm{WiFi})$.

- Sensores complementarios como GPS, brújula y acelerómetro.

- Software:

- Una aplicación o programa que se ejecute desde el dispositivo a utilizar.

- Servicios web o un servidor de contenidos de RA.

Como una derivación de la Realidad Virtual, la RA exige la existencia de una estructura de creación, que permita la correcta visualización de los contenidos que se

\footnotetext{
${ }^{8}$ Los códigos QR (quick response) son marcadores gráficos que permiten almacenar información en un contexto bidimensional de fácil lectura para los dispositivos portátiles.
} 
quieren representar. En los niveles base (Figura 1.4) se encuentra el software que controla el entorno simulado, cuyos elementos van desde el rastreo y registro de datos del dispositivo, hasta el renderizado de los datos a visualizar (de Paiva Guimarães \& Farinazzo Martins, 2014).

Figura 1.4: Estructura de construcción para RA.

\section{Usuario}

Aplicación

Dispositivos de interacción y técnicas
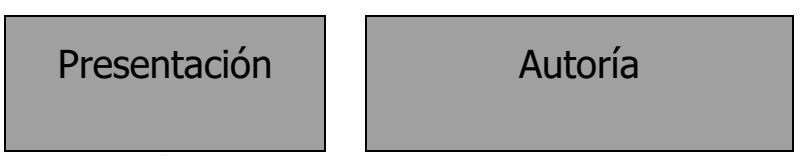

\section{Rastreo y registro}

Tecnología de visualización

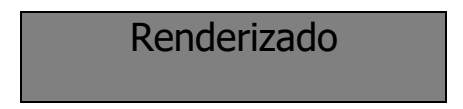

Fuente: de Paiva Guimarães \& Farinazzo Martins, (2014)

El usuario es el evaluador final de la tecnología, que debe construirse siguiendo los principios propios del diseño de software: elicitación de requisitos, análisis, diseño, implementación, verificación, mantenimiento y documentación (García-Bermejo Giner, 2014; Whitten \& Bentley, 2007).

\subsection{Tipologías de RA}

Existen diversas taxonomías de RA, que clasifican este tipo de tecnología de acuerdo a las diversas formas de implementaciones que se presentan. Una clasificación inicial (Kipper \& Rampolla, 2012), la cual está definida por las características del hardware a utilizar, divide a los sistemas de RA en dos tipos: fija y móvil. Mientras que un sistema móvil aporta al usuario la posibilidad de efectuar desplazamientos sobre un medio determinado, los sistemas fijos son inflexibles en este aspecto.

Otra clasificación de RA está relacionada con el tipo de reconocimiento o lectura que realiza el sistema (Minguell, Font, Cornellas, \& Regás, 2012; Prendes Espinosa, 2015). Esta nueva clasificación tiene en cuenta los niveles o grados de complejidad del objeto marcador o del reconocimiento. Se pueden emplear diferentes tipos de objetos reconocibles (trackables): 
- Marcadores (markers): se caracterizan por la simplicidad gráfica de su presentación, que es una derivación de matrices de pixeles con profundidades de color de 1 bit, de tal modo que pueden ser reconocidas fácilmente empleando cámaras digitales (Figura 1.5)

Figura 1.5: Marcador $\mathrm{QR}^{9}$

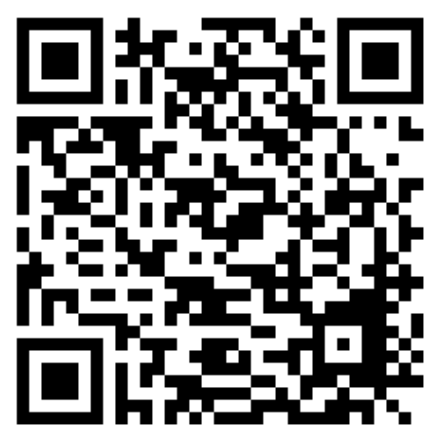

- Imágenes: para este caso, el objeto reconocible que da lugar a la activación de la RA corresponde a imágenes que actúan como marcadores con una mayor elaboración en su diseño gráfico. Este tipo de RA se denomina "sin marcadores" (markerless), ya que finalmente no se emplea un código, sino que más bien el identificador es una imagen con diferentes dimensiones, texturas y colores (Figura 1.6).

Figura 1.6: Markeless presente en una caja de medicamentos ${ }^{10}$

\footnotetext{
${ }_{9}$ Marcador que permite la visualización de la Catedral Nueva de Salamanca mediante Junaio.

${ }^{10}$ Aplicación Digi-Eye de Rohto que permite la actuación en directo de la cantante virtual Hatsune Miku, creada con el software de síntesis de voz Vocaloid (Harbort, 2014).
} 


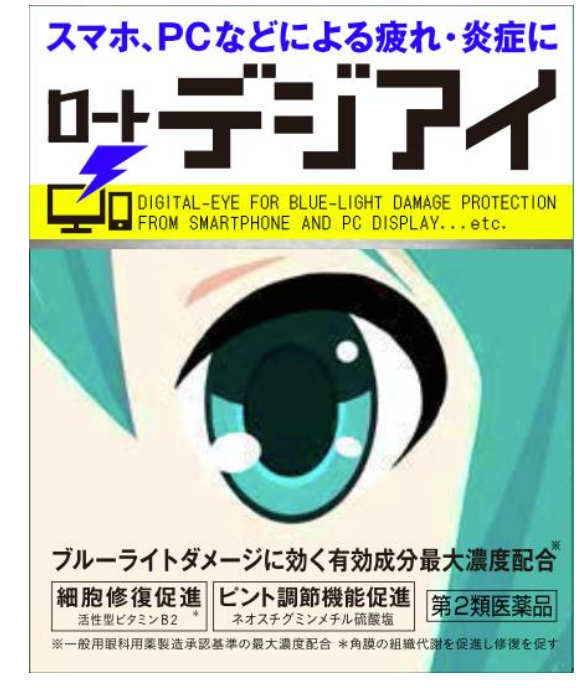

- Objetos: En la actualidad, existen aplicaciones que son capaces de reconocer objetos completos, tridimensionales y con texturas complejas como son piezas mecánicas, maquetas, caras o incluso edificaciones. Esto ha significado la evolución de los rastreadores, permitiendo la posibilidad de prescindir de una gráfica impresa o intrusiva (Figura 1.7).

Figura 1.7: Objeto tridimensional como marcador para RA.

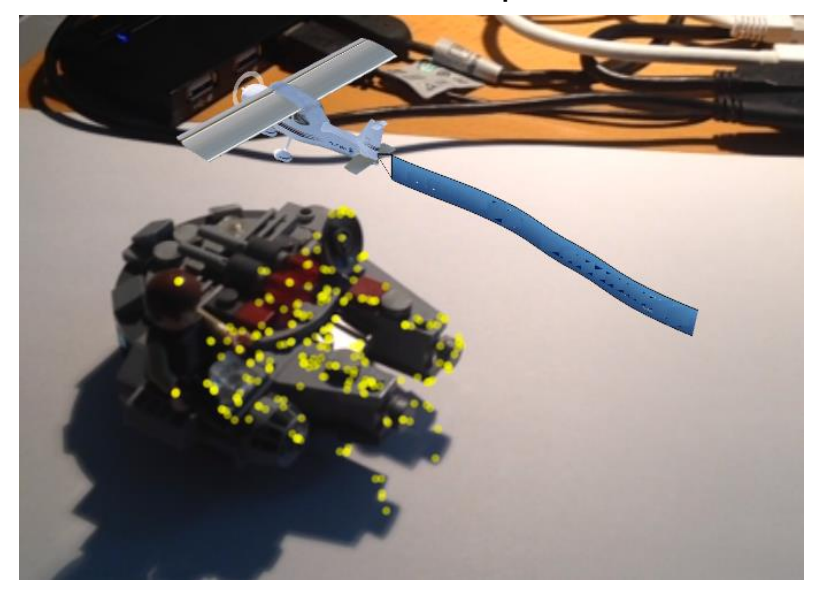

- Por localización: mediante los sensores presentes en los dispositivos móviles, es posible realizar el proceso de RA. En función de las coordenadas de localización y la movilidad, se activa la visualización del modelo virtual. Este nivel se conoce también como Realidad Aumentada Móvil y no se hace necesario la utilización de rastreadores. 
Los niveles de complejidad en la detección de los objetos reconocidos -o su inexistencia-, están directamente relacionados con las altas prestaciones de hardware existentes, en donde los niveles de procesamiento, la posibilidad de capturar imágenes en alta definición y la utilización de sensores complementarios, permiten experiencias menos complejas en su implementación y con un mayor grado de presencialidad en el visualización de la información digital.

Una última clasificación de sistemas de RA está definida por la interacción que se tiene con estos programas. La mayoría de las interacciones que se realizan mediante RA en la actualidad, tienen como objeto la interoperabilidad mediante elementos visuales. De esta manera es posible encontrar una diversidad de métodos que permiten realizar actividades en RA (Kipper \& Rampolla, 2012):

- Interfaces de Usuario Tangibles (TUI por sus siglas en inglés): es un sistema que permite una combinación más profunda entre la realidad y los datos digitales, generando una sensación física de la información virtual. Estos sistemas de RA incluyen elementos hápticos (tacto), que se combinan con la información virtual superpuesta a la información real, permitiendo una mejora significativa en la interacción física con los elementos virtuales.

- Interfaces de RA colaborativas: en estos sistemas de RA se utilizan múltiples pantallas que permiten visualizar la información virtualizada, de tal modo que la experiencia es compartida y utilizada de manera remota por diversos usuarios.

- Interfaces híbridas: en estos sistemas se combinan diferentes interfaces que se complementan entre sí, permitiendo al usuario interactuar con el contenido en diversas formas. El objetivo de estos sistemas, es implementar una plataforma flexible de interacción que sea interoperable entre distintos tipos de hardware.

- Interfaces multimodales: en los sistemas de RA multimodales se combinan una serie de métodos de interacción con los datos virtualizados. Esta interacción se realiza con objetos reales de manera natural y fluida, como ocurre con el dictado, el tacto, los gestos naturales del cuerpo, o la mirada. 
Hasta la fecha, las únicas limitaciones en torno a la visualización y la interacción con información en RA, proviene de las características del hardware, y hay una dependencia directa de los elementos de portabilidad y procesamiento que requiere esta tecnología. Sin embargo, la próxima generación de estos sistemas, radicará en la mimetización con otros elementos como son los vestibles ${ }^{11}$, mediante la creación de gafas y relojes con capacidad de procesamiento y conexión.

\subsection{Realidad Aumentada Móvil}

Una de las variantes más atractivas de la RA es su posibilidad de portabilidad, mediante tabletas y teléfonos inteligentes, los cuales ya cuentan con una potencia similar a la que poseen los ordenadores portátiles o de escritorio. La visualización de contenidos en RA tiene así como elemento añadido un contexto de movilidad, que permite la creación de actividades ubicuas, sin las limitaciones espaciales de los lugares fijos, ni la necesidad de entornos cuidadosamente acondicionados para su correcto funcionamiento (Aurelia, Raj, \& Saleh, 2014; Aydin, Gensel, Genoud, Calabretto, \& Tellez, 2013; Höllerer \& Feiner, 2004; Jamali et al., 2014).

En la actualidad, tabletas y teléfonos inteligentes cuentan con herramientas que permiten una adecuada implementación de contenidos de RA y que definen este nuevo contexto "móvil" (Pei, Cai, \& Shi, 2013; Wen, Deneka, Helton, Dünser, \& Billinghurst, 2014):

- Pantallas portátiles de alta resolución las cuales permiten la visualización y la implementación de la información conjunta de datos digitales y la realidad ${ }^{12}$

- Cámaras que detectan la información presentada en la realidad.

\footnotetext{
${ }^{11}$ En la actualidad, compañías como Sony, Hawei, Samsung y Apple ya tienen en fase beta diversos dispositivos vestibles o portables en el mercado, pero sin el nivel de masificación que tienen las tabletas y smartphones en los diversos mercados mundiales.

12 Se considera alta definición (HD por sus siglas en inglés) resoluciones superiores a $1280 \times 720$ pixeles. El iPad Air 2 tiene una resolución de 2048x1536 pixeles, superior a la resolución WXGA (1366x768) que despliegan monitores y tarjetas de video de ordenadores convencionales.
} 
- Sensores de localización como GPS y WiFi que permiten la obtención de la localización del usuario y su entorno en tiempo real, permitiendo a los programas enviar información y recursos en función de la localización del usuario.

- Herramientas como acelerómetros o giroscopios, que permiten la complementación de datos de localización.

Así, este concepto de movilidad con la interacción de construcciones digitales, se conoce como Realidad Aumentada Móvil (RAM o también conocida como RA basada en localización), permitiendo al usuario acceder a características que se encuentran en la tecnología de la RA, pero sin las restricciones físicas de un entorno delimitado. Feiner y Höllerer (2004) identificaron inicialmente seis componentes necesarios para constituir un verdadero entorno de RAM:

- La presencia de una plataforma informática que procese toda la información relevante existente en el mundo real, y permita el procesamiento de los datos y la visualización de contenidos de RA.

- La visualización de los objetos virtuales complementados con un escenario real mediante una pantalla portátil.

- El registro digital del entorno en que se encuentra el usuario. La captura de estos datos se realiza mediante la cámara y los sensores de orientación presentes en el dispositivo, que ayudan la visualización de la información en RA correctamente alineada con el entorno real.

- La presencia de un dispositivo portable (por ejemplo gafas de RA) que permita la interacción tecnológica con los datos y el trabajo colaborativo con otros usuarios.

- La implementación de una red inalámbrica que permita la comunicación inmediata con otros usuarios y con bases de datos centralizadas.

- El almacenamiento de datos y la existencia de tecnología de acceso que proporcione al usuario información complementaria sobre su entorno, aportando así los datos pertinentes para aumentar la realidad circundante. 
En la actualidad, estas características están presentes en tabletas y teléfonos inteligentes, que, aunque no son dispositivos vestibles, mantienen todas las características esenciales para la generación de un ambiente de RAM programado.

Un valor añadido que otorga la RAM es la posibilidad de generar un efecto de navegación sobre el territorio, produciendo una perspectiva nueva que permite descubrir la información más allá de la información planimétrica presentada mediante coordenadas de localización (Figura 1.8). La visualización de un mapa digital de dos dimensiones es reemplazada por la interacción y contextualización en primera persona que otorgan estos dispositivos (Hofmann \& Mosemghvdlishvili, 2014). Para este caso, la información aumentada está definida directamente por la localización del usuario y su visualización mediante el dispositivo.

Figura 1.8: Implementación de Realidad Aumentad Móvil en un contexto de navegación.

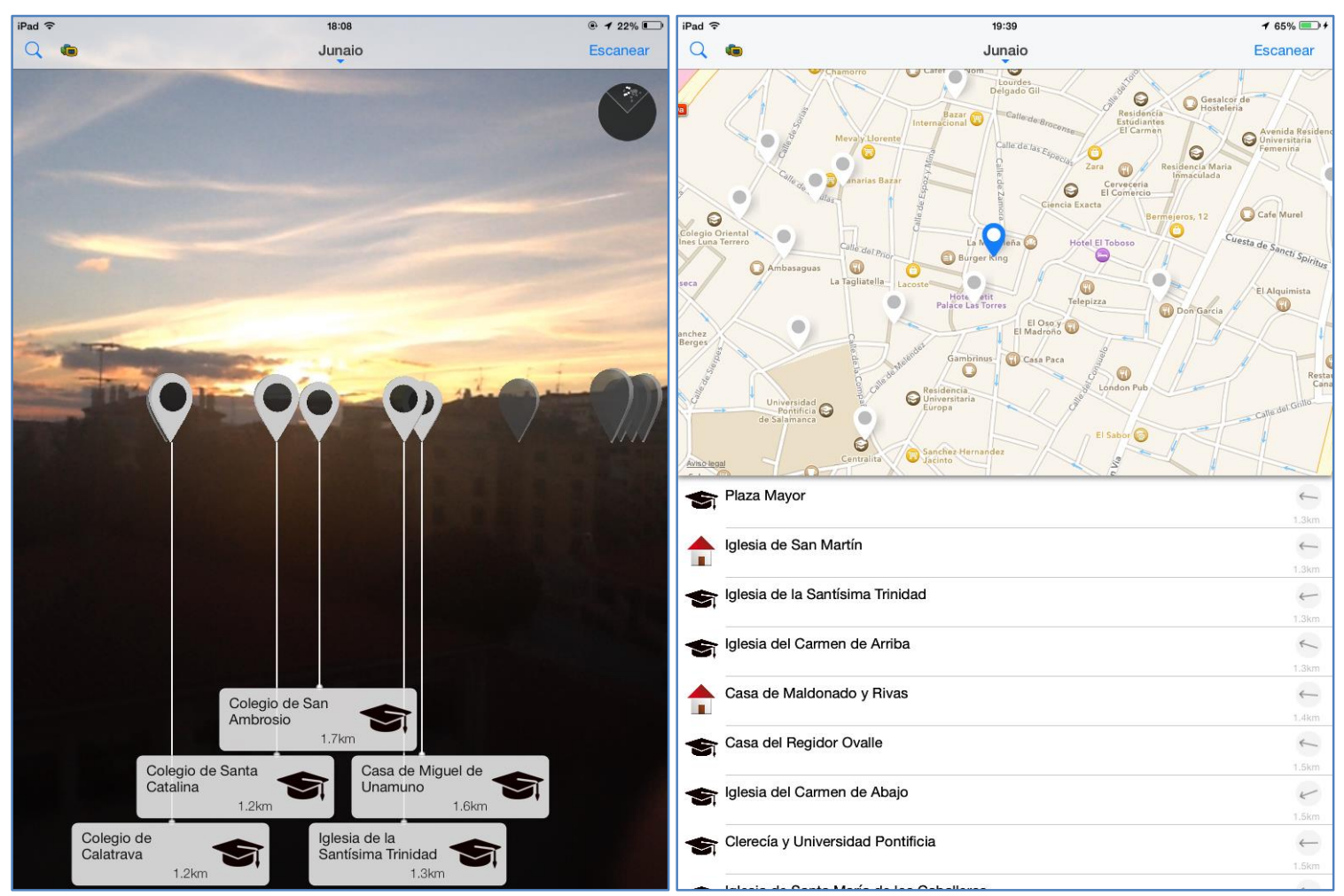

Fuente: Elaboración propia.

La RAM ha mostrado efectividad para desplegar elementos y contenidos a largas distancias pero con fuertes imprecisiones (<50 metros) para localizaciones cercanas (Aurelia et al., 2014). Sin embargo esta derivación de la RA permitiría a los usuarios visualizar los contenidos fuera del aula y de un contexto formal de enseñanza, aportando 
de este modo la posibilidad de indagar en las temáticas que se están enseñando con la ayuda de la información real de fenómenos reales (Cheng \& Tsai, 2012). Adicionalmente, empleando las interfaces de los dispositivos móviles y aprovechando su portabilidad, podrían construirse actividades educativas basadas en consultas, en las cuales los estudiantes dispondrían de una experiencia totalmente personalizada en un contexto del ambiente real que los circunda (Jan \& Squire, 2007). También el aprendizaje situado es considerado un contexto pedagógico adecuado para la implementación de la RAM con el fin de situar a los estudiantes en un contexto de auténtica investigación científica (FitzGerald et al., 2012; Pei et al., 2013).

\subsection{Educación y Realidad Aumentada}

Dentro de la incorporación de nuevas herramientas en los ambientes educativos, la RA es una de las más destacadas e importantes tecnologías desarrolladas para este fin (Adams, 2005; L. Johnson, Smith, Willis, Levine, \& Haywood, 2011; Martínez Landa, 2015). Esto se encuentra relacionado con las características que tiene la RA cómo tecnología, particularmente en lo concerniente a la posibilidad de generar un entorno inmersivo e interactivo.

La sensación de inmersión que tienen los usuarios tiene importantes consecuencias en contextos educativos digitales (Dede, 2009):

- La posibilidad de generar múltiples perspectivas de visualización en las que el usuario puede cambiar el contexto de referencia, y que pueden pasar de ser exocéntricas (la visualización desde el exterior del objeto) a egocéntricas (una visualización desde el interior del objeto).

- El contexto de un aprendizaje situado en donde, en un mismo nivel, el contexto y el conocimiento temático son aplicados para mejorar su comprensión y proceso de aprendizaje. Generar entornos virtuales de aprendizaje completos es un proceso complejo, sin embargo estos modelamientos de un mundo virtual o aumentado, permitirían a los estudiantes comprender los contenidos en un contexto real.

- Los estudiantes podrían aplicar su conocimiento adquirido en nuevos contextos o situaciones, generándose un fenómeno de transferencia de contenidos o de aprendizaje.

De la misma manera, González (2013) presenta tres razones complementarias para la utilización de la RA en educación: permite la utilización de contenidos didácticos que no 
son posibles de otra manera; permite una continuidad del proceso de aprendizaje en el hogar; y aporta elementos como interactividad, elementos lúdicos, experimentación y trabajo colaborativo. Por otro lado, la RA, debido a su alta interactividad como tecnología y metodología, se adapta muy bien a paradigmas como el Aprendizaje Basado en Problemas o la Enseñanza Orientada a la Acción (Ai-Lim Lee \& Wong, 2014; Gibbs, 1988).

Adicionalmente, una serie de estudios han probado los efectos de la RA en diferentes dimensiones y temáticas educativas, como son procesos y cambio conceptual (Shelton \& Stevens, 2004); emulación en trabajos de laboratorio (Andujar, Mejías, \& Marquez, 2011); espacialidad y territorialización (Huang, Schmidt, \& Gartner, 2012); aprendizaje basado en consultas (Squire \& Klopfer, 2007), entre otros. Los resultados de estos estudios demuestran las actitudes positivas hacia esta herramienta, particularmente en lo concerniente a la satisfacción en el uso y la percepción de utilidad.

\subsubsection{Aprendizaje móvil (m-learning) y RA}

El m-learning se encuentra directamente relacionado con el e-learning, pasando a ser una tipología independiente, en donde los procesos de enseñanza y aprendizaje tienen un contexto electrónico-tecnológico, de dinamismo o desplazamiento y de portabilidad que ofrecen ciertos dispositivos con un alto rendimiento en procesamiento y almacenamiento de información digital.

Como lo establece Sánchez et al. (2013; 2014) se reconocen una variedad de matices frente a la posible definición de lo que debe ser $m$-learning, poniendo el énfasis en los siguientes elementos:

- Definiciones que se limitan sólo al desarrollo tecnológico (Quinn, 2000).

- Definiciones más amplias que incluyen el posible rol de los estudiantes (O'Malley et al., 2005; Winters, 2007).

- Definiciones que establecen tres pilares fundamentales del m-learning: hardware, interface y diseño pedagógico (Petrova \& Li, 2009).

Si hubiera que situar en una escala jerárquica el $m$-learning, definida por complejidades y procesos involucrados, éste se encontraría situado un nivel más allá del e-learning, pero anterior al desarrollo de un escenario real de aprendizaje en un contexto 
de u-learning (Sánchez Prieto et al., 2014). De esta manera, m-learning sería una evolución natural del e-learning, permitiendo a los estudiantes y usuarios tener un proceso de aprendizaje mediante la tecnología móvil, siendo una primera etapa constitutiva de lo que se entiende como u-learning (Conde, Muñoz, \& García, 2008).

De esta manera, la RA en un contexto de educación en movilidad responde a la necesidad de crear nuevas estructuras didácticas efectivas en estos modelos de enseñanza y aprendizaje desde la tecnología (Fuxin, 2012). Sin embargo, la RA en sistema móviles y aplicados a la educación en sus diferentes niveles (educación primaria, secundaria, terciaria; educación formal e informal) sigue siendo un proceso de adopción reciente y debe ser estudiado y evaluado con más detenimiento (Jamali et al., 2014).

\subsubsection{Aprendizaje Situado (u-learning) y RA}

La tecnología móvil y portable que existe en estos momentos ha generado nuevas formas de implementación de estrategias educativas, que hibridan las situaciones entre el mundo virtual y el real en un ambiente de aprendizaje, siendo la RA una de estas estrategias que está siendo explorada en diferentes contextos educativos. Esta tecnologías permitirían a los estudiantes experimentar una forma particular de aprendizaje basado en la realidad, proceso que se adaptaría a sus conductas utilizando los elementos y herramientas que ofrecen y capturan estos dispositivos (Hwang, Tsai, \& Yang, 2008; $\mathrm{H}$. Norman, Din, \& Nordin, 2011). Así, esta forma de aprendizaje que combina la tecnología móvil, sus respectivos sensores y la posibilidad de acceder a los contenidos desde los contextos personales de los estudiantes y sus situaciones, se le conoce como Aprendizaje Ubicuo -o u-learning- (N. Burbules, 2010; Caldeiro \& Schwartzman, 2013; Hwang et al., 2008; H. Norman et al., 2011; Sánchez Prieto et al., 2014; Zhao, Wan, \& Okamoto, 2010). Comparado con el m-learning, el u-learning sería el nivel máximo existente en el e-learning (Pei et al., 2013). De acuerdo a Zhao, Wan y Okamoto (2010) los entornos en u-learning mantiene una mayor flexibilidad y personalización, respecto a los aspectos generales presentados en los entornos e-learning (Figura 1.9).

Figura 1.9: diferentes dominios en e-learning y u-learning 


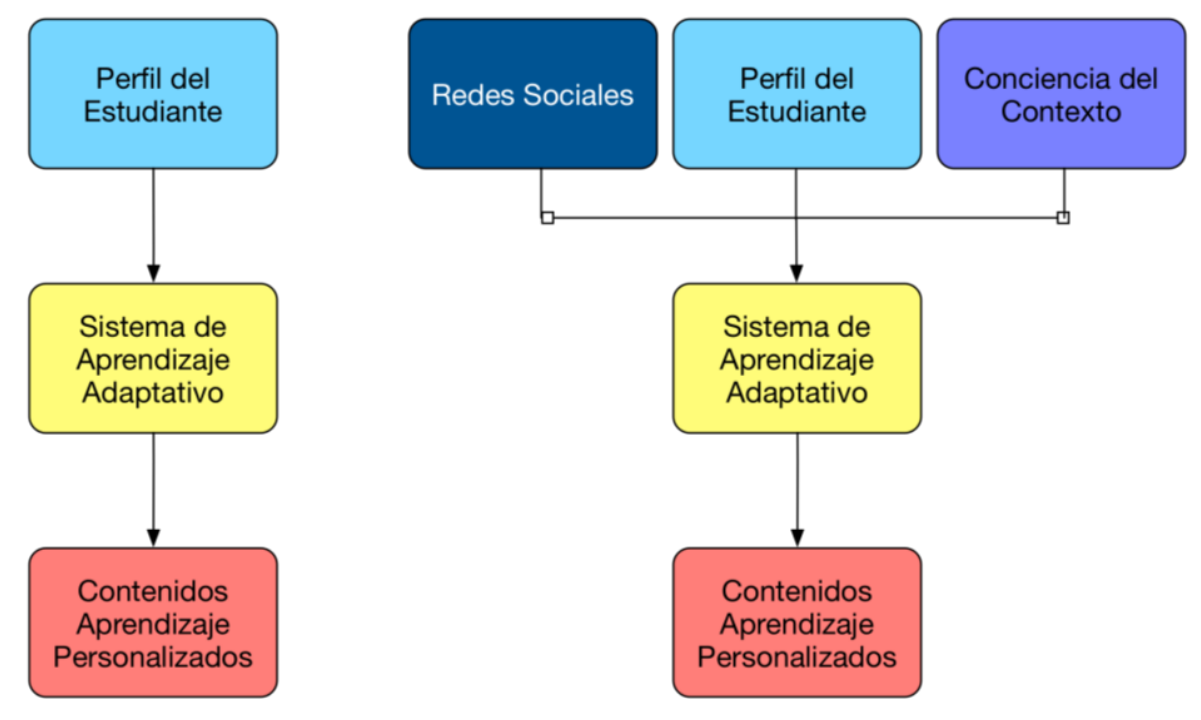

Fuente: Elaboración propia, en base a Zhao, Wan y Okamoto (2010)

Es importante destacar que el u-learning no es una equivalencia directa al aprendizaje móvil, el cual no solamente se enfatiza en el uso de comunicaciones inalámbricas personales, sino también en el uso de los sensores que proveen de otros datos que permiten enriquecer el contexto de localización del aprendizaje. De esta manera, las mayores diferencias son debidas a la "Conciencia del Contexto" y al monitoreo constante mediante el dispositivo, que permitiría al sistema u-learning evaluar las condiciones de la realidad y la resolución de problemas o la potenciación de habilidades de los usuarios (Tabla 1.1).

Tabla 1.1 Comparación de contextos de aprendizaje m-learning y u-learning (Hwang et al., 2008)

Sistema de Aprendizaje

\begin{tabular}{l|l|l}
\hline \multicolumn{1}{|c|}{ Ítem } & \multicolumn{1}{c|}{ m-learning } & \multicolumn{1}{c}{ u-learning } \\
\hline $\begin{array}{l}\text { Conocimiento del } \\
\text { contexto de } \\
\text { aprendizaje de los } \\
\text { estudiantes }\end{array}$ & $\begin{array}{l}\text { Por acceso al portafolio o } \\
\text { sistema (base de datos) de } \\
\text { aprendizaje }\end{array}$ & $\begin{array}{l}\text { Por acceso al portafolio o sistema } \\
\text { (base de datos) de aprendizaje, } \\
\text { además de la detección del } \\
\text { contexto personal del estudiante } \\
\text { (por ejemplo: localización, } \\
\text { temperatura, intensidad lumínica) } \\
\text { y las situaciones ambientales en } \\
\text { el mundo real. }\end{array}$ \\
\hline $\begin{array}{l}\text { Acceso a los servicios } \\
\text { de aprendizaje o } \\
\text { materiales de } \\
\text { enseñanza. }\end{array}$ & $\begin{array}{l}\text { Los estudiantes acceden } \\
\text { activamente al sistema } \\
\text { mediante redes WiFi o 3G/4G }\end{array}$ & $\begin{array}{l}\text { El sistema activamente provee } \\
\text { servicios personalizados a los } \\
\text { estudiantes basados en su } \\
\text { contexto. }\end{array}$ \\
\hline
\end{tabular}




\section{Contenido del portafolio de aprendizaje}

Soporte
personalizado

Registro de los comportamientos en línea del estudiante
Registro de los comportamientos en línea, de los datos y elementos del mundo real y la correspondiente información ambiental del estudiante

Basado en comportamientos personales y situaciones ambientales particulares del estudiante en el mundo real.

Los servicios de aprendizaje no se verían interrumpidos aun cuando el estudiante se encuentre en desplazamiento, y el ambiente de aprendizaje (incluyendo dispositivos y redes) cambien.

De esta manera, la búsqueda de un proceso de aprendizaje auténtico o efectivo, ha llevado a la creación de entornos que ayudan a los estudiantes a fusionar entornos virtuales de aprendizaje con situaciones del mundo real.

En comparación con otros paradigmas, como la teoría del Aprendizaje Situado ${ }^{13}$, mediante la RA es posible obtener un proceso de aprendizaje más significativo y que permitiría la resolución de problemas de una manera más efectiva, respecto a los efectos generados mediante la enseñanza directa (FitzGerald et al., 2012; Lave \& Wenger, 1991). Así, los procesos de aprendizaje se encuentran profundamente relacionados con los contextos personales de los estudiantes, los cuales se producen en el día a día, no existiendo un sentido de aprendizaje sin la presencia de una situación práctica real (Pei et al., 2013). Casi la totalidad de las implementaciones educativas desarrolladas con $e$ learning son formas de Aprendizaje Aumentado. La interacción constante y en diversos niveles que los estudiantes y usuarios realizan con las herramientas informáticas permiten establecer la existencia de un constante proceso de aprendizaje virtualizado. El Aprendizaje Aumentado está directamente relacionado con la Inteligencia Aumentada ${ }^{14}$, la que permite el procesamiento de capacidades para el procesamiento de la información de

${ }^{13}$ Es una forma de aprendizaje donde el proceso fundamental es la adaptación del entorno al estudiante. Al utilizar una solicitud de aprendizaje desde un requisito determinado, el estudiante puede obtener una mayor compresión del tema de estudio. A su vez existe un estímulo constante del descubrimiento y el aprendizaje (Biggs, 2012; Doswell, 2006).

14 La Inteligencia Aumentada, también referido como Cognición Aumentada, denota el uso efectivo de la información tecnológica que permite un mejoramiento en las capacidades de la inteligencia humana (Cerf, 2013; Engelbart, 1962). 
la mente humana mediante una cognición distribuida (Billinghurst, 2002; Goel \& Bhardawaj, 2014). Desde lo anterior, la Inteligencia Aumentada permite el soporte adicional para la autonomía de las personas mediante diversos tipos de herramientas que colaboran en su aprendizaje.

\subsubsection{Elementos que deben estar presentes en el diseño de actividades de aprendizaje en $R A$}

Al igual que en las implementaciones educativas realizadas en m-learning (Camacho \& Lara, 2011; Elias, 2011; Franklin, 2011; Sánchez Prieto et al., 2013, 2014), las aplicaciones de RA que tienen un objetivo educativo, deberían cumplir los siguientes requisitos para un adecuado proceso educativo:

- Módulos de contenidos breves y directos: de acuerdo a las características de las tabletas y smartphones para acceder a los recursos educativos y su principal ventaja de operar on demand (en cualquier momento y lugar), se recomienda el diseño de módulos de duración breve que no superen los 5 minutos.

- Flexibilidad y simplicidad: se debe tener en consideración las diferencias de capacidades de los estudiantes en temáticas con TIC con el fin de adaptar los contenidos para un proceso de enseñanza exitoso.

- Accesibilidad y tolerancia al error: las actividades generadas deben tener una interfaz intuitiva que permita la corrección rápida de errores relacionados con la navegación y el uso del dispositivo.

- Multimedia: la RA es un recurso más que debe estar relacionado con otros elementos integrados como audio, video, imágenes, considerando los aspectos de flexibilidad y síntesis mencionados anteriormente.

- Orientado a la acción: las tabletas y los smartphones no son el objetivo del proceso educativo, por lo tanto la metodología debe estar orientada a lo práctico e interactivo. 
- Comunicación y visibilidad: la portabilidad y la conectividad de estos dispositivos debería conducir a la creación de actividades colaborativas, y permitir la posibilidad de compartir las contribuciones generadas en el proceso de aprendizaje.

- En constante renovación y actualización: los contenidos que se utilizan en $m$ learning y que se relacionan directamente con la utilización de RA, deben hacer referencia a la metodología utilizada, ya que los dispositivos móviles y sus sistemas de software se encuentran en una rápida evolución, incorporando mejoras que pueden ser traspasadas al proceso educativo propuesto.

- Adaptado a las características de los dispositivos: no todos los dispositivos son iguales y difieren en potencia de procesamiento, tamaño, sensores, memoria, etc. Cada actividad ideada debe ser adaptada a los diferentes tipos de hardware y software para que el proceso educativo sea exitoso.

Un último aspecto a considerar por los autores, corresponde a la adecuada formación del profesorado en los aspectos de m-learning, teniendo en cuenta aspectos como la adaptación a un medio tecnológico hiperdinámico, en donde la generación de conocimiento y tecnología experimenta un crecimiento exponencial, por lo que es imprescindible ir adquiriendo nuevas capacidades pedagógicas.

De manera paralela, Cuendet, Bonnard, Do-Lenh y Dillenbourg (2013) plantean dos elementos fundamentales para la utilización de la RA en procesos de aprendizaje: (1) El sistema de RA propuesto debería ser lo suficientemente flexible para que el profesor lo adapte a las necesidades de sus estudiantes; (2) el sistema de RA implementado debería tener en consideración las restricciones presentes en el contexto educativo al cual se aplica. Este último elemento, a pesar de ser poco preciso por la complejidad que se presentan en los escenarios educativos, es una consideración que puede ser aplicada a cualquier contexto de e-learning.

\subsubsection{Experiencias sobre RA y Educación.}

Se han tenido en consideración ocho factores en la utilización de la RA como recurso educativo, para determinar las características y alcance que cada estudio ha tenido en su ámbito de aplicación. Las experiencias han sido seleccionadas para España y la región de 
Latinoamérica, debido al alcance cultural y tecnológico de ambas realidades. De esta manera, los parámetros adaptados de FitzGerald (2012) son:

- Dispositivo o tecnología utilizada: relacionado con el tipo de hardware utilizado, que va desde los ordenadores de sobremesa y portátiles (ambas consideradas herramientas estáticas) hasta la utilización de smartphones, tabletas o gafas de RA.

- Modo de interacción: está referido al tipo de interacción que se desarrolla con los contenidos en RA presentados. Por un lado se encuentra la información pasiva/asimilativa, en la que el estudiante sólo recibe información no pudiendo interactuar con los contenidos; y por otro la activa/exploratoria en donde existe un modo de exploración de los contenidos en donde se les ánima a descubrir y explorar la información presentada.

- Método de retroalimentación sensorial al usuario: se refiere a la forma de percepción que tiene el usuario con los recursos en RA. A pesar que todos los métodos tienen características visuales y sonoras, estos se subdividen en textos, imágenes, audios, videos y modelos tridimensionales.

- Tipo de experiencia: la aplicación de herramientas en RA puede ser individual o grupal, de acuerdo al objetivo que se persiga con la experiencia, y los recursos que se utilicen.

- Implementación móvil o estática: la experiencia se ha realizado en un contexto de trabajo de campo, con elementos de RAM o de manera tradicional en el aula y con un docente guía del proceso.

- Participantes: corresponde a los usuarios (estudiantes) partícipes de la experiencia con RA.

- Actividades de aprendizaje: corresponde al contexto educativo en que se utiliza la herramienta de RA. 
Para el caso de España, la utilización de RA en el ámbito educativo ha estado principalmente contextualizada en el ámbito universitario, en grados de ingeniería y ciencias exactas, aunque hay experiencias en institutos y colegios con interesantes resultados (Tabla 1.2). La mayoría de las experiencias estudiadas utilizan tecnologías estáticas para la visualización de RA (ordenadores de sobremesa y detectores de códigos $\mathrm{QR}$ ) con modelos concretos que visualizan información de modelos tridimensionales simplificados como son figuras geométricas, polígonos o pequeños objetos. Por otro lado, para el caso de Latinoamérica (Tabla 1.3), las experiencias estudiadas están enfocadas a estudiantes de primaria, con recursos tridimensionales previamente creados y contenidos pertenecientes a los programas de estudio de cada realidad. 
Tabla 1.2: Taxonomía inicial de RA aplicada a la Educación en experiencias españolas (adaptado de Fittzgeral et al., 2012)

\begin{tabular}{|c|c|c|c|c|c|c|c|}
\hline $\begin{array}{l}\text { Nombre del } \\
\text { proyecto }\end{array}$ & $\begin{array}{l}\text { Dispositivo } \\
0 \\
\text { tecnología } \\
\text { utilizada }\end{array}$ & Modo de interacción & $\begin{array}{l}\text { Método de } \\
\text { retroalimentaci } \\
\text { ón sensorial al } \\
\text { usuario }\end{array}$ & $\begin{array}{l}\text { Tipo de } \\
\text { experiencia: } \\
\text { personal o } \\
\text { compartida }\end{array}$ & $\begin{array}{l}\text { Implementaci } \\
\text { ón móvil o } \\
\text { estática }\end{array}$ & Participantes & Actividades de aprendizaje \\
\hline $\begin{array}{l}\text { L-ELIRA: Learning } \\
\text { industrial elements } \\
\text { means augmented } \\
\text { reality (Martín } \\
\text { Gutiérrez \& } \\
\text { Meneses } \\
\text { Fernández, 2014) }\end{array}$ & $\begin{array}{l}\text { Ordenador de } \\
\text { sobremesa }\end{array}$ & $\begin{array}{c}\text { Pasivo/asimilativo } \\
\text { mediante capa de } \\
\text { información. } \\
\text { Visualización de } \\
\text { modelos exploratorios. }\end{array}$ & $\begin{array}{l}\text { Visual con } \\
\text { modelos 3D }\end{array}$ & Personal & Estática & $\begin{array}{c}\text { Estudiantes } \\
\text { universitarios de } \\
\text { Grado de Ingeniería } \\
\text { Mecánica }\end{array}$ & $\begin{array}{l}\text { Mediante RA se pretendió mejorar } \\
\text { el proceso de comprensión sobre } \\
\text { el diseño y normalización de } \\
\text { elementos mecánicos sobre } \\
\text { ingeniería Mecánica. }\end{array}$ \\
\hline $\begin{array}{l}\text { GLUEPS-AR } \\
\text { (Muñoz Cristóbal } \\
\text { et al., 2014) }\end{array}$ & $\begin{array}{l}\text { Ordenador de } \\
\text { sobremesa / } \\
\text { Tabletas / } \\
\text { Smartphones }\end{array}$ & $\begin{array}{c}\text { Pasivo/asimilativo } \\
\text { mediante capa de } \\
\text { información. } \\
\text { Activo/exploratorio(regis } \\
\text { tro de } \\
\text { datos/herramientas de } \\
\text { consulta). }\end{array}$ & $\begin{array}{l}\text { Mixto: Visual (VG, } \\
\text { 3D), texto video }\end{array}$ & $\begin{array}{l}\text { Personal y en } \\
\text { grupos }\end{array}$ & $\begin{array}{l}\text { Portátil y } \\
\text { estática }\end{array}$ & $\begin{array}{c}\text { Estudiantes } \\
\text { universitarios del } \\
\text { grado de Magisterio } \\
\text { de Infantil. }\end{array}$ & $\begin{array}{c}\text { Sistema que tiene como objetivo } \\
\text { poner en la práctica escenarios } \\
\text { territoriales con elementos físicos } \\
\text { y virtuales. }\end{array}$ \\
\hline $\begin{array}{l}\text { AR-Dehaes (Martín } \\
\text { Gutiérrez et al., } \\
\text { 2010) }\end{array}$ & $\begin{array}{l}\text { Ordenador de } \\
\text { sobremesa }\end{array}$ & $\begin{array}{l}\text { Pasivo/asimilativo } \\
\text { mediante capa de } \\
\text { información. } \\
\text { Visualización de } \\
\text { modelos exploratorios. }\end{array}$ & $\begin{array}{l}\text { Visual con } \\
\text { modelos 3D }\end{array}$ & Personal & Estática & $\begin{array}{l}\text { Estudiantes del } \\
\text { grado de } \\
\text { Arquitectura e } \\
\text { Ingeniería. }\end{array}$ & $\begin{array}{l}\text { Entrego a los estudiantes una } \\
\text { serie de ejercicios para el } \\
\text { entrenamiento del pensamiento } \\
\text { espacial }\end{array}$ \\
\hline $\begin{array}{l}\text { RA en documentos } \\
\text { e imágenes (Diego } \\
\text { Obregón, 2014) }\end{array}$ & $\begin{array}{l}\text { Ordenador de } \\
\text { sobremesa / } \\
\text { Tabletas / } \\
\text { Smartphones }\end{array}$ & $\begin{array}{l}\text { Pasivo/asimilativo } \\
\text { mediante capa de } \\
\text { información. } \\
\text { Visualización de } \\
\text { modelos exploratorios. }\end{array}$ & $\begin{array}{l}\text { Mixto: Visual 3D, } \\
\text { texto, video, } \\
\text { audio }\end{array}$ & $\begin{array}{l}\text { Personal y en } \\
\text { grupos }\end{array}$ & Estática & $\begin{array}{l}\text { Estudiantes de } \\
\text { tercer ciclo de } \\
\text { primaria }\end{array}$ & $\begin{array}{l}\text { Los estudiantes generan un libro } \\
\text { con contenidos sobre RA de la } \\
\text { península de la Magdalena } \\
\text { (Santander) }\end{array}$ \\
\hline $\begin{array}{l}\text { ARLE: Augmented } \\
\text { Reality Learning } \\
\text { Environment } \\
\text { (Arribas, Gutiérrez, } \\
\text { Gil, \& Santos, } \\
\text { 2014) }\end{array}$ & $\begin{array}{c}\text { Tabletas / } \\
\text { Smartphones }\end{array}$ & $\begin{array}{c}\text { Pasivo/asimilativo } \\
\text { mediante capa de } \\
\text { información. } \\
\text { Activo/exploratorio(regis } \\
\text { tro de } \\
\text { datos/herramientas de } \\
\text { consulta). }\end{array}$ & $\begin{array}{l}\text { Mixto: Visual (VG, } \\
\text { 3D), texto video }\end{array}$ & Personal & Portátil & $\begin{array}{l}\text { Profesores y } \\
\text { estudiantes de } \\
\text { secundaria. }\end{array}$ & $\begin{array}{l}\text { Entorno de aprendizaje basado en } \\
\text { RA con contenidos multimedia } \\
\text { sobre electricidad y electrónica. }\end{array}$ \\
\hline $\begin{array}{c}\text { La RA. Una } \\
\text { experiencia real } \\
\text { (Sánchez Cabana, } \\
\text { 2011) }\end{array}$ & $\begin{array}{l}\text { Ordenador de } \\
\text { sobremesa }\end{array}$ & $\begin{array}{c}\text { Pasivo/asimilativo } \\
\text { mediante capa de } \\
\text { información. } \\
\text { Visualización de } \\
\text { modelos exploratorios }\end{array}$ & $\begin{array}{l}\text { Visual con } \\
\text { modelos 3D }\end{array}$ & $\begin{array}{l}\text { Personal y en } \\
\text { grupos }\end{array}$ & Estática & $\begin{array}{l}\text { Estudiantes de } \\
\text { instituto }\end{array}$ & $\begin{array}{c}\text { Los estudiantes generan modelos } \\
\text { 3D sobre dibujo técnico } \\
\text { (axonométrico). La experiencia } \\
\text { ayudó a desarrollar la capacidad } \\
\text { visual de los estudiantes }\end{array}$ \\
\hline $\begin{array}{l}\text { Proyecto espiRA } \\
\text { (Reinoso, 2012) }\end{array}$ & $\begin{array}{l}\text { Ordenador de } \\
\text { sobremesa } \\
\text { /Tabletas } \\
\text { Smartphones }\end{array}$ & $\begin{array}{l}\text { Pasivo/asimilativo } \\
\text { mediante capa de } \\
\text { información. } \\
\text { Visualización de } \\
\text { modelos exploratorios }\end{array}$ & $\begin{array}{l}\text { Mixto: Visual 3D, } \\
\text { texto, video, } \\
\text { audio }\end{array}$ & $\begin{array}{l}\text { Personal y en } \\
\text { grupos }\end{array}$ & $\begin{array}{l}\text { Portátil y } \\
\text { estática }\end{array}$ & $\begin{array}{l}\text { Profesores y } \\
\text { estudiantes de } \\
\text { secundaria }\end{array}$ & $\begin{array}{l}\text { Proyecto de contenidos de } \\
\text { geolocalización y RA mediante } \\
\text { una plataforma de fácil utilización. }\end{array}$ \\
\hline
\end{tabular}

Fuente: Elaboración propia. 
Tabla 1.3: Taxonomía inicial de RA aplicada a la Educación en experiencias latinoamericanas (adaptado de FitzGerald et al., 2012)

\begin{tabular}{|c|c|c|c|c|c|c|c|}
\hline $\begin{array}{l}\text { Nombre del } \\
\text { proyecto }\end{array}$ & $\begin{array}{l}\text { Dispositivo } \\
\text { o } \\
\text { tecnología } \\
\text { utilizado }\end{array}$ & Modo de interacción & $\begin{array}{l}\text { Método de } \\
\text { retroalimentaci } \\
\text { ón sensorial al } \\
\text { usuario }\end{array}$ & $\begin{array}{l}\text { Tipo de } \\
\text { experiencia: } \\
\text { personal o } \\
\text { compartida }\end{array}$ & $\begin{array}{l}\text { Implementaci } \\
\text { ón móvil o } \\
\text { estática }\end{array}$ & Participantes & Actividades de aprendizaje \\
\hline $\begin{array}{l}\text { Proyecto Saltet } \\
\text { (Ramirez \& } \\
\text { Cassinerio, 2014) }\end{array}$ & Tabletas & $\begin{array}{l}\text { Pasivo/asimilativo mediante } \\
\text { capa de información. } \\
\text { Visualización de modelos } \\
\text { exploratorios. }\end{array}$ & $\begin{array}{l}\text { Visual con } \\
\text { modelos 3D }\end{array}$ & $\begin{array}{l}\text { Personal y en } \\
\text { grupos }\end{array}$ & Estática & $\begin{array}{l}\text { Estudiantes de } \\
\text { Educación } \\
\text { Inicial } \\
\text { (Infantil) y } \\
\text { Primaria }\end{array}$ & $\begin{array}{c}\text { Uso de RA en niños de } 5 \text { años con } \\
\text { contenidos sobre circulación vial, ciclo del } \\
\text { agua, el esqueleto humano y los } \\
\text { sentidos, en un contexto de trabajo } \\
\text { colaborativo. }\end{array}$ \\
\hline \multirow{2}{*}{$\begin{array}{c}\text { Proyecto } \\
\text { "Nuestra } \\
\text { experiencia con } \\
\text { RA" (Cadillo } \\
\text { I eńn. Dn13) } \\
\text { RA sobre web y } \\
\text { video en tiempo } \\
\text { real: Plataforma } \\
\text { de trabajo } \\
\text { colaborativo para } \\
\text { asistir al diseño } \\
\text { arquitectónico } \\
\text { (Suazo, 2008) }\end{array}$} & $\begin{array}{l}\text { Ordenador } \\
\text { de } \\
\text { sobremesa }\end{array}$ & $\begin{array}{l}\text { Pasivo/asimilativo mediante } \\
\text { capa de información. } \\
\text { Visualización de modelos } \\
\text { exploratorios. }\end{array}$ & $\begin{array}{l}\text { Visual con } \\
\text { imágenes }\end{array}$ & $\begin{array}{l}\text { Personal y en } \\
\text { grupos }\end{array}$ & Estática & $\begin{array}{l}\text { Estudiantes de } \\
\text { Primaria }\end{array}$ & $\begin{array}{l}\text { Creación de aplicaciones mediante } \\
\text { Scratch para la enseñanza de } \\
\text { programación y de contenidos en RA en } \\
\text { niños de EGB. }\end{array}$ \\
\hline & $\begin{array}{l}\text { Ordenador } \\
\text { de } \\
\text { sobremesa }\end{array}$ & $\begin{array}{l}\text { Pasivo/asimilativo mediante } \\
\text { capa de información. } \\
\text { Activo/exploratorio(registro de } \\
\text { datos/herramientas de } \\
\text { consulta). }\end{array}$ & $\begin{array}{l}\text { Visual con } \\
\text { modelos 3D }\end{array}$ & $\begin{array}{l}\text { Personal y en } \\
\text { grupos }\end{array}$ & Estática & $\begin{array}{l}\text { Estudiantes del } \\
\text { grado de } \\
\text { Arquitectura }\end{array}$ & $\begin{array}{l}\text { Uso de la RA para mostrar proyectos } \\
\text { arquitectónicos y cómo se incorpora a las } \\
\text { personas inexpertas en interpretar } \\
\text { planimetrías, u obtener información más } \\
\text { completa que desde proyecciones } \\
\text { planas/pasivas como fotografías o } \\
\text { dibujos. Se suma el concepto de la } \\
\text { telepresencia sincrónica }\end{array}$ \\
\hline $\begin{array}{l}\text { AuthorAR } \\
\text { (Moralejo, Sanz, } \\
\text { Pesado, \& } \\
\text { Baldassarri, } \\
\text { 2014) }\end{array}$ & $\begin{array}{l}\text { Ordenador } \\
\text { de } \\
\text { Sobremesa }\end{array}$ & $\begin{array}{l}\text { Pasivo/asimilativo mediante } \\
\text { capa de información. } \\
\text { Activo/exploratorio(registro de } \\
\text { datos/herramientas de } \\
\text { consulta). }\end{array}$ & $\begin{array}{l}\text { Visual con } \\
\text { modelos 3D }\end{array}$ & $\begin{array}{l}\text { Personal y en } \\
\text { grupos }\end{array}$ & Estática & $\begin{array}{l}\text { Estudiantes de } \\
\text { secundaria y } \\
\text { primaria. }\end{array}$ & $\begin{array}{l}\text { Sistema de RA que genera actividades de } \\
\text { estructuración de frases en el contexto } \\
\text { de sujeto-acción-sujeto mediante } \\
\text { registradores que mantienen la } \\
\text { información digital. }\end{array}$ \\
\hline $\begin{array}{c}\text { Math4Life } \\
\text { (Caspa, de la } \\
\text { Cruz, \& Yarnold, } \\
\text { 2011) }\end{array}$ & $\begin{array}{l}\text { Ordenador } \\
\text { de } \\
\text { Sobremesa }\end{array}$ & $\begin{array}{l}\text { Pasivo/asimilativo mediante } \\
\text { capa de información. } \\
\text { Visualización de modelos } \\
\text { exploratorios. }\end{array}$ & $\begin{array}{l}\text { Visual con } \\
\text { imágenes }\end{array}$ & $\begin{array}{l}\text { Personal y en } \\
\text { grupos }\end{array}$ & Estática & $\begin{array}{l}\text { Niños } \\
\text { preescolares y } \\
\text { de primer y } \\
\text { segundo grado } \\
\text { de primaria. }\end{array}$ & $\begin{array}{c}\text { Propuesta de RA enfocada en estudiantes } \\
\text { de } 3^{\circ} \text { grado de primaria con el fin de } \\
\text { incrementar de manera significativa los } \\
\text { aprendizajes en matemáticas. }\end{array}$ \\
\hline $\begin{array}{l}\text { ArgentinaVirtual } \\
\text { (EducAR, 2014) }\end{array}$ & $\begin{array}{l}\text { Ordenador } \\
\text { de } \\
\text { Sobremesa }\end{array}$ & $\begin{array}{l}\text { Pasivo/asimilativo mediante } \\
\text { capa de información. } \\
\text { Visualización de modelos } \\
\text { exploratorios. }\end{array}$ & $\begin{array}{l}\text { Visual con } \\
\text { imágenes }\end{array}$ & $\begin{array}{l}\text { Personal y en } \\
\text { grupos }\end{array}$ & Estática & $\begin{array}{l}\text { Estudiantes y } \\
\text { profesores en } \\
\text { general. }\end{array}$ & $\begin{array}{l}\text { Sistema que permite mediante RA, } \\
\text { mostrar elementos de diferentes museos } \\
\text { de toda Argentina, para que los niños } \\
\text { puedan conocerlos sin tener que viajar } \\
\text { hasta ellos. }\end{array}$ \\
\hline $\begin{array}{l}\text { Uso de la RA } \\
\text { (Cadillo León, } \\
\text { 2015) }\end{array}$ & $\begin{array}{l}\text { Ordenador } \\
\text { de } \\
\text { Sobremesa }\end{array}$ & $\begin{array}{l}\text { Pasivo/asimilativo mediante } \\
\text { capa de información. } \\
\text { Visualización de modelos } \\
\text { exploratorios }\end{array}$ & $\begin{array}{l}\text { Visual con } \\
\text { imágenes }\end{array}$ & Personal & Estática & $\begin{array}{l}\text { Estudiantes de } \\
\text { educación } \\
\text { primaria. }\end{array}$ & $\begin{array}{c}\text { Desarrollo de una aplicación usando RA y } \\
\text { visión artificial para desarrollar } \\
\text { habilidades kinestésicas y lógicas en los } \\
\text { niños. }\end{array}$ \\
\hline
\end{tabular}

Fuente: Elaboración propia. 


\subsection{Debilidades de la Realidad Aumentada}

A pesar que las investigaciones iniciales han mostrado diversos aspectos prometedores de la RA y la RAM en el campo de la educación, todavía se presentan diversos aspectos que continúan siendo una debilidad para este tipo de implementaciones tecnológicas.

\subsubsection{Debilidades en el ámbito pedagógico}

Para algunos autores (Dünser, Walker, Horner, \& Bentall, 2012; FitzGerald et al., 2012; Jamali et al., 2014) la tecnología de RA todavía no presenta un grado importante de madurez en el ámbito educativo formal, debido a diversos factores:

- La escasez de contenidos educativos creados para este tipo de tecnología.

- La falta de una comprensión detallada y educativa de los contenidos temáticos que se quieren representar en implementar RA. No todos los fenómenos pueden ser representados e implementados con este tipo de tecnología.

- Lo novedoso de la tecnología y la experiencia en RA podría ir en detrimento de la experiencia de aprendizaje propuesta.

- Las limitaciones tecnológicas (características y capacidad de los dispositivos, la ausencia de conexión a la red, entre otros) pueden incidir en el cómo y dónde ocurren los procesos de aprendizaje.

Existen algunas investigaciones que muestran una actitud positiva por parte de los estudiantes en torno a la utilización de dispositivos móviles y de recursos digitales en los procesos de enseñanza-aprendizaje (Dündar \& Akçayır, 2014). Sin embargo, en cuanto a la percepción de los educadores y profesores existe una opinión dividida en torno al uso de estos sistemas y tecnologías para la educación formal (Ifenthaler \& Schweinbenz, 2013), teniendo reparos en la capacitación en el uso de este tipo de tecnologías y el verdadero rendimiento de los estudiantes en sus procesos de aprendizaje. 


\subsubsection{Debilidades en el ámbito tecnológico}

El principal condicionante en el ámbito técnico es la elección de un sistema móvil o fijo de RA, que debería tener como objetivo la posibilidad de permitir al usuario centrarse en la aplicación y contenidos sobre RA, en lugar de la operatividad del propio dispositivo. Esto, con el fin de hacer la experiencia más natural y socialmente aceptable, permitiendo que los objetivos educativos planteados superen al simple despliegue tecnológico. Sin embargo, también hay otros elementos que se deben tener en consideración:

- En la generación de recursos digitales para su uso en RA, se hace necesaria una alta capacitación y experticia en la creación de modelados tridimensionales, texturas y animación digital. A su vez, la implementación de estos recursos requiere de importantes habilidades en programación e implementación informática.

- Los altos costos en infraestructura (hardware y software) para la implementación de esta herramienta como recurso educativo.

- Las limitaciones propias de los dispositivos en algunos de sus sensores o funcionalidades (conectividad con sistemas de navegación o cobertura de la red 3G ० 4G).

En la actualidad, muchos de estos condicionantes están siendo abordados mediante la creación de aplicaciones que no requieren competencias específicas en el manejo de programación e implementación de software. Por ejemplo, las notables capacidades de almacenamiento de los dispositivos actuales hacen que la conexión a WiFi o $3 \mathrm{G}$ no sea esencial para disponer de información, limitándose su uso a obtener con precisión la ubicación del usuario. De este modo se pueden usar técnicas de RAM sin unos requisitos de conectividad elevados. 
Además, es posible encontrar en la red algunos recursos 3D para $\mathrm{RA}^{15}$, pero que requieren una adecuada interacción operativa (importación-exportación de los recursos) y una adecuada contextualización educativa.

15 Ejemplo de estas iniciativas son 3D Warehouse de Sketchup (https://3dwarehouse.sketchup.com, consultado el 3 de septiembre de 2014) en donde existe una gama de recursos creados por una diferentes usuarios en torno a una comunidad de creadores. 


\subsection{Resumen}

En el presente capítulo se ha realizado una síntesis de lo que es la RA, sus características y sus derivaciones, tanto en las dimensiones tecnológicas como educativas. La idea ha sido mostrar la evolución de un sistema tecnológico que lleva más de 30 años de desarrollo, pero cuyo auge y masificación (derivado de las potencialidades de los dispositivos móviles, particularmente de tabletas y smartphones) ha sido relativamente reciente. En una primera parte se abordan los aspectos técnicos de la RA, con sus formas de implementación, elementos e interfaces de despliegue. De esta manera, la RA se puede considerar un sistema intermedio entre lo que puede ser la realidad absoluta (análoga) y la realidad virtual (digital), siendo esta última una emulación total de un ambiente mediante un sistema informático.

Posteriormente, se lleva a cabo una caracterización de la RAM, un tipo de RA que se relaciona directamente con la portabilidad de los sistemas móviles (además de la complejidad de sus sensores), y la cual tiene características particulares como son la geolocalización, lo que permiten una mayor personalización de la experiencia por parte de los usuarios.

Adicionalmente, se presenta a la RA desde la dimensión educativa, contextualizándola en estructuras como son el m-learning y particularmente en el ulearning, determinando sus características, analogías y formas de implementación en procesos de enseñanza-aprendizaje. Así, el análisis de experiencias en el ámbito español y latinoamericano, ha permitido establecer un contexto del cómo esta tecnología está siendo abordada en los diferentes escenarios educativos en que se plantean.

Finalmente, se exponen las debilidades y limitaciones en la implementación definitiva de esta tecnología en contextos educativos y sociales generales, permitiendo evaluar su pertinencia y posibilidades en la propuesta que se quiere realizar desde el ámbito del patrimonio territorial a nivel local. 
Capítulo II

Aplicación de los dispositivos móviles a la navegación peatonal, geotecnología, representación territorial y contextos educativos 



\section{APLICACIÓN DE LOS DISPOSITIVOS MÓVILES A LA}

\section{NAVEGACIÓN PEATONAL, GEOTECNOLOGÍA, REPRESENTACIÓN TERRITORIAL Y CONTEXTOS EDUCATIVOS}

\subsubsection{Introducción}

Desde sus inicios como ente social, el ser humano se ha involucrado con el territorio, los paisajes y los lugares, generando diversas herramientas condicionadas a su contexto histórico para la comprensión de estos sistemas: desde la simple representación gráfica en papel (mapa), pasando a la brújula, el astrolabio y los sistemas de coordenadas (latitud y longitud), hasta la complejidad digital actual con la implementación de servidores de mapas, los sistemas globales de navegación por satélite y la información colaborativa sobre estas herramientas, elementos propios de la Web 2.0 y $3.0^{16}$.

Ya se ha hablado del potencial de los dispositivos móviles y las enormes capacidades en torno al procesamiento y visualización de información digital. Conviene también destacar una de las dimensiones fundamentales de los datos virtuales: su localización. En términos simples, la localización, se podría definir como la situación euclidiana de estos objetos (su expresión en un sistema de coordenadas $X, Y$ y Z conocido). Esto supone nuevas perspectivas del cómo entendemos estos elementos desde su dimensión espacial y del cómo se relacionan entre sí en un escenario territorial real, en una forma no sólo tridimensional, sino multidimensional, con unas características, relaciones y magnitudes que definen el sistema completo.

Intentar representar escenarios de la complejidad multidimensional que tiene el territorio, en un sistema sintético bidimensional, como puede ser el papel o una pantalla, es una tarea compleja que tiene muchos elementos que deben ser considerados en su síntesis, replicación y emulación. Sin embargo, en estos momentos el alcance tecnológico, y particularmente el de los dispositivos móviles, ha permitido una revolución en la forma

\footnotetext{
${ }^{16}$ La Web 2.0 corresponde al momento que en la World Wide Web permite la interoperabilidad, usabilidad y los contenidos generados por los usuarios, y en donde se presenta la masificación de las redes sociales (O'Reilly, 2005, 2006). En cuanto a la definición de Web 3.0, no existe un claro consenso en su definición, implementación y características. Sin embargo se le asocia a la Web Semántica, a la implementación de la Inteligencia Artificial, los datos 3D y la información Geoespacial (Berners-Lee, Hendler, \& Lassila, 2001; Brodkin, 2007).
} 
en que se representan, consultan y acceden los datos espaciales. Actualmente, casi cualquier dispositivo móvil ofrece posibilidades de visualización de mapas que nunca antes estuvieron a nuestro alcance, o que requerían potentes sistemas especializados para su creación y despliegue. Y estos nuevos mapas ofrecen, además, importantes posibilidades de interacción con el usuario.

Claramente nos encontramos en un nuevo estadio de representación espacial y procesamiento de datos territoriales, en donde el mapeo inteligente-que es personalizado y se ajusta a nuestra ubicación instantánea- ha llevado a nuevas situaciones, integraciones y percepciones que deben ser abordadas como un conjunto tecnológico que está siendo aplicado a contextos sociales (Joo Nagata, 2013; Joo Nagata, García-Bermejo Giner, \& Muñoz Rodríguez, 2015).

Son diversas las disciplinas de las Ciencias Sociales que han empleado metodologías para intentar crear teorías que describan las relaciones que se producen entre la tecnología, el medio y la interacción entre los usuarios. En particular, y ya desde mediados de la década de los 80, las investigaciones de Suchman (2006) se enfocan en el uso de las tecnologías con acciones situadas en un ambiente rico en posibles interacciones, lo que marca un inicio en las investigaciones para determinar las verdaderas relaciones que existen entre tecnología y territorio. De esta manera, una de las consecuencias de la utilización de la masificación de los datos territoriales mediante dispositivos móviles ha sido la Navegación Peatonal, que al igual que la navegación realizada en otros medios como los automóviles en calles y caminos o embarcaciones en el mar, es un proceso que se realiza a la mayor escala existente (1:1) asistido por las herramientas informáticas disponibles.

Por otro lado, los mapas digitales se han masificado en la última década mediante el desarrollo de la web 2.0, permitiendo la interoperabilidad mediante estándares como XML y HTML. Esto aporta nuevas oportunidades para el desarrollo de esta técnica (Hanchard, 2013), entre las cuales cabe destacar las siguientes: 
1. La "prosumición"17 en donde la producción de los mapas puede ser realizada por los consumidores-usuarios con programas e interfaces de programación de aplicaciones abiertas al público

2. La ubicación de eventos propios de las redes sociales. Esto es, las interacciones sociales que se desarrollan y se expresan en la red tienen también una localización en el espacio.

Conviene también mencionar el alto grado de participación y flexibilidad en la creación de estos contenidos que se expresan en el territorio (Figura 2.1), generando por ejemplo sistemas digitales completamente flexibles en modo y grado como es OpenStreetMap ${ }^{18}$, proyecto colaborativo para la generación de información geográfica digital. Obsérvese que este proyecto permite añadir información propia, que refuerza a la ya existente cuando la cartografía es insuficiente en algún sentido. Por contraposición, también se dispone de sistemas que sólo ofrecen los servicios de consulta de la información territorial, con datos previamente establecidos por grupos o entidades privadas (Nokia Here Maps ${ }^{9}$ y Apple Maps' ${ }^{0}$ ).

\footnotetext{
17 Un "prosumidor" (o "prosumer" en idioma inglés) es un acrónimo de las palabras 'productor' y 'consumidor', y que marca una tendencia emergente propia de los servicios presentes en la web 2.0 (Dumova \& Fiordo, 2010)

18 http://www.openstreetmap.org.

${ }^{19} \mathrm{http}: / /$ www.here.com.

${ }^{20} \mathrm{https}: / /$ mapsconnect.apple.com.
} 
Figura 2.1 Clasificación de las aplicaciones sociales con localización por modo y grado de prosumición(basado en Fischer, 2014)

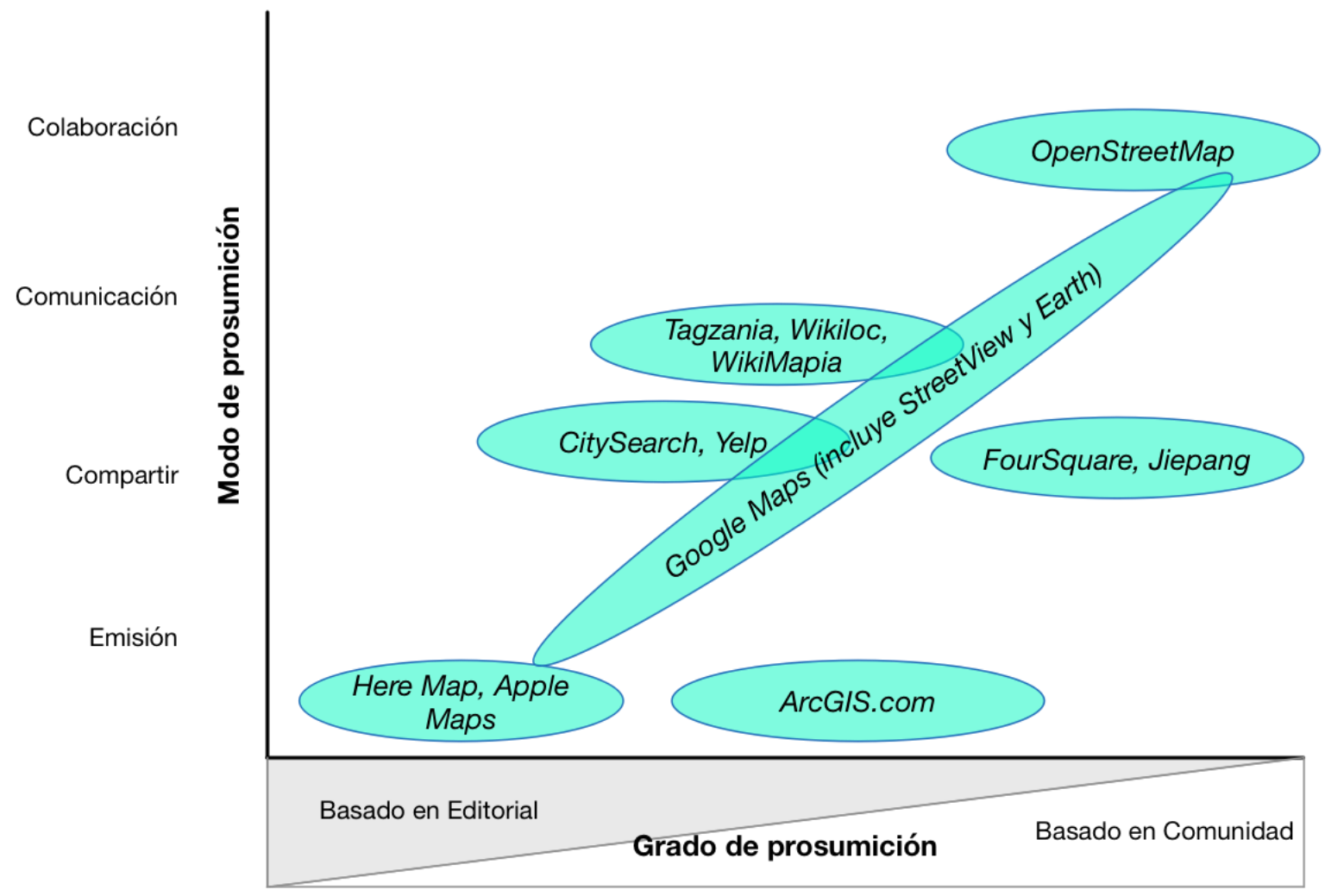

Dilucidar cómo estas nuevas formas de representación de datos espaciales es comprendida e incorporada en los procesos de aprendizaje, es una labor que se ha llevado a cabo desde hace algún tiempo, definiendo inicialmente competencias y ejemplos que se desarrollan en la enseñanza de diferentes disciplinas relacionadas con el ámbito territorial.

\subsection{Modelamiento y análisis del territorio a través de diferentes técnicas de representación y abstracción}

Intentar representar un fenómeno tridimensional o incluso multidimensional, que tiene una estructura que supera la simple percepción humana, es una labor compleja ${ }^{21}$ que requiere de técnicas y representaciones adecuadas a este tipo de fenómenos. Además, la síntesis de dichas estructuras en un modelo que sólo tiene dos dimensiones las que pueden representarse en papel (planos y mapas) o en pantallas (ordenadores, tabletas y teléfonos inteligentes)- hace más dificultosa una reproducción fidedigna de la

${ }^{21}$ El diámetro ecuatorial de la Tierra es de $12.756 \mathrm{~km}$ y el eje polar son $12.714 \mathrm{~km}$, con una circunferencia ecuatorial (máxima) de 45.075 km (Strahler \& Strahler, 2000). 
superficie terrestre y sus elementos. Sin embargo, se ha creado una serie de técnicas y convenciones que han permitido superar estos inconvenientes, generando lo que se conoce como la disciplina cartográfica, una de las encargadas de perfeccionar de manera constante estas herramientas, sus elementos y sus implementaciones. Además, con el advenimiento de los ordenadores, gracias a su enorme capacidad de proceso y almacenamiento, la cartografía se ha visto favorecida con la mejora de sus técnicas ${ }^{22}$ y la masificación de sus contenidos, llegando en la actualidad a la movilidad, ubicuidad y personalización de la información en torno a la localización.

\subsubsection{Mapas, cartas y planos}

La realización de mapas o representaciones del espacio ha sido parte de la historia del ser humano en su intento de comprender su entorno, establecer su relación con la naturaleza, mostrar su magnitud en el contexto del mundo conocido y comprender su lugar como ser individual y social en un sistema territorial complejo.

La primera representación reconocida como mapa es una semejanza de la ciudad de Çatalhöyük en Anatolia (anteriormente conocida como Hüyük Huyuk), que data aproximadamente del año 700 a. C. (Meece, 2006). Se trata de un mural situado en una de las pocas paredes que aún perduran, y que al ser excavadas mostraban lo que parece ser una imagen de la población a vista de pájaro, y la erupción de un volcán próximo. Esta sencilla representación en blanco y negro es hasta el momento el primer predecesor de los actuales mapas.

En las antiguas civilizaciones griega y romana la creación de los mapas comenzó con Anaximandro de Mileto en el siglo VI a. C. Mucha de la información territorial generada por estas civilizaciones se conoce a través de descripciones o referencias literarias, ya que las obras originales fueron destruidas o han desaparecido a lo largo del tiempo (Thrower, 2002). Fue en esta época en donde se comienzan a debatir cuestiones como dónde está el centro del mundo y cómo se pueden clasificar las regiones del mundo conocido en esos momentos. La idea de una Tierra redonda también se hace plausible y fue completada por el cálculo que realiza Eratóstenes de Alejandría (276-196 a. C.) sobre la circunferencia

\footnotetext{
22 Las disciplinas complementarias a la cartografía son la geodesia, que es la ciencia que busca determinar el tamaño y forma real de la Tierra teniendo como parámetro su campo gravitatorio (Heiskanen \& Moritz, 1985), y la fotogrametría, que es la herramienta que permite obtener información de los fenómenos de la superficie terrestre mediante la medición de imágenes fotográficas (Deagostini Routin \& Murillo Forero, 1978).
} 
real de nuestro planeta ${ }^{23}$. Posteriormente en el siglo II d. C. Claudio Ptolomeo construye una representación del mundo conocido llamado "Ecúmene" (Berggren, 2000), además de su obra Geographia, que aporta instrucciones para elaborar mapas y sistemas de posicionamiento mediante meridianos y paralelos locales.

Ya en la realidad medieval presente en Europa, se establece el termino de 'Mapamundl, representaciones cartográficas las cuales eran elaboradas artesanalmente. Han sobrevivido 1100 de estas representaciones de las cuales, 900 se encuentran en incunables (Woodward, 1987, p. 286). No solamente en Europa se dieron avances en la disciplina cartográfica: existen mapas de origen chino que datan del siglo IV pertenecientes al Estado de Qin, durante la época de los Reinos Combatientes. Destaca el libro Xin Yi Xiang Fa Yao, cuyo autor fue Su Song en el año 1092, en donde se presenta una carta astronómica con una proyección de Mercator, considerándose los mapas impresos de más antigua data (Miyajima, 1998). En el mundo árabe también se realizaron importantes avances en la disciplina, como la Tabula Rogeriana, realizada en 1154 por Muhammad al-Idrisi, representación cartográfica que incorpora las tierras del África y el Extremo Oriente conocido, además de la incorporación de parte del océano Índico, logrando ser la representación más exacta de su tiempo (Thrower, 2002).

La aparición de la brújula supuso un nuevo impulso para la cartografía, existiendo en Europa en el siglo XIII un gran interés por la aplicación en el ámbito de la navegación marítima. De esta manera nacieron los portulanos, cartas de navegación cuya finalidad era ayudar a los pilotos de los navíos de la época. Se caracterizaban por la exageración en las formas de las costas, y con una notable exactitud para las costas del Mediterráneo y las del Mar Muerto (T. Campbell, 1987).

Terminada la Edad Media, comenzó un importante auge de la cartografía relacionada con la época de los descubrimientos, además del desarrollo de los conocimientos del mundo musulmán y judío en torno al desarrollo de los mapas. Además, el perfeccionamiento de la brújula, el telescopio, el sextante, la definición de elementos

\footnotetext{
${ }^{23}$ Eratóstenes se dio cuenta de que los rayos del Sol caían perpendicularmente sobre Syene (Assuán) durante el solsticio de verano en el hemisferio norte y que no se proyectaba sombra en las estructuras verticales. En el mismo día del año, en la ciudad de Alejandría, que se encontraba al norte de Syene, las edificaciones verticales proyectaban una sombra que presentaba un valor 1/50 de un círculo exacto. Sabiendo que ambas ciudades se encontraban en el mismo meridiano, la única explicación posible a dicho fenómeno era la curvatura (o esfericidad) de la superficie terrestre en que se encontraban ambos lugares. Obteniendo la distancia que separa a ambos lugares (5000 estadios, unidad de medida de la época) y con algunos simples cálculos trigonométricos, Eratóstenes pudo obtener un valor muy aproximado de la superficie real de la Tierra cifrado en 250.000 estadios (Sagan, 1982; Thrower, 2002).
} 
como la longitud ${ }^{24}$ y la topografía, propiciaron una época emergente para la disciplina cartográfica. Se redescubrieron (o copiaron) importantes obras cartográficas del mundo antiguo, como las obras de Ptolomeo, ayudando a las empresas imperiales que funcionarían a lo largo del Renacimiento (Thrower, 2002). Hacia 1570 Gerardus Mercator acuña la palabra Atlas para describir una colección de mapas. Esto es la base para que Abraham Ortelius realice su primera compilación de mapas modernos o Atlas Mundial, conocido como Theatrum Orbis Terrarum (Crane, 2003). Además, Mercator crea una proyección cartográfica cilíndrica y conforme (elementos que se desarrollarán posteriormente), realizada con elementos geométricos, proporcionando mucha más precisión para el desarrollo de la navegación mundial que la que se realizaba en la época.

Ya en los siglos XVII y XVIII, la cartografía se torna realmente una herramienta objetiva, con el uso de técnicas matemáticas, geométricas y astronómicas. De hecho, uno de los grandes desafíos de la representación terrestre era la medición de las alturas del relieve (estableciendo un eje $Z$ ) presente en la superficie terrestre, lo cual se hizo posible mediante el perfeccionamiento de técnicas como la trigonometría, además de la creación de instrumentos como el teodolito. Estas técnicas e instrumentos permitirían la consolidación de métodos como la representación isométrica, conocida también como curvas de nivel (Garfield, 2013). El desarrollo de la tecnología en el ámbito militar permitió la consolidación de la información planimétrica, y dio lugar a la generación de criterios de consistencia, regularidad y uniformidad en un contexto de conflictos militares (Black, 2008).

Otro hito importante para la localización y el mapeo de la superficie terrestre, fue el establecimiento del meridiano 0, o meridiano principal, en el observatorio astronómico de Greenwich localizado en Londres. Para el año 1884, en la Conferencia Internacional del Meridiano realizada en Washington DC, se define dicha localización como estándar en el mapeo y localización. Hasta ese año, existían diversos meridianos definidos localmente para la estimación de la longitud. Debido al auge mercantil y la preponderancia que tenía el imperio Británico en aquel periodo, se define dicha localización como punto estándar para el desarrollo de la navegación y el mapeo mundial (Van der Merwe, 2012).

La cartografía y la representación del territorio han sido disciplinas muy permeables a la evolución tecnológica, con avances constantes que han permitido importantes logros

\footnotetext{
${ }^{24}$ La longitud, vital para la localización de los navíos, resultaba muy difícil de determinar hasta la invención de los relojes portátiles exactos durante la mitad del siglo XVIII (Thrower, 1996).
} 
en la forma y exactitud de los datos que se quieren visualizar. Ya desde la distante época en que los mapas eran exclusivas construcciones artesanales con una limitada difusión, se ha mejorado su realización, además de crear y perfeccionar técnicas complementarias. El advenimiento de las brújulas, la imprenta, el telescopio, el sextante, el cuadrante y la escala de Vernier han permitido la creación de mapas y planos más precisos, con la capacidad de reproducir adecuadamente dicha información territorial. En la segunda mitad del siglo XX, los avances tecnológicos en la electrónica y la informática han permitido, aún más, incrementar las precisiones de esta técnica. Las pantallas y monitores de ordenador, plotters, impresoras, scanners y los sensores remotos, han permitido una mejor visualización, procesamiento y análisis de la información territorial. De manera particular destacan el desarrollo de las bases de datos espaciales, las cuales han expandido las posibilidades en la generación y difusión de la cartografía en contextos digitales.

Desde una dimensión sociológica, García Rojas (2008) establece que estas herramientas son una compleja "construcción social", conteniendo un discurso que se sitúa desde el poder político y cultural de la sociedad que hace dicha realización. Incluso investigadores como Steven Weber dilucidan que conceptos geopolíticos como el de "Estado-Nación", se crean como subproductos no intencionados a partir de los avances en la cartografía desarrollados en el siglo XV (Branch, 2011). Para otros autores, se ha comenzado la etapa de la "espacialidad digital", la cual es parte de la vida cotidiana de las personas, las cuales demandan de manera permanente sistemas informáticos asociados a la representación del territorio y la localización de contenido en modelos digitales (Calvo, 2011; Capel, 2009; López, 2012). Así se llega a un nuevo estadio de la creación, almacenamiento y difusión de los datos espaciales en la red, etapa que se conoce como Neogeografía, concepto que describe la masificación de estas tecnologías digitales, las que mediante diversos tipos de dispositivos y técnicas informáticas son utilizadas por personas y usuarios no técnicos en representación, creación y análisis de datos geográficos, derivado del uso informal que habitualmente se les realiza a estas herramientas (Brovelli, Minghini, \& Zamboni, 2015; Flanagin \& Metzger, 2008; Goodchild, 2007, 2008, 2009; M. Graham, 2010; Lingel \& Bishop, 2014). Esta información territorial se hace visible, en un primer momento, mediante el desarrollo de la cartografía digital, la cual tiene una amplia difusión en Internet y que corresponde a la estructura básica de la representación del espacio, llevadas a las dimensiones topológicas que los ordenadores interpretan como dato, con facilidad de creación, almacenamiento y difusión de dicha información. 


\subsubsection{Otras formas de representación y observación de la superficie terrestre}

Los mapas no son la única forma de representación espacial existente. También se han realizado otros tipos de modelos y técnicas que han ayudado a emular los elementos espaciales. En este caso, destacan el globo terráqueo, un modelo a escala de la Tierra, pero que contiene las tres dimensiones espaciales, no sufriendo distorsión en su modelamiento a diferencia de las representaciones de dos dimensiones. El globo terráqueo más antiguo que se conserva, el Erdapfel, data de 1492 y fue construido por un cartógrafo alemán llamado Martin Behaim en la ciudad de Núremberg (Woodward, 1989). Durante el Renacimiento también se desarrolló la construcción de globos celestes y terrestres, alguno de los cuales fueron utilizados para la navegación, sobre todo en sectores de altas latitudes, los cuales eran de mayor dificultad en la representación. De esta manera destaca Johann Schönner, cuyas obras en globos terrestres para el año 1520 ya comienzan a presentar los territorios de Sudamérica y África (Covington, 2007). En la actualidad, los globos terráqueos son utilizados para la visualización y explicación de fenómenos a escala planetaria como son la latitud, longitud, inclinación del eje terrestre o continentalidad, entre otros. De esta misma manera, debido al tamaño del modelo sólo permite la representación de fenómenos que tienen un real impacto planetario, siendo muy poco práctico para elementos que ocurren a escalas mayores ${ }^{25}$. El equivalente actual de los globos terráqueos son los respectivos digitales, conocidos como globos terráqueos virtuales, los cuales permiten una representación de un modelo 3D digital de la Tierra, logrando elementos de interactividad de la información con el cambio de tamaño (escala) y la superposición de datos a través de diversas fuentes digitales, existiendo una diversidad importante de programas para diversas plataformas (Tabla 2.1).

25 Un globo terráqueo realizado a escala 1:50.000 tendría una circunferencia ecuatorial equivalente a 800 metros de perímetro, el equivalente a 2,67 veces la altura de la torre Eiffel. 
Tabla 2.1 Globos Terráqueos Virtuales y sus características

\begin{tabular}{|c|c|c|c|c|c|c|}
\hline Nombre & $\begin{array}{l}\text { Año de } \\
\text { aparici } \\
\text { ón }\end{array}$ & $\begin{array}{l}\text { Sistema } \\
\text { Operativo }\end{array}$ & $\begin{array}{l}\text { Tipo de } \\
\text { licencia }\end{array}$ & $\begin{array}{l}\text { Capas } \\
\text { de datos } \\
\text { externas }\end{array}$ & $\begin{array}{c}\text { Referencia } \\
\text { básica } \\
\text { (Transporte, } \\
\text { servicios } \\
\text { básicos, } \\
\text { nombres de } \\
\text { calle, etc.) }\end{array}$ & $\begin{array}{c}\text { Herramientas } \\
\text { (Integración } \\
\text { GPS, medición } \\
\text { de distancias, } \\
\text { herramienta de } \\
\text { creación de } \\
\text { datos, capas y } \\
\text { video) }\end{array}$ \\
\hline $\begin{array}{l}\text { Google } \\
\text { Earth }^{26}\end{array}$ & 2005 & Todos & Freeware & $\begin{array}{l}\text { Solo .kml } \\
\text { y .kmz }\end{array}$ & $\mathrm{Si}$ & $\mathrm{Si}$ \\
\hline $\begin{array}{l}\text { NASA } \\
\text { World } \\
\text { Wind }^{27}\end{array}$ & 2004 & Windows & $\begin{array}{l}\text { Código } \\
\text { abierto }\end{array}$ & $\mathrm{Si}$ & No & $\mathrm{Si}$ \\
\hline ArcGlobe $^{28}$ & 1999 & Windows & $\begin{array}{l}\text { Software } \\
\text { Propietario }\end{array}$ & $\mathrm{Si}$ & No & $\mathrm{Si}$ \\
\hline Marble $^{29}$ & 2006 & $\begin{array}{l}\text { Todos (no } \\
\text { incluye SO } \\
\text { móviles como } \\
\text { Android e } \\
\text { iOS). }\end{array}$ & $\begin{array}{l}\text { Licencia } \\
\text { Pública } \\
\text { General } \\
\text { Reducida de } \\
\text { GNU }\end{array}$ & No & $\mathrm{Si}$ & Algunas \\
\hline osgEarth ${ }^{30}$ & 2009 & $\begin{array}{c}\text { Todos (no } \\
\text { incluye SO } \\
\text { móviles como } \\
\text { Android e iOS. }\end{array}$ & $\begin{array}{l}\text { Licencia } \\
\text { Pública } \\
\text { General } \\
\text { Reducida de } \\
\text { GNU }\end{array}$ & No & $\mathrm{Si}$ & Algunas \\
\hline
\end{tabular}

Fuente: Elaboración propia.

Otra técnica de visualización del territorio pero de más reciente implementación, corresponde a la fotografía aérea, que consiste en la captura de imágenes del territorio desde una posición elevada, normalmente desde aparatos aéreos como aviones, helicópteros, globos, entre otros. Los comienzos de esta técnica se remontan hacia el año 1858 cuando el fotógrafo francés Gaspard Félix Tournachon, capturó una imagen de la ciudad de Paris desde un globo tripulado. Sin embargo, no quedan registros de aquella experiencia realizada (R. Graham \& Read, 1986). No fue hasta la I Guerra Mundial en donde el uso de esta tecnología comenzó avances importantes, con nuevos objetivos como el de realizar reconocimientos sobre el terreno en el avance de tropas, el desarrollo de puestos de defensa y determinar las condiciones del campo de batalla. En este desarrollo, fue Frederick Victor Laws del Royal Flying Corps quien, mediante el uso de fotografías tomadas de manera vertical desde un avión y superponiéndolas al menos un $60 \%$,

\footnotetext{
${ }^{26}$ http://www.google.com/earth/

${ }^{27} \mathrm{http}: / /$ worldwind.arc.nasa.gov/java/

$28 \mathrm{http}: / /$ www.esri.com

${ }^{29}$ http://marble.kde.org

30 http://osgearth.org
} 
permitió conseguir efectos de visión estereoscópica (3D), ayudando al análisis cartográfico de los escenarios de guerra y de la inteligencia militar, beneficiando al ejército inglés. Para 1939 la técnica se había perfeccionado, creándose el N¹ Photographic Reconnaissence Unit (PRU) que sirvió para la RAF durante la II Guerra Mundial, liderando técnicas en la toma de fotografías aéreas (Fernández García, 2000). En la actualidad, los usos de la fotografía aérea van desde la creación de la cartografía (como técnica propia en los levantamientos fotogramétricos), a estudios de usos del suelo, planes urbanísticos o estudios ambientales por mencionar algunos (Figura 2.2). 
Figura 2.2 Fotografía aérea de Salamanca. Vuelo Americano Serie A 1945-1946 (Instituto Geográfico Nacional, 1946)

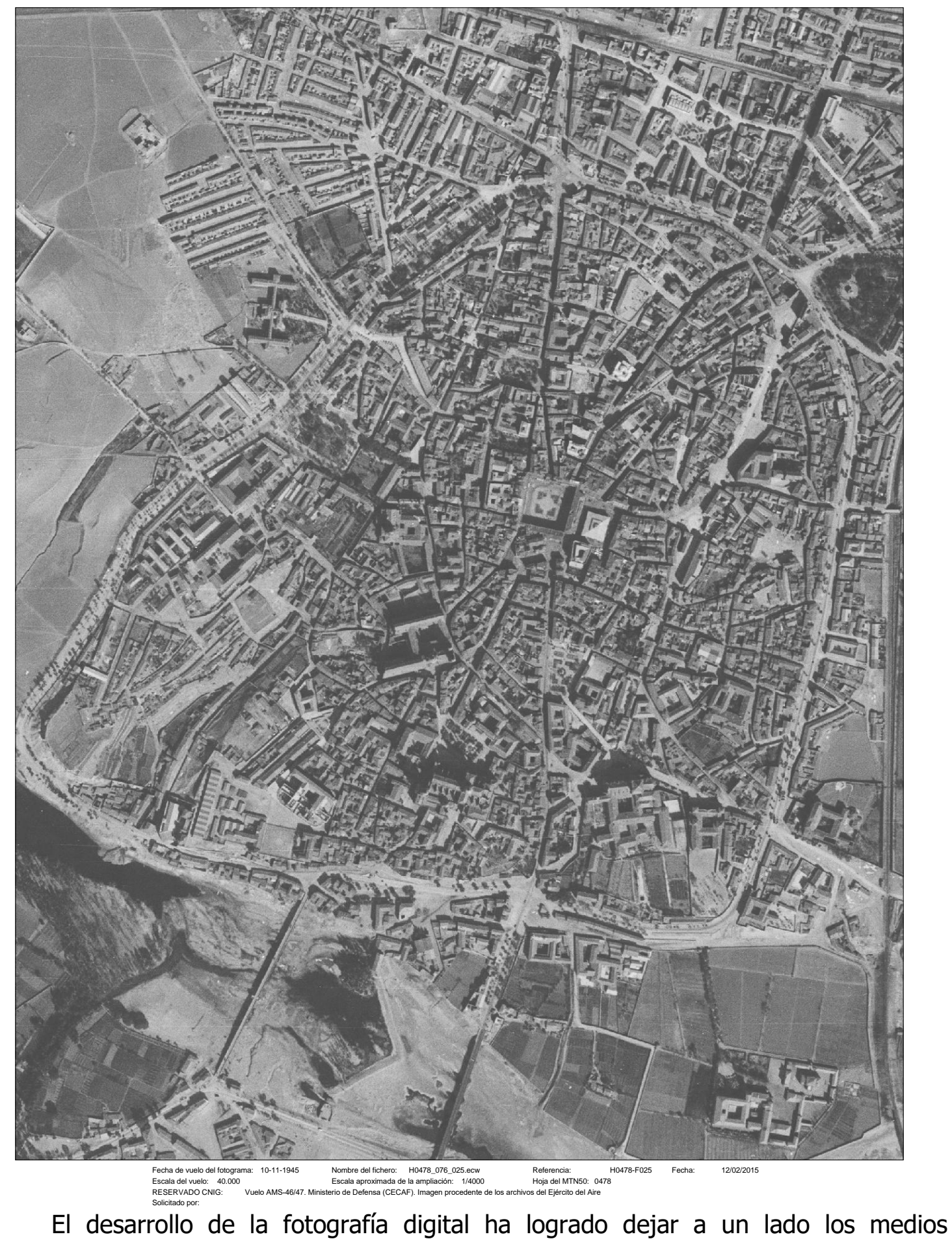
fotoquímicos y ópticos que se utilizaban en los inicios del desarrollo de esta técnica, permitiendo una serie de ventajas para su implementación (Trinder, 2015):

- Estabilidad dimensional: es posible abarcar mayores dimensiones de cobertura, además de predefinir resoluciones según las necesidades de las capturas de imágenes. 
- Visualización más fácil: su visualización en pantalla es inmediata y no requiere procesos de revelado e impresión.

- Tratamiento por software: es posible realizar mejoras vía software como la aplicación de filtros, realces o redimensionamientos.

- Procedimientos automáticos: es posible automatizar las labores de tratamiento de las imágenes.

- Resultado en formato digital: esta cualidad permite la optimización en el almacenamiento, distribución, procesamiento y visualización de la información obtenida.

De esta manera, es posible acceder a una serie de recursos de fotografías aéreas de diversos años y lugares, descargables en línea, como son el Centro Nacional de información Geográfica de España ${ }^{31}$, el Earth Resources Observation and Science (EROS) Center ${ }^{32}$ de Estados Unidos y el Sistema Nacional de Información de Ambiental de Chile ${ }^{33}$.

Avanzado el siglo XX, específicamente en la década de los 50 y en conjunto con la carrera espacial, comienza la utilización de sensores instalados en plataformas extraplanetarias. De esta manera el primer satélite en fotografiar la superficie de la Tierra corresponde a la nave Explorer 6 de los Estados Unidos, que en el día 14 de agosto de 1959 pudo obtener imágenes del sector central del océano Pacífico (European Space Agency, 2009), dando inicio a una etapa crucial en la captación de información territorial mediante métodos digitales y de manera remota. Otro hito importante dentro de la utilización de estas herramientas corresponde al programa Landsat de los Estados Unidos, el cual es, hasta el día de hoy, el mayor programa de captura de imágenes desde 1972, con 8 plataformas espaciales lanzadas en distintos momentos (National Aeronautics and Space Administration, 2015), pero que sigue vigente en la actualidad. En estos momentos, una serie de países se encuentran desarrollando programas para la captura de imágenes

\footnotetext{
${ }^{31}$ En http://fototeca.cnig.es

${ }^{32}$ En http://eros.usgs.gov/\#/Find_Data/Products_and_Data_Available/NAPP

${ }^{33}$ En http://ide.mma.gob.cl/
} 
de la superficie terrestre, y también existen compañías privadas que ofrecen imágenes satelitales de carácter comercial. Se estima que en la actualidad existen más de 1.100 satélites activos (Ritter, 2014), tanto privados como gubernamentales y con una gran diversidad de objetivos como la observación meteorológica, oceanografía, geología, navegación o planeamiento regional entre otros.

Figura 2.3 Modelo Digital de Elevaciones y Banda Infrarroja de datos del satélite Landsat 5

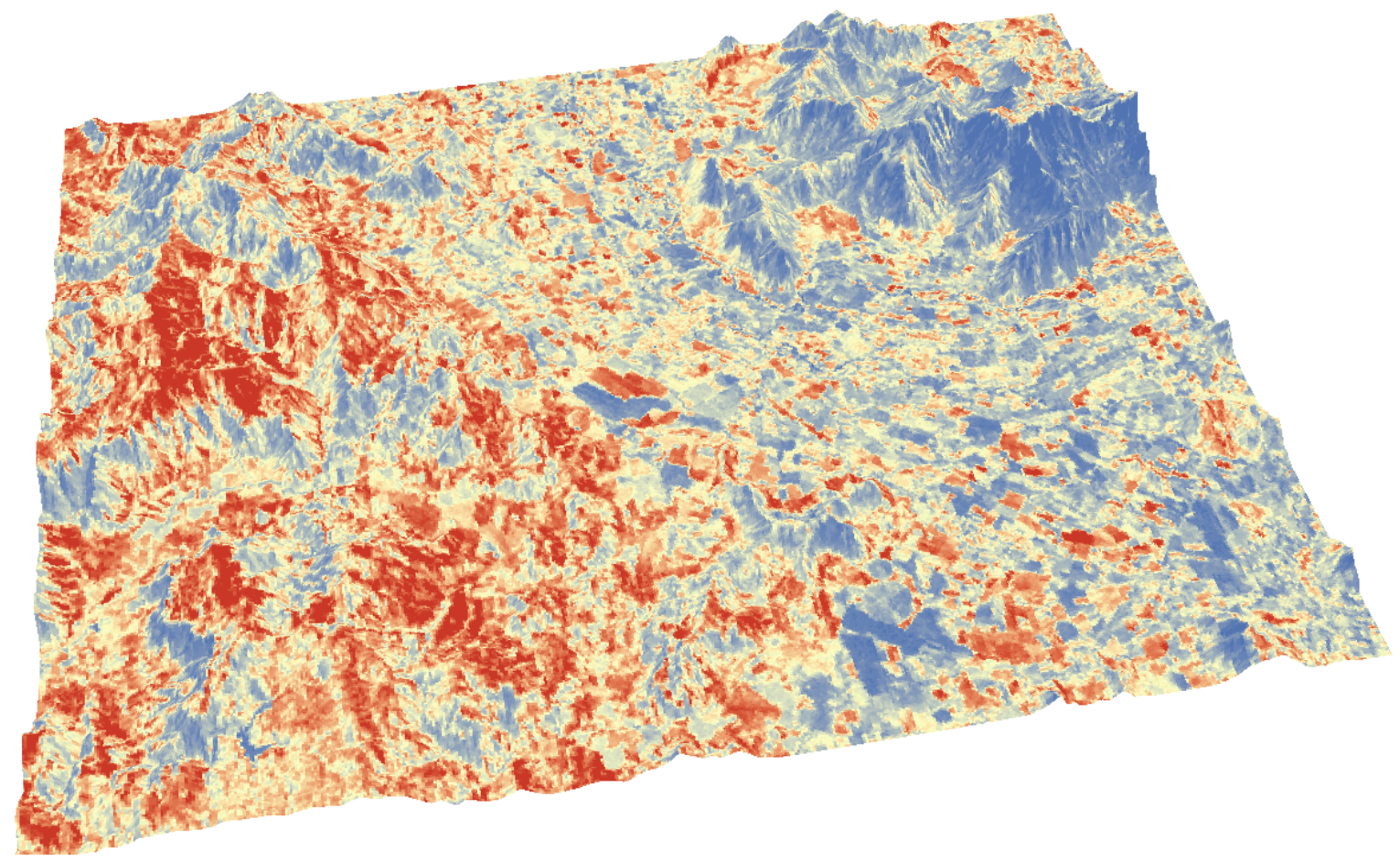

Fuente: Elaboración propia con datos NASA Landsat Program (2003)

Uno de los aspectos fundamentales en torno al desarrollo de la tecnología satelital y del desarrollo de sensores remotos, corresponde al aumento de los niveles de resolución espectral ${ }^{34}$ que existen en este tipo de instrumentos (Chuvieco Salinero, 1996). Esto quiere decir que ya no sólo es posible visualizar imágenes con datos constituyentes del espectro

\footnotetext{
${ }^{34}$ Las imágenes satelitales tienen asociadas cuatro tipo de resoluciones según las cualidades del aparato: Resolución Temporal referido a la frecuencia que un satélite obtiene imágenes de un mismo sector geográfico; resolución espacial que corresponde al grado de detalle que se puede visualizar una imagen (tamaño pixel versus superficie); resolución radiométrica que corresponde al número de valores o niveles digitales que puede tomar un pixel, según los datos recogidos por el satélite; y resolución espectral que hace referencia a los niveles de longitud de onda del espectro electromagnético que el satélite puede capturar y convertir en información.
} 
de luz visible ${ }^{35}$, sino que también se cuenta con la opción de obtener información referente de otras secciones o bandas del espectro electromagnético. El significado de este avance radica en la posibilidad de captar y entender los escenarios territoriales más allá de la visualización que otorgan los sentidos humanos, pudiendo ampliar el espectro de la comprensión de los fenómenos en su real complejidad (Figura 2.3).

\subsubsection{Elementos relativos a la representación}

Como técnica, los principales mecanismos que deben aplicarse en una representación del territorio, que deben ser abordados por la cartografía y que se aplican finalmente en la visualización del territorio que entregan los dispositivos digitales, son los siguientes:

- Representación bidimensional del territorio, que es un objeto tridimensional. Este problema se trata mediante geodesia y a través de proyecciones cartográficas (Errázuriz \& González, 1992).

- Generalización de los contenidos, debido a la complejidad de la realidad de la superficie terrestre. Es necesario omitir características o detalles que no son relevantes para el propósito final de la representación territorial deseada (Errázuriz \& González, 1993).

- Armonización del diseño gráfico de la representación que se quiere lograr y mostrar, con el fin de obtener una fácil y adecuada lectura de la información, y considerando los aspectos estéticos del modelo creado (Errázuriz, 1988).

El objetivo perseguido es generar un modelo que permita una representación simplificada de la superficie terrestre, en el que aparecen algunos de los elementos o propiedades de la superficie real, sean estos visibles o invisibles, concretos o abstractos. Esta representación sería un modelo analítico (o conceptual) cuyo objetivo es aportar una imagen o visualización inteligible de un sistema territorial (Joly, 1988).

\footnotetext{
${ }^{35}$ El espectro visible abarca aproximadamente los 0,4 a $0,7 \mu \mathrm{m}$ de longitud de onda mientras que el sensor espectral del satélite Landsat 8 abarca los 0,433 a $2.300 \mu \mathrm{m}$.
} 
En este sentido, se utilizan primordialmente dos dimensiones, $\mathrm{X} \mathrm{e} \mathrm{Y}$-normalmente latitud y longitud-, que aportan la localización o posición. Se trata de las ya conocidas coordenadas geográficas. Los valores de estas variables $\mathrm{X}$ e $\mathrm{Y}$ permiten calcular otras magnitudes, de mayor complejidad como la superficie y el perímetro (Figura 2.4 y Tabla 2.2 Propiedades y representaciones de los elementos geométricos).

Figura 2.4 Elementos de abstracción geométrica utilizados en cartografía

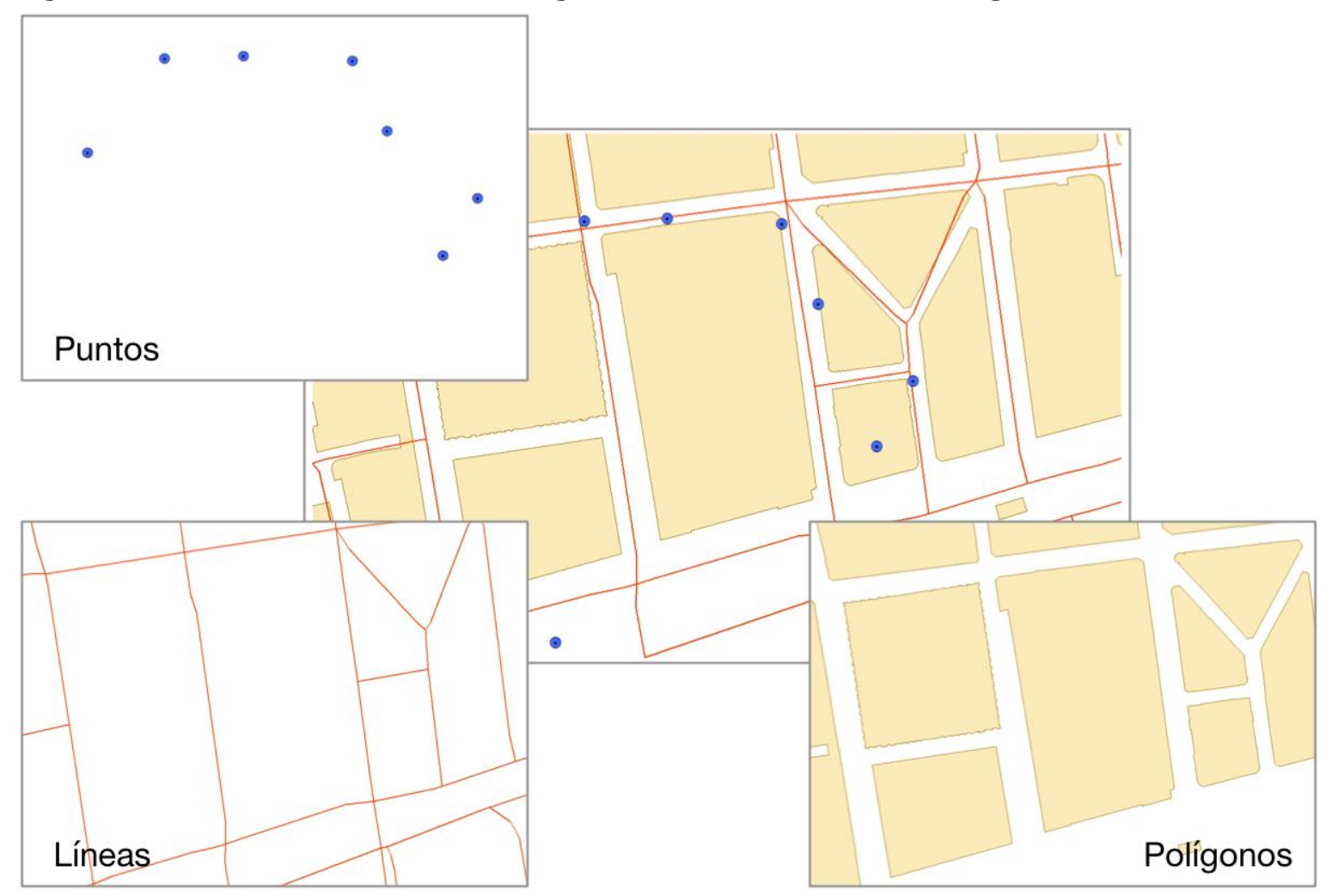

Fuente: Elaboración propia.

En la base de datos que se utiliza en el presente trabajo, ambos valores ha sido definidos con el tipo double, debido a la características de la información que se visualiza, correspondiente a la localización de fenómenos que se establecen como puntuales. Desde luego, es importante mencionar que tradicionalmente la georreferenciación de datos se expresa con los siguientes formatos:

- $\quad$ Grados decimales $\left(12,3456^{\circ}\right.$ s; $\left.78,91011^{\circ} \mathrm{w}\right)$

- Grados, minutos y segundos (120 23'34" s; $78^{\circ} 59^{\prime} 54^{\prime \prime}$ w)

- $\quad$ Grados y minutos decimales ( $\left.12^{\circ} 23,55^{\prime} s ; 78^{\circ} 59,89^{\prime} w\right)$ 
También es importante recordar que la latitud, como distancia angular, se define como el ángulo existente entre el plano del ecuador y un punto situado sobre la superficie de la Tierra, medido a lo largo del meridiano en que se encuentra dicho lugar. Las líneas que se generan mediante de esta manera se llaman paralelos.

En cuanto a la longitud, es la distancia angular que existe entre punto de la superficie terrestre y el meridiano de Greenwich -conocido también como meridiano 0, meridiano base o primer meridiano-, medida a lo largo del meridiano correspondiente. Evidentemente, la equivalencia entre grados de longitud y $\mathrm{km}$ de distancia al meridiano 0, dependerá de la latitud del punto considerado: por ejemplo, el circulo máximo que es la línea del Ecuador, tiene un perímetro de $40.075,004 \mathrm{~km}$, en donde cada grado de latitud (10) equivale a $111,319 \mathrm{~km}$. Sin embargo, a medida aumenta la latitud (por ejemplo el paralelo del Trópico de Cáncer) el perímetro disminuye $(36.767,8413 \mathrm{~km})$ por lo que $1^{0}$ de latitud equivale $111,135 \mathrm{~km}$ (Figura 2.5).

\footnotetext{
${ }^{36}$ El sistema UTM es un sistema de coordenadas basada en la proyección de Mercator. Se diferencia del sistema de Coordenadas Geográficas en que las magnitudes de los valores de Latitud y Longitud no se expresan en grados angulares sexagesimales, sino en metros de acuerdo a los parámetros de los husos definidos.
} 
Figura 2.5 Dimensión de la longitud en función de la latitud ${ }^{37}$

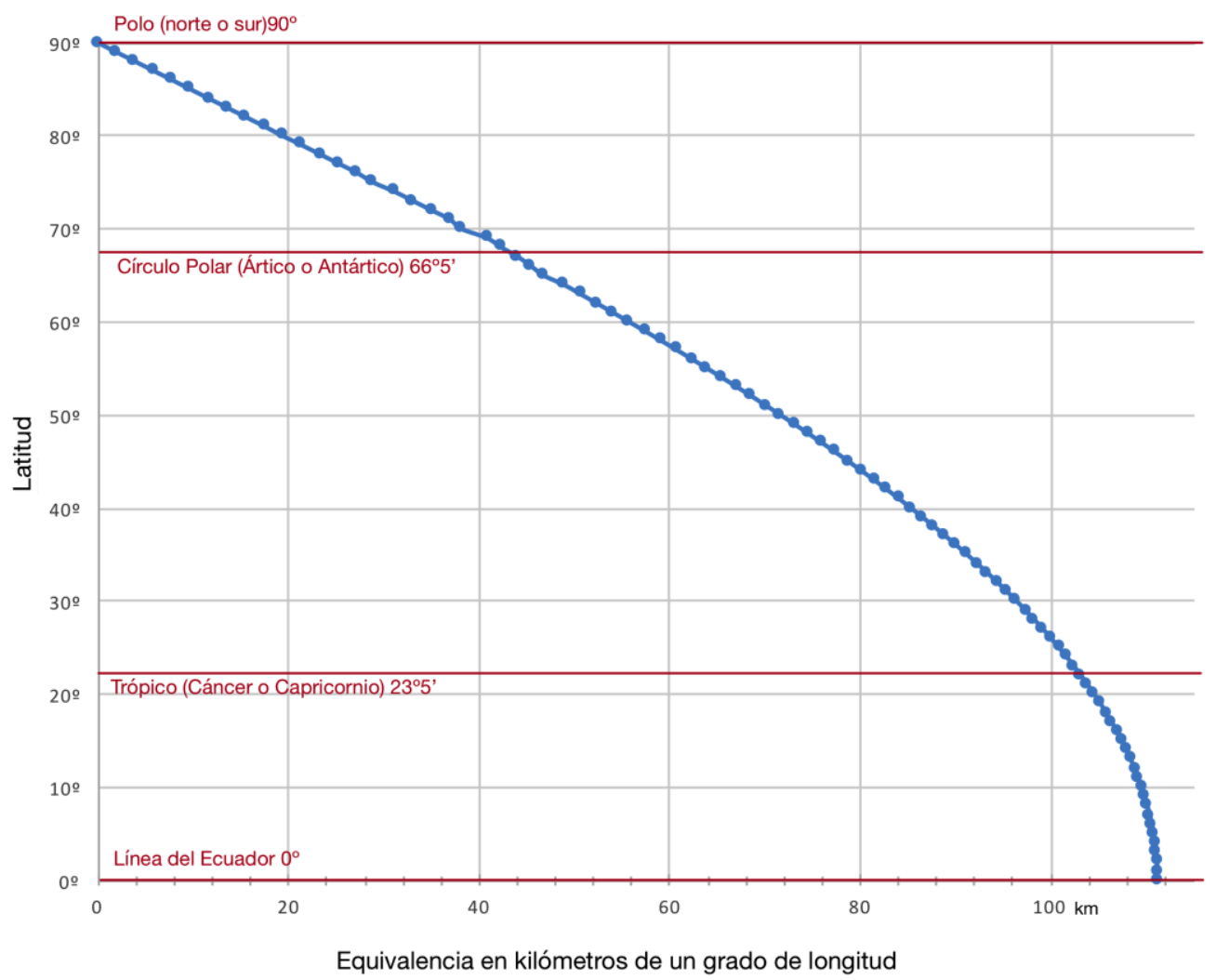

Fuente: Elaboración propia.

Por otra parte, la tercera variable -Z-, comúnmente muestra la altitud del punto respecto a la superficie media en ese punto del territorio. Sin embargo, dependiendo de la cartografía utilizada, este valor puede tomar otros valores de cualitativo o cuantitativo, o quizá se aporten ambos datos. Existen además otras informaciones que, en el caso de estar asociadas a unas coordenadas, permiten la representación de una diversidad importante de fenómenos que no necesariamente pueden ser captados a simple vista, o que por la complejidad del dato, requieren instrumental particular para la obtención de dicha información ${ }^{38}$.

\footnotetext{
${ }^{37}$ La forma real de la Tierra es la de un geoide la cual no puede ser representada en un plano de dos dimensiones con un sistema de coordenadas regular. Es por ello que se utiliza un elipsoide de referencia, que al ser un cuerpo regular, permite la proyección a un plano y con ello el cálculo de distancias relativas. En el gráfico se ha utilizado el World Geodetic System 84 (WGS84) cuyos parámetros son: semieje mayor igual a 6,378,137.0 m, semieje menor igual a 6,356,752.0 m y el achatamiento igual a f: 1/298.257223563.

${ }^{38}$ Información de radiación ultravioleta, ruido eléctrico o nivel socioeconómico de un ayuntamiento, son datos que no se pueden visualizar a simple vista y que a veces corresponden a construcciones o significado de mayor complejidad que son sintetizados en un concepto el cual puede ser representado en un mapa.
} 
Tabla 2.2 Propiedades y representaciones de los elementos geométricos

Tipo de representación

Propiedad

Ejemplo

\begin{tabular}{|c|c|c|}
\hline Punto & Solo localización & Sitios, referencias \\
\hline Línea & Localización y longitud & $\begin{array}{l}\text { Calles, caminos, ríos, tendido } \\
\text { eléctrico, límites administrativos, etc. }\end{array}$ \\
\hline Polígono & $\begin{array}{l}\text { Localización establecida por } \\
\text { el centrodo, longitud } \\
\text { (perímetro) y superficie } \\
\text { (área). }\end{array}$ & $\begin{array}{l}\text { Barrios, sectores, cuerpos de agua, } \\
\text { unidades político-administrativas, } \\
\text { etc. }\end{array}$ \\
\hline
\end{tabular}

Fuente: Elaboración propia.

La escala como concepto, viene directamente de las ciencias matemáticas y pretende establecer la relación, constante, que existe entre la realidad (terreno) y la representación en unidades lineales. Sin embargo, la escala en la cartografía analógica o digital no es una simple relación de proporcionalidad entre modelo y realidad. Es una forma de sintetizar y abstraer una forma de una sección de territorio sobre una superficie del modelo, el cual abarcará unos centímetros de representación. Esta representación debe considerar los diversos ordenes de magnitud que existen en los fenómenos territoriales, los cuales pueden abarcar desde cientos y miles de kilómetros (por ejemplo un Estado Nación o un sistema montañoso) hasta decenas de metros o menos (un ayuntamiento, un municipio, o un cerro). De esta manera, la variación de la escala afecta a la cantidad de información que se puede representar debido a la necesidad insalvable de simplificar y generalizar la imagen en representaciones de escala muy pequeña. Joly $(1985,1988)$ establece que para desarrollar una adecuada generalización que se relacione con la escala se deben tener en consideración tres aspectos:

- Es preciso seleccionar los elementos importantes de la representación planimétrica en función del objetivo con que se realiza, estableciendo su valor intrínseco o su papel como referencia para otras informaciones (por ejemplo, el nombre de las calles permite determinar la localización relativa de los elementos temáticos que se realmente se quieren destacar en el plano). En este sentido, sería ideal representar siempre el nombre de la calle en el plano generado, pero no siempre es posible y se pierden referencias importantes.

- Es preciso llevar a cabo una "generalización estructural", esto es, una esquematización de la representación, en donde se eliminan o atenúan elementos secundarios para darles mayor valor a los caracteres temáticos que se quiere resaltar y que de otra manera podrían perderse como consecuencia de un exceso 
de información. Por ejemplo, los números de calle y las direcciones de circulación no deben mostrarse a determinadas escalas.

- Es preciso establecer armónicamente la posición de los elementos representados, con el fin de mantener las relaciones espaciales existentes en el territorio, aunque lo anterior pueda llevar a un desplazamiento o deformación de determinados hitos, con el fin de mantener la legibilidad la comprensibilidad de la información representada.

Es importante mencionar que los procesos de generalización no corresponden a simples acciones de reducción gráfica: requieren una interpretación conjunta de los elementos que van a ser representados, así como del contexto real en donde se expresan y del sentido gráfico con que se entrega la información expresada finalmente en el modelo. La resolución final de una representación territorial es un problema espacial, que demuestra que existe una relación directa entre la extensión de una zona homogénea, y la cantidad y características de criterios de representación que deben ser considerados en el modelo que se quiere plasmar. En la realidad, los criterios son numerosos y detallados: cuanto mayor sea el área a cubrir, mayor será la cantidad de características que, en principio, se pueden representar. Esto va desde los detalles físicos de los elementos presentes en el territorio, hasta las relaciones que puedan existir entre diversos objetos.

Además, cada elemento presente en la superficie de la Tierra tiene una historia. Se ha intentado manifestar el pasado importante de los elementos que lo tienen, por lo que cada sistema territorial se ha dotado en cierto sentido de una dimensión temporal, lo cual aporta un valor diferencial frente a otros sistemas territoriales ya existentes. Así, hablar de homogeneidad para la representación, adquiere características de relatividad, quedando condicionada por la escala espacio-temporal del sistema que se quiere representar (C. Bertrand, Bertrand, \& Rodríguez Martínez, 2007). Estas variaciones espacio-temporales no pueden representarse, en general, empleando unidades similares, como consecuencia de su distinta naturaleza. Entonces la escala adquiere una nueva relevancia debido a que los fenómenos se expresan con unas características distintivas que dependen del tiempo. Se han resumido en la Tabla 2.3 las escalas espacio-temporales presentes en posible representación del territorio. 
Tabla 2.3 Escalas tempo-espaciales (Joly, 1982)

\begin{tabular}{|c|c|c|c|c|c|c|c|c|c|}
\hline Orden & $\begin{array}{c}\text { Extensión } \\
\text { espacial }\end{array}$ & \multicolumn{2}{|c|}{ Orden físico } & \multicolumn{2}{|c|}{$\begin{array}{c}\text { Orden } \\
\text { biológico }\end{array}$} & \multicolumn{2}{|c|}{ Orden humano } & Ejemplo & $\begin{array}{l}\text { Escala de } \\
\text { representación }\end{array}$ \\
\hline 10 & $\geq 10^{7} \mathrm{~km}^{2}$ & Zona & \multirow{3}{*}{$\begin{array}{l}10^{7-9} \\
\text { años }\end{array}$} & Zona & \multirow[t]{2}{*}{$\begin{array}{l}10^{5-6} \\
\text { años }\end{array}$} & Zona & \multirow[t]{2}{*}{$\begin{array}{l}10^{5-6} \\
\text { años }\end{array}$} & $\begin{array}{c}\text { Plataformas } \\
\text { continentales, } \\
\text { océanos, zonas } \\
\text { tropicales, Asia } \\
\text { de los monzones }\end{array}$ & $\leq 1: 10.000 .000$ \\
\hline $2^{\circ}$ & $10^{6}-$ & $\begin{array}{l}\text { Dominio } \\
\text { Sistema }\end{array}$ & & Dominio & & $\begin{array}{l}\text { Domini } \\
\quad 0\end{array}$ & & $\begin{array}{c}\text { Dominio } \\
\text { herciniano. } \\
\text { Sistema Alpino y } \\
\text { Andino }\end{array}$ & $\begin{array}{l}1: 5.000 .000 \\
1: 1.000 .000\end{array}$ \\
\hline 30 & $10^{5}-$ & $\begin{array}{l}\text { Sub- } \\
\text { sistema }\end{array}$ & & \multicolumn{2}{|c|}{$\begin{array}{l}\text { Región } 10^{4-5} \\
\text { años }\end{array}$} & \multicolumn{2}{|c|}{$\begin{array}{l}\text { Provincia } 10^{3-4} \\
\text { años }\end{array}$} & $\begin{array}{l}\text { Macizo central, } \\
\text { Cuenca de } \\
\text { grandes ríos }\end{array}$ & $\begin{array}{l}1: 500.000 \\
1: 200.000\end{array}$ \\
\hline 40 & $10^{4}-$ & Región & \multirow{2}{*}{$\begin{array}{l}10^{6-7} \\
\text { años }\end{array}$} & & & Región & \multirow{2}{*}{$\begin{array}{l}10^{3-} \\
\text { años }\end{array}$} & $\begin{array}{l}\text { Norte grande } \\
\text { chileno }\end{array}$ & $\begin{array}{l}1: 200.000 \\
1: 100.000\end{array}$ \\
\hline $5^{0}$ & $10^{3}-$ & País & & \multicolumn{2}{|c|}{$\begin{array}{l}\text { Geosistema } 10^{3-4} \\
\text { años }\end{array}$} & País & & & $\begin{array}{c}1: 100.000 \\
1: 50.000\end{array}$ \\
\hline $6^{0}$ & $10^{2}-$ & \multicolumn{2}{|c|}{$\begin{array}{c}\text { Formas } \\
\text { decakilométricas } \\
10^{5-6} \text { años }\end{array}$} & \multicolumn{2}{|c|}{$\begin{array}{c}\text { Geofacies } 10^{2-3} \\
\text { años }\end{array}$} & \multirow{2}{*}{\multicolumn{2}{|c|}{$\begin{array}{c} \\
\text { Manzana } \\
\text { (cuadra) } 10^{3-4} \\
\text { años }\end{array}$}} & $\begin{array}{c}\text { Sección de valle, } \\
\text { delta y } \\
\text { humedales. } \\
\text { Ciudades }\end{array}$ & $\begin{array}{l}1: 20.000 \\
1: 10.000\end{array}$ \\
\hline 70 & $10-$ & \multicolumn{2}{|c|}{$\begin{array}{l}\text { Formas } \\
\text { kilométricas } 10^{4-} \\
{ }^{5} \text { años }\end{array}$} & \multicolumn{2}{|c|}{$\begin{array}{l}\text { Geotopo } 10^{2} \\
\text { años }\end{array}$} & & & $\begin{array}{l}\text { Vertientes, cono } \\
\text { de deyección. } \\
\text { Barrio urbano }\end{array}$ & $\begin{array}{l}1: 5.000 \\
1: 2.000\end{array}$ \\
\hline $8^{\circ}$ & $1-$ & \multicolumn{2}{|c|}{$\begin{array}{c}\text { Formas } \\
\text { hectométricas } \\
10^{3-4} \text { años }\end{array}$} & \multicolumn{2}{|c|}{$\begin{array}{c}\text { Biotopo 1-10 } \\
\text { años }\end{array}$} & \multicolumn{2}{|c|}{$\begin{array}{c}\text { Manzana } 10^{2} \\
\text { años }\end{array}$} & $\begin{array}{l}\text { Lecho de río. } \\
\text { Sector costero. } \\
\text { Manzana de } \\
\text { ciudad }\end{array}$ & $\begin{array}{l}1: 2.000 \\
1: 1.000\end{array}$ \\
\hline 90 & $\leq 1 \mathrm{Ha}$ & \multicolumn{2}{|c|}{$\begin{array}{l}\text { Microformas } 10^{1-} \\
\quad{ }^{3} \text { años }\end{array}$} & & & \multicolumn{2}{|c|}{$\begin{array}{l}\text { Parcela 1-10 } \\
\text { años }\end{array}$} & $\begin{array}{c}\text { Detalle de } \\
\text { corrosión. } \\
\text { Micropoblación. } \\
\text { Inmueble. }\end{array}$ & $\begin{array}{c}1: 1.000 \\
1: 100\end{array}$ \\
\hline $10^{\circ}$ & en $\mu$ & \multicolumn{2}{|c|}{$\begin{array}{l}\text { Formas } \\
\text { microscópicas } \\
\text { Roca }\end{array}$} & \multicolumn{2}{|c|}{ Célula } & \multicolumn{2}{|c|}{ 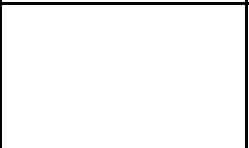 } & $\begin{array}{c}\text { Textura } \\
\text { litológicas. } \\
\text { Mantos vegetales } \\
\text { y animales. }\end{array}$ & $x 100$ \\
\hline $11^{\circ}$ & en $\tilde{A}$ & \multicolumn{2}{|c|}{$\begin{array}{c}\text { Formas } \\
\text { ultramicroscópic } \\
\text { as Mineral }\end{array}$} & \multicolumn{2}{|c|}{ Molécula } & & & $\begin{array}{c}\text { Texturas } \\
\text { mineralógicas. } \\
\text { Estructuras } \\
\text { atómicas }\end{array}$ & x 1.000 a 10.000 \\
\hline
\end{tabular}

Otro elemento a considerar es la representación bidimensional que se le quiere realizar a una forma tridimensional. La superficie terrestre puede ser representada mediante un cuerpo regular39, lo que normalmente se conoce como elipsoide de referencia. Es relativamente sencillo convertir este elipsoide representativo en una esfera como un globo terráqueo. El problema radica en transformar este elipsoide en una

${ }^{39}$ La distancia desde la superficie de la Tierra hasta su centro no es homogénea y existen diversos radios según el punto donde se localice la medición. En particular, el radio polar es de 6357 kilómetros y el radio ecuatorial es de 6378 kilómetros. 
representación con dos dimensiones (mapa), para lo cual la solución se encuentra en proyectar dicha figura regular, pudiendo existir un millar de soluciones geométricas posibles, sintetizándolas en aproximadamente 200 proyecciones que intentan esta representación adecuada, pero siempre con grados de inconvenientes importantes (Figura 2.6). Las aplicaciones cartográficas instaladas en servidores web como son Google Maps, OpenStreetMap, Bing o Apple Maps utilizan la proyección de Mercator, la cual es una proyección cilíndrica, en donde las direcciones verticales norte-sur son siempre verticales y las oeste-este toman el sentido horizontal. También, al ser una proyección de carácter conforme, las formas de los polígonos (unidades territoriales, edificios, plazas, etc.) no sufren deformación, como su ocurre con otro tipo de proyecciones.

Figura 2.6 Proyecciones de Mercator (en gris), Mollweide (rojo) y Plate Carrée (naranja) Fuente: Elaboración propia.

\subsection{Cartografía en la era digital}

En la actualidad existe un importante número de autores (M. de Smith, Goodchild, \& Longley, 2015; Maliene, Grigonis, Palevičius, \& Griffiths, 2011; Strobl, 2014) que establecen que existe una resurgimiento de los elementos de localización. Este regreso o "giro espacial" (spatial turn) ha dado lugar a lo que se podría llamarse la Sociedad de la Geoinformación -por analogía con la Sociedad de la Información, la que será descrita con más detalle en el capítulo 3-. A través de la infraestructura digital existente en la vida cotidiana, son pocas las tareas, intereses y actividades de una persona no contienen ni requieren información sobre la localización. De esta manera, la localización ya no es solamente un valor que expresa la posición euclidiana de un objeto o fenómeno, sino que también expresaría un contexto, con una proximidad y una distancia. La localización es un dato inicial muy efectivo, y sirve como integrador de información, sobre todo por la diversidad de dominios y dimensiones con que se podría representar la realidad. Esta integración espacial relaciona diversas capas de información o dominios de interés, transformando el simple concepto de localización en uno más complejo, como es el de lugar (Goodchild, 2011).

En este sentido, están apareciendo nuevas dimensiones con la relación de técnicas y estructuras de datos. Un ejemplo de esto es la Cibercartografía, concepto acuñado por Taylor en 1997, y que se define como la organización, presentación, análisis y comunicación de información espacialmente referenciada con una amplia variedad de 
temas de interés para la sociedad, en un contexto de interactividad, dinamismo y experiencia multisensorial de los cuales se hace uso en interfaces multimedia y multimodales (Okuku Oloo \& Van der Krapf, 2015; D. R. F. Taylor, 2005; D. R. F. Taylor \& Caquard, 2006).

Todas estas herramientas van cobrando una verdadera importancia, permitiendo recolectar, recuperar, transformar y visualizar datos sobre el mundo real, almacenándolos en medios digitales con todas las ventajas que implica este proceso (Burrough \& McDonnell, 1998; Huisman \& de By, 2009). Además, es posible integrar, agrupar y unificar la información territorial existente, transformando la información disponible en un nuevo contexto al que en un momento anterior no se tenía acceso, permitiendo una mejor evaluación de estos datos con características territoriales (Dangermond, 2004). Así, se genera un sistema de soporte digital que facilita la decisión, integrando datos referenciados espacialmente en un ambiente de respuestas a problemas (Sengupta, 2007), y que en la actualidad tiene la posibilidad de situarse en un sistema móvil y con acceso a datos de forma permanente.

De esta manera, los datos espaciales digitales permiten representar la realidad en términos de una serie de cualidades digitales abstractas (Del Bosque, Fernández, MartínForero, \& Pérez, 2012):

- Su posición concreta (o localización absoluta) respecto a un sistema de coordenadas establecidas -comúnmente latitud y longitud-.

- Los atributos del fenómeno que se expresa en el territorio pueden ser temáticos o descriptivos, concretos o abstractos, siempre en relación a su situación en el territorio.

- La relaciones territoriales (elementos de proximidad, influencia o superposición) que se presentan entre los fenómenos en un contexto topológico, permiten la combinación de características cualitativas en torno a las propiedades y reglas que tienen estos elementos en función de sus interconexiones.

Burrough y McDonnell (1998) sintetizan las etapas del modelamiento de datos territoriales en 3 fases generales, que van desde los modelos conceptuales del mundo real hasta la forma final de representación que percibe el usuario. Hay una etapa intermedia que corresponde al modelado de los datos, en 2 y 3 dimensiones, y que a su vez pueden 
dividirse en vectoriales (para redes y polígonos con funciones topológicas), rasterizados y redes irregulares de triángulos (Figura 2.7).

Figura 2.7 Etapas del proceso de observación de los fenómenos del mundo real convertidos en modelos de datos estandarizados (Burrough y McDonnell, 1998)

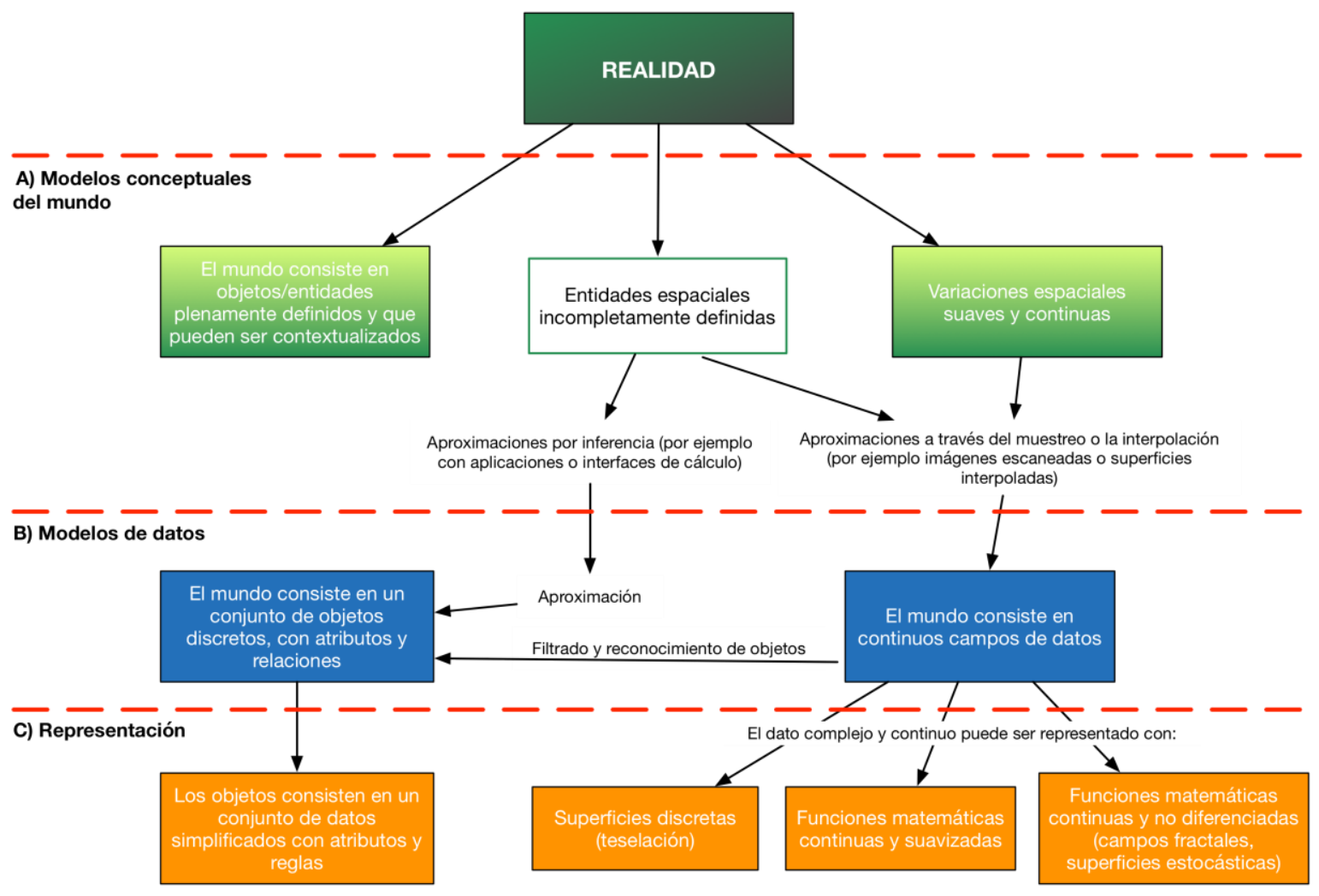

\subsection{El contexto de las geotecnologías}

Buzai (2011) plantea que ha existido una larga evolución de la información territorial hacia un contexto digital, y esa evolución ha ido pasando por diversas etapas y escenarios. Sin duda, el comienzo fue el el trabajo en papel, que daría lugar después a las definiciones de Sistemas de Información Geográfica (SIG) con una clara estructura informática-digital ${ }^{40}$. A partir de la década de 1980, se comienzan a integrar diversos aspectos tecnológicos que finalmente se reciben el nombre de técnicas Geoinformáticas o Geotecnología (Awange \& Kiema, 2013; Baranovskiy \& Zharikova, 2014; Rocha Salamanca \& Díaz Vega, 2010). Esto requería la implementación de bases de datos alfanuméricas y sistemas gráficos combinadas en un sistema establecido de georreferenciación. En este

\footnotetext{
40 Los Sistemas de Información Geográfica tienen su aparición en el año 1964 (Dacey, 1971), y se definen como un conjunto de elementos (herramientas informáticas, usuarios, metodologías) que permite la integración de una serie de mecanismos para el almacenamiento, análisis y representación de datos territoriales (Amirian, Basiri, Gales, Winstanley, \& McDonald, 2015; Dangermond, 2004; GIS Wiki, 2012).
} 
caso se establecen los SIG como núcleo de la Geotecnología, que irá dando lugar a derivaciones con elementos multimedia, y pasará a hacer uso de sistemas en la nube, a la Neogeografía ${ }^{41}$, a los sistemas de navegación por satélite, la fotogrametría, el webmapping ${ }^{42}$, la RA y la Realidad Virtual. En todos estos casos, el objetivo es la adquisición, almacenamiento, procesamiento, presentación y difusión de datos con características espaciales (Ehlers, 2008). Adicionalmente se cree que el $80 \%$ de la información existente tiene un componente geográfico (Velazco Flórez, 2013), masificándose, los cuales podrían tener un gran valor en la comprensión de fenómenos derivados del uso de la conectividad y la portabilidad digital, por lo que se hace necesario su organización, procesamiento, almacenamiento y administración, en lo que se conoce como Big Data (Camargo Vega, Joyanes Aguilar, \& Camargo Ortega, 2015; Ortiz Morales, Joyanes Aguilar, \& Giraldo Marín, 2015). En este contexto, Joyanes Aguilar (2014) específica los tipos y estructura de datos digitales que se contextualizan en el contexto del Big Data y que se pueden relacionar con los datos geoespaciales que se establecen en la actualidad (Tabla 2.4).

Tabla 2.4 Tipos de datos y ejemplos con información geoespacial

\begin{tabular}{|c|c|c|c|}
\hline Tipo de dato & Definición & Ejemplo & $\begin{array}{l}\text { Ejemplos con datos } \\
\text { geoespaciales }\end{array}$ \\
\hline Estructurado & $\begin{array}{l}\text { Datos con formato o } \\
\text { esquemas fijos que } \\
\text { poseen campos } \\
\text { predeterminados }\end{array}$ & $\begin{array}{l}\text { Hojas de cálculo y } \\
\text { archivos }\end{array}$ & $\begin{array}{l}\text { Archivo de texto con } \\
\text { separador de comas } \\
(. c s v), \text { Formato de } \\
\text { representación vectorial } \\
\text { en SIG (.shp), archivo } \\
\text { informático de dibujo } \\
\text { computarizado CAD } \\
(. d w g)\end{array}$ \\
\hline Semiestructurados & $\begin{array}{l}\text { Datos que no tienen } \\
\text { formatos fijos, pero } \\
\text { contienen etiquetas y } \\
\text { otros marcadores. }\end{array}$ & $\begin{array}{c}\text { Texto de } \\
\text { etiquetas XML y } \\
\text { HTML. }\end{array}$ & $\begin{array}{c}\text { Formato de Intercambio } \\
\text { GPS }(. g p x) \text {, Lenguaje de } \\
\text { marcado basado en XML } \\
\text { para representar datos } \\
\text { geográficos }(. \mathrm{km})\end{array}$ \\
\hline
\end{tabular}

\footnotetext{
${ }^{41}$ La Neogeografía corresponde a la masificación social de la información territorial espacial y que tiene como contexto tecnológico los mapas virtuales o el webmapping-propios del desarrollo de la web 2.0-, con la utilización de dispositivos con GPS, en donde elementos como la etiquetación y la georreferenciación, están presentes en un contexto de propio de la redes sociales (Goodchild, 2007, 2008).

${ }^{42}$ El servicio de webmapping está referido a los procesos de generación, composición gráfica y visualización digital de datos geoespaciales a través de estándares web conocidos como GML (Geographic Markup Language) y que cuenta con formatos como el .shp, .dwg y $. \mathrm{km} /$ entre otros (Mitchell, 2005). De manera particular se encuentran los Web Map Service (WMS), un protocolo estandarizado en donde se representan mapas con valores georreferenciados a partir de una base de datos de información geográfica (Open Geospatial Consortium, 2006; Scharl, 2007).
} 


\begin{tabular}{|c|c|c|c|}
\hline No Estructurados & $\begin{array}{c}\text { Datos sin tipos } \\
\text { definidos que se } \\
\text { almacenan } \\
\text { principalmente como } \\
\text { documentos u objetos } \\
\text { sin estructura } \\
\text { uniforme. }\end{array}$ & $\begin{array}{c}\text { Audio, vídeo, } \\
\text { fotografía, } \\
\text { elementos } \\
\text { multimedia, } \\
\text { formatos de texto } \\
\text { libre (correos } \\
\text { electrónicos } \\
\text { artículos; libros; } \\
\text { mensajería } \\
\text { instantánea). }\end{array}$ & $\begin{array}{c}\text { Especificaciones para } \\
\text { formatos de archivos de } \\
\text { imagen usado por las } \\
\text { cámaras digitales (Exif), } \\
\text { direcciones de calles y } \\
\text { lugares. }\end{array}$ \\
& &
\end{tabular}

Fuente: Adaptado de Joyanes (2014).

\subsection{Los mapas en un contexto de movilidad}

Ya desde la masificación de Internet a mediados de los 90 y con el incremento de la informática portátil desde mediados de la primera década del siglo XXI, se ha logrado el acceso a la información digital sin la necesidad de definir previamente escenarios y contextos relativos a la consulta de datos (el trabajo, la escuela, o un laboratorio de ordenadores). Por otro lado, en cuanto a la información territorial, son los mapas, ahora en nuestros dispositivos móviles, los que se mantienen en el dominio como lenguaje de la información espacial que puede ser implementada en aplicaciones portátiles (Joo Nagata, García-Bermejo Giner, \& Muñoz Rodríguez, 2015; Martí, Feliu, \& Varga, 2014; Riera, Redondo, \& Fonseca, 2014). De manera paralela, existe un incremento importante en la utilización de los servicios basados en localización (LBS location-based services) por parte de un elevado número de aplicaciones informáticas que van, desde las redes sociales, hasta la creación de documentación e información de diverso tipo (Abbas, Michael, \& Michael, 2014). La existencia de equipos con mapas móviles y el acceso inalámbrico a redes $o$ internet hace posible que las personas se encuentren con información sobre su entorno, sean estos eventos cercanos o lejanos, se encuentren ya realizándose o se desarrollen en un tiempo futuro. La masificación de los mapas en este contexto de portabilidad ha derivado en la generación de nuevas estructuras de creación de información, en donde las restricciones de diseño -principalmente en los referido al tamaño y las interfaces de los dispositivos- se han visto impuestas por la necesidad de obtener mejores experiencias en usabilidad y desempeño de los datos espaciales (Reichenbacher \& Meng, 2005). Los contenidos y el diseño de una cartografía para un dispositivo móvil necesitan, no sólo adecuarse a los actuales requisitos de hardware, sino también a las habilidades cognitivas de los usuarios en un escenario transportable y por tanto omnipresente. 
La cartografía convencional -como técnica-, requería el aprendizaje de métodos, convenciones y términos para poder realizar una adecuada lectura de la información territorial presentada, pero estos fundamentos no pueden ser replicados directamente en un contexto de aplicación móvil. La cartografía móvil debe ser una emulación adecuada del contexto territorial que circunda una consulta digital, con una alta capacidad de expresar información selectiva. Así, unos esquemas simplificados como los que otorgan los puntos de interés (POI por sus siglas en inglés) o los gráficos topológicos con estructuras de aproximaciones, pueden tener mejores resultados que complejas representaciones derivadas de diseños en otros formatos (Figura 2.8).

Figura 2.8 Esquema topológico de la red metro de Santiago de Chile, en una interfaz móvil (Empresa de Transporte de Pasajeros Metro S.A., 2015)

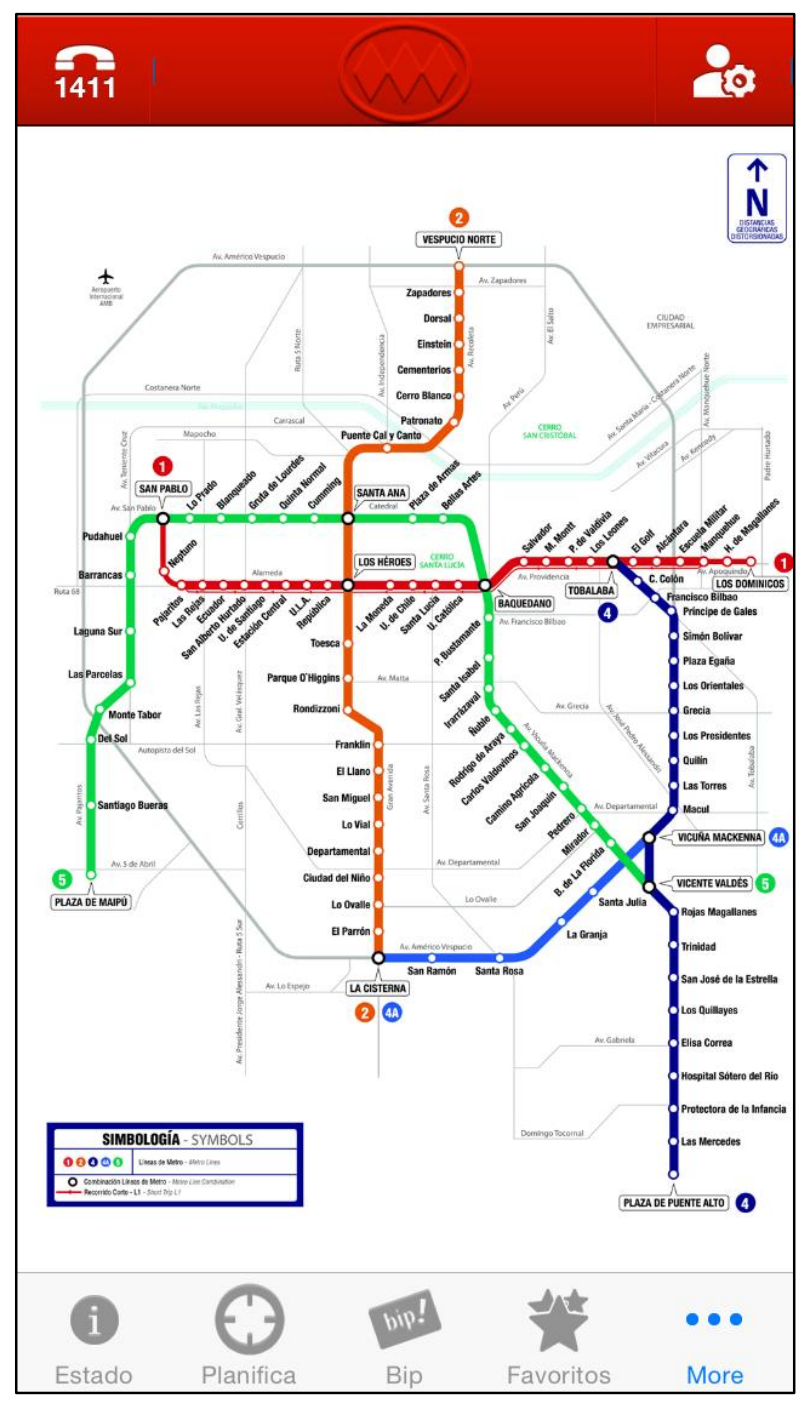

Otro elemento a tener en consideración es la naturaleza temporal de una cartografía móvil, la cual tiende -en condiciones habituales- a utilizarse una única vez, 
respondiendo a los requisitos particulares, es decir, se debe representar información muy particular para usuarios con necesidades exclusivas que se realiza en un contexto de consulta inmediata, propia de los dispositivos móviles.

Otro aspecto relevante es el cómo ha evolucionado la tipología de aplicaciones que requieren información territorial. Las aplicaciones móviles han otorgado una importante riqueza y funcionalidad a este tipo de cartografía portátil debido a los tipos de información y tecnología que se van incorporando en el uso del hardware portátil. Para Meng y Reichenbacher (2005), una cartografía móvil puede ser entendida de acuerdo a las relaciones entre el uso previsto de los datos y el esfuerzo de aprendizaje de la información, lo cual se sintetiza en los siguientes elementos (página 6):

- En un estímulo visual que está por ser apreciado. El diseño general debe llamar la atención y debe ser entendido como una sola unidad visual.

- Debe ser comprendida como una obra de arte que ha de ser apreciada. Los aspectos estéticos de la aplicación son percibidos y evaluados por los usuarios, y pueden significar la diferencia entre el éxito y el fracaso de la aplicación.

- Como un documento informativo con valor añadido. Una cartografía permite la resolución de tareas espaciales permitiendo mostrar al usuario información en un contexto territorial.

- Como una estructura de conocimientos regenerativa que permite la divulgación de sus contenidos. Los usuarios pueden cambiar datos (ideas, información, situación, contextos, etc.) de manera sincrónica o asincrónica mediante un mapa y representarlos en un contexto de localización.

- En una representación simbólica que necesita ser decodificada. En términos generales la información presentada responde preguntas como "¿qué es?", "¿dónde está?", "¿cuánto es?", "¿qué distancia hay de un lugar a otro", "¿por qué es así?" mediante símbolos y sus relaciones. Puede interpretarse en virtud de la leyenda del mapa, así como utilizando herramientas interactivas previamente definidas y la asociación que realizan los usuarios. 
- Como un agente de información confiable, en donde el conocimiento procedimental sobre el "cómo hacer" y "en qué orden" se realiza mediante instrucciones e interacciones intuitivas por parte del usuario.

El contexto informático ${ }^{43}$ es también un elemento importante que marca la diferencia entre lo que es la cartografía móvil y la cartografía común, permitiendo la obtención de nuevos contextos en la consulta y despliegue de la información territorial. De esta manera y durante el uso de mapas móviles, el contexto en que se encuentra el usuario tomaría una nueva dimensión, adecuándose a la realidad concreta en que se encuentra en ese momento y lugar. Nivala y Sarjakoski (2005) identifican ocho aspectos relevantes que se tienen en cuenta en la cartografía para móviles, en donde la base de la visualización de la información la proporciona el usuario y los objetivos de uso de la información. Estos aspectos en que los móviles aportan especiales ventajas para la cartografía son los que se muestran a continuación:

- Localización: la mayor ventaja de los mapas móviles frente a los tradicionales es la información en tiempo real, contextualizada por la ubicación del usuario. Los mapas visualizados en un dispositivo se adaptan en datos y contenidos a la localización del usuario, permitiendo un dinamismo en torno a la información superando los datos que se pueden presentar en una cartografía tradicional.

- Sistema móvil: la variedad de tipos de dispositivos móviles (hardware y software) crece continuamente en la actualidad, por lo que la información territorial debe ser interoperable y adaptable a diferentes tipos de sistemas. Desde los simple GPS navegadores se ha llegado a sistemas informáticos complejos, portátiles y móviles, que permiten no solo el despliegue de la información, sino también el procesamiento de los datos espaciales que el usuario necesite.

- Propósito de uso: existen diferentes y posiblemente ilimitadas situaciones en las que se necesitan representaciones específicas, con mayor o menor grado de complejidad y detalle de la información. Los mapas móviles deben adaptarse a

\footnotetext{
${ }^{43}$ En este caso, el contexto sería cualquier información que puede ser utilizada para caracterizar la situación de una entidad -persona, lugar u objeto- donde se hace relevante la interacción entre el usuario y la aplicación, además de la situación en que se encuentran estos dos últimos elementos (G. Chen \& Kotz, 2000; Dey, 2001; Perera, Zaslavsky, Christen, \& Georgakopoulos, 2014).
} 
cada situación y a los requisitos particulares de los usuarios. En la cartografía tradicional, los mapas eran clasificados en función de su utilidad (planos callejeros, cartografía geológica, mapas políticos, etc.), contenido de representación (cartografía temática o topográfica) y escala (planos, cartas y mapas). Con los dispositivos móviles la representación territorial pasa a ser multidimensional, adaptándose en tiempo real a los requerimientos de información de los usuarios.

- Tiempo: en este contexto se encuentran dos elementos temporales: momento del día y momento del año. Los elementos presentes en el territorio tienen diferentes tipos de comportamientos en ambos contextos, que deben ser tenidos en cuenta para la visualización final de la información. En la cartografía tradicional, al igual que en la fotografía, se representa un momento determinado de la situación territorial. Por contraparte, en una cartografía móvil es posible tener información en tiempo real, adaptada a diferentes contexto temporales.

- Entorno físico: este tipo de contexto puede variar en función de los diferentes escenarios que existen en el territorio. Por ejemplo, las ciudades y las montañas son contextos diferentes que requieren diferentes tipos de representación y precisan tipologías de datos diferentes, los cuales pueden ser desplegados y procesados por un dispositivo móvil, permitiendo la personalización de los datos en función del contexto físico particular.

- Historial de navegación: la información de contextos previos puede ayudar a mejorar y optimizar la representación y navegación en función de los requisitos actuales de los usuarios.

- Orientación: este es el aspecto más importante en lo referente al usuario y la utilización de mapas móviles. La representación debe desplegarse de manera correcta en función del movimiento y localización del usuario, por lo que los sensores adicionales de los dispositivos (acelerómetro, giroscopio, magnetómetro, giroscopio y GPS) permiten la obtención de la información necesaria para una correcta orientación.

- Elementos culturales y sociales: algunas veces la forma en que se utiliza la cartografía móvil y la experiencia que aporta, pueden diferir por aspectos culturales 
y sociales. Los tipos de consulta y la información proporcionada por los usuarios podrían condicionar los datos entregados. Ejemplo de esta situación corresponde a en que hombres y mujeres utilizan los teléfonos inteligentes y la forma en que se comprende la información territorial desde representaciones abstractas. La localización sobre la superficie de la Tierra, o los estándares establecidos por cada país también producen condiciones que deben ser consideradas en los datos territoriales (hemisferios, latitud, sistemas de coordenadas o magnitud, por mencionar algunos).

- Usuario: además del propósito de uso, esta es una de las características más complejas de determinar. El contexto del usuario está definido con parámetros que van desde las capacidades físicas para utilizar dispositivos móviles (edad, velocidad en el uso del teclado táctil), a los elementos cognitivos y de habilidad perceptual (memoria, capacidad de aprendizaje, toma de decisiones). Cabe incluir, incluso, las diferencias en la personalidad (género, actitud hacia la informática, estado emocionales).

También es posible considerar las acciones analógicas que se llevan a cabo empleando datos territoriales y transformar esas acciones en estructuras informáticas equivalentes informáticas, traduciendo a instrucciones y almacenamiento (soporte) esos datos, con formato digital (Tabla 2.5).

Tabla 2.5 Acciones básicas espaciales utilizadas en contexto de movilidad (Reichenbacher, 2005)

\begin{tabular}{|c|c|c|c|c|c|c|}
\hline Acción & $\begin{array}{c}\text { Interroga } \\
\text { ntes }\end{array}$ & Objetivos & Operaciones & Servicios & Parámetros & Soporte \\
\hline $\begin{array}{l}\text { Orientación y } \\
\text { localización } \\
\text { Localización } \\
\text { en el } \\
\text { territorio. }\end{array}$ & $\begin{array}{l}\text { ¿dónde } \\
\text { estoy? } \\
\text { ¿dónde esta } \\
\text { \{persona | } \\
\text { objeto\}? }\end{array}$ & $\begin{array}{l}\text { Localizar } \\
\text { personas y } \\
\text { objetos }\end{array}$ & $\begin{array}{l}\text { Posicionamiento } \\
\text { Geocodificación } \\
\text { Geodecodificación }\end{array}$ & $\begin{array}{l}\text { Entregar la } \\
\text { posición de } \\
\text { objetos y } \\
\text { personas }\end{array}$ & $\begin{array}{l}\text { Coordenada } \\
\text { Objeto } \\
\text { Dirección } \\
\text { Nombre de } \\
\text { lugar }\end{array}$ & $\begin{array}{l}\text { Orientación } \\
\text { en el espacio }\end{array}$ \\
\hline $\begin{array}{l}\text { Navegación } \\
\text { Navegación a } \\
\text { través del } \\
\text { espacio. } \\
\text { Planificación } \\
\text { de rutas. }\end{array}$ & $\begin{array}{l}\text { ¿cómo llego } \\
\text { a \{nombre } \\
\text { de lugar | } \\
\text { dirección | } \\
X, Y\} \text { ? }\end{array}$ & $\begin{array}{l}\text { Encontrar } \\
\text { una ruta a } \\
\text { destino }\end{array}$ & $\begin{array}{l}\text { Posicionamiento } \\
\text { Geocodificación } \\
\text { Geodecodificación } \\
\text { Enrutamiento }\end{array}$ & $\begin{array}{l}\text { Entregar rutas } \\
\text { e instrucciones } \\
\text { de navegación }\end{array}$ & $\begin{array}{l}\text { Punto de inicio } \\
\text { Punto de } \\
\text { destino } \\
\text { Waypoints } \\
\text { como } \\
\text { localizaciones }\end{array}$ & $\begin{array}{l}\text { Búsqueda de } \\
\text { rutas a través } \\
\text { del espacio }\end{array}$ \\
\hline $\begin{array}{l}\text { Búsqueda } \\
\text { Búsqueda de } \\
\text { personas y } \\
\text { objetos }\end{array}$ & $\begin{array}{l}\text { ¿dónde es } \\
\text { el \{cercano } \\
\text { I más } \\
\text { relevante\} } \\
\& \text { \{persona } \\
\text { | objeto\}? }\end{array}$ & $\begin{array}{l}\text { Localización } \\
\text { de personas } \\
\text { y objetos } \\
\text { según } \\
\text { criterios de } \\
\text { búsqueda }\end{array}$ & $\begin{array}{l}\text { Posicionamiento } \\
\text { Geocodificación } \\
\text { Geodecodificación } \\
\text { Calculo de } \\
\text { distancias y áreas } \\
\text { Localización de } \\
\text { relaciones }\end{array}$ & $\begin{array}{l}\text { Descubrir } \\
\text { disponibilidad } \\
\text { de servicios; } \\
\text { localización de } \\
\text { personas/objet } \\
\text { os }\end{array}$ & $\begin{array}{l}\text { Localización } \\
\text { Área/radio } \\
\text { Objeto/categor } \\
\text { ía }\end{array}$ & $\begin{array}{l}\text { Búsqueda de } \\
\text { objetos } \\
\text { relevantes; } \\
\text { Búsqueda de } \\
\text { personas. }\end{array}$ \\
\hline Identificación & $\begin{array}{l}\text { ¿qué hay } \\
\text { \{objeto\}? }\end{array}$ & $\begin{array}{l}\text { Identificación } \\
\text { de personas }\end{array}$ & $\begin{array}{l}\text { Directorio } \\
\text { Selección }\end{array}$ & $\begin{array}{l}\text { Entrega } \\
\text { (semántica) de }\end{array}$ & Objeto & $\begin{array}{l}\text { Información } \\
\text { sobre objetos }\end{array}$ \\
\hline
\end{tabular}




\begin{tabular}{|c|c|c|c|c|c|c|}
\hline $\begin{array}{l}\text { Identificación } \\
\text { y } \\
\text { reconocimient } \\
\text { o de personas } \\
\text { y objetos. }\end{array}$ & $\begin{array}{l}\text { ¿dónde hay } \\
\text { \{objeto\}? }\end{array}$ & $\begin{array}{l}\text { y objetos; } \\
\text { cuantificación } \\
\text { de objetos }\end{array}$ & $\begin{array}{l}\text { Búsqueda espacial } \\
\text { y temática }\end{array}$ & $\begin{array}{l}\text { información } \\
\text { sobre } \\
\text { personas/objet } \\
\text { os }\end{array}$ & & $\begin{array}{l}\text { del mundo } \\
\text { real para ser } \\
\text { utilizados en } \\
\text { la situación de } \\
\text { consulta }\end{array}$ \\
\hline $\begin{array}{l}\text { Chequeo } \\
\text { Cheque de } \\
\text { eventos. } \\
\text { Determinación } \\
\text { del estado de } \\
\text { los objetos. }\end{array}$ & $\begin{array}{l}\text { ¿qué } \\
\text { sucede } \\
\text { \{aquí | } \\
\text { ahí\}? }\end{array}$ & $\begin{array}{l}\text { Conocer que } \\
\text { sucede; } \\
\text { Conocer el } \\
\text { estado de los } \\
\text { objetos. }\end{array}$ & & $\begin{array}{l}\text { Entrega de la } \\
\text { información y } \\
\text { el estado de } \\
\text { objeto. } \\
\text { Información } \\
\text { de evento }\end{array}$ & $\begin{array}{l}\text { Tiempo } \\
\text { Localización } \\
\text { Objeto }\end{array}$ & $\begin{array}{l}\text { Búsqueda de } \\
\text { eventos } \\
\text { relevantes. } \\
\text { Información } \\
\text { sobre el } \\
\text { estado de los } \\
\text { objetos del } \\
\text { mundo real } \\
\text { para ser } \\
\text { utilizados en } \\
\text { la situación de } \\
\text { la consulta. }\end{array}$ \\
\hline
\end{tabular}

\subsection{Criticas a estos sistemas}

Las geotecnologías son herramientas que llevan más de 30 años presentes en el desarrollo de información geoespacial, teniendo un auge definitivo con la implementación de la web 3.0. Sin embargo, existe una serie de autores (G. Bertrand, Lindón, \& Hiernaux, 2006; Tapiador, 2006) que plantean una serie de interrogantes en torno a la utilización de estas herramientas, particularmente en contextos educativos y de análisis de procesos sociales:

- La falta importante de datos confiables sobre el territorio y el acceso real de esa información para el ciudadano.

- Las limitaciones tecnológicas presentes por el continuo aumento en los requerimientos en la capacidad de almacenamiento, conexión y procesamiento de datos.

- La simplificación de métodos de trabajo analíticos, llevados a la simple superposición de información en un mapa digital (abuso en la síntesis de regiones homogéneas).

- Los altos costos en la implementación de una adecuada infraestructura informática para la creación y difusión de contenidos territoriales.

- Problemas éticos derivados del creciente protagonismo de empresas comerciales en la implementación de sus productos geoinformáticos, la utilización de la información creada por los usuarios y la responsabilidad de las comunidades 
científicas en los usos finales de los datos (usos bélicos, espionaje, pérdida de privacidad).

- La falta de un adecuado contexto temático para implementar correctamente la metodología geotecnológica.

A pesar de lo anterior y desde la dimensión educativa, existen algunas investigaciones que presentan una percepción positiva en torno a estas herramientas por parte de los estudiantes (Favier \& van der Schee, 2014; Joo Nagata, 2013; Joo Nagata, García-Bermejo Giner, \& Muñoz Rodríguez, 2015; Kerski, 2003; Patterson, 2007). Es cierto que esta tecnología está muy extendida, pero esto no ocurre de forma reglada, sino que se aplica en contextos informales.

\subsection{La representación de la Tierra como elemento didáctico en la enseñanza}

Las Ciencias Sociales también se han hecho parte en la forma en que las personas comprenden y aprenden la constitución, magnitud y el sentido espacial-territorial. Desde la psicología y la educación, diversos autores (Armstrong, Gardner, \& Diéguez, 2006; Gardner, 1999; Mora, 1995) han establecido modelos de inteligencia en donde se establece que no es una única capacidad, sino que agrupa diferentes dimensiones cada una de manera específica. En el caso de Thurstone, identificó 7 dimensiones diferentes, las que llamo Factores o Habilidades Primarias las cuales son: fluidez verbal, comprensión verbal, rapidez perceptiva, razonamiento inductivo, aptitud numérica, memoria y la aptitud espacial, esta última consistente en la habilidad para reconocer una figura en un espacio determinado. Tiempo después Gardner establece su la "Teoría de las Inteligencias Múltiples", en la cual la inteligencia humana no es algo unitario, sino que se componen de estructuras múltiples, distintas y con algún grado de dependencia. De esta manera él define ocho tipos de inteligencias: inteligencia lingüístico-verbal, lógicamatemática, musical, corporal cinestésica, intrapersonal, interpersonal, naturalista y

\section{espacial.}




\subsubsection{Inteligencia espacial}

Dentro del contexto de lo cotidiano, la navegación y el uso de mapas espaciales mentales son parte de nuestra compresión del mundo. Así, las distancias, localizaciones y relaciones en el y con el territorio, forman parte de un proceso cognitivo y radican en el propio pensamiento humano. La resolución de estos problemas espaciales por medios informáticos hace necesaria la generación de una estructura de navegación, además de la caracterización de un modelo territorial que permita entender la realidad espacial de los sujetos (Gardner, 1999, 2006). Estos elementos ya han sido replicados con los sistemas cartográficos y de navegación, que desde tiempos antiguos, han tratado de representar y comunicar escenarios territoriales, y que en la actualidad se valen de componentes digitales con información en tiempo real.

La inteligencia espacial permite también visualizar objetos desde perspectivas y orientaciones diferentes, permitiendo detectar y enfocar nuevas formas de abordar situaciones, fenómenos y sistemas territoriales, con decisiones óptimas para cada caso. Todas las personas tendríamos la capacidad de obtener, comprender, procesar y comunicar la información que se presenta con tres dimensiones -desde el nivel más básico que es la localización-, y que se encuentra caracterizada por aspectos como textura, forma, color y la relación que existe entre estas cualidades (Newcombe \& Frick, 2010; Van Schaik, 2008). Así, la inteligencia espacial estaría relacionada con cómo los sujetos perciben y construyen su realidad desde la apreciación de los elementos que constituyen el espacio, pudiendo esta información mental ser reproducida en una fase posterior ${ }^{44}$. De la misma manera, existe la posibilidad de reconocer patrones espaciales en diferentes circunstancias, con la detección de diferentes objetos y sus relaciones en nuevos escenarios, otorgando la categoría de comprensión a esta información territorial. Otro de los elementos constitutivos de la inteligencia espacial, corresponde a la posibilidad de prever cambios territoriales y sus consecuencias, determinando los efectos que existirían en el entorno inmediato de la persona ${ }^{45}$.

\footnotetext{
${ }^{44}$ Ejemplo de esto corresponde a los mapas de rutas mentales que crean las personas sobre las ciudades, los destinos que usualmente utilizan y las vías de desplazamiento que reconocemos.

${ }^{45}$ En los procesos de conducción y en la planificación de rutas, las personas pueden evaluar rápidamente cambios posibles y sus consecuencias en caso de modificación de los patrones que habitualmente utilizan: por ejemplo, utilizar una calle adjunta para sobrellevar un accidente o incidente en la rutas, lo que en términos de distancia sería incrementar el recorrido, pero en términos de tiempo se traduciría en una optimización del nuevo escenario definido para cumplir el objetivo (ruta).
} 
Algunos autores (Del Grande, 1990; Gutiérrez, 1991; Noriega Biggio, Maris Vázquez, \& Maris García, 2011) desglosan la inteligencia espacial en los aspectos siguientes:

- Relaciones espaciales: toda persona tiene la capacidad de identificar correctamente las relaciones que se producen entre fenómenos y objetos situados en el espacio, estableciendo perspectivas, formas o implementaciones de estas relaciones.

- Visualización espacial: es la capacidad de crear una imagen mental teniendo como dato fuente las tres dimensiones, generando la posibilidad de crear cambios o transformaciones mentales de esta imagen y aprender de estas modificaciones.

- Orientación espacial: Es la capacidad que permite relacionar la posición de un objeto o unos elementos en el espacio, desde el punto de vista del individuo que lo está visualizando o con otro elemento el cual puede actuar como objeto de referencia territorial.

Otro elemento que forma parte de esta inteligencia espacial, es la capacidad de navegación (o enrutamiento), la cual es una de las habilidades que forman parte del comportamiento humano, y que permite el desplazamiento a través de distintos entornos y ambientes, convirtiéndolos en estructuras espaciales conocidas o familiares, y definidos por la interacción dinámica entre la percepción de los individuos y la memoria de un espacio previamente conocido o aprendido (Brunyé et al., 2014; Montello, 2005). En esta interacción, propia de la navegación, se requieren al menos cinco estrategias para su implementación (Foo, Warren, Duchon, \& Tarr, 2005; Trullier, Wiener, Berthoz, \& Meyer, 1997):

- Orientación del aparato locomotor

- Navegación hacia el punto de interés

- Integración de la ruta con el contexto real

- Navegación basada en rutas 
- Navegación basada en mapas

En un contexto general, estas estrategias se basan en: a) un nivel básico de mecanismos de estímulos y respuestas, que se expresan en el desplazamiento cotidiano de una ruta bien aprendida; o b) en el desarrollo de estrategias de nivel superior en las que se define la comprensión de la estructura espacial del entorno y la creación de nuevas rutas (atajos, definición de vías óptimas).

Newcombe y Frick (2010) establecen 4 puntos del por qué se debería mejorar las habilidades en el desarrollo de la inteligencia espacial:

- La inteligencia espacial tiene una importancia evolutiva y adaptativa. Todos los seres móviles del planeta deben tener la capacidad de viajar y desplazarse por el mundo que les rodea para poder sobrevivir.

- En función de este contexto evolutivo, se ha establecido que el pensamiento espacial es el principal complemento del pensamiento verbal y parte fundamental del concepto de inteligencia.

- El pensamiento espacial ayuda en el razonamiento visual, y en dimensiones que no necesariamente son espaciales. En diagramas o gráficos con metáforas espaciales es posible entender relaciones o jerarquías en base al despliegue de la información en un contexto espacial.

- El pensamiento espacial es fundamental para las disciplinas que se desarrollan en ciencias exactas, tecnología, ingeniería y matemáticas. Muchos de los fenómenos y procesos que presentan estas disciplinas se desarrollan en un contexto tridimensional, en donde se hace necesario la inteligencia espacial para la correcta comprensión de estos contenidos.

\subsubsection{Aprendizaje con aplicaciones geotecnológicas}

Una de las tendencias fundamentales en el desarrollo general de las TIC ha sido la aparición de las aplicaciones basadas en localización, la que ha facilitado y dirigido la 
toma de conciencia que ha tenido la información espacial en la interacción personal y social.

Desde hace algunos años, los procesos de aprendizaje han estado enfocados al desarrollo de Competencias como proceso de enseñanza-aprendizaje. La definición de este concepto y sus características está determinada por la incorporación de habilidades, conocimientos y actitudes (recursos) en un contexto específico, que permita la solución de problemas específicos por parte de los estudiantes (Garagorri, 2007; Martínez Abad, 2013; Perrenoud, 2008; Rychen \& Salganik, 2006; Tobón, Pimienta, \& García, 2010). Estas competencias superan el desarrollo de las habilidades básicas o "el saber hacer", es decir, los estudiantes no solamente desarrollan el saber qué hacer, sino además el cuándo utilizarlo, en un marco psicopedagógico constructivista centrado en el aprendizaje (Mastache, 2007).

Es entonces que las competencias que se desarrollan en el estudio y análisis de la categoría espacio ${ }^{46}$, se enmarcan dentro del amplio espectro que cubre las Ciencias Sociales, orientándose a la formación de personas reflexivas y participativas conscientes de su rol en las dimensiones temporales y territoriales (Santisteban \& Pagès, 2011a). Es importante mencionar que en la formación actual ${ }^{47}$, las escalas de presentación de los fenómenos (particularmente en lo referido a lo local y lo global) quedan en categorías que se pueden sobreponer y que deben entenderse en su conjunto para una real determinación de la complejidad de lo espacial. Dicha comprensión sobrepasa los límites impuestos por lo euclidiano y lo proporcional, tomando un rol que supera lo tangible y concreto. De esta manera, las competencias que se presentarían en este rol del aprendizaje de lo territorial, quedarían definidas por tres grandes dimensiones (Tabla 2.6):

\footnotetext{
${ }^{46}$ Espacio, territorio, paisaje, lugar, región y geosistema pueden ser diferentes categorías de un mismo fenómeno complejo con estructuras de comprensión y escalas de análisis diferentes. Para los objetivos de la presente tesis se utilizarán como sinónimos y explican los mismos elementos que se consideran en la construcción de la experiencia espacial del ser humano (Garrido, 2005).

${ }^{47}$ En estos momentos, los procesos de formación avanzan hacia la construcción de una perspectiva plural y multidimensional, con una clara interpretación crítica, valorando el entorno territorial, social y cultural en el que se desenvuelve el ser humano, permitiendo considerar la intervención en el medio ambiente, generando conciencia y proponiendo soluciones a problemas a su realidad social y física-natural, contribuyendo así al desarrollo sostenible, a la preservación de los recursos naturales y al cuidado del entorno.
} 
Tabla 2.6 Competencias planteadas en la utilización de TIC para el estudio del territorio. Basado en Ehlers (2008); Boix y Olivella (2007); Rød, Larsen, y Nilsen (2010); De Miguel González (2014).

\begin{tabular}{|c|c|}
\hline Dimensión & Competencia \\
\hline $\begin{array}{l}\text { I. Conocimiento y comprensión } \\
\text { del territorio y su organización. }\end{array}$ & $\begin{array}{l}\text { Identificación de los elementos que constituyen el } \\
\text { espacio, sus interrelaciones, y comprensión de cómo } \\
\text { estos elementos son el resultado (causalidad) de las } \\
\text { interacciones de las sociedades con el medio en el } \\
\text { que se desarrollan. } \\
\text { Comparación de unidades territoriales: } \\
\text { - Comparación de elementos naturales y } \\
\text { sociales que se dan en diferentes territorios. } \\
\text { Comparación de territorios (desde su escala, } \\
\text { tamaño, elementos constituyentes, influencia } \\
\text { del medio natural o social, etc. o el conjunto } \\
\text { de estos elementos como sistema). } \\
\text { Comparación de elementos presentes en el } \\
\text { territorio (indicadores: densidad, grado de } \\
\text { constitución, localización, etc.). }\end{array}$ \\
\hline $\begin{array}{l}\text { II. Conocimiento y comprensión } \\
\text { de técnicas de representación } \\
\text { del territorio (cartografía, } \\
\text { imágenes satelitales, GPS, redes } \\
\text { sociales geolocalizadas, etc.) }\end{array}$ & $\begin{array}{l}\text { Identificación y relación de los tipos de } \\
\text { representación relevantes (cartografía, modelos } \\
\text { digitales de elevación, datos basados en mapas de } \\
\text { píxeles, modelos vectoriales, etc.) } \\
\text { Conocimiento y manejo de los elementos básicos de } \\
\text { la representación del espacio que permiten la } \\
\text { comunicabilidad y replicabilidad de la información } \\
\text { sobre el territorio. }\end{array}$ \\
\hline
\end{tabular}


Adquisición de las destrezas básicas de localización y orientación con medios informáticos y su transposición en la realidad.

III. Destrezas básicas para la obtención de información territorial
Comprensión y utilización de procedimientos de medición, ubicación y posicionamiento sobre el territorio, con sus representaciones básicas en TIC.

Obtención, registro y sistematización de información territorial para responder a preguntas de carácter científico.

Obtención, registro y sistematización de información territorial para responder a preguntas de carácter científico.

Relacionar los elementos naturales con los fenómenos sociales presentes en el territorio, mediante la utilización abstracciones creadas por instrumentos o modelos científicos en un contexto TIC.

Fuente: Elaboración propia.

\subsubsection{Experiencias sobre Geotecnologías y Educación}

A continuación, se comentará brevemente el uso de las geotecnologías en diversos tipos de entornos educativos actuales, especificando su alcance y contexto. Las experiencias han sido seleccionadas para España y la región de Latinoamérica, evaluándose cinco dimensiones con sus respectivas características (Tabla 2.8 y Tabla 2.8):

- Dispositivo o tecnología utilizada

- Tipo de experiencia (personal o compartida) 
- Implementación (móvil o estática)

- Participantes

- $\quad$ Actividades de aprendizaje

Para el caso español, la utilización de herramientas geotecnológicas en contextos educativos formales se presenta a nivel universitario (García González, 2013; Santos Preciado, 2012), y también se encuentran experiencias iniciales que se desarrollan a nivel escolar (Fernández Campos, González Mendizábal, \& Pérez Gómez, 2012; Fombona Cadavieco, 2014; Gros Salvat \& Forés Miravalles, 2013). Este tipo de herramientas se emplean para fomentar el desarrollo de competencias tecnológicas, y para presentar contenidos que pueden ser situados espacialmente y comprendidos digitalmente, siendo los Sistemas de Información Geográfica (SIG) la tecnología de mayor utilización (García González, 2013; Ibarra Marinas, Martínez Hernández, Rubio Iborra, Pérez Resina, \& Figueres Cuesta, 2015).

Para el caso de latinoamérica, las experiencias actuales están enfocadas a estudiantes universitarios de grados relacionados con la temática del manejo y estudio del territorio (Arce, 2013; Tavera Momphotez, 2013). Los entornos de utilización de estas herramientas son principalmente estáticos (ordenadores de sobremesa) y las experiencias apuntan a la visualización y lectura de datos territoriales digitales, más que a la generación de información por parte de los estudiantes (Joo Nagata \& Valdés Durán, 2011; Navia Bueno, Joo Nagata, \& Guerra Pinto, 2014). En ambos casos, se prefiere la utilización de herramientas SIG, frente a la implementación educativa de otras metodologías geotecnológicas (Buzai et al., 2012; Flores Rodríguez, 2014; Tavera Momphotez, 2013). 
Tabla 2.7 Taxonomía inicial de geotecnologías aplicadas a la Educación: experiencias españolas

\section{Nombre del proyecto}

\section{Dispositivo o \\ tecnología}

utilizada
Tipo de experiencia:
personal o

compart

\section{Implementaci \\ ón móvil o \\ estática}

Participantes

Compartida en grupos Implementación

de trabajo

(1)

\begin{tabular}{|c|c|c|c|c|}
\hline $\begin{array}{l}\text { Servidores de } \\
\text { mapas: arcgis.com }\end{array}$ & $\begin{array}{l}\text { Compartida en grupos } \\
\text { de trabajo }\end{array}$ & $\begin{array}{l}\text { Implementación } \\
\text { móvil }\end{array}$ & $\begin{array}{l}\text { Estudiantes } \\
\text { universitarios de } \\
\text { segundo ciclo. }\end{array}$ & $\begin{array}{l}\text { Adquisición de competencias geoespaciales } \\
\text { mediante cartografía online y flipped } \\
\text { classroom }\end{array}$ \\
\hline $\begin{array}{l}\text { Sistemas de } \\
\text { Información } \\
\text { Geográfica }\end{array}$ & Personal y en grupos & Estática y virtual & $\begin{array}{l}\text { Estudiantes } \\
\text { Universitarios }\end{array}$ & $\begin{array}{l}\text { Aplicación de un nuevo modelo de } \\
\text { enseñanza virtual mediante la utilización de } \\
\text { sistemas de información geográfica en el } \\
\text { marco europeo. Visualización de ejemplos y } \\
\text { obtención de destrezas en torno a esta } \\
\text { herramienta. }\end{array}$ \\
\hline $\begin{array}{l}\text { Servidores de } \\
\text { mapas: Google Maps }\end{array}$ & Personal & Estática & $\begin{array}{l}\text { Estudiantes de } \\
\text { secundaria }\end{array}$ & $\begin{array}{l}\text { Proyecto colaborativo en la creación de } \\
\text { contenidos sobre literatura y su } \\
\text { espacialización mediante Google Maps. }\end{array}$ \\
\hline Geolocalización & Personal y grupos & $\begin{array}{l}\text { Implementación } \\
\text { móvil }\end{array}$ & $\begin{array}{l}\text { Estudiantes de } \\
\text { secundaria }\end{array}$ & $\begin{array}{l}\text { Estudio cualitativo enfocado con } \\
\text { metodología de entrevistas y } \\
\text { geolocalización, en donde los estudiantes } \\
\text { realizaban análisis espacial con tecnología } \\
\text { móvil. }\end{array}$ \\
\hline $\begin{array}{l}\text { Sistemas de } \\
\text { Información } \\
\text { Geográfica: GvSIG }\end{array}$ & Personal y grupos & Estática & $\begin{array}{l}\text { Estudiantes } \\
\text { universitarios }\end{array}$ & $\begin{array}{l}\text { Creación de competencias en TIC, } \\
\text { particularmente en geoherramientas, con el } \\
\text { fin de representar contenidos sociales que se } \\
\text { presentan en un contexto local. }\end{array}$ \\
\hline Geolocalización & Personal y grupos & $\begin{array}{l}\text { Implementación } \\
\text { móvil }\end{array}$ & $\begin{array}{l}\text { Estudiantes de } \\
\text { secundaria }\end{array}$ & $\begin{array}{l}\text { Diagnóstico de los estudiantes en su } \\
\text { contexto cotidiano utilizando herramientas } \\
\text { geolocalizadas. }\end{array}$ \\
\hline $\begin{array}{l}\text { Servidores de } \\
\text { mapas: WMS. } \\
\text { Sistemas de } \\
\text { Información } \\
\text { geográfica. }\end{array}$ & Personal y grupos & Estática & $\begin{array}{l}\text { Estudiantes de } \\
\text { Secundaria }\end{array}$ & $\begin{array}{l}\text { Integración de las TIC, mediante los } \\
\text { sistemas de información geográfica y } \\
\text { servidores de mapas, con recursos de } \\
\text { biología y geología para los estudiantes y } \\
\text { docentes. }\end{array}$ \\
\hline
\end{tabular}

geográfica.

\section{geoespaciales a través del web \\ mapping y la enseñanza inversa en \\ las aulas universitarias (de Lázaro \\ Torres, de Miguel González,}

La enseñanza virtual de los sistemas de información geográfica (SIG) en

la Universidad Nacional de Educación

a Distancia (UNED). Acomodación al

marco del espacio europeo de

educación superior (EEES) (Santos

Preciado, 2012)

Callejeros literarios: una propuesta

para la educación literaria

(Fernández Campos et al., 2012)

El uso de la geolocalización en

educación secundaria para la mejora

del aprendizaje situado: Análisis de

dos estudios de caso (Gros Salvat \&

Forés Miravalles, 2013)

El lenguaje visual y cartográfico en

las enseñanzas humanísticas. Planos

de Metro de Albacete. Cartografías

utópicas (García González, 2013)

La interactividad de los dispositivos móviles geolocalizados, una nueva

relación entre personas y cosas

(Fombona Cadavieco, 2014)

Aplicación de Web Map Services en la elaboración de un bloque temático de la materia de Biología y Geología de $4^{\circ}$ de ESO (Ibarra Marinas et al. 2015)

Fuente: Elaboración propia. 
Tabla 2.8 Taxonomía inicial de geotecnologías aplicada a la Educación: experiencias latinoamericanas

Nombre del proyecto

Los Sistemas de Información

Geográfica (SIG) en la enseñanza de

la geografía desde nivel básico hasta

universitario. Una nueva experiencia

educativa en México (Flores

Rodríguez, 2014)

Mobile learning: aprendizaje móvil

como complemento de una

estrategia de trabajo colaborativo

con herramientas Web 2 y entorno

virtual de aprendizaje WebUNLP en

modalidad de blended learning

(Arce, 2013)

Google Earth como recurso de

aprendizaje en la Formación Inicial

Docente en las Áreas de Historia y

Geografía (Joo Nagata \& Valdés

Durán, 2011)

Perspectivas y alcances de la

enseñanza de los SIG y la

teledetección en la universidad de

Guanajuato (Flores Rodríguez, 2014)

El patrimonio en la Web 2.0: Atlas virtual del Campus Macul

Universidad Metropolitana de

Ciencias de la Educación (UMCE)

(Navia Bueno et al., 2014)

Geografía y Sistemas de Información Geográfica (SIG) en la escuela secundaria. Reflexiones y propuestas

para el trabajo en las aulas de la

República Argentina (Buzai et al.

2012)

Desarrollo del producto multimedial

como apoyo a la enseñanza a través

de un módulo básico sobre sistemas

de información geográfica -SIG-

(Tavera Momphotez, 2013)

Fuente: Elaboración propia.

\section{Dispositivo o \\ tecnología}

utilizada

personal $o$

compartida

\section{Implementaci \\ ón móvil o}

estática

\begin{tabular}{|c|c|c|c|c|}
\hline $\begin{array}{l}\text { Sistemas de } \\
\text { Información } \\
\text { Geográfica }\end{array}$ & Personal y en grupos & Estática & $\begin{array}{l}\text { Niveles básicos de } \\
\text { enseñanza en } \\
\text { México }\end{array}$ & $\begin{array}{l}\text { Cartografía social de los contextos, sociales, } \\
\text { económicos y culturales del territorio local. } \\
\text { Construcción de mapas complementado con } \\
\text { la enseñanza tradicional. }\end{array}$ \\
\hline $\begin{array}{l}\text { Servidores de } \\
\text { mapas: Google Maps }\end{array}$ & Personal y en grupos & Móvil & $\begin{array}{l}\text { Estudiantes } \\
\text { universitarios }\end{array}$ & $\begin{array}{l}\text { Desarrollo de aprendizajes de contenidos } \\
\text { territoriales (m-learning) mediante la } \\
\text { utilización de equipos portátiles y } \\
\text { localización sobre el territorio. }\end{array}$ \\
\hline $\begin{array}{l}\text { Globos Virtuales } \\
\text { (GV): Google Earth }\end{array}$ & Personal y en grupos & Estática & $\begin{array}{l}\text { Estudiantes } \\
\text { Universitarios de } \\
\text { Formación Inicial } \\
\text { Docente }\end{array}$ & $\begin{array}{l}\text { Uso de Google Earth para presentar y } \\
\text { comprender la magnitud de fenómenos } \\
\text { geográficos de Chile y elementos culturales } \\
\text { históricos de civilizaciones originarias. }\end{array}$ \\
\hline $\begin{array}{l}\text { Sistemas de } \\
\text { Información } \\
\text { Geográfica y } \\
\text { teledetección }\end{array}$ & Personal y en grupos & Estática & $\begin{array}{l}\text { Estudiantes } \\
\text { universitarios }\end{array}$ & $\begin{array}{l}\text { Incorporación de herramientas } \\
\text { geotecnológicas en la enseñanza y } \\
\text { aprendizaje de las disciplinas en ingeniería. } \\
\text { Desarrollo de competencias geoespaciales } \\
\text { en los estudiantes. }\end{array}$ \\
\hline $\begin{array}{l}\text { Globos Virtuales } \\
\text { (GV): Google Earth. } \\
\text { Servidores de } \\
\text { mapas: Google Maps }\end{array}$ & Personal y en grupos & Estática & $\begin{array}{l}\text { Estudiantes } \\
\text { universitarios }\end{array}$ & $\begin{array}{l}\text { Visualización y comprensión del patrimonio } \\
\text { arquitectónico a escala local mediante } \\
\text { geotecnologías. Desarrollo de competencias } \\
\text { para la creación de recursos didácticos y su } \\
\text { contexto patrimonial y social. }\end{array}$ \\
\hline $\begin{array}{l}\text { Sistemas de } \\
\text { Información } \\
\text { Geográfica }\end{array}$ & Personal y en grupos & Estática & $\begin{array}{l}\text { Estudiantes } \\
\text { secundarios }\end{array}$ & $\begin{array}{l}\text { Creación de competencias en geografía para } \\
\text { el aula mediante herramientas como los } \\
\text { sistemas de información geográfica. } \\
\text { Espacialización de contenidos territoriales } \\
\text { que la disciplina enseña. }\end{array}$ \\
\hline $\begin{array}{l}\text { Sistemas de } \\
\text { Información } \\
\text { Geográfica }\end{array}$ & Personal y en grupos & Estática & $\begin{array}{l}\text { Estudiantes } \\
\text { universitarios }\end{array}$ & $\begin{array}{l}\text { Crear competencias en la enseñanza } \\
\text { mediante sistemas de información } \\
\text { geográfica como herramienta para el análisis } \\
\text { territorial de diversos contextos. }\end{array}$ \\
\hline
\end{tabular}

\section{Participantes}

Aprendizaje 
Llevando a cabo un análisis más pormenorizado de los estudios mostrados en las Tablas Tabla 2.7 y Tabla 2.8, se pueden extraer algunas conclusiones importantes en lo que respecta al empleo de las geotecnologías en los entornos de enseñanza-aprendizaje.

En primer lugar la utilización de las geotecnologías en contextos de enseñanza continúa siendo principalmente para la educación universitaria, y esto es debido a la cantidad de competencias previas requeridas para su adecuada implementación y manejo: desde conocimientos de informática -bases de datos, representación digital, comprensión de la estructura de la información digital-, hasta conocimientos disciplinares propios del estudio del territorio -análisis geométrico, proyecciones cartográficas, topografía, diseño gráfico- (Buzai et al., 2012; Fombona Cadavieco, 2014; Joo Nagata \& Valdés Durán, 2011; Tavera Momphotez, 2013). Otro factor que explica esta situación radica en la cantidad de recursos tecnológicos de que es preciso disponer para la utilización de estas herramientas (hardware), encareciendo las posibles aplicaciones educativas, sobre todo en niveles de enseñanza inicial y obligatoria (Flores Rodríguez, 2014). Por otro lado, existe una enorme cantidad de conocimientos en variadas disciplinas que deben ser distribuidos, contextualizados y enlazados con estas herramientas para lograr su adecuada implementación desde un ámbito educativo (Knowles \& Hillier, 2008).

A pesar de que existen algunos modelos conjuntos de aplicación tecnológicopedagógico, como son el modelo Technological PedAgogical Content Knowledge-TPACK0 el de Objetos de Aprendizaje ${ }^{48}$, no existen implementaciones claramente explicitas que permitan comprender el verdadero alcance educativo de estas herramientas. De las experiencias consultadas, en su mayoría utilizan el método de Aprendizaje Basado en Problemas, aunque los diseños metodológicos propuestos no lo plantean de forma directa (Flores Rodríguez, 2014; García González, 2013; Ibarra Marinas et al., 2015). Sin embargo, los ejemplos se enmarcan en problemas que se desarrollan en el contexto de escalas territoriales locales y regionales (la comunidad, el barrio, el entorno inmediato) en donde es posible tener un contacto con la realidad de manera concreta, con información directa que es aportada por el entorno inmediato, lo que facilita su posible comprensión. También existe la utilización de herramientas informáticas de fácil acceso e implementación (ordenadores de escritorio y software libre o freeware), y con contenidos temáticos diversos en donde se responde a preguntas como "¿dónde se produce el

\footnotetext{
${ }^{48}$ Dichos modelos será explicados en el capítulo siguiente.
} 
fenómeno...?", "¿qué ha cambiado desde...?", "¿cuánto ha cambiado...?", "¿qué ocurriría si...?' mediante la utilización de geotecnologías en contenidos disciplinares (Navia Bueno et al., 2014).

Otro elemento común en las experiencias analizadas, es la utilización de ordenadores de escritorio (plataformas fijas) en el contexto de enseñanza en el aula, en donde los contenidos se presentan en el territorio y pueden ser visualizados y comprendidos desde esta dimensión, en una analogía directa a lo que se realiza con otras metodologías como son los trabajos de campo. Las implementaciones móviles, que no son masivas en el uso de geotecnologías en educación, se basan la utilización de teléfonos inteligentes teniendo como contexto la localización del estudiante en el ambiente en que se desenvuelve, dejando de lado otros dispositivos como son las tabletas, los cuales podrían tener una mayor potencialidad debido al tamaño de presentación de la información y a su usabilidad (Henderson \& Yeow, 2012; Whalley et al., 2014).

De esta manera, las geotecnologías se presentan como el complemento didáctico TIC que utilizan otras disciplinas para presentar sus contenidos temáticos en un ambiente de enseñanza-aprendizaje, los cuales deben tener una expresión territorial -el espacio como soporte o escenario de los hechos- que permita su visualización y análisis por parte de los estudiantes.

A pesar del potencial que poseen las experiencias existentes en la literatura científica, existen ciertas limitaciones que se presentan de modo generalizado en las mismas. Podemos agruparlas en tres dimensiones básicas:

- En el ámbito teórico existe una ausencia general de un contexto conceptual tecnológico y pedagógico que se articule y funcione con las actividades propuestas en los diferentes casos estudiados. La mayoría de la experiencias se diluyen como meros informes de actividades, sin establecer objetivos y reales resultados tanto en los aspectos tecnológicos como educativos. Además, la presencia de un contexto teórico permitiría comprender y situar mejor los pilares desarrollados en cada investigación, sus metodologías y las conclusiones a que se llega, determinando su impacto e innovación en el plano educativo. A pesar que las experiencias analizadas se sitúan dentro de paradigmas educativos conocidos (e-learning, m-learning, flipclass, Aprendizaje Basado en Problemas por mencionar algunos), su contextualización no se realiza de manera explícita, ni presentando los alcances reales de las actividades propuestas a estos lineamientos teóricos. Otro punto 
importante es la ausencia de entornos basados en movilidad tecnológica para el aprendizaje en la mayoría de los estudios -elementos fundamentales en el desarrollo de las geotecnologías actuales con la geolocalización como referente principal- (Velazco Flórez, 2013), lo cual hace que planteamientos como el de Aprendizaje Situado - ulearning- (N. C. Burbules, 2012; Joo, Park, \& Choi, 2014; H. Norman et al., 2011) no se encuentren presentes en un contexto temático y metodológico ad hoc para este fin.

- Para el ámbito tecnológico la mayoría de las experiencias presentan un déficit en la infraestructura para el despliegue de datos territoriales, particularmente en aspectos como los que a continuación se indican:

- La utilización de programas que sólo tienen capacidades de visualización de información, sin la posibilidad de crear, editar y analizar datos espaciales (derivando la interacción con tecnología a la simple consulta de datos).

- La utilización exclusiva de ambientes estáticos de enseñanza debido al uso de ordenadores de sobremesa.

- El uso de información digital básica (normalmente calles y sus nombres) presente en servidores de consulta de libre como Google Maps.

- La ausencia de personalización de contenidos territoriales -particularmente en lo referido a la escala de presentación de datos-, esto es, en las temáticas que se implementan los contenidos disciplinares que normalmente se presentan en el entorno inmediato los cuales requieren un mayor nivel de detalle y resolución.

Sin embargo, es importante mencionar que la gran facilidad de acceso a datos territoriales generales ha facilitado la consulta e implementación genérica de modelos espaciales a escalas pequeñas (región, país, continente o planeta). Además, la existencia en la actualidad de una diversidad importante de software libre y freeware geotecnológico, ha permitido solucionar algunos de los inconvenientes que se aprecian en las experiencias educativas (Santos Preciado, 2012). Otro punto digno de mención es la ausencia en la incorporación de otras técnicas informáticas complementarias a las herramientas geotecnológicas como son la Realidad Aumentada, las redes sociales con la diseminación de contenidos, el almacenamiento en la nube, o la personalización de los ecosistemas de 
aprendizaje, complementando y creando nuevos procesos de presentación, comprensión de los datos y de los fenómenos disciplinares, y posiblemente, enriqueciendo las intervenciones de aprendizaje que se persiguen con estas herramientas.

- En la dimensión metodológica, fue posible observar que casi todas las experiencias no presentan una evaluación adecuada de los procesos de aprendizaje ni de los resultados derivados de su aplicación, quedando en su mayoría como propuestas de implementación de recursos didácticos en un contexto TIC. De la misma manera, las geotecnologías, al ser un conjunto de herramientas multidimensionales ${ }^{49}$ sobre el territorio que se complementan con otros contenidos, pueden lograr resultados particulares $-\mathrm{y}$ no necesariamente replicables- de los procesos planteados en torno a los problemas y datos sugeridos sobre el territorio. Además, todas las etapas para la utilización de información espacial son complejas y tienen su particularidad 50 , lo cual afecta o condiciona los procesos de aprendizajes propuestos (Buzai et al., 2012; Milson, 2011). Otro punto importante a mencionar es que las experiencias no tienen prácticas de evaluación formales, por lo que es no es posible saber el real impacto de estas herramientas dentro del proceso educativo. Las metodologías se plantean desde la preparación de los recursos geotecnológicos y su implementación, siguiendo estrategias de presentación de contenidos y su aplicación, pero no mostrando su evaluación y grado de eficacia en los resultados que se pretende obtener en dichas experiencias (de Lázaro y Torres et al., 2015; Fernández Campos et al., 2012; Flores Rodríguez, 2014; Ibarra Marinas et al., 2015; Joo Nagata \& Valdés Durán, 2011; Santos Preciado, 2012; Tavera Momphotez, 2013).

En conclusión, todas las experiencias analizadas se presentan en torno a la tutorización y exposición de contenidos -clases tradicionales con el uso de tecnología- y sus temáticas particulares desde metodologías con geotecnologías, no presentando los resultados concretos obtenidos, ni evaluando los procesos planificados. Tampoco existen pruebas y datos concretos sobre un aprendizaje real con estas herramientas en comparación con medios tradicionales no TIC. Las evidencias de los resultados de las experiencias presentadas no permiten inferir las consecuencias educativas de la utilización de estas herramientas (de Lázaro y Torres et al., 2015), a pesar de que en la mayoría de

\footnotetext{
49 La multidimensionalidad se encuentra constituida por los componentes de hardware, software, datos espaciales, métodos de análisis y procesamiento, y los usuarios, que unifican todo el sistema (Buzai \& Baxendale, 2006; Tomlinson, 2008).

50 Por ejemplo, en la creación de datos espaciales se hace necesario el conocimiento en fundamentos de Cartografía y Topografía, además de competencias propias de Informática.
} 
las investigaciones se concluye que existe un incremento en las capacidades en los procesos de enseñanza-aprendizaje implementados. Por otro lado, las experiencias se plantean como implementaciones con importantes innovaciones educativas, ya que proponen la integración de una serie de herramientas tecnológicas digitales a procesos educativos que se desarrollan de manera tradicional, permitiendo la inclusión de estas nuevas técnicas en el logro de competencias espaciales generales y disciplinares particulares (Joo Nagata \& Valdés Durán, 2011; Santos Preciado, 2012).

Así, entre las pocas evidencias científicas que aportan las experiencias analizadas se puede destacar el aumento en la comprensión de los contenidos temáticos otorgándoles un contexto territorial, dentro de un proceso que se vuelve dinámico, interactivo y sincrónico a través de estas tecnologías, complementando su dimensión teórica y transformándola en una solución práctica que puede ser comprendida en su implementación, manejo y visualización (Buzai et al., 2012; de Lázaro y Torres et al., 2015; García González, 2013; Ibarra Marinas et al., 2015; Navia Bueno et al., 2014). De esta manera, se produce la articulación de 3 dimensiones -pedagógica, disciplinar y tecnológica- que se integran situándose más allá de la simple exposición de elementos tecnológicos o únicamente de contenidos temáticos (Doering, Veletsianos, \& Sharber, 2008).

Partiendo de esta situación, la presente investigación trata de abordar las debilidades existentes en los métodos educativos ya implementados, diseñando estrategias formales para alcanzar avances en el estado del arte de las geotecnologías aplicadas a la Educación en los aspectos siguientes:

- La efectividad de estas herramientas (particularmente en lo referido la navegación asistida y los servidores de mapas desplegados en ambientes portátiles) en los procesos de aprendizaje de contenidos disciplinares y sus resultados, comparando su implementación con procesos de enseñanza tradicional y presentando los resultados de manera concreta y cuantificable. Otro aspecto novedoso corresponde a la contextualización del despliegue de la experiencia educativa con geotecnologías desde el ámbito cualitativo, obteniendo los datos desde los participantes del proceso mediante entrevistas a los profesores y estudiantes, permitiendo la referencia de los procesos planteados desde la dimensión personal y cognitiva del estudio. 
- Establecer la movilidad y la portabilidad como variables del proceso de aprendizaje con geotecnologías, permitiendo una mayor efectividad en el sistema de aprendizaje planteado, con la personalización de contenidos temáticos, permitiendo su posible replicabilidad con otras áreas y disciplinas (situación propia de la Programación Orientada a Objetos y los Objetos de Aprendizaje).

- La adecuada complementación e implementación de herramientas geotecnológicas con otro tipo de aplicaciones como es la RA, con el fin de generar un modelo informático complejo que tiene como fin la enseñanza de contenidos personalizados. Se puede lograr una metodología con mayor efectividad respecto a herramientas y situaciones tradicionales de enseñanza, debido a las características tecnológicas (affordance, presencialidad, interactividad) del sistema implementado. 


\subsection{Resumen}

En el presente capítulo se ha presentado el estado actual de desarrollo de lo que se conoce como las geotecnologías, abordando de manera particular su implementación en contextos portátiles y móviles, y su situación en la incorporación en la formación y enseñanza de las personas. Adicionalmente se ha desarrollado una síntesis que muestra la evolución de la información territorial, desde sus comienzos analógicos -en lo que es el papel y el dibujo-, hasta el desarrollo de las técnicas que se presentan hoy en día, en donde los datos digitales, sus estructuras y tipologías, son utilizadas en un contexto de desarrollo geotecnológico para la visualización y tratamiento de datos, desde diferentes disciplinas temáticas hasta la representación de los datos a distintas escalas sobre el territorio.

También se ha realizado una breve caracterización de la forma en que se ha abordado tecnológicamente el tratamiento de los elementos de la representación territorial (proyección, escala, coordenadas), que ha permitido una nueva contextualización de la información en estructuras digitales, desde el webmapping hasta la incorporación del Big Data para el almacenamiento y procesamiento de este tipo de información. De manera paralela se presentan las críticas relativas a la utilización de estas herramientas geotecnológicas, particularmente en su uso en escenarios educativos y sociales, y estableciendo su pertinencia y la posibilidad de implementación desde la dimensión territorial, temática y tecnológica. También se ha planteado una contextualización de la dimensión educativa que tienen estas herramientas, abordando sus características, contextos de uso y las formas de implementación. Se han estudiado las competencias que se pueden desarrollar y requerir para la adopción de este tipo de tecnologías, relacionándolo con diversas macro dimensiones formativas. Además, se han analizado una serie de experiencias en los ámbitos español y latinoamericano, obteniendo un diagnóstico inicial de los escenarios educativos en donde se implementan estas tecnologías. También se presentan los aspectos comunes existentes en los resultados de las experiencias educativas, las conclusiones globales que se extraen y las limitaciones principales que se observan en los estudios a nivel tecnológico, metodológico y teórico.

Finalmente, se plantean los aportes de la presente tesis indicando los aspectos novedosos y diferenciadores con respecto a los trabajos y desarrollos expuestos en el estado del arte realizado y que pretenden ser el valor agregado de este trabajo de investigación. 

Capítulo III

Contexto social de la tecnología en los procesos educativos 



\section{CONTEXTO SOCIAL DE LA TECNOLOGÍA EN LOS PROCESOS EDUCATIVOS}

\subsection{Introducción}

Más que intentar establecer un diagnóstico certero del estado actual de la Sociedad del Conocimiento o de la forma en que se desarrolla el contexto contemporáneo de las TIC, el presente capítulo estudia los efectos de la cada vez más amplia difusión de las innovaciones tecnológicas cuando estas son puestas en práctica en contextos educativos. Este fenómeno se produce como reflejo de lo que ocurre en los procesos sociales y que se observa en un marco mundial de la utilización de la tecnología.

En una visión general, los múltiples fenómenos sociales que componen la estructura de la civilización (educación, cultura, economía, comunicación, etc.) están alcanzando niveles de complejidad nunca antes presenciados por la sociedad a lo largo de su historia51. Lo que en un primer momento se estableció como una nueva etapa histórica de la civilización humana -postmodernismo-, contiene características que le son particulares, difíciles de cuantificar, predecir y posiblemente comprender, en lo que algunos autores definen como una "modernidad líquida". Esto se dice en referencia a la adaptabilidad de ese estado de la materia a las condiciones del medio, situación que las sociedades actuales se encuentran, adaptándose de forma constante a los cambios en el tiempo y los contenidos, y también a las dinámicas que están produciendo en sus diferentes ámbitos.

El valor que toma protagonismo en este mundo de enorme difusión y liquidez de la información no es otro que la experiencia. La experiencia, como referente personal, contiene elementos que la hacen particular y pueden otorgar un valor agregado al conocimiento general: el saber adquiere elementos de creación personal, es (auto)relevante e interrelacionado y contiene un significado que lo hace valioso y único.

\footnotetext{
${ }^{51}$ A modo de ejemplo de este dinamismo en la estructura social se encuentra el portal de videos YouTube que además funciona como una red social: en la actualidad se estima que tiene alojados en sus servidores 120 millones de videos, que requerirían aproximadamente 230 años para visualizarlos en su totalidad (Muñoz, 2015). Y también debe tenerse en cuenta la ahora antigua Ley de Moore, piedra angular del avance de la informática en materia de hardware hace algunos años, y que básicamente afirmaba que las capacidades se multiplicaban por dos, y los precios se dividían por dos, con una periodicidad que no llegaba a los dos años. Por lo planteado por su autor "mi ley dejará de cumplirse dentro de 10 o 15 años"- (Pastor, 2007). Esto significa cambios proporcionales a $2^{15}$. Adicionalmente y como referencia, la relación actual entre precio y capacidad de almacenamiento de 0,03 dólares por gigabyte (Komorowski, 2014). Estos son solo dos aspectos que demuestran la complejidad informacional en el mundo en que vivimos hoy.
} 
Así, intentar unir los aspectos tecnológicos y educacionales en este contexto temporal no es sólo un gran desafío social, sino que también es una meta que se debe tener como objetivo, reconociendo los procesos que están relacionados con la formación de las personas y adaptándolos a sus necesidades y a los de la sociedad en general.

Este capítulo es una presentación sintética de contenidos que van desde el planteamiento educativo, pasando por estructuras filosóficas y sociales, llegando hasta los paradigmas tecnológicos que se articulan en torno al concepto clave de "aprender en una sociedad tecnológica", pero con la particularidad de que estos procesos son únicos, complejos, dinámicos y desarrollados desde la experiencia, entregando un valor particular al universo social en que se vive, con un constante dinamismo y que va más allá de postmodernismo -o post-postmodernismo-. $Y$ es que se tiene como contexto una modernidad de forma líquida, siempre cambiante, siempre en evolución. El capítulo se organiza en un conjunto de secciones que abarcan y entrelazan una diversidad de ideas que representan un viaje colectivo en torno a la dinámica del cómo evolucionan los procesos sociales y tecnológicos, cómo se aprende y el cómo se relacionan materias, significados y contenidos con procesos personales y tecnológicos que se encuentran en diferentes niveles.

En la primera parte se aborda de manera general la configuración de la Sociedad de la Información y particularmente su evolución con las TIC, además de los procesos de difusión de las innovaciones -particularmente en lo referido a las tecnologías informáticas, estableciendo su evolución en el tiempo y sus impactos en la sociedad. Se intenta ir ejemplificando esta dinámica con la dinámica temporal que ha tenido la RA como tecnología innovadora.

En una segunda parte se lleva a cabo una contextualización de lo que significa este momento histórico en torno a la complejidad (Edgar Morin), las TIC y la modernidad líquida (Zygmunt Bauman), en donde el dinamismo marcado es parte de la realidad importante de la construcción del mundo, particularmente en los escenarios generales presentes en Iberoamérica.

Finalmente en la tercera parte de este capítulo se plantean, desde la dimensión teórico-educativa, los elementos y procesos que conducen esta investigación, revelando el paradigma base desde los planteamientos de John Dewey, los conceptos relevantes y 
los modelos educativos que forman el cuerpo teórico de nuestro planteamiento de investigación.

\subsection{Sociedad, complejidad y TIC: estableciendo un escenario}

\subsubsection{Sociedad del Conocimiento frente a una Sociedad de la Información}

Un punto de partida necesario para intentar comprender la realidad en que se sitúa la sociedad actual, es determinar el rol que están cumpliendo los avances tecnológicos en el desarrollo y estructura de las comunidades en sus constantes intentos de alcanzar el bienestar. Este punto se encuentra marcado por la diferenciación entre los conceptos de "Sociedad de la Información" o "Sociedad del Conocimiento" principio parecen similares, pero que tienen trasfondos desiguales, y con ello, implicaciones diferentes en lo que respecta a cómo se configuran, entienden e interpretan esta nuevas condiciones en los ámbitos sociales del ser humano (Martínez Abad, 2013).

En una "Sociedad de la Información"s3 el protagonismo lo determinan los medios digitales que permiten la creación y divulgación de los datos a escala global. Este constante traspaso de información digital se hace presente en muchos sectores de la sociedad, traduciéndose en nuevas formas de organización social y productiva (Castells, 2010; CEPAL, 2003; Joyanes Aguilar, 1997). Por otro lado, en una "Sociedad del Conocimiento" no solamente se hace referencia a la complejidad de los soportes tecnológicos, diferenciándose de una etapa anterior - Sociedad Industria/ por las nuevas formas de producir conocimiento dando importancia al uso de las TIC y su implementación en las actividades económicas. Además:

\footnotetext{
52 El concepto fue desarrollado en 1969 por Peter Drucker, experto en administración empresarial, que le dedicó un capítulo en su obra "La Era de la Discontinuidad" a «La Sociedad del Conocimiento». En este capítulo desarrollaba, a su vez, una idea anterior, apuntada en 1962 por Fritz Machlup, la de «Sociedad de la Información» (Brey, 2009, p. 19).

${ }^{53}$ Es importante destacar el concepto de Cibersociedad, presentado por Joyanes (1997), el cual, como sinónimo de Sociedad de la Información "...se sustenta en el hecho de que la información es un recurso o bien económico fundamental y base del desarrollo social actual. La información es un bien que no se agota con su consumo, es más, puede que se enriquezca en un desarrollo ideal y utópico hasta valores incalculables, naciendo otra nueva y rica información que cada vez va produciendo más información" ( $p$. $169)$, estableciéndose como una de las primera referencias en torno al valor que toma la información en una nueva etapa conocida como Sociedad del Conocimiento.
} 
- El conocimiento es unos de los pilares del crecimiento económico, junto con el capital y el trabajo, siendo fundamental para la creación de productos con un alto valor agregado que a su vez dan lugar a servicios y tangibles ricos en complejidad y también en conocimiento (Bell, 2001; Krüger, 2006);

- Los procesos educativos adquieren un nuevo rol con dimensiones que parten de la formación inicial, pasando a la profesional, hasta llegar a la formación a lo largo de la vida (López i Amat, 2010; OECD, 2001; Reich, 1992);

Así, la 'Sociedad del Conocimiento' queda establecida en función de cambios habidos en ciertas áreas de la tecnología y también en algunas actividades económicas que se encuentran fuertemente enlazadas con la actuación de las TIC. Los ámbitos implicados parten de la planificación de la educación y la formación, pasan por la organización de la información entendida como gestión de conocimiento, y llegan a las formas de entender las actividades laborales con conocimiento (Brey, 2009; Jara et al., 2015; Krüger, 2006).

\subsubsection{Precauciones en torno a esta Sociedad del Conocimiento, en un contexto de aprendizaje}

La Sociedad del Conocimiento es un concepto de entrada que ya no solamente abarca los corpus teóricos de la economía o la sociología: se ha transformado en un punto común en las Ciencias Sociales debido al impacto transversal -desde lo político hasta lo educativo- y a diferentes escalas -desde lo personal hasta lo nacional- que tienen la información y la tecnología sobre el quehacer humano. Sin embargo, la construcción de un concepto tan general que todo lo puede ser, debe ser presentada con atención. Autores como Heidnereich (2003) proponen una postura escéptica frente al fenómeno, planteando interrogantes como la definición inherente de sociedad en la cual, el conocimiento, es una base fundamental de su composición: ninguna sociedad existe sin disponer de algún tipo de conocimiento (como se cita en Krüger, 2006).

Otro punto importante lo establece Innerarity $(2009,2011)$ en donde la sociedad actual está abocada a una particular especie de ignorancia que es consecuencia del contexto y las características propias de la modernidad -y el exceso- de datos en que se encuentra inmersa. La complejidad tecnológica no solo facilitaría el intercambio de 
información en diferentes magnitudes y escalas, sino que también sería fuente de nuevas dificultades que es necesario abordar. Estas precauciones se expresarían en las formas siguientes:

- Los datos en crudo no sirven para representar el carácter no inmediato de nuestra experiencia de mundo. Los avances actuales de la ciencia no hacen más fácil la comprensión de la realidad, sino por el contrario, la complejizan a niveles tales que solo es posible entender una parte general de un sistema cada vez más complejo. Y, como consecuencia, cuanto más complejo es el sistema "realidad", más se cae en la tentación simplista de aceptar los fundamentos y hechos sin la conocer la naturaleza del por qué funcionan, relacionan o producen los fenómenos, dando todo por la facilidad que significa dar todo por supuesto. En síntesis, la aceptación sin el comprender. Lo anterior se produce por la complejidad de los conocimientos generados por las ciencias en la actualidad, los cuales, en su mayoría, cada vez se relacionan menos con la experiencia inmediata de la vida cotidiana de los individuos y por tanto, resultan incompresibles para el sentido común y con ello, excluyen la posibilidad de crear un correcto entendimiento.

- La cantidad y densidad de la información existente es enorme. En la actualidad el saber de la humanidad se duplica cada cinco años, pero el conocimiento generado se ha vuelto excesivamente fragmentado o especializado, lo cual da lugar a que la visión de conjunto de los fenómenos de la realidad sea más difícil de alcanzar. A lo anterior se le agrega que la sociedad se encuentra en un maremágnum de sobrecargas de información que no tienen directrices ni guías, y esta sociedad no dispone de una capacidad de procesamiento humano que permita y logre su entendimiento y el posterior paso para la generación de saber ${ }^{54}$.

- Existen diversas interacciones y a veces complejas mediaciones tecnológicas con la realidad. Al parecer, en este mundo interconectado, el saber se encuentra en todas partes, con expertos y temáticas que confluyen, principalmente, en el ciberespacio. Sin embargo, nuestra capacidad de autosuficiencia se ve cuestionada en el momento en que mucha información no se puede comprobar, ni siquiera

\footnotetext{
${ }^{54}$ La búsqueda del concepto "Sociedad de la Información" en www.google.es arroja 22.800 .000 millones de resultados (consultado el 7 de enero de 2016). Dedicando solamente un minuto para la visita de cada resultado, se necesitarían 43,37 años para poder consultar la totalidad de la información obtenida.
} 
entender: aparatos que no sabemos cómo funcionan (a manera de ejemplo coches, ordenadores, electrodomésticos por mencionar algunos) o sucesos y eventos que no se pueden comprobar de manera inmediata poniendo en duda su veracidad. Toda la información se encuentra sumida en profundas cajas negras en donde solo es posible comprender y procesar los simples "outputs" que generan dichos sistemas, pero sus componentes y sus interrelaciones tienen que aceptarse como reales y certeras.

A pesar de esta situación, las sociedades tienen la posibilidad de adaptarse mediante una suerte de resiliencia estructural, que les permite avanzar hacia nuevas etapas en donde la información adquiera un nuevo valor y forma: el saber.

\subsubsection{Cuando la información se convierte en saber}

Así en esta Sociedad del Conocimiento, el asunto principal radica en el cómo se procesa y entiende la simple recolección de datos y se transforma en algo más importante y con valor agregado, lo que se conoce como conocimiento. El conocimiento ya no sería la simple información, aislada de contexto, origen y objetivo en sí, sino que también lleva consigo en su construcción la experiencia del que la interpreta, el juicio de quien la valora, la intuición y la incorporación de valores de discernimiento, y así aporta un orden coherente, con lógica y relevancia práctica (Innerarity, 2011, p. 27). Los simples datos iniciales, que se caracterizan por ser de diversa naturaleza, con estructuras y elementos heterogéneos en su composición y expresión, no conllevan la distinción fundamental de lo que es utilidad, reflexión y sentido. Al aportar esas propiedades a la información se logra lo que es el saber, un tipo de conocimiento que está verificado y legitimado por un mecanismo institucional válido como son los grupos o las sociedades científicas (Lesemann, 2014).

\subsubsection{La apuesta de la educación en la Sociedad del Conocimiento. De la implementación de los datos al creación de políticas del saber}

La inclusión de las TIC en los procesos educativos va estableciendo -no necesariamente de manera explícita y premeditada- la creación de lazos entre disciplinas, desde acciones conjuntas, mezcladas e integradoras, intentando visualizar una realidad que es sumamente compleja y que tiene múltiples formas de lectura e interpretación. En 
otras palabras, se pretende la creación de un saber que tenga un significado para el que lo comprenda, lo utilice y lo enseñe. Lo que en un primer momento es un problema de atomización de conocimientos o de aislamiento en la comprensión de los fenómenos que se encuentran profundamente interrelacionados en la realidad, hace necesario el establecimiento de marcos y estructuras generales en la compresión de la información para tratar de comprender, o al menos iniciar, un nivel de conciencia que establezca que el mundo real está formado por diversas dimensiones, capas e interrelaciones, las cuales funcionan como un todo que es particular. Así, se trata de evitar la hiperespecialización o aislamiento de contenidos- propia de esta época tratando de crear un modelo investigativo donde confluyen diferentes conocimientos, temáticas, métodos y experiencias:

"El conocimiento pertinente debe enfrentar la complejidad. Complexus, significa lo que está tejido junto; en efecto, hay complejidad cuando son inseparables los elementos diferentes que constituyen un todo (como el económico, el político, el sociológico, el psicológico, el afectivo, el mitológico) y que existe un tejido interdependiente, interactivo e inter-retroactivo entre el objeto de conocimiento y su contexto, las partes y el todo, el todo y las partes, las partes entre ellas. Por esto, la complejidad es la unión entre la unidad y la multiplicidad. Los desarrollos propios a nuestra era planetaria nos enfrentan cada vez más y de manera cada vez más ineluctable a los desafíos de la complejidad. En consecuencia, la educación debe promover una «inteligencia general» apta para referirse, de manera multidimensional, a lo complejo, al contexto en una concepción global." (Morin, 1999, pp. 15-16).

La idea no es terminar con la especialización y el reduccionismo de las disciplinas en este contexto de globalidad informacional, sino más bien, hacer frente al conocimiento desde la complejidad, dimensión que toma un nuevo significado y que va más allá de entender de manera sistémica las distintas realidades que existen. Desde esta perspectiva, temáticas y disciplinas que en un primer momento pueden aparecer aisladas -la educación, la tecnología y el territorio- se perciben como formantes de un sistema complejo, intentando comprender desde estas dimensiones en conjunto, las realidades que se crean como sociedad y sujetos. 
Si desde hace mucho tiempo se reconoce la importancia de los procesos educativos en el avance y mejora de las sociedades y más particularmente de las personas, la incorporación de las TIC genera un nuevo escenario, en donde se podría dar respuesta a los grandes desafíos en torno al desarrollo con las dimensiones éticas, sociales, productivas, culturales y políticas, con ese marco general conocido como Sociedad del Conocimiento. De esta manera, cada región ha tenido implementaciones de diversa índole en la incorporación de las TIC al ámbito educativo y que hasta el día de hoy continúan siendo parte fundamental por incorporarse al escenario global desde estos aspectos.

\subsubsection{Caso latinoamericano}

En el caso latinoamericano la incorporación de las TIC en el ámbito educativo, ha perseguido como objetivo la constante mejora de los niveles educativos e indicadores de desarrollo. Como lo establecen Hilbert, Bustos y Ferraz (2015), los primeros proyectos de TIC implementados en educación se presentan a finales de la década de 1980 con el fin de disminuir la brecha digital de la región, teniéndose en cuenta que nos encontramos en un mundo cada vez más basado en la tecnología. De esta manera se establece como objetivo general modernizar los procesos de enseñanza-aprendizaje e implementar la informatización en las dimensiones administrativas y académicas de los centros educativos. De esta manera, y desde el año 2002, se han establecido una serie de reuniones que se sintetizan en el "Plan de Acción Regional sobre la Sociedad de la Información en América Latina y el Caribe (eLAC)" cuyo objetivo fundamental es determinar las necesidades tecnológicas de los países de la región en relación a los marcos globales establecidos en la cumbre "Objetivos de Desarrollo del Milenio". Hasta la fecha ha habido tres versiones del plan (eLAC2007, eLAC2010 y eLAC2015), en donde se plantea que las TIC son un instrumento para el desarrollo económico y de la inclusión social de los países (Sunkel, Trucco, \& Espejo, 2013).

En una escala más concreta de visualización, la mayoría de los países de la región han pasado a una siguiente fase, que va más allá de la implementación inicial de las TIC en los procesos educativos (Figura 3.1), configurándose una nueva etapa en donde se establece la formulación, ejecución y evaluación de proyectos educativos de mayor complejidad y mejores alcances en términos tecnológicos y educativos (Guerra \& Jordán, 2010). 
Figura 3.1 Políticas nacionales de TIC en América Latina y el Caribe

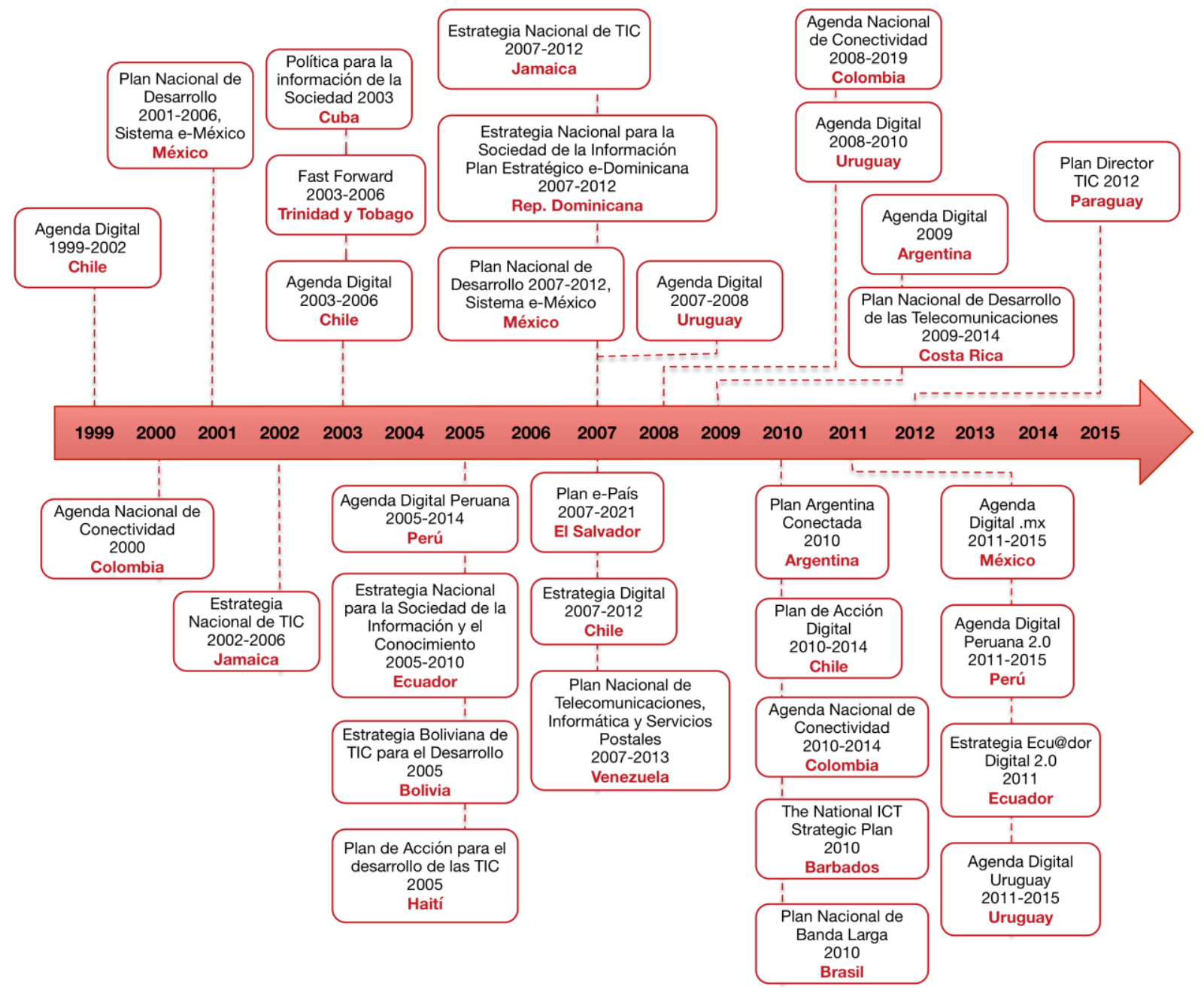

Fuente: Guerra y Jordán (2010)

Esta implementación de las TIC dentro de la región ha presentado diferentes formas y experiencias, teniendo antecedentes de comienzo en la década de los 70 del siglo XX con la inclusión de la radio y la televisión en los procesos educativos, para pasar en una segunda etapa a la incorporación de los ordenadores y al acceso generalizado a internet, hasta llegar al momento actual con la implantación de los dispositivos móviles en el aula (Sunkel et al., 2013).

Todas estas incorporaciones e iniciativas han tenido como resultado un avance muy irregular en lo tocante a la incorporación de las TIC y también en lo que respecta a su verdadera efectividad en el ámbito educativo. Dentro de la región existen países en los que la cobertura TIC continúa siendo muy reducida, y el acceso generalizado a 
ordenadores a nivel escolar se encuentra en niveles lejanos a los estándares mundiales ${ }^{55}$. De manera paralela hay países con una fuerte implementación de las tecnología y con planes y programas revisados de manera constante y actualizados según los requisitos educativos como es el caso de Chile, Uruguay y Brasil (Jara \& Toledo, 2009).

\subsubsection{Situación en España}

Dentro del entorno europeo y particularmente en el español, las TIC se han convertido en un medio de transformación y dirección para las actividades económicas. Desde el año 2000, a través de la reunión del Consejo de Europa que se realizó en Lisboa, se planteó convertir a la Unión Europea (UE) en una economía basada en el conocimiento, con altas capacidades de competitividad y dinamismo. En este contexto se puso en marcha el "Plan de Acción Global eEurope i2010" cuyo objetivo era que todos los ciudadanos, escuelas, empresas y administraciones pudiesen acceder a las nuevas tecnologías de información y comunicación. Este plan de acción pretendía alcanzar tres objetivos (Valle, 2011):

- La construcción de un espacio único europeo de la información.

- Reforzar la innovación y la inversión de las investigaciones en materia de TIC.

- Lograr una sociedad europea de la información basada en la inclusión.

De manera local, España crea el Instituto de Tecnologías Educativas y de Formación del Profesorado -INTEF- dependiente Ministerio de Educación, Cultura y Deporte, el cual realiza informes de manera periódica y es el responsable de la integración de las TIC en el ámbito educativo (Ministerio de Educación, Cultura y Deporte España, 2015). El INTEF ha desarrollado diversos políticas para la incorporación de las TIC en el ámbito educativo destacando el Plan Avanza (2005-2010) cuyo objetivo es tener una inversión del 3\% del PIB español en investigación y desarrollo (Vignola, Pardo Mellado, \& Peris Garcia, 2011).

${ }^{55}$ Aproximadamente 4 estudiantes por ordenador (Instituto de Tecnologías Educativas, 2011). 
De manera específica, en el ámbito investigativo, la mayoría de los estudios sobre la situación española de las TIC en la educación se concretan en seis factores (Colás Bravo \& Casanova Correa, 2010, p. 125):

- Uso e infraestructura de las TIC en los centros escolares.

- Iniciativas y actitudes hacia las TIC por parte del profesorado y los centros.

- Frecuencia de uso de las TIC en las actividades curriculares.

- Producción de materiales.

- Información sobre las TIC.

- Contexto escolar.

Al igual que en el caso latinoamericano, la implementación de TIC en los centros educativos se realiza de manera heterogénea sin ser tampoco extensiva, lo que se explicaría por diversas variables asociadas al uso integrador de las tecnologías en procesos educativos (de Pablos Pons, Colás Bravo, \& González Ramírez, 2010).

Un claro indicador del escenario que se produce es el porcentaje de ordenadores presentes en los hogares (Figura 3.2) en donde se puede visualizar que el promedio general de los países de Organización para la Cooperación y Desarrollo Económico (OCDE) corresponde al 77,2\%, mientras que España presenta un 71,5\%. Los países latinoamericanos participes de esta organización se encuentran muy por debajo del promedio actual (Brasil 45,4\%, Chile 43,9\% y México 30\%). 
Figura 3.2 Porcentaje de familias con acceso a un ordenador desde casa, año 2011 países OCDE

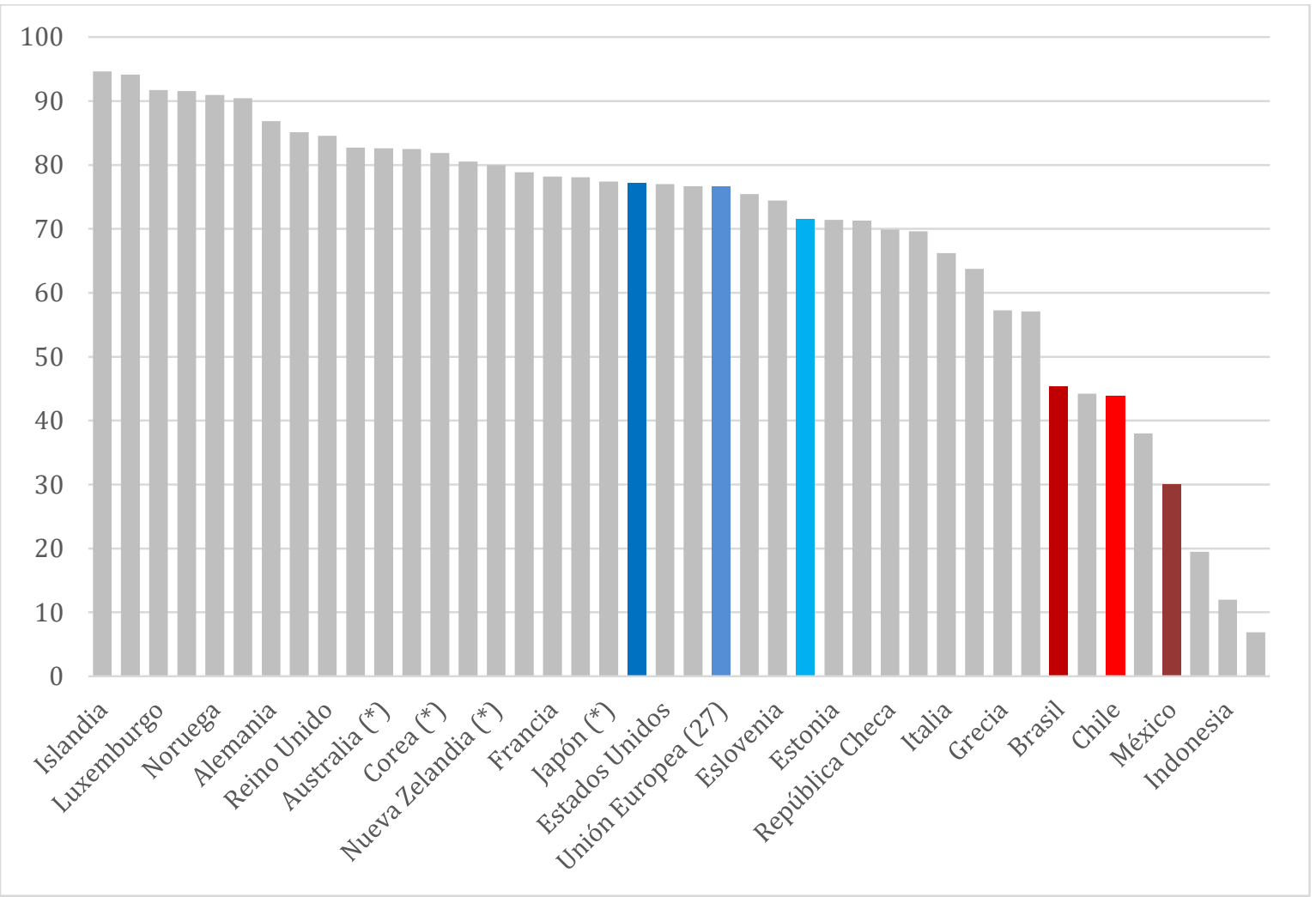

Fuente: Elaboración propia tomando como base datos de la Organización para la Cooperación y Desarrollo Económico -OCDE- (2015).

\subsection{Difusión de las innovaciones, adopción de tecnologías y su impacto en}

\section{los recursos dirigidos a la educación}

Dentro de la cultura general moderna se hace uso de una vieja maldición, supuestamente de origen chino -aunque no existen fuente confiables que establezcan su real origen-, que refleja las paradojas propias de esta época: "ojalá vivas tiempos interesantes". Esos tiempos "aburridos" eran sin cambios, con una aparente estabilidad e incluso muy predecibles en el estado general de las cosas. Por contraposición, los tiempos interesantes como los actuales, se encuentran enmarcados en el constante devenir de los cambios, de las adaptaciones, las revoluciones y de las evoluciones, las que parecieran ser extremadamente dinámicas, difíciles de comprender y atender con oportunidad. Estos tiempos interesantes comenzarían con lo que diversos sociólogos e historiadores han llamado postmodernismo, en donde la sociedad entra en una nueva etapa en que el conocimiento se encuentra en un estado constante de legitimación a causa de los impactos de la transformación tecnológica, alterando las estructuras y reglas de la ciencia, las artes y la literatura (Bellisario, 2001; Harvey, 1998; Lyotard, 1987). Sin embargo, esta versión 
2.0 de lo que fue la modernidad no es un concepto suficiente para definir el estado y dinámica actual de las cosas, o mejor dicho, no se encuentra lo suficientemente aceptado debido a los aspectos inconmensurables que intenta abarcar ${ }^{56}$. Es por lo que aparece entonces la noción de modernidad líquida:

"...en la que el peso de la construcción de pautas y la responsabilidad del fracaso caen primordialmente sobre los hombros del individuo. La licuefacción debe aplicarse ahora a las pautas de dependencias e interacción, porque les ha tocado el turno. Esas pautas son maleables hasta un punto jamás experimentado ni imaginado por las generaciones anteriores, ya que, como todos los fluidos, no conservan mucho tiempo su forma. Darles formas es más fácil que mantenerlas en forma" (Bauman, 2004, p. 13).

De esta manera, esta suerte de modernidad en estado líquido se transforma en los tiempos interesantes que se encuentran presentes hoy en día y que se manifiestan en el constante cambio no solo de situaciones y contextos sociales, sino también de tecnologías, de su forma de expresión y de su desarrollo.

\subsubsection{La Sociedad del Conocimiento tiene como base la modernidad líquida}

Utilizando como metáfora el estado líquido de la materia, Bauman (2004, 2013) plantea que esta modernidad, similar a la del siglo XIX y XX, pero que tiene como foco principal a los sujetos y el sentimiento de incertidumbre y de constante cambio, en una analogía de los fluidos que no se detienen y se adaptan a situaciones externas sin formar una condición perdurable como los sólidos. Esta modernidad líquida sería una continuación de la modernidad, pero en donde los ingredientes adicionales del caos y la incertidumbre social son fuertes influencias que exigen una reconfiguración constante:

"A diferencia de la era de modernidad «sólida» que la precedió, que vivía enfocada hacia la «eternidad» (una forma abreviada de referirse a un estado de uniformidad perpetua, monótona e

\footnotetext{
${ }^{56}$ Otro especialistas y disciplinas utilizan los términos de "fin de la historia", "post-postmodernidad", "segunda modernidad" o "sobremodernidad".
} 
irrevocable), la modernidad líquida no se fija ningún objetivo ni traza línea de meta alguna y sólo asigna una cualidad permanente al estado de fugacidad. El tiempo fluye, ya no «sigue su curso inexorable». Hay cambios, siempre los hay, siempre son nuevos, pero no hay ningún destino ni punto final, ni tampoco expectativa alguna de cumplir misión. Cada momento vivido esta preñado de un nuevo comienzo y de su final (antaño enemigos jurados, hoy gemelos siameses)" (Bauman, 2013, p. 90).

La creación y adopción de nuevas ideas, conceptos y tecnologías son en la actualidad una constante en la modernidad líquida, que tiene fuertes repercusiones, no sólo en la simple comercialización de innovaciones, sino también con importantes impactos sobre los procesos sociales. Esta relación entre la tecnología y la constitución de la sociedad actual tiene diferentes aristas, ya existiendo estudios y datos sobre el impacto en los modos de producción y consumo, la conformación de nuevos procesos sociales particularmente los educativos- que comienza en la segunda mitad del siglo XX (Harvey, 1998). Así, existen nuevas teorías y modelos (como la Difusión de las Innovaciones y los Ciclos de Exceso de Expectativas) que se han planteado con el fin de determinar cómo se comportan estos procesos, permitiendo observar los cambios y posibles influencias dentro de una sociedad, y son una muestra del comportamiento liquido de las actividades económicas que tienen consecuencias en los ámbitos sociales.

\subsubsection{Difusión de las innovaciones}

La Teoría de Difusión de las Innovaciones fue planteada por Everett Rogers en 1962, y afirma que la difusión es un proceso en el cual la innovación se comunica mediante ciertas fuentes o canales en algún momento en un sistema social determinado (Rogers, 2003). Los principales elementos en la difusión de estas nuevas ideas serían (p. 36):

○ Una innovación

- La comunicación de esa innovación mediante canales

○ Tiempo

- Entre los miembros de un sistema social 
Un punto importante en la teoría de Rogers es que las innovaciones planteadas tienen diferentes procesos de evolución, las cuales se encuentran condicionados por las variaciones de su permanencia temporal y por la difusión que se realiza en contextos sociales $^{57}$. Lo anterior se puede sintetizar en tres grandes fases (Figura 3.3): una adopción temprana de la tecnología que sólo afecta a una cantidad mínima de usuarios, normalmente innovadores, que se arriesgan en la prueba de nuevas ideas, procesos y tecnologías; una fase de despegue, en donde el nivel de ventas y utilización comienza a incrementarse según avanza el tiempo; y una última etapa, en donde existe una verdadera masificación de la innovación en la sociedad, quedando solamente los adoptadores tardíos que son los últimos en incorporar y utilizar la tecnología propuesta, ya en un estado de uso cotidiano.

Figura 3.3 Proceso de difusión de innovaciones (Rogers, 2003)

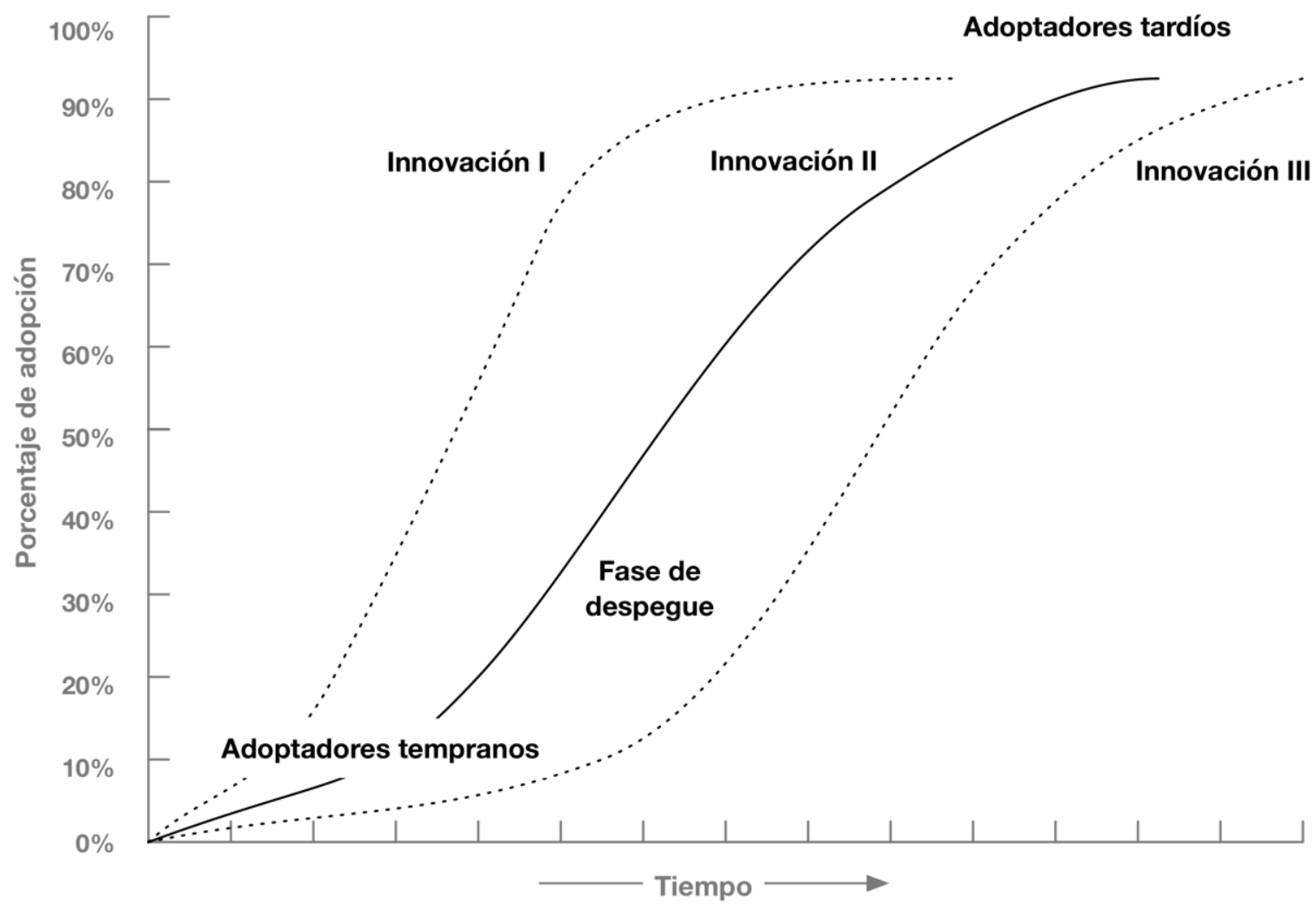

\footnotetext{
${ }^{57}$ Un ejemplo concreto de la dinámica de las difusión de estas innovaciones corresponde a las tecnologías desarrolladas para la reproducción de la música: los discos de vinilo se han mantenido por más de un siglo como tecnología musical, lo cual supuso una revolución en la industria discográfica, y que como tecnología, sigue vigente al día de hoy (Perpetua, 2011). Por el contrario, el MiniDisc (tecnología desarrollada por Sony), sólo tuvo una breve existencia y con un mercado muy centrado en Japón, teniendo un ciclo de vida del producto efímero para la industria musical, con únicamente 19 años en circulación y desarrollo (Faulkner, 2012; Riyad, 2008).
} 
De esta manera y contextualizando la dinámica que se genera en la difusión de las innovaciones, para el caso de la curva I, la tecnología que marca este proceso de innovación se encuentra relacionada con la adopción de Internet en los procesos educativos (UNESCO Institute for Information Technologies in Education, 2000), que, desde su masificación comercial ${ }^{88}$ hasta el presente, es parte importante de los procesos de enseñanza-aprendizaje en todos los niveles (Korte \& Hüsing, 2006; Stošić \& Stošić, 2015), con una continua mejora relacionada con los avances que se realizan en el ámbito tecnológico. En síntesis, desde el desarrollo de una tecnología hasta su masificación en la sociedad, el periodo temporal que transcurre es breve, teniendo impactos rápidos en el medio en que se desenvuelve. En el caso de la curva II, se puede observar que la fase de despegue de la innovación necesita un mayor periodo de maduración para su correspondiente masificación. Ejemplo de lo anterior ha sido el crecimiento de las geotecnologías, particularmente en lo referido a los Sistemas de Información Geográfica (Onsrud \& Pinto, 1991), en donde ya existen diferentes áreas de implementación y utilización (administración, defensa, investigación, servicios, etc.), cuya dinámica e incremento ha estado relacionado con el desarrollo tecnológico informático -movilidad, almacenamiento en la nube, web 3.0-, contextualizándose con la implementación de este tipo de técnica y sus respectivas variaciones (Fu \& Sun, 2011; Grønfeldt Winther, 2015). Para el caso de la educación, la incorporación de esta herramienta en procesos de aprendizaje ha sido más lenta debido a factores como el acceso a recursos tecnológicos, a datos espaciales y a la implementación de estructuras didácticas adecuadas para su utilización (White, 2008). La curva III muestra la lenta incorporación de elementos de innovación, que se ejemplifica en la incorporación de la tecnología de RA en los procesos educativos. Lo anterior se explicaría debido a las constantes variaciones en los avances tecnológicos en torno al despliegue y lectura gráfica, que dan lugar a nuevas etapas de desarrollo e implementación tecnológica, que para este caso, se han visto relacionadas con el desarrollo de dispositivos portátiles de alta gama, hardware portable y el desarrollo de la Realidad Virtual (S.-G. Lee, Trimi, Byun, \& Kang, 2011).

\footnotetext{
${ }^{58}$ El año de comienzo de la World Wide Web corresponde a 1991, pero el hito importante corresponde al 30 de abril de 1980 en donde la tecnología web pasa a tener un dominio de carácter público permitiendo su masificación. En el año 1994 Berners Lee funda el el World Wide Web Consortium (W3C) que permite asegurar un estándar en el manejo y diseño de los datos que se usarían en Internet (Sturm, 2012).
} 
Paralelo a lo anterior, este planteamiento de Rogers (2003) contiene una categorización de las personas que hacen la adopción correspondiente según la etapa en que se ha realizado el proceso de utilización de la innovación. De esta manera, se ha establecido que la utilización de la innovación es inevitable, pero dependiendo del tipo de proceso y la posible apertura al cambio, esto puede ser gradual o con un menor dinamismo, teniendo un impacto en los procesos de enseñanza-aprendizaje mediado por la tecnología lo cual debe ser considerado en cómo estas tecnologías son introducidas en el marco general de la sociedad (Surry \& Ely, 2001; White, 2008). Esta categorización de los individuos se pueden desglosar en 5 tipos cuyo único criterio es la apertura a la innovación tecnológica: de esta manera existen usuarios innovadores, adoptadores tempranos, mayoría temprana, mayoría tardía y rezagados, los cuales están relacionados con la posible masificación de una tecnología (Figura 3.4).

Figura 3.4 Categorización de adoptadores tomando como base la tecnología de innovación utilizada. Adaptado de Rogers (2003).

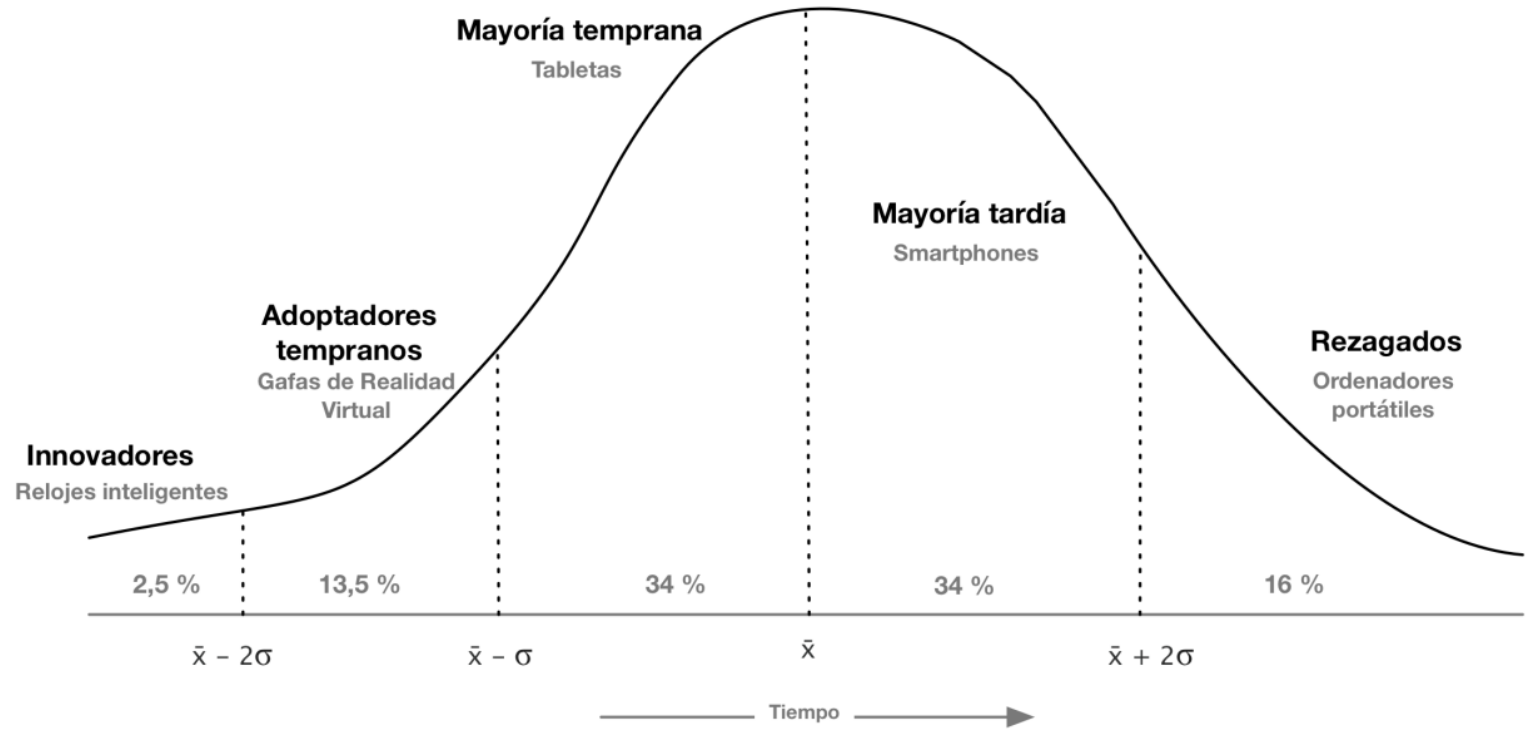

Fuente: Elaboración propia.

Este modelo permite explicar de manera simplificada la forma en que evoluciona y se masifica un tipo de tecnología a lo largo del tiempo. Sin embargo, se cree que esta teoría con sus etapas son elementos insuficientes para comprender la complejidad de los modelos de incorporación de la tecnología (sobre los aspectos anteriormente referidos por Bauman del estado líquido de los fenómenos presentes en esta etapa histórica), sobre todo comprendiendo que existen procesos cíclicos y de constantes mejoras que afectan a algunas innovaciones (ejemplo de lo anterior ha sido la mejora constante de los teléfonos 
móviles desde los dumbphones hasta los smartphones), que hacen que la estructura de la curva no sea esta, o que se establezcan otros impactos a lo largo del tiempo en una sociedad. Otro punto relevante es que no todas las tecnologías llegan a su fase de madurez, siendo superadas por otras innovaciones que se presentan en el mercado (es lo sucedido a las PDA o Personal Digital Assistant, tecnología que desapareció y fue reemplazada por las tabletas), lo cual hace que el modelo planteado no pueda representar adecuadamente escenarios futuros de comportamiento de la sociedad frente a una innovación (Blu-ray respecto al DVD).

\subsubsection{Los Ciclos de Exceso de Expectativas (overexpectation)}

Desde el año 1995 la empresa consultora Gartner, realiza los ejercicios de los Ciclos de Exceso de Expectativas (Hype Cycle), en donde se mide el avance de la innovaciones tecnológicas con una serie de indicadores que se comparan con las expectativas que se generan, graficando de manera evolutiva su posible potencial en el mercado (Gartner, 2015). Cada Ciclo de Exceso de Expectativas contiene cinco fases dentro del gráfico de evolución de una innovación (Figura 3.5):

A. Lanzamiento tecnológico: tras los procesos de $I+D$, en esta etapa se realiza un potencial avance tecnológico que marca el inicio posible de una adaptación de la innovación tecnológica en la sociedad. Se implementan las primeras prueba de concepto y existe un interés inicial en los medios de comunicación. Normalmente no existen productos utilizables y la viabilidad comercial del producto no está comprobada (ejemplo: pantallas holográficas con despliegue volumétrico).

B. Pico de expectativas exageradas: la difusión temprana de información de la innovación por parte de los medios, produce una serie de experiencias de relativo éxito, y, que de forma paralela, va acompañada por la existencia de fracasos y prácticas fallidas. Algunas personas adquieren la tecnología, pero la gran mayoría no se arriesga debido a la inmadurez de la innovación (ejemplo: Internet de las cosas).

C. Abismo de la desilusión: El interés inicial por la innovación se desvanece en implementaciones que no es posible desarrollar. Las inversiones en los procesos tecnológicos continúan únicamente si los creadores y proveedores participantes 
mejoran la estructura de la innovación con el fin de satisfacer las necesidades de los usuarios (ejemplo: Realidad Aumentada).

D. Rampa de consolidación: Se crean más ejemplos de cómo la tecnología puede beneficiar al usuario. Comienza el real entendimiento de la innovación y su puesta en práctica. En esta fase, se empieza a desarrollar una segunda y tercera generación de productos que hacen posibles la masificación de la innovación y el desarrollo de actividades y emprendimientos relacionados con esa tecnología (ejemplos: impresión 3D y servicios en la nube).

E. Meseta de la productividad: la adopción de la innovación tecnológica comienza a masificarse. Los criterios para evaluar la viabilidad por parte del proveedor están claramente definidos, permitiendo ofrecer un producto estable y adaptado a los diferentes requisitos existentes. Comienza a desarrollarse un amplio mercado en torno a la tecnología, tomando relevancia dentro de la sociedad (ejemplos: tecnología móvil con el desarrollo de tabletas y móviles inteligentes, además de actividades derivadas como el $m$-learning). 
Figura 3.5 Ciclos de Exceso de expectativas (Gartner, 2015)

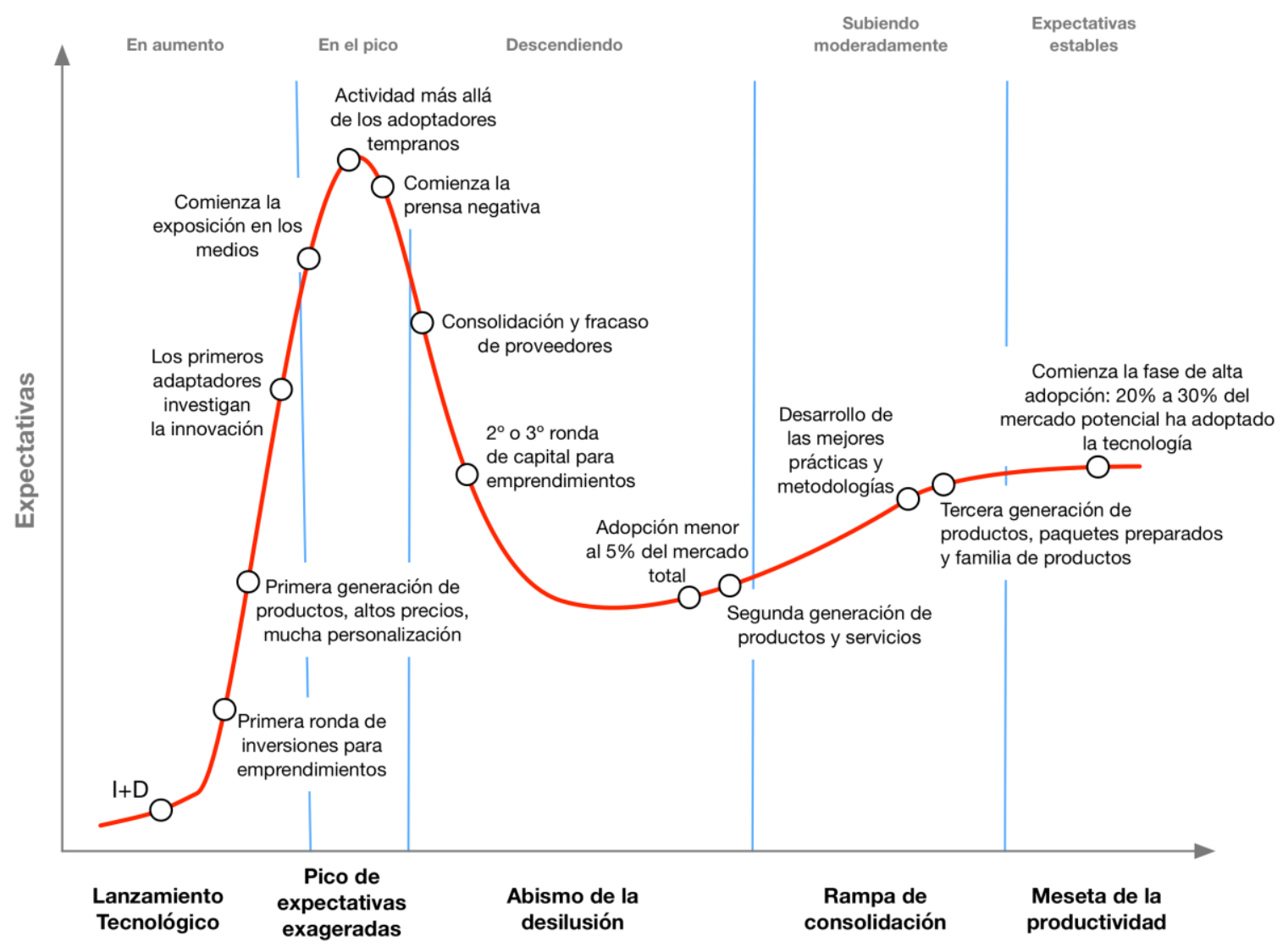

Tiempo

Aunque es un modelo conceptual muy utilizado en marketing, la utilización de los Ciclos de Exceso de Expectativas se encuentra condicionado a la presentación de innovaciones frente a las actitudes particulares de una sociedad, por lo que es posible aplicarlo a dimensiones tan variadas como los negocios o la industria del entretenimiento (Zinger, 2014) en incluso a los ámbitos tecnológicos que se incorporaran en las actividades educativas. Existen diversas investigaciones que utilizan este modelo en la implementación de tecnologías en la educación y determinan cual ha sido su impacto real, además de su posible evolución (Campani \& Vaglio, 2015; Jari Laru \& Järvelä, 2013; J. Laru, Naykki, \& Järvelä, 2015).

Para el caso de la tecnología de RA en este ciclo, esta se encuentra dentro de lo que Gartner denomina como "abismo de desilusión", aunque las estimaciones establecen que es muy probable que se encuentre cerca de pasar a las siguientes fases, que permitirán una productividad más sustentable y diversificada para esta tecnología. Correlacionado directamente con la masificación de productos como Google Glass o el 
sistema iOS en diferentes dispositivos ${ }^{59}$, estos contextos pueden regenerar el interés en la RA, con nuevas aplicaciones e implementaciones (Zinger, 2014). Es importante establecer que el desarrollo de una la innovación no se frena junto con la caída en el ciclo, pudiendo tener una segunda fase de productividad (Figura 3.6).

Figura 3.6 Evolución de la RA en los Ciclos de Exceso de Expectativas

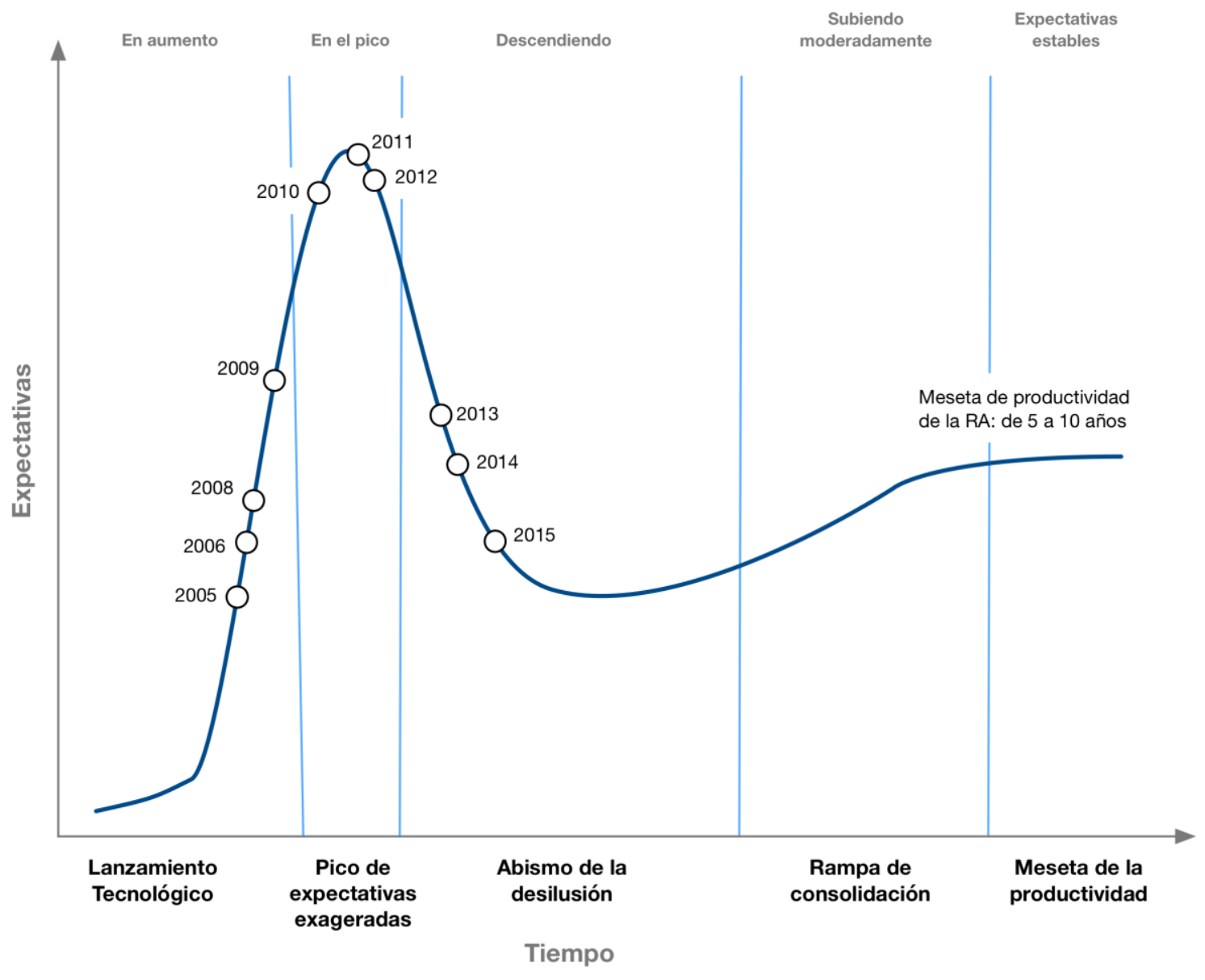

Fuente: Elaboración propia tomando como base datos de Gartner (2015).

Se muestran a continuación algunos de los factores que influyen en cómo la innovación tecnológica se transforma rápidamente en un producto masivo, y con fuertes implicaciones sociales (Nuchera, Idoipe, \& Torres, 2008):

${ }^{59}$ El 21 de mayo de 2015 Apple adquiere la empresa de desarrollo de RA Metaio, con el fin de comenzar el desarrollo en tecnologías de realidad virtual y aumentada en sus dispositivos (Miller \& Constine, 2015). 
- El alto valor de la innovación tecnológica aplicada a un producto o servicio, logrando el desarrollo de clústeres económicos y generando una verdadera cadena de valor.

- La simplicidad de su uso con curvas de aprendizaje poco pronunciadas.

- La utilización de la infraestructura actual.

- El desarrollo y soporte a largo plazo de la innovación tecnológica.

Entre las críticas que hay en el planteamiento de este modelo de funcionamiento de las innovaciones, se cuenta el hecho consistente en que el comportamiento y evolución de una tecnología no sigue un patrón cíclico, sino que más bien corresponde a una evolución constante de un proceso tecnológico que tiene una etapa final (Veryard, 2005). Además, el modelado real del comportamiento de las innovaciones tecnológicas no es necesariamente posible, debido a que es un proceso con claras características sociológicas -muchas veces inexplicables- que afecta impredeciblemente a algunas formas de demanda de tecnología y productos (Aranda, 2006).

\subsection{Modernidad líquida en la educación. Contexto teórico de la tecnología en la enseñanza}

Como ya se ha visualizado en los apartados anteriores, el contexto histórico presente ha generado elementos, patrones, relaciones y problemas que se observan en las actuales prácticas sociales y que se encuentran marcados por las TIC. Aunque la dinámica social actual en esta Sociedad del Conocimiento se ha esbozado brevemente en este capítulo presentado algunos elementos destacados referentes a la evolución y demanda de las TIC, es importante mencionar que existirían otras consecuencias en ámbitos tan diferentes, que van desde las temáticas político-regionales, las influencias sobre las acciones económicas, la composición y estructura de los mercados de trabajo y la morfología de las ciudades, solo por mencionar algunas. Sin embargo, se ha expuesto una importante base para poder determinar y contextualizar las prácticas educativas en esta modernidad liquida con un cambio en los modos que la tecnología condicionan su desarrollo e impacto.

Si en la era moderna industrial (o sólida en el contexto de Bauman) los libros y la imprenta eran el referente tecnológico, el aprendizaje desarrollado en el currículo estaba 
agrupado en temas derivados del contenido y trabajo que se desarrollaba en el marco de distintas disciplinas (matemáticas, geografía, historia, ciencias naturales, etc.). De esta manera, el objetivo principal del aprendizaje era el de los contenidos que debían aprender los sujetos, con el fin de entender el funcionamiento del mundo para desenvolverse de manera correcta en él, y que debían ser enseñados en la educación formal (Lankshear, Peters, \& Knobel, 2000). De esta manera la educación queda establecida tomando como base dos grandes supuestos (Jaeger, 2001):

a. Desde la experiencia de las personas, y pese a la diversidad heterogénea de los hechos, existe un orden sobre el mundo y la realidad concreta es inmutable, lo cual da sentido a que los conocimientos puedan ser transmitidos de maestros a discípulos.

b. Existen leyes que sustentan y rigen la propia naturaleza humana, que es parte de la realidad entendida como mundo, por lo cual también es inmutable.

Claramente, si la educación actual se plantea desde estos supuestos, se va a encontrar en serias dificultades ya que en la Sociedad del Conocimiento se requiere un esfuerzo enorme para mantener cualquiera de estos dos supuestos y de un esfuerzo mayor para percibirlos como elementos evidentes (Bauman, 2015). Si la cultura y el conocimiento pasan a ser elementos extremadamente dinámicos, cambiantes y efímeros, se requiere una alta capacidad de aprendizaje y adquisición de nuevas competencias que puedan ser adaptadas a este tiempo presente, y con ello la creación de nuevas metodologías y disciplinas enfocadas en la posibilidad de enfrentarse adecuadamente a estos constantes cambios.

Como se dijo en capítulos anteriores, el m-learning, a través de su representación del e-learning, no sería una disciplina convencional educativa, ya que no correspondería a una construcción tradicional de la enseñanza derivada de las áreas existentes y de los currículums formales de educación que han sido implementados, en lo previamente planteado por Jaeger (2001). En esta forma de aprendizaje tampoco se parcelaría o dividiría la estructura de los conocimientos y métodos que se utilizan en su aplicación, sino más bien esa estructura se conjuga y se vuelve transversal en lo tocante a los contenidos, desde los conocimientos temáticos tradicionales (conocimiento disciplinar), pero con los métodos y formas en los que la tecnología se hace presente. Entonces se pretende reunir o consolidar, mediante esta interacción, los saberes y métodos fragmentados, intentando una construcción del conocimiento multidimensional, que en la actualidad se encuentra 
dividido en desarrollos disciplinares especializados y fragmentados (Sessano \& Corbetta, 2015). Esto está permitiendo una comprensión de la realidad desde la mayor complejidad posible. Así, la construcción de escenarios híbridos multidimensionales crearía comprensiones complejas y menos parceladas de lo que se entiende por realidad, favoreciendo el aprendizaje como fin último un de un proceso educativo.

Desde los grandes paradigmas presentes en la enseñanza, destacan los planteamientos que realiza John Dewey (1859-1952), quien estableció elementos fundamentales para el entendimiento del desarrollo de una teoría que intenta explicar cómo los estudiantes aprenden de manera permanente, con la interacción del entorno y activamente, más allá de una base o contexto general, como lo que se expresa en los currículums escolares de los procesos formales de aprendizaje. En términos generales, las ideas de Dewey planteaban que los estudiantes son algo más que simples receptores pasivos de conocimientos ${ }^{60}$, y que el proceso de enseñanza-aprendizaje sería más efectivo si estos actores son parte activa de este proceso (Dewey, 1943). Otro elemento importante a lo que se refería Dewey, es sobre la efectividad real de la educación mediante la experiencia: los estudiantes deben tener la oportunidad de entrelazar los contenidos y disciplinas con sus propias experiencias personales y conocimientos previos obtenidos de su quehacer cotidiano. Además, Dewey estableció la necesidad de que los alumnos se comprometieran directamente con su entorno, en lo que llegó a ser conocido como el aprendizaje experiencial, donde el conocimiento proviene de las impresiones que se adquieren sobre los objetos en un estado natural. Según Dewey:

"Yo considero que la unidad fundamental de la nueva pedagogía se encuentra en la idea de que existe una íntima y necesaria relación entre los procesos de la experiencia real y la educación. Si esto es cierto, entonces el desarrollo positivo y constructivo de su propia idea básica dependerá de que se posea una idea correcta de la experiencia" (Dewey, 1943, p. 68).

Esta forma de visualizar la forma de enseñanza dio lugar más tarde a un número significativo de otros enfoques similares, como el Aprendizaje Basado en Problemas o el Aprendizaje Basado en la Indagación (Wheeler, 2015). En este trabajo, dicha conjunción

\footnotetext{
${ }^{60}$ El contexto contemporáneo de Dewey a principios del siglo XX, se relaciona con una educación tradicional de enseñanza-aprendizaje en donde los estudiantes debe únicamente aprender de los contenidos, siendo solamente simples espectadores de este proceso. Él plantea ideas radicales para un comienzo de siglo que traería muchos avances en educación más allá del conductismo y el constructivismo.
} 
de elementos desarrollados por Dewey se encuentran relacionados con planteamientos en torno a cómo se aprende desde y con una realidad que presenta elementos multisistémicos presentes en el territorio: elementos históricos, arquitectónicos, culturales y patrimoniales, con significados y magnitudes diversas. Todo lo anterior enlazado mediante elementos propios de las relaciones espaciales (particularmente en lo referido a la localización y la distancia), en donde la experiencia es inmediata y con fuertes implicaciones para los individuos. Así, se pretende propiciar la adquisición de capacidades en distintos sentidos (Favier \& van der Schee, 2014; Golledge \& Stimson, 1997):

- Para el reconocimiento de distribuciones y patrones territoriales;

- Para establecer conexiones entre elementos y localizaciones;

- Para percibir la asociación y correlación espacial de los fenómenos;

- Para la creación y compresión de jerarquías territoriales;

- Finalmente, para situar el mundo real dentro de un marco de referencia que pueda ser replicado.

Además, el contexto anterior incorpora la variable affordance ${ }^{11}$ que engloba en particular la forma en que se componen, relacionan y abstraen, las construcciones sobre el territorio y sus elementos, sintetizado en una herramienta digital que permite la visualización, compresión y modelamiento de esta información.

Otro elemento que planteó Dewey, fue el desarrollar un enfoque más equilibrado en los elementos que componen el complejo sistema educativo, dando igual preponderancia en el proceso de aprendizaje a los docentes y los contenidos. Para Dewey, el rol de los docentes se definía como algo más que simples instructores o presentadores de contenidos, sino más bien como actores que juegan un rol facilitador y de guía en un proceso en que los estudiantes tienen la oportunidad de descubrir nuevos fenómenos para su aprendizaje, desarrollando así sujetos activos e independientes dentro de su sistema de formación (Dewey, 1989; Jover \& Fernández, 2015). Así, estos planteamientos se condicen con la utilización de metodologías como el m-learning, la aplicación de

\footnotetext{
${ }^{61}$ Affordance es un neologismo que en el castellano se traduce como "ofrecimiento" o "enacción", siendo la estimulación necesaria que un objeto o herramienta entrega para que una persona (o agente) tenga la oportunidad de realizar dicha acción. Particularmente dicha acción está referida a la posible interacción persona-ordenador y el término, atribuido a J.J. Gibson en 1977, fue utilizado por Don Norman (D. Norman, 2013, p. 11): "The term affordance refers to the relationship between a physical object and a person (or for that matter, any interacting agent, whether animal or human, or even machines and robots). An affordance is a relationship between the properties of an object and the capabilities of the agent that determine just how the object could possibly be used". Se podría decir que la enacción es el espectro global de forma de usar un elemento.
} 
geotecnologías y la RA, entregando el desarrollo de este enfoque en donde el docente no solo tiene nuevas herramientas didácticas para el desenvolvimiento del contenido, sino que también es parte importante como facilitador del proceso de enseñanza-aprendizaje generando experiencia desde la contemplación de la realidad, sus elementos e interrelaciones:

'Cuanto más definida y sinceramente se afirme que la educación es un desarrollo dentro, por y para la experiencia, tanto más importante es que se tengan concepciones claras de lo que es la experiencia" (Dewey, 1943, p. 74).

Existiendo un panorama complejo de las teorías de aprendizaje ${ }^{62}$, en donde se entrelazan disciplinas científicas, elementos teóricos, conceptos y estructuras paradigmáticas, presentaremos algunos modelos que en la actualidad se adecúan a la interrelación de diversos elementos, además del contexto de complejidad que plantea Morin (1984), con objeto de complementar la necesidad de la experiencia en los procesos educativos que describe Dewey con la forma de comprender la realidad. De la misma manera, creemos que la diversidad de este escenario teórico demuestra que las personas no tienen una única forma de realizar un complejo proceso como es el aprendizaje, teniendo en consideración la compleja realidad en que se desenvuelven, los fenómenos que les rodean y las herramientas de que disponen. De esta manera un proceso que tiene diversos niveles y elementos como es la complejidad del aprendizaje se sintetizaría de la siguiente manera:

'El aprendizaje es la adquisición de información que el sistema saca del ecosistema. Esta adquisición se efectúa a partir de un dispositivo innato (estrategia y organización cognitiva) y a partir de una búsqueda errante las más de las veces, al azar (scanning), del sistema en el ecosistema. El aprendizaje consiste, en cierto sentido, en hacer que los eventos signifiquen, en transformar el evento-ruido en evento-señal, incluso en evento-signo: «El ruido es transformado en señal por el aprendizaje»... ...De este modo, el aprendizaje conduce a una «visión del mundo» que nos rodea; a partir de

\footnotetext{
${ }^{62}$ Millwood (2013) establece, a manera de resumen, un mapa conceptual con 22 teorías de aprendizaje que se sitúan desde el Aprendizaje Situado hasta el Constructivismo Social. De manera paralela, plantea la presencia de 25 teóricos del aprendizaje, los cuales en 10 conceptos claves, han hecho aportes importantes a la construcción de la disciplina pedagógica.
} 
entonces, el ecosistema encuentra su analogon en el cerebro del que ha aprendido "(Morin, 1984, pp. 178-179)

El significado, elemento de este complejo sistema entendido como aprendizaje, se interrelaciona con otros niveles o subsistemas y sus elementos: el "evento-ruido" que sería el nivel básico, el de la simplicidad de la captación de la información y que se sintetiza en el simplemente "observar" o "escuchar"; el "evento-señal" correspondería a la información que toma un primera etapa de comprensión pasando a otro nivel o subsistema -"registrar" y "describir"-; y el "evento-signo" en donde la información captada del medio puede ser replicada mediante un lenguaje estandarizado abstracto (como la escritura o las matemáticas) obteniendo una interpretación de la realidad -"analizar", "definir" y "modelar"-.

Otro punto que conviene destacar, es lo referido a cuáles son los elementos involucrados en el desarrollo educativo: a pesar que tradicionalmente los objetivos de los procesos de enseñanza-aprendizaje habían sido los "saberes docentes" (o saberes disciplinares), desde el año 1990 ha comenzado un giro importante hacia la "pedagogía de los docentes" (Shulman, 1986). Esto ha transformado la manera de enseñar y aprender, estableciendo procesos holísticos que no sólo se adapten a los requisitos presentes en la actualidad, sino que también requieren una formación constante y lo más completa posible para poder comprender la complejidad del mundo moderno. Entre los modelos metodológicos que se adaptan a una interpretación compleja de la realidad, y que se encuentran relacionados en distintos grados con el desarrollo tecnológico de la presente tesis cabe mencionar el TPACK y los Objetos de Aprendizaje, teniendo como unidades referenciales la territorialización, la tecnología móvil y su inclusión educativa.

\subsubsection{Comprendiendo e implementando la complejidad de un proceso:}

\section{Modelo Technological PedAgogical Content Knowledge}

En 1986 Shulman desarrolla un análisis profundo a lo que llamó Contenido Pedagógico del Conocimiento (PCK Pedagogical Content Knowledge), en donde estos tres importantes elementos son parte crucial de los conocimientos de los docentes, destacando la importancia de no analizar estos componentes por separado (Shulman, 1986). Desde este punto de partida, Mishra y Koehler han desarrollado un completo marco de referencia, incluyendo un elemento adicional: el conocimiento tecnológico -Technological Knowledge- (Mishra \& Koehler, 2006). De esta manera se desarrolla lo que se conoce 
como Technological PedAgogical Content Knowledge (TPACK) que es un modelo que identifica los tipos de conocimiento que un docente necesita dominar para incorporar de manera adecuada las TIC en los procesos de enseñanza que desarrolla (Edwards \& Nuttall, 2015; Koh, Chai, \& Lee, 2015; Mishra \& Koehler, 2006). Así estas formas integradas de saberes se estructuran como (Koh et al., 2015): Conocimiento Pedagógico del Contenido (Pedagogical Content Knowledge -PCK-), Contenido Tecnológico del Conocimiento (Technological Content Knowledge -TCK-), Conocimiento Pedagógico de la Tecnología (Technological Pedagogical Knowledge -TPK-), y el Conocimiento Didáctico del Contenido Tecnológico (Technological Pedagogical Content Knowledge -TPACK-). Junto con el Conocimiento Tecnológico (Technological Knowledge -TK-), Conocimiento Pedagógico (Pedagogical Knowledge -PK-), y el Conocimiento del Contenido (Content Knowledge (K-), estos siete tipos de conocimiento constituyen el marco general presente en el TPACK (Figura 3.7).

Figura 3.7 Estructura del modelo TPACK

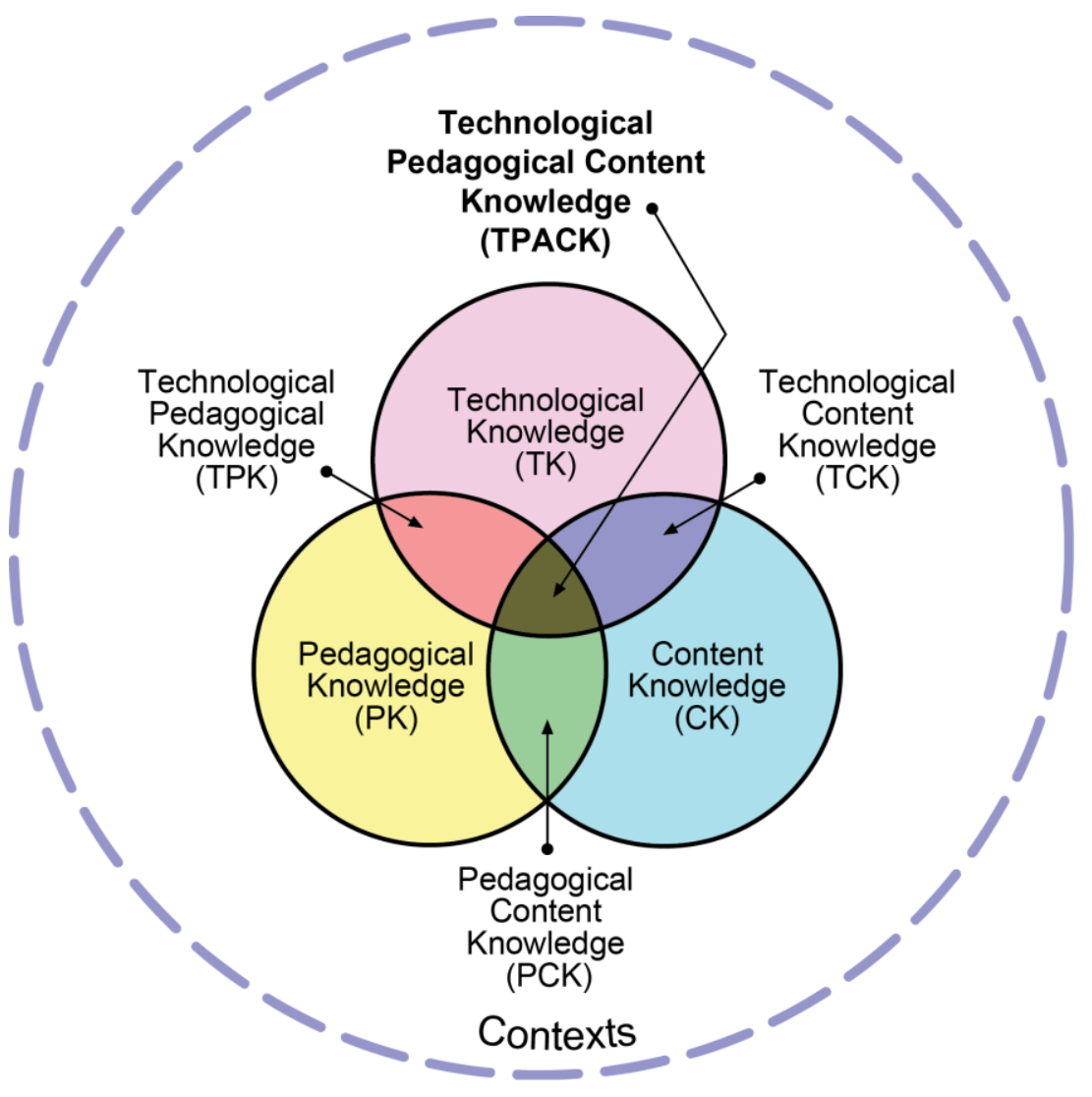

Fuente: Koehler (2012). 
Una de las disciplinas complejas es la Geografía ${ }^{63}$, como representación y soporte de las dimensiones Patrimoniales del territorio, y que se adapta a este modelo debido a sus propios contenidos, así como a las herramientas tecnológicas que utiliza para la presentación y análisis de los datos de su objeto de estudio. De esta manera, investigaciones como la de Doering y Veletsianos (Doering, Scharber, et al., 2009; Doering, Koseoglu, Scharber, Henrickson, \& Lanegran, 2014; Doering et al., 2008; Doering, Veletsianos, Scharber, \& Miller, 2009) establecen la necesidad de implementar un marco de desarrollo TPACK en la enseñanza de no sólo la geografía, sino también en otras ciencias sociales. Esto genera un modelo que nombran como G-TPACK (Geography Technological PedAgogiCal Knowledge) en el cual los docentes utilizan diversas herramientas geotecnológicas en un contexto de modelo pedagógico, con una diversidad de contenidos disciplinares que finalmente tienen el territorio como punto en común (Figura 3.8). De esta manera, se desarrolla el entendimiento de la complejidad de las interconexiones entre estos tres componentes con lo que debería ser el conocimiento docente en la actualidad.

\footnotetext{
63 "El desarrollo de las ciencias de la Tierra y de la ecología revitaliza a la geografía, ciencia compleja por principio en la medida que concierne a la física terrestre, a la biosfera y a las implantaciones humanas. Marginada por las disciplinas triunfantes, privada de pensamiento organizador más allá del posibilismo de Vidal de la Blache o del determinismo de Ratzel, la geografía, que por lo demás proporcionó sus profesionales a la ecología y a las ciencias de la Tierra, recupera sus perspectivas multidimensionales, complejas y totalizadoras" (Morin, 2002, p. 31). La informática también pertenece a las disciplinas complejas, no sólo por su enfoque sistémico para abordar la comprensión de la realidad, sino también como herramienta fundamental para representar, modelar y simular otros sistemas complejos como el universo, el clima, el crecimiento poblacional, etc. (Rodríguez Zoya \& Aguirre, 2011).
} 
Figura 3.8 Estructura del modelo G-TPACK

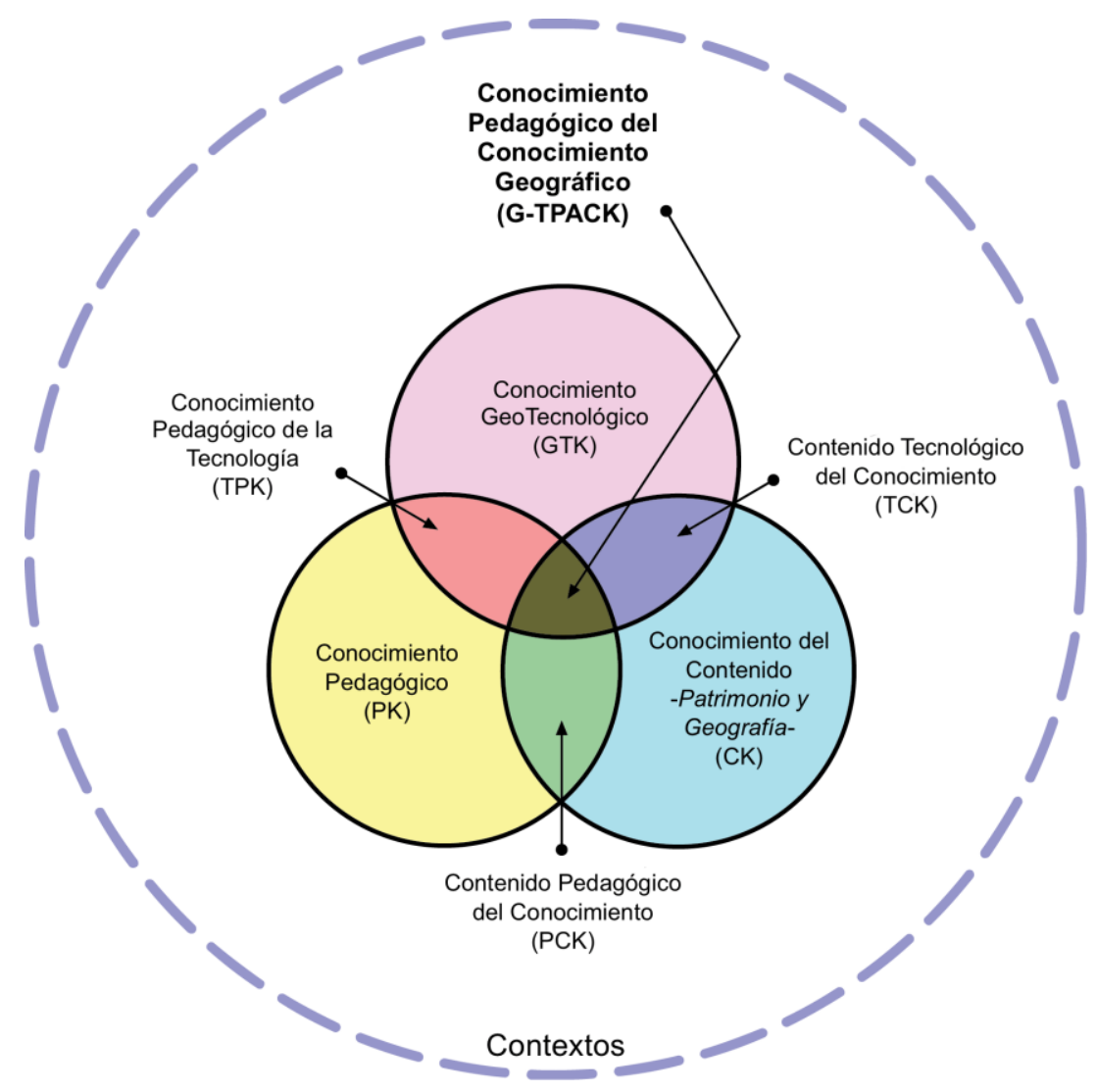

Fuente: Doering, Veletsianos y Sharber (2008)

Así, en esta visión que proporciona el G-TPACK, los docentes deberían ser capaces de ${ }^{64}$ :

A. Saber más que simplemente utilizar la tecnología, particularmente en los contextos de análisis y representación del territorio (por ejemplo, el uso de GPS no puede limitarse a determinar la ubicación);

B. Crear conocimientos disciplinares que dejen de ser modelos aislados y descontextualizados en una realidad compleja (por ejemplo, los contenidos de Patrimonio Arquitectónico no pueden reducirse a listas de nombres y fechas);

C. Utilizar contenidos que serán aplicados con un contexto pedagógico que establece un objetivo de aprendizaje (por ejemplo, el Aprendizaje Basado en Problemas).

${ }^{64}$ Esto puede complementarse con métodos como el Aprendizaje Basado en Problemas (ABP) correspondiente a una forma de enseñanza en donde el estudiante es el constructor de su propio aprendizaje en donde deben encontrar una respuesta, con la ayuda de un docente, a un problema o pregunta planteada desde un contexto real (Morales \& Landa, 2004). 
Más que comprender las complejas relaciones e interconexiones que existen entre estos tres grandes bloques, este modelo utiliza el sistema completo que se genera por esta conjunción con el fin de crear un entorno complejo de conocimiento de enseñanzaaprendizaje (Doering et al., 2008). Nuestra investigación toma estos elementos desde todas estas dimensiones, con las particularidades que aporta el m-learning (TK), la evaluación pedagógica (PK) y los contenidos sobre patrimonio en el territorio (CK), creando una estructura que puede ser adaptable y replicable a diferentes realidades (Figura 3.9).

Figura 3.9 Modelo de la investigación desde la estructura TPACK

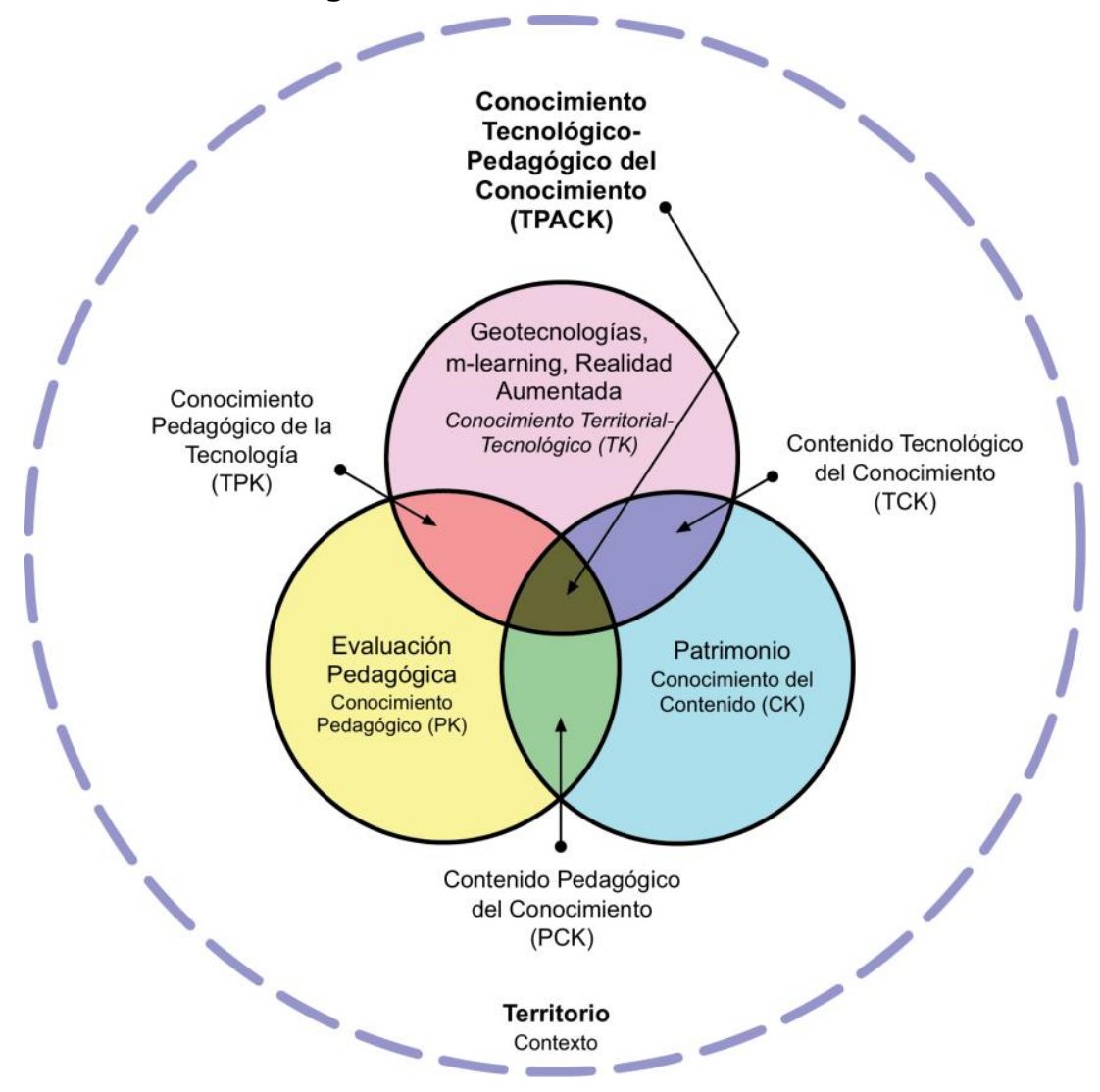

Fuente: Elaboración propia.

\subsubsection{Un modelo que se surge de la Informática y que se transfiere a la}

\section{Educación: los Objetos de Aprendizaje}

Si la Informática, con la estructura de datos digitales y los sistemas de información, ha realizado un enorme avance en torno a los elementos del cómo se construye, 
sistematiza, procesa y reutiliza la información, con el advenimiento de las TIC y particularmente con la web 2.0, estos modelos de manejo de los datos son adquiridos, replicados y adaptados rápidamente a los procesos educativos. De esta manera, las metodologías como la Programación Orientada a Objetos (POO) se adaptan a una dimensión en donde los procesos de enseñanza-aprendizaje son la base fundamental de un sistema complejo, generándose estructuras como son los Objetos de Aprendizaje (OA), con estándares e implementaciones utilizados en la incorporación de la tecnología en los ámbitos educativos. Existen muchas definiciones de lo que es un OA (Hori et al., 2016; Kurilovas, Kubilinskiene, \& Dagiene, 2014; Wiley, 2000), y desde el ámbito más tecnológico se encuentra la de IEEE Learning Technologies Standards Committee (2005, p. 3):

"Any entity, digital or nondigital, that may be used for learning, education, or training",

Dicha definición sintética lleva más de 12 años sin variaciones dentro de la conceptualización de este modelo. Sin embargo, como los OA son principalmente desarrollados y utilizados desde una dimensión pedagógica, tenemos la definición de Morales Morgado (2007, p. 55) en la cual, un OA corresponde a:

"...una unidad educativa con un objetivo mínimo de aprendizaje asociado a un tipo concreto de contenido y actividades para su logro, caracterizada por ser digital, independiente, y accesible a través de metadatos con la finalidad de ser reutilizada en diferentes contextos y plataformas."

Dicha definición tiene todos los aspectos necesarios como implementación metodológica que se desarrolla desde los campos informáticos y que se se hace presente en las estructura de enseñanza educativa.

Un OA contiene diferentes elementos que lo conforman, permitiendo su adaptabilidad y reutilización de de los contenidos educacionales, los cuales se presentan en un marco informático que permite incorporar características como interoperabilidad y la incorporación de metadatos. De esta manera proyectos como el Multicultural Interdisciplinary Handbook: tools for learning history and geography in a multicultural perspective -MIH- (Peñalvo García et al., 2012) desarrollan un despliegue educativo de temáticas multiculturales europeas -las cuales pueden ser adaptadas a los requisitos de enseñanza de cada país participante-, contenidos en una estructura de OA (Figura 3.10). 
Figura 3.10 Modelo de Objeto de Aprendizaje del Proyecto MIH

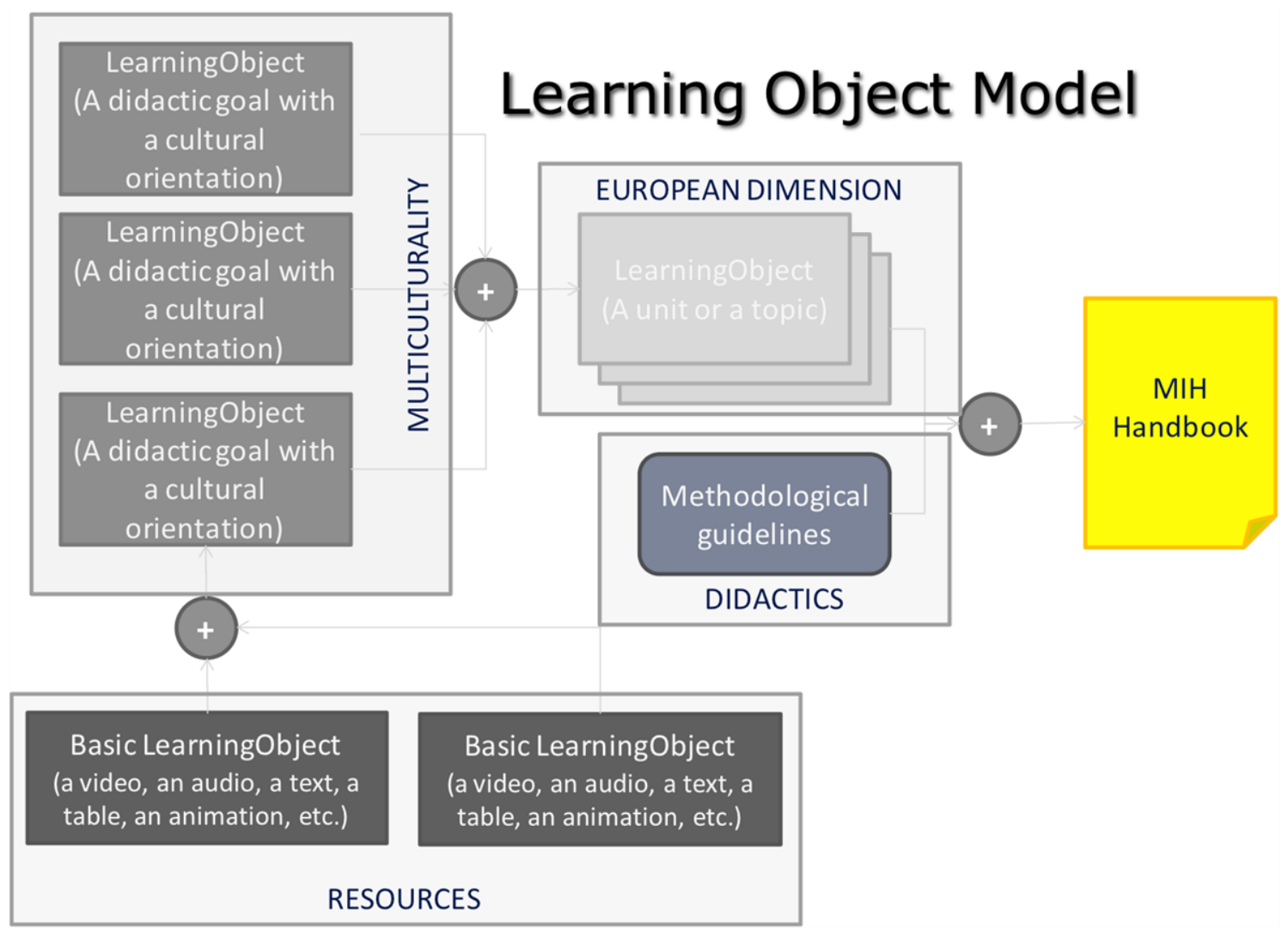

Fuente: Peñalvo-García, Zangrando, Seoane Pardo, García Holgado, Szczecinska, J., Baldner y Crivellari (2012).

De acuerdo con Beck (2010) un OA para definirse como tal, debe tener funcionalmente-, las siguientes características:

- Tradicionalmente los procesos educativos están pensados para desarrollarse en un tiempo largo (una o varias horas), mientras que en los OA las unidades de aprendizaje definidas en general, están pensadas para desarrollarse en tiempos que van de dos a quince minutos. Esto requiere una nueva forma de desarrollar e implementar el material educativo a utilizar.

- Cada elemento y temática presente en un OA puede ser abordado de forma independiente, lo que se conoce como elemento autocontenido.

- Cada elemento presente en un OA puede ser utilizado y adaptado en diferentes contextos educativos (reutilización). 
- Al igual en la POO, los OA pueden ser ensamblados, es decir, su utilización puede ser agrupada con el fin de generar una estructura especifica de aprendizaje.

- Para su mejor utilización, un OA cuenta con elementos de metadatos, los cuales describen la información contenida en el mismo.

Otros autores (Sicilia \& Garcia, 2003) incorporan otras especificaciones a los OA:

- Durabilidad

- Interoperabilidad

- Accesibilidad

- Reusabilidad

En el caso de las tres primeras cualidades, estas responden a las características tecnológicas de la implementación realizadas para la creación de un $\mathrm{OA}$, normalmente relacionadas con la utilización de estándares web. Particularmente la característica de Accesibilidad se refiere a la capacidad de que un OA pueda ser localizado mediante métodos apropiados a través de sus registros de metadatos. En torno a la Usabilidad, posiblemente la característica más difícil de definir, esta se encuentra supeditada directamente a los diseños y requisitos de los procesos de enseñanza-aprendizaje, más que a las características tecnológicas de la implementación informática desarrollada.

Este principio básico de los OA se ha llevado al m-learning con una serie de experiencias y aplicaciones con estándares específicos para la movilidad (Chan, Sharples, Vavoula, \& Lonsdale, 2004; Marzal \& Pedrazzi, 2015; Sharples, Corlett, \& Westmancott, 2002). Además, estas investigaciones incorporan elementos como el aprendizaje situado y el aprendizaje informal, características propias que ofrecen los procesos de aprendizaje mediante los actuales dispositivos.

Así, dentro de este contexto, se plantea la aplicación de este principio de OA en un contexto móvil (Figura 3.11), aplicación en la cual los contenidos patrimoniales pueden ser adaptados a condiciones y temáticas locales como en este caso se presenta con ciudades y sus características diferentes, con objetivos de aprendizaje definidos. De la misma manera, el núcleo temático general como lo es el patrimonio, puede ser 
reemplazado o adaptado a otras unidades temáticas educativas, en función de los lineamientos metodológicos y los objetivos didácticos. Los recursos que implementamos en este $\mathrm{OA}$ inicial, cumplen la funcionalidad que son interoperables y reutilizables (imágenes, videos, datos geoespaciales y modelos de RA), lo que permite la adaptabilidad de los contenidos a los contextos de aprendizaje establecidos. En el ámbito informático, la construcción de la aplicación móvil ha sido estructurada en un contexto de POO, lo que permite la reusabilidad de su estructura, con la creación de clases y la utilización de frameworks particulares, permitiendo la adaptación y constante mejora del código en desarrollo.

Figura 3.11 Objeto de Aprendizaje planteado en un contexto móvil

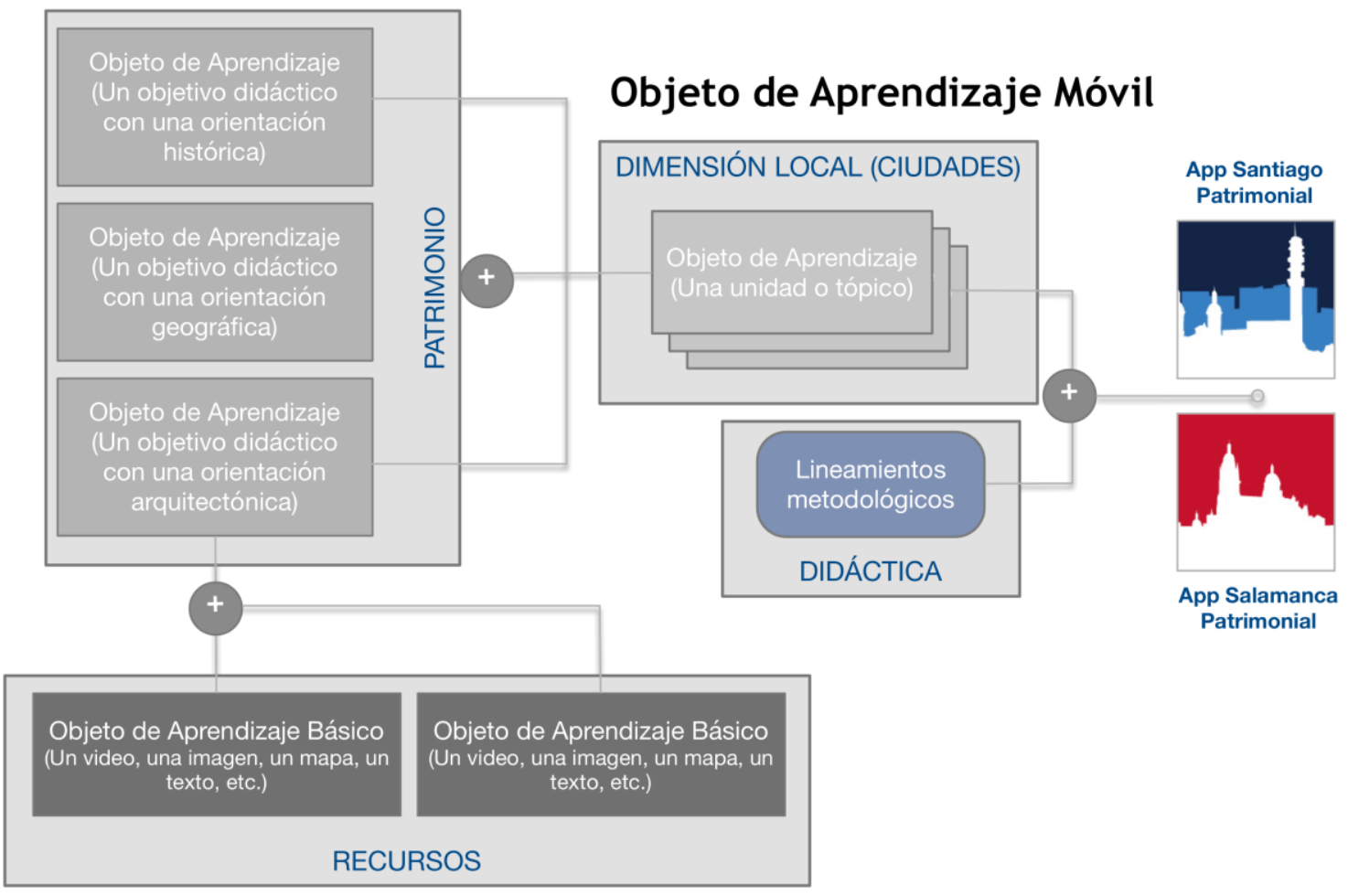

Fuente: Elaboración propia.

A pesar de que la estructura general de la aplicación va dirigida a plantearse como una unidad de OA móvil, existen algunos aspectos que deben ser incorporados y que van más allá de esta tesis: el desarrollo y la utilización de los estándares existentes ${ }^{65}$

65 Los OA tienen características tecnológicas para su distribución, en lo que se conoce como Modelo de Referencia de Objetos Compartibles de Contenido (SCORM) y que ha sido definido por diversas organizaciones internacionales (Hori et al., 2016; IEEE Learning Tecnnologies Standards Committee, 2005). Desde un modelo SCORM se realiza un empaquetamiento de los contenidos en donde se organizan, 
(particularmente en lo referido a la interoperabilidad de los datos de información geoespacial y en RA).

\subsection{Resumen}

En este capítulo se ha presentado una breve contextualización teórica de los conceptos, paradigmas y estructuras sociales, educativas y tecnológicas de la presente investigación. Adicionalmente y dentro del contexto de la Sociedad del Conocimiento, se ha querido poner de manifiesto el fuerte dinamismo -a modo de un contexto líquido, siempre cambiante, siempre en evolución- que presenta hoy en día la incorporación de la tecnología en los diversos ámbitos sociales, así como su respectiva adaptación e impacto en los procesos de enseñanza-aprendizaje. En la actualidad, dichos procesos son fuertemente dinámicos, estableciendo patrones de evolución que deben ser modelados si se quiere abordar su comprensión, así como su posible impacto. Estos procesos de evolución tecnológica también dejan su impronta en el ámbito educativo, los cuales se han adaptado a los requisitos con metodologías como son los OA o TPACK.

Desde las bases teóricas generales referentes a las estructuras del conocimiento y la formación, se establece un marco para esta tesis propuesto con las ideas de Zygmunt Bauman, Edgar Morin y John Dewey, quienes desde los conceptos de modernidad líquida, complejidad y experiencia, aportan los pilares teóricos necesarios para esta investigación. Es en esta formación en la Sociedad del Conocimiento, donde se mantienen estas dimensiones básicas, las que, finalmente, podrían traducirse como una posible interpretación y construcción de la realidad. Hacia un nivel más específico y ya relacionando directamente la tecnología y los procesos educativos, contextualizamos dos referentes metodológicos que aportan algunos significados a la tesis: los modelos TPACK y la OA. Cada uno con sus características, aportan elementos en los ámbitos pedagógicos y tecnológicos que son implementados en el estudio de manera particular, hacia las temáticas de patrimonio y movilidad.

Finalmente, realizamos una breve síntesis del estado del arte en que encuentran las TIC en las áreas de estudios (España y Latinoamérica), y también de su implementación en la sociedad mediante políticas públicas, particularmente en el ámbito de la educación,

comprimen y etiquetan los contenidos, los cuales pueden ser reconocidos y ejecutados por un Sistema de Gestión de Aprendizaje (LMS como Blackboardo Moodle). 
queriendo establecer el marcado dinamismo de esta área en la actual Sociedad del Conocimiento. 

Capítulo IV

Marco Metodológico y diseño de la investigación 



\section{MARCO METODOLÓGICO Y DISEÑO DE LA INVESTIGACIÓN}

\subsection{Introducción}

Para el desarrollo de la tesis y considerando tanto los planteamientos teóricos relacionados, como los elementos técnicos y tecnológicos utilizados para su implementación, se han propuesto 4 ámbitos metodológicos importantes. Estos ámbitos abarcan la arquitectura y el desarrollo del software respectivo, la evaluación de la aplicación en contextos educativos, la recopilación de datos y, por último, el análisis cuantitativo y cualitativo de la funcionalidad y usabilidad del programa en el marco del $m$ learning/u-learning. También se tienen en consideración los aspectos referidos a la consulta de fuentes secundarias y de antecedentes teóricos que permitan el logro de los objetivos y que enmarcan el desarrollo de la tesis, entendida como una actividad científica con claros lineamientos formales.

Debido a la diversidad de los objetivos planteados, se han desarrollado diferentes procedimientos metodológicos para poder abordarlos de manera correcta. Así, la sección empírica de esta tesis plantea tres grandes fases metodológicas ${ }^{66}$ específicas, las cuales intentan abordar y cumplir cada objetivo planteado. En una primera fase se realiza el levantamiento de los datos temáticos sobre patrimonio territorial mediante la elaboración de un instrumento de catastro y diagnóstico de edificaciones patrimoniales, utilizando además otras fuentes secundarias. De este modo se establece un marco temático que se aplicará en la implementación informática. Así, se definen hitos, eventos, unidades y rutas patrimoniales que serán desarrollados y contextualizados en un ambiente portable y móvil (Gómez Delgado \& Barredo Cano, 2005; Henríquez \& Quense, 2009; Palma Herrera, 2013). De manera paralela, se realiza la construcción del módulo NPM-RA mediante un contexto tecnológico de arquitectura y programación encapsulada y adaptable, teniendo como soporte inicial el sistema operativo $\operatorname{iOS}^{67}$ y sus frameworks relacionados -

\footnotetext{
${ }^{66}$ Este enfoque cuantitativo-cualitativo también es conocido con otras denominaciones, como pueden ser enfoque mixto, investigación integrativa, métodos múltiples o estudios de triangulación por mencionar algunas (Hernández, Fernández, \& Baptista, 2010; R. B. Johnson \& Onwuegbuzie, 2004; Sandelowski, Voils, \& Barroso, 2006). Hernández et al (2010) la define como "... una integración sistemática de los métodos cuantitativo y cualitativo en un solo estudio con el fin de obtener una «fotografía» más completa del fenómeno. Estos pueden ser conjuntados de tal manera que las aproximaciones cuantitativa y cualitativa conserven sus estructuras y procedimientos originales" (p. 546).

${ }^{67}$ Esta tesis comenzó con la utilización del lenguaje de programación Objective-C -Cocoa Touch- en el año 2013, derivando hacia el lenguaje Swift 2.2 para comienzos del año 2016. Este cambio en el lenguaje básico
} 
Localización, Navegación y Realidad Aumentada- (Allan, 2012; Bennett, Fisher, \& Lees, 2010; Hillegass, 2011; Hillegass \& Conway, 2013; Hollemans, 2015; Mathias \& Gallagher, 2015).

En una segunda fase, se estudiaron y analizaron las investigaciones y desarrollos previos en cuanto a la relación entre los NPM-RA y el e-learning y u-learning, determinando las líneas, características y aspectos relevantes en su contextualización establecida con los contenidos patrimoniales. De esta manera, se desarrolló una metodología cuasiexperimental (D. T. Campbell \& Stanley, 1993; Hernández, Fernández, \& Baptista, 2010), evaluando en un contexto educativo real y mediante un instrumento (test de múltiples opciones), la herramienta informática desarrollada y comparándola con otros procesos educativos que utilizan herramientas similares. La variable dependiente - nivel de aprendizaje- se mide antes y después de la realización de la actividad $m$-learning/ $u$ learning propuesta sobre un grupo de sujetos -alumnos-. De manera paralela, se aplicó el mismo instrumento de medición pero en un escenario educativo tradicional, establecido en un aula y con ordenadores de sobremesa como aplicación pedagógica de las TIC. Los resultados de ambas experiencias se han analizado y comparado, determinando los grados de aprendizaje y la existencia de diferencias entre grupos debidas a sus distintas experiencias. Desde la dimensión cualitativa y como tercera fase, se planteó una metodología de entrevistas con el fin de comprender el contexto y significado de la experiencia educativa propuesta con la aplicación, estableciendo así dimensiones y conceptos derivados de un contexto personal de los participantes (Kvale, 2011; Martín Izard, 2011; Yang, 2013; Yin, 1994).

\subsection{Objetivos e hipótesis de la investigación}

Desde los planteamientos teóricos establecidos en los capítulos anteriores, la presente investigación tiene como objetivo primordial determinar el rol que cumplen las herramientas MPN y RA en un contexto de movilidad, como el que otorgan las tabletas, en ambientes educativos. En las investigaciones sobre el tema que existen hasta el momento, sólo se evalúa este tipo de tecnologías de manera independiente o en contextos fijos establecidos. Además, no existen experiencias que realicen la construcción de 
herramientas, ni la determinación entre diferentes tipos de grupos y sus características. De esta manera, se pretende realizar aportes con datos teóricos y empíricos sobre el tema en torno a la relevancia de las herramientas móviles en contextos educativos y particularmente, situados en temáticas territoriales.

Así, se ha propuesto como objetivo general de investigación el diseño, desarrollo y evaluación de una aplicación móvil con un Sistema de Navegación Peatonal Móvil-Realidad Aumentada (NPM-RA) mediante frameworks de Localización, Navegación y Realidad Aumentada que permita la presentación de contenidos sobre patrimonio y territorio, estableciendo su eficacia sobre los procesos de adquisición de conocimiento en un contexto de m-learning/u-learning con tecnología móvil (tabletas) en comparación con otros métodos similares (elearning). Desde este contexto general, se derivan los siguientes objetivos, los cuales serán desarrollados mediante la metodología propuesta:

I. Establecer el proceso de construcción de la aplicación NPM-RA mediante un contexto tecnológico de arquitectura y programación encapsulada y adaptable adecuado para un ambiente de movilidad y portabilidad propia de los dispositivos móviles.

A. Implementar una aplicación móvil ("app") siguiendo el ciclo de vida del desarrollo de software, particularmente en lo referido al diseño, la implementación, su verificación, despliegue (o instalación) y mantenimiento.

B. Determinar los requisitos para la realización de la aplicación, particularmente los referidos a la dimensión territorial y patrimonial, contextualizando las áreas de estudio, los elementos para su despliegue y presentación en un escenario educativo, a través de metodologías de recopilación y análisis espacial.

C. Implementar los datos en la aplicación NPM-RA, estableciendo el tipo información y la estructura de datos a presentar y obtener (Input/Output). 
II. Determinar la efectividad de la aplicación NPM-RA en el contexto de $\boldsymbol{m}$ learning/ u-learning a través de un ejemplo concreto sobre el territorio y el patrimonio cultural, mediante la aplicación herramientas de evaluación del aprendizaje y comparando dicha metodología con procesos similares.

A. Elaborar un instrumento de evaluación para determinar la efectividad de la aplicación diseñada y validación por jueces expertos del mismo.

B. Implementar un instrumento de evaluación (pre-test y post-test) y determinar su validez y fiabilidad como instrumento de evaluación.

C. Seleccionar una muestra a la cual se aplicará el instrumento de evaluación y la aplicación NPM-RA.

D. Realizar el análisis estadístico exploratorio, descriptivo e inferencial de los datos obtenidos con el instrumento de evaluación (pre-test y post-test) y hacer una valoración de la efectividad de la aplicación NPM-RA en un contexto educativo.

III. Determinar y comprender las experiencias logradas con la aplicación NPM-RA por parte de los usuarios (alumnos y profesores), identificando los aspectos relevantes y factores claves que se deriven de la usabilidad generada en el contexto educativo del m-learning/ u-learning sobre el territorio en un contexto de portabilidad-movilidad.

A. Establecer y determinar las experiencias personales en el proceso de utilización de dispositivos móviles (tabletas) en un proceso de educativo $\mathrm{m}$ learning/ u-learning soportado con recursos como son la NPM y la RA.

B. Determinar los factores y elementos claves que se presentan en el proceso de utilización de tecnología móvil (NPM y RA) en un proceso educativo situado sobre el territorio.

C. Establecer las dificultades que plantean los usuarios en la utilización de la tecnología móvil en un contexto de movilidad. 
De manera complementaria a los antecedentes teóricos y a los objetivos anteriormente planteados, la hipótesis de trabajo de la tesis es la siguiente:

\section{Los alumnos que utilizan la aplicación MPN-RA en un contexto m- learning/u-learning, alcanzan niveles más altos de aprendizaje respecto a los alumnos que utilizan la tecnología tradicional, particularmente en contextos de enseñanza tradicional.}

De manera paralela, se plantean algunas hipótesis secundarias derivadas de la hipótesis general:

1. No existen diferencias significativas entre el sexo de los participantes y el nivel de aprendizaje obtenido una vez realizada la experiencia educativa con la aplicación móvil o con un escenario e-learning.

2. No existen diferencias significativas entre la nacionalidad de los participantes y el nivel de aprendizaje obtenido derivado de esta actividad.

\subsection{Delimitación de los contextos territoriales mediante el patrimonio.}

\subsubsection{Obtención de datos base para la delimitación territorial-patrimonial}

Desde el contexto territorial y patrimonial, se utilizó información secundaria proveniente de bases de datos espaciales georreferenciadas oficiales (Tabla 4.1 y Tabla 4.2), que fue complementada con bibliografía especializada que permitió la definición general del contenido temático patrimonial de la aplicación. 
Tabla 4.1 Datos territoriales para Santiago de Chile

\begin{tabular}{l|l|l|}
$\begin{array}{l}\text { Tipo de } \\
\text { información }\end{array}$ & Fuente de datos & Tipo \\
\hline $\begin{array}{l}\text { Inmuebles y lugares } \\
\text { patrimoniales }\end{array}$ & Consejo de Monumentos Nacionales (2015a) & Vectorial (Punto) \\
$\begin{array}{l}\text { Imagen del área de } \\
\text { estudio }\end{array}$ & $\begin{array}{l}\text { Secretaría de Planificación de Transporte } \\
\text { (2012) }\end{array}$ & Raster (Ortofotografía) \\
\hline Eje de calles & $\begin{array}{l}\text { Gobierno Regional Metropolitano de Santiago } \\
\text { de Chile (2013) }\end{array}$ & Vectorial (Línea) \\
\hline Predios y solares & $\begin{array}{l}\text { Gobierno Regional Metropolitano de Santiago } \\
\text { de Chile (2013) }\end{array}$ & Vectorial (Polígono) \\
\hline Elevaciones & USGS - Nasa (2013) & $\begin{array}{l}\text { Modelo Digital de } \\
\text { Elevaciones }\end{array}$ \\
\hline
\end{tabular}

Fuente: Elaboración propia.

Tabla 4.2 Datos territoriales para Salamanca (España)

\begin{tabular}{llll}
$\begin{array}{l}\text { Tipo de } \\
\text { información }\end{array}$ & Fuente de datos & Tipo \\
\hline $\begin{array}{l}\text { Inmuebles y lugares } \\
\text { patrimoniales } \\
\text { Imagen del área de } \\
\text { estudio }\end{array}$ & $\begin{array}{l}\text { Junta de Castilla y León (2010), Edilux } \\
\text { (2002), Núñez (2001) }\end{array}$ & $\begin{array}{l}\text { Instituto Geográfico Nacional de España } \\
\text { (2015) }\end{array}$ & Raster (Ortofotografía) \\
\hline Eje de calles & $\begin{array}{l}\text { Open Street Map (2015) } \\
\text { Predios y solares }\end{array}$ & Open Street Map (2015) & Vectorial (Línea) \\
\hline Elevaciones & USGS - Nasa (2014) & Vectorial (Polígono) \\
\hline
\end{tabular}

Fuente: Elaboración propia.

Debido a la gran cantidad de datos existente para cada área de estudio, ha sido preciso efectuar una cuidadosa selección de los inmuebles y lugares para el desarrollo del contexto temático patrimonial. Se ha recopilado y desarrollado información territorial empleando una ficha evaluada por especialistas de diversas áreas, especializaciones y contextos relacionados con la temática a utilizar: profesores, historiadores, antropólogos, geógrafos y arquitectos. Todos ellos hicieron posible una correcta definición contextual del instrumento de recopilación de datos para su posterior implementación educativa e informática (Figura 4.1).

\footnotetext{
${ }^{68}$ Los datos se han extraído de la bibliografía y se georreferenciaron digitalmente.
} 
Figura 4.1: Especialistas que participaron en la evaluación del instrumento de patrimonio $(n=18)$

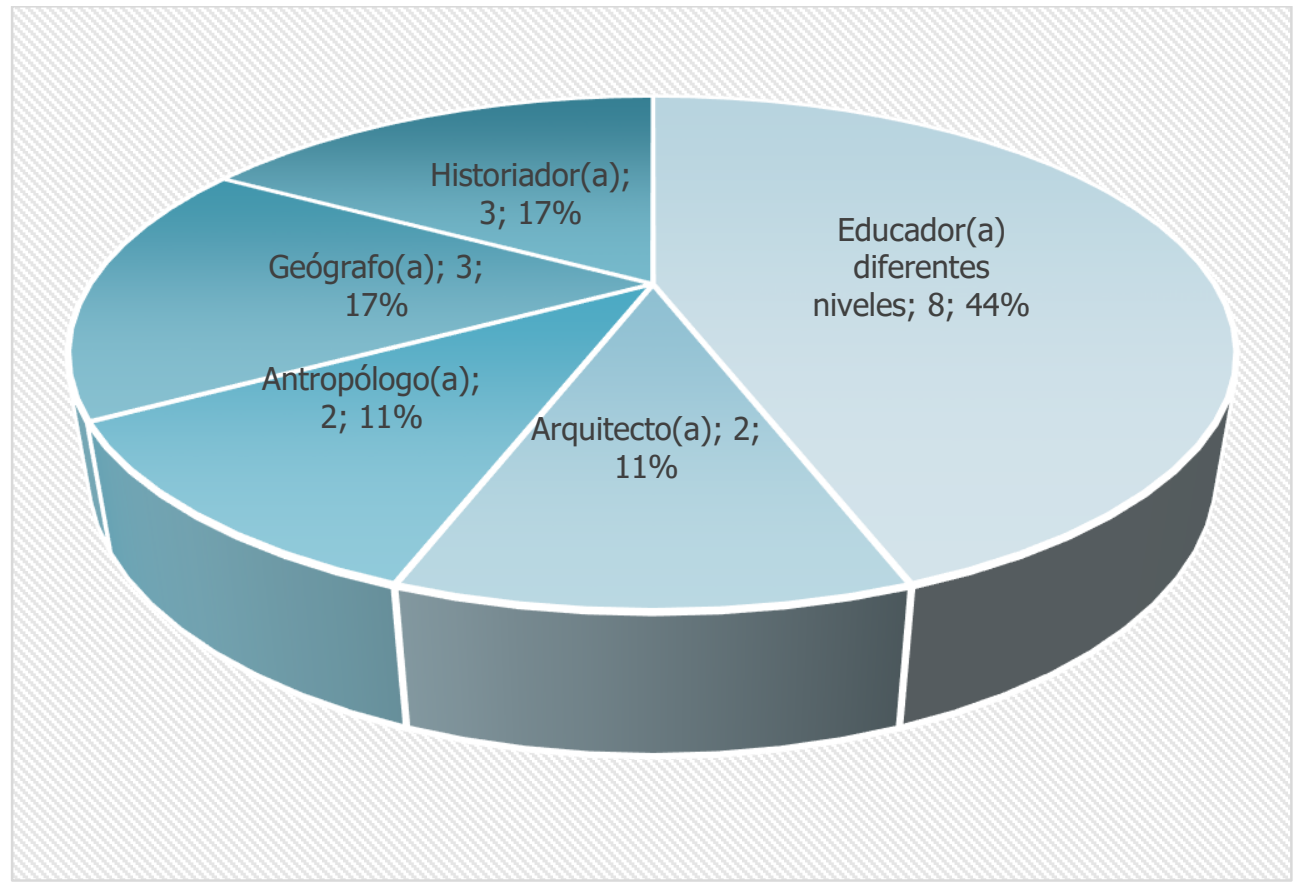

Fuente: Elaboración propia.

En el instrumento desarrollado para la elaboración de los contenidos patrimoniales y educativos se midieron tres dimensiones generales para su implementación digital (Tabla 4.3):

I. Identificación general: elementos de localización y descripción de inmueble que será utilizado en la aplicación (8 ítems).

II. Antecedentes históricos y patrimoniales: descripción del contexto histórico y patrimonial del inmueble ( 9 ítems).

III. Dimensión educativa del inmueble: elementos y características que educativas que se derivan de los elementos patrimoniales del inmueble (6 ítems). 


\section{Tabla 4.3 Elementos utilizados para la selección de elementos patrimoniales Dimensión Ítem \\ Descripción}

1. Nombre de la edificación o lugar Identificación común al inmueble.

2. Tipo $\quad$ Corresponde al uso actual que se le otorgo al inmueble. Por ejemplo: edificación civil doméstica/ edificación civil pública/ edificación religiosa /edificación militar.

3. Dirección nominal

4. Localización Absoluta

I.

Identificación

5. Localización Relativa

6. Categoría patrimonial cultural que posee la edificación

7. Descripción de intervención arquitectónica realizada

8. Tipo de legislación atingente

1. Fecha de construcción

2. Hitos históricos significativos

3. Estilo arquitectónico

II.

Antecedentes

Históricos-

Patrimoniales

4. Características esenciales, modificaciones y alteraciones arquitectónicas.

5. Creador o Arquitecto

6. Evolución de su uso y funcionalidad

7. Personajes relevantes ligados al espacio patrimonial

8. Documentación fotográfica atingente

9. Cambio en la funcionalidad
Localización en base a la calle y el número en que se sitúa la edificación.

Ubicación en coordenadas geográficas de la estructura. Se considera el lugar de observación del usuario.

Ubicación dinámica respecto de la localización del usuario en un momento t y su distancia hasta la edificación o lugar. Se mide en tiempo

Monumento histórico, patrimonio de la humanidad, entre otros.

Según criterios estilísticos y museológicos, como son: reestructuración funcional y estructural; conservación, preservación y restauración; intervención de puesta en valor y exposición en museo.

Protección arquitectónica y patrimonial.

Fecha aproximada de construcción inicial. No incluye posteriores modificaciones.

Eventos históricos significativos presentes en el inmueble y que son de referencia para la ciudad en su contexto general.

Corresponde a la clasificación temporal de la edificación en cuanto a parámetros de forma, técnicas, materiales, decoración, período entre otros. Relacionado con la historia de la arquitectura.

Se mencionan y caracterizan las modificaciones y alteraciones relevantes que ha tenido la edificación a lo largo del tiempo.

Corresponde al realizador de la obra. Puede ser el mandante o su diseñador.

Se mencionan los cambios de uso y utilización del edificio a lo largo de su existencia.

Corresponde a las personas importantes relacionadas directa o indirectamente con el edificio.

Información fotográfica histórica del emplazamiento. En este campo se utilizarán datos digitales multimedia.

Campo booleano relacionado con el campo "Evolución de uso y funcionalidad".

El valor se realiza desde el contexto histórico, arqueológico, patrimonial, museológico, geográfico, entre otros. 


\begin{tabular}{|l|l|l|}
$\begin{array}{l}\text { Educativa del } \\
\text { Inmueble }\end{array}$ & $\begin{array}{l}\text { 2. Elementos y concepciones } \\
\text { ideológicas asociados al inmueble }\end{array}$ & $\begin{array}{l}\text { Elementos significativos desarrollados por } \\
\text { nuestras sociedades, que se asocien al legado } \\
\text { histórico, los valores estéticos, artísticos, } \\
\text { tecnológicos, entre otros. }\end{array}$ \\
\cline { 2 - 3 } & 3. Análisis histórico-figurativo & $\begin{array}{l}\text { Definición estética y valorización crítica del bien } \\
\text { patrimonial. }\end{array}$ \\
\hline 4. Análisis socio-funcional & $\begin{array}{l}\text { Relación entre el bien inmueble y su relación } \\
\text { con el resto de la ciudad, su contexto; } \\
\text { concepto de paisaje cultural. }\end{array}$ \\
\hline & $\begin{array}{l}\text { 5. Presencia de elementos que } \\
\text { permitan una aproximación científica } \\
\text { al pasado }\end{array}$ & $\begin{array}{l}\text { A través de procedimientos de observación, } \\
\text { interpretación y análisis. }\end{array}$ \\
\hline 6. Diversidad de elementos & $\begin{array}{l}\text { Presencia de elementos que permitan un } \\
\text { abordaje interdisciplinar al inmueble } \\
\text { patrimonial cultural. }\end{array}$ \\
\hline
\end{tabular}

Fuente: Elaboración propia.

Los inmuebles y lugares seleccionados en esta recopilación de información de datos patrimoniales, se hallarán en los Anexos 01 y 02.

Para la unidad temática sobre patrimonio, se utilizó un sector del centro histórico de la ciudad de Santiago de Chile, cuyos antecedentes históricos-generales establecen su origen hacia el año 800 con la instalación de los primeros asentamientos sedentarios prehispánicos. En el 12 de febrero de 1541 se produce su fundación y la ciudad adquiere el nombre con que es conocida hasta la actualidad (De Ramón, 1992). Para la aplicación se han establecido 57 monumentos patrimoniales (Consejo de Monumentos Nacionales de Chile, 2015b) en una superficie que abarca aproximadamente las 25,16 hectáreas (Figura 4.2) 
Figura 4.2 Santiago de Chile y edificaciones patrimoniales consideradas

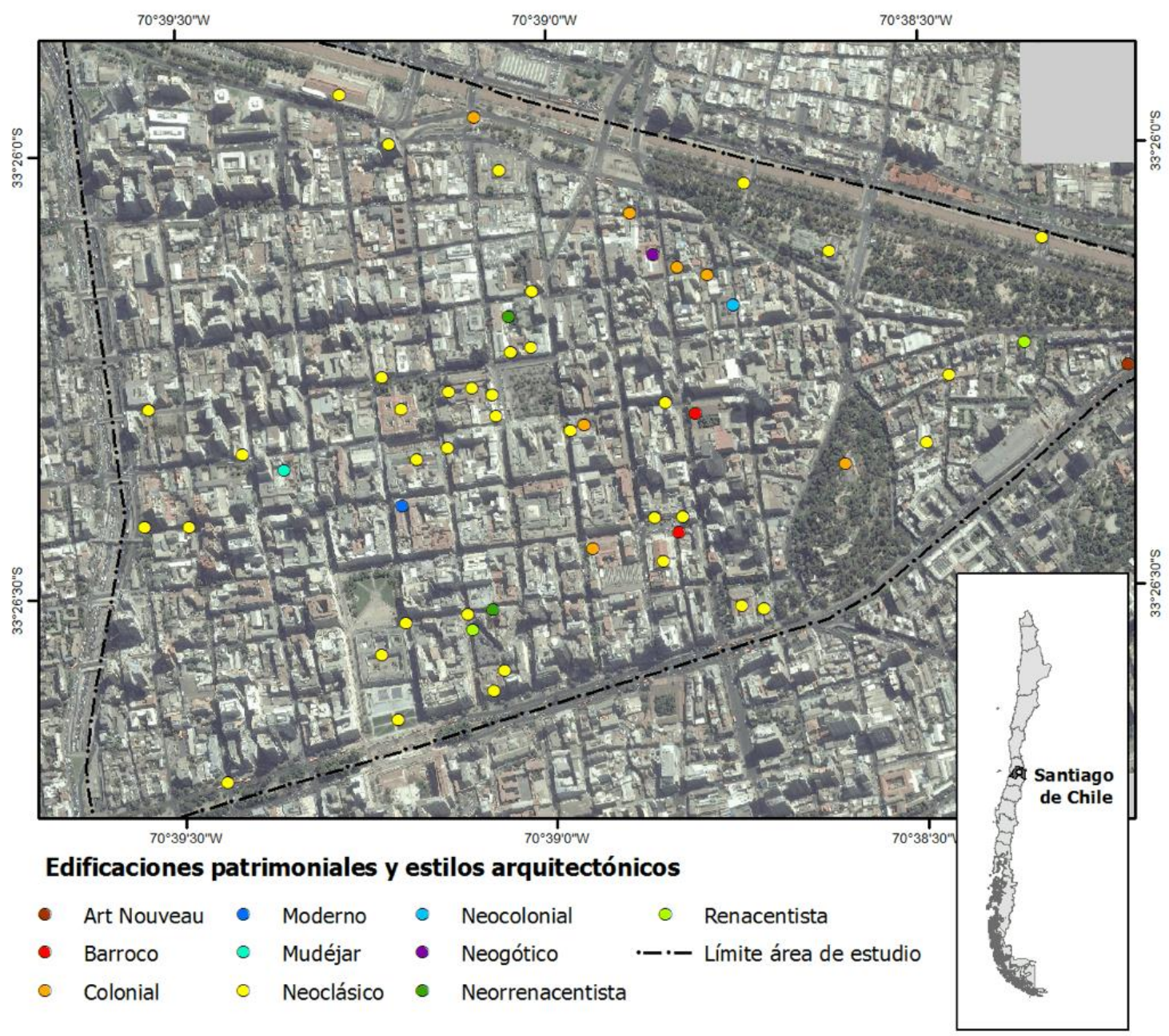

Fuente: Elaboración propia.

Por otro lado, se sitúa la ciudad de Salamanca (España), la cual es contenedora de un fuerte carácter y contenido histórico-patrimonial, lo que se expresa en la cantidad de inmuebles e hitos urbanos presentes en su planta más antigua. El centro urbano tiene sus orígenes en la época de la primera Edad de Hierro, hace aproximadamente 2700 años (González García, 1982). Hacia el año 1102 se presentan los primeros cimientos para lo que se conoce como la ciudad actual, la cual tiene importantes influencias de culturas diversas, con estilos artísticos de diversa índole (T. González \& de Celis, 1998). De esta manera, para los propósitos de esta investigación, el casco antiguo de Salamanca con sus 125,28 hectáreas de extensión, fue definido como el límite de contenidos temáticos y peatonales, con 72 inmuebles patrimoniales definidos (Figura 4.3). 
Figura 4.3 Salamanca (España) y edificaciones patrimoniales

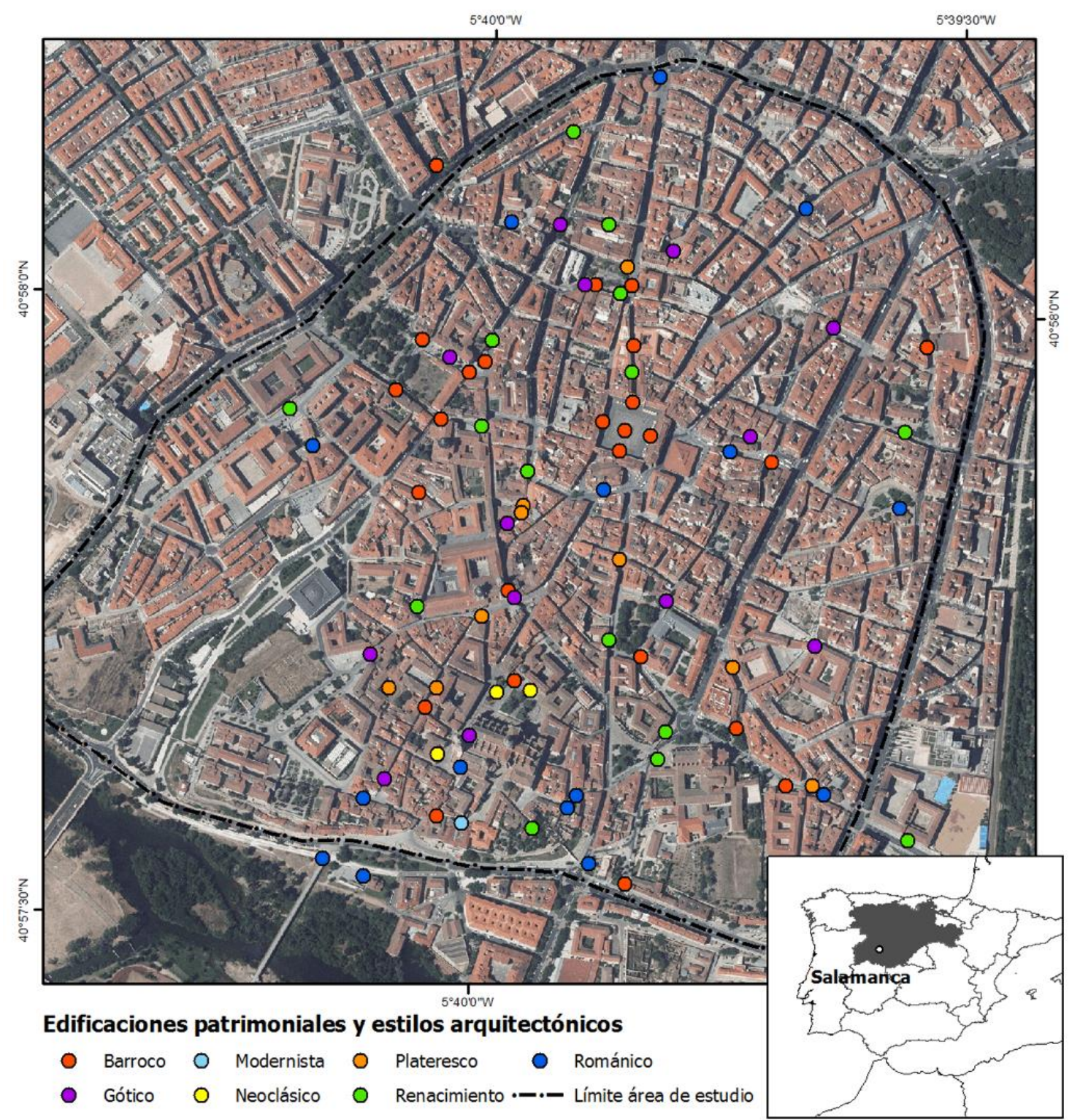

Fuente: Elaboración propia.

\subsubsection{Metodología de análisis espacial utilizadas}

Para el conjunto de los datos territoriales se han utilizado e integrado técnicas de Evaluación Multicriterio -EMC-, las cuales corresponden a un método en donde se sintetizan diversas características del territorio mediante la sumatoria de los factores que se consideran positivos y restando los valores que se consideran negativos para la actividad que se quiere evaluar. Esto hace posible una visualización ponderada de los elementos analizados y reflejando su grado de interés en función de los objetivos 
planteados en la investigación. Se han utilizado varios Sistemas de Información Geográfica -SIG-69 (Gómez Delgado \& Barredo Cano, 2005; Henríquez \& Quense, 2009; Palma Herrera, 2013) con el fin de abordar diversas variables de la dimensión territorial en el patrimonio, desde perspectivas y aspectos que sean funcionales para el desarrollo $\mathrm{m}$ learning/ u-learning (Colls \& Colls, 2013; Galani, Mazel, Maxwell, \& Sharpe, 2013; Kokalj, Pehani, Goodchild, Gaffney, \& Oštir, 2013; Ramsey, 2013). Las variables propuestas se sintetizan en la Tabla 4.4 y Figura 4.4:

Tabla 4.4 Variables utilizadas en la evaluación EMC

Objetivo

Criterio

\section{Descripción del criterio y la función ( fuzzy)}

\begin{tabular}{|c|c|c|}
\hline \multirow{4}{*}{$\begin{array}{l}\text { Ambiente } \\
\text { Urbano }\end{array}$} & Inmuebles y lugares patrimoniales & $\begin{array}{l}\text { Cobertura de datos booleanos: } \\
\text { Presencia o ausencia de información. }\end{array}$ \\
\hline & Eje de calles & $\begin{array}{l}\text { Estandarización de datos de acuerdo a } \\
\text { tipo de vía: peatonal, calle, pasaje, } \\
\text { autovía, etc. Criterios definidos en base } \\
\text { a la facilidad y dificultad para el } \\
\text { desplazamiento peatonal. }\end{array}$ \\
\hline & Predios y solares & $\begin{array}{l}\text { Cobertura de datos booleanos: } \\
\text { Presencia o ausencia de información. }\end{array}$ \\
\hline & Elevaciones (pendiente) & $\begin{array}{l}\text { Función simétrica: mayor aptitud entre } \\
\text { los } 0^{\circ} \text { y los } 25^{\circ} \text { de pendiente para el } \\
\text { desplazamiento peatonal. }\end{array}$ \\
\hline \multirow{5}{*}{$\begin{array}{l}\text { Antecedentes } \\
\text { Históricos - } \\
\text { Patrimoniales }\end{array}$} & $\begin{array}{l}\text { Características esenciales, } \\
\text { modificaciones y alteraciones } \\
\text { arquitectónicas. }\end{array}$ & $\begin{array}{l}\text { Estandarización de acuerdo a } \\
\text { reclasificación de datos de mayor a } \\
\text { menor número y tipo de } \\
\text { modificaciones. }\end{array}$ \\
\hline & $\begin{array}{l}\text { Evolución de su uso y } \\
\text { funcionalidad }\end{array}$ & $\begin{array}{l}\text { Cobertura de datos booleanos: } \\
\text { Presencia o ausencia de información. }\end{array}$ \\
\hline & $\begin{array}{l}\text { Personajes relevantes ligados al } \\
\text { espacio patrimonial }\end{array}$ & $\begin{array}{l}\text { Cobertura de datos booleanos: } \\
\text { Presencia o ausencia de información. }\end{array}$ \\
\hline & $\begin{array}{l}\text { Documentación fotográfica } \\
\text { atingente }\end{array}$ & $\begin{array}{l}\text { Cobertura de datos booleanos: } \\
\text { Presencia o ausencia de información. }\end{array}$ \\
\hline & Cambio en la funcionalidad & $\begin{array}{l}\text { Cobertura de datos booleanos: } \\
\text { Presencia o ausencia de información. }\end{array}$ \\
\hline
\end{tabular}

Fuente: Elaboración propia.

${ }^{69}$ El EMC es equivalente al método de sumatorio lineal ponderado establecido por Gómez y Barrero (2005), en donde:

$$
r_{i}=\sum_{j=1}^{n} W_{j} V_{i j}
$$

$\mathrm{r}_{\mathrm{i}}$ es la aptitud alternativa $\mathrm{i}$

$\mathrm{W}_{\mathrm{j}}$ el peso del criterio o factor $\mathrm{j}$

$\mathrm{V}_{\mathrm{ij}}$ es el valor ponderado de la alternativa $\mathrm{i}$ en el criterio o factor $\mathrm{j}$ 
Figura 4.4 Modelo de datos territoriales utilizados

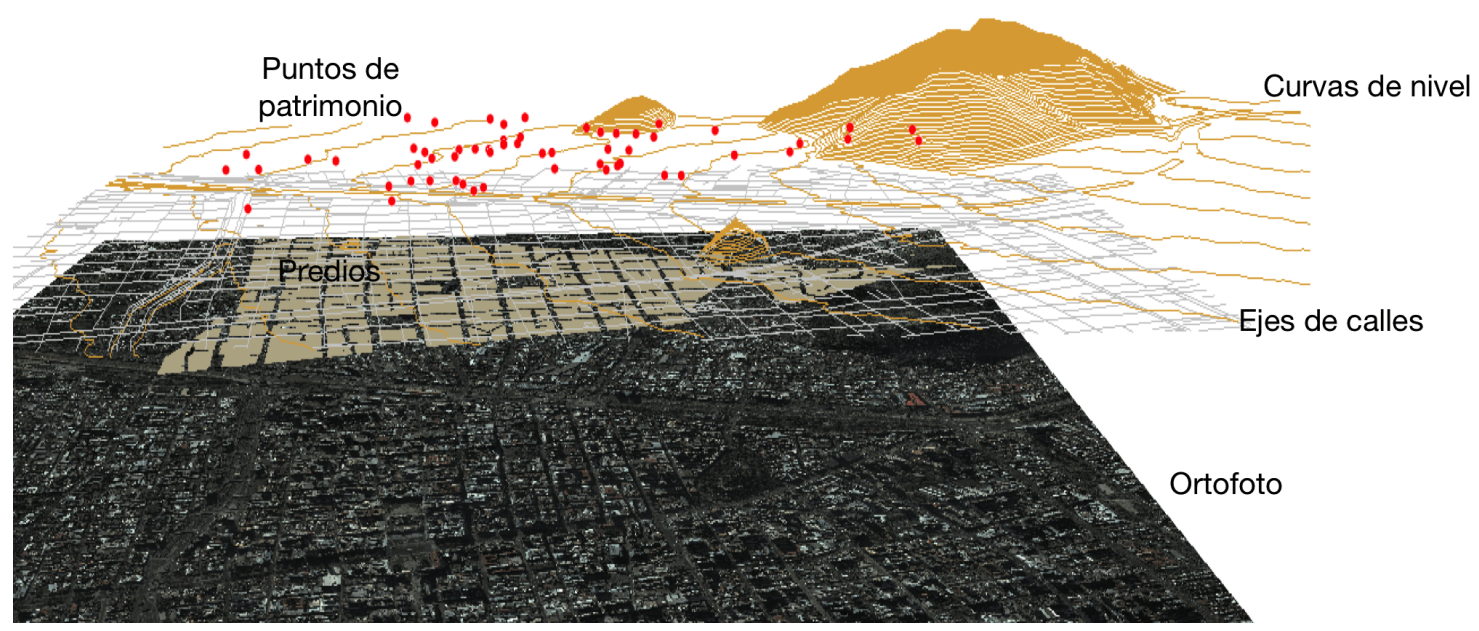

Fuente: elaboración propia.

Los datos obtenidos con esta síntesis en un valor multicriterio, permiten el adecuado modelamiento de un desplazamiento dentro de un contexto de navegación peatonal, teniendo como referencia principal los elementos patrimoniales sobre el territorio. Estos valores multicriterio se expresan territorialmente en la Figuras Figura 4.5 y Figura 4.6 (mapas de calor en donde las isolíneas corresponde al valores de aptitud patrimonial-peatonal), siendo la fase de preliminar en la síntesis de datos para la definición de las áreas para las rutas patrimoniales que serán incluidas en los dispositivos móviles. 
Figura 4.5 Valor multicriterio de aptitud patrimonial-peatonal. Santiago de Chile.

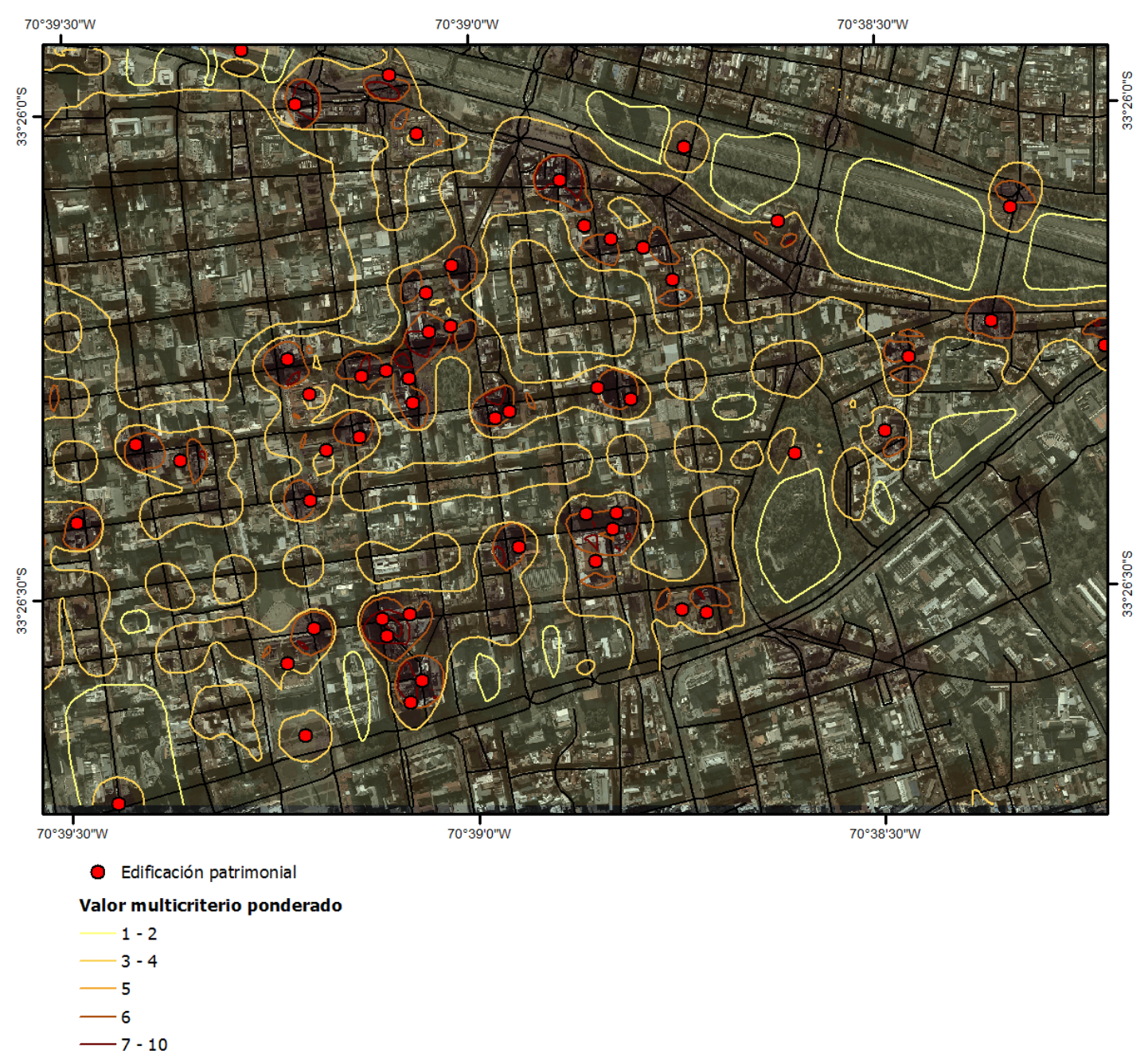

Fuente: elaboración propia. 
Figura 4.6 Valor multicriterio de aptitud patrimonial-peatonal. Salamanca (España)

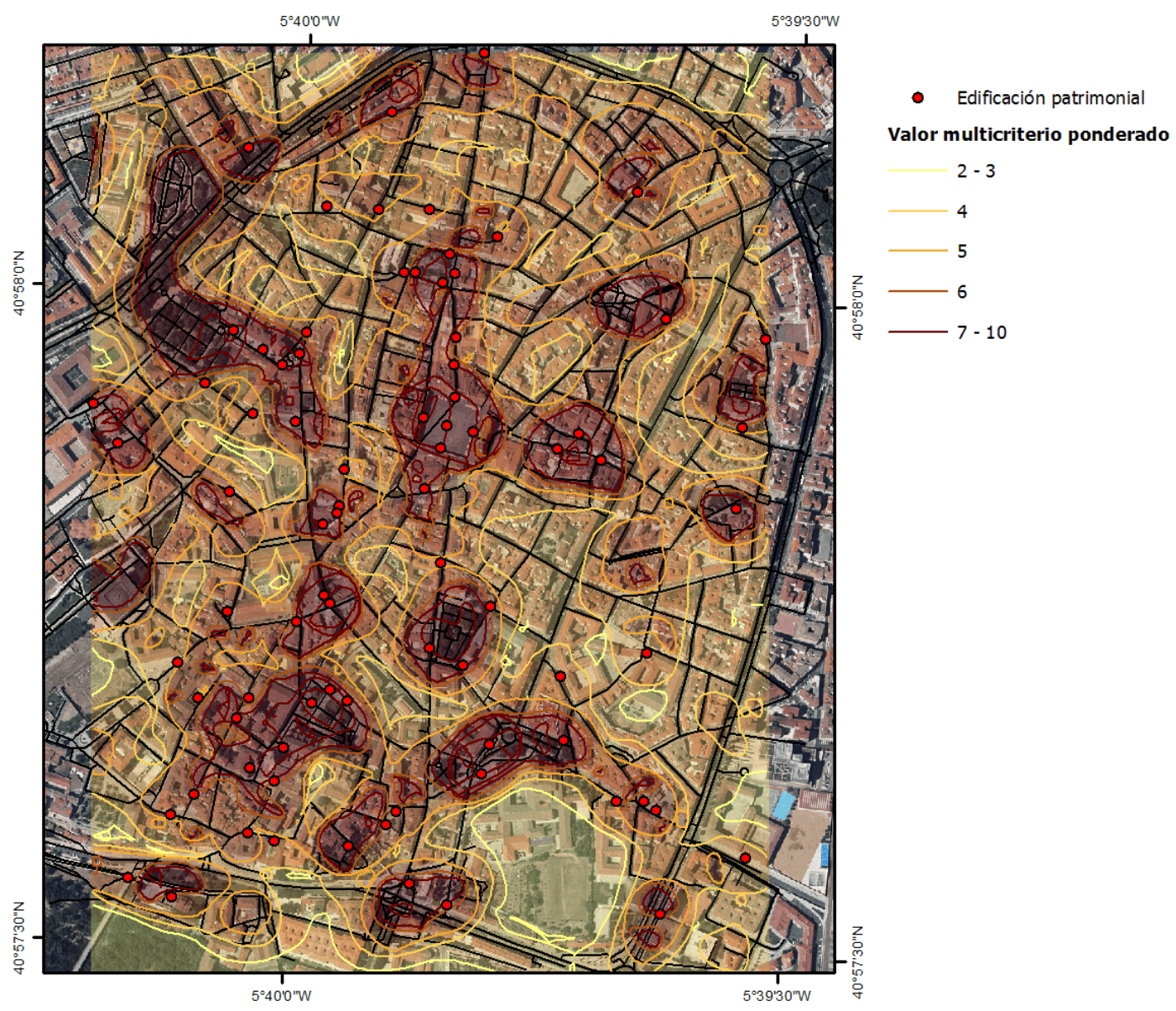

Fuente: elaboración propia.

Esta síntesis de valores ponderados se sintetiza en las Tablas Tabla 4.5 y Tabla 4.6, en donde se puede establecer que los valores de magnitud se encuentran dispersos en el ámbito territorial seleccionado, pero que para el caso de la ciudad de Salamanca, los valores de ECM ponderado son mayores y concentrados marcando diferencias con lo que respecta a la ciudad de Santiago. 
Tabla 4.5 Resumen de los valores ECM por ruta. Santiago de Chile
Ruta
Media ECM
ECM Ponderado
Número
Hectáreas por superficie

de hitos

A: Sector oriental de la
ciudad
B: Santa Lucía y alrededores
C: Museo de Bellas Artes y
alrededores
D: Sector norte de la ciudad
E: Sector sur de la ciudad.
Barrio Cívico
F: Sector centro. Plaza de
Armas y alrededores
G: Tribunales de Justicia y
alrededores

\begin{tabular}{|c|c|c|c|}
\hline 75 & 6,11 & 5 & 29,99 \\
\hline 86 & 13,17 & 8 & 2,62 \\
\hline 106 & 7,87 & 10 & 32,17 \\
\hline 87 & 4,51 & 5 & 22,69 \\
\hline 155 & 19,80 & 10 & 39,83 \\
\hline 53 & 1,55 & 11 & 22,48 \\
\hline 126 & 42,40 & 8 & 19,83 \\
\hline
\end{tabular}

Fuente: Elaboración propia.

Tabla 4.6 Resumen de los valores ECM por ruta. Salamanca (España)
Ruta
Media ECM
ECM Ponderado
Número
Hectáreas por superficie
de hitos
A: Plaza Mayor y sus alrededores
B: Sector noroccidental de la
C: Sector centro oriental de la ciudad antigua
D: Sector centro occidental de la ciudad antigua
E: Convento de San Esteban $y$ sus alrededores
F: Clerecía de Salamanca y alrededores
G: Universidad de Salamanca $y$ sus alrededores
H: Catedrales y Plaza de Anaya
I: Sector sur de la ciudad antigua

\begin{tabular}{|c|c|c|c|}
\hline 65 & 2,64 & 8 & 7,00 \\
\hline 84 & 76,91 & 12 & 19,97 \\
\hline 50 & 3,30 & 7 & 12,15 \\
\hline 76 & 18,02 & 10 & 1,66 \\
\hline 136 & 78,23 & 12 & 25,53 \\
\hline 89 & 6,93 & 10 & 9,36 \\
\hline 50 & 52,84 & 5 & 3,55 \\
\hline 62 & 455,14 & 6 & 3,96 \\
\hline 83 & 11,40 & 9 & 7,01 \\
\hline
\end{tabular}

Fuente: Elaboración propia.

Teniendo los sectores con mayor potencialidad para el desplazamiento peatonal y visualización de elementos patrimoniales, se procedió a la creación de una delimitación y subdivisión de mayor precisión del área de estudio mediante la definición de los polígonos de Thiessen y el establecimiento de los centros de gravedad espacial respectivos 
determinados por los valores EMC. Los polígonos de Thiessen corresponden a una definición geométrica ${ }^{70}$ que permite delimitar un plano euclidiano mediante la interpolación simple de puntos de referencia, basado en la distancia euclidiana entre dichos puntos (Garnica Berrocal \& Galvis Causil, 2014; Rahimi \& Malek, 2015; She et al., 2015).

Para esta investigación, los puntos definitorios en los polígonos de Thiessen corresponden a los centros de gravedad presentes dentro del área de estudio de acuerdo a su localización espacial y los valores EMC obtenidos (Figura 4.7 y Figura 4.8). Dichos límites fueron finalmente ajustados a los ejes de calles resultando la delimitación final de las áreas para su posterior delimitación.

70 Siendo una distancia euclidiana se tiene entonces:

$$
\|p-q\|=\sqrt{\left(p_{x}-q_{x}\right)^{2}+\left(p_{y}-q_{y}\right)^{2}}
$$

Donde $p$ es un punto distintivo, y $q$ también es un punto de la región de un sitio en $\mathrm{p}_{\mathrm{i}}$. De esta manera la región de $p_{i}$ se encuentra establecida por la intersección de los semiplanos generados al determinar los bisectores de $p_{i}$ hacia $p_{j}$ :

$$
V\left(p_{i}\right)=\bigcap_{j=1, j \neq i}^{n} h\left(p_{i}, p_{j}\right)
$$

Por lo que $V\left(p_{i}\right)$ está compuesto por la intersección de $\mathrm{n}-1$ semiplanos que componen la región convexa. 
Figura 4.7 Polígonos de Thiessen en función del EMC sin ajuste de ejes. Santiago de Chile

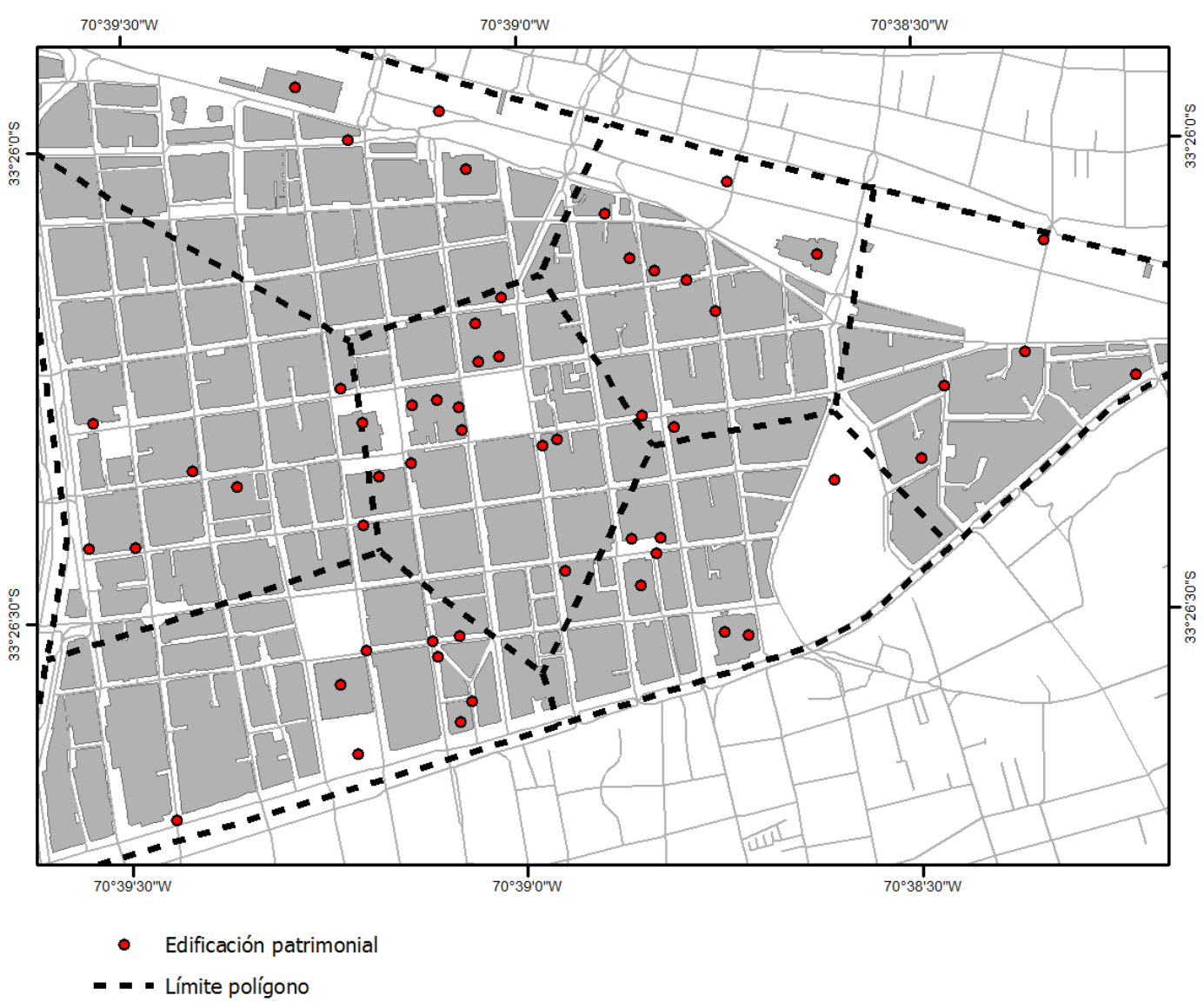

Fuente: elaboración propia. 
Figura 4.8 Polígono de Thiessen en función del EMC sin ajuste de ejes. Salamanca (España)

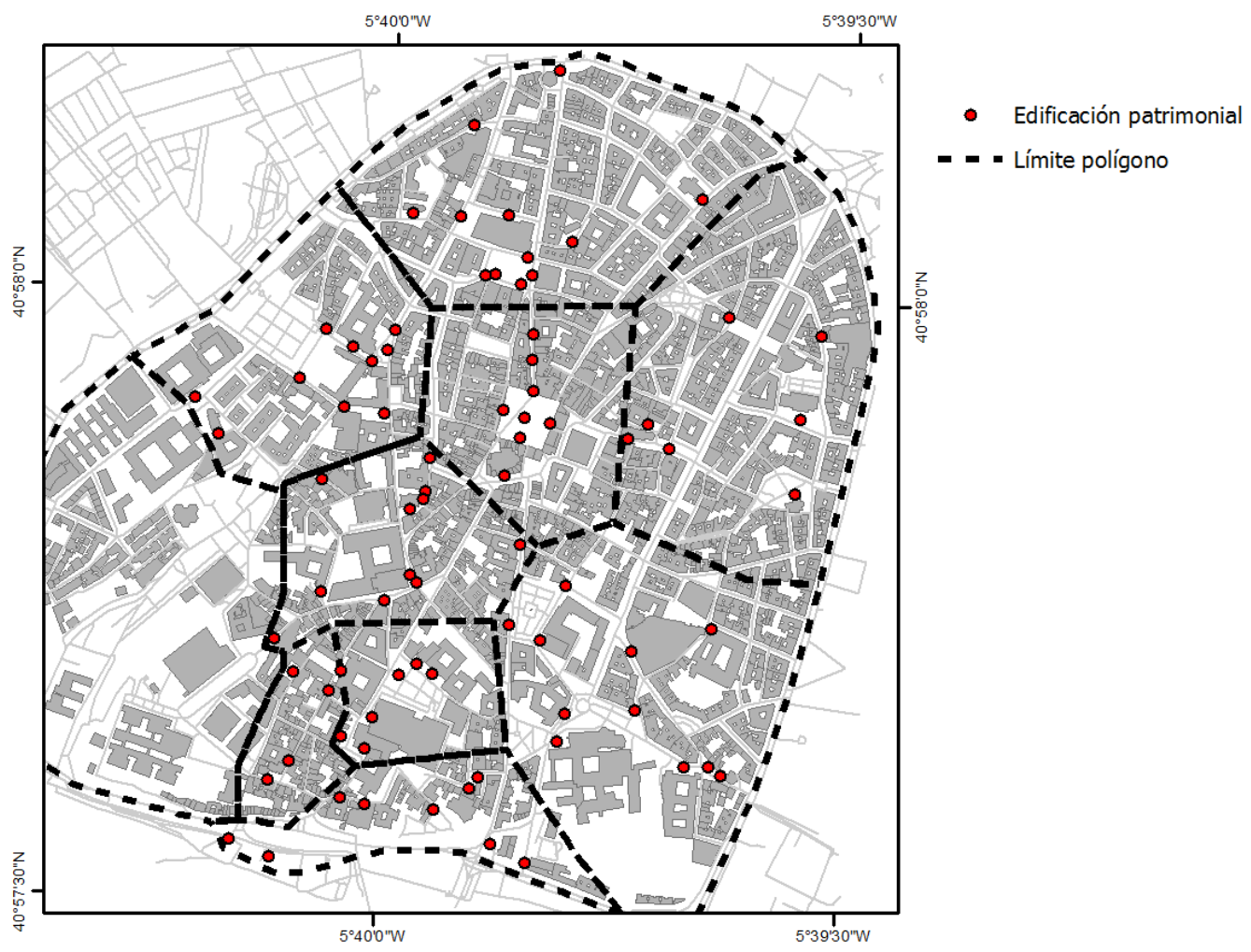

Fuente: elaboración propia.

Buscando el desarrollo de modelos de desplazamiento eficientes en donde se pudiera conjugar el universo de variables descritas anteriormente, se utilizó un análisis espacial basado en redes (Law \& Collins, 2015; Sevtsuk \& Mekonnen, 2012). Configurando un modelo de desplazamiento peatonal basado en los ejes de calles y los puntos de patrimonio definidos, se determinó un modelo que representa los requisitos de desplazamiento para cada ciudad elegida, además de las posibles áreas de servicio para cada inmueble en función del tiempo desplazamiento (Enviroment Research System Investigation, 2016), los cuales se representaron en áreas delimitadas con sus elementos patrimoniales presentes. Dichas áreas han dado lugar a "rutas" que contienen los elementos patrimoniales correspondientes (Figura 4.9 y Figura 4.10). 
Figura 4.9 Rutas patrimoniales para Santiago de Chile

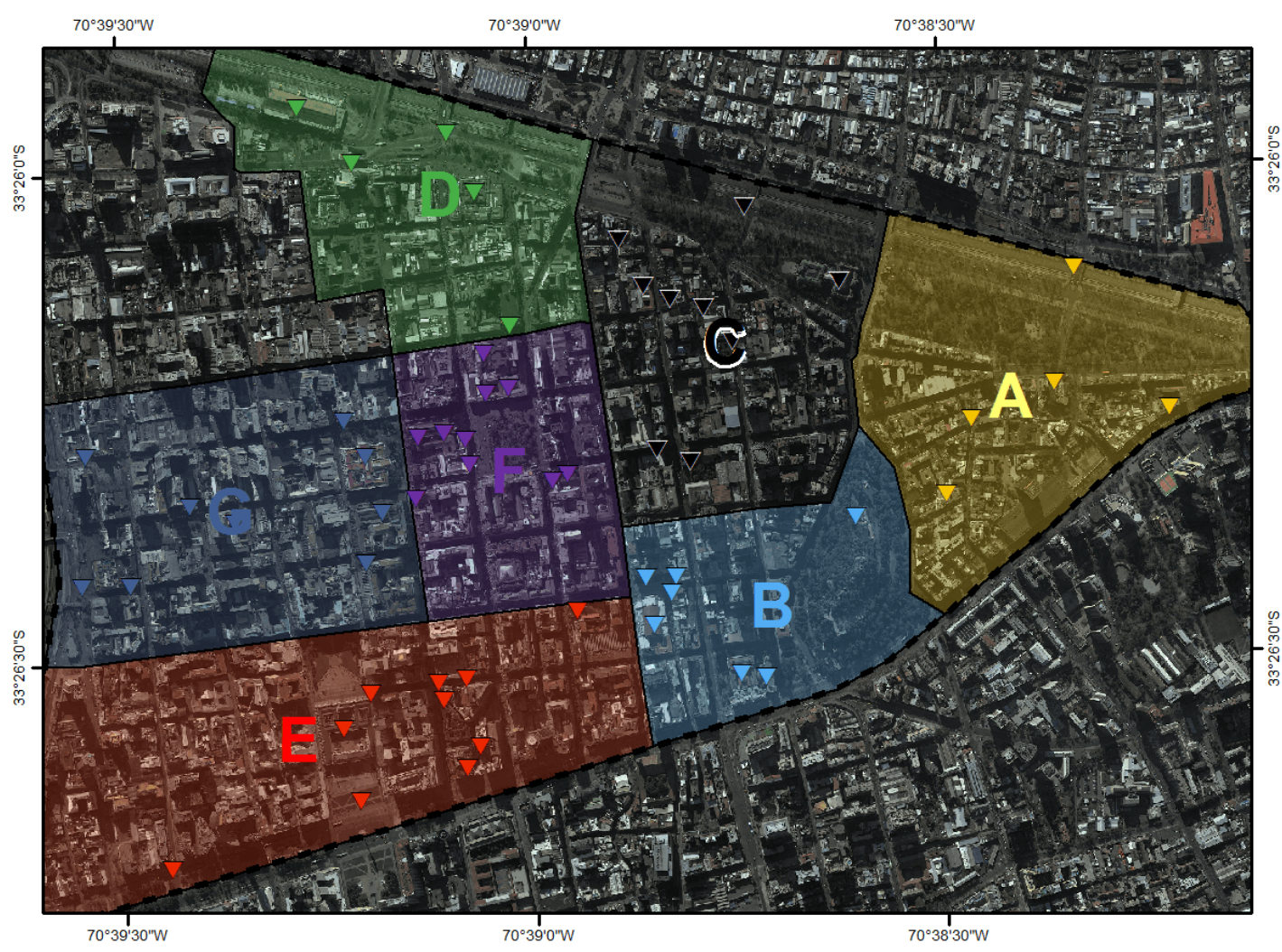

\section{Nombre ruta}

\begin{tabular}{l|l}
\hline Ruta A: Sector oriental de la ciudad & Ruta D: Sector norte de la ciudad \\
\hline Ruta B: Santa Lucía y alrededores & Ruta E: Sector sur de la ciudad. Barrio Cívico \\
\hline Ruta C: Museo de Bellas Artes y alrededores & Ruta F: Sector centro. Plaza de Armas y alrededores \\
\hline Ruta G: Tribunales de Justicia y alrededores & \\
\hline
\end{tabular}

Fuente: Elaboración propia. 
Figura 4.10 Rutas patrimoniales, Salamanca (España)

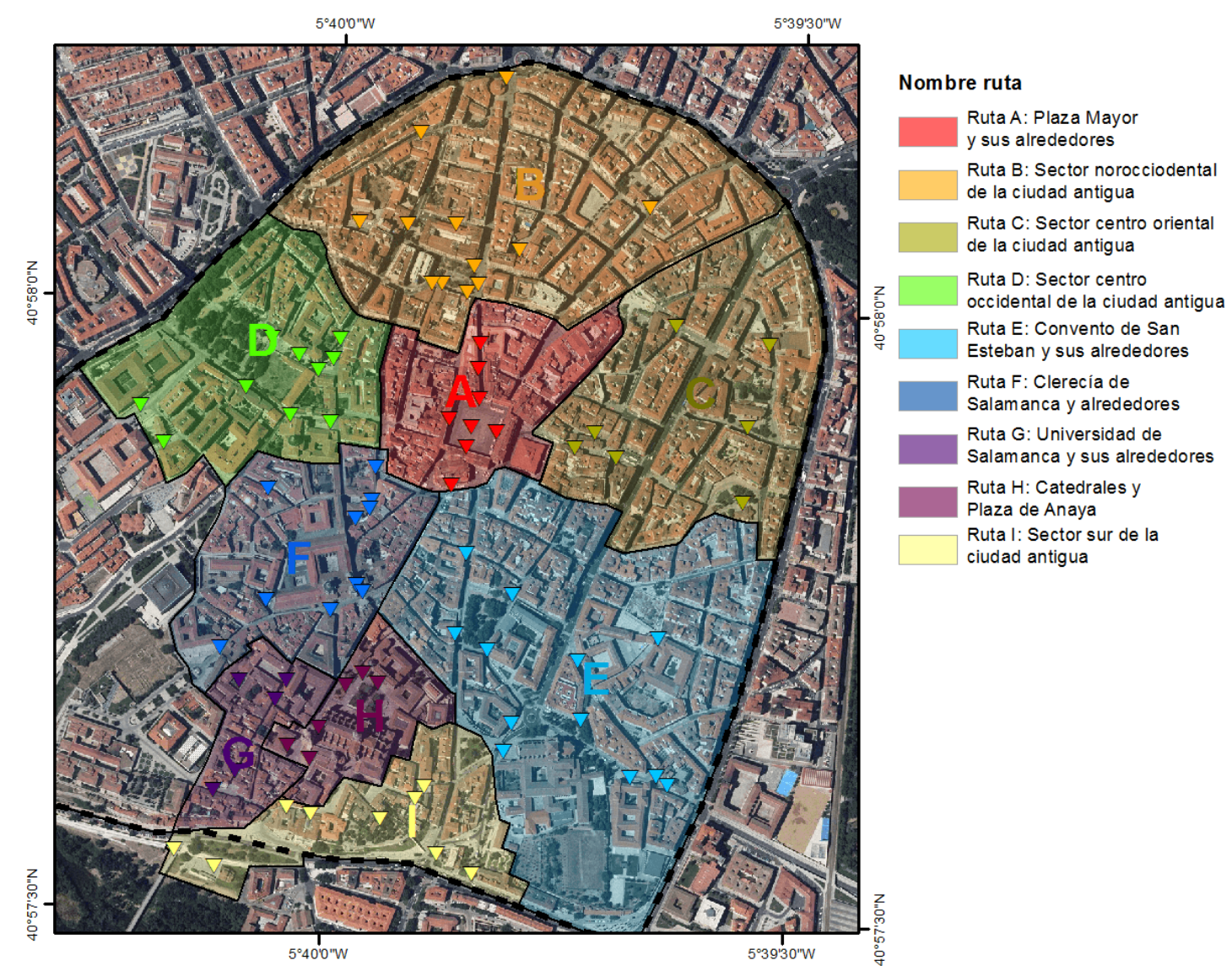

Fuente: Elaboración propia.

Complementariamente, la temática sobre patrimonio fue implementada a través de los lugares iconográficos principales de las ciudades de Salamanca -España- y Santiago de Chile teniendo en consideración la creación e incorporación de los elementos multimedia respectivos: modelos CAD y espaciales en tres dimensiones, fotografías, reseñas de texto, audios o/y videos. Estos son el valor agregado funcional y temático que se establecerá como conocimiento a difundir mediante esta herramienta.

\subsection{Fase de desarrollo e implementación de software NPM-RA}

En esta fase se realizó la creación e implementación de la aplicación NPM-RA que como es lógico sigue el "ciclo de vida del desarrollo de software" (Elliott, 2004; Montilva, 
Arapé, \& Colmenares, 2003), utilizando la variante conocida como Modelo de Cascada71, en la cual se estructura la aplicación informática en una serie de fases que se implementan de manera secuencial (Joyanes Aguilar, 2008; Whitten \& Bentley, 2007) y que permiten cumplir con los objetivos planteados desde la dimensión informática de la investigación. La complejidad de esta etapa se encuentra enmarcada por el contexto en que se producen los sistemas de información existentes, lo cual permite una adaptabilidad e interoperabilidad de la estructura de datos que se quiere utilizar, genera eficiencia que permite el adecuado manejo de los recursos y facilita su posterior mantenimiento (Figura 4.11).

Figura 4.11 Etapas del ciclo de vida del software (Joyanes Aguilar, 2008).

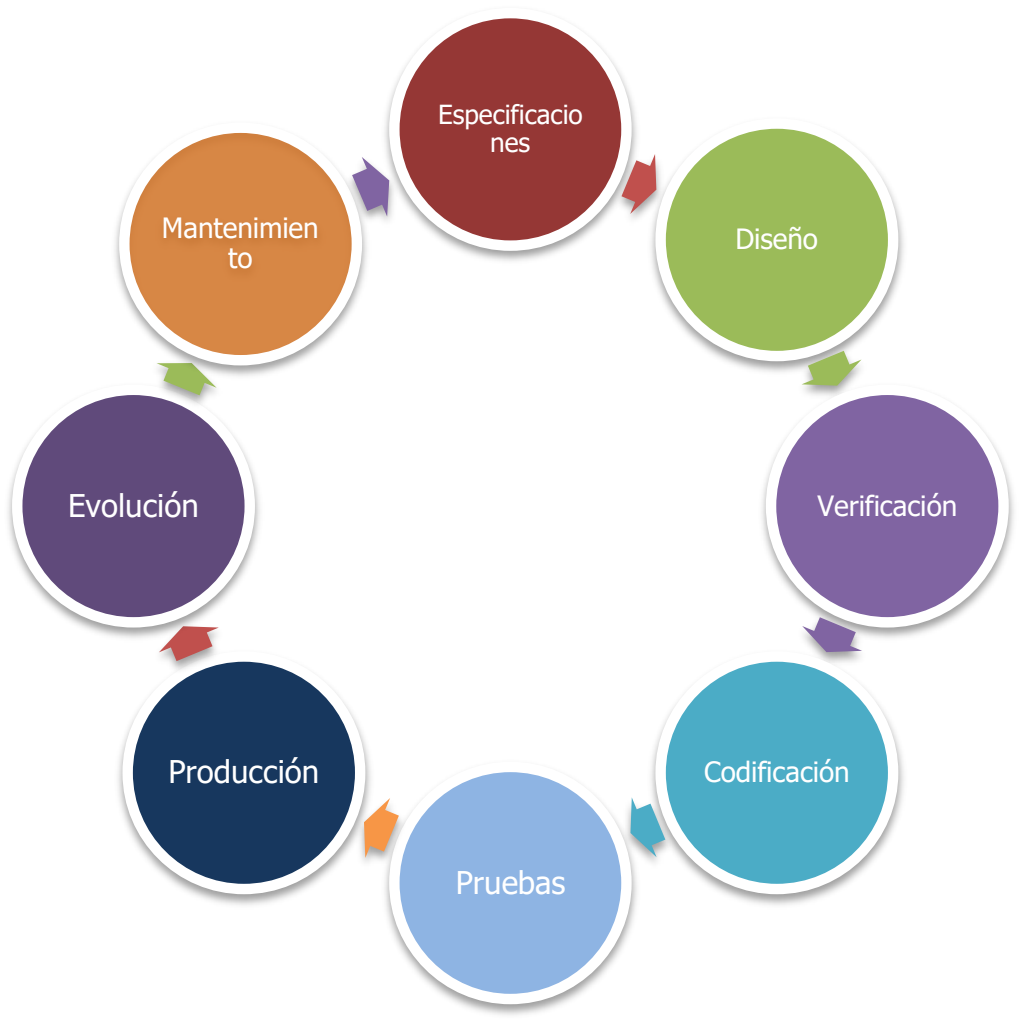

De esta manera, la aplicación móvil fue concebida como un proyecto en diversos estadios con algunos solapamientos en el tiempo, revisiones constantes entre etapas y la omisión de algunas fases, debido a los objetivos contextualizados desde el planteamiento

${ }^{71}$ Existen diversos modelos de desarrollo de software entre los cuales cabe mencionar los que siguen: el modelo de cascada, en espiral, el modelo iterativo e incremental, el desarrollo ágil (Whitten \& Bentley, 2007). Cada uno tiene sus variaciones, adaptaciones y particularidades en el proceso de creación de programas informáticos. 
de la tesis ${ }^{72}$. Además, se realizó una constante iteración en un prototipo con pruebas de campo, repitiendo cada fase con nueva información o adaptación antes de entregar un sistema estable que se pudiera evaluar empíricamente.

\subsubsection{Elicitación de requisitos para el desarrollo de la investigación}

En esta primera fase se definió el alcance de la aplicación en función de los objetivos de la investigación planteados en la tesis. Desde las ideas iniciales sobre implementar dentro de un contexto de m-learning, RA y NPM, se han planteado los requisitos generales necesarios para obtener desde el ámbito informático la herramienta necesaria para utilizar y comprobar la hipótesis planteada. Lo anterior se realiza desde la fase del marco teórico de la investigación, incluyendo la selección del hardware, software y las experiencias educativas y temáticas que se han desarrollado en estos ámbitos. De esta manera, la elicitación de requisitos para el desarrollo del software se encuentra enmarcada por los objetivos, las hipótesis y el estudio empírico de la tesis (sección 4.2). En términos generales, el objetivo es desarrollar una herramienta informática en un contexto de movilidad que permita la presentación de contenidos patrimoniales y territoriales con el fin de determinar su potencialidad como herramienta didáctica en procesos educativos situados, propios de las actividades que se generan en trabajos de campo. De manera paralela, el mecanismo aportado por esta aplicación puede ser aplicable en diferentes contextos (disciplinas que enseñan sobre contenidos que se encuentran expresados en la superficie terrestre) y escalas (desde lo local hasta lo continental). De manera particular se puede establecer que:

- Los datos de entrada de la aplicación: corresponden a los datos generados en la etapa anterior con el análisis patrimonial, espacial y educativo de los inmuebles y zonas catastradas, incluyendo su definición informática (valores válidos, tipo de estructura de datos, forma de almacenamiento e interoperabilidad) e información adicional (modelos de RA, imágenes, textos, datos). Dichos datos deben estar almacenados de manera local (dentro del dispositivo) debido a las limitaciones en

\footnotetext{
${ }^{72}$ El desarrollo informático se plantea desde la perspectiva de la investigación, teniendo interés secundario el desarrollo comercial o/y industrial. Ciertamente, el desarrollo realizado es válido para la obtención de los objetivos propuestos.
} 
infraestructura tecnológica en lo referido a la transferencia de datos que se pueden aplicar en los escenarios donde se va a aplicar la experiencia cuasiexperimental.

- Los datos de salida: corresponde a la visualización de esta información mediante una interfaz de usuario gráfica desarrollada para un contexto móvil y situado, adaptando los contenidos entregados a los diferentes escenarios patrimoniales que se quiere utilizar. De manera paralela, utilizando los sensores propios del dispositivo móvil, es posible obtener información sobre el uso y la situación temporal-espacial de los recursos multimedia presentados, permitiendo su posterior relación con el contexto educativo.

En un primer momento se ha pensado que el software sea utilizado en un contexto educativo formal, dentro de las actividades propias de los centros educativos y en las materias que tienen dentro de sus planes y programas los contenidos que se exponen en la aplicación (patrimonio), por lo que en un primer momento los usuarios finales se traducen en alumnos en edad escolar y maestros/profesores que necesitan un recursos didáctico enmarcado en un contexto TIC. Sin embargo, debido a los contenidos y estructuras de datos que se plantea en su diseño, es posible llegar a un público general interesado en el tema patrimonial, educativo o turístico de las ciudades elegidas para la experiencia, el cual podría ser abordado mediante las tiendas virtuales presentes en la actualidad.

Por otro lado, la investigación se enmarca dentro de un contexto de m-learning, en el cual se han elegido las tabletas como dispositivo de implementación de los contenidos. Desde el ámbito técnico las razones de esta situación son las siguientes:

- A diferencia de un ordenador portátil, permiten una mejor movilidad debido a su tamaño y autonomía.

- Por su tamaño de pantalla, permiten una mejor visualización de contenidos respecto a smartphones.

- La potencia de las tabletas en torno a su hardware incorporado, permite el despliegue de contenidos similares a los visualizados en un ordenador. 
Sin embargo, son los elementos presentes en el ámbito pedagógico los que han determinado su elección como dispositivo para la implementación de la aplicación:

- Permite el trabajo cooperativo entre alumnos, permitiendo el desarrollo de actividades entre dos o más alumnos por dispositivo (S. Taylor \& Procter, 2014).

- Se ha observado la percepción entre alumnos y profesores consistente en que una de actividad educativa formal se encuentra relacionada con el uso de tabletas, más que con un smartphone debido a que este dispositivo se encuentra asociado a actividades de ámbito personal. En síntesis la expectativa de los usuarios en torno al uso del dispositivo es diferente y tiene contextos claramente definidos (Dündar \& Akçayır, 2014).

- Existen aplicaciones que, por sus contenidos, interfaz y operatividad, dentro de un contexto de portabilidad funcionan mejor en una tableta que en un smartphone. Ejemplo de esto son las aplicaciones de ofimática (Word, Excel, Pages, Numbers), editores gráficos de imágenes o CAD, administración de contenidos, etc. (McPherson, 2016).

Dentro de este contexto, la tableta iPad se posiciona como el instrumento más adecuado debido a sus características de hardware y software, además de su penetración en el mercado de los dispositivos móviles ${ }^{73}$. Adicionalmente, se ha desarrollado una serie de congresos y publicaciones en torno a la utilización del iPad en entornos educativos, destacando el International Conference on the use of iPads in Higher Education -IHE-, que lleva realizándose desde 2011, y en el año 2016 se realizó en la ciudad de San Francisco en Estados Unidos (Henderson \& Yeow, 2012; IHE, 2016; S. Taylor \& Procter, 2014; Whalley et al., 2014).

De manera complementaria a los elementos descritos anteriormente, se ha definido la utilización de una aplicación nativa ( $a p p$ ) para tabletas, respecto otro tipo de desarrollo, como son la implementación de un servicio web para dispositivos móviles

\footnotetext{
${ }^{73}$ Apple ha vendido 1,1 mil millones de dispositivos con iOS desde el año 2013, no incluyendo iPod Touch (Niu, 2015).
} 
(.htm). Las razones de esta elección quedan establecidas por Summerfield (2012) y Han Rebekah Wong (2012):

- En la actualidad existe una mayor preferencia de los usuarios por aplicaciones nativas hechas para dispositivos móviles que sitios web de contenidos adaptados.

- Las aplicaciones generan una mejor experiencia de usuario respecto a sitios web.

- El hardware de los dispositivos móviles se adapta mejor a los recursos utilizados por las aplicaciones en la implementación del software respectivo (por ejemplo, la posibilidad de escalar imágenes y de contenidos gráficos particulares).

- La interacción que se logra con una aplicación nativa es más natural para el usuario respecto a los sitios web.

- Las aplicaciones móviles permiten usar elementos propios del sistema operativo móvil y del dispositivo (GPS, cámara, sensores), además de los datos internos existentes (agenda, calendario, entre otros).

- Es posible compartir la información que se obtiene del dispositivo móvil con otras aplicaciones nativas presentes (agendas, redes sociales, aplicaciones de edición, etc.).

- La utilización de una aplicación nativa no necesariamente requiere de una conexión de datos a Internet.

- Su incorporación en tiendas virtuales (Apple Store, Google Store) permite, directamente, su fácil masificación, e indirectamente, su constante evaluación por una comunidad de usuarios quienes califican según su percepción, la calidad de la aplicación.

También existen desventajas que han sido consideradas dentro de este contexto de investigación, las cuales ha sido valoradas para garantizar el correcto resultado de los objetivos propuestos. Entre las desventajas principales se encuentran: 
- El desarrollo propio del software, el cual incluye la implementación de lenguajes particulares para cada herramienta y dispositivo, las constantes actualizaciones de software (de iOS 5.0 a iOS 9.3 y de lenguajes de programación como Objective-C y Swift).

- Limitaciones en torno a la variedad de dispositivos existentes en el mercado, en donde cada tipo de hardware y su respectivo sistema operativo requieren de desarrollos informáticos particulares. En esta investigación, la implementación de los recursos educativos se encuentra dirigido al ámbito de tabletas con sistema operativo iOS (ver 4.4.3).

- El tiempo y costo de desarrollo. A diferencia de una aplicación web, los costos y tiempos de implementación pueden ser mayores debido a la diferencias de plataformas y la organización de los contenidos.

Estas posibles debilidades fueron abordadas dentro del marco de la investigación, resolviéndolas en función de los resultados de otras experiencias estudiadas y evaluando las condiciones técnicas y materiales para la aplicación de las pruebas empíricas que se realizarían posteriormente en un contexto educativo.

\subsubsection{Análisis de requisitos o especificación de requisitos de software}

Ya determinados los objetivos generales que se quieren implementar en la aplicación móvil, se procedió a la especificación particular de los requisitos de software, haciendo un análisis de las opciones que existen en la actualidad en materia de RA y mapas (navegación). Como se pudo visualizar en los capítulos anteriores, para ambas herramientas existen un conjunto de utilidades, características y formas de despliegue de la información, que se adaptan a ecosistemas informáticos particulares. Es así que dentro de este análisis se tuvieron en cuenta diferentes aspectos de los SDK sobre RA y mapas, particularmente dentro de un contexto iOS con el fin de obtener las herramientas adecuadas para el desarrollo e implementación de la aplicación propuestas (Tabla 4.774).

\footnotetext{
${ }^{74}$ La tabla completa se hallará en el Anexo 03
} 
Tabla 4.7 Comparación de SDK de Realidad Aumentada

\begin{tabular}{|c|c|c|c|c|c|c|c|c|c|c|}
\hline $\begin{array}{l}z \\
\text { z } \\
3 \\
\frac{0}{0}\end{array}$ & $\begin{array}{l}\text { 굼 } \\
0 \\
\text { 음 } \\
\overline{\bar{n}} \\
\frac{\Phi}{2} \\
\frac{0}{0}\end{array}$ & 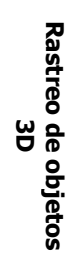 & 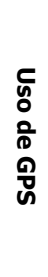 & 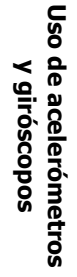 & 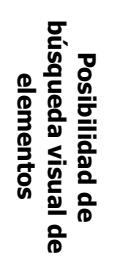 & 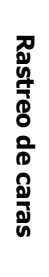 & 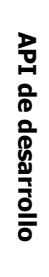 & 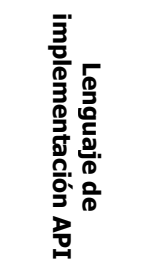 & 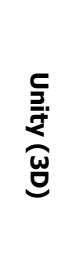 & 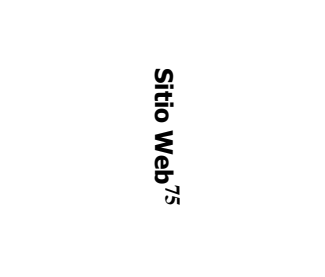 \\
\hline ARLab & $\begin{array}{l}\text { Gratuito + Con } \\
\text { opción SDK } \\
\text { comercial }\end{array}$ & & Sí & Sí & Sí & Sí & & Objective-C & & http://www.arlab.com \\
\hline ARmedia & $\begin{array}{l}\text { Gratuito + Con } \\
\text { opción SDK } \\
\text { comercial }\end{array}$ & Sí & Sí & Sí & & No & & Objective-C & Sí & $\begin{array}{l}\text { http://www.inglobetechnolog } \\
\text { ies.com }\end{array}$ \\
\hline ARToolkit & $\begin{array}{l}\text { Gratuito + Con } \\
\text { opción SDK } \\
\text { comercial }\end{array}$ & & & & & & & $\begin{array}{l}\text { Objective- } \\
\text { C/Swift }\end{array}$ & & http://artoolkit.org \\
\hline $\begin{array}{l}\text { Augmented } \\
\text { Pixels }\end{array}$ & $\begin{array}{l}\text { Gratuito + Con } \\
\text { opción SDK } \\
\text { comercial }\end{array}$ & & & & & & & Objective-C & & http://augmentedpixels.com \\
\hline Aurasma & $\begin{array}{l}\text { Gratuito + Con } \\
\text { opción SDK } \\
\text { comercial }\end{array}$ & & & & Sí & & & Objective-C & & http://www.aurasma.com \\
\hline Catchoom & $\begin{array}{l}\text { Gratuito + Con } \\
\text { opción SDK } \\
\text { comercial }\end{array}$ & & & & Sí & & Sí & Objective-C & Sí & http://www.catchoom.com \\
\hline D'Fusion & $\begin{array}{l}\text { Sólo con SDK } \\
\text { comercial }\end{array}$ & & Sí & Sí & Sí & Sí & & Objective-C & Sí & $\begin{array}{l}\text { http://www.t- } \\
\text { immersion.com/products/dfu } \\
\text { sion-suite }\end{array}$ \\
\hline $\begin{array}{c}\text { Kudan AR } \\
\text { Engine }\end{array}$ & $\begin{array}{l}\text { Gratuito + Con } \\
\text { opción SDK } \\
\text { comercial }\end{array}$ & Sí & Sí & Sí & Sí & Sí & & Objective-C & $\begin{array}{c}\text { Sí } \\
\text { con } \\
\text { SLAM }\end{array}$ & http://www.kudan.eu \\
\hline $\begin{array}{l}\text { MAXST AR } \\
\text { SDK } 2.0\end{array}$ & $\begin{array}{l}\text { Gratuito + Con } \\
\text { opción SDK } \\
\text { comercial }\end{array}$ & & & & & & & Objective-C & Sí & http://www.maxst.com \\
\hline Metaio & $\begin{array}{l}\text { Gratuito + Con } \\
\text { opción SDK } \\
\text { comercial }\end{array}$ & Sí & Sí & Sí & Sí & Sí & Sí & Objective-C & Sí & http://www.metaio.com \\
\hline Mixare & Código abierto & & Sí & & & & & Objective-C & & http://www.mixare.org \\
\hline $\begin{array}{l}\text { Obvious } \\
\text { Engine }\end{array}$ & $\begin{array}{l}\text { Sólo con SDK } \\
\text { comercial }\end{array}$ & & & & & & & Objective-C & Sí & $\begin{array}{l}\text { http://www.obviousengine.c } \\
\text { om }\end{array}$ \\
\hline PanicAR & $\begin{array}{l}\text { Gratuito + } \\
\text { Con opción } \\
\text { SDK } \\
\text { comercial }\end{array}$ & & Sí & Sí & & & & Objective-C & & http://www.dopanic.com \\
\hline $\begin{array}{l}\text { PRAugmente } \\
\text { dReality }\end{array}$ & $\begin{array}{l}\text { Código } \\
\text { abierto }\end{array}$ & & & & & & & Objective-C & & $\begin{array}{l}\text { https://github.com/promet } \\
\text { /PRAugmentedReality }\end{array}$ \\
\hline Robocortex & $\begin{array}{l}\text { Gratuito + } \\
\text { Con opción }\end{array}$ & Sí & & Sí & Sí & & & Objective-C & Sí & $\begin{array}{l}\text { http://www.robocortex.co } \\
\text { m }\end{array}$ \\
\hline
\end{tabular}

${ }^{75}$ Consultados el día 17 de febrero de 2016 y anteriormente el 14 de abril de 2014. 


\begin{tabular}{|c|c|c|c|c|c|c|c|c|c|c|}
\hline & $\begin{array}{l}\text { SDK } \\
\text { comercial }\end{array}$ & & & & & & & & & \\
\hline String & $\begin{array}{l}\text { Gratuito + } \\
\text { Con opción } \\
\text { SDK } \\
\text { comercial }\end{array}$ & & & & & & & Objective-C & Sí & $\begin{array}{l}\text { http://www.poweredbystri } \\
\text { ng.com }\end{array}$ \\
\hline UART & $\begin{array}{l}\text { Código } \\
\text { abierto }\end{array}$ & & & & & & & Objective-C & & http://www.gatech.edu \\
\hline Viewdle & $\begin{array}{l}\text { Sólo con SDK } \\
\text { comercial }\end{array}$ & & & & & Sí & & Objective-C & & http://www.viewdle.com \\
\hline Vuforia & $\begin{array}{l}\text { Gratuito + } \\
\text { Con opción } \\
\text { SDK } \\
\text { comercial }\end{array}$ & Sí & No & Sí & Sí & No & Sí & Objective-C & Sí & http://www.vuforia.com \\
\hline Wikitude & $\begin{array}{l}\text { Gratuito + } \\
\text { Con opción } \\
\text { SDK } \\
\text { comercial }\end{array}$ & Sí & Sí & Sí & Sí & & Sí & Objective-C & & http://www.wikitude.com \\
\hline Xloudia & $\begin{array}{l}\text { Sólo con SDK } \\
\text { comercial }\end{array}$ & Sí & Sí & Sí & Sí & Sí & Sí & Objective-C & Sí & http://www.xloudia.com \\
\hline $\begin{array}{l}\text { xpose visual } \\
\text { search }\end{array}$ & $\begin{array}{l}\text { Sólo con SDK } \\
\text { comercial }\end{array}$ & & & & Sí & & Sí & Objective-C & & http://www.buzzar.net \\
\hline yvision & $\begin{array}{l}\text { Gratuito + } \\
\text { Con opción } \\
\text { SDK } \\
\text { comercial }\end{array}$ & & & & & & Sí & Objective-C & & http://www.yvision.com \\
\hline $\begin{array}{l}\text { Zenitum } \\
\text { Feature } \\
\text { Tracker }\end{array}$ & $\begin{array}{l}\text { Sólo con SDK } \\
\text { comercial }\end{array}$ & & Sí & & & & & Objective-C & & http://www.zenitum.com \\
\hline
\end{tabular}

Fuente: Elaboración propia tomando como base datos de Davis (2016).

La cantidad de SDK existentes en torno a lo que RA se refiere, es un indicador de que son una industria con un desarrollo intensivo, pero que a su vez, al no existir implementaciones nativas para iOS o Android, la implementación óptima de esta herramienta en la aplicación se encuentre supeditada a condiciones exteriores de desarrollo. Debido a la estructura de los contenidos que se presentan en la aplicación, el SDK que mejor se adaptaba a los requisitos para el proyecto era el ofrecido por Metaio76, que cual presentaba un marco de desarrollo en RA consistente en diferentes componentes

${ }^{76}$ La empresa fue comprada por Apple Inc. durante el mes de mayo de 2015, cesando sus servicios el 20 de diciembre de 2015. Esta noticia se entendió en los mercados como la adquisición de la mejor compañía de RA existente en el mercado debido a la elevada calidad de implementaciones informáticas que realizaba Metaio.- Consiguientemente, cabe la posibilidad que a medio plazo Apple implemente su propia biblioteca de RA dentro de lo que es el desarrollo y mejoramiento de iOS (CNNExpansion, 2015; Miller \& Constine, 2015). En el contexto particular de la tesis, esto significó que durante los primeros meses de 2016 se haya utilizado, de manera provisional, Wikitude como software de RA hasta la incorporación definitiva de una biblioteca propia por parte de Apple. Como es habitual, Apple mantiene un silencio sepulcral al respecto (Mayo de 2016). 
de despliegue y visualización en renderizado, captura y rastreo de información visual (Amin \& Govilkar, 2015). Cada elemento de la implementación se desarrolla de manera encapsulada y las diferentes funcionalidades se utilizan mediante la una API, en que es posible utilizar modelos virtuales desarrollados con SketchUp Pro 2015 y Blender 2.73 (formato de intercambio .dae). Estos modelos fueron implementados posteriormente en el entorno de desarrollo para iOS. Otras características influyeron en la en la elección de Metaio son (Figura 4.12 y Figura 4.13):

a) Entrega un alto nivel de abstracción inicial en la generación de los recursos en RA, lo que permite al desarrollador asumir las implementaciones desde un bajo nivel, permitiendo el diseño y el desarrollo de módulos con mayor facilidad y eficiencia con una rápida adecuación a los entornos nativos de Apple.

b) La presencia de un potente motor de renderizado 3D y seguimiento de objetos permitiendo el desarrollo de aplicaciones y módulos que pueden ser ejecutadas en una diversidad de dispositivos móviles y fijos.

c) De forma nativa ofrece soporte para su estructura de archivos (.obj, . $f b x$, modelos .md2) y también para archivos de intercambio 3D (.dae), permitiendo una mayor flexibilidad en el desarrollo de las aplicaciones y módulos.

De esta manera fue posible la implementación de los modelos de RA tanto en un contexto de movilidad presentes en las tabletas con la aplicación creada, y de forma paralela, en una situación de estacionalidad (PC de escritorio) para la aplicación de la sección empírica de la investigación -este escenario establecido como grupo control-, entregando las mismas condiciones de implementación de los recursos en este tipo de módulo informático, y permitiendo su posterior comparación y análisis, elementos que tratan detalladamente en la Sección 4.5. 
Figura 4.12 Modelo de RA Palacio de la Moneda, Santiago de Chile

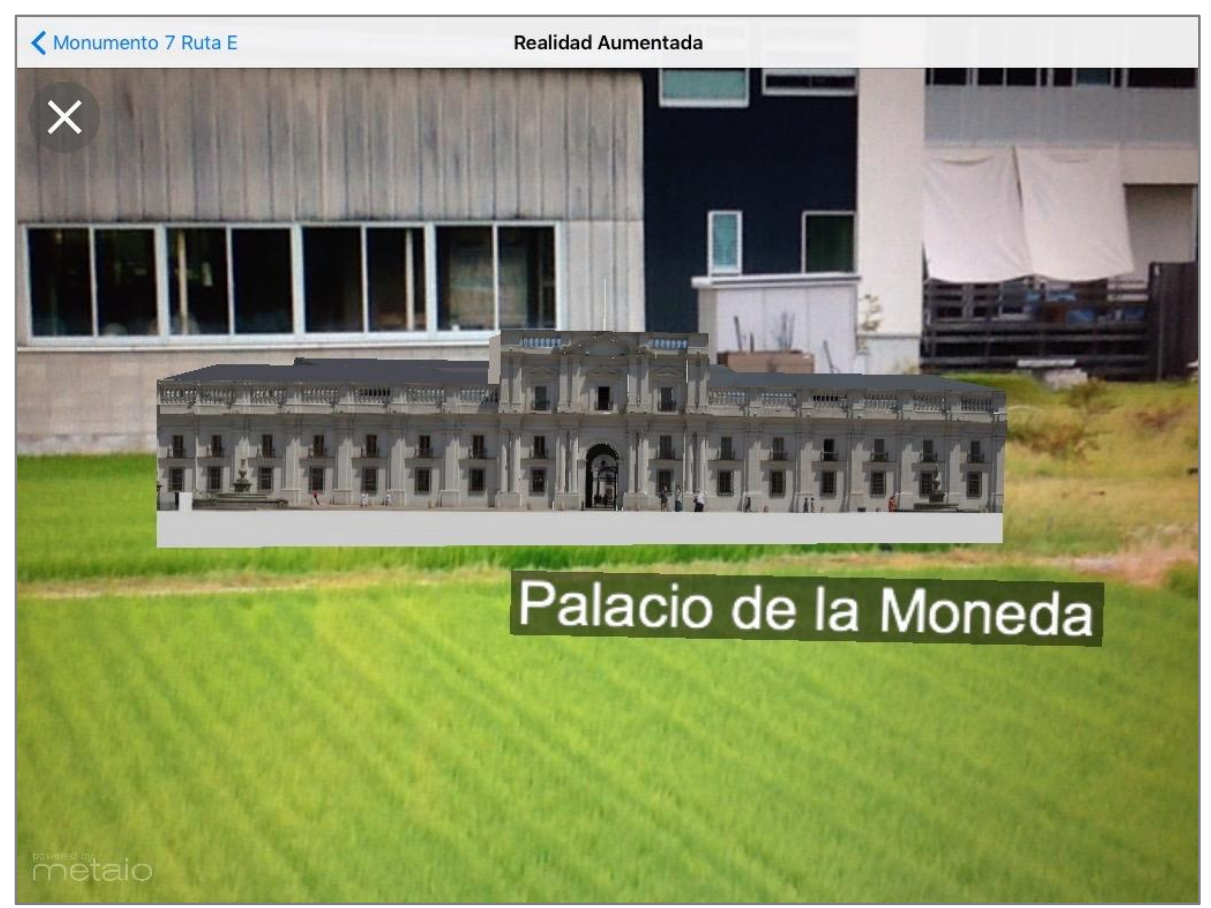

Fuente: Elaboración propia

Figura 4.13 Modelo en RA Catedral Nueva de Salamanca

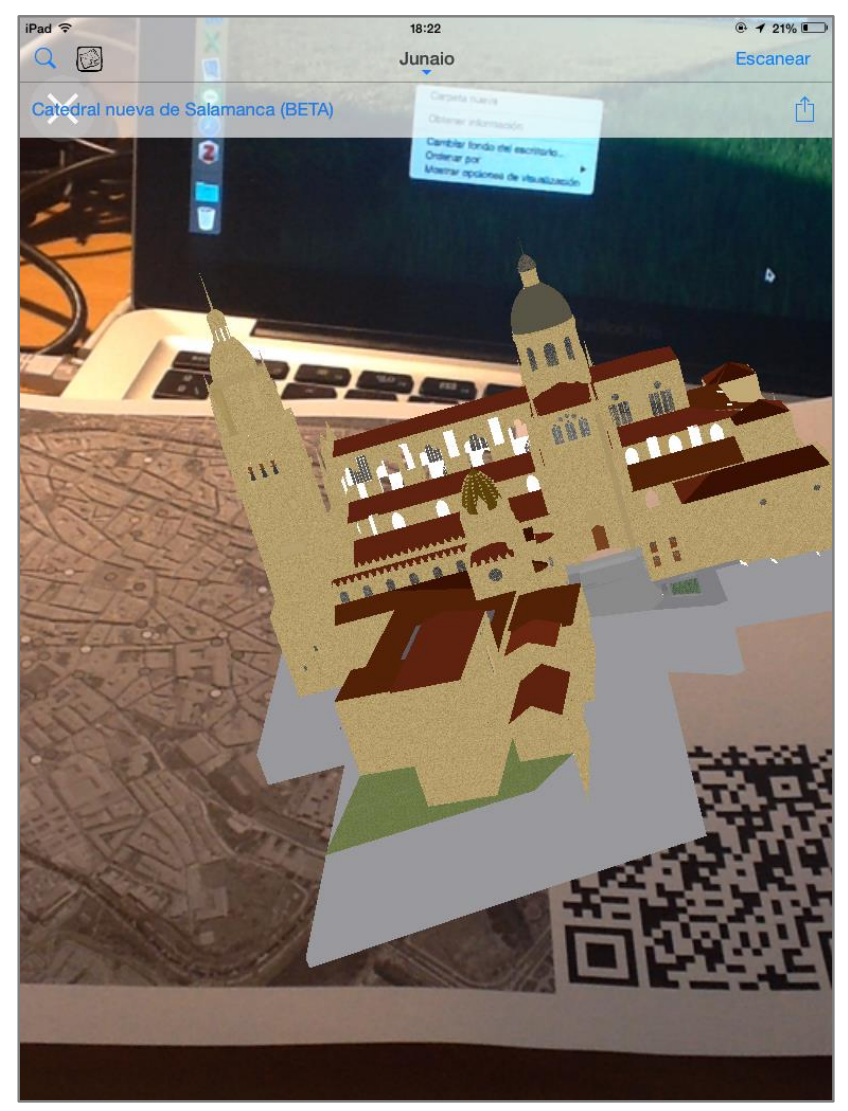

Fuente: Elaboración propia 
En el ámbito de la cartografía móvil (y con ello la navegación peatonal), se hizo necesaria la implementación de un módulo de representación territorial para su incorporación en la aplicación móvil que pudiera adecuarse a los contenidos planteados, las estructuras de información utilizadas, facilidad en su implementación y que permitiera la correcta visualización de los usuarios en un contexto de movilidad. Como se estableció en el Capítulo 2 de la investigación, la información con características territoriales toma una especial énfasis en el desarrollo de la web 2.0 y 3.0, y particularmente en su implementación en contextos móviles, los cuales tienen, en esencia, la localización y lo situado como ventajas comparativas a tecnologías equivalentes y fijas (Shekhar et al., 2016). De esta manera, existen en la actualidad una importante cantidad de desarrollos informáticos relacionados con la representación territorial -Web Map Service (WMS)-, los cuales tienen diferentes características y elementos: desde sus opciones de implementación, hasta la tipología de los datos, pasando por la licencia de los datos, y los niveles de actualización, por mencionar algunos (Tabla 4.8).

Tabla 4.8 Comparación de servicios de mapas en línea77

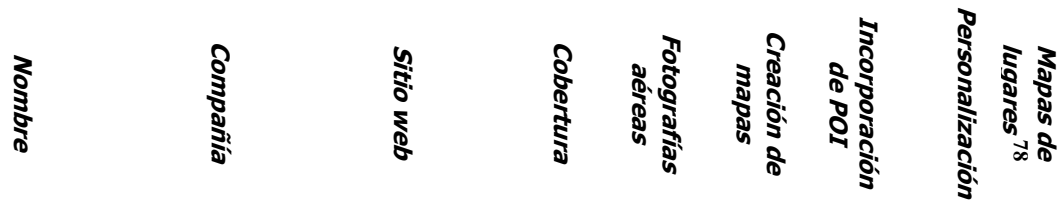

\begin{tabular}{|l|l|l|l|l|l|l|l|l|l|l|}
\hline $\begin{array}{l}\text { Bing Maps } \\
\text { (antes Nokia } \\
\text { Here) }\end{array}$ & Microsoft & $\begin{array}{l}\text { http://www.bin } \\
\text { g.com/maps/ }\end{array}$ & Global & Sí & No & Sí & No & $\begin{array}{l}\text { Sí AJAX. WPF, WP, Android, } \\
\text { Sís, Silverlight, REST, SOAP, } \\
\text { Windows (.NET, JS) }\end{array}$ \\
\hline Google Maps & Google & $\begin{array}{l}\text { http://maps.go } \\
\text { ogle.com }\end{array}$ & Global & Sí & Sí & Sí & Sí & Sí Web (Javascript), iOS SDK, \\
Android SDK
\end{tabular}

Fuente: Elaboración propia.

\footnotetext{
${ }^{77}$ La tabla completa se hallará en el Anexo 04.

${ }^{78}$ Estadios, centros comerciales, campus universitarios, etc.
} 
A pesar que Google Maps es la aplicación y servicio WMS más popular de este tipo (Marc, 2014; C. Smith, 2013), se evaluaron otras alternativas que pudieran adaptarse mejor al desarrollo y la implementación de este tipo de información en la aplicación. De esta manera los elementos considerados fueron de carácter operativo estableciendo los siguientes parámetros de apreciación:

- OpenStreetMap es el único servicio de los analizados que tiene una licencia Abierta de Bases de Datos (también conocida como ODbL), lo que permite su libre distribución y uso. Sin embargo las funcionalidades de navegación y tracking no se encuentra disponibles para dispositivos móviles (Open Street Map, 2016).

- Particularmente, Google Maps y Apple Maps guardan en la memoria caché de los dispositivos la información territorial que se haya examinado con anterioridad, lo que permite el ahorro de los datos desde el traspaso desde los servidores correspondientes (uso de red).

- En términos de precisión de datos de localización, interface de usuario (GUI) y experiencia de uso, instrucciones y modos de navegación, tanto los servicios de Google como de Apple, mantienen WMS con una alta calidad y prestación, no existiendo diferencias significativas en su utilización (Stobbing, 2015).

- En torno a su implementación en aplicaciones iOS, Apple Maps al ser un framework nativo, permite su fácil incorporación en un contexto de desarrollo, tanto en lenguajes como Swift o Objective- $C$, facilitando la interoperabilidad de los datos dentro del contexto móvil, adecuándose con facilidad a la estructura del hardware utilizado. Además, el servicio Apple Maps no se encuentra limitado por elementos operativos especiales como el requisito de claves de desarrollo ( $A P I$ keys, servers key o credenciales especiales) o la restricción al número de consultas diarias que permite el servicio de datos a sus servidores WMS.

De esta manera, se eligió Apple Maps debido a su interoperabilidad con otros frameworks a utilizar en el sistema (de manera específica con el framework CoreLocation), la posibilidad de implementación y recopilación de datos espaciales y la experiencia e 
interfaz de usuario de altas prestaciones, las cuales permiten una configuración adecuada para el contexto que educativo que se desarrolló la etapa empírica de la investigación ${ }^{79}$.

\subsubsection{Diseño del software}

Para el diseño de la aplicación se utilizó el entorno de desarrollo integrado (IDE por sus siglas en inglés) Xcode a través de los lenguajes Objetive- ${ }^{80}$ y Swift ${ }^{81}$, complementado con la implementación de los frameworks respectivos para la generación del software en un ambiente móvil iOS (Allan, 2012; Bennett et al., 2010; Hillegass, 2011; Hillegass \& Conway, 2013; Hollemans, 2015; Mathias \& Gallagher, 2015). Los frameworks específicos utilizados para la elaboración de la aplicación son los que se muestran a continuación (Tabla 4.9):

Tabla 4.9 Frameworks para la implementación de la aplicación NPM-RA

\begin{tabular}{|l|l|l|} 
Nombre & Descripción & Implementación \\
\hline UIKit & $\begin{array}{l}\text { Colección de clases orientada al despliegue } \\
\text { de la interfaz gráfica de usuario que se } \\
\text { utiliza en iOS. }\end{array}$ & $\begin{array}{l}\text { Escenas, tablas, transiciones y } \\
\text { bibliotecas de objetos en } \\
\text { general. }\end{array}$ \\
\hline MapKit & $\begin{array}{l}\text { Entrega una interface para la incorporación } \\
\text { de mapas directamente en la aplicación. }\end{array}$ & $\begin{array}{l}\text { Mapas incrustados, puntos de } \\
\text { interés y superposición de las } \\
\text { regiones de interés. }\end{array}$ \\
\hline CoreLocation & $\begin{array}{l}\text { Determina la localización del dispositivo, } \\
\text { utilizando los elementos de hardware } \\
\text { incorporados. }\end{array}$ & $\begin{array}{l}\text { Localización y rumbo de } \\
\text { actividad. }\end{array}$ \\
\hline Metaio SDK & Despliegue de elementos de RA. & $\begin{array}{l}\text { Escenas de RA con los } \\
\text { modelos de los edificios } \\
\text { patrimoniales. }\end{array}$ \\
\hline
\end{tabular}

Fuente: Elaboración propia.

De esta manera, la aplicación NPM-RA fue implementada en función de la extensión territorial definida en cada área de estudio y las características de la información

\footnotetext{
79 Se planteó la posibilidad de generar un servicio WMS propio con las áreas de estudio, mediante la implementación de software libre como MapServer (http://mapserver.org) o Spot (http://freecode.com/projects/spot/) con datos alojados para su consulta. Sin embargo, debido a los lineamientos de la investigación y las funcionalidades en mapas requeridas se decidió por Apple Maps como componente espacial de la aplicación. En este caso, se quería evitar el pernicioso síndrome NIH ( not invented here).

80 Objective- $C$ corresponde a un lenguaje orientada a objetos. Contiene un conjunto de extensiones del lenguaje C derivadas de Smalltalk uno de los primero lenguajes orientados a objetos (Apple Inc., 2009).

${ }^{81}$ Swift es un lenguaje de programación multiparadigma que fue presentado el año 2014 por Apple y que corresponde a la unión de lo mejor de $\mathrm{C}$ y Objective-C, sin las restricciones de compatibilidad presentes en C (Apple Inc., 2014).
} 
patrimonial utilizada (Tabla 4.3), considerándose los factores obtenidos en el análisis espacial de la fase anterior, la interacción con otros elementos dentro del delimitación previamente definida y los objetivos pedagógicos perseguidos. Con lo anterior, se generó una propuesta de navegación que guía al alumno en el proceso educativo en torno a la temática patrimonial de Salamanca y Santiago de Chile. Así en la aplicación se implementa:

- Una visión territorial general de la ruta propuesta, que se visualiza en un mapa digital (MapKit en un entorno iOS-iPad).

- Una adaptación automática de la visión territorial dependiente de la posición del dispositivo (MapKity CoreLocation).

- La posibilidad de generación de diversas escalas de representación espacial según los requisitos del usuario (MapKit).

- La posibilidad de la visualización y consulta de otros fenómenos urbanos representados (Cocoa Touch y Metaio).

Dichas implementaciones podrían tener consecuencias en la comprensión de la información espacial por parte de los alumnos y con ello, en la forma que se desarrolla el proceso aprendizaje en el ámbito de la navegación y la contextualización territorial de los fenómenos con la mediación de tecnología móvil, elementos que serán comprobados mediante los pasos metodológicos presentados en la sección 4.5.

La interfaz de la aplicación muestra la información de geolocalización de los datos de patrimonio definidos, así como la ubicación del dispositivo (CoreLocation). Se obtiene información general en el servidor de Apple Maps (MapKit), que luego se complementa con la información territorial patrimonial de las ciudades elegidas, previamente seleccionadas y analizadas para los fines educativos planteados. De manera complementaria, el framework de RA (Metaio) presenta los recursos realizados para la plataforma, en función de los datos de localización y los puntos de interés previamente definidos. Dichos contenidos corresponden a los modelos 3D y recursos multimedia de cada inmueble patrimonial, siendo la estructura de la aplicación lo que se presenta en la Figura 4.14. 
Figura 4.14 Diagrama de la aplicación móvil en donde se despliegan el Sistema de Navegación Peatonal, Realidad Aumentada y la información almacenada

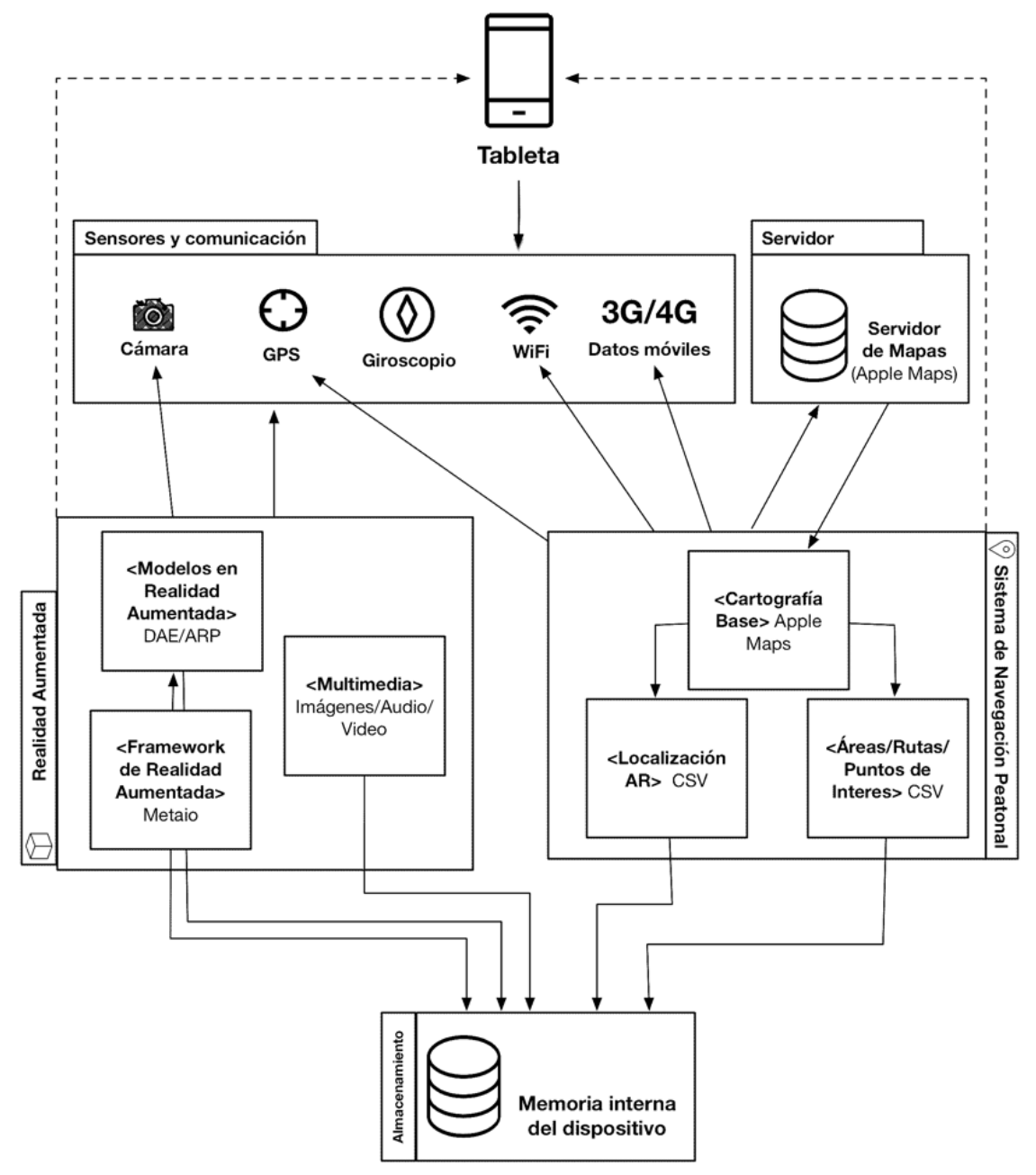

Fuente: Elaboración propia.

La aplicación se basa en una arquitectura que está orientada a la encapsulación y la herencia del código, determinando las fortalezas y oportunidades en un ambiente altamente dinámico y cambiante (Cox \& Novobilski, 1993). Para la escritura de datos primarios territoriales obtenidos durante la experiencia (localización y rumbo en el desplazamiento del usuario), el principal instrumento utilizado corresponde al software creado, el cual ha generado un archivo de registro con las actividades realizadas en cada dispositivo utilizado (.log). La aplicación obtiene mediciones que se realizan en segundo plano en relación con la interfaz implementada, las consultas realizadas, la conectividad utilizada, el traspaso de datos, la localización de los usuarios y la dirección de desplazamiento. 


\subsubsection{Implementación}

En esta etapa se desarrolló el diseño del programa escrito en los lenguajes de desarrollo respectivos. Como se mencionó previamente, los lenguajes utilizados fueron, en un inicio, Objective-C para la aplicación de Santiago de Chile y Swift para el desarrollo de los contenidos de Salamanca (siendo la última implementación en su versión 2.2). Es importante mencionar que al comienzo de esta investigación, Objective- $C$ se planteaba como la lingua franca de desarrollo que Apple implementó para todos sus dispositivos y las bibliotecas de Cocoa y Cocoa Touch se encuentran ampliamente desarrolladas en dicho lenguaje, facilitando su depuración e implementación en el desarrollo del código (Hillegass, 2011; Hillegass \& Conway, 2013; Mathias \& Gallagher, 2015). De la misma manera, su compatibilidad con bibliotecas y estructuras del lenguaje $C$, hacen que el desarrollo sea expedito y claro. De manera complementaria, la aparición de Swift marca un importante hito para el desarrollo de Apple, ya que la compañía ha implementado un lenguaje seguro con el desarrollo de elementos definidos y la eliminación de código inseguro (Ejemplo de esto es la simplificación de la sintaxis y la incorporación con elementos como los opcionales); flexible en el contexto de la programación multiparadigma (Orientado a Objetos, funcional, imperativo y estructurado en bloques), dinámico y extensible que puede coexistir e interoperar con elementos de Objective-C. Presenta una licencia de software libre Apache 2.0 lo que permite generar una comunidad de contribuidores en el desarrollo del lenguaje y en la actualidad se presenta en las plataformas iOS, OS X, watchOS, tvOS. Existe también una plataforma de desarrollo de Swift para Linux (Apple Inc., 2016; Hollemans, 2015).

\subsubsection{Verificación}

Las etapas de prueba fueron ejecutadas de manera paralela durante el desarrollo del software, comprobando cada estructura por separado (interfaz en iOS, mapasnavegación, RA e información patrimonial) y posteriormente en su conjunto con el desarrollo preliminar de una beta de prueba. Con esta versión de la aplicación y con el fin de alcanzar los objetivos propuestos en el ámbito empírico de la investigación con el trabajo de campo, se procedió a realizar las pruebas respectivas, teniendo énfasis en tres aspectos particulares: 
a) En lo referido al acceso a datos de Internet (conectividad): A pesar que la mayor parte de la información (multimedia, modelos de RA) forma parte de la aplicación desarrollada, algunos elementos como los mapas requieren conexión a datos desde Internet. La falta de disponibilidad de redes WiFi de acceso libre en las áreas de estudio llevo a la necesidad de utilizar dispositivos complementarios ${ }^{82}$-aunque en condiciones de conectividad ideales innecesarios- con el fin de lograr el acceso adecuado a datos. Utilizando medios con 3G (mediante anclaje a red o tethering) se crearon pequeños hotspots de datos para el área definida para la implementación de la actividad educativa.

b) Verificación de los niveles de precisión de las tabletas: Se consideró la verificación de los niveles de precisión métrica de los datos georreferenciados derivados del sensor GPS presentes en las tabletas. A pesar de que los iPad cuentan con tecnología $\mathrm{aGPS}^{83}$, lo que permite la mejora de los valores obtenidos de localización, existen errores en los datos derivados de diferentes fuentes como son el ruido por la distorsión en las radiofrecuencias o el efecto multitrayectoria (derivado de superficies reflectoras como edificios y zonas urbanas). De esta manera, en pruebas de campo, se han determinado márgenes de error de 15 metros en la lectura de los datos, valores que se consideran en el momento del procesamiento de la información georreferenciada.

c) Corrección de errores derivados de la visualización de datos. en los trabajos de verificación de la aplicación se puso el énfasis en el correcto despliegue de información sobre los hitos y los lugares de patrimonio, además de la funcionalidad de los recursos multimedia incorporados a la aplicación.

\footnotetext{
${ }^{82}$ Se utilizó un ordenador portátil Lenovo ThinkPad X240 con banda ancha móvil integrada (Ericsson N5321), un iPhone 4s y uno $5 c$ para la implementación del tethering. La velocidad máxima de transferencia de datos de cada equipo fue de $3 \mathrm{MB} / \mathrm{s}$, valor suficiente para dar servicio al número de iPads utilizados en la experiencia educativa.

${ }^{83}$ Assisted Global Positioning System (aGPS) es un sistema de posicionamiento global por satélite, en donde el proceso inicial de descarga de información de localización, denominado primer posicionamiento o posicionamiento inicial (tiempo para el primer posicionamiento o Time To First Fix -TTFF-), se realiza mediante el acceso a redes de celulares (GSM), Ethernet, WiFi o similares, utilizando los datos obtenidos de un servidor externo y lo combinará con la información de la celda o antena de telefonía móvil para conocer la posición y saber qué satélites están situados sobre el dispositivo (Rubino, 2009).
} 


\subsubsection{Mantenimiento}

En informática, el momento del mantenimiento llega cuando el software se ha completado y puede ser distribuido entre los usuarios (Joyanes Aguilar, 2008). Para el caso de esta aplicación, el mantenimiento se encontrará referido a dos importantes secciones: mantenimiento programado y las acciones debidas a errores imprevistos.

- Mantenimiento programado: se han realizado las adaptaciones respectivas derivadas de cada nueva actualización de sistema operativo (la aplicación comenzó a desarrollarse en una versión iOS 5.1 basadas en .XIB hasta a la actual 9.2.1 estructurada en storyboards ${ }^{84}$ ), implementando métodos depurados y corrigiendo los métodos desaconsejados para cada versión de software. Desde este ámbito el próximo mantenimiento programado se establece para el mes de octubre de 2016 con el presencia de iOS 10.0 y Swift 3.0.

- Errores imprevistos: la aplicación cuenta con un registro de eventos de funcionamiento que dirige la información a un archivo .log, el cual informa de los errores y fallos que existen derivados de su funcionamiento. A diferencia del mantenimiento programado, este tipo de correcciones se realiza en el momento en que se detecta algún inconveniente dentro del desarrollo creado.

\subsection{Marco metodológico de la experiencia educativa: fase cuantitativa}

\subsubsection{Diseño de la investigación. Estudio Experimental}

El estudio empírico de la presente tesis se enmarca dentro de un proceso metodológico de corte mixto, en la que su sección cuantitativa presenta un diseño de tipo cuasiexperimental (D. T. Campbell \& Stanley, 1973, 1993; Hernández et al., 2010) en donde se aplica un instrumento (prueba de alternativas) en un contexto de pre-test y post-test a un 'grupo experimental' (tratamiento de aplicación móvil) y a un 'grupo control' (tratamiento con ordenador de escritorio). Así, la variable dependiente -nivel de

\footnotetext{
${ }^{84}$ Un .XIB es un archivo XML de Interface Builder de Xcode que permite especificar los componentes propios de una vista para una aplicación iOS. Por otro lado un storyboard es esencialmente un único archivo que permite el desarrollo de todas las escenas que se implementarán en una aplicación de iOS. El uso de Storyboards, más novedoso, puede suponer notables mejoras en el desarrollo de la aplicación.
} 
aprendizaje- se mide antes y después de realizar la intervención educativa (tratamiento) con las tabletas y ordenadores, respectivamente a dos grupos de alumnos de educación formal (Tabla 4.10), con el fin de medir sus niveles de aprendizaje derivados por el tratamiento realizado (Figura 4.15).

Tabla 4.10 Diseño cuasiexperimental pre-test/post-test con grupo experimental (Aplicación móvil) y grupo control (Ordenador de escritorio)

\begin{tabular}{|c|c|c|c|}
\hline Sujetos & Pre-test & Tratamiento & Post-test \\
\hline $\begin{array}{c}\text { Alumnos de Chile } \\
\text { (Santiago) }\end{array}$ & $\sqrt{ } \sqrt{ }$ & Aplicación móvil & $\sqrt{ }$ \\
\cline { 2 - 4 } & $\sqrt{ } \sqrt{ }$ & Ordenador de Escritorio & $\sqrt{ }$ \\
\hline $\begin{array}{c}\text { Alumnos de España } \\
\text { (Salamanca) }\end{array}$ & $\sqrt{ } \sqrt{ }$ & Aplicación móvil & $\sqrt{ }$ \\
\cline { 2 - 4 } & $\sqrt{ } \sqrt{ }$ & Ordenador de Escritorio & $\sqrt{ }$ \\
\hline
\end{tabular}

Fuente: elaboración propia. 
Figura 4.15 Estructura de la sección cuantitativa de la investigación

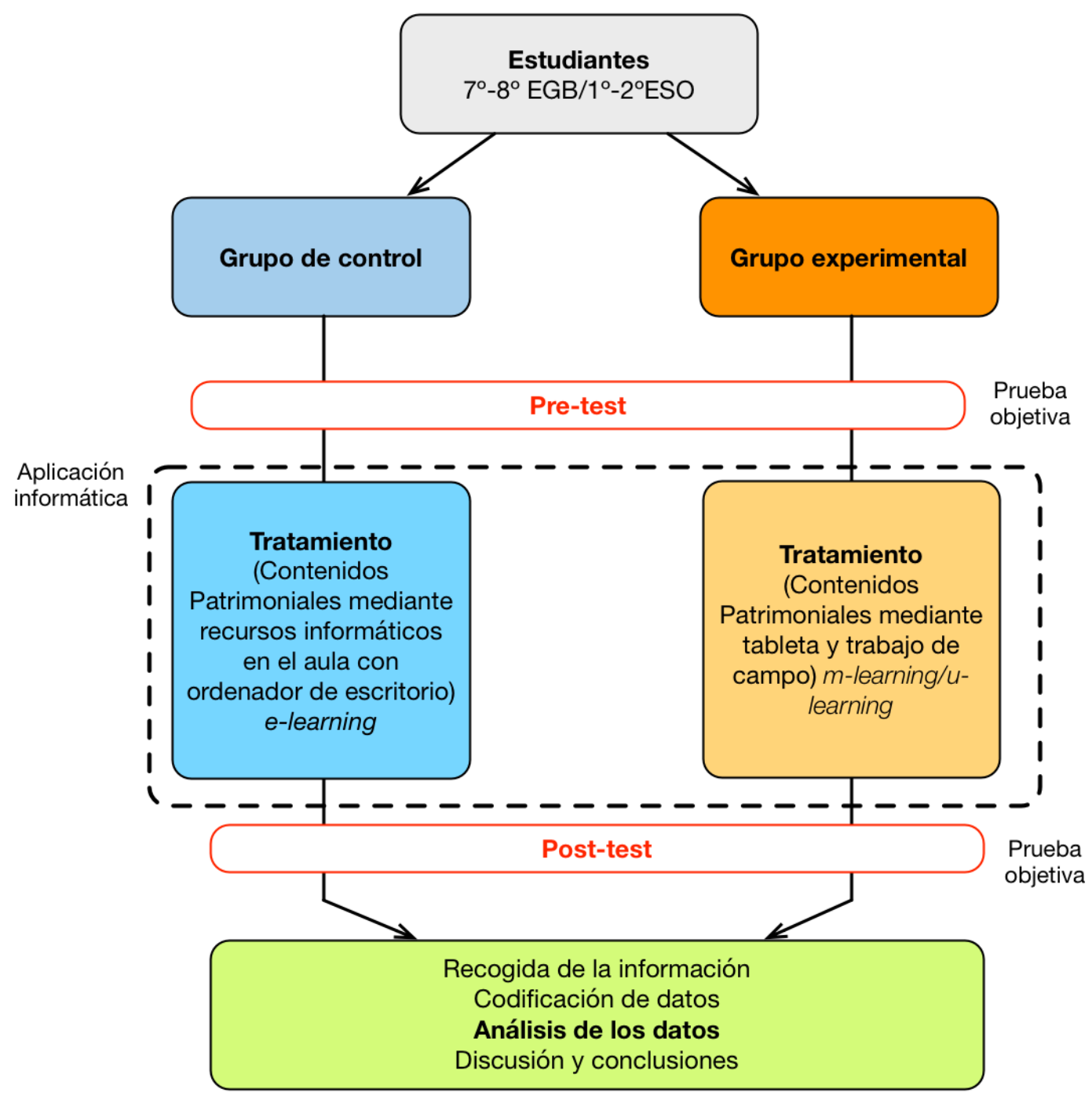

Fuente: elaboración propia.

\subsubsection{Variables e instrumentos}

Debido a la naturaleza propia de la investigación, $y$, en lo referido particularmente a esta etapa de desarrollo en donde se intenta realizar una comprobación empírica del fenómeno m-learning ( $\mathrm{y}$ que tiende hacia el u-learning) en un contexto real de aprendizaje, se hace mención a las variables participantes en el planteamiento de la hipótesis general y que definen posteriormente los métodos aplicados. Al ser una sección de características cuasiexperimentales, se espera que las variables extrañas que pudieran sesgar los resultados se aleatoricen debido a al tipo de muestra utilizada (Martínez Abad, 2013). Se podrían identificar las siguientes variables: 
- Debidas al sujeto participante -alumnos-: la existencia de conocimientos previos sobre el patrimonio en la ciudad, inteligencia general, motivación en la actividad. Debido a la estructura de la muestra, se espera que estas variables extrañas estén distribuidas de manera aleatoria.

- Debidas al dispositivo y la aplicación: estructura de la aplicación, contenidos referenciales, recursos, composición de la interfaz gráfica de usuario, desempeño de hardware. Para cada experiencia educativa ( $m$-learning/u-learning o elearning), los contenidos, recursos y la estructura general de los softwares son los mismos, solo diferenciándose en la utilización del hardware (iPad frente a ordenador de escritorio) y la presencia/ausencia del sistema de navegación peatonal.

- Definidas por el contexto: como los sujetos de la muestra corresponden a alumnos en edad escolar, las variables presentes en el contexto formativo no tienen impacto ya que se encuentra en un ambiente educativo formal el cual presenta estándares y condiciones que son similares para todos los participantes, particularmente en los referidos al grupo de comparación. De la misma manera se sitúan otras variables como el tipo de aula, tipo de centro educativo, las características de los docentes que están a cargo de cada grupo, elementos que sí pueden tener impacto en las mediciones, pero que se aseguró con ciertos grados de control como, grupos del mismo centro educativo y nivel educativo o formación con el mismo docente. En este último caso todos los grupos de comparación tuvieron el mismo profesor-tutor dirigiendo el tratamiento de principio a fin de las actividades.

De esta manera, la variable independiente corresponde a la aplicación móvil o de PC de escritorio con contenidos sobre patrimonio con recursos con RA y localización, la que fue manipulada para observar su efecto sobre el variable dependiente o el nivel de aprendizaje (competencia saber) que obtienen los sujetos participantes. Esta variable dependiente es sintetizada en un instrumento del tipo prueba objetiva que intenta medir la diferencia en el nivel alcanzado en el aprendizaje de contenidos patrimoniales antes y después de la implementación de los recursos digitales propuestos. Así, la competencia 
saber corresponde a la obtención de un conjunto de conocimientos que pueden ser generales o específicos (Martínez Abad, 2013; Martínez, Navarro, \& Sánchez, 2012; Martínez Clares \& Echeverría Samanes, 2009) y que fue medida mediante la prueba tipo de 25 ítems con 4 opciones de respuesta para cada experiencia -Salamanca o Santiago de Chile- (Anexo 05). Temáticamente los contenidos del test se dividen en tres ámbitos específicos:

A. - Contexto histórico temporal: se pretende mostrar las relaciones entre el pasado y el presente, teniendo en consideración el sentido del tiempo como elemento social y cultural, mostrando sus diversas etapas, personajes relevantes y momentos significativos de una comunidad (Santisteban \& Pagès, 2011b). Lo anterior se relaciona con los siguientes ámbitos, permitiendo contextualizar temporalmente los elementos y fenómenos que se muestran para el aprendizaje.

B. - Elementos arquitectónicos y morfológicos urbanos: desde este ámbito se pretende lograr la mayor valoración de las obras arquitectónicas como un bien cultural que es necesario conocer y preservar para las actuales y futuras generaciones (Llobet, 2011). También permite visualizar la riqueza cultural en las diferentes etapas de la historia de la ciudad, permitiendo entender no solo el pasado, sino también los elementos constitutivos que se reflejan en la expresión del presente.

C.- Localización y espacialidad: desde el ámbito local de cada ciudad y ruta, se pretende lograr el aprendizaje basado en consultas, la comprensión visualespacial mediante las representaciones digitales del territorio, el contraste de la información territorial mediante las relaciones existentes y el desarrollo de habilidades de razonamiento espacial (Artvinli, 2010; Biebrach, 2007).

La tabla de especificaciones (tablas Tabla 4.11 y Tabla 4.12) se ha realizado considerando los contenidos que se presentan en la aplicación móvil y en su equivalente en entornos fijos, respecto a los objetivos que se persiguen para cada contenido. Partiendo de la taxonomía de Bloom, el instrumento medirá tres niveles de destreza básicos de los sujetos (Bloom, Hastings, \& Madaus, 1985; Churches, 2009; Rodríguez Conde, 2011):

Conocimiento (o concepto): correspondería al nivel más básico o general, en donde se recuperan, recuerdan o reconocen los contenidos que se encuentran en 
nuestra memoria. Las actividades digitales que se plantean a este nivel son el examen que se va a realizar.

Comprensión: corresponde a la construcción de los significados de los elementos y procesos de los contenidos en la experiencia de aprendizaje. Para este objetivo las actividades digitales están establecidas con la representación territorial (mapa) y los modelos de RA mediante la explicación y caracterización de éstos.

Análisis: determinar las relaciones que se establecen entre los elementos y procesos (o entre ambos), descomponiendo en el material en unidades. Las actividades digitales que se van a utilizar también son los mapas y los modelos de RA, pero teniendo en consideración cada elemento y proceso que componen una representación digital respecto a símil presente en la realidad (características, entorno, dimensiones, etc.).

Tabla 4.11 Especificaciones para el instrumento de evaluación. Experiencia de Santiago de Chile

\begin{tabular}{|c|c|c|c|c|}
\hline \multirow[b]{2}{*}{$\begin{array}{l}\text { Bloque de } \\
\text { contenidos }\end{array}$} & \multicolumn{3}{|c|}{ Procesos } & \multirow[b]{2}{*}{$\begin{array}{c}\text { Total de } \\
\text { ítems }\end{array}$} \\
\hline & $\begin{array}{c}\text { Ítems de } \\
\text { objetivos de } \\
\text { conocimiento }\end{array}$ & $\begin{array}{c}\text { Ítems de } \\
\text { objetivos de } \\
\text { comprensión }\end{array}$ & $\begin{array}{l}\text { Ítems de } \\
\text { objetivos de } \\
\text { aplicación }\end{array}$ & \\
\hline \multicolumn{5}{|c|}{ 1.- Contexto histórico-temporal } \\
\hline $\begin{array}{l}\text { 1a.- Personajes } \\
\text { y elementos } \\
\text { históricos } \\
\text { relevantes }\end{array}$ & $\begin{array}{c}2-3-13-18- \\
19-21\end{array}$ & & & $6(16,2 \%)$ \\
\hline $\begin{array}{l}\text { 1b.- Fechas } \\
\text { importantes }\end{array}$ & $\begin{array}{c}5-8-10-11- \\
18-21\end{array}$ & & & $5(13,5 \%)$ \\
\hline $\begin{array}{l}\text { 1c.- Procesos } \\
\text { sociales } \\
\text { relacionados }\end{array}$ & & 7 & & $1(2,7 \%)$ \\
\hline \multicolumn{5}{|c|}{ 2.- Elementos arquitectónicos y morfológicos urbanos } \\
\hline $\begin{array}{l}\text { 2a.- Estilos } \\
\text { arquitectónicos } \\
\text { dominantes }\end{array}$ & $\begin{array}{c}1-4-9-12- \\
17-20\end{array}$ & & & $6(16,2 \%)$ \\
\hline $\begin{array}{l}\text { 2b.- Formas y } \\
\text { estructuras }\end{array}$ & 14 & $6-23$ & 14 & $4(1,8 \%)$ \\
\hline
\end{tabular}




\begin{tabular}{|c|c|c|c|c|}
\hline $\begin{array}{l}\text { arquitectónicas - } \\
\text { urbanas }\end{array}$ & & & & \\
\hline $\begin{array}{l}\text { 2c.- Usos } \\
\text { urbanos de los } \\
\text { elementos } \\
\text { patrimoniales }\end{array}$ & $\begin{array}{c}8-9-10-16- \\
25\end{array}$ & & 7 & $6(16,2 \%)$ \\
\hline \multicolumn{5}{|c|}{ 3.- Localización y espacialidad } \\
\hline $\begin{array}{l}\text { 3a.- Sentido de } \\
\text { localización en } \\
\text { el territorio } \\
\text { mediante } \\
\text { modelamiento } \\
\text { (plano o RA) }\end{array}$ & & $23-24$ & 22 & $3(8,1 \%)$ \\
\hline $\begin{array}{l}\text { 3b.- Relación } \\
\text { espacial entre } \\
\text { elementos } \\
\text { patrimoniales }\end{array}$ & & 24 & $6-15-22$ & $4(1,8 \%)$ \\
\hline $\begin{array}{l}\text { 3c.- Magnitud } \\
\text { de los } \\
\text { fenómenos } \\
\text { patrimoniales en } \\
\text { el territorio }\end{array}$ & & & $6-14$ & $2(5,4 \%)$ \\
\hline TOTAL & $23(62,2 \%)$ & $6(16,2 \%)$ & $8(21,6 \%)$ & $37(100 \%)$ \\
\hline
\end{tabular}

Fuente: elaboración propia.

Tabla 4.12 Especificaciones para el instrumento de evaluación. Experiencia de Salamanca

\begin{tabular}{|c|c|c|c|c|}
\hline \multirow[b]{2}{*}{$\begin{array}{l}\text { Bloque de } \\
\text { contenidos }\end{array}$} & \multicolumn{3}{|c|}{ Procesos } & \multirow[b]{2}{*}{$\begin{array}{l}\text { Total de } \\
\text { ítems }\end{array}$} \\
\hline & $\begin{array}{c}\text { Ítems de } \\
\text { objetivos de } \\
\text { conocimiento }\end{array}$ & $\begin{array}{c}\text { Ítems de } \\
\text { objetivos de } \\
\text { comprensión }\end{array}$ & $\begin{array}{c}\text { Ítems de } \\
\text { objetivos de } \\
\text { aplicación }\end{array}$ & \\
\hline \multicolumn{5}{|c|}{ 1.- Contexto histórico-temporal } \\
\hline $\begin{array}{l}\text { 1a.- } \\
\text { Personajes } \\
\text { históricos } \\
\text { relevantes }\end{array}$ & $\begin{array}{c}3-6-8-9-13 \\
-19-23\end{array}$ & 6 & 7 & $9(23,1 \%)$ \\
\hline $\begin{array}{l}\text { 1b.- Fechas } \\
\text { importantes }\end{array}$ & $11-25$ & & & $2(5,1 \%)$ \\
\hline $\begin{array}{l}\text { 1c.- Procesos } \\
\text { sociales } \\
\text { relacionados }\end{array}$ & 1 & & & $1(2,5 \%)$ \\
\hline
\end{tabular}




\section{2.- Elementos arquitectónicos y morfológicos urbanos}

\begin{tabular}{|c|c|c|c|c|}
\hline $\begin{array}{l}\text { 2a.- Estilos } \\
\text { arquitectónicos } \\
\text { dominantes }\end{array}$ & $\begin{array}{c}1-12-15-17 \\
-18-22\end{array}$ & & & $6(15,4 \%)$ \\
\hline $\begin{array}{l}\text { 2b.- Formas y } \\
\text { estructuras } \\
\text { arquitectónicas } \\
\text { - urbanas }\end{array}$ & $5-6-8-9-14$ & 14 & $2-7-10$ & $9(23,1 \%)$ \\
\hline $\begin{array}{l}\text { 2c.- Usos } \\
\text { urbanos de los } \\
\text { elementos } \\
\text { patrimoniales }\end{array}$ & $16-20-21-24$ & & & $4(1,3 \%)$ \\
\hline \multicolumn{5}{|c|}{ 3.- Localización y espacialidad } \\
\hline $\begin{array}{l}\text { 3a.- Sentido } \\
\text { de localización } \\
\text { en el territorio } \\
\text { mediante } \\
\text { modelamiento } \\
\text { (plano o RA) }\end{array}$ & 7 & 4 & 4 & $3(7,7 \%)$ \\
\hline $\begin{array}{l}\text { 3b.- Relación } \\
\text { espacial entre } \\
\text { elementos } \\
\text { patrimoniales }\end{array}$ & & & 15 & $1(2,5 \%)$ \\
\hline $\begin{array}{l}\text { 3c.- Magnitud } \\
\text { de los } \\
\text { fenómenos } \\
\text { patrimoniales } \\
\text { en el territorio }\end{array}$ & & & $2-4-10-15$ & $4(1,3 \%)$ \\
\hline TOTAL & $26(66,6 \%)$ & $3(7,7 \%)$ & $10(25,6 \%)$ & $39(100 \%)$ \\
\hline
\end{tabular}

Fuente: elaboración propia.

Se aplicó un instrumento adicional a los sujetos una vez finalizada la experiencia educativa, consistente en una encuesta de satisfacción (Martín Izard, 2011) relativa al ejercicio realizado en un contexto TIC, a los materiales utilizados, a los contenidos propuestos y a sus respectivas implementaciones. Los ítems incluidos son los que pueden verse a continuación (Tabla 4.13): 
Tabla 4.13 Especificaciones para la encuesta de satisfacción

Pregunta

1. No me encuentro cómodo(a) usando la aplicación

2. La aplicación me entrega confianza en el uso de las tabletas (o PC)

3. Es fácil navegar dentro de la aplicación utilizada

4. La información desplegada en la aplicación no siempre es precisa

5. La aplicación me ha dado una positiva impresión de los contenidos sobre patrimonio

6. La aplicación me ha entregado información importante para mi aprendizaje

7. El diseño gráfico de la aplicación no es visualmente atractivo

8. Es difícil utilizar la aplicación

9. Me fue entregada información suficiente para el uso de la aplicación

10. Me gusta la información que despliega la aplicación

Fuente: Elaboración propia en base a Chen, Chou, \& Huang (2016) y Favier \& van der Schee (2012).

Los tipos de preguntas planteados tienen como posible respuesta una escala Likert con 5 niveles, que van desde el "muy de acuerdo" (5) al "muy desacuerdo" (1). La facilidad de la puntuación de estas respuestas, entregan una primera aproximación de la percepción de los participantes en torno a la aplicación y a la intervención educativa realizada, que se complementa en la sección siguiente con un análisis cualitativo.

\subsubsection{Descripción del tratamiento}

Particularmente, la presente investigación tiene dos formas de tratamiento que se diferencian en la forma que se aplican los contenidos que se quieren enseñar. Como la variable independiente son los niveles de aprendizaje, la cual se encontrará sujeta a los instrumentos (móvil -tableta- vs estacional -PC de escritorio-), las actividades y grupos se definieron en dos grandes escenarios de intervención educativa: utilización de tabletas en el trabajo de campo ( $m$-learning y u-learning); y utilización de ordenadores con enseñanza tradicional (e-learning). 
Ambos escenarios fueron aplicados para las muestras de los distintos países, con los mismos métodos e instrumentos, teniendo sólo como variación los contenidos patrimoniales los cuales se encontraban en función del contexto local en donde se desarrolló la actividad. De esta manera los tratamientos fueron:

\subsubsection{Utilización de tablets en el trabajo de campo (m-learning/u-}

\section{learning).}

- Título. Santiago Patrimonial y Salamanca Patrimonial

- Fechas. La intervención educativa se desarrolló en los días 4 y 7 de agosto de 2015 para el caso de Santiago de Chile y el 14 de marzo de 2016 para el caso de Salamanca en España.

- Duración. Cada intervención educativa tuvo una duración de alrededor de 4 horas, condicionada por el desplazamiento de los alumnos entre los hitos patrimoniales de cada experiencia educativa realizada.

- Modalidad. Se realizó el trabajo de campo correspondiente a las zonas E (Santiago) y A (Salamanca) $)^{85}$.

- Objetivos de la actividad. Los objetivos de la intervención educativa se establecieron en tres grandes ámbitos:

- Identificar espacialmente la relación entre legado y patrimonio material a partir de un recorrido por el casco histórico de cada ciudad.

- Relacionar el concepto de legado histórico con el legado arquitectónico y funcional de edificios, iglesias y barrios, considerando aspectos sociales y de diseño de cada obra.

- Comprender cómo el patrimonio material se asocia a la idea del monumento nacional como un símbolo de identidad y legado histórico.

\footnotetext{
${ }^{85}$ Ver figuras 1.9 y 1.10
} 
De manera complementaria, el trabajo de campo se propone como recurso didáctico y un espacio de aprendizaje único para la comprensión del entorno de la ciudad histórica y sus elementos patrimoniales, actividad mediada por un entorno TIC y $\mathrm{m}$ learning. Se posibilita el conocimiento concreto del medio y sus elementos, en donde el alumno visualiza y conoce su realidad circundante. De esta manera se confrontarán los aspectos teóricos con la práctica planteada, comprobando conceptos en relación con el patrimonio, sus interrelaciones y descubriendo nuevos elementos para su aprendizaje.

- Contenidos. como ya se ha establecido en la sección de elicitación de contenidos de la investigación (sección 4.4.1), los contenidos de las actividades están relacionados con los elementos patrimoniales de cada ciudad (Tabla 4.14).

Tabla 4.14 Contenidos para cada intervención educativa

Contenidos para Santiago de Chile (Ruta E)

\begin{tabular}{l|l}
\hline Hito 1: Iglesia de San Agustín & $\begin{array}{l}\text { Hito 1: Palacio de Montellano e Iglesia de la } \\
\text { Santísima Trinidad }\end{array}$ \\
\hline Hito 2: Club de La Unión & Hito 2: Palacio de los Figueroa \\
\hline $\begin{array}{l}\text { Hito 3: Sector calle Nueva York, La Bolsa y } \\
\text { Club de la Unión }\end{array}$ & Hito 3: Plaza Mayor \\
\hline Hito 4: Bolsa de Comercio & Hito 4: Pabellón Real - Plaza Mayor \\
\hline $\begin{array}{l}\text { Hito 5: Edificio del Banco de Santander (ex } \\
\text { Hotel Mundial) }\end{array}$ & Hito 5: Pabellón de San Martín - Plaza Mayor \\
\hline Hito 6: Iglesia de Las Agustinas & Hito 6: Pabellón de Petrineros - Plaza Mayor \\
\hline $\begin{array}{l}\text { Hito 7: Intendencia de Santiago (Ex edificio del } \\
\text { Diario Ilustrado) }\end{array}$ & $\begin{array}{l}\text { Hito 7: Pabellón Consistorial o del } \\
\text { Ayuntamiento - Plaza Mayor }\end{array}$ \\
\hline $\begin{array}{l}\text { Hito 8: Palacio de la Moneda. Antigua Real } \\
\text { casa de la Moneda }\end{array}$ & Hito 8: Iglesia de San Martín \\
\hline $\begin{array}{l}\text { Hito 9: Barrio Cívico - Eje Bulnes - Parque } \\
\text { Almagro }\end{array}$ & \\
\hline $\begin{array}{l}\text { Hito 10: Ex Casa Rivas, conocida también } \\
\text { como la antigua "Ferretería Montero" }\end{array}$ & \\
\hline Fuente: elaboracion propia. & \\
\hline
\end{tabular}

Contenidos para Salamanca España

(Ruta A)

Fuente: elaboración propia.

- Actividades. Los alumnos, en grupos de dos personas, recorrieron las áreas de estudio definidas con las tabletas, visualizando los recursos digitales de los elementos patrimoniales a estudiar. El docente servía de guía general de la actividad, además de complementar con información presentada en los dispositivos. De manera paralela se 
instaba a la reflexión e intercambio de ideas sobre los fenómenos visualizados en los dispositivos y en el contexto del escenario real en que se desarrollaba la actividad.

- Recursos. El recurso educativo utilizado corresponde a la aplicación AR-NPM realizada e implementada en las tabletas para su visualización en el trabajo de campo (ver sección 4.4 y Figura 4.16 y Figura 4.17).

Figura 4.16 Escena de la Aplicación "Santiago Patrimonial" (versión 1.0 aplicación RANPM)

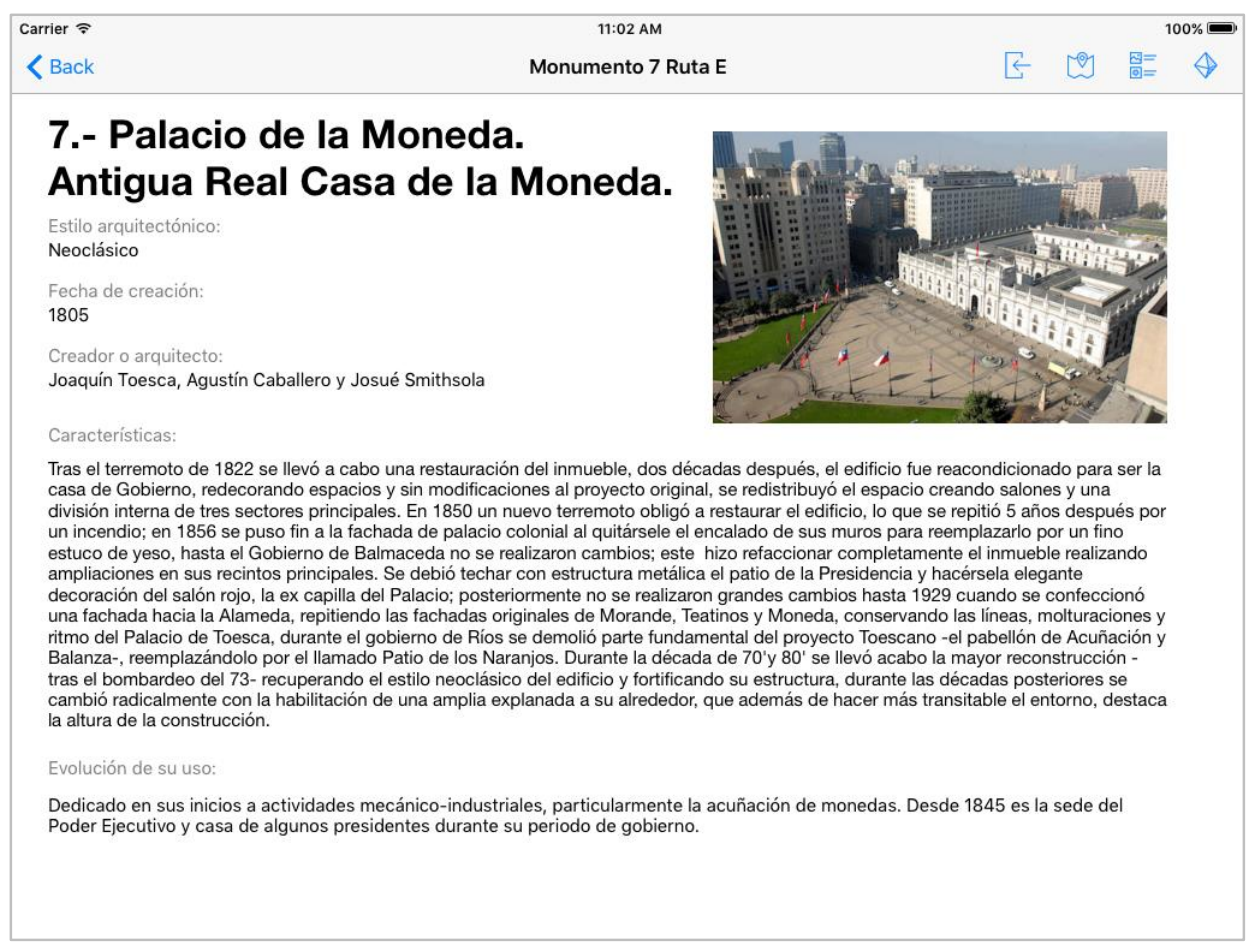

Fuente: Elaboración propia 
Figura 4.17 Escena de la Aplicación "Salamanca Patrimonial" (versión 1.1 aplicación RANPM)

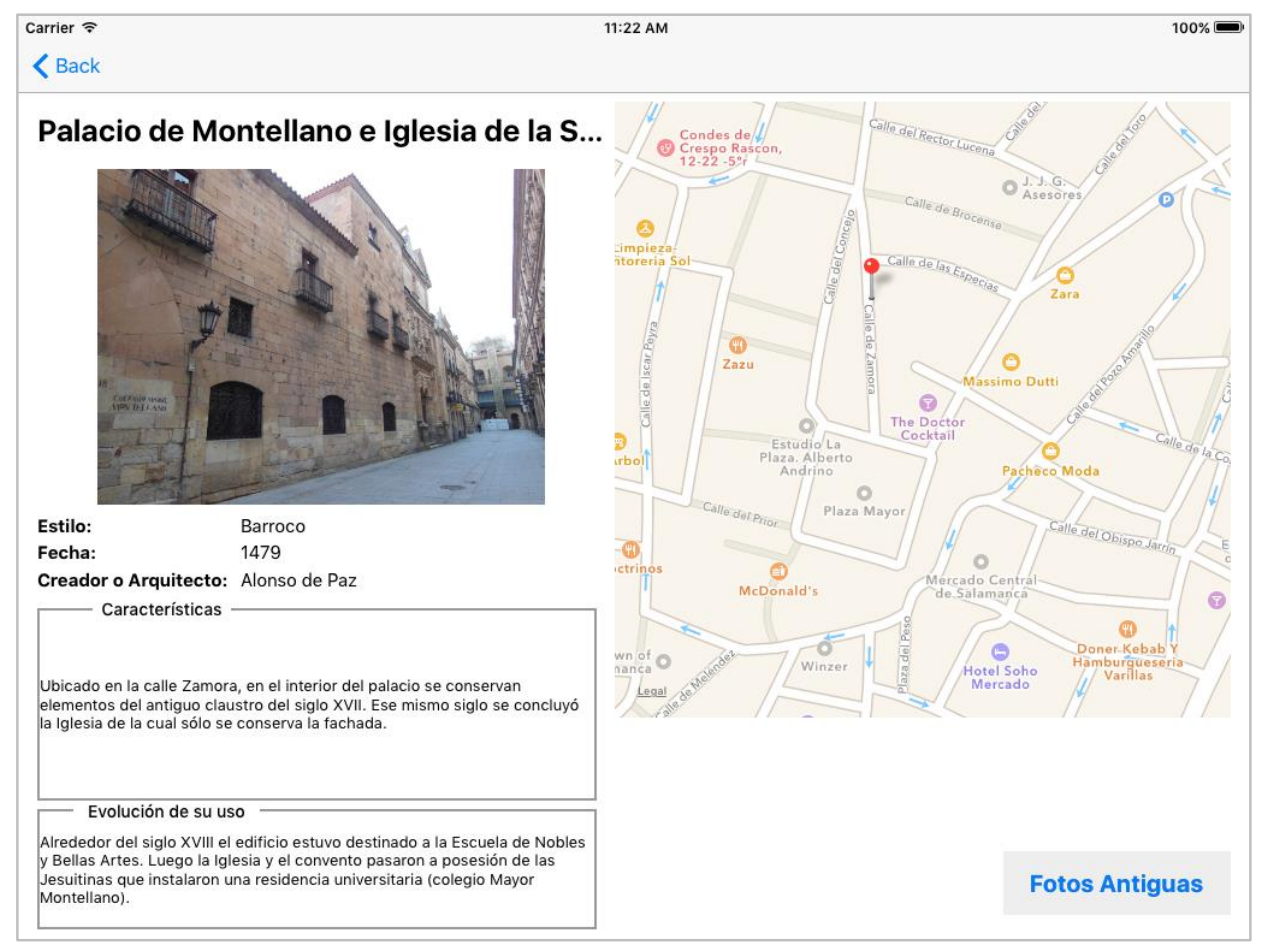

Fuente: Elaboración propia

- Metodología. La modalidad de trabajo se estableció de manera presencial, en la cual se intentaba promover la reflexión y generación de ideas y relaciones sobre los contenidos que se estaban presentando en los recursos tecnológicos utilizados. Cada hito visualizado integra contenidos teóricos, que son relacionados con elementos reales y sus ejemplos respectivos en los recursos digitales.

- Evaluación. Los alumnos se evaluaron al comienzo de la actividad (pre-test) y al final de la intervención educativa. La evaluación de la actividad consta de dos instrumentos: Una prueba con alternativas (25 ítems con 4 opciones cada uno) y una escala de satisfacción del tipo Likert (con opciones de respuesta de 1 a 5, siendo 1 totalmente en desacuerdo y 5 totalmente de acuerdo) frente a la actividad (véanse los Anexos 05 y 06). Cada uno de estos instrumentos se aplicaron en papel.

\subsubsection{Utilización de ordenadores con enseñanza tradicional (e- learning).}

- Título. Santiago Patrimonial y Salamanca Patrimonial 
- Fechas. la intervención educativa se desarrolló en los días 11 y 21 de agosto de 2015 para el caso de Santiago de Chile y 17 de marzo de 2016 para el caso de Salamanca en España.

Duración. Cada intervención educativa tuvo una duración de alrededor de 2,5 horas.

Modalidad. Presencial con enseñanza directa en un aula con ordenadores de escritorio.

Objetivos de la actividad. Los objetivos generales de la intervención educativa se plantearon en el mismo ámbito que en la actividad desarrollada para el trabajo de campo:

- Identificar espacialmente la relación entre legado y patrimonio material a partir de la presentación de los contenidos por el casco histórico de cada ciudad.

- Relacionar el concepto de legado histórico con el legado arquitectónico y funcional de edificios, iglesias y barrios, considerando aspectos sociales y de diseño de cada obra.

- Comprender cómo el patrimonio material se asocia a la idea del monumento nacional como un símbolo de identidad y legado histórico.

- Contenidos. Los contenidos presentados fueron los mismos que se utilizaron en la intervención con el trabajo de campo de la actividad (ver Tabla 4.14).

- Actividades. De la misma manera que en el trabajo de campo, los alumnos en grupo de dos, trabajaron en los ordenadores de escritorio, visualizando los recursos digitales de los elementos patrimoniales a estudiar en una plataforma realizadas en un contexto de objetos de aprendizaje. De la misma manera, el docente servía de guía general de la actividad, además de complementar con información presentada en los dispositivos. De manera paralela se instaba a la reflexión e intercambio de ideas sobre los fenómenos visualizados en los dispositivos y en el contexto del escenario real en que se desarrollaba la actividad.

- Recursos. Para este tipo de experiencia se utilizó el programa eXeLearning 2.0.4 que permite la creación y publicación de contenidos educativos en un formato HTML. Para el caso de la NPM, este elemento fue reemplazado con la utilización de Google Maps 
y CloudsCities para modelos digitales de terreno. Para los elementos de RA se utilizaron modelos realizados para Metaio pero con la utilización de webcam en un entorno de PC de escritorio (Figura 4.18 y Figura 4.19).

Figura 4.18 eXeLearning implementado para la experiencia educativa en aula (ordenador de sobremesa)

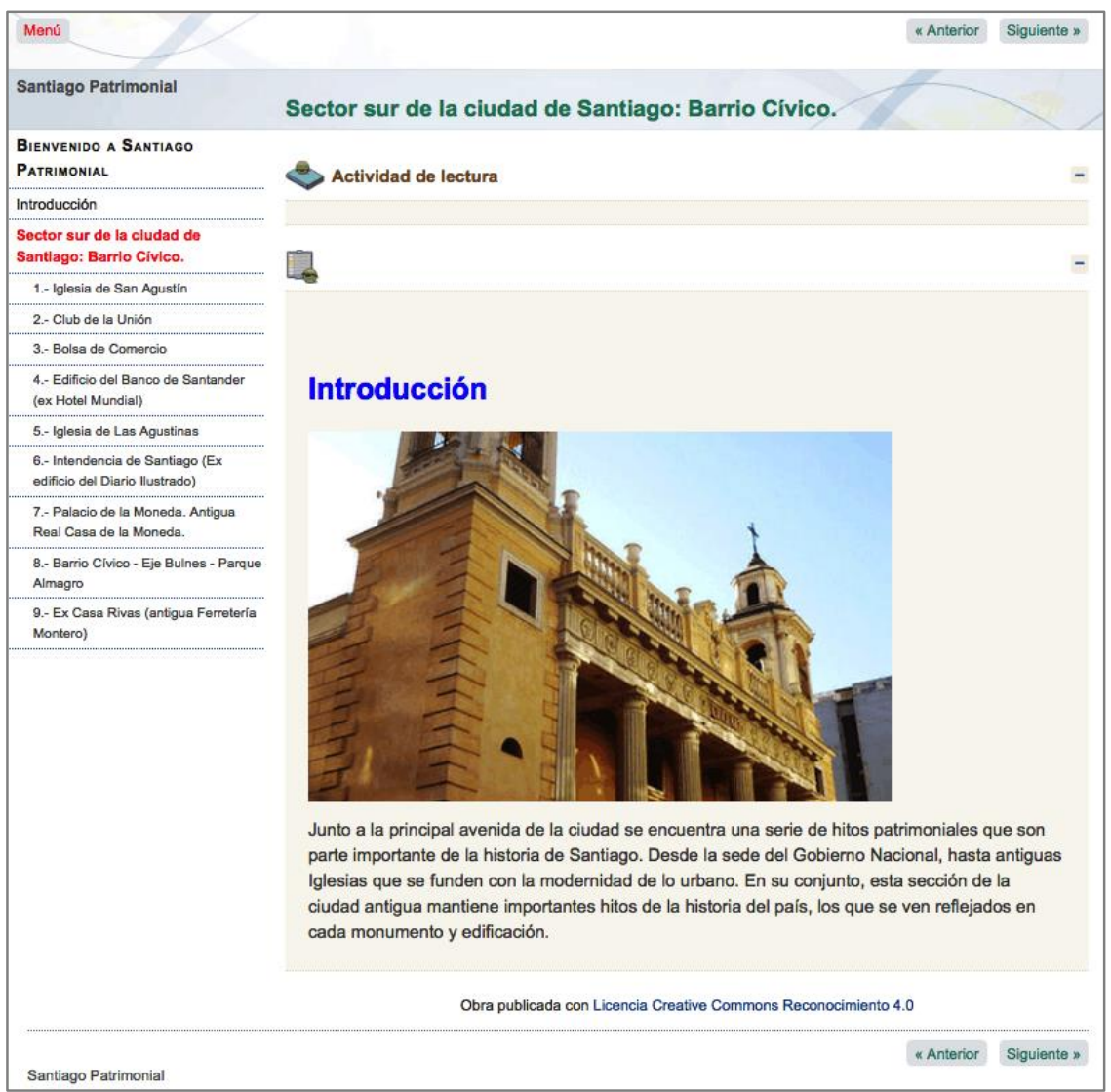

Fuente: Elaboración propia. 
Figura 4.19 Modelo digital de terreno sobre la ciudad de Salamanca

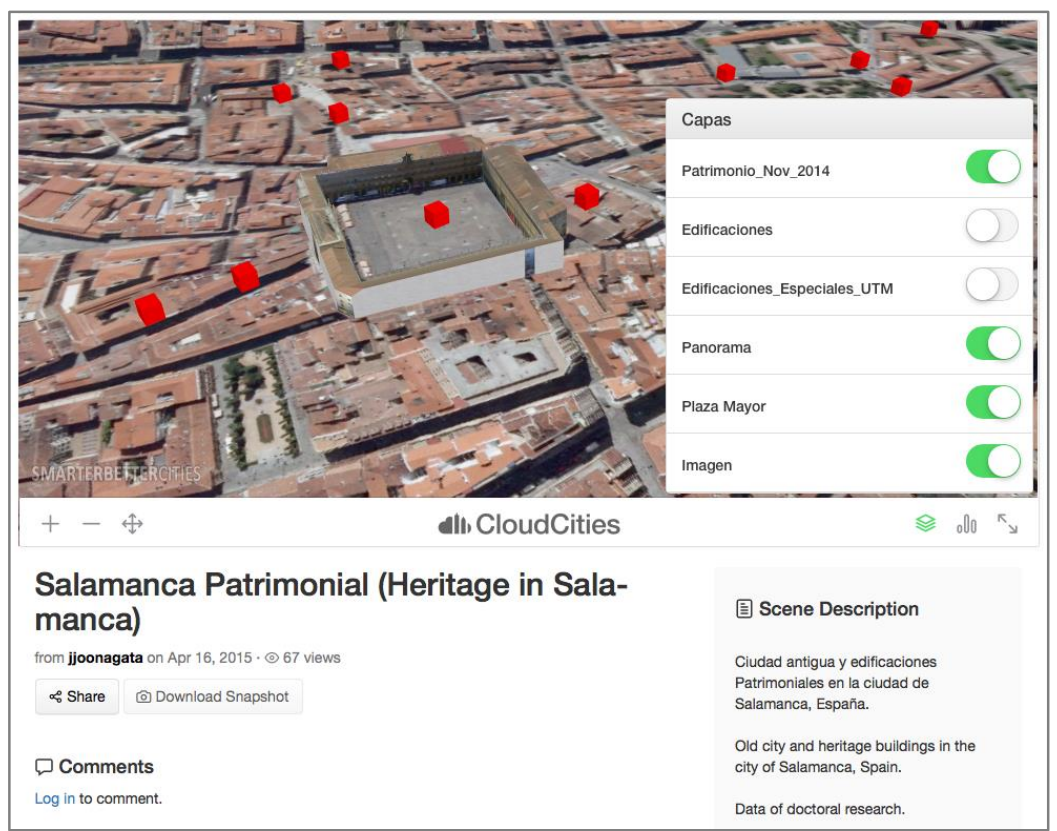

Fuente: Elaboración propia.

- Metodología. La modalidad de trabajo se estableció de manera presencial, a la manera de una clase lectiva guiada, teniendo como recurso los contenidos presentados en los recursos digitales. De la misma manera que en la experiencia anterior, se intentaba promover la reflexión y generación de ideas y relaciones sobre los contenidos que se estaban presentando en los recursos tecnológicos utilizados. Cada hito visualizado se integra contenidos teóricos, los cuales eran relacionados con los recursos digitales elaborados.

- Evaluación. De la misma manera que en el grupo anterior, los alumnos se evaluaron al comienzo de la actividad (pre-test) y al final de la intervención educativa (post-test). La evaluación de la actividad incluyó los mismos instrumentos que la intervención con tabletas.

\subsubsection{Fiabilidad y validez de los instrumentos de medición}

Para la determinación real de los objetivos e hipótesis de la investigación se ha realizado una evaluación de la fiabilidad y validez ${ }^{86}$ de los instrumentos utilizados después

86 La fiabilidad debe ser una propiedad que establece el grado de consistencia y estabilidad de los datos (puntuaciones) que se obtienen a lo largo de la medición de un instrumento. Es importante mencionar que la propiedad de fiabilidad no es una propiedad inherente de los test, sino que se deriva de las 
de cada tratamiento realizado (intervención educativa). Se pretende valorar la importancia de estos elementos y cómo tienen su representación en la variable dependiente dentro del instrumento de medición realizado. De esta manera esta sección se subdivide en tres secciones: Diseño del instrumento, análisis de ítems y validez de las escalas.

\subsubsection{Diseño del instrumento}

El diseño del instrumento de evaluación se inició en una primera fase desde los contextos establecidos en el marco teórico, teniendo en cuenta el aprendizaje en un contexto móvil y situado, conteniendo los elementos temáticos de patrimonio y territorio como elementos centrales de las competencias que se pretenden lograr, las que en este caso están referidas al conocimiento, comprensión y al análisis de los fenómenos patrimoniales, agrupados en las dimensiones de contexto histórico-temporal; elementos arquitectónicos y morfológicos urbanos; y localización y espacialidad (Tabla 4.11 y Tabla 4.12).

El instrumento se compone de 25 ítems con 4 opciones de respuesta (véase los Anexos 05 y 06), cuya aplicación se realizó de manera tradicional (papel y lápiz), incorporándose un identificador único con el fin de poder comparar los datos entre los valores pre-test/post-test obtenidos. En torno a las variables sociodemográficas consultadas, éstas fueron la edad del participante, el centro educativo a cual pertenece y el sexo. Cada iPad contaba con una identificación particular (letras A, B, C, etc.), solicitando a los participantes de la actividad experimental la incorporación de esa identificación en la prueba. Para lograr una mayor colaboración en las intervenciones educativas experimentales y de control por parte de los alumnos participantes, se mencionó que el mejor logro de cada grupo obtendría un premio (una tableta por cada grupo o una gift card para la tienda virtual Google Play) por su desempeño en la prueba pos-test, esto con el fin de lograr una mayor atención a la actividad de tratamiento. En la cuantificación de la prueba objetiva aplicada durante el pre-test/pos-test se asignó con 1 punto cada acierto y con valor 0 cada respuesta errónea.

interpretaciones e inferencias de los datos obtenidos (Prieto \& Delgado, 2010). En lo referente a la validez, esta se refiere a la capacidad que tiene el instrumento de medición (test/prueba objetiva) para determinar de manera significativa y adecuada los elementos por el cual ha sido diseñado (Abad, Olea, Ponsoda, \& García, 2011; Prieto \& Delgado, 2010). 


\subsubsection{Validez de las escalas}

Se ha realizado una validez de contenido que fue llevada a cabo por jueces externos para cada área territorial donde se ha realizado la experiencia. A pesar que los instrumentos miden las mismas dimensiones, los contenidos patrimoniales, territoriales e históricos, debido los antecedentes recopilados tienen características diferentes, por lo que lo que cada instrumento se evaluó teniendo a jueces relacionados con cada lugar. Para el caso de Santiago de Chile se ha utilizado 12 jueces expertos áreas relacionadas con el instrumento realizado:

- Un Maestro de secundaria en Historia, Geografía y Ciencias Sociales / Doctor en Educación, mención en Didáctica de las Ciencias Sociales. Profesor ayudante, Universidad Metropolitana de Ciencias de La Educación.

- Un Maestro de secundaria en Historia, Geografía y Ciencias Sociales, con grado de Máster en Currículum. Coordinador de gestión curricular de Postgrado en la Universidad Tecnológica de Chile Inacap.

- Una Maestra de secundaria en Historia, Geografía y Ciencias Sociales / Doctora en Historia. Investigadora del Centro de Estudios Históricos, Universidad Bernardo O'Higgins.

- Un Arquitecto/Máster en Patrimonio Arquitectónico. Universidad de Barcelona. Coordinador del área de Patrimonio del Colegio de Arquitectos de Chile.

- Un Maestro de secundaria en Historia, Geografía y Ciencias Sociales/Máster en Geografía y doctorando en Geografía. Profesor ayudante Universidad Academia de Humanismo Cristiano.

- Un Geógrafo/Maestro de secundaria en Geografía y Ciencias Sociales, Doctor en Educación y Profesor ayudante de la Escuela de Historia, Universidad Alberto Hurtado.

- Un Geógrafo/Maestro de secundaria en Geografía y Ciencias Sociales, Doctor en Educación y Profesor titular de la Escuela de Geografía, Universidad Academia de Humanismo Cristiano. 
- Un Maestro de secundaria en Historia, Geografía y Ciencias Sociales/Profesor ayudante, Doctor en Educación, mención en Didáctica del Patrimonio. Profesor ayudante de la Pontificia Universidad Católica de Chile.

- Una Maestra de secundaria en Historia, Geografía y Ciencias Sociales con grado de Máster en Currículum. Encargada de área de historia en enseñanza media. Colegio San Alberto Hurtado, Fundación Belén Educa.

- Una Geógrafa/Doctora en Educación con mención en educación ambiental.

- Un Maestro de secundaria en Historia, Geografía y Ciencias Sociales, en ejercicio en el centro educativo Henry Fayol de Santiago de Chile.

- Una Maestra de secundaria en Historia, Geografía y Ciencias Sociales, En ejercicio en el centro Educacional Héroe Arturo Pérez Canto.

Para el caso de la intervención realizada en Salamanca España, el instrumento fue validado por 8 jueces relativos a los contenidos y contextos que se aplicará el instrumento:

- Una Maestra en Educación Infantil/Doctoranda en de la Universidad de Salamanca. Con especialización en Psicopedagogía y Master en formación en TIC.

- Un Arquitecto. En ejercicio en la Comunidad de Canarias y encargado de Proyectos y Dirección de Obras.

- Un Maestro de Secundaria, Licenciado en Filosofía y Ciencias de la Educación/ Doctor en Educación de la Universidad de Salamanca. Profesor Asociado de la Universidad de Salamanca.

- Un Licenciado en Administración/Máster en Gestión y Políticas de Educación Superior/Doctorando de la Universidad de Salamanca.

- Un Maestro de Enseñanza Secundaria y Bachillerato (Griego, latín, Cultura Clásica, Historia Antigua, Informática...)/Licenciado en Filología Clásica y Lingüística 
Indoeuropea. Jefe de Departamento de Lenguas Clásicas, Instituto de Educación Secundaria Claudio Moyano de Zamora (Castilla y León).

- Un Maestro de Ciencias/ Doctor en Educación, Universidad de Salamanca.

- Un Maestro en ejercicio del Instituto de Educación Secundaria Torres Villarroel.

- Un Maestro de Español como Lengua Extranjera/Máster en Enseñanza del Español como Lengua Extranjera y Máster de Profesor de Enseñanza Secundaria y Bachillerato. Con experiencia en academias como profesor de idioma español como Lengua Extranjera.

Los jueces tuvieron la posibilidad de ver y analizar la herramienta de evaluación con cada ítem y la propuesta de cada dimensión definida. De esta manera los jueces realizaron una evaluación consistente en la determinación de la calidad de cada ítem del instrumento conforme a 4 criterios:

- Adecuación: en qué medida el ítem es adecuado para el nivel educativo propuesto (70 EGB a 2 Medio -Chile-;10 - $2^{\circ}$ de la ESO -España-).

- Claridad: La expresión de la consulta es clara para los alumnos.

- Pertinencia con respecto a los contenidos temáticos: Precisión con la que el ítem evalúa los contenidos propuestos (contexto histórico-temporal; elementos arquitectónicos y morfológicos urbanos; y localización y espacialidad).

- Pertinencia con respecto a los niveles de destreza básico: en qué medida el ítem evalúa y representa los niveles propuestos en la taxonomía de Bloom (Conocimiento, Comprensión y Aplicación).

Cada uno de estos criterios se realizó en una escala de tipo Likert con 5 opciones que van desde el "Muy en desacuerdo" hasta el "Muy en desacuerdo". Adicionalmente, todos los ítems incluyen una sección para comentarios en la cual se podía añadir observaciones para el cambio en el planteamiento o la estructura del ítem y/o con indicaciones acerca de cambios o mejoras a introducir en el instrumento de evaluación. 
Los resultados de esta evaluación se hallarán en los Anexos 07 y 08 . De esta manera, las preguntas con un valor en el coeficiente de variación ${ }^{87}$ sobre el $45 \%$ en los cuatro criterios consultados, además de valores iguales o inferiores a 3,5 en la media y mediana (valores nominales de "ninguno", "en desacuerdo" y "muy en desacuerdo"), fueron revisados y reformulados tomando como base los comentarios planteados por los evaluadores. Así, teniendo en consideración las observaciones y recomendaciones de los jueces, se procedió a la modificación y adaptación del instrumento con el fin de optimizarlo para el contexto educativo planteado. Para el caso del instrumento planteado para la experiencia en Chile y en función de las dimensiones consultadas los resultados son los siguientes:

- Adecuación de contenidos: se estableció la modificación de las preguntas ITEM06 ITEM08 e ITEM14, particularmente en lo referente a la presentación de la pregunta y la utilización de distractores sencillos y comprensible por parte de los alumnos, sin conceptualizaciones complejas o desconocidas. Se solicitó adecuar la pregunta a la presentación de los contenidos según aparecía en el instrumento de tratamiento (tableta u ordenador de escritorio).

- Claridad de los contenidos: se recomendó la revisión y reformulación de los ITEM06 e ITEM14 poniendo en énfasis la eliminación de conceptos técnicos que no son relevantes o no se encuentren presentes en el tratamiento a aplicar. También se establecieron problemas de redacción o interpretación los cuales fueron corregidos.

- Pertinencia de contenido: el único elemento con baja puntuación y recomendaciones de formulación correspondió al ITEM07, el cual fue revisado y se eligió su reformulación desarrollándose según los contenidos del tratamiento propuesto.

- Pertinencia de destreza: en particular, los ITEM06 e ITEM07 no establecían con claridad las destrezas que pretendían medir y la forma en que estas se relacionaban con los contenidos consultados.

\footnotetext{
${ }^{87}$ El coeficiente de variación corresponde al valor de la desviación típica dividido por el valor promedio que se obtiene de la evaluación de la pregunta en la escala Likert. Este indicador, expresado en porcentaje, establece que los valores altos mantienen un importante grado de variabilidad y dispersión en los registros que tiene la evaluación de la pregunta.
} 
De esta manera, las preguntas ITEM06 e ITEM07 sufrieron modificaciones profundas según los datos obtenidos, teniéndose en cuenta las observaciones concretas de los jueces que evaluaron el instrumento.

En el instrumento a utilizar para la experiencia en España, los resultados son los siguientes:

- Adecuación de contenidos: se estableció la modificación de las preguntas ITEM01, ITEM04, ITEM05, ITEM07, ITEM11, ITEM13 e ITEM14 en lo referente a la presentación de las preguntas con la utilización de distractores fáciles de comprender. Se solicitó adecuar la pregunta a la presentación de los contenidos según lo presentado en el instrumento de tratamiento (tableta u ordenador de escritorio).

- Claridad de los contenidos: se recomendó la revisión y reformulación de los ITEM02, ITEM04, ITEM05, ITEM07, ITEM13, ITEM14 e ITEM24 poniendo en énfasis la eliminación de conceptos técnicos que no son relevantes o no se encuentren presentes en el tratamiento a aplicar. También se establecieron problemas de redacción o interpretación los cuales fueron corregidos.

- Pertinencia de contenido: el único elemento con baja puntuación y recomendaciones de formulación correspondió al ITEM09, el cual fue revisado y se eligió su reformulación desarrollándose según los contenidos del tratamiento propuesto.

- Pertinencia de destreza: solo el ITEM04 por el coeficiente de variación obtenido, no establecía con claridad las destrezas que pretendían medir y como estas se relacionaban con los contenidos consultados.

De esta manera, las preguntas ITEM04 e ITEM07 sufrieron modificaciones profundas según los datos obtenidos ya que presentaban bajas puntaciones en más de una dimensión, teniéndose en cuenta las observaciones concretas de los jueces que evaluaron el instrumento. 


\subsubsection{Análisis de ítems}

Para este caso, que se utilizó una prueba de alternativas (variables dicotómicas) se realizó un análisis que incluyó el índice de dificultad (Abad, Olea, Ponsoda, \& García, 2011; Rodríguez Conde, 2011) y el índice de discriminación clásico (Abad et al., 2011), además del índice de discriminación con correlación biserial-puntual ( $r_{b p}$ ) (Abad et al., 2011).

- Índice de dificultad: se realizó una valoración de los ítems de la prueba objetiva mediante el índice de dificultad ${ }^{88}$, indicador que representa la proporción de alumnos que responde correctamente a la prueba objetiva aplicada. Los valores obtenidos son interpretados con la siguiente tabla, estableciendo la dificultad de los ítems planteados para la evaluación:

Tabla 4.15 Clasificación dificultad de ítems (Pomés \& Argüelles, 1991)

Dificultad

\begin{tabular}{|c|c|}
\hline Muy difícil & 0 a $15 \%$ \\
\hline Difícil & $15 \%$ a $40 \%$ \\
\hline Moderada & $40 \%$ a $60 \%$ \\
\hline Fácil & $60 \%$ a $85 \%$ \\
\hline Muy Fácil & 85 a $100 \%$ \\
\hline
\end{tabular}

En el caso de una prueba objetiva los valores de dificultad deben encontrarse en proporción en donde los valores de dificultad moderada, debería tener un porcentaje similar de ítems fáciles y difíciles, además de pocos ítems muy fáciles o muy difíciles. Para este caso, tanto como el pre-test como post-test son el mismo instrumento, los resultados en el índice de dificultad son diferentes explicado por el tratamiento realizado para ambos grupos (Tabla 4.16 y Tabla 4.17).

${ }^{88}$ El índice de dificultad es una relación inversa en donde cuanto mayor sea la dificultad del ítem menor será su índice (Wood, 1960). Su fórmula es:

$$
p_{i}=\frac{A_{i}}{N_{i}}
$$

En donde $\mathrm{p}_{\mathrm{i}}$ corresponde al índice de dificultad del ítem; $\mathrm{A}_{i}$ el número de aciertos del ítem i y $\mathrm{N}_{i}$ el número de aciertos más el número de errores en el ítem $i$. 
Tabla 4.16 Índice de dificultad para la intervención educativa en Chile $(n=145)$

Pre-test

\begin{tabular}{|c|c|c|}
\hline Ítem & $\begin{array}{l}\text { Índice de } \\
\text { dificultad }\end{array}$ & Categoría \\
\hline Pre1 & $45,52 \%$ & Moderada \\
\hline Pre2 & $2,00 \%$ & Difícil \\
\hline Pre3 & $62,76 \%$ & Fácil \\
\hline Pre4 & $22,76 \%$ & Difícil \\
\hline Pre5 & $28,28 \%$ & Difícil \\
\hline Pre6 & $25,52 \%$ & Difícil \\
\hline Pre7 & $21,38 \%$ & Difícil \\
\hline Pre8 & $2,69 \%$ & Difícil \\
\hline Pre9 & $21,38 \%$ & Difícil \\
\hline Pre10 & $33,79 \%$ & Difícil \\
\hline Pre11 & $25,52 \%$ & Difícil \\
\hline Pre12 & $2,69 \%$ & Difícil \\
\hline Pre13 & $21,38 \%$ & Difícil \\
\hline Pre14 & $15,17 \%$ & Difícil \\
\hline Pre15 & $17,93 \%$ & Difícil \\
\hline Pre16 & $24,83 \%$ & Difícil \\
\hline Pre17 & $2,00 \%$ & Difícil \\
\hline Pre18 & $15,17 \%$ & Difícil \\
\hline Pre19 & $31,72 \%$ & Difícil \\
\hline Pre20 & $22,76 \%$ & Difícil \\
\hline Pre21 & $3,34 \%$ & Difícil \\
\hline Pre22 & $25,52 \%$ & Difícil \\
\hline Pre23 & $28,28 \%$ & Difícil \\
\hline Pre24 & $15,86 \%$ & Difícil \\
\hline Pre25 & $21,38 \%$ & Difícil \\
\hline
\end{tabular}

Fuente: Elaboración propia.
Post-test

\begin{tabular}{|c|c|c|}
\hline Ítem & $\begin{array}{c}\text { Índice de } \\
\text { dificultad }\end{array}$ & Categoría \\
\hline Post1 & $71,03 \%$ & Fácil \\
\hline Post2 & $6,69 \%$ & Fácil \\
\hline Post3 & $93,10 \%$ & Muy fácil \\
\hline Post4 & $68,28 \%$ & Fácil \\
\hline Post5 & $66,90 \%$ & Fácil \\
\hline Post6 & $74,48 \%$ & Fácil \\
\hline Post7 & $7,34 \%$ & Fácil \\
\hline Post8 & $57,93 \%$ & Moderada \\
\hline Post9 & $63,45 \%$ & Fácil \\
\hline Post10 & $31,03 \%$ & Difícil \\
\hline Post11 & $5,34 \%$ & Moderada \\
\hline Post12 & $75,17 \%$ & Fácil \\
\hline Post13 & $57,93 \%$ & Moderada \\
\hline Post14 & $51,72 \%$ & Moderada \\
\hline Post15 & $24,14 \%$ & Difícil \\
\hline Post16 & $42,76 \%$ & Moderada \\
\hline Post17 & $59,31 \%$ & Moderada \\
\hline Postícil
\end{tabular}

Para el caso de Chile mientras que en el pre-test encontramos una prueba que tiene una alta dificultad en la mayoría de sus ítems, una vez aplicada el tratamiento de control para los grupos experimental y de control, la prueba objetiva presenta una proporción en sus 
valores, teniendo 1 ítem muy fácil, 9 ítems fáciles, 8 ítems moderados y 7 ítems con características difíciles.

Tabla 4.17 Índice de dificultad para la intervención educativa en España ( $n=33$ )

Pre-test

\begin{tabular}{|c|c|c|}
\hline Ítem & $\begin{array}{c}\text { Índice de } \\
\text { dificultad }\end{array}$ & Categoría \\
\hline Pre1 & $51,52 \%$ & Moderada \\
\hline Pre2 & $27,27 \%$ & Difícil \\
\hline Pre3 & $72,73 \%$ & Fácil \\
\hline Pre4 & $27,27 \%$ & Difícil \\
\hline Pre5 & $51,52 \%$ & Moderada \\
\hline Pre6 & $45,45 \%$ & Moderada \\
\hline Pre7 & $21,21 \%$ & Difícil \\
\hline Pre8 & $63,64 \%$ & Fácil \\
\hline Pre9 & $54,55 \%$ & Moderada \\
\hline Pre10 & $45,45 \%$ & Moderada \\
\hline Pre11 & $24,24 \%$ & Difícil \\
\hline Pre12 & $6,61 \%$ & Fácil \\
\hline Pre13 & $21,21 \%$ & Difícil \\
\hline Pre14 & $39,39 \%$ & Difícil \\
\hline Pre15 & $54,55 \%$ & Moderada \\
\hline Pre16 & $33,33 \%$ & Difícil \\
\hline Pre17 & $24,24 \%$ & Difícil \\
\hline Pre18 & $27,27 \%$ & Difícil \\
\hline Pre19 & $36,36 \%$ & Difícil \\
\hline Pre20 & $21,21 \%$ & Difícil \\
\hline Pre21 & $15,15 \%$ & Difícil \\
\hline Pre22 & $21,21 \%$ & Difícil \\
\hline & $3,30 \%$ & Difícil \\
\hline Pre & $12,12 \%$ & Muy difícil \\
\hline & $39,39 \%$ & Difícil \\
\hline
\end{tabular}

Fuente: Elaboración propia.
Post-test

\begin{tabular}{|c|c|c|}
\hline Ítem & $\begin{array}{c}\text { Índice de } \\
\text { dificultad }\end{array}$ & Categoría \\
\hline Post1 & $93,94 \%$ & Muy fácil \\
\hline Post2 & $69,70 \%$ & Fácil \\
\hline Post3 & $87,88 \%$ & Muy fácil \\
\hline Post4 & $75,76 \%$ & Fácil \\
\hline Post5 & $54,55 \%$ & Moderada \\
\hline Post6 & $6,61 \%$ & Fácil \\
\hline Post7 & $27,27 \%$ & Difícil \\
\hline Post8 & $69,70 \%$ & Fácil \\
\hline Post9 & $69,70 \%$ & Fácil \\
\hline Post10 & $45,45 \%$ & Moderada \\
\hline Post11 & $75,76 \%$ & Fácil \\
\hline Post12 & $75,76 \%$ & Fácil \\
\hline Post13 & $54,55 \%$ & Moderada \\
\hline Post14 & $57,58 \%$ & Moderada \\
\hline Post15 & $48,48 \%$ & Moderada \\
\hline Post16 & $75,76 \%$ & Fácil \\
\hline Post17 & $63,64 \%$ & Fácil \\
\hline Post18 & $6,61 \%$ & Fácil \\
\hline Post19 & $63,64 \%$ & Fácil \\
\hline Post20 & $51,52 \%$ & Moderada \\
\hline Post21 & $75,76 \%$ & Fácil \\
\hline Post22 & $54,55 \%$ & Moderada \\
\hline Post23 & $72,73 \%$ & Fácil \\
\hline $57,58 \%$ & Moderada \\
\hline Post25 & $63,64 \%$ & Fácil \\
\hline
\end{tabular}

- Índice de discriminación clásico. Como la prueba y particularmente los ítems miden las mismas competencias, se espera que los mayores puntajes en todas las respuestas del test deberá tener altas probabilidades de contestar correctamente un determinado 
ítem. De la misma manera, debemos considerar el caso contrario, es decir, el sujeto que tuvo bajas puntuaciones en la prueba objetivas, debería tener pocas posibilidades de contestar un ítem determinado. De esta manera los ítems deben ser capaces de discriminar ${ }^{89}$ los sujetos que tuvieron buenos puntajes generales de los que no. Cuanto mayor sea el valor del índice, mayor será su discriminación (Abad et al., 2011). Los valores del índice de discriminación obtenidos están clasificados según lo expresado en la Tabla 4.18:

Tabla 4.18 Clasificación de discriminación de ítems (Pomés \& Argüelles, 1991)

Valor Di

\begin{tabular}{c|c|}
\hline$, 00 \mathrm{a}, 14$ & No discrimina \\
\hline$, 15 \mathrm{a}, 29$ & Discrimina poco \\
\hline$, 30 \mathrm{a}, 49$ & Discrimina bien \\
\hline 50 a 1 & Discrimina muy bien
\end{tabular}

De esta manera, se eliminaron los ítems que resultaron tener valores menores o iguales que, 14 (no discrimina).

${ }^{89}$ La fórmula del índice de discriminación es:

$$
D_{i}=\frac{G A_{\text {aciertos }}-G B_{\text {aciertos }}}{N_{\text {grupomayor }}}
$$

En donde: $\mathrm{D}_{i}$ corresponde al índice de discriminación del ítem $\dot{i}_{;} \mathrm{GA}_{\text {aciertos }}$ corresponde al número de aciertos en el ítem $i$ del $27 \%$ de personas con las puntuaciones más altas en la prueba objetiva; $\mathrm{GB}_{\text {aciertos }}$ corresponde al número de aciertos en el ítem $i$ del $27 \%$ de personas con las puntuaciones más bajas en la prueba objetiva; y $\mathrm{N}_{\text {grupomayor }}$ corresponde al número de personas en el grupo más numeroso (GA o GB). 
Tabla 4.19 Índice de discriminación prueba objetiva aplicada en Chile Pre-test

Post-test

\begin{tabular}{|c|c|c|c|c|c|}
\hline Ítem & $\begin{array}{c}\text { Índice de } \\
\text { Discriminación }\end{array}$ & Discriminación & Ítem & $\begin{array}{c}\text { Índice de } \\
\text { Discriminación }\end{array}$ & Discriminación \\
\hline Pre1 & 15 & Poco & Post1 & ,23 & Poco \\
\hline Pre2 & ,33 & Bien & Post2 & ,38 & Bien \\
\hline Pre3 & 15 & Poco & Post3 & ,08 & No discrimina \\
\hline Pre4 &, 44 & Bien & Post4 &, 44 & Bien \\
\hline Pre5 & ,36 & Bien & Post5 & ,56 & Muy bien \\
\hline Pre6 & ,38 & Bien & Post6 & ,56 & Muy bien \\
\hline Pre7 & 10 & No discrimina & Post7 & ,54 & Muy bien \\
\hline Pre8 & ,31 & Bien & Post8 & 62 & Muy bien \\
\hline Pre9 & 15 & Poco & Post9 & ,56 & Muy bien \\
\hline Pre10 & ,33 & Bien & Post10 & ,03 & No discrimina \\
\hline Pre11 & ,18 & Poco & Post11 & ,64 & Muy bien \\
\hline Pre12 & ,31 & Bien & Post12 &, 54 & Muy bien \\
\hline Pre13 & ,26 & Poco & Post13 & 67 & Muy bien \\
\hline Pre14 & ,05 & No discrimina & Post14 & ,38 & Bien \\
\hline Pre15 & 13 & No discrimina & Post15 & 15 & Poco \\
\hline Pre16 & ,23 & Poco & Post16 & ,56 & Muy bien \\
\hline Pre17 & ,26 & Poco & Post17 & ,51 & Muy bien \\
\hline Pre18 & 10 & No discrimina & Post18 & ,31 & Bien \\
\hline Pre19 & ,21 & Poco & Post19 & ,28 & Poco \\
\hline Pre20 &, 44 & Bien & Post20 &, 54 & Muy bien \\
\hline Pre21 & ,28 & Poco & Post21 & ,28 & Poco \\
\hline Pre22 & ,36 & Bien & Post22 & ,33 & Bien \\
\hline Pre23 & 18 & Poco & Post23 &,- 18 & No discrimina \\
\hline Pre24 & ,23 & Poco & Post24 & ,31 & Bien \\
\hline Pre25 & 13 & No discrimina & Post25 &, 44 & Bien \\
\hline
\end{tabular}

Fuente: Elaboración propia.

Para la utilización de este indicador, se ha hecho énfasis en los valores obtenidos en el post-test, debido a que una correcta discriminación debe ser considerada teniendo en cuenta del tratamiento realizado a los grupos de cada intervención educativa. De esta manera y con los resultados de la 
Tabla 4.19, 4 ítems discriminan poco, 7 discriminan bien, 11 discriminan muy bien y 3 ítems no discriminan. Estos últimos ítems son:

- 3) Es un personaje que se encuentra enterrada en la Iglesia de San Agustín y que fue conocida como la Quintrala. Su verdadero nombre es...

- 10) ¿durante qué años el edificio de la sede del Banco Santander en Chile funcionó como hotel?

- 23) La única fachada que contiene tres accesos en el Palacio de la Moneda corresponde a...

Dada la estructura de estos ítems que no discriminan se ha decidido eliminar los 3 para los análisis posteriores. Para el caso del ítem Post3 la respuesta se encuentra condicionada al ser información, que, debido a un contexto cultural mediático ${ }^{90}$ fuera del alcance de la investigación, se transformó en un dato sin discriminación real. El ítem Post1, aparte de no discriminar, en los índices de dificultad pre-test/post-test obtuvo un valor de difícil. Esto es debido a que la competencia estaba referida a conocimiento, en un contexto de fechas exactas, difícil de aprender y contextualizar dentro de una línea de tiempo. Por último, el ítem Post23, de la misma manera que el ítem anterior, aparte de no discriminar, mantiene una dificultad importante en torno a su respuesta (opciones similares, situación del sentido espacial).

${ }^{90}$ En la fecha de aplicación del test se encontraba en la televisión pública la teleserie "La Quintrala" cuya protagonista está referida el contexto del ítem. 
Tabla 4.20 Índice de discriminación prueba aplicada en España Pre-test

Post-test

\begin{tabular}{|c|c|c|c|c|c|}
\hline Ítem & $\begin{array}{c}\text { Índice de } \\
\text { Discriminación }\end{array}$ & Discriminación & İtem & $\begin{array}{c}\text { Índice de } \\
\text { Discriminación }\end{array}$ & Discriminación \\
\hline Pre1 & ,22 & Poco & Post1 & ,11 & No discrimina \\
\hline Pre2 & ,22 & Poco & Post2 & ,56 & Muy bien \\
\hline Pre3 & ,56 & Bien & Post3 & 11 & No discrimina \\
\hline Pre4 & ,22 & Poco & Post4 &,- 11 & No discrimina \\
\hline Pre5 & ,22 & Poco & Post5 &, 44 & Bien \\
\hline Pre6 & 67 & Muy bien & Post6 & ,33 & Bien \\
\hline Pre7 & ,00 & No discrimina & Post7 &, 44 & Bien \\
\hline Pre8 &,- 11 & No discrimina & Post8 & ,33 & Bien \\
\hline Pre9 & ,33 & Bien & Post9 &, 44 & Bien \\
\hline Pre10 & 11 & No discrimina & Post10 & ,33 & Bien \\
\hline Pre11 & ,00 & No discrimina & Post11 & 67 & Muy bien \\
\hline Pre12 & 67 & Muy bien & Post12 & 67 & Muy bien \\
\hline Pre13 &, 00 & No discrimina & Post13 & 89 & Muy bien \\
\hline Pre14 &, 11 & No discrimina & Post14 & 67 & Muy bien \\
\hline Pre15 & ,33 & Bien & Post15 & ,22 & Poco \\
\hline Pre16 & ,22 & Poco & Post16 & ,33 & Bien \\
\hline Pre17 &,- 44 & No discrimina & Post17 &, 44 & Bien \\
\hline Pre18 & ,22 & Poco & Post18 & ,56 & Muy bien \\
\hline Pre19 & ,33 & Bien & Post19 &, 44 & Bien \\
\hline Pre20 &, 00 & No discrimina & Post20 & ,78 & Muy bien \\
\hline Pre21 & ,22 & Poco & Post21 & ,22 & Poco \\
\hline Pre22 &,- 11 & No discrimina & Post22 & 67 & Muy bien \\
\hline Pre23 & 11 & No discrimina & Post23 &, 44 & Bien \\
\hline Pre24 & ,22 & Poco & Post24 & ,67 & Muy bien \\
\hline Pre25 & ,22 & Poco & Post25 & ,33 & Bien \\
\hline
\end{tabular}

Fuente: Elaboración propia.

De la misma manera que en el caso de Chile, se utilizaron los valores del post-test considerando la utilización del tratamiento y su posterior resultado. De esta manera y con 
los resultados de la , 1 ítem discrimina poco, 11 discriminan bien, 9 discriminan muy bien y 3 ítems no discriminan. Estos últimos ítems son:

- 1) El estilo arquitectónico de la Plaza Mayor de Salamanca es...

- 3) El arquitecto de la Plaza Mayor de Salamanca fue...

- 4) El pabellón presente en la Plaza Mayor situado hacia la dirección sur corresponde a...

Se ha decidido eliminar los ítems 3 y 4 del análisis posterior debido a su escaso nivel de discriminación, además de presentar valores en el indicado de dificultad con categoría de muy fácil (post3) y fácil (post4), lo que se puede visualizar en la Tabla 4.17. Por otra parte, se ha dejado el ítem 1 ya que es la única pregunta relacionada con la dimensión de los "Procesos Sociales Relacionados", como se puede ver en la Tabla 4.12. Los ítems eliminados están relacionados con la Plaza Mayor, situación que puede explicar la facilidad de respuesta y la escasa capacidad de discriminación: al ser preguntas de un elemento patrimonial tan importante y referencial, los alumnos rápidamente pueden asociar la información que es consultada, no teniendo en consideración el rendimiento general del instrumento.

- Índice de discriminación con correlación biserial-puntual $\left(r_{b p}\right)^{11}$ : corresponde a otro método que permite discriminar si los ítems discriminan adecuadamente a los sujetos evaluados (Abad et al., 2011). Con este indicador, se realiza una correlación entre el ítem analizado y el valor total del mismo ítem en el test, permitiendo un análisis en el contexto completo del instrumento. Los valores se interpretan como si fueran datos obtenidos de una correlación de Pearson (Tabla 4.21).

${ }^{91}$ La fórmula de este índice es:

$$
r_{b p}=\frac{X_{p}-X_{q}}{S_{X}} \sqrt{p q}
$$

Donde $\mathrm{X}_{\mathrm{p}}$ y $\mathrm{X}_{\mathrm{q}}$ son las medias en el test de los que acertaron el ítem y de los que no lo acertaron, $\mathrm{S}_{\mathrm{x}}$ es la desviación típica en el test y $\mathrm{p}$ es la proporción de sujetos que acertó el ítem. q es equivalente a 1-p. 
Tabla 4.21 Correlación biserial puntual para la prueba objetiva aplicada en Chile

Pre-test

\begin{tabular}{|c|c|c|}
\hline Ítem & $\mathbf{r b p}_{\mathrm{bp}}$ & Calificación \\
\hline Pre1 & 156 & Pobre \\
\hline Pre2 & 295 & Buena \\
\hline Pre3 & 169 & Pobre \\
\hline Pre4 & ,419 & Excelente \\
\hline Pre5 & ,327 & Buena \\
\hline Pre6 & ,303 & Buena \\
\hline Pre7 & 104 & Pobre \\
\hline Pre8 & ,254 & Buena \\
\hline Pre9 & , 179 & Pobre \\
\hline Pre10 & ,263 & Buena \\
\hline Pre11 & ,218 & Buena \\
\hline Pre12 & ,303 & Buena \\
\hline Pre13 & 234 & Buena \\
\hline Pre14 & , 106 & Pobre \\
\hline Pre15 & ,103 & Pobre \\
\hline Pre16 & ,184 & Pobre \\
\hline Pre17 & ,281 & Buena \\
\hline Pre18 & ,154 & Pobre \\
\hline Pre19 & 177 & Pobre \\
\hline Pre20 &, 426 & Excelente \\
\hline Pre21 & 289 & Buena \\
\hline Pre22 & ,251 & Buena \\
\hline Pre23 & , 183 & Pobre \\
\hline Pre24 & 179 & Pobre \\
\hline Pre25 & 186 & Pobre \\
\hline
\end{tabular}

Post-test

\begin{tabular}{|c|c|c|}
\hline Ítem & $r_{b p}$ & Calificación \\
\hline Post1 & ,281 & Buena \\
\hline Post2 & ,416 & Excelente \\
\hline Post3 & ,347 & Buena \\
\hline Post4 & ,363 & Buena \\
\hline Post5 & ,461 & Excelente \\
\hline Post6 & ,580 & Excelente \\
\hline Post7 & ,464 & Excelente \\
\hline Post8 & ,501 & Excelente \\
\hline Post9 & ,457 & Excelente \\
\hline Post10 & 105 & Pobre \\
\hline Post11 & ,393 & Buena \\
\hline Post12 & ,541 & Excelente \\
\hline Post13 & ,590 & Excelente \\
\hline Post14 & ,275 & Buena \\
\hline Post15 & 154 & Pobre \\
\hline Post16 & ,474 & Excelente \\
\hline Post17 & ,473 & Excelente \\
\hline Post18 & ,276 & Buena \\
\hline Post19 & ,310 & Buena \\
\hline Post20 & ,564 & Excelente \\
\hline Post21 & ,341 & Buena \\
\hline Post22 & ,335 & Buena \\
\hline Post23 &,- 112 & Pésima \\
\hline Post24 & ,326 & Buena \\
\hline Post25 & ,426 & Excelente \\
\hline
\end{tabular}

Fuente: Elaboración propia.

Todas las correlaciones obtenidas mediante este indicador mantienen valores positivos. Particularmente en los valores de los post-test, se tienen correlaciones positivas fuertes, a excepción del ítem Post23, que presenta un valor negativo, siendo descartado para el análisis posterior del instrumento. 
Tabla 4.22 Correlación biserial puntual para la prueba objetiva aplicada en España

Pre-test

\begin{tabular}{|c|c|c|}
\hline Ítem & $\mathbf{r}_{\mathrm{bp}}$ & Calificación \\
\hline Pre1 & ,148 & Pobre \\
\hline Pre2 & 192 & Pobre \\
\hline Pre3 &, 487 & Excelente \\
\hline Pre4 & ,154 & Pobre \\
\hline Pre5 & ,349 & Buena \\
\hline Pre6 & ,533 & Excelente \\
\hline Pre7 & 144 & Pobre \\
\hline Pre8 &,- 016 & Pobre \\
\hline Pre9 & ,242 & Buena \\
\hline Pre10 & 129 & Pobre \\
\hline Pre11 &,- 027 & Pobre \\
\hline Pre12 & ,335 & Buena \\
\hline Pre13 & ,021 & Pobre \\
\hline Pre14 & 180 & Pobre \\
\hline Pre15 & ,242 & Buena \\
\hline Pre16 & ,095 & Pobre \\
\hline Pre17 &,- 341 & Pésima \\
\hline Pre18 & 117 & Pobre \\
\hline Pre19 & ,295 & Buena \\
\hline Pre20 &, 021 & Pésima \\
\hline Pre21 & 278 & Buena \\
\hline Pre22 &,- 102 & Pésima \\
\hline Pre23 &,- 041 & Pobre \\
\hline Pre24 & ,368 & Buena \\
\hline Pre25 & 111 & Pobre \\
\hline
\end{tabular}

Post-test

\begin{tabular}{|c|c|c|}
\hline Ítem & $\mathbf{r b p}_{\text {bp }}$ & Calificación \\
\hline Post1 & 203 & Buena \\
\hline Post2 &, 438 & Excelente \\
\hline Post3 & ,068 & Pobre \\
\hline Post4 &,- 151 & Pésima \\
\hline Post5 & ,367 & Buena \\
\hline Post6 & ,331 & Buena \\
\hline Post7 & ,312 & Buena \\
\hline Post8 & ,320 & Buena \\
\hline Post9 & ,260 & Buena \\
\hline Post10 & 261 & Buena \\
\hline Post11 & ,531 & Excelente \\
\hline Post12 & 674 & Excelente \\
\hline Post13 & ,736 & Excelente \\
\hline Post14 & ,589 & Excelente \\
\hline Post15 & ,313 & Buena \\
\hline Post16 & ,309 & Buena \\
\hline Post17 & 448 & Excelente \\
\hline Post18 & 428 & Excelente \\
\hline Post19 & ,533 & Excelente \\
\hline Post20 & ,598 & Excelente \\
\hline Post21 & 198 & Pobre \\
\hline Post22 & ,545 & Excelente \\
\hline Post23 & 405 & Excelente \\
\hline Post24 & 493 & Excelente \\
\hline Post25 & 307 & Buena \\
\hline
\end{tabular}

Fuente: Elaboración propia.

Para el caso del instrumento aplicado en España es posible ver que los valores obtenidos en el pre-test no presentan valores que establezcan correlaciones significativas. 
Sin embargo, para los resultados obtenidos en el post-test existe un cambio en los valores de correlación, aumentando el grado existente entre los ítems y el puntaje total obtenido, generándose valores mayores respecto a los datos presentes en el pre-test. Con estos nuevos datos se ha agregado el ítem 21 para su eliminación por su bajo nivel de correlación en obtenido (Tabla 4.22).

\subsubsection{Población y muestra. Estudio cuasiexperimental}

Los participantes en este estudio corresponden a 178 alumnos de educación formal de centros educativos de Chile (ciudad de Santiago pertenecientes a los niveles de 70 y $8^{\circ}$ de enseñanza básica $n=145$ ) y España (Salamanca $1^{\circ}$ y $2^{\circ}$ de la ESO $n=33$ ). Teniendo como referencia las poblaciones pertenecientes para cada área los tamaños son equivalentes a $\mathrm{N}_{\text {santiago }}=237.455^{92}$ y $\mathrm{N}_{\text {salamanca }}=40.808^{93}$. Utilizando el cálculo para el tamaño muestral de poblaciones finitas (Arnal, Rincón, \& Latorre, 1992) que está dado por:

$$
n=\frac{N \times Z_{\alpha}^{2} \times p \times q}{d^{2} \times(N-1)+Z_{\alpha}^{2} \times p \times q}
$$

En donde,

N: Es el valor total de la población.

$Z \alpha$ : Valor Z para un nivel de confianza $1-\alpha$

p: Proporción esperada del parámetro a estudiar.

\footnotetext{
92 Ministerio de Educación Chile (2015).

${ }^{93}$ Valor obtenido del Instituto Nacional de Estadísticas de España (en http://www.ine.es/dynt3/inebase/index.htm?type=pcaxis\&file=pcaxis\&path=\%2Ft13\%2Fp001\%2Fe03\%2 F\%2Fa2013-2014, consultado el 9 de marzo de 2016). Este valor está conformado por los alumnos de segundo ciclo de los centros públicos presentes en la Comunidad de Castilla y León.
} 


\section{$q: 1-p$}

d: nivel de error máximo admitido posible.

Con la utilización de esta fórmula (con un nivel de significación $\alpha=.05 ; \mathrm{p}=\mathrm{q}=$

.5; y error máximo del 3\%) se obtiene como tamaño muestral a 1.062 sujetos para Santiago de Chile y 1.040 para Salamanca en España. Debido a la naturaleza de la investigación con un planteamiento de estructura cuasiexperimental, dicho muestreo no era posible de obtener por limitación de tiempo y recursos. De esta manera para asegurar la representatividad de la muestra obtenida, se ha realizado el contraste de hipótesis de correspondencia entre las distribuciones teórica y la muestral, mediante la prueba de bondad de ajuste basada en Chi cuadrado (Tabla 4.23, Tabla 4.24 y Tabla 4.25).

Tabla 4.23 Distribución de población y muestra de alumnos de 70 EGB Chile.

Sexo

Población

(fi)

\section{Mujer}

Hombre

Total

59.607

60.003

119.610

(\%)

Frecuencia

$49,83 \%$

$5,17 \%$

$100,00 \%$ teórica $(\mathbf{n}=\mathbf{5 0})$ 34,39

Frecuencia empírica

Chi Cuadrado

34,61

69,00

37,00

32,00

69,00
,200

,200

,396

Fuente Elaboración propia.

Como el valor del estadístico de contraste es $\chi^{2}{ }_{1 ; 00}=, 529>\chi^{2}=, 396$, se acepta la $\mathrm{H}$, en donde la distribución muestra se ajusta a la poblacional para 70 EGB para Santiago de Chile (Colegio 1).

Tabla 4.24 Distribución de población y muestra de alumnos de $8^{\circ}$ EGB Chile

Sexo

Población

Población

(\%)

Frecuencia

Frecuencia

Chi

(fi) teórica empírica Cuadrado

\begin{tabular}{c|c|}
\hline Mujer & 59.116 \\
\hline Hombre & 58.727 \\
\hline Total & 119.610 \\
\hline
\end{tabular}

Fuente Elaboración propia. 
Como el valor del estadístico de contraste es $\chi_{1 ; .05}^{2}=, 7963>\chi^{2}=, 066$, se acepta la $\mathrm{H}$, en donde la distribución muestra se ajusta a la poblacional para $1^{0}$ de educación secundaria para Santiago de Chile (Colegio 2).

Tabla 4.25 Distribución de población y muestra de alumnos de $1^{\circ}$ y $2^{\circ}$ de ESO España

Sexo Población

(fi)
Población

(\%)
Frecuencia teórica $(\mathbf{n = 5 0 )}$
Frecuencia empírica

\section{4,00}

15,83
33,00

\begin{tabular}{c|c|c|c|c|c|}
\hline Mujer & 19.571 & $47,96 \%$ & 17,17 & 14,00 &, 590 \\
\hline Hombre & 21.237 & $52,04 \%$ & 15,83 & 19,00 &, 640 \\
\hline Total & 40.808 & $100,00 \%$ & 33,00 & 33,00 & 1,222 \\
\hline
\end{tabular}

Chi Cuadrado

Fuente Elaboración propia.

Como el valor del estadístico de contraste es $\chi_{1 ; .05}^{2}=3,841>\chi^{2}=1,229$, se acepta la $\mathrm{H}$, en donde la distribución muestra se ajusta a la poblacional para $1^{\circ}$ y $2^{\circ}$ ESO de Salamanca, España (Colegio 3).

Tampoco existió un muestreo al azar como en otros modelos experimentales, estando en este caso los grupos constituidos de forma natural por el contexto escolar en que se presentaban, con niveles y cursos previamente ya formados, en lo que se conoce como muestreo probabilístico por conveniencia / incidental / accidental. Así, en este ejercicio, no existió un muestreo en donde se asignara a los sujetos de manera aleatoria para cada grupo con el fin de obtener la medición de la variable independiente. De esta manera y para todas las experiencias educativas realizadas (tableta/ordenador de escritorio; Chile/España), la asignación aleatoria no era posible por razones prácticas (Kirk, 1995). En esta investigación, el diseño cuasi-experimental aplicado se planteó como un plan de trabajo con el fin de establecer el impacto del tratamiento (uso de herramientas e-learning, m-learning) en un contexto donde los sujetos (alumnos) como unidades de observación no fueron asignados de manera aleatoria (Arnau, 1995). De esta manera, se tuvieron en consideración estos elementos para asegurar los correctos resultados de la metodología: 
- Manipulación de la variable independiente, mediante la configuración adecuada de los tratamientos realizados para cada grupo. De manera adicional, se estableció que cada grupo de sujetos tuvieran los mismos conocimientos previos sobre el tema de patrimonio, relacionado particularmente en el proceso formativo que estaban teniendo en los centros educativos respectivo.

- La no existencia de aleatorización en la formación de los grupos. Cada curso de sujetos en la que fue aplicado el tratamiento de control correspondían a grupos formados con más de un semestre de antelación, relacionado con los calendarios escolares formales de cada país, lo que garantizaba la equivalencia inicial de los sujetos a la prueba objetiva y la intervención educativa94.

- Control de las variables de distracción, las que se refieren particularmente a los contextos naturales (centro educativo) de los alumnos, alejados de un laboratorio en donde se puede controlar el ambiente donde se desarrolló el tratamiento. Para este caso, la validez de los resultados y el control de estas variables de distracción se aseguró con la representatividad de la muestra en relación a que tanto el grupo control (ordenador de escritorio) como el grupo experimental (tabletas) tenían el mismo profesor(a)/maestro(a) responsable de las clases de historia, geografía y ciencia sociales; ambos grupos fueron constituidos en el mismo centro educativo en el mismo periodo lectivo; los grupos corresponden al mismo nivel escolar; y corresponden al mismo país.

\subsubsection{Análisis de los datos}

Adicionalmente se aplicaron una serie de técnicas estadísticas, tanto psicométricas como exploratorias (de tipo descriptivo, correlacional, inferencial y multivariante), a partir de los resultados obtenidos en el test para medir la validez del instrumento elaborado adhoc y de la propia experiencia. Se parte en este caso desde la perspectiva de la Teoría

\footnotetext{
94 El principal problema de la falta de aleatorización radica en que si la equivalencia inicial de los grupos de sujetos no se encuentra garantizada, es posible cuestionar que las diferencias obtenidas entre los grupos después de la intervención (post-test) se deban realmente al efecto del tratamiento. Esta situación atenta contra la validez interna de la investigación, poniendo en cuestión la posible relación causal existente entre las variables independientes y dependientes. De esta manera, la igualdad de los grupos es controlada mediante la medida pre-test con valores que puedan ser comparados.
} 
Clásica de los Test (Abad et al., 2011; Muñiz, 2010). De manera específica, las técnicas utilizadas son:

- Previo a los análisis correspondientes, los valores obtenidos fueron transformados a una escala $\mathrm{T}$, con media 50 y desviación típica de 15 , con el fin de permitir la comparación de los resultados obtenidos de los instrumentos Pre-Test y Post-Test, para su representación en los diagramas de densidad y de cajas.

- Análisis exploratorio de los datos obtenidos en el test con los datos de posición percentiles-, medidas de dispersión -varianza, desviación típica, rango y coeficiente de variación- y medidas de forma de la muestra -asimetría y curtosis(Hernández et al., 2010; Nieto Martín, 2011).

- Determinación de las funciones de densidad para comprobar el ajuste de la muestra a una distribución normal. La aplicación del test de Levene que permite contrastar la bondad de ajuste con respecto a la homocedasticidad o homogeneidad de varianzas (Martínez Abad, 2013).

- Aplicación de pruebas paramétricas para realizar la inferencia respectiva (contraste de hipótesis), utilizando la t de Student, si los datos presentan una distribución normal, con el fin de comparar la dependencia o independencia de dos variables diferencia de medias para muestras relacionadas- (Hernández et al., 2010). En caso de encontrar valores atípicos extremos en los ítems analizados, se empleará el cálculo con una media recortada al 5\% (Borges del Rosal, Cañadas Osinski, \& Sánchez Bruno, 2000).

- En el caso que los datos no presenten una distribución normal, se procederá a la aplicación de contrastes no paramétricos, particularmente la prueba de los rangos con signo de Wilcoxon y U de Mann-Whitney (Berlanga Silvente \& Rubio Hurtado, 2012). Para el caso particular de los datos obtenidos de Chile, se ha realizado un análisis de varianza con medidas repetidas -ANOVA-MR- (Berlanga Silvente \& Rubio Hurtado, 2012; Pardo Merino, 2002), con el fin de estudiar el efecto de los tratamientos en un contexto intrasujetos, es decir, el contexto Pre-Test/Post-Test realizado con la experiencia educativa. 
- Para todos los casos se aplicó el cálculo de la potencia de la prueba y el tamaño del efecto, el cual se encuentra basado en el estadístico $\mathrm{g}$ de Hedges para la prueba t (Cárdenas Castro \& Arancibia Martini, 2014; Mayr, Buchner, Erdfelder, \& Faul, 2007), el cálculo de la probabilidad de superioridad (Grissom \& Kim, 2011) y el tamaño del efecto basado en la correlación (Corder \& Foreman, 2009) en el caso de utilizar el contraste no paramétrico.

Para la aplicación de los contrastes de hipótesis se utilizó los softwares IBM SPSS 21 complementado con los programas MS-Excel 2013 y R en su versión 3.2.4. Por último, se procedió a la valoración del instrumento de satisfacción aplicada a los alumnos, mediante el uso de técnicas de estadística descriptiva, teniendo en consideración los parámetros del tipo de tratamiento aplicado.

Como elemento de análisis añadido para esta sección cuantitativa, y con el fin de complementar los datos obtenidos con el instrumento de evaluación, se realizó un análisis y valoración de la satisfacción de los alumnos, con el objetivo de asegurar la información del tratamiento efectuado. Dicho análisis se realizó mediante el uso de estadísticas descriptivas a los datos obtenidos mediante un cuestionario de satisfacción de 10 preguntas de tipo Likert, que se hallará en el Anexo 06.

\subsection{Marco metodológico de la experiencia educativa: fase cualitativa}

Desde un enfoque diferenciado pero complementario, en este ejercicio de investigación se aplicó una metodología cualitativa, entrevistando a varios de los sujetos participantes de la experiencia educativa y con esto, permitiendo generar una visión global de los elementos y contextos que se encuentran presentes en la intervención mediada por la tecnología con herramientas que están en constante evolución y adaptación. Aplicando esta dimensión cualitativa al estudio, se pretende profundizar el problema planteado en la hipótesis general desde el enfoque natural y social en que se desarrolla, es decir, desde la perspectiva establecida por los propios actores participantes (Ruiz Olabuénaga, 2012; Yang, 2013). Flick (2007) plantea que mediante una metodología cualitativa es posible analizar las experiencias de los sujetos o sus comunidades, relacionándolo con sus historias de vida o con sus prácticas en determinados contextos, personales o grupales, íntimos o profesionales. La generación de esta información se deriva del análisis del 
conocimiento cotidiano, las posibles interacciones y comunicaciones mediante la observación y el registro de estas dinámicas. Otros elementos a considerar dentro de la aplicación de una metodología cualitativa son (Pérez Serrano, 1994, p. 70):

- Como metodología es ideal para aplicar en estudios de pequeña escala (nivel micro), intentando profundizar en la situación como objeto de investigación.

- Con la metodología cualitativa es posible señalar aspectos y diferencias que podrían cumplir un cierto rol dentro de un sistema social o explicar aspectos que no se pueden abordar con la metodología cuantitativa.

- El enfoque que se desarrolla en una metodología cualitativa se orienta al descubrimiento y comprensión de lo que tiene significado es relevante y consiente para los participantes.

Desde la dimensión educativa, la metodología cualitativa se adapta a las investigaciones, ya que los procesos educativos corresponden a una realidad socio-cultural que es compleja, singular y que se encuentra establecida en un contexto social particular. Además existen elementos que diferencian este tipo de metodologías con las actividades experimentales (Albert Gómez, 2006):

- Los procesos y fenómenos educativos, la mayoría de la veces, son únicos, difíciles de replicar y repetir.

- Existe una dificultad añadida en torno a la multiplicidad de variables que se insertan dentro de un contexto educativo, muchas de las veces imposible de abordar en su totalidad.

- Las actividades y fenómenos educativos son multidisciplinares pudiéndose abordar desde diferentes perspectivas.

Así, la metodología cualitativa, a diferencia de la cuantitativa, no pretende obtener la generalización de resultados, sino más bien la comprensión del fenómenos en su complejidad, permitiendo una posible orientación en contexto educativos similares (Yang, 
2013, p. 121). En el caso de la presente tesis, la investigación cualitativa queda justificada por tres dimensiones planteadas por Yang (2013):

- La utilización de tabletas en ambientes educativos formales es un fenómeno sociocultural complejo;

- La utilización de tabletas en ámbitos educativos continúa siendo una práctica novedosa y que se encuentra en continuo desarrollo y evolución;

- El uso educativo que se le realiza a esta herramienta no es una práctica masificada, presentándose en experiencias pedagógicas localizadas y particulares.

Se puede agregar que las experiencias educativas se refieren a las tabletas como un instrumento educativo que es parte del aula formal, no utilizando su potencial como recurso tecnológico en contexto de movilidad o trabajo de campo, situación que se hace necesario comprender y establecer desde este tipo de metodología.

\subsubsection{Contexto metodológico cualitativo de la entrevista}

Dentro de la diversidad de metodologías presentes en el marco cualitativo, de manera particular esta investigación utilizó la entrevista, como marco de obtención de información sobre acontecimientos y elementos subjetivos de las personas estudiadas (Martín Izard, 2011), elementos que no pueden ser obtenidos mediante otros medios tradicionales de índole cuantitativo. Hernández et al (2010) definen a la entrevista como una reunión entre dos actores (el entrevistador y el entrevistado) que se comunican para el intercambio de información, lográndose una comunicación y la creación en conjunto de significados respecto al contexto, tema o situación.

Kvale (2011) reconoce 7 etapas de la investigación desarrollada con entrevistas, reconociendo que, a pesar que no existen estructuras funcionales o normas estandarizadas, la utilización de este método mantiene idealmente una progresión lineal, permitiendo guiar adecuadamente el trabajo de obtener información (Tabla 4.26): 
Tabla 4.26 Las siete etapas de la investigación con entrevistas

\section{Ítem Descripción}

1. Organización

Temática

2. Diseño

3. Entrevista

4. Transcripción

5. Análisis

6. Verificación

7. Informe
Formulación del propósito de una investigación y la concepción del tema que se va a investigar antes de empezar las entrevistas.

Planeamiento del diseño del estudio. Este diseño de estudio se emprende en relación con la obtención del conocimiento pretendido y teniendo en cuenta las implicaciones morales del estudio.

Realización de las entrevistas basándose en una guía de entrevista y con un enfoque reflexivo hacia el conocimiento que se busca y la relación interpersonal de la situación de entrevista.

Preparación del material de entrevista para el análisis, que incluye por lo general una transcripción del habla oral a texto escrito.

Decisión, a partir del propósito y el tema de la investigación, y de la naturaleza del material de entrevista, de los modos de análisis que son apropiados para las entrevistas.

Establecimiento de la validez fiabilidad y capacidad de generalización de los hallazgos de la entrevista. La fiabilidad se refiere a la coherencia de los resultados y la validez a si el estudio con entrevistas ha investigado lo que se pretende que investigue.

Comunicación de los hallazgos del estudio y los métodos aplicados en una forma que se ajuste a los criterios científicos, tomando en consideración los aspectos éticos de la investigación y que desemboque en un producto que resulte interesante.

Fuente: Kvale, 2011.

\subsubsection{Grado de estructuración y finalidad de la entrevista aplicada}

Debido al contexto y temática de investigación, las entrevistas realizadas corresponden al tipo estructurada (Brinkmann, 2014; Martín Izard, 2011; Vela Peón, 2001), en donde, desde un guion preestablecido, ordenado y dirigido, se plantearon las preguntas para obtener la información necesaria en el contexto de la investigación. Particularmente, la metodología de la entrevista tiene la ventaja de facilitar al investigador la posibilidad de encontrar diferencias individuales y particulares de los cambios en la situación experimentada, pudiendo individualizarse y contextualizarse para poder llegar a un nivel de comunicación más profundo. De esta manera, las preguntas se desarrollaron de manera cerrada, realizando un contexto de entrevista rígida buscando la exactitud de la información aunque fuera limitada. En este tipo de entrevistas las preguntas han sido elaboradas con anticipación, y aunque se plantea un escenario rígido de las consultas, 
existe la posibilidad de flexibilizar su aplicación con el fin de ayudar a la sistematización de la información obtenida (Vargas Jiménez, 2012). En cuanto al tipo de preguntas realizadas a los maestros/profesores, se les formularon preguntas en 4 ámbitos con 23 ítems (Tabla 4.27):

Tabla 4.27 Preguntas realizadas a los profesores/docentes

Ámbito

\begin{tabular}{l}
\hline $\begin{array}{l}\text { Información } \\
\text { sociodemográfica }\end{array}$ \\
$\begin{array}{l}\text { Experiencia con la } \\
\text { tecnología }\end{array}$ \\
\\
Práctica docente con \\
TIC
\end{tabular}

\section{Experiencia educativa realizada}

\section{Preguntas}

- ¿qué edad tienes?

- ¿cuánto tiempo ejerces tu actividad como maestra(o)?

- ¿empleas algún tipo de tecnología?

- ¿desde cuándo ocupas el ordenador?

- ¿en tu contexto familiar empleaban ordenador?

- ¿usas algún otro dispositivo?

- ¿tienes acceso a Internet? ¿dónde?

- cusas TIC en tu quehacer como maestra(o)?

- ¿ ¿cuál es el uso real y las posibilidades que les das a las TIC en tu quehacer docente?

- ¿estás de acuerdo con el uso de TIC en la enseñanza formal?

- ¿qué actividades con el uso de TIC haces en el colegio?

- En términos generales ¿qué te pareció la experiencia educativa realizada?

- chabías usado tabletas en alguna actividad educativa en el colegio?

- ¿ ¿qué te pareció la aplicación utilizada?

- ¿qué te pareció el uso de esta herramienta como material didáctico en el contexto de la enseñanza del patrimonio?

- ¿qué te pareció el contexto de trabajo de campo realizado?

- ¿qué te pareció el uso educativo de estos mapas portátiles, sobre todo en esta experiencia?

- ¿ ¿qué te pareció el uso del sistema de navegación?

- ¿qué te pareció la implementación de la realidad aumentada en esta experiencia?

- ¿qué elementos, situaciones o cosas no te gustaron de la actividad educativa realizada?

- ¿ ¿volverías a realizar esta actividad y que elementos mejorarías si tuvieras que volver a realizar esta experiencia educativa?

- ¿es mejor una actividad en el aula o como trabajo de campo con estas herramientas?

- ¿crees que en el trabajo de campo el profesor era prescindible?

Fuente: Elaboración propia. 
En cuanto al tipo de preguntas realizadas a los alumnos, se realizaron consultas en 4 ámbitos con 23 ítems (Tabla 4.28):

Tabla 4.28 Preguntas realizadas a los alumnos

\begin{tabular}{|c|c|c|}
\hline Ámbito & Preg & untas \\
\hline \multirow{2}{*}{$\begin{array}{l}\text { Información } \\
\text { sociodemográfica }\end{array}$} & - & ¿qué edad tienes? \\
\hline & - & ¿cuántas personas componen tu grupo familiar? \\
\hline \multirow{5}{*}{$\begin{array}{l}\text { Experiencia con la } \\
\text { tecnología }\end{array}$} & - & ¿empleas algún tipo de tecnología? \\
\hline & - & ¿desde cuándo empleas el ordenador? \\
\hline & - & ¿en tu contexto familiar empleas el ordenador? \\
\hline & - & ¿usas algún otro dispositivo? \\
\hline & - & ¿tienes acceso a Internet? ¿dónde? \\
\hline \multirow{5}{*}{$\begin{array}{l}\text { Uso educativo } \\
\text { personal de TIC }\end{array}$} & _ & $\begin{array}{l}\text { ¿los profesores/maestras utilizan algún tipo TIC en sus } \\
\text { clases? }\end{array}$ \\
\hline & - & $\begin{array}{l}\text { ¿haces alguna labor o tarea del colegio con la ayuda de } \\
\text { tecnología? }\end{array}$ \\
\hline & - & ¿qué actividades con el uso de TIC haces en el colegio? \\
\hline & - & $\begin{array}{l}\text { ¿crees que a los profesores les gusta usar TIC en sus } \\
\text { clases? }\end{array}$ \\
\hline & - & ¿te gustan las clases con el uso de TIC o sin ellas? \\
\hline \multirow{9}{*}{$\begin{array}{l}\text { Experiencia educativa } \\
\text { realizada }\end{array}$} & - & $\begin{array}{l}\text { En términos generales ¿qué te pareció la experiencia } \\
\text { educativa realizada? }\end{array}$ \\
\hline & 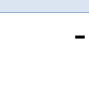 & $\begin{array}{l}\text { ¿habías usado tabletas en alguna actividad educativa en el } \\
\text { colegio? }\end{array}$ \\
\hline & - & ¿qué te pareció la aplicación utilizada? \\
\hline & - & $\begin{array}{l}\text { ¿qué te pareció el uso de esta herramienta como material } \\
\text { didáctico en el contexto de la enseñanza del patrimonio? }\end{array}$ \\
\hline & - & ¿qué te pareció el trabajo de campo realizado? \\
\hline & _ & $\begin{array}{l}\text { ¿qué te pareció el uso educativo de estos mapas } \\
\text { portátiles, sobre todo en esta experiencia? }\end{array}$ \\
\hline & - & ¿qué te pareció el uso del sistema de navegación? \\
\hline & 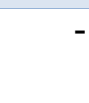 & $\begin{array}{l}\text { ¿qué te pareció la implementación de la realidad } \\
\text { aumentada en esta experiencia? }\end{array}$ \\
\hline & & $\begin{array}{l}\text { ¿qué elementos, situaciones o cosas no te gustaron de la } \\
\text { actividad educativa realizada? }\end{array}$ \\
\hline
\end{tabular}

Fuente: Elaboración propia. 
Todas las entrevistas fueron registradas en audio y posteriormente transcritas en información textual, en las cuales sólo se realizaron pequeñas modificaciones o variaciones para facilitar su comprensión. Dichas alteraciones se han dejado explicitas con marcadores -paréntesis- (véase los Anexos 09 y 10). Teniendo en consideración que puede haber diferencias y cambios de interpretación, debido al proceso de trascripción (en el lenguaje escrito y hablado las formas de comunicación son distintas), para asegurar la representación de la información escrita por parte de los entrevistados, se les entregó la versión textual de su entrevista para que realizarán sus observaciones, comentarios y finalmente la respectiva aprobación del texto y su contenido para su posterior análisis.

Desde el ámbito de la funcionalidad que persigue la entrevista, esta se planteó como un instrumento de modalidad final con el fin de conocer la percepción de los sujetos, sus impresiones, sentimientos, etc. acerca de la experiencia y herramienta utilizada dentro de su contexto de aprendizaje. De esta manera, una vez conocidos los resultados de las evaluaciones de la prueba objetiva, se procedió a la elección de los sujetos para la aplicación de la entrevista. Dependiendo de los grupos de sujetos entrevistados (alumnos o profesoras, profesores) se definieron algunos parámetros particulares de aplicación (Kvale, 2011):

a. Para el caso de los alumnos se estableció una introducción general a la actividad realizada, estableciendo el contexto de la entrevista, la presentación del entrevistador, la consulta de los datos del sujeto a entrevistar (edad, nivel, antigüedad en el colegio, grupo familiar). Paralelamente se aseguró el rapportss estableciendo un espacio físico de confianza donde se desarrolló la entrevista (normalmente el despacho de la maestra(o) encargado de curso, otras veces la sala de clases). Para complementar y facilitar la dinámica comunicativa, se utilizó un lenguaje coloquial, usando jergas, muletillas y formas de hablar que permitieran distender la conversación, particularmente con los alumnos. La duración establecida de la entrevista fue de 30 minutos, y el cierre de la actividad se estableció con la lectura de los puntos abordados en la conversación, con el fin de corregir o completar alguna información, y la consulta al alumno sobre la

\footnotetext{
95 Una fase previa en la entrevista lo constituye el rapport con el fin de lograr una correcta conexión psicológica y emocional entre entrevistado y entrevistador (C. M. Davis, 2006).
} 
posibilidad de agregar algún elemento o comentario que considerada importante mencionar.

b. Para el caso de los maestros o profesores, se estableció la misma presentación general, explicando el propósito de la entrevista que se iba a realizar. Paralelamente se consultó sobre el contexto de su trabajo educativo (especialidad educativa, experiencia en el área de trabajo, periodo de labores en el centro educativo), mientras que para asegurar adecuadamente el rapport se estableció definiendo un contexto físico cómodo para la entrevista, escenario que fue propuesto por los entrevistados, desarrollándose en despachos o en zonas de sus preferencias. La duración planteada de la entrevista fue de 45 minutos en promedio, y el cierre de la actividad se estableció con la lectura de los puntos abordados y obtenidos con el dialogo de preguntas y respuestas realizadas, esto con el fin de que los docentes pudieran corregir, realizar observaciones o completar alguna información entregada por ellos. Finalmente, se les consultó sobre la opción de incorporar elementos importantes para el escrito o la posibilidad de agregar algún comentario a los datos ya entregados.

\subsubsection{Número de participantes en el proceso de entrevistas}

A diferencia de modelos y herramientas cuantitativas, para el desarrollo de la entrevistas se hace necesario contar con un tipo de fuente de información que tiene características flexibles y adaptables al contexto de la búsqueda de datos que se pretende obtener sujetos-. Mertens (2010) señala que el número de entrevistas se establece desde la búsqueda de un contexto general a uno particular: se comienza desde los ambientes generales donde se produce el fenómeno (Santiago de Chile o Salamanca en España), se agrupan en unidades (grados, niveles o cursos de los alumnos) hasta llegar a los individuos. De esta manera, para este caso se dan diversas particularidades en la elección de los casos:

- En un contexto general se utilizó una muestra de casos-tipo (Hernández et al., 2010), ya que el objetivo de la recopilación de esta información es la riqueza, profundidad y calidad de la información, más que la estandarización y generalización de datos. 
- De manera particular, por un lado, se utilizó el criterio de muestra por casos extremos (Creswell, 2008) con el fin de determinar las características y fenómenos que se alejaron de la normalidad entregada por los resultados del análisis cuantitativo. De esta manera se entrevistó a los alumnos con mejores resultados ( 3 para el caso de Chile y 1 para el caso de España) y a los que tuvieron un peor resultado ( 2 para el caso de Chile y 1 para el caso de España) en la prueba objetiva -post-test- aplicado.

- Para el caso de los docentes participantes como coordinadores y observadores se utilizó el tipo de muestra por oportunidad (Hernández et al., 2010) referida principalmente a los maestros y profesores que acompañaron a los alumnos y que pudieron observar y participar en el proceso, ya que por sus características, pudieron entregar valiosa información sobre el rendimiento educativo de la intervención tecnológica propuesta (3 para el caso de Chile y 1 para España).

\subsubsection{Técnicas de análisis de los datos obtenidos}

Una vez obtenida la información de los sujetos seleccionados se procede al análisis de los datos mediante un modelo inductivo, generando y estableciendo categorías que representen, comprueben o contradigan la estructura teórica propuesta. Utilizando los planteamientos de Huberman y Miles (1994), se establecen los siguientes pasos:

- La reducción de datos obtenidos en la entrevistas, estableciendo su respectiva transcripción a texto escrito, además de su selección, codificación y abstracción. En esta etapa, esta reducción de datos se derivó en la cuantificación de conceptos y elementos, la selección y resumen de contenidos relevantes ${ }^{96}$.

- En torno a la presentación de los datos, se muestra la información recabada y reducida en función del análisis realizado, de manera organizada con el fin de ayudar a su análisis, contextualización y la construcción de conclusiones. Los resultados pueden visualizarse en nubes de palabras, gráficos, tablas, textos ampliados, entre otros recursos.

\footnotetext{
${ }^{96}$ Este proceso se llevó a cabo mediante el software de análisis estadístico ATLAS.ti versión 1.0.26 para Mac OS X.
} 
- Finalmente se realiza el proceso de construcción de las conclusiones, teniendo en consideración la verificación de la información obtenida.

En este caso, la entrevista como parte esencial de esta investigación, se realizó utilizando la siguiente estructura (Figura 4.20):

Figura 4.20 Estructura del análisis de las entrevistas

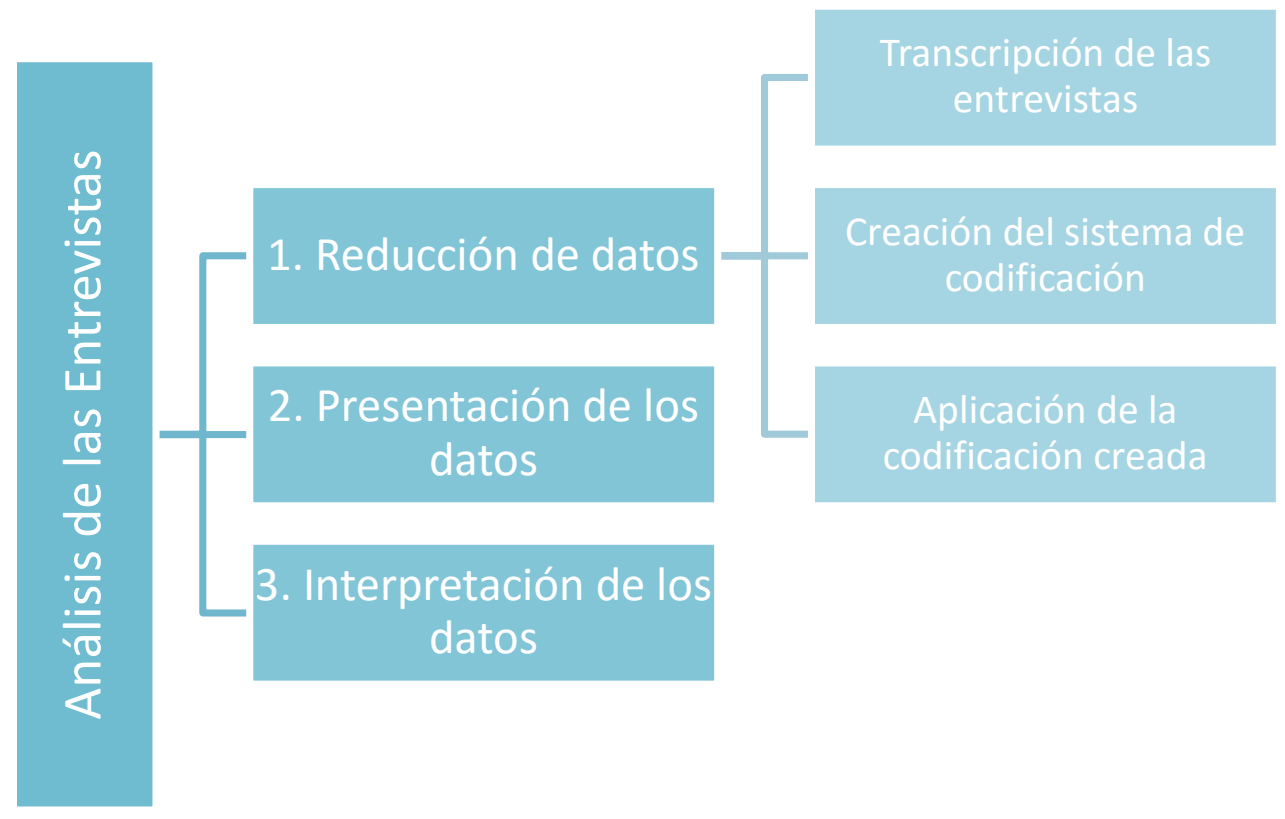

Fuente: elaboración propia basada en Ling (2013)

Así, desde el diseño sistemático con el desarrollo de fases operativas (Corbin \& Strauss, 2014), se procedió al análisis de las entrevistas, generando categorías derivadas de la revisión de los antecedentes recopilados, realizando una segmentación de los elementos singulares de la información que sean importantes para la investigación (Hernández et al., 2010; Huberman \& Miles, 1994; Yang, 2013). Una vez obtenidas las primeras categorías derivadas de la información de las entrevistas se comenzó a agrupar y ordenar estos elementos en torno al concepto general de aprendizaje con recursos tecnológicos, desarrollando sus dimensiones, variaciones y elementos relevantes desde esta idea central (subcategorías). Cada subcategoría fue clasificada en una dimensión 
mayor permitiendo establecer un escenario cualitativo de las experiencias desde sus protagonistas, asignándole una codificación representativa para su posterior análisis (Tabla 4.29 y Tabla 4.30 ).

Tabla 4.29 Sistema de categorías utilizadas en la entrevista para los docentes

\section{Categoría}

\section{Antecedentes sociales- particulares. Elementos sociodemográficos de los docentes}

\section{Uso personal de la tecnología. Actitudes y funcionalidades que otorgan a la tecnología en su vida personal.}

\section{Uso de la tecnología en contexto educativo. Actitudes y funcionalidades que otorgan a la tecnología en el ámbito profesional docente.}

\section{Evaluación de la experiencia, desde el sentido personal y profesional}

\section{Subcategoría}

Codificación

\begin{tabular}{|l|c|}
\hline Contexto social educativo & PRO1.1 \\
\hline Contexto familiar tecnológico & PRO1.2 \\
\hline Experiencia con la tecnología & PRO2.1 \\
\hline Actitudes frente a la tecnología & PRO2.2 \\
\hline $\begin{array}{l}\text { Tipología en el uso de la herramienta } \\
\text { educativa. }\end{array}$ & PRO2.3 \\
\hline
\end{tabular}

Percepción tecnológica en contextos educativos formales

PRO3.1

Utilización de TIC en las actividades educativas. Práctica docente con tecnología

Obtención de objetivos educativos

PRO3.3

Adaptación de los recursos TIC

PRO3.4

Estrategias educativas con TIC.

PRO3.5

Interacción con los alumnos en contextos TIC

PRO3.6

Percepción de la actividad de trabajo de campo para el aprendizaje

PRO4.1

Percepción educativa de los mapas digitales y la NPM

PRO4.2

Percepción educativa de la RA PRO4.3

Percepción educativa de las tabletas PRO4.4

Limitaciones de los recursos usados en la experiencia

PRO4.5

Sentimiento en torno a estas experiencias (tabletas y ordenador de escritorio).
PRO4.6

Fuente: Elaboración propia. 
La categoría Antecedentes sociales-particulares-Elementos sociodemográficos de los docentes reúne las referencias en torno a la información general del entrevistado, sirviendo de proceso de transición entre el rapporty las consultas siguientes.

En cuanto a la categoría Uso personal de la tecnología-Actitudes $y$ funcionalidades que otorgan a la tecnología en su vida personal, agrupa la información sobre la percepción de los entrevistados hacia las TIC, su nivel y tipo de uso que realizan en sus contextos personales. Se establecieron referencias a cualidades, tipos de plataformas, preferencias y utilidad a las herramientas informáticas generales.

En torno a la categoría Uso de la tecnología en contexto educativoActitudes $y$ funcionalidades que otorgan a la tecnología en el ámbito profesional docente, se establecen las ideas en torno a la tecnología en la práctica docente, sus características y percepciones dentro del sistema de educación formal en que se desenvuelven.

Finalmente en Evaluación de la experiencia, desde el sentido personal y profesional, se reúnen las referencias sobre la actividad desarrollada, la percepción sobre la actividad y el conjunto de herramientas utilizadas, las dificultades, limitaciones encontradas, con los planteamientos en torno a la posible inclusión de estos sistemas. 
Tabla 4.30 Sistema de categorías utilizadas en la entrevista para los alumnos

Categoría

Subcategoría

\begin{abstract}
1. Antecedentes socialesparticulares. Elementos sociodemográficos de los alumnos
\end{abstract}

\section{Uso personal de la tecnología. Actitudes y funcionalidades que otorgan a la tecnología en su vida personal.}

\section{Uso de la tecnología en contexto educativo. Actitudes y funcionalidades que otorgan a la tecnología en su aprendizaje formal}

\section{Evaluación de la experiencia, desde el sentido personal y profesional}

Fuente: Elaboración propia.

\begin{tabular}{|l|l|}
\hline Contexto social educativo & EST1.1 \\
\hline Contexto familiar tecnológico & EST1.2 \\
\hline
\end{tabular}

Experiencia con la tecnología

EST2.1

Actitudes frente a la tecnología

EST2.2

Tipología en el uso de la herramienta de herramientas tecnológicas

EST2.3

Percepción tecnológica en contextos educativos formales

EST3.1

Utilización de TIC en las actividades educativas. Aprendizaje formal con

EST3.2 tecnología

Estrategias que utilizan para su aprendizaje con herramientas TIC.

Interacción entre compañeros/alumnos $\quad$ EST3.4

en contextos TIC de aprendizaje

\begin{tabular}{l|l} 
Percepción sobre el aprendizaje con & EST4.1
\end{tabular}

mapas digitales y la NPM

Percepción sobre el aprendizaje con RA $\quad$ EST4.2

Percepción sobre el aprendizaje con

EST4.3

tabletas

Sentimiento en torno a la experiencia de $\quad$ EST4.4

trabajo de campo con tabletas.

La categorización realizada a las entrevistas de los alumnos fue similar a la de los docentes, pero con variaciones en el contexto de las preguntas y dimensiones establecidas. Así, en la categoría Antecedentes sociales-particulares-Elementos sociodemográficos de los alumnos se reunieron las referencias en torno a la información general de los alumnos y su contexto personal, entregando un punto de inicio para las siguientes consultas.

En cuanto a la categoría Uso personal de la tecnología-Actitudes $\boldsymbol{y}$ funcionalidades que otorgan a la tecnología en su vida personal, agrupa la información sobre la percepción de los entrevistados hacia las TIC, su nivel y tipo de uso que realizan en sus contextos personales (familiares, amigos). También se establecieron 
referencias a las cualidades, tipos de plataformas, preferencias y utilidad a las herramientas informáticas generales.

En la categoría Uso de la tecnología en contexto educativo-Actitudes $y$ funcionalidades que otorgan a la tecnología en el ámbito profesional docente, se establecen las ideas y conceptos esenciales de los entrevistados que tienen en torno a la tecnología en sus procesos de aprendizaje formal, teniendo en cuenta sus características y percepciones dentro de la comunidad escolar en que participan.

En la última categoría Evaluación de la experiencia, desde el sentido personal y profesional, se establecen las referencias sobre la intervención educativa desarrollada (tratamiento) desde aspectos como son la percepción sobre la actividad realizada, la percepción al conjunto de herramientas utilizadas, las dificultades, limitaciones encontradas, desde la perspectiva particular como alumno y como partícipe de un grupo curso. 


\subsection{Resumen}

En el presente capítulo se ha realizado una exposición de la metodología utilizada para el desarrollo de la tesis, sus características e indicadores, dividida en 3 etapas que abarcan, desde los aspectos tecnológicos hasta los elementos puramente metodológicos, pasando por el contenido temático territorial. De la misma manera, se han expuesto los objetivos que busca este marco metodológico, que desde una escala general se presenta como del tipo mixto o cuantitativo-cualitativo, permitiendo conocer mejor la realidad de las intervenciones realizadas en un contexto de m-learning, u-learning y el tradicional directo con el uso de TIC en un aula, entendido como e-learning.

Desde la dimensión temática, la idea es trabajar con la síntesis de variables territoriales a través de un modelo de Evaluación Multicriterio teniendo como base las características patrimoniales de cada ciudad como áreas de implementación. Desde la dimensión tecnológica se ha apostado por una metodología conocida como Modelo de Cascada, clásica en el desarrollo del software y válida en particular para el desarrollo aplicaciones móviles y con lenguajes de programación orientados a objetos. La fase experimental de la tesis está marcada por un diseño cuasiexperimental pre-test/post-test con grupo control, que, mediante la implementación de una prueba objetiva -la cual se valida dentro de la Teoría Clásica de los Tests- y en diferentes escenarios de aplicación, evalúa el posible potencial de la herramienta y tecnología en contextos de aprendizaje. Finalmente, se plantea un ámbito cualitativo de acción investigativa como perspectiva complementaria, en la que se emplean como recursos las entrevistas y su análisis, lo cual permite abordar aspectos que no son posibles de conocer desde una orientación puramente cuantitativa. 
Capítulo V

Desarrollo y resultados 



\section{DESARROLLO Y RESULTADOS}

\subsection{Modelos de desplazamiento territorial}

\subsubsection{Modelado de rutas}

Desde la implementación de las zonas patrimoniales para cada ciudad, el establecimiento de su red de desplazamiento (ejes de calles) y los hitos patrimoniales seleccionados, se establecieron los modelos de navegación peatonal conducentes a las experiencias educativas definidas como tratamiento. Así, los valores generales obtenidos establecen que la longitud total de las redes para las zonas E de Santiago y A de Salamanca son de $11.150,1$ y 4.044,13 metros, las cuales se encuentran en el planteamiento del contexto de navegación peatonal desarrollado para la implementación educativa. Para la elaboración de estos modelos se tuvo en consideración una serie de condiciones base preestablecidas para la obtención de los resultados que se expresan territorialmente:

- En los escenarios modelados no se tiene en consideración la estructura topográfica (en lo referente a la pendiente) de las zonas establecidas, elemento que podría condicionar el desplazamiento de los usuarios y el modelo generado, es decir, sólo se consideraron los valores $\mathrm{X}$ e $\mathrm{Y}$ (posición geográfica) correspondientes a objetos presentes en el territorio.

- No hay diferencias entre tipos de vías existentes (peatonales y de desplazamiento vehicular), tampoco hay referencia del sentido del tránsito vehicular, ni se consideró la condición horaria (momento del día) en los volúmenes de movimiento peatonal y vehicular que se presentan en las redes analizadas. De esta manera, se plantea un modelo topológico simplificado con la utilización de arcos (polylines) y sus intersecciones. Sin embargo, como condición sine qua non, todas las líneas modeladas en la definición de la ruta permiten el desplazamiento peatonal hacia los hitos patrimoniales.

- No se consideran las acciones de detención propias de cada hito (visualización de recursos educativos, consulta de datos), o las detenciones derivadas por los elementos de la normalización de desplazamiento (restricciones debidas a semáforos y otras normas de circulación peatonal). 
- La velocidad de desplazamiento se establece en un valor constante de 5 kilómetros/hora o 83,33 metros/minuto, correspondiente a la velocidad promedio de una persona al caminar (Browning, Baker, Herron, \& Kram, 2006; Mohler, Thompson, Creem-Regehr, Pick, \& Warren, 2007). Se obtiene así una cota superior razonable, puesto que en una actividad didáctica será frecuente hallar velocidades menores.

De esta manera los modelos establecidos (Figura 5.1 y Figura 5.2) muestran un desplazamiento idealizado de 1.669,45 metros con 10 hitos para la zona E en Santiago de Chile y 455,16 metros para la zona A localizada en Salamanca con la referenciación de 8 hitos en el modelo establecido. 
Figura 5.1 Modelo de desplazamiento peatonal, zona E Santiago de Chile

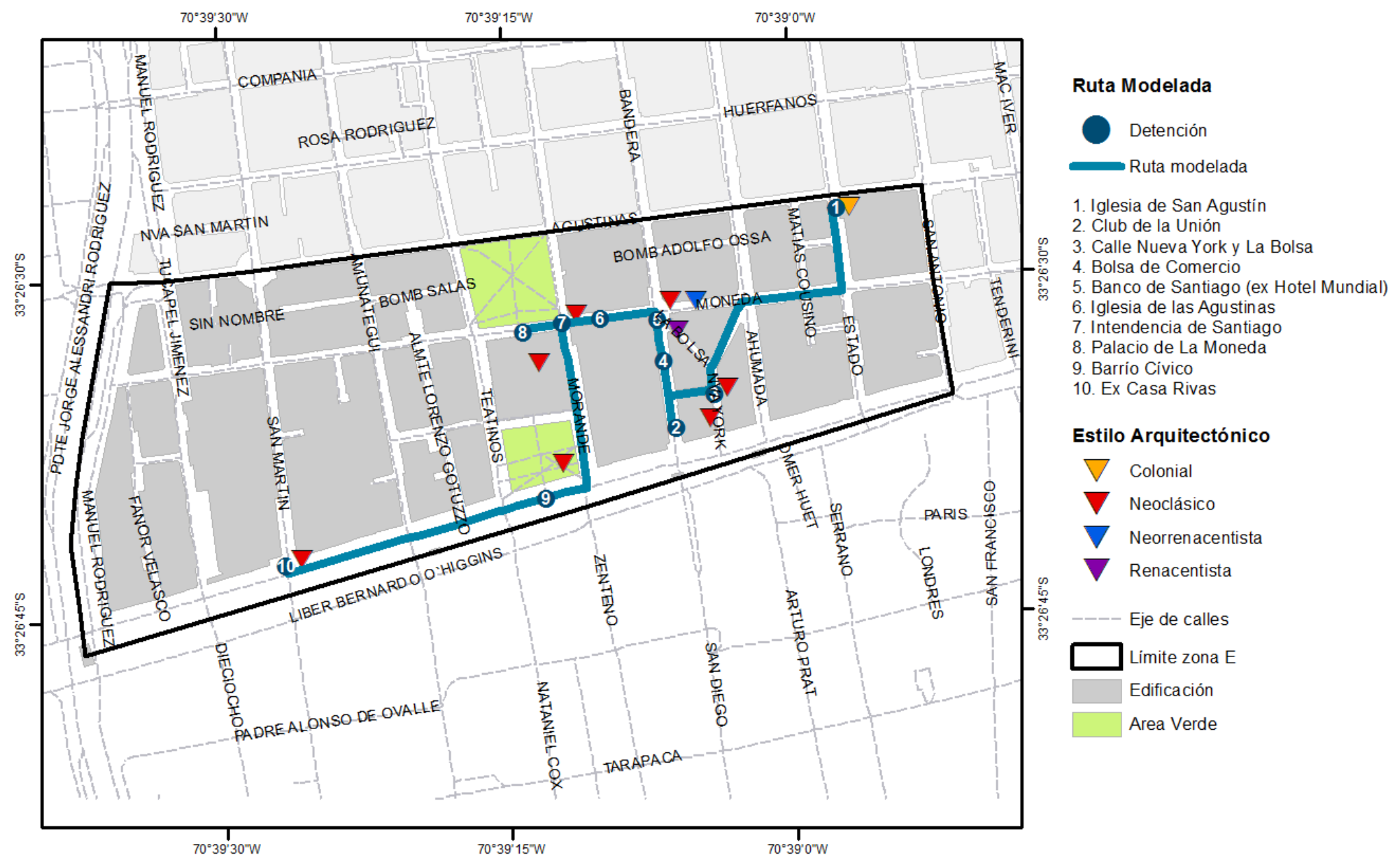

Fuente: Elaboración propia 
Figura 5.2 Modelo de desplazamiento peatonal, zona A Salamanca, España

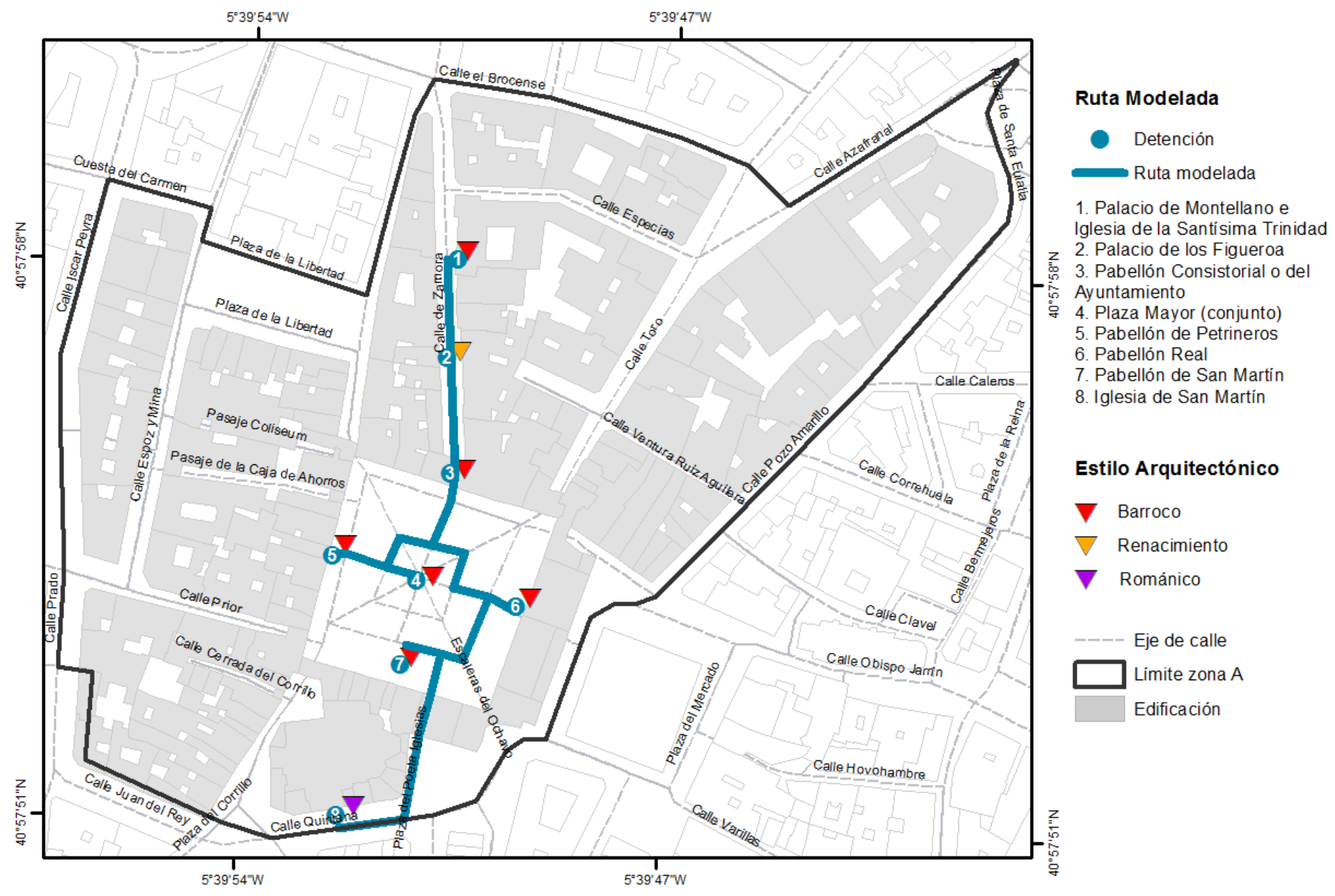

Fuente: Elaboración propia 


\subsubsection{Determinación de áreas de servicios en función del tiempo}

De manera paralela, se realizó el modelado en función de la variable tiempo derivada de los desplazamientos, teniendo como punto de inicio el hito 1 de cada zona definida para el desarrollo de la intervención educativa, permitiendo una planificación adecuada de las actividades propuestas (Figura 5.3 y Figura 5.4). Estos datos proporcionan una referencia del factor tiempo (valor Z) en cada zona propuesta, y del cómo se distribuye dentro del contexto territorial que se ha definido desde la temática patrimonial y de desplazamiento (vías). Así, para el caso de la zona E en Santiago de Chile, el modelo plantea un tiempo estimado de entre 20 y 40 minutos de desplazamiento, mientras que para la zona A en Salamanca, España, los tiempos fluctúan entre los 7 y 12 minutos. Dichas diferencias se derivan por el área cubierta para la implementación, la densidad de hitos patrimoniales y la cantidad y magnitud de las vías de acceso situados en cada zona (Tabla 5.1).

Tabla 5.1 Magnitudes de los modelos de desplazamiento peatonal y patrimonial

Santiago de Chile

\begin{tabular}{|c|c|c|}
\hline & Santiago de Chile & Salamanca, España \\
\hline Superficie total & 212,86 hectáreas & 102,97 hectáreas \\
\hline Superficie zonas & 46,11 hectáreas (zona E) & 6,99 hectáreas (zona $A$ ) \\
\hline Total hitos & 57 & 79 \\
\hline Hitos zona & 10 & 8 \\
\hline $\begin{array}{l}\text { Densidad de hitos } \\
\text { (total) }\end{array}$ & 0,267 hitos/hectárea & 0,767 hitos/hectárea \\
\hline $\begin{array}{l}\text { Densidad de hitos } \\
\text { (zonas) }\end{array}$ & 0,217 hitos/hectárea (zona E) & $\begin{array}{c}\text { 1,143 hitos/hectárea (zona } \\
\text { A) }\end{array}$ \\
\hline Ejes zona (polyline) & 147 & 119 \\
\hline Longitud ejes & $11.150,1$ metros & $4.044,13$ metros \\
\hline Densidad de ejes & 3,188 ejes/hectárea (zona E) & $\begin{array}{c}\text { 17,004 ejes/hectárea (zona } \\
\text { A) }\end{array}$ \\
\hline
\end{tabular}

Fuente: Elaboración propia
Salamanca, España

Esta información se contrasta con los resultados obtenidos mediante los dispositivos iPad, permitiendo un adecuada comparación de los modelos generados por ordenador y los resultados reales derivados de los dispositivos móviles. 
Figura 5.3 Tiempos de desplazamientos, zona E Santiago de Chile

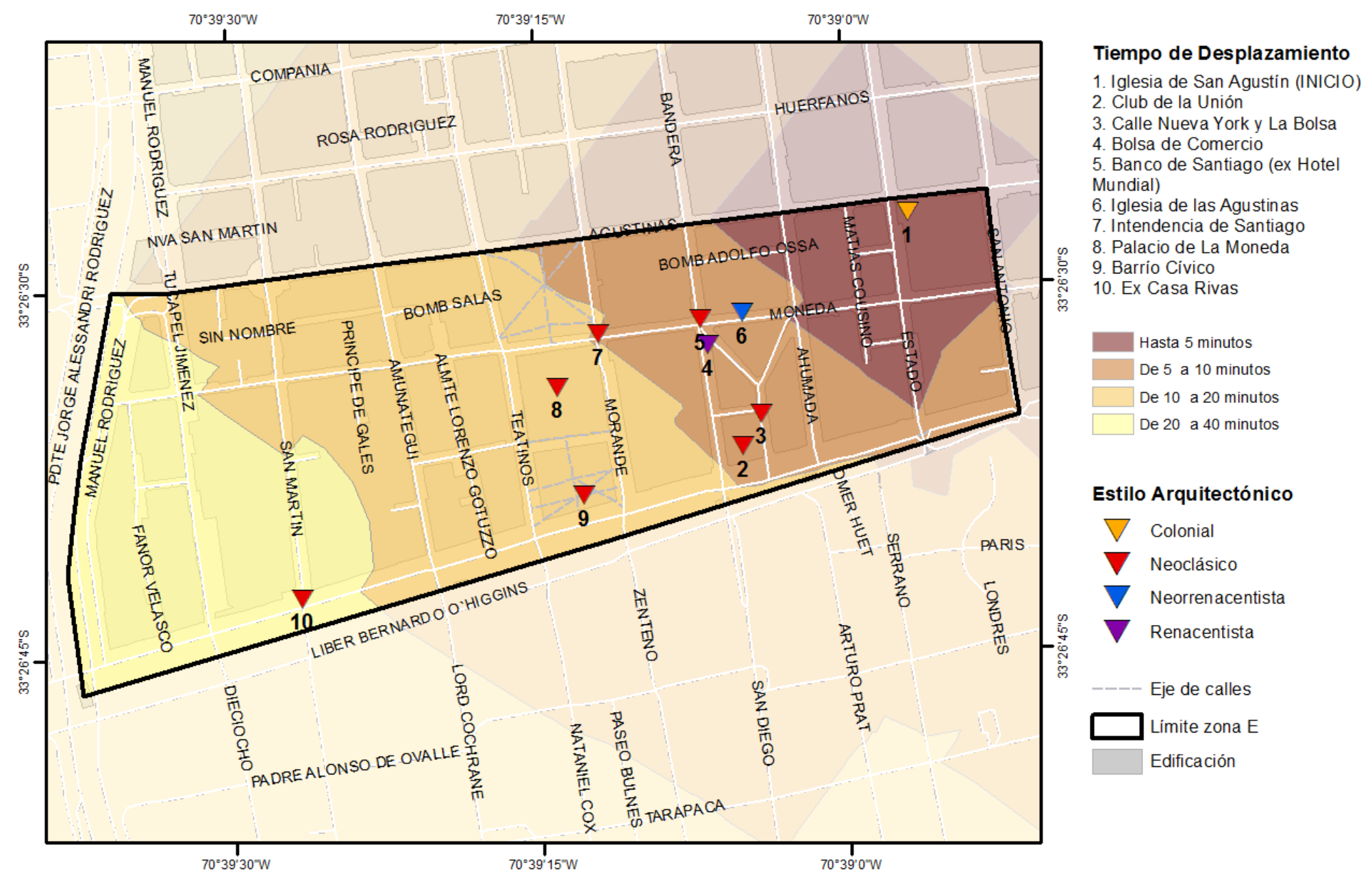

Fuente: Elaboración propia. 
Figura 5.4 Tiempos de desplazamientos, zona A Salamanca, España

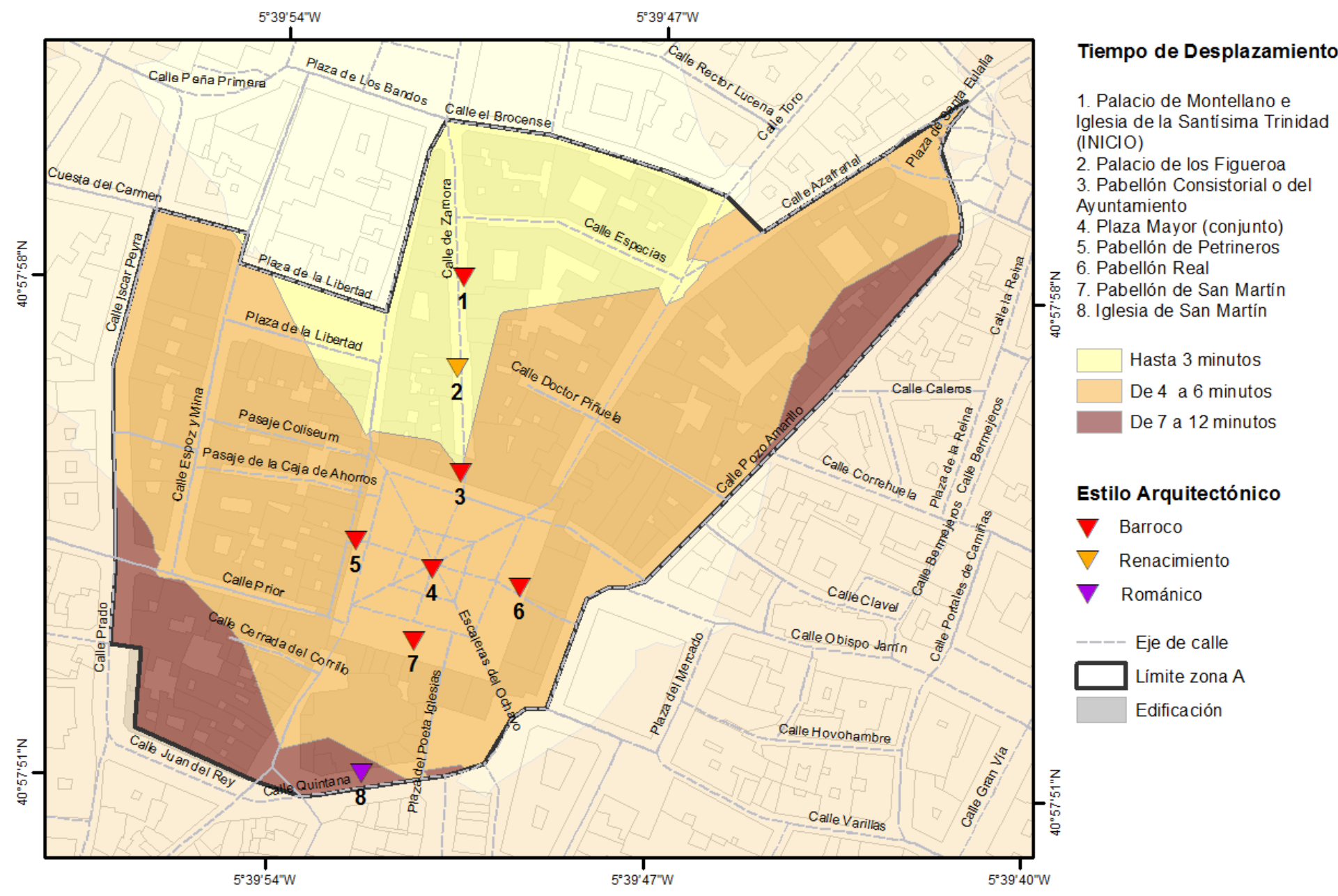

Fuente: Elaboración propia. 
Los datos obtenidos por los modelos de ordenador son representaciones aproximadas de una ruta ideal que puede ser implementada en el contexto espacial, siendo uno de los antecedentes básicos para la implementación y el desarrollo de las actividades educativas propuestas para cada ciudad. Así, estos modelos permiten:

- Una optimización de una ruta de navegación, más allá del simple planteamiento euclidiano del desplazamiento, en donde se realiza una aproximación de la estructura de movilización a seguir (Figura 5.1 y Figura 5.2).

- La determinación de los tiempos de desplazamiento (Figura 5.3 y Figura 5.4), permitiendo contextualizar la duración de las actividades educativas para cada hito patrimonial.

La configuración de los periodos de desplazamiento (isócronas) queda condicionada por la morfología de la estructura de la red utilizada, más allá de sus volúmenes de tráfico o la implementación física vial, por lo que para el caso de Santiago de Chile se puede observar una estructura regular de las isócronas adquiriendo formas de rombos irregulares, y que es consecuencia del plano de damero presente en la planta urbana tradicional de la ciudad. Para el caso de Salamanca se presenta una estructura irregular de las isócronas, aunque el centro natural del modelo queda establecido por la Plaza Mayor, como punto central del área de estudio y de la ciudad propiamente dicha.

Desde estas configuraciones espaciales realizadas, las actividades educativas realizadas en el trabajo de campo y con la utilización de las tabletas como instrumento para la recopilación de los datos de posicionamiento, se ha realizado una síntesis del volumen de la información obtenida. Mediante un archivo .log (Anexo 11) el cual se ha implementado por la propia aplicación, se han registrado los valores de posición y tiempo de cada dispositivo, siendo los resultados los siguientes (Tabla 5.2):

Tabla 5.2 Cantidad de registros (puntos) por experiencia desarrollada con iPad

Santiago de Chile ${ }^{97}$

Salamanca, España

\begin{tabular}{c|c|c|}
\hline Total de registros & 27.302 & 5.634 .563 \\
\hline Registros utilizados & 993 & 15.490 \\
\hline
\end{tabular}

Fuente: elaboración propia

${ }^{97}$ Sólo se obtuvieron los registros válidos de 2 IPads para el desarrollo de la actividad. 
Estos datos registrados fueron procesados y simplificados por su volumen de información, permitiendo generar los mapas de calor respectivos para cada zona, representando el nivel de frecuencia con que los dispositivos se situaron en un lugar determinado (Figura 5.5 y Figura 5.6), permitiendo obtener el comportamiento en el desplazamiento de los sujetos participantes en las actividades de tratamiento con iPad. 
Figura 5.5 Localización de los puntos de ruta, Santiago de Chile

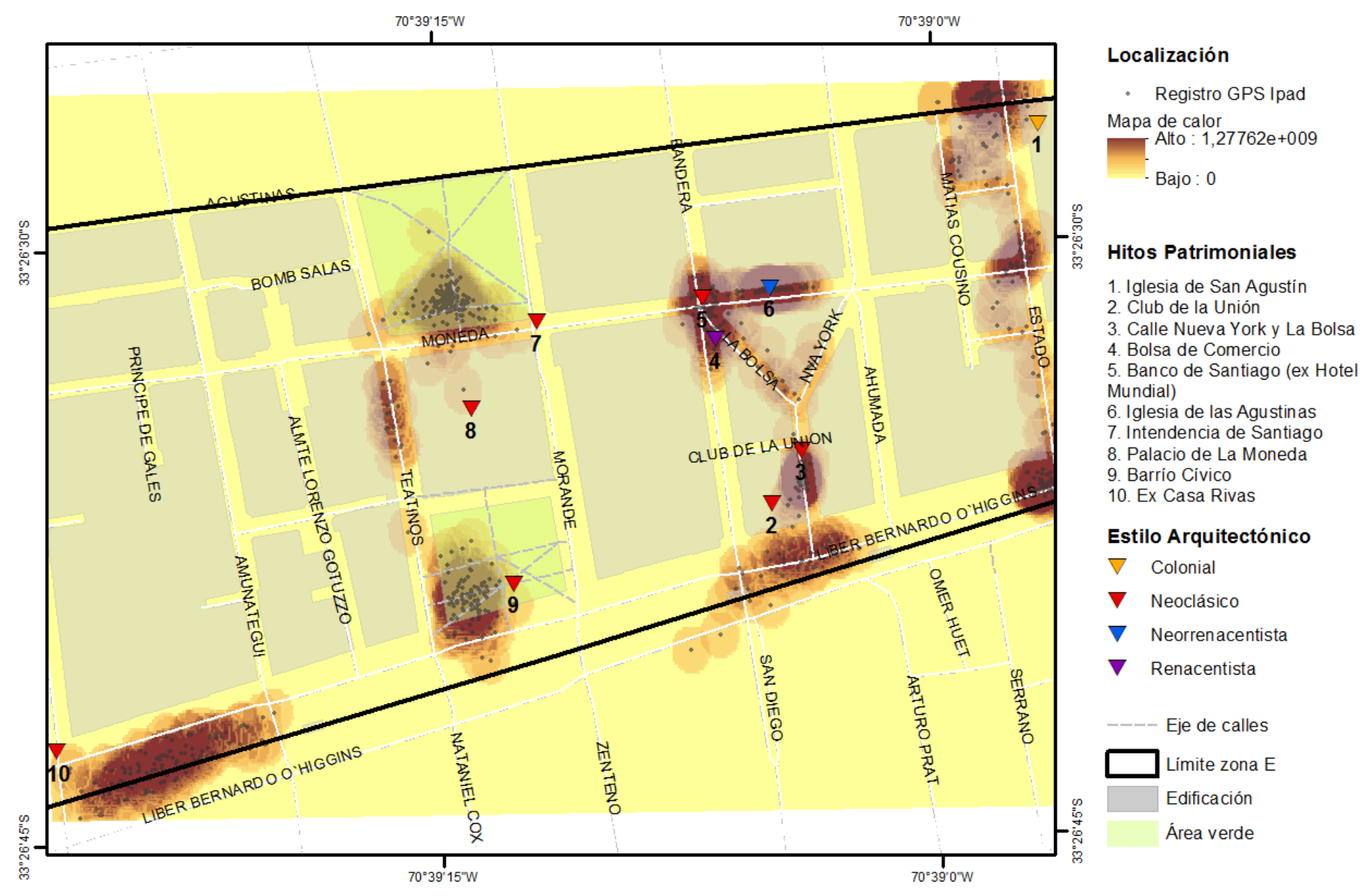

Fuente: Elaboración propia 
Figura 5.6 Localización de los puntos de ruta, Salamanca, España

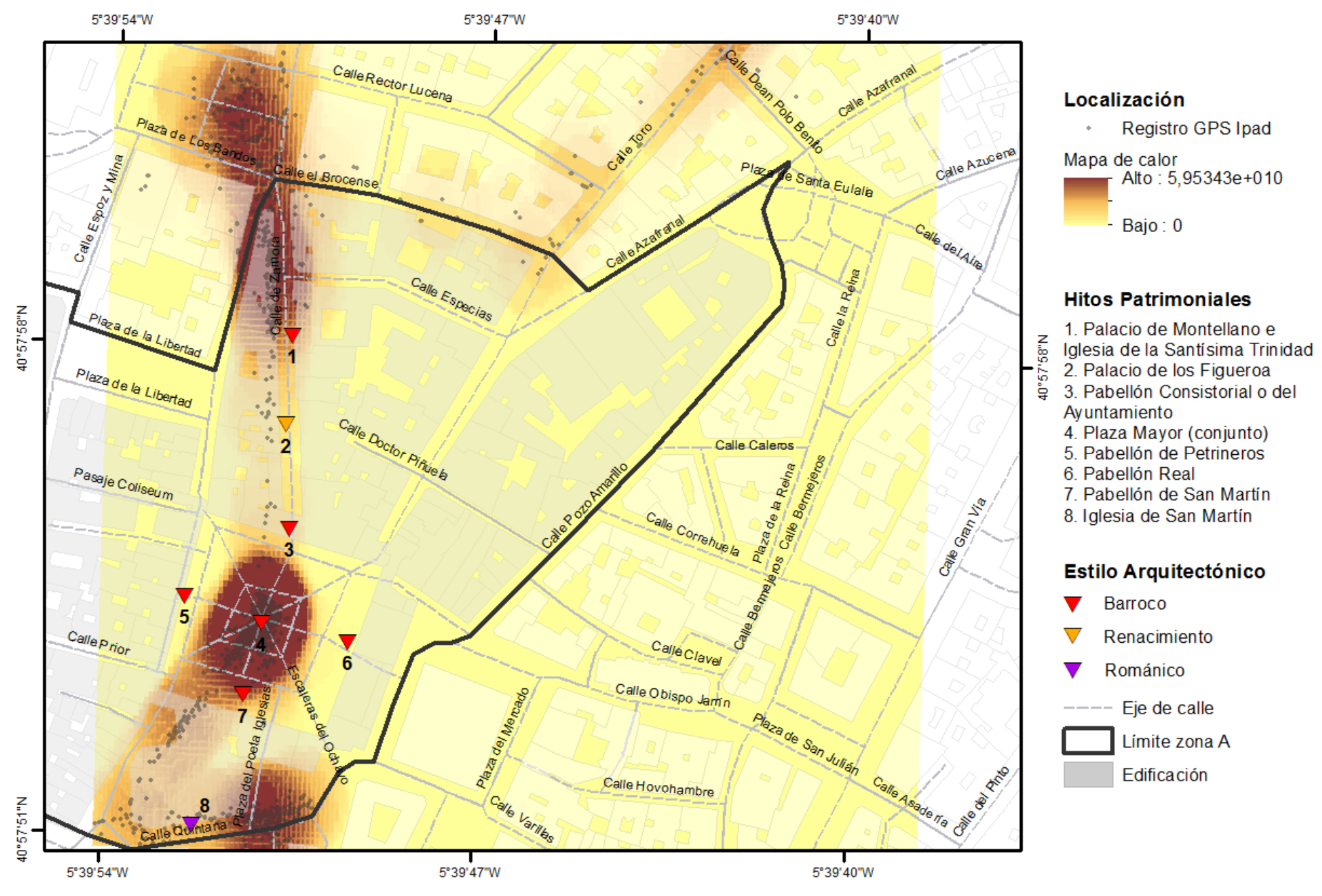

Fuente: Elaboración propia 
En términos de distribución y localización del desplazamiento de los usuarios, los valores obtenidos desde los iPads se relacionan con los modelos espaciales elaborados, debido a que el sistema de navegación incorporado en Apple Maps, planteaba a los sujetos las mismas rutas y direcciones de desplazamiento que en los modelos de desplazamiento en redes simulados por ordenador. Sin embargo, para el caso de Salamanca, se presentó una variación en el modelo de desplazamiento, entre los hitos 7 y 8 (Figura 5.2 y Figura 5.6), el cual se planteaba por el acceso desde la plaza del Poeta Iglesia, pero que fue realizado por el portal de la Plaza del Corrillo, derivado del sistema de navegación y sus elementos. Dicha diferencia responde a la estructura de la red y los valores definidos en el sistema de navegación de Apple Maps. Así todo, con el fin de seguir el experimento planteado, se siguió con las instrucciones derivadas del dispositivo móvil.

De acuerdo con los resultados de la Tabla 5.3, las diferencias entre los tiempos de desplazamientos estimados y los obtenidos por los dispositivos difieren en los valores registrados. Esto se debe a que entre los valores observados se encuentra el tiempo implementado para cada actividad educativa desarrollada en los hitos patrimoniales. Además, el modelo estimado solo contiene una simplificación de las directrices a seguir para el desplazamiento en la red, más que la información precisa del tiempo de demora en cada desplazamiento.

Tabla 5.3 Tiempo modelado y observado para las rutas definidas

Santiago de Chile

\begin{tabular}{|c|c|c|c|c|}
\hline $\begin{array}{c}\text { Segmento } \\
\text { ruta }\end{array}$ & $\begin{array}{c}\text { Tiempo } \\
\text { estimado por } \\
\text { modelo }\end{array}$ & $\begin{array}{c}\text { Tiempo } \\
\text { observado } \\
\text { (iPad)* }\end{array}$ & $\begin{array}{c}\text { Tiempo } \\
\text { estimado por } \\
\text { modelo }\end{array}$ & $\begin{array}{c}\text { Tiempo } \\
\text { observado } \\
\text { (iPad)* }\end{array}$ \\
\hline $\mathbf{1 - 2}$ & $05: 43,300$ & $0: 11: 09$ & $01: 26,600$ & $0: 21: 10$ \\
\hline $\mathbf{2}-\mathbf{3}$ & $01: 31,400$ & $0: 16: 59$ & $00: 45,400$ & $0: 10: 29$ \\
\hline $\mathbf{3 - 4}$ & $03: 39,400$ & $0: 13: 16$ & $00: 28,400$ & $0: 09: 58$ \\
\hline $\mathbf{4 - 5}$ & $00: 51,900$ & $0: 12: 25$ & $00: 29,200$ & $0: 14: 42$ \\
\hline $\mathbf{5}-\mathbf{6}$ & $01: 01,800$ & $0: 16: 13$ & $00: 42,800$ & $0: 19: 04$ \\
\hline $\mathbf{6 - 7}$ & $03: 05,700$ & $0: 21: 15$ & $00: 41,500$ & $0: 17: 07$ \\
\hline $\mathbf{7 - 8}$ & $01: 22,200$ & $0: 15: 43$ & $01: 46,500$ & $0: 19: 57$ \\
\hline $\mathbf{8 - 9}$ & $01: 22,200$ & $0: 18: 48$ & & \\
\hline $\mathbf{9 - 1 0}$ & $05: 14,600$ & $0: 19: 20$ & & \\
\hline Total & $\mathbf{2 3 : 5 2 , 5 0 0}$ & $\mathbf{2 : 2 5 : 0 9}$ & $\mathbf{0 6}: \mathbf{2 0 , 4}$ & $\mathbf{1 : 5 2 : 2 7}$ \\
\hline * Incluye el tiempo de actividad realizada en cada hito. & & \\
\hline
\end{tabular}

Fuente: elaboración propia 


\subsection{Software NPM-RA}

El desarrollo de la aplicación móvil como instrumento de tratamiento de la experiencia educativa y como elemento base del sistema informático implementado, se expone como un punto referencial para la implementación de las actividades educativas que se quieren medir y contrastar desde la dimensión empírica de la tesis doctoral. El planteamiento de la estructura informática cuenta con los aspectos generales de una aplicación informática móvil, y se establece como la parte cliente de una estructura cliente/servidor ${ }^{98}$ (Cubillo Arribas, 2014). De esta manera, en el diagrama de casos de uso de la aplicación desde el punto de la operatividad, queda representado en la Figura 5.7:

Figura 5.7 Diagrama de Casos de Uso de la Aplicación RA-NPM

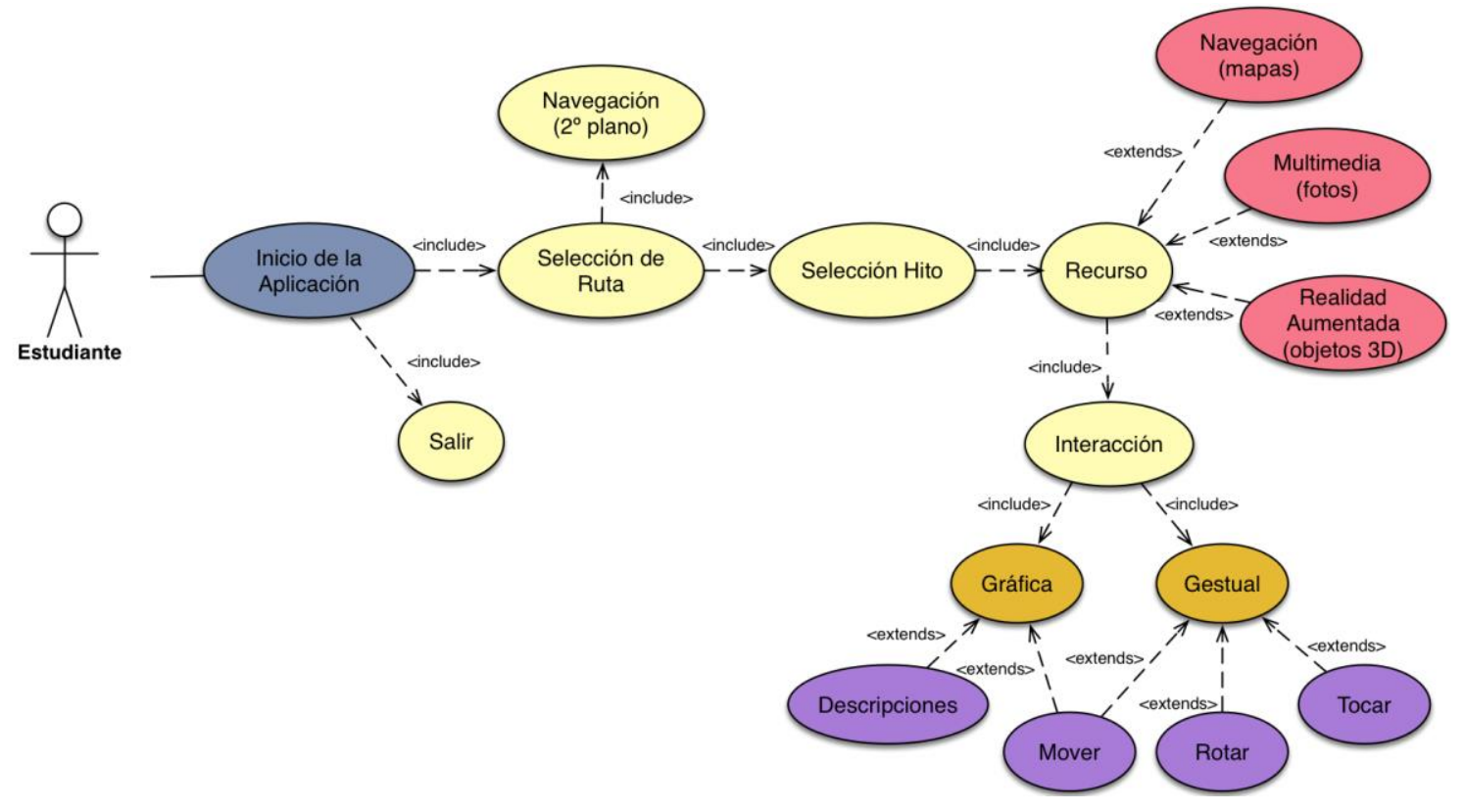

Fuente: Elaboración propia

La arquitectura del proyecto se encuentra implementada en el entorno de desarrollo integrado Xcode ${ }^{99}$, mediante un fichero de referencia .xcodeproj,

\footnotetext{
${ }^{98}$ Como se ha dicho en la metodología, los datos utilizados desde un servidor corresponden a la información geoespacial referida a los mapas y el sistema de navegación. La mayoría de los datos (AR y multimedia) forman parte de la aplicación y son consultados de manera local, debido a las posibles limitaciones que existen en la conectividad en las áreas de estudio y para lograr una fluidez en la experiencia educativa.

${ }^{99}$ Se ha comenzado con la versión de Xcode 5.1 en Objective-C hasta la versión 7.3.1 en su implementación con el lenguaje Swift 2.2.
} 
correspondiente a un repositorio de todos los archivos, recursos e información requerida para la construcción de la aplicación (Apple Inc., 2011). Cada proyecto implementado para el desarrollo de la aplicación móvil contiene la siguiente información:

- Referencias a los archivos fuente

- Código fuente (archivos .h .m y .swift)

- Bibliotecas y frameworks

- Archivos de recursos (.csv, .jpg, .png)

- Archivos de interface (.xib, .nib y storyboards)

- Organización mediante grupos de los archivos en la estructura del entorno de desarrollo

- Configuraciones de la construcción y nivel del proyecto

Así, cada elemento se almacena en una carpeta especifica de la estructura interna del proyecto .xcodeproj. Dicha estructura puede ser visualizada en la Figura 5.8. 
Figura 5.8 Estructura de las aplicaciones móviles de Santiago y Salamanca en el proyecto para Xcode

\begin{tabular}{|c|c|c|c|}
\hline$\nabla$ 国 Salamanca & $?$ & $\nabla$ [ & M \\
\hline CoreLocation.framework & & 5 Images.xcassets & M \\
\hline DMapKit.framework & & Assets & \\
\hline$\nabla$ Boceto_02 & & $\checkmark \square$ Imagenes & \\
\hline [9] Main.storyboard & M & $\mathbf{\text { Ruta } \mathrm { E }}$ & \\
\hline 1.) AboutViewController.swift & & h RutaEDetailsViewController.h & \\
\hline A. AppDelegate.swift & & m RutaEDetailsViewController.m & \\
\hline BasicRoute.swift & & h AnotacionesHitosE.h & \\
\hline (1) RouteData.swift & & m AnotacionesHitosE.m & \\
\hline (2) Mapinfo.swift & M & h AnotacionesHitosEView.h & \\
\hline (3) StartupViewController.swift & & m AnotacionesHitosEView.m & \\
\hline (1) RouteSelectionViewController.swift & M & h HitosEViewController.h & \\
\hline (1) RouteViewController.swift & M & m HitosEViewController.m & \\
\hline (1) RouteMilestoneAnnotation.swift & & h HitoEDetails.h & \\
\hline (2) MilestoneViewController.swift & & m HitoEDetails.m & \\
\hline (5) SiteViewController.swift & M & h HitoEDetailsViewController.h & \\
\hline SiteData.swift & & m HitoEDetailsViewController.m & \\
\hline D. OldPicsViewController.swift & & h HitoETableViewController.h & \\
\hline OldPicsViewCell.swift & & m HitoETableViewController.m & \\
\hline (3) OldPicsDetailController.swift & & Hito 1 Ruta E & M \\
\hline DAO.swift & & Hito 2 Ruta E & M \\
\hline 대 Images.xcassets & & D Hito 3 Ruta E & M \\
\hline (x) LaunchScreen.xib & M & Hito 4 Ruta E & M \\
\hline Dupporting Files & M & Hito 5 Ruta E & M \\
\hline Dr_8_of & & Hito 6 Ruta E & M \\
\hline$\rightarrow$ r_7_of & & - $\mathrm{Dito} 7$ Ruta E & M \\
\hline$\rightarrow \quad r$ r6_of & & Hito 8 Ruta E & M \\
\hline Dr_5_of & & Hito 9 Ruta E & M \\
\hline$\rightarrow r_{-} 4$ of & & h AnotacionesHitosView.h & \\
\hline$\rightarrow$ r_3_of & & m AnotacionesHitosView.m & \\
\hline$D r_{2}$ 2_of & & h AnotacionesHitos.h & \\
\hline Dr_1_of & & m AnotacionesHitos.m & \\
\hline$\rightarrow r_{\text {r_o_of }}$ & M & h RutasViewController.h & \\
\hline Boceto_02Tests & & m RutasViewController.m & \\
\hline$\rightarrow$ datafiles & & h ViewController.h & \\
\hline D ImagesMisc & & m ViewController.m & \\
\hline$\square$ fondos & & h RutaDetails.h & \\
\hline DIconos & & m RutaDetails.m & \\
\hline - Milestone_images & & h LasRutasTableViewController.h & \\
\hline Products & & m LasRutasTableViewController.m & \\
\hline$\Rightarrow r_{-} 0_{-} b f_{-} x$ & & h RutaDetailsViewController.h & \\
\hline$\rightarrow r_{-} 0_{-}$thn_x & & In RutaDetailsViewController.m & \\
\hline - r $r_{-} b_{-} b f_{-} x$ & & (19) Main.storyboard & M \\
\hline - r r 1_thn_x & & LaunchScreen.xib & \\
\hline
\end{tabular}

Fuente: Elaboración propia.

La descripción general de cada carpeta dentro de la estructura de la aplicación es la siguiente (Tabla 5.4): 
Tabla 5.4 Elementos del proyecto para cada aplicación

\section{Santiago de Chile Salamanca, España} (Objective-C)

(Swift)

Descripción

\begin{tabular}{|c|c|c|}
\hline $\begin{array}{l}\text { Santiago Patrimonial } \\
\text { RA (root) }\end{array}$ & Salamanca (root) & $\begin{array}{l}\text { Archivos generales de la aplicación } \\
\text { incluyendo LaunchScreen.xib, } \\
\text { Main.storyboard, ViewController y } \\
\text { AppDelegate }\end{array}$ \\
\hline Hito $\mathrm{n}$ ruta $\mathrm{n}$ & r_n_bf & Archivos de funcionamiento para cada ruta \\
\hline Imágenes & r_n_of_x / r_n_thn_x & Fotografías de los hitos y rutas \\
\hline \multirow[t]{2}{*}{ Framework } & Framework & Framework utilizados en la aplicación. \\
\hline & Datafiles & $\begin{array}{l}\text { Archivos .csv con los datos de cada hito y } \\
\text { ruta }\end{array}$ \\
\hline Images.xcassets & Images.xcassets & Imágenes de la aplicación (íconos y fondos) \\
\hline
\end{tabular}

Fuente: Elaboración propia.

\subsubsection{Aplicación Santiago Patrimonial (AR-NPM 1.0)}

En términos de desarrollo, las diferencias entre cada aplicación radican en aspectos funcionales como la cantidad de clases, métodos utilizados y la llamada a los recursos y variables que se presenta en cada escena. Desde el punto de vista de la interface gráfica, tanto los elementos componentes como su comportamiento dentro de lo que es el sistema, son similares en ambos lenguajes de desarrollo. De esta manera, la versión 1.0 de la aplicación se presentó en el programa "Santiago Patrimonial" el cual fue implementado en el lenguaje Objective-C. En la Tabla 5.5 se pueden observar la interface y las clases asociadas para cada escena de la aplicación. La síntesis de métodos asociados a cada clase se puede ver en la Figura 5.9. 
Tabla 5.5 Escenas de la aplicación Santiago Patrimonial (AR-NPM 1.0)

Escena

Descripción

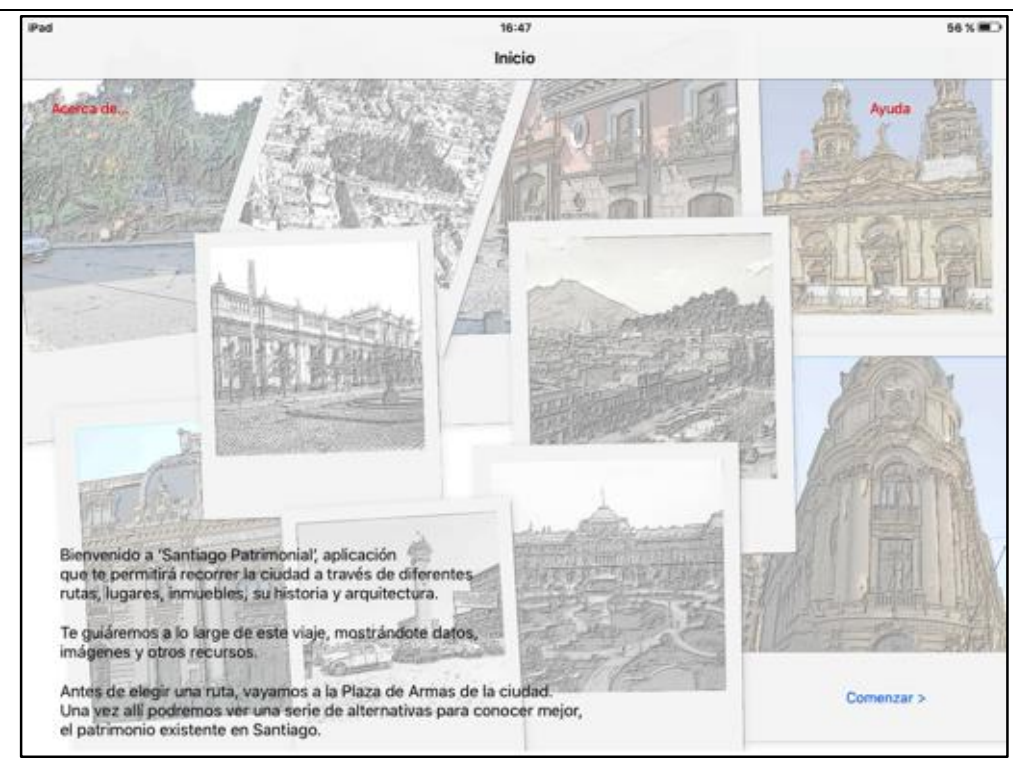

Escena de presentación

\section{Clases asociadas:}

AppDelegate

ViewController

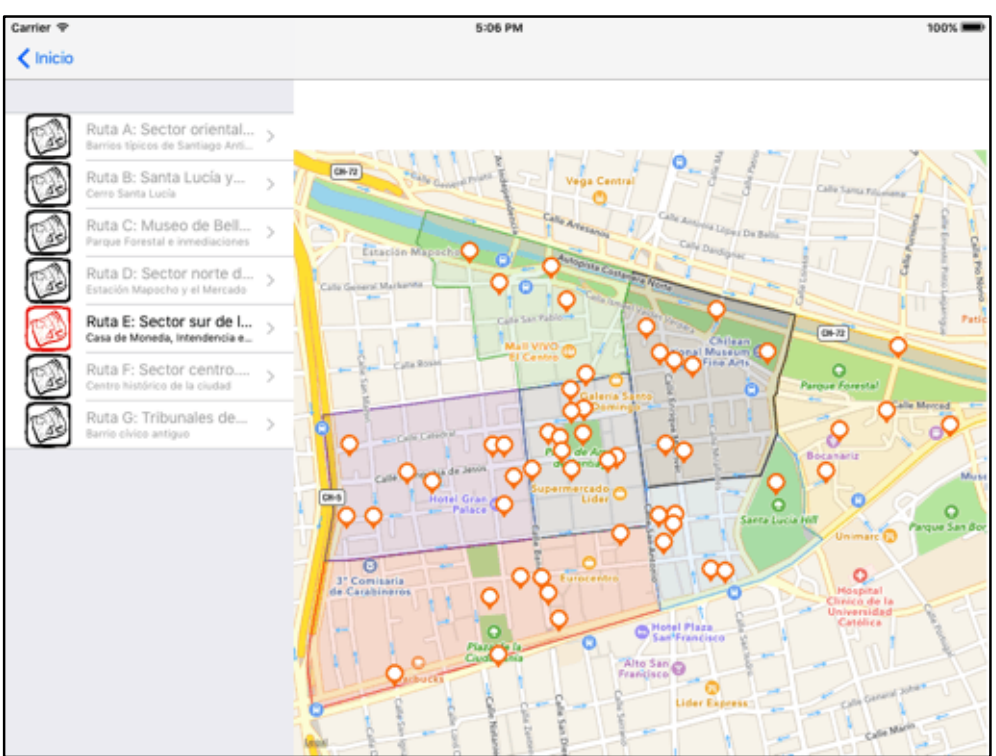

Presentación espacial del área de estudio con la división de zonas y la presentación de hitos.

\section{Clases asociadas:}

RutasDetailsViewController

RutaDetails

AnotacionesHitos 

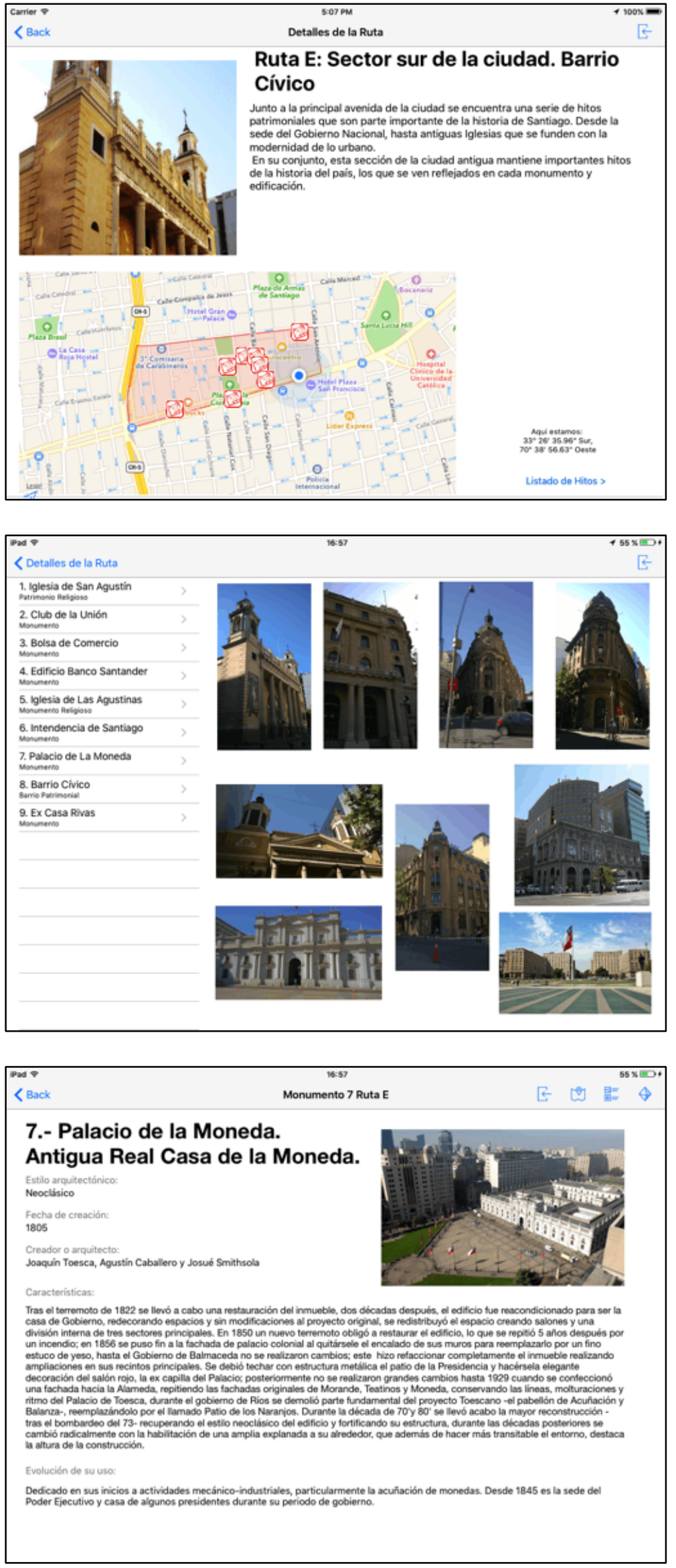

Presentación espacial de la ruta seleccionada ( $n+1$ que va desde la ruta $A$ a la $G$ ) con presentación de hitos y estableciendo el contexto de localización del usuario.

\section{Clases asociadas:}

HitosEViewController*

HitoEDetails*

RutaEDetails*

* Cada zona tiene su clase controladora que va desde la A hasta la $\mathrm{F}$

Tabla con presentación de hitos y estableciendo el contexto de localización del usuario.

\section{Clases asociadas:}

HitosEDetailsViewController* AnotacionesHitoE*

* Cada zona tiene su clase controladora que va desde la $\mathrm{A}$ hasta la $\mathrm{F}$

Presentación y contenidos del hito seleccionado.

\section{Clases asociadas:}

Hito1RutaEViewController 

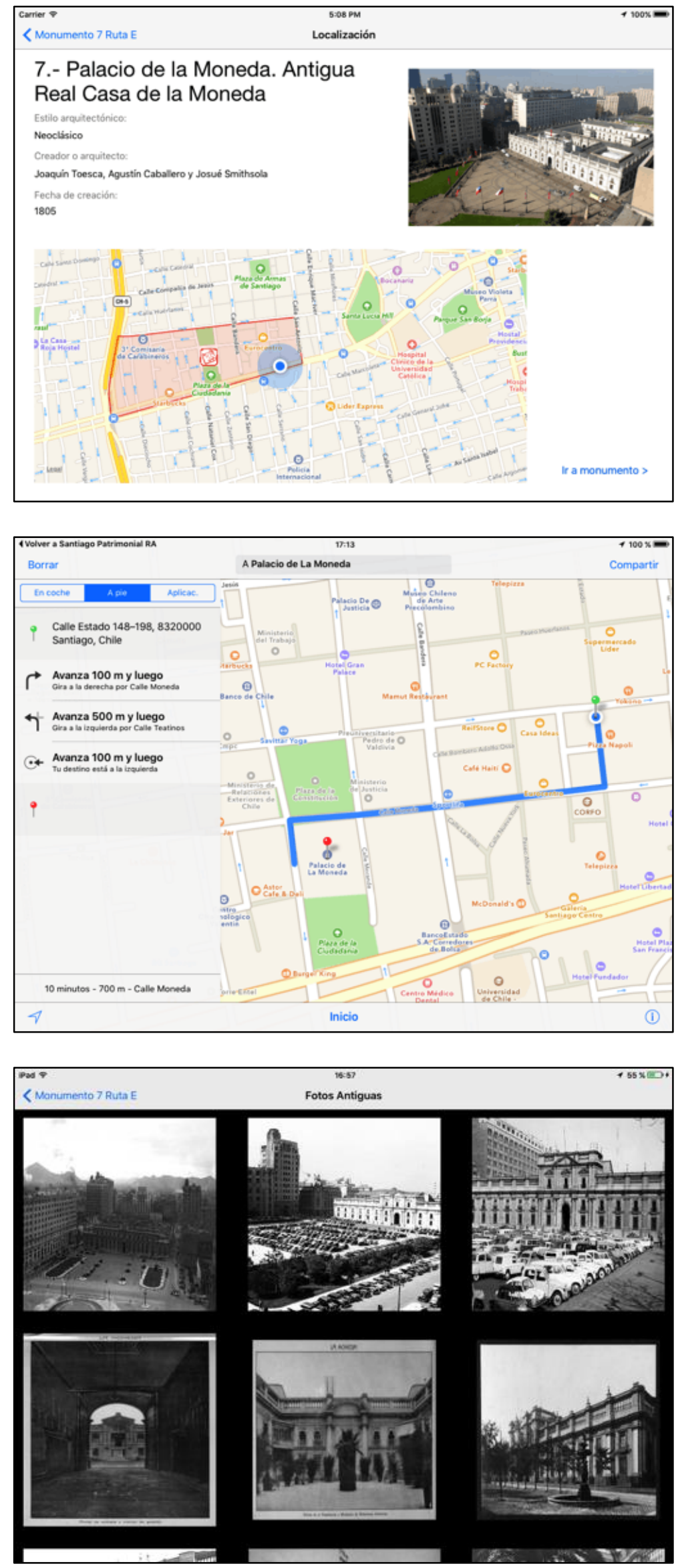

Presentación espacial del hito patrimonial de la ruta seleccionada. Transición al sistema de navegación peatonal.

\section{Clases asociadas:}

Hito1RutaEMapViewController

Sistema de navegación peatonal en Apple Maps. Planteamiento de la ruta general. Se realiza la propuesta de navegación en curso por parte del sistema, la cual es modificada según datos de localización del dispositivo.

\section{Aplicación complementaria}

Apple Maps para iOS

Presentación de recursos multimedia (Fotos antiguas) relacionados con el hito en visita.

\section{Clases asociadas:}

Fotos1HitoEViewCell

Fotos1CollectionViewController 


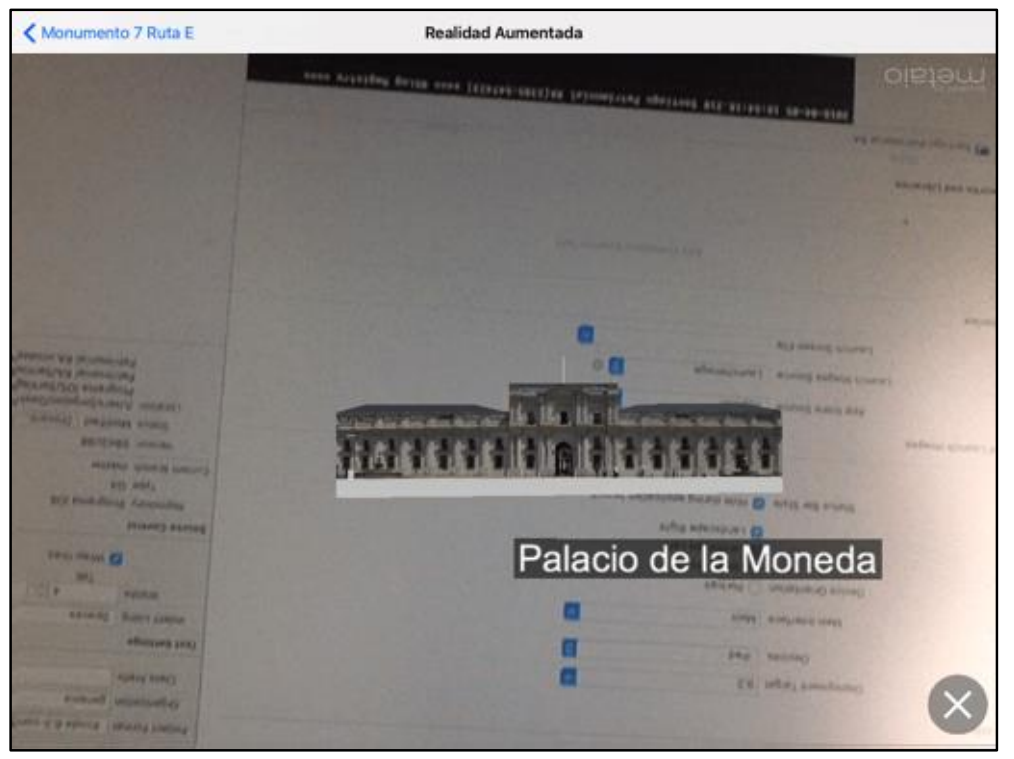

Presentación de recursos

multimedia (Realidad

Aumentada) relacionado con el hito en visita.

\section{Clases asociadas} (framework Metaio):

ARELViewController MetaioSDKDelegate

GestureHandlerIOS

MetaioSDKViewController

IARELInterpreterIOSDelegate

TemplateARELViewController

Fuente: Elaboración propia 
Figura 5.9 Diagrama de clases simplificado para la aplicación Santiago Patrimonial (AR-NPM 1.0)
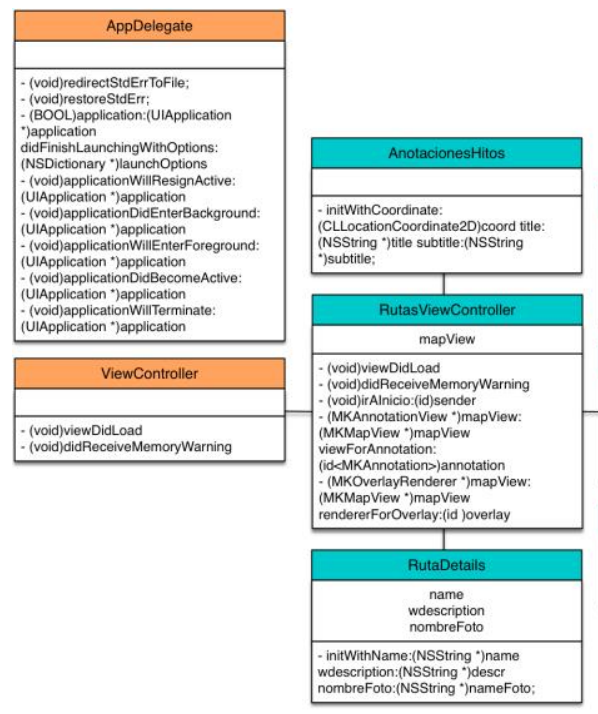

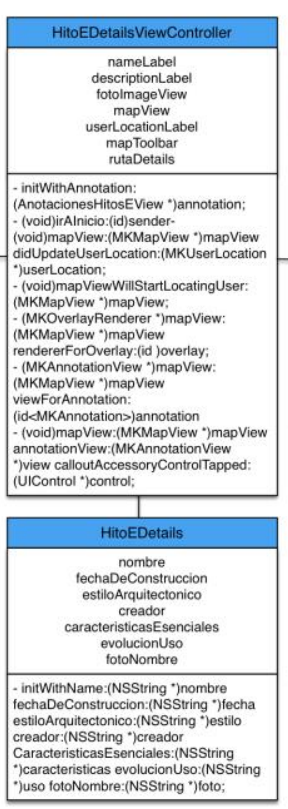

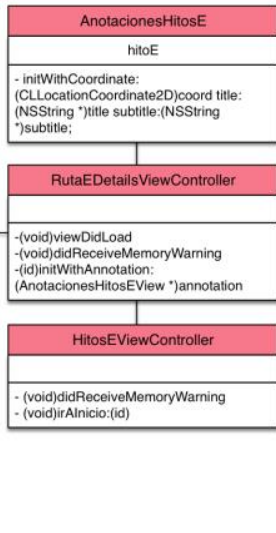

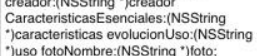
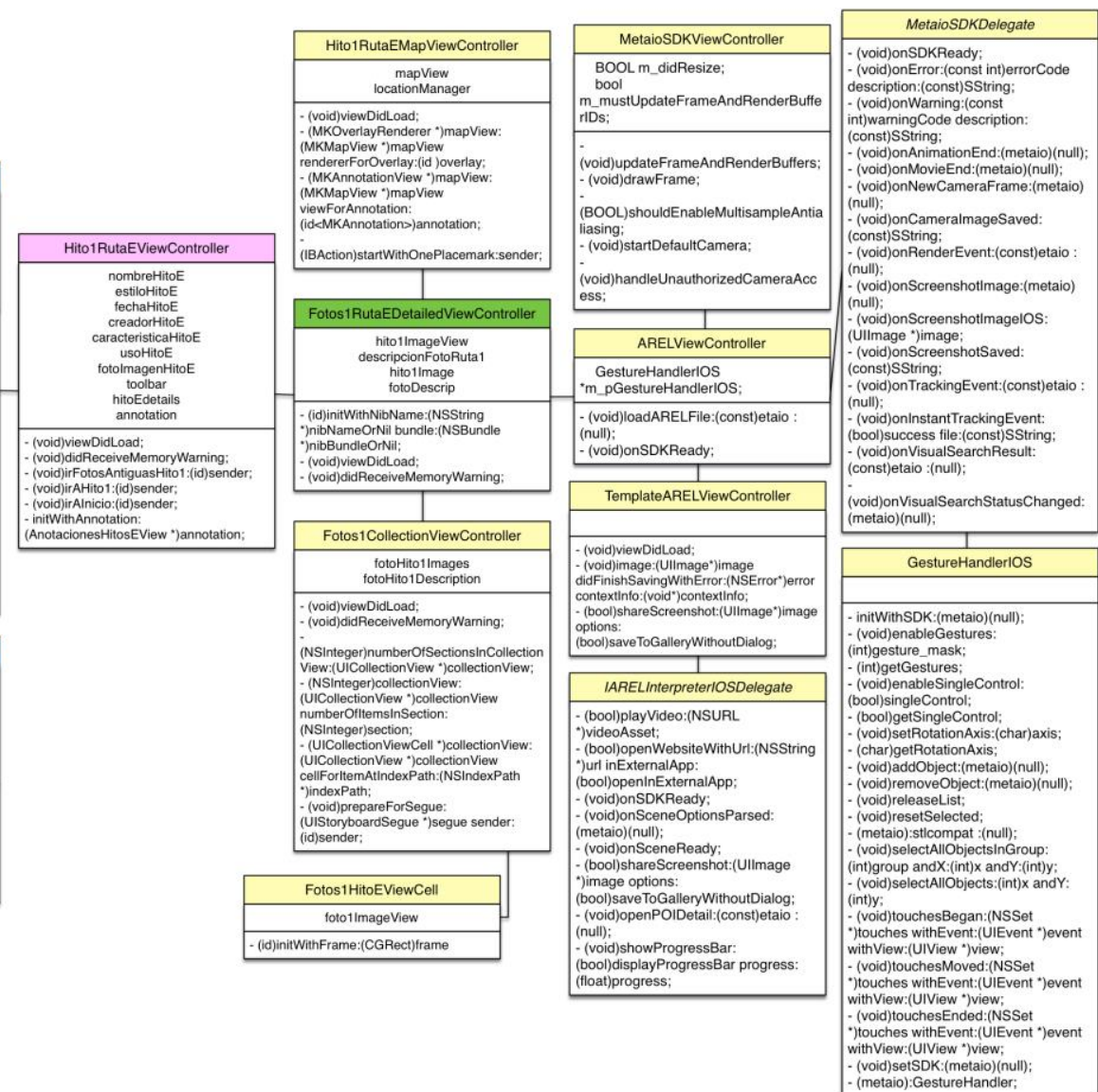

Fuente: Elaboración propia 


\subsubsection{Aplicación Salamanca Patrimonial (AR-NPM 2.0)}

Posterior al desarrollo de versión 1.0 y obtenidos los resultados del trabajo de campo en Santiago Chile, se desarrolló la versión 2.0 de la aplicación, que fue la utilizada en la actividad educativa sobre la ciudad de Salamanca. Esta nueva versión contiene importantes actualizaciones y modificaciones tanto en su desarrollo como en su contenido. El principal cambio se presenta en la utilización del lenguaje Swift 2.2, con ventajas asociadas como la simplificación en el número y cantidad de clases utilizadas, la síntesis en el código desarrollado y la utilización de archivos de intercambio para los datos de contenido patrimonial (.cSV), lo que permite la interoperabilidad de la información desde fuentes externas mediante archivos de texto, facilitando la incorporación y edición de los datos con medios externos (editores de textos, planillas de cálculo). También existe una mejora en la interfaz gráfica con la incorporación de elementos visuales (por ejemplo la utilización de miniaturas en sustitución de íconos en el sistema de mapas sobre el área de estudio). La estructura de las escenas (Tabla 5.6) y el diagrama de clases (Figura 5.10) muestran la simplificación en la cantidad de clases y en la generación de objetos, teniendo la misma operatividad que la versión 1.0 de la aplicación.

Tabla 5.6 Escenas de la aplicación Salamanca Patrimonial (AR-NPM 2.0)

Escena

Descripción

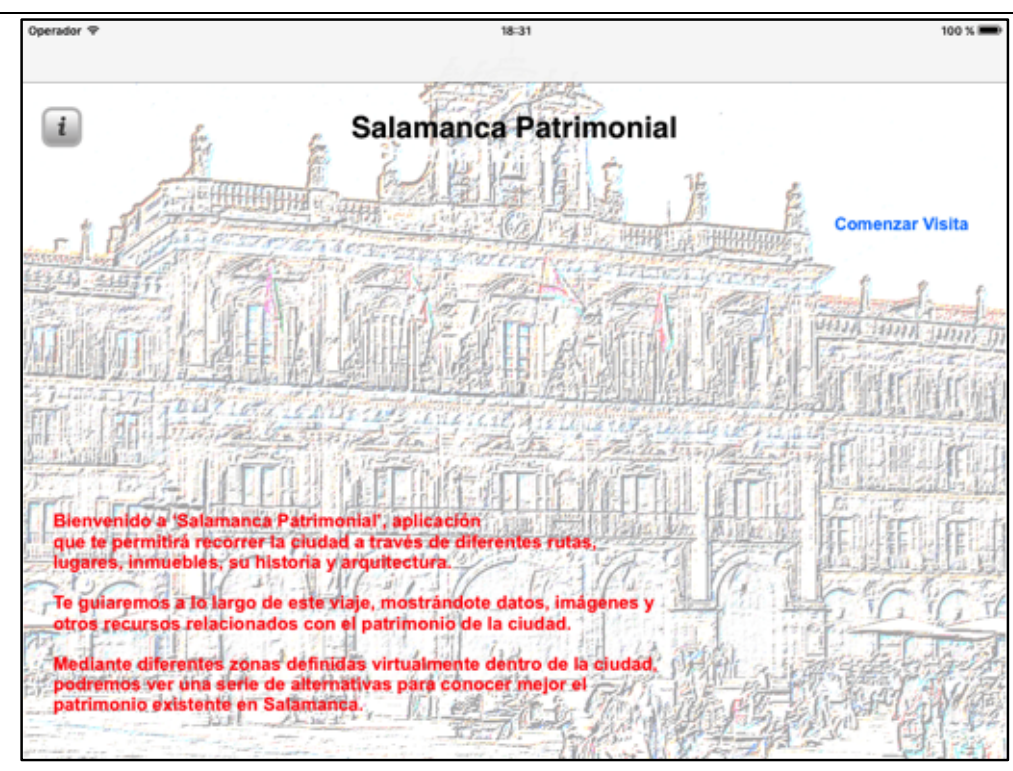

Escena de presentación

Clases asociadas:

AppDelegate

StartupViewController 


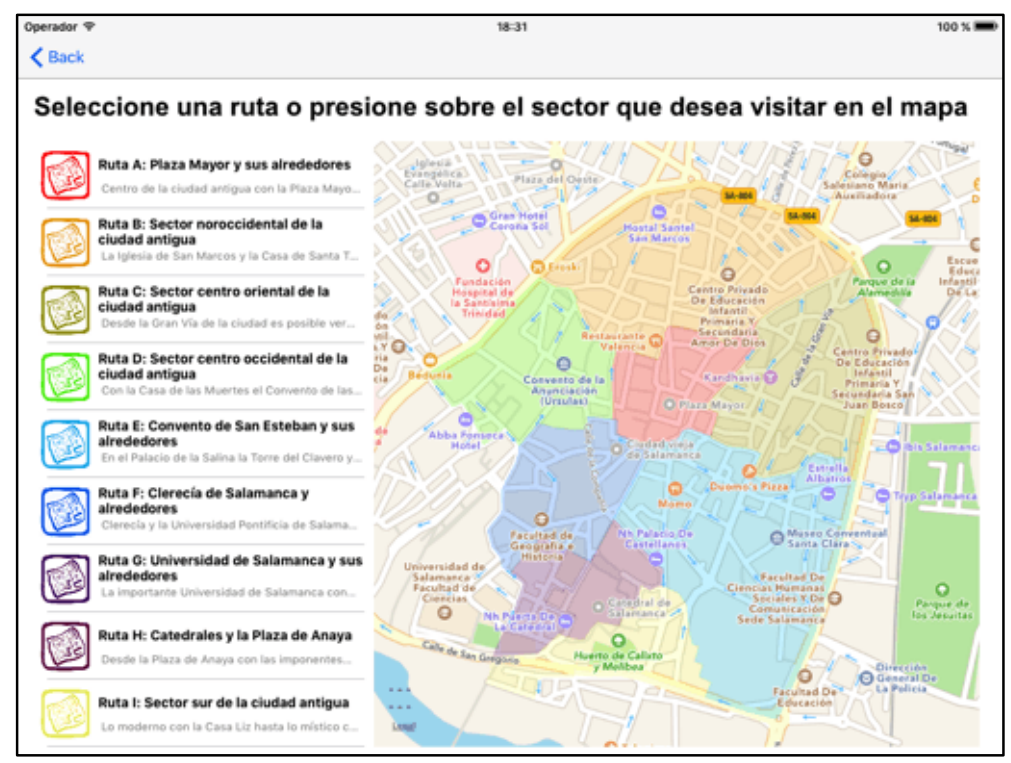

Presentación espacial del área de estudio con la división de zonas y la presentación de hitos.

\section{Clases asociadas:}

RouteSelectionViewControlle $r$

BasicRoute

RouteData

Mapinfo

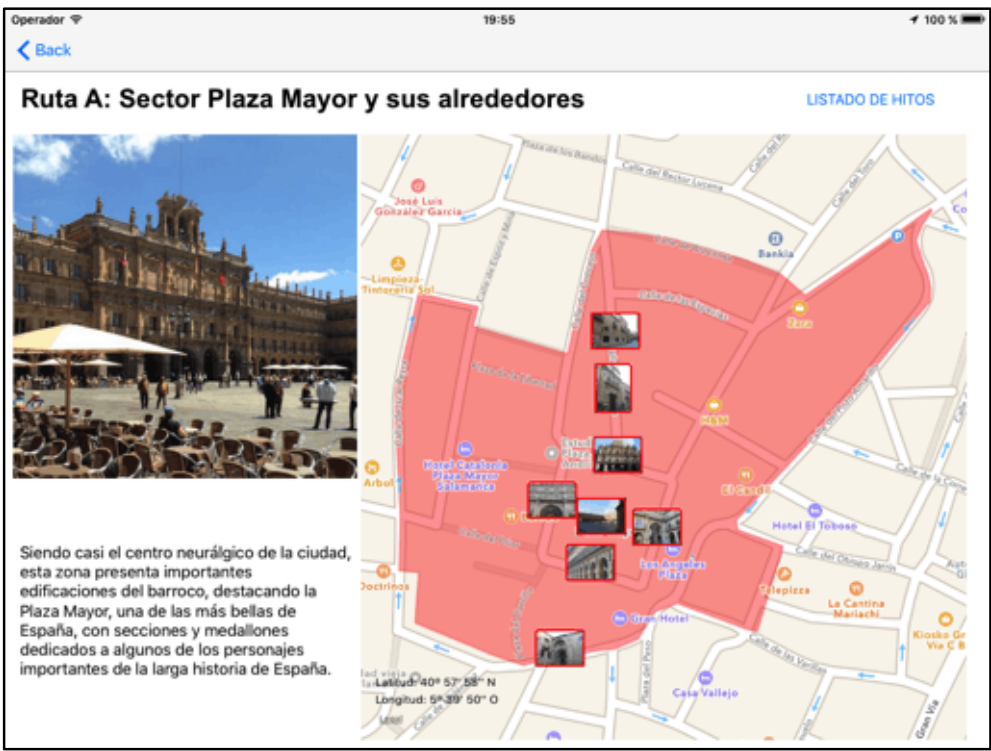

Presentación espacial de la ruta seleccionada, con presentación de hitos y estableciendo el contexto de localización del usuario.

\section{Clases asociadas:}

RouteViewController

RouteData

RouteMilestoneAnnotation

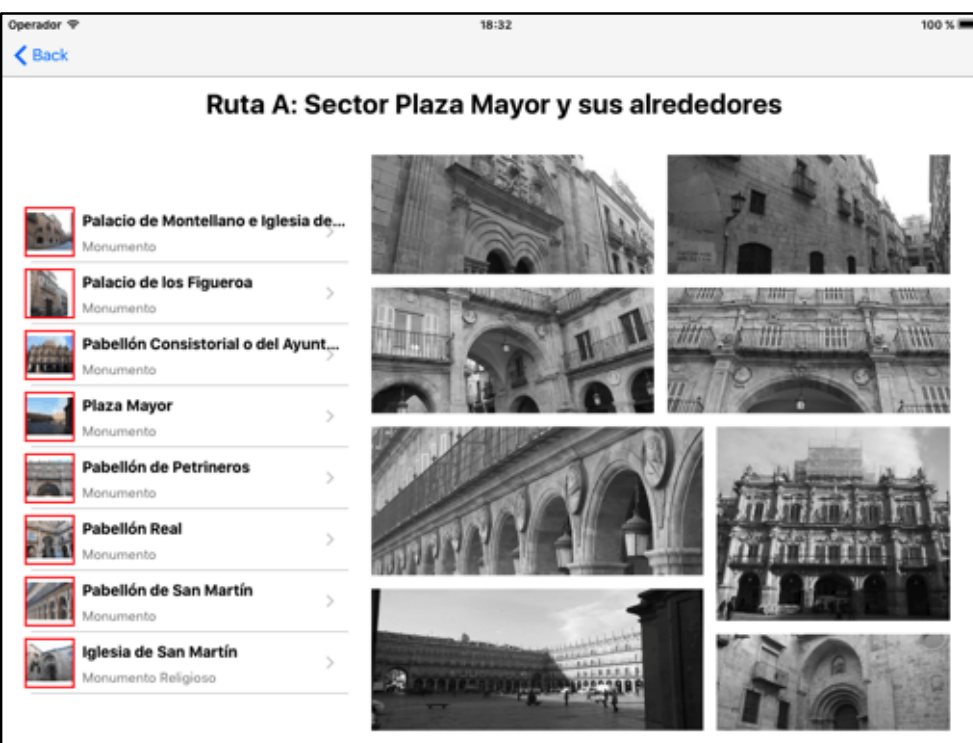

Tabla con presentación de hitos y estableciendo el contexto de localización del usuario.

\section{Clases asociadas:}

MilestoneViewController

RouteMilestoneAnnotation 

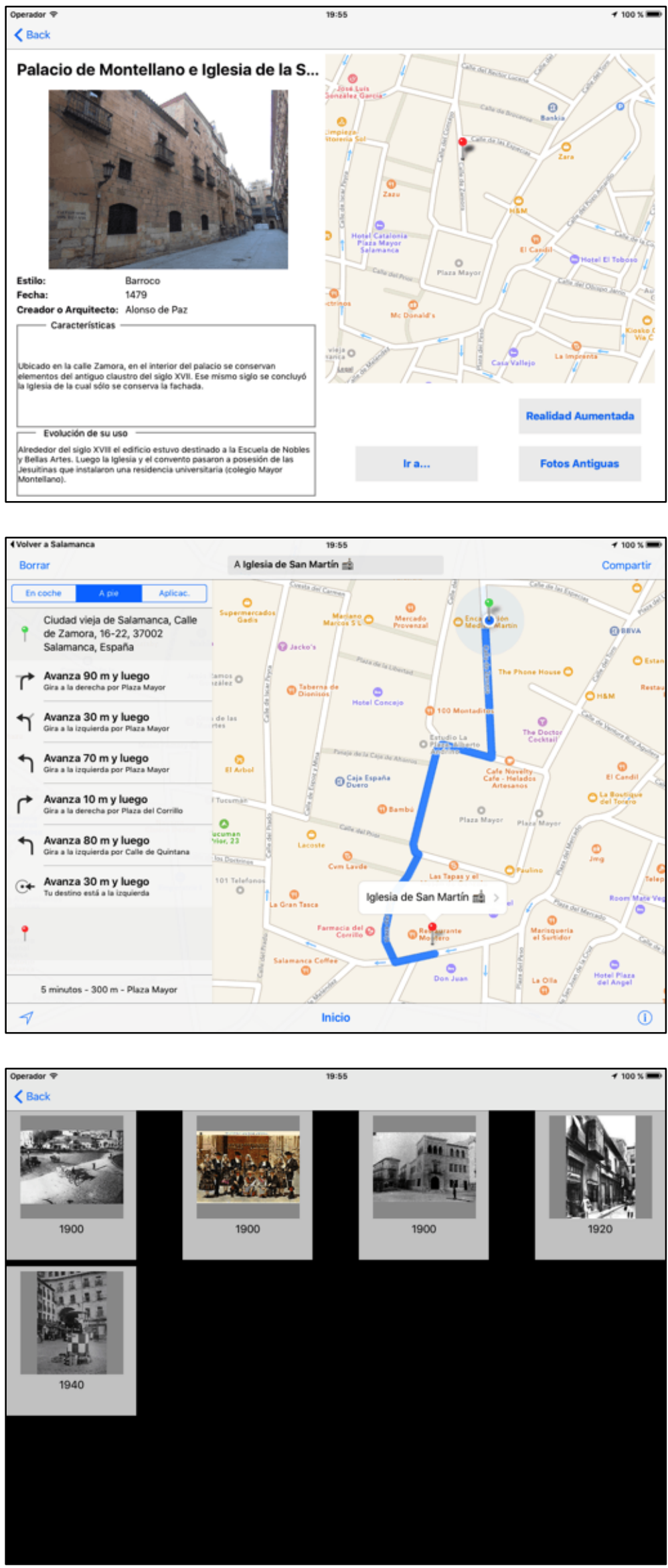

Presentación espacial del hito patrimonial de la ruta seleccionada. Transición al sistema de navegación peatonal y los recursos multimedia.

\section{Clases asociadas:}

SiteViewController

\section{SiteData}

Mapinfo

RouteMilestoneAnnotation

Sistema de navegación peatonal en Apple Maps. Planteamiento de la ruta general. Se realiza la propuesta de navegación en curso por parte del sistema, la cual es modificada según datos de localización del dispositivo.

\section{Aplicación complementaria}

Apple Maps para iOS

Presentación de recursos multimedia (Fotos antiguas) relacionados con el hito en visita.

\section{Clases asociadas:}

OldPicsViewController

OldPicsViewCell

OldPicsDetailController

DAO 


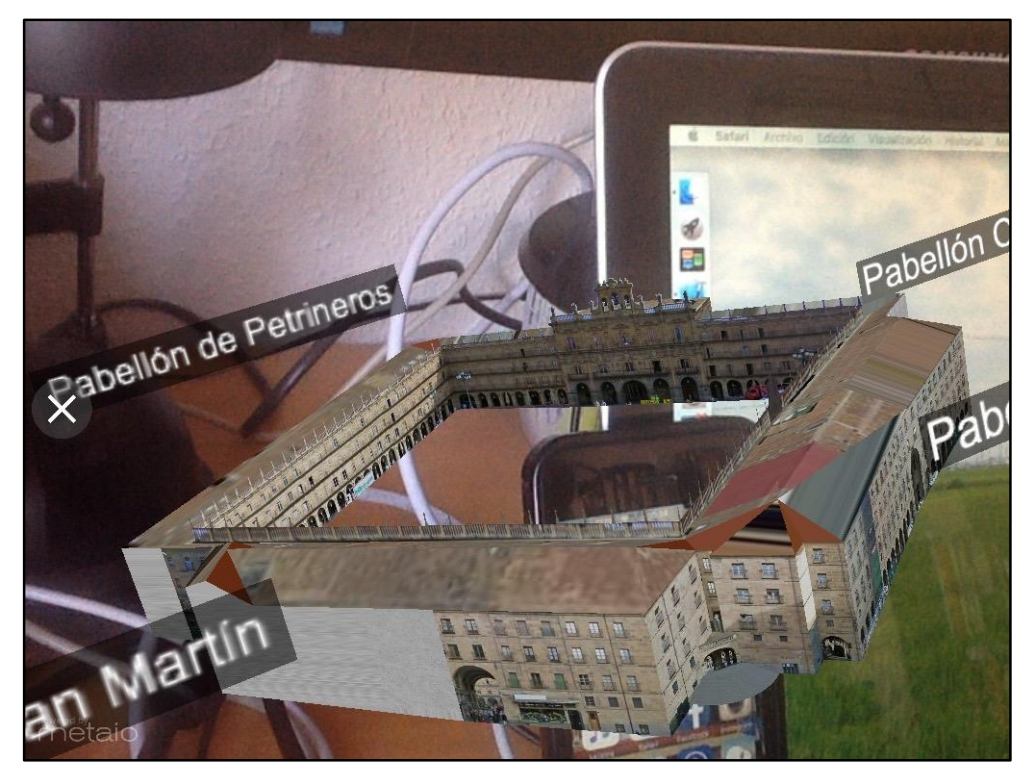

Presentación de recursos multimedia (Realidad Aumentada) relacionado con el hito en visita.

\section{Clases asociadas} (framework Metaio)**: ARELViewController MetaioSDKDelegate GestureHandlerIOS MetaioSDKViewController IARELInterpreterIOSDelegat e

TemplateARELViewController

** Estas clases están construidas en Objective-C y Swift permite su utilización.

Fuente: elaboración propia.

Es importante mencionar que en la aplicación AR-NPM 2.0, al igual que en su versión 1.0, los modelos de RA se encuentran implementados mediante un framework desarrollado en Objective-C de la empresa Metaio, y con ello la lectura de los modelos gráficos realizados en archivos .dae previamente desarrollados en Blender y SketchUp. Una de las potencialidades del lenguaje Swift utilizado en la nueva versión corresponde a la posibilidad de realizar llamadas a elementos, objetos y clases implementados anteriormente en Objective- $\mathrm{C}^{100}$, con la absoluta compatibilidad y fluidez en el entorno de desarrollo y despliegue de los datos en el contexto de una nueva aplicación. Lo anterior facilita la implementación de los recursos recreados para la RA, en un sistema diferente de implementación del lenguaje de desarrollo.

\footnotetext{
100 Muchas de las bibliotecas presentes en Metaio están implementadas en $\mathrm{C}++$, y son invocadas desde la implementación en Objective-C. De esta manera, Swift, de manera indirecta, hace posible la utilización de estos recursos con la lectura del framework.
} 
Figura 5.10 Diagrama de clases aplicación Salamanca Patrimonial (AR-NPM 2.0)
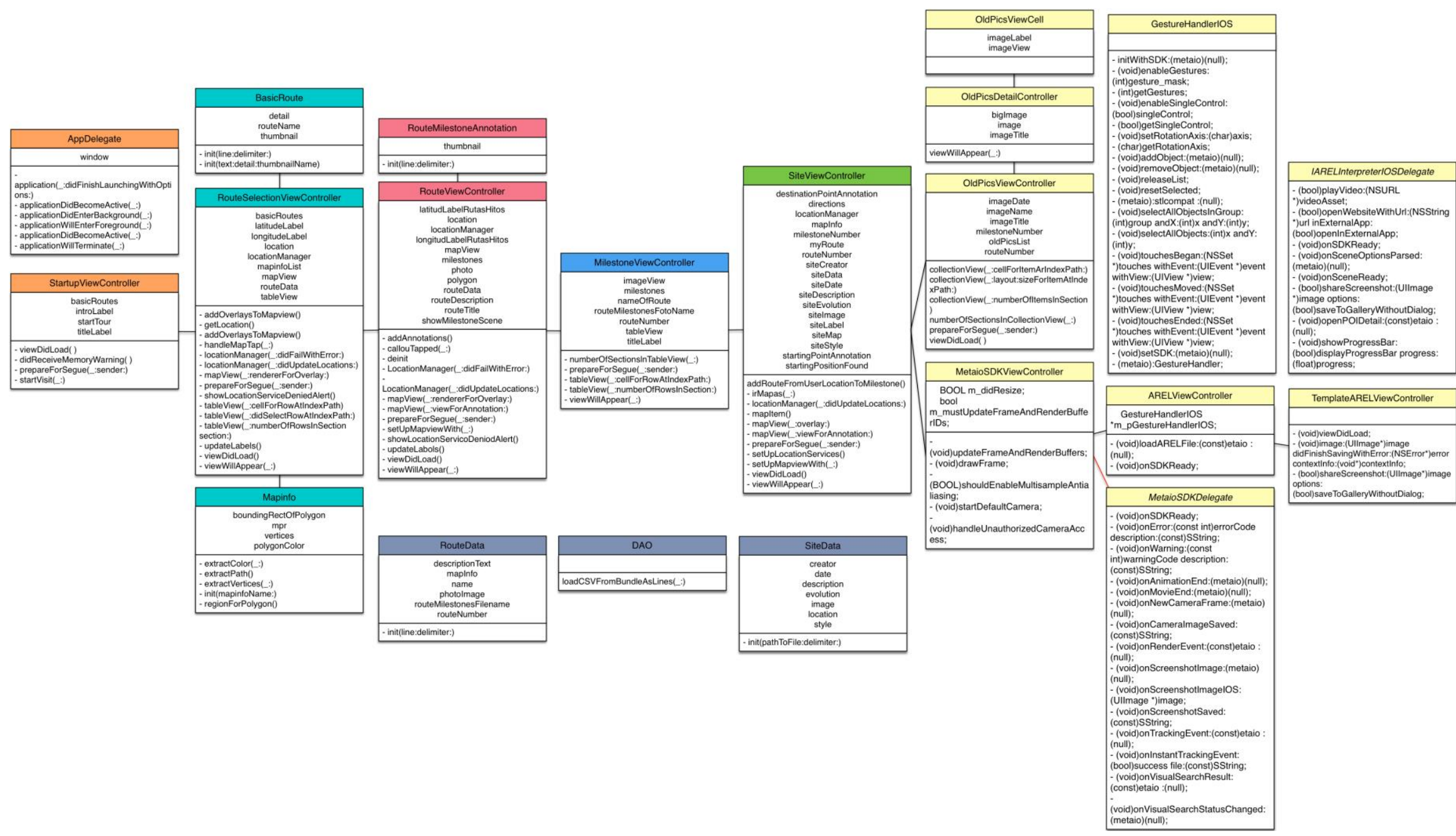

Fuente: Elaboración propia 


\subsection{Resultados de la fase cuantitativa de la experiencia educativa}

\subsubsection{Estudio exploratorio de las variables}

En esta etapa de la tesis se presentan los resultados con la exploración general de los datos, presentando las características de las distribuciones de las variables definidas para la investigación en el ámbito de la intervención educativa planteada, tanto para el caso de Chile como el de España.

\subsubsection{Pre-Test: Análisis gráfico con los constructos totales de cada experiencia}

En una primera parte se realizarán los análisis en función de los resultados totales de los instrumentos planteados para la experiencia de Chile, como la de España. Es importante mencionar que el instrumento agrupa tres ítems de contenidos (elementos Históricos, Arquitectónicos y de Localización) y tres ítems de procesos (Conocimiento, Comprensión y Aplicación) los cuales se reúnen en los valores Pre-Test y Post-Test del instrumento de evaluación aplicado a los sujetos de ambos países.

Gráfico 5.1 Función de densidad Pre-Test según tratamiento, experiencia de Chile
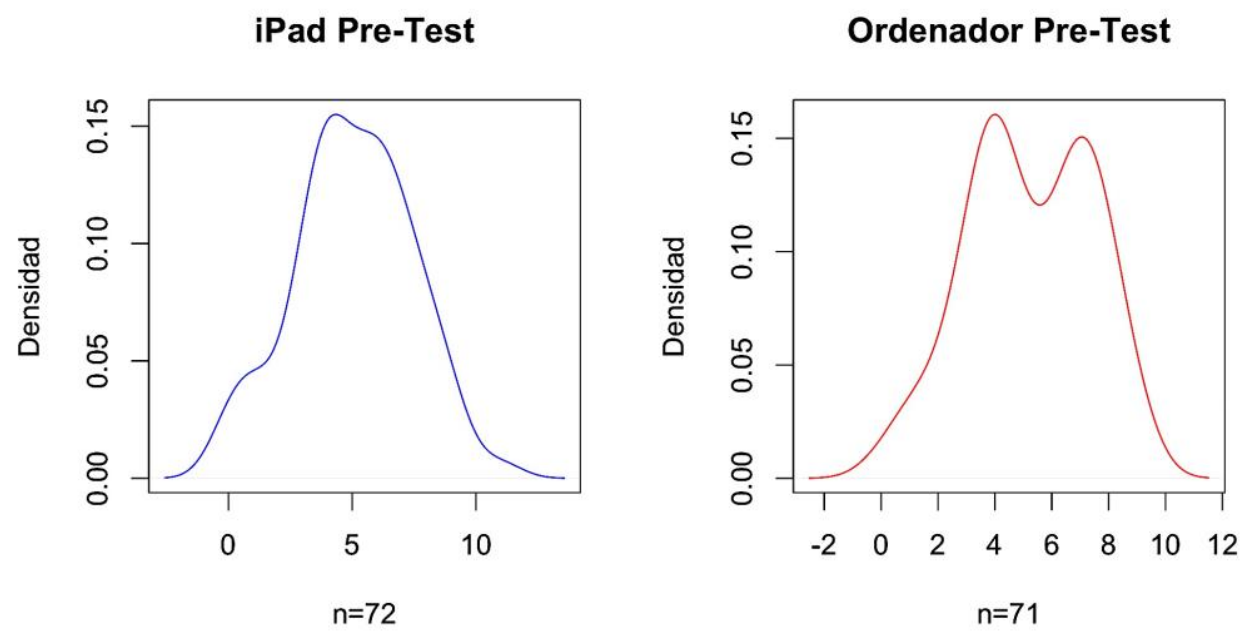

Fuente: Elaboración propia. 
Las funciones de densidad totales para la experiencia realizada en Chile en el contexto de Pre-Test -momento antes de aplicar el tratamiento que se realizan en investigaciones cuasiexperimentales- (Gráfico 5.1) presentan valores con una distribución que tiende a la curva normal, con una asimetría positiva en su estructura. La forma de las curvas es del tipo leptocúrtica, aunque para el caso del tratamiento realizado con ordenador, no mantiene una forma continua, presentando dos valores punta. Dichas formas se encuentran condicionadas por las puntuaciones obtenidas en el Pre-Test realizado.

Gráfico 5.2 Diagramas de cajas Pre-Test según tratamiento, experiencia de Chile

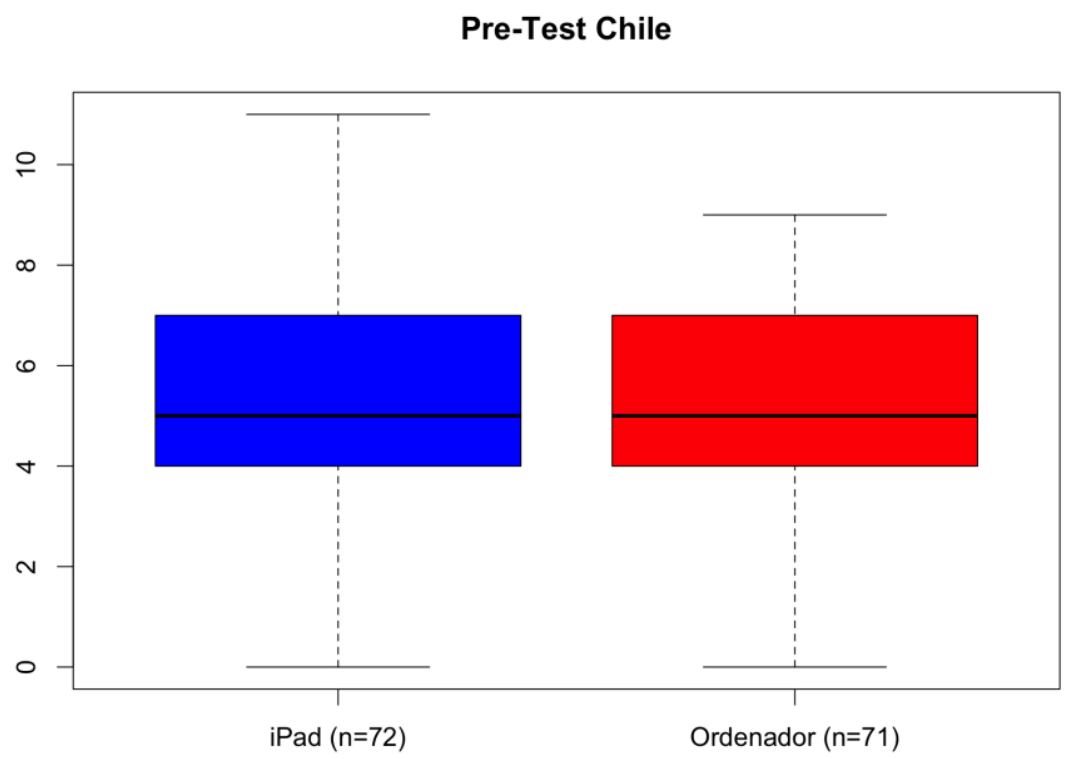

Fuente: Elaboración propia.

De manera complementaria, los diagramas de cajas confirman una distribución normal de los datos Pre-Test (Gráfico 5.2), en donde los valores de mediana coinciden en ambos grupos. La asimetría para el grupo ordenador tiende a ser levemente negativa. 
Gráfico 5.3 Función de densidad Pre-Test según tratamiento, experiencia de España
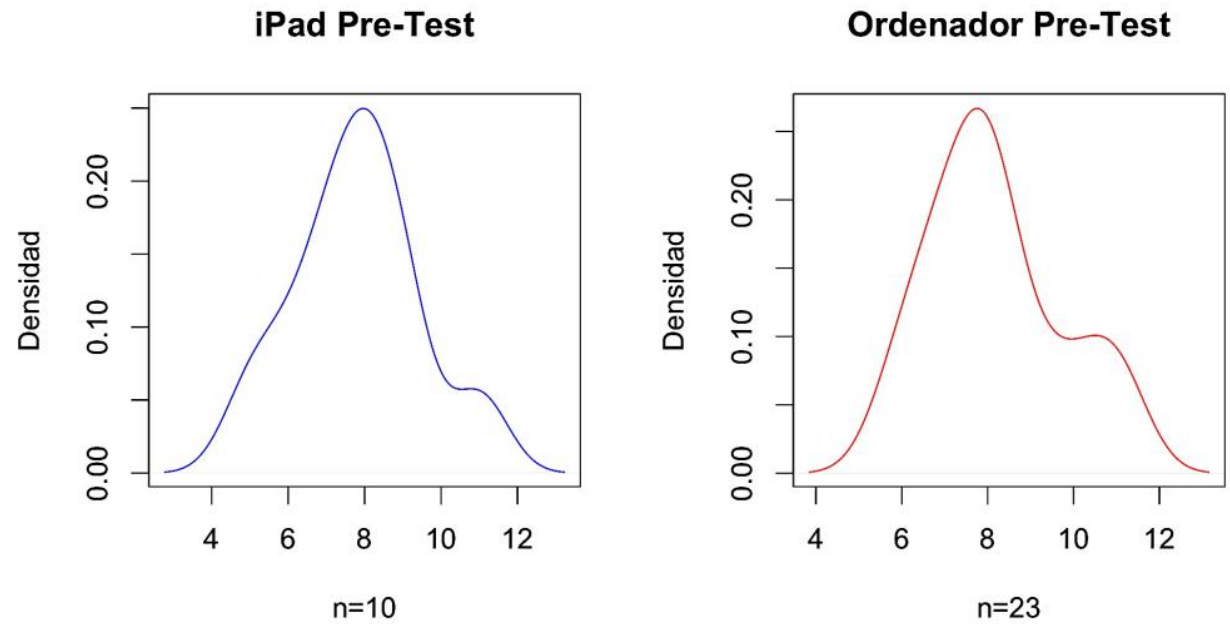

Fuente: Elaboración propia.

De manera particular, para el caso Pre-Test realizado en España (Gráfico 5.3), los gráficos de densidad presentan una distribución que tiende a la normalidad, aunque con formas leptocúrticas y asimetrías escasamente positivas. Los valores de media coinciden en ambos grupos, y se sitúan en los 8 puntos, lo cual puede visualizarse en los diagramas de cajas correspondientes (Gráfico 5.4). 
Gráfico 5.4 Diagramas de cajas Pre-Test según tratamiento, experiencia de España Pre-Test España

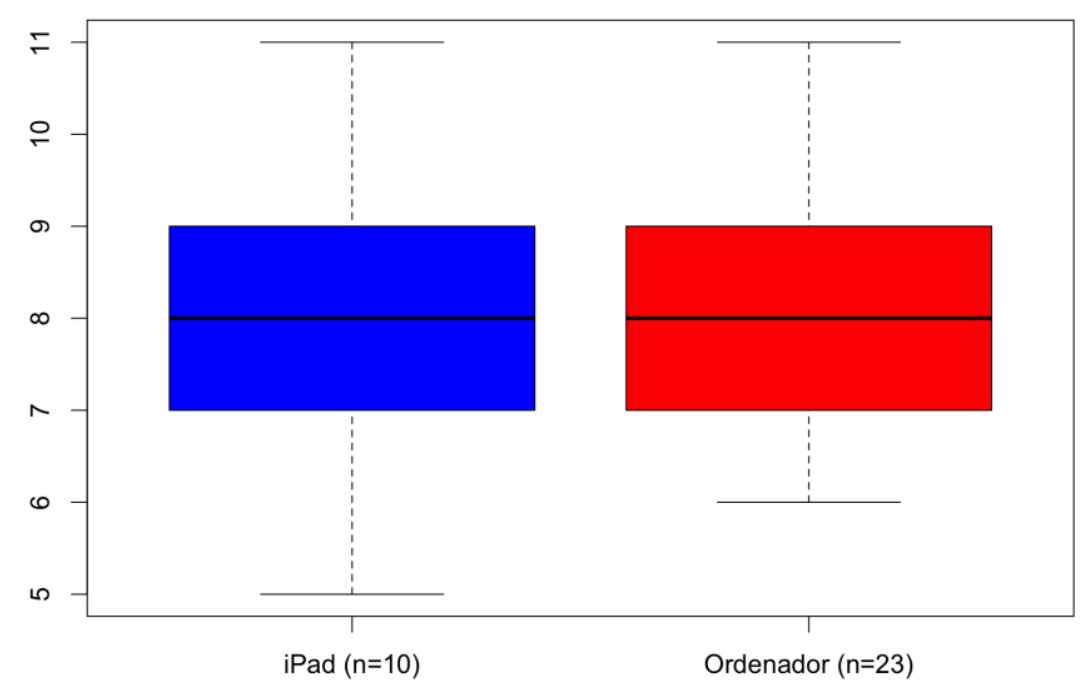

Fuente: Elaboración propia.

5.3.1.2 Pre-Test: Análisis estadístico básico y contrastes de normalidad según tratamiento

Complementando la información gráfica anterior, la Tabla 5.7 realiza una síntesis de los resultados estadísticos básicos para los datos recopilados para la etapa Pre-Test de cada intervención educativa. 
Tabla 5.7 Pre-Test. Exploración de estadísticos básicos

Asimetría

Curtosis

\begin{tabular}{|c|c|c|c|c|c|c|}
\hline Ítem & Mediana & $\begin{array}{c}\text { Amplitud } \\
\text { Intercuartílica }\end{array}$ & Valor & Error típ. & Valor & Error típ. \\
\hline $\begin{array}{c}\text { Tratamiento } \\
\text { iPad Chile } \\
\text { (n=72) }\end{array}$ & 5 & 3 &,- 102 &, 283 &,- 220 &, 559 \\
\hline $\begin{array}{c}\text { Tratamiento } \\
\text { Ordenador Chile }\end{array}$ & 5 & 3 &,- 212 &, 285 &,- 745 &, 563 \\
\hline $\begin{array}{c}\text { (n=71) } \\
\text { Tratamiento } \\
\text { iPad España } \\
\text { (n=10) }\end{array}$ & 8 & 2 &, 215 &, 687 &, 565 & 1,334 \\
\hline $\begin{array}{c}\text { Tratamiento } \\
\text { Ordenador }\end{array}$ & 8 & 3 &, 555 &, 481 &,- 495 &, 935 \\
\hline España (n=23) & & & & & \\
\hline Finte: Elaboracion
\end{tabular}

Fuente: Elaboración propia.

Los valores de los indicadores (Tabla 5.7) muestran que los datos generales obtenidos en el Pre-Test para ambos países, presentan una distribución normal de los registros. La forma de la curva generada es platicúrtica y para el caso de Chile las asimetrías obtenidas tienden hacia valores negativos.

Se han utilizado los gráficos Q-Q para representar los valores empíricos respecto a la tendencia de posible de los valores esperados para los grupos analizados.

Gráfico 5.5 Q-Q normales Pre-Test según tratamiento, experiencia de Chile

Pre-Test. Tratamiento iPad

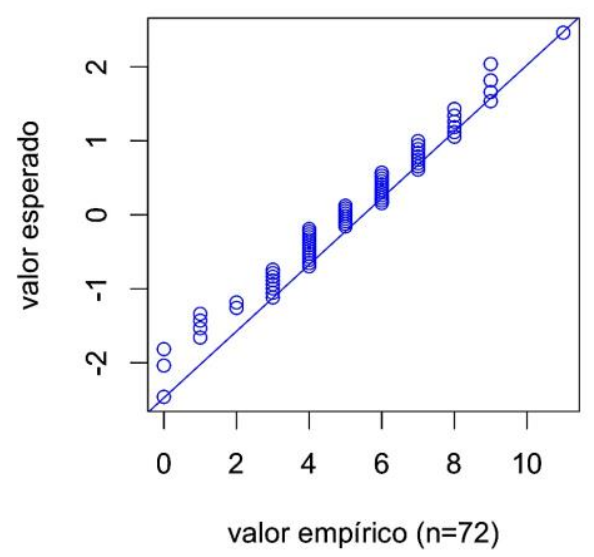

Pre-Test. Tratamiento Ordenador

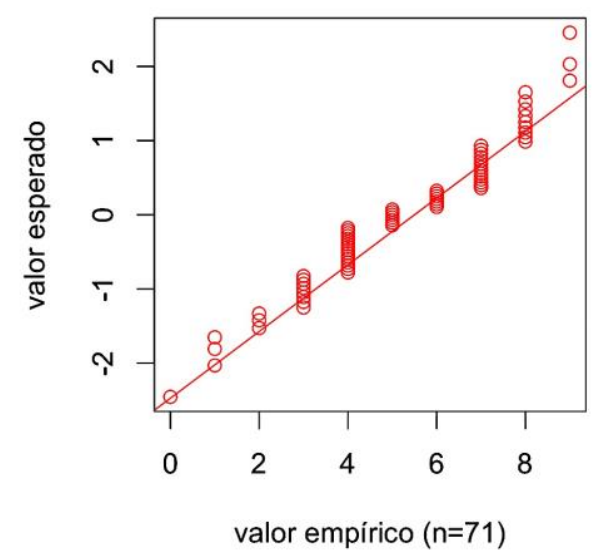

Fuente: Elaboración propia. 
Los valores empíricos representados en los diagramas Q-Q para los datos Pre-Test de Chile (Gráfico 5.5) muestran que la mayoría de los datos se ajustan a la recta de valores esperados. De manera paralela, dicha recta toma una pendiente regular que establece la presencia de una distribución normal en los datos empíricos y estimados.

Gráfico 5.6 Q-Q normales Pre-Test según tratamiento, experiencia de España

Pre-Test. Tratamiento iPad

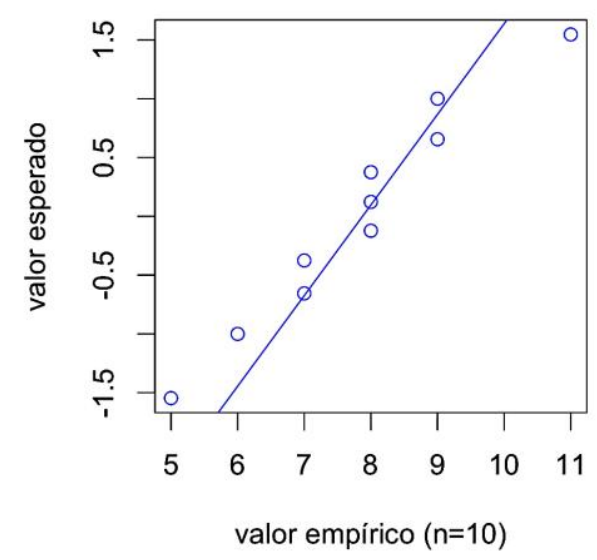

\section{Pre-Test. Tratamiento Ordenador}

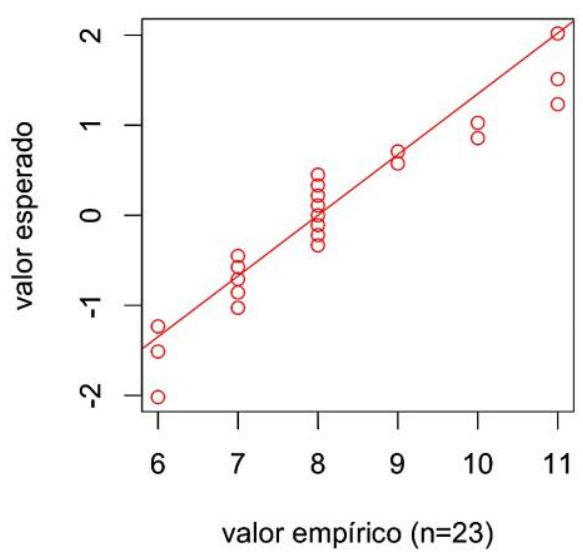

Fuente: Elaboración propia.

Para el caso de los datos obtenidos en España, los valores empíricos también se ajustan a los valores esperados representados en las rectas (Gráfico 5.6). Sin embargo, el grupo iPad al tener un número de sujetos reducidos, la pendiente de la recta es mayor debido al contexto Pre-Test y el número de participantes en la experiencia. 
Tabla 5.8 Test de normalidad de Kolmogorov-Smirnov Pre-Test.

\begin{tabular}{|c|c|c|c|}
\hline Ítem & $D^{101}$ & $\mathbf{z}$ & p. \\
\hline $\begin{array}{l}\text { Tratamiento iPad Chile } \\
(n=72)\end{array}$ & 0,100 & 0,852 & ,463 \\
\hline $\begin{array}{c}\text { Tratamiento Ordenador } \\
\text { Chile }(n=71)\end{array}$ & 0,157 & 1,324 & ,060 \\
\hline $\begin{array}{l}\text { Tratamiento iPad España } \\
\qquad(n=10)\end{array}$ & 0,153 & 0,483 & 974 \\
\hline $\begin{array}{c}\text { Tratamiento Ordenador } \\
\text { España }(n=23)\end{array}$ & 0,240 & 1,152 & 141 \\
\hline $\begin{array}{l}\text { Tratamiento iPad Chile } \\
\qquad(n=72)\end{array}$ & 0,100 & 0,852 & ,463 \\
\hline $\begin{array}{c}\text { Tratamiento Ordenador } \\
\text { Chile }(n=71)\end{array}$ & 0,157 & 1,324 & ,060 \\
\hline
\end{tabular}

Fuente: Elaboración propia.

Como se establece en la Tabla 5.8 todos los ítems del Pre-Test para los resultados generales, tienden a una distribución normal. De esta manera, se acepta la hipótesis en la cual se establece que los registros tienen un comportamiento concordante con una distribución normal esperada en los datos.

\subsubsection{Post-Test: Análisis gráfico con los constructos totales de cada experiencia}

Posterior a la aplicación de los tratamientos respectivos a los grupos participantes para cada país, se aplica el instrumento de evaluación realizado. Los primeros resultados se sintetizan en el análisis grafico siguiente:

${ }^{101}$ Valor que establece la diferencia absoluta más alta entre la frecuencia acumulada teórica y la observada. 
Gráfico 5.7 Función de densidad Post-Test según tratamiento, experiencia de Chile
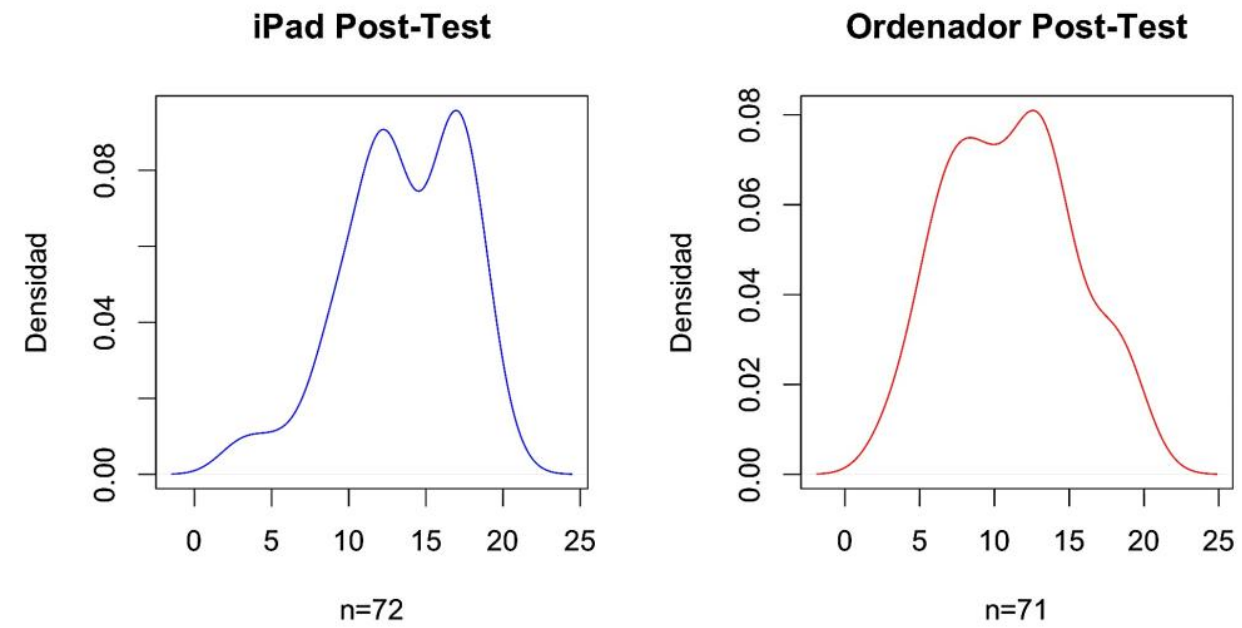

Fuente: Elaboración propia.

Las distribuciones presentes en las funciones de densidad Post-Test (Gráfico 5.7) muestran un comportamiento normal de la estructura general de los datos para ambos grupos. Se puede observar que la amplitud de los valores empíricos aumenta, aunque las curvas siguen teniendo una forma leptocúrtica, con una leve asimetría negativa. Además, para ambos grupos, las curvas presentan dos valores punta consecuencia de la presencia de más de un valor que se establece como tendencia central. 
Gráfico 5.8 Diagramas de cajas Post-Test según tratamiento, experiencia de Chile

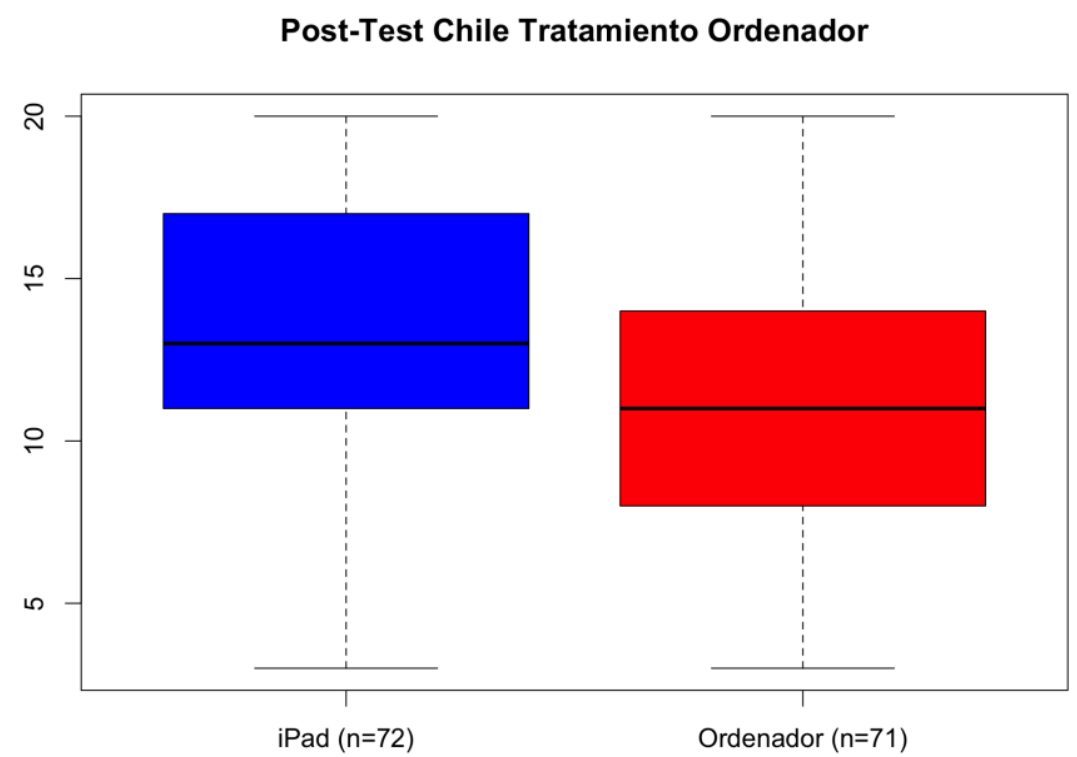

Fuente: Elaboración propia.

El diagrama de cajas (Gráfico 5.8) confirma los datos anteriormente presentados sobre la distribución normal de los valores para ambos grupos. Sin embargo, es posible apreciar que el grupo iPad presenta una mayor asimetría negativa respecto al grupo ordenador. De la misma manera los valores de mediana son superiores en el grupo iPad siendo esto, una primer evidencia de un mejor rendimiento respecto al grupo que hizo uso de ordenadores. 
Gráfico 5.9 Función de densidad Post-Test según tratamiento, experiencia de España
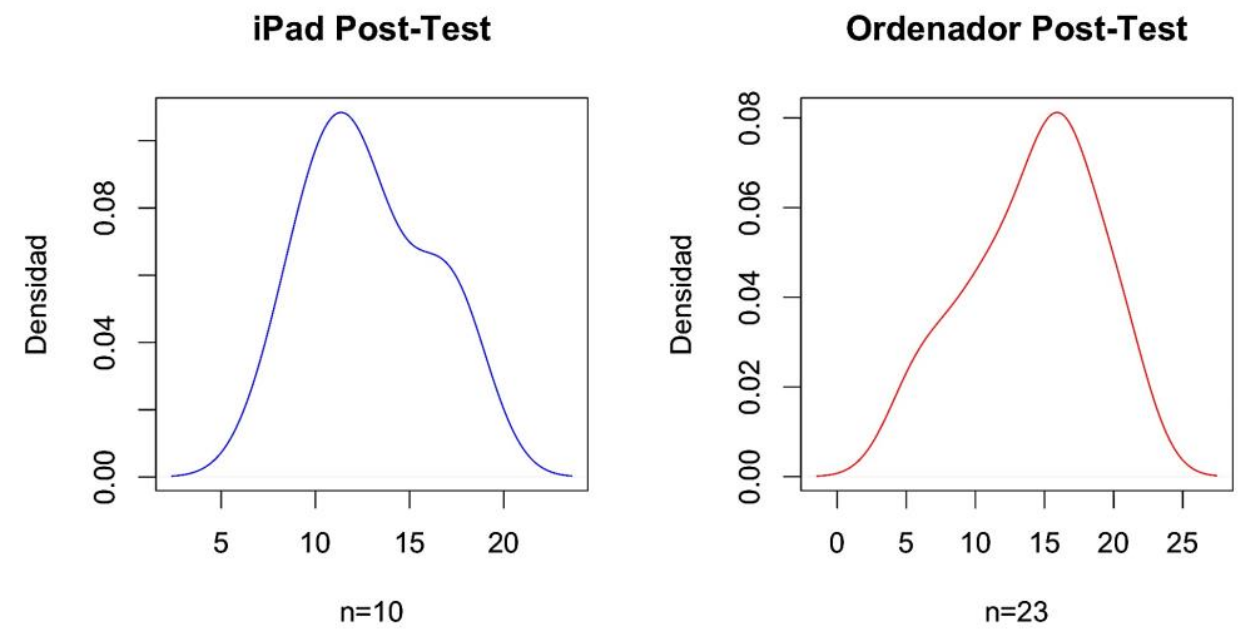

Fuente: Elaboración propia.

Para el caso de España, las distribuciones de densidad Post-Test para ambos tratamientos (Gráfico 5.9) también es posible observar comportamientos normales con forma leptocúrtica de las curvas graficadas. Sin embargo, existen notorias diferencias en la asimetría que se presentan en cada curva, siendo para el grupo iPad con una tendencia positiva y la del grupo ordenador con una leve tendencia negativa de los datos en torno a los valores centrales. 
Gráfico 5.10 Diagramas de cajas Post-Test según tratamiento, experiencia de España

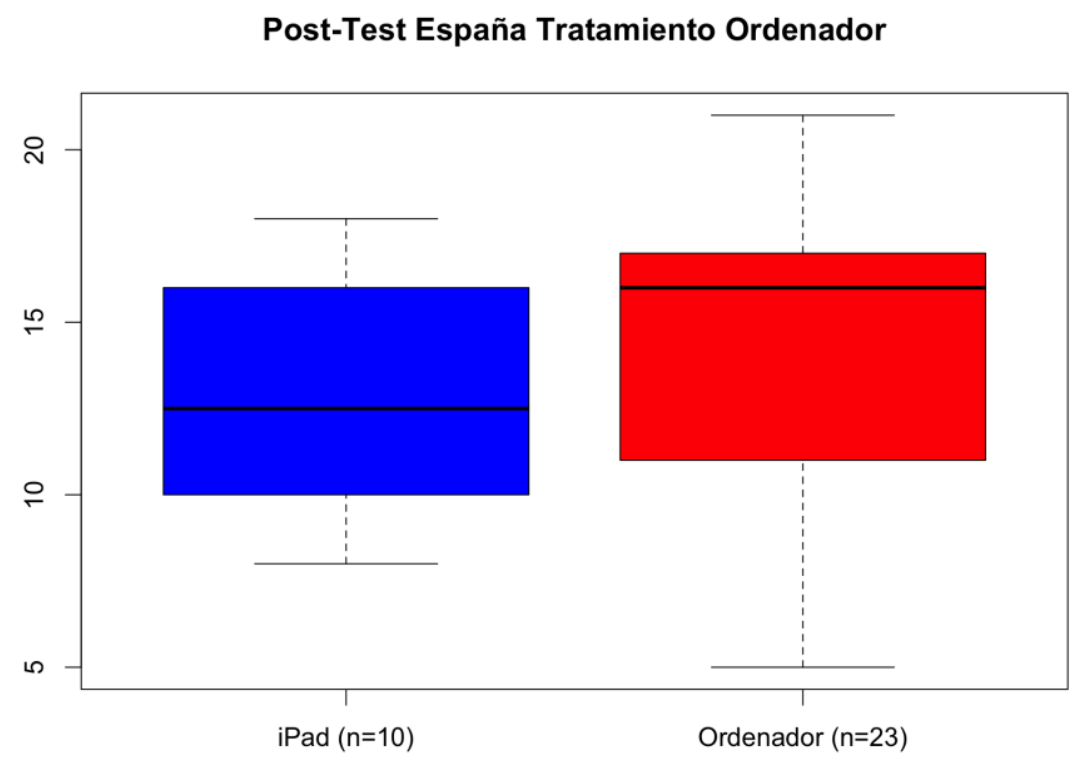

Fuente: Elaboración propia.

Los diagramas de cajas de España (Gráfico 5.10), complementan la información anterior y establecen una distribución normal de los datos. Sin embargo, el grupo ordenador tiene un leve mejor rendimiento que el grupo iPad, aunque los datos se encuentran con una mayor dispersión en sus valores. Es importante destacar que el grupo iPad cuenta con un limitado número de sujetos $(n=10)$ lo que dificulta extraer generalizaciones sobre las posible diferencias obtenidas en el muestreo realizado.

\subsubsection{Post-Test: Análisis estadístico básico y contrastes de normalidad} según tratamiento

El análisis gráfico anterior muestra un comportamiento normal de los datos obtenidos para cada grupo. Dicha información es complementada con los valores de asimetría y curtosis para la información obtenida en el Post-Test. 
Tabla 5.9 Post-Test. Exploración de estadísticos básicos

Asimetría

\section{Curtosis}

\begin{tabular}{|c|c|c|c|c|c|c|}
\hline Ítem & Mediana & $\begin{array}{c}\text { Amplitud } \\
\text { Intercuartílica }\end{array}$ & Valor & Error típ. & Valor & Error típ. \\
\hline $\begin{array}{c}\text { Tratamiento iPad } \\
\text { Chile }(n=72)\end{array}$ & 13,000 & 6 &,- 641 &, 283 &, 061 &, 559 \\
$\begin{array}{c}\text { Tratamiento } \\
\text { Ordenador Chile } \\
(n=71)\end{array}$ & 11,000 & 6 &, 163 &, 285 &,- 730 &, 563 \\
\hline $\begin{array}{c}\text { Tratamiento iPad } \\
\text { España }(n=10)\end{array}$ & 12,500 & 2 &, 337 &, 687 &,- 977 & 1,334 \\
\hline $\begin{array}{c}\text { Tratamiento } \\
\text { Ordenador }\end{array}$ & 16,000 & 8 &,- 416 &, 481 &,- 640 &, 935 \\
\hline
\end{tabular}

Fuente: Elaboración propia.

Los valores obtenidos en los indicadores Post-Test (Tabla 5.9) muestran que los registros para ambos países se presentan con una distribución normal. Sin embargo, los valores de mediana y de la amplitud Intercuartílica son mayores a los registrados en el Pre-Test. Se destaca el valor de curtosis para el grupo iPad de Chile, cuyos datos esperados y empíricos genera una forma mesocúrtica en la distribución de los registros.

Gráfico 5.11 Q-Q normales Post-Test según tratamiento, experiencia de Chile

Post-Test. Tratamiento iPad

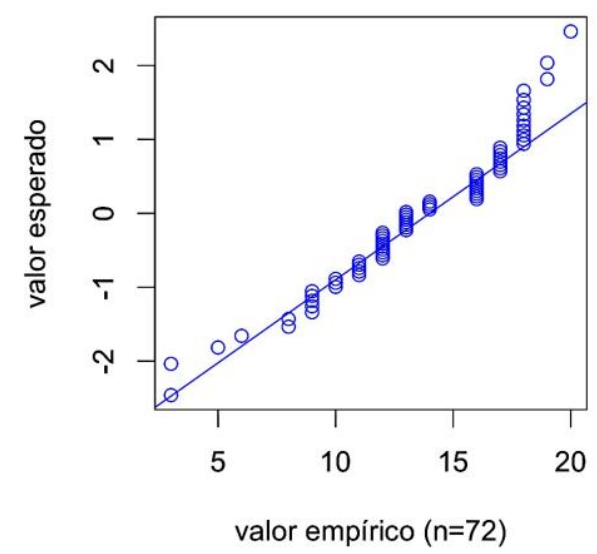

Post-Test. Tratamiento Ordenador

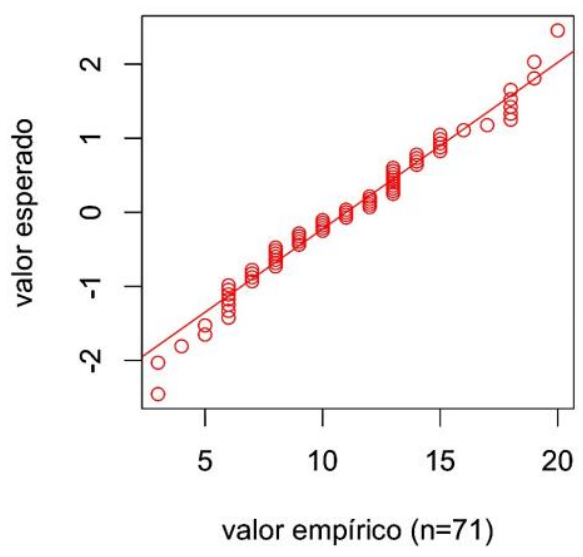

Fuente: Elaboración propia. 
Los valores empíricos representados en los diagramas Q-Q para los datos PostTest de Chile (Gráfico 5.11) muestran que la mayoría de los datos se ajustan a la recta de valores esperados, exceptuando los registros que se presentan en sectores extremos. También es posible observar que la amplitud de los valores empíricos aumenta, presentándose una mayor coincidencia con la recta de valores esperados.

Gráfico 5.12 Q-Q normales Post-Test según tratamiento, experiencia de España

Post-Test. Tratamiento iPad

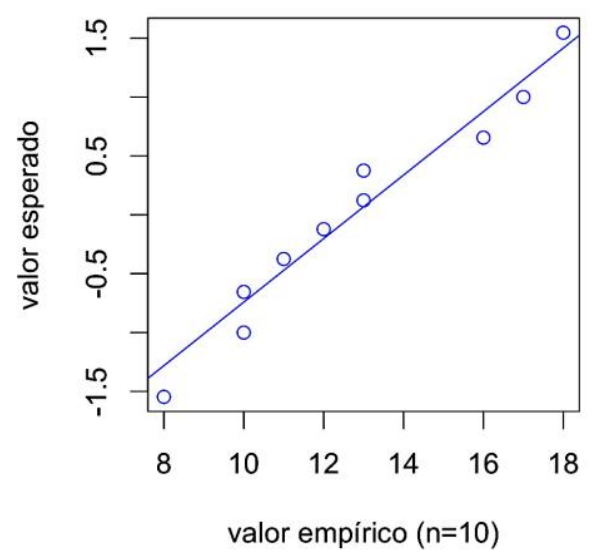

\section{Post-Test. Tratamiento Ordenador}

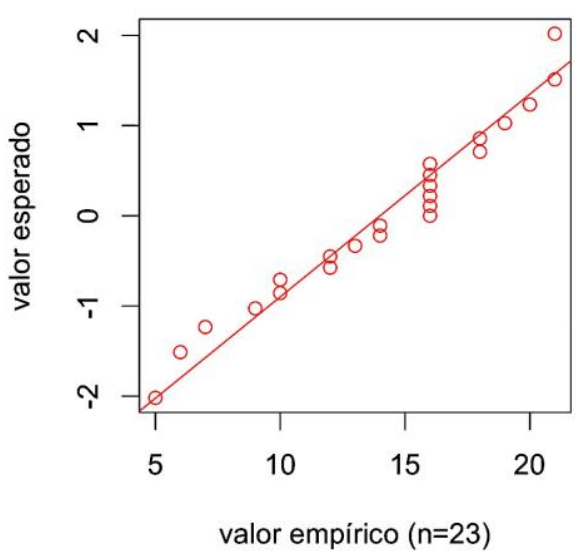

Fuente: Elaboración propia.

En los datos Post-Test de España, los valores empíricos también se ajustan a los esperados representados en las rectas Q-Q (Gráfico 5.12). Para ambos grupos, los valores empíricos y esperados se ajustan hacia una distribución normal, aunque el limitado número de sujetos condiciona posteriores tratamientos de contraste hacia pruebas no paramétricas. 
Tabla 5.10 Test de normalidad de Kolmogorov-Smirnov Post-Test.

\begin{tabular}{|c|c|c|c|}
\hline Ítem & $D^{102}$ & z & p. \\
\hline $\begin{array}{l}\text { Tratamiento iPad Chile } \\
(n=72)\end{array}$ & 0,165 & 1,400 & ,040 \\
\hline $\begin{array}{l}\text { Tratamiento Ordenador } \\
\text { Chile }(n=71)\end{array}$ & 0,091 & 0,768 & ,598 \\
\hline $\begin{array}{l}\text { Tratamiento iPad España } \\
(n=10)\end{array}$ & 0,176 & 0,556 & 917 \\
\hline $\begin{array}{l}\text { Tratamiento Ordenador } \\
\text { España }(n=23)\end{array}$ & 0,178 & 0,854 & ,459 \\
\hline
\end{tabular}

Fuente: Elaboración propia.

Aplicando el test de normalidad de Kolmogorov-Smirnov a los datos generales Post-Test (Tabla 5.10), todos los grupos sitúan los valores hacia una distribución normal de los datos, con excepción del tratamiento iPad en Chile, con una significancia asintótica igual a ,040.

\subsubsection{Pre-Test: Análisis gráfico de las distribuciones por ítem}

El análisis de las distribuciones por ítem se ha realizado en función de la definición del instrumento de evaluación aplicado durante las etapas de Pre-Test y Post-Test con el fin de determinar la posible normalidad de las distribuciones de datos obtenidas. Particularmente para el caso de España, debido al limitado número de sujetos participantes ( $n=33$ ), se ha decidido aplicar contrastes no paramétricos en la sección posterior ${ }^{103}$ (5.3.2). Sin embargo, en el Anexo 12 se presentan los análisis gráficos y estadísticos para los valores obtenidos.

\footnotetext{
102 Valor que establece la diferencia absoluta más alta entre la frecuencia acumulada teórica y la observada.

${ }^{103}$ Esto, con el fin de evitar errores de Tipo II aceptando Hipótesis Nulas como verdaderas, situación derivada de aceptar una distribución normal con un número limitado de sujetos (Morales Vallejo, 2012).
} 
Gráfico 5.13 Función de densidad Pre-Test. Elementos de contenido, experiencia de Chile
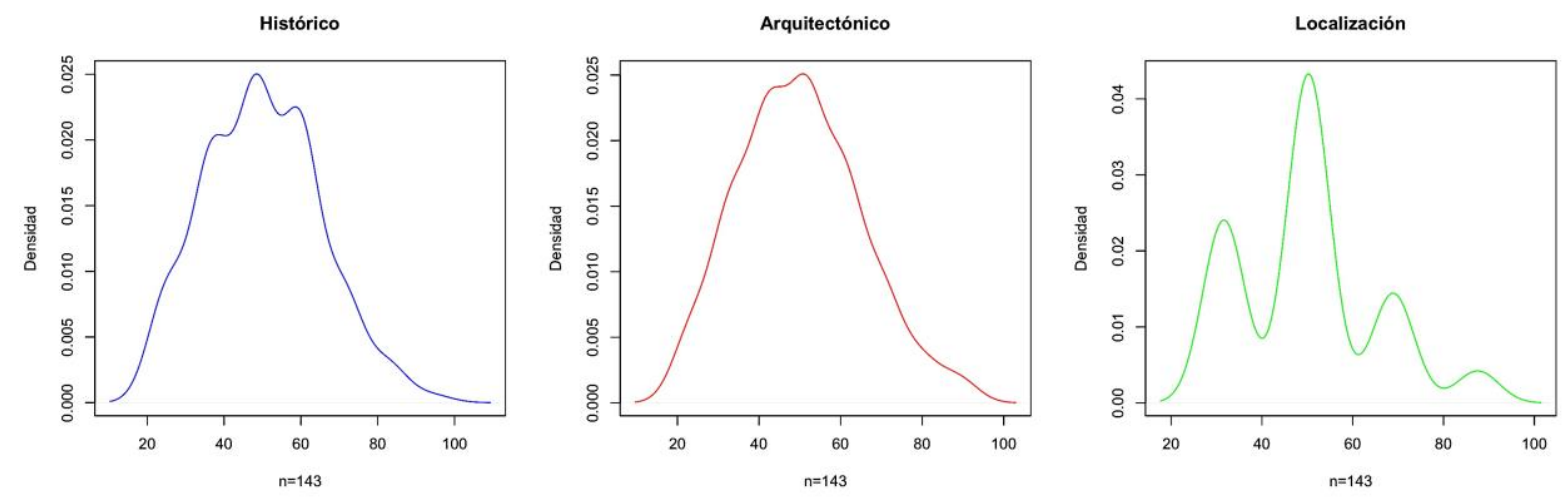

Fuente: Elaboración propia.

En cuanto los elementos de contenido, los cuales incluyen los ítems Histórico, Arquitectónico y de Localización estructurados en el instrumento Pre-Test (Gráfico 5.13), es posible observar que los valores presentan una distribución que tiende a una curva normal con una asimetría positiva en los valores de registro, aunque con formas cercanas a del tipo leptocúrtica. Sin embargo, los valores referidos a la dimensión de Localización, se presenta una curva con 3 puntas indicando la presencia de otros valores de en donde los datos centrales (moda) obtienen registros importantes, definiendo la forma de la curva. Esto es explicado por la reducida cantidad de ítems que componen el contenido de Localización.

En cuanto a los resultados de los diagramas de cajas (Gráfico 5.14) es posible observar que en los valores obtenidos en los ítems de contenido, presentan distribuciones que tienden a la normalidad, con algunos registros que presentan valores atípicos. De manera paralela, los datos observados en los contenidos de Localización coinciden con los valores mínimos en $\mathrm{Q}_{1}$, estableciendo otro tipo de estructura de distribución de los datos la que no coincide con uno normal. 
Gráfico 5.14 Diagramas de cajas Pre-Test. Elementos de contenidos, experiencia de Chile Pre-Test Chile. Contenido

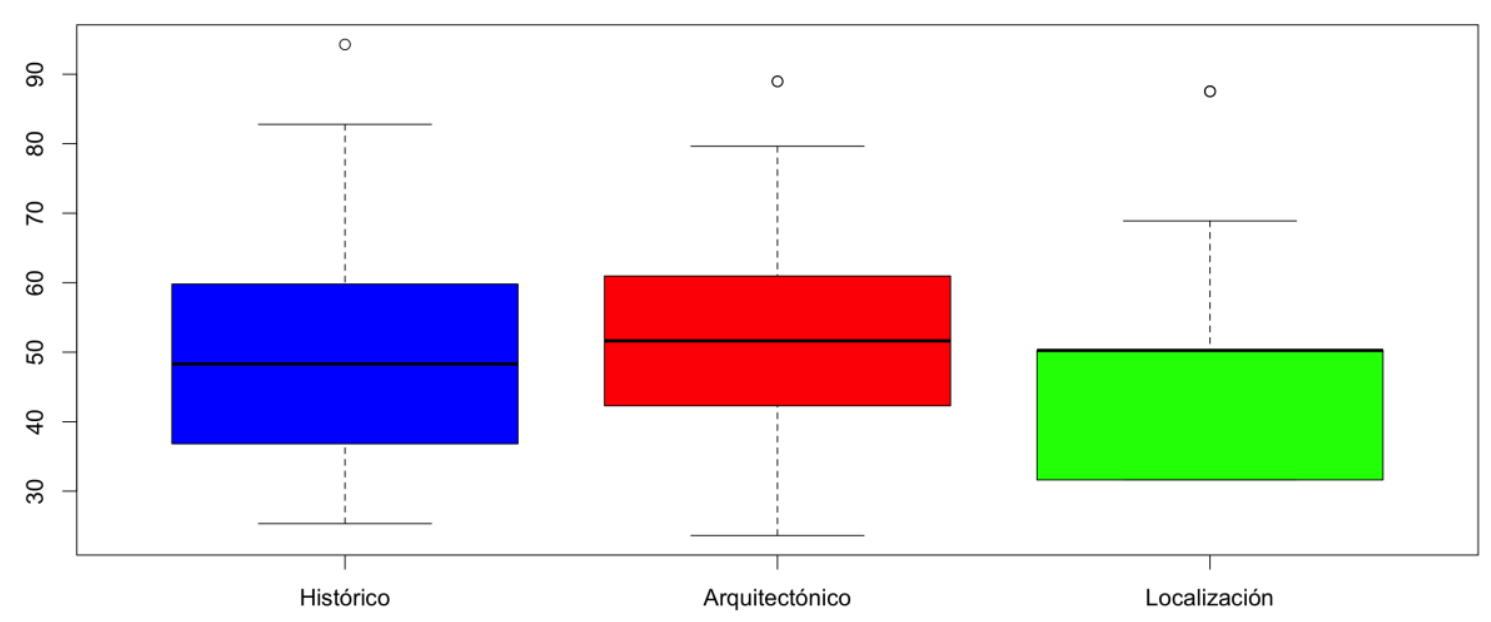

Fuente: Elaboración propia.

Gráfico 5.15 Función de densidad Pre-Test. Elementos de contenido, experiencia de Chile, iPad
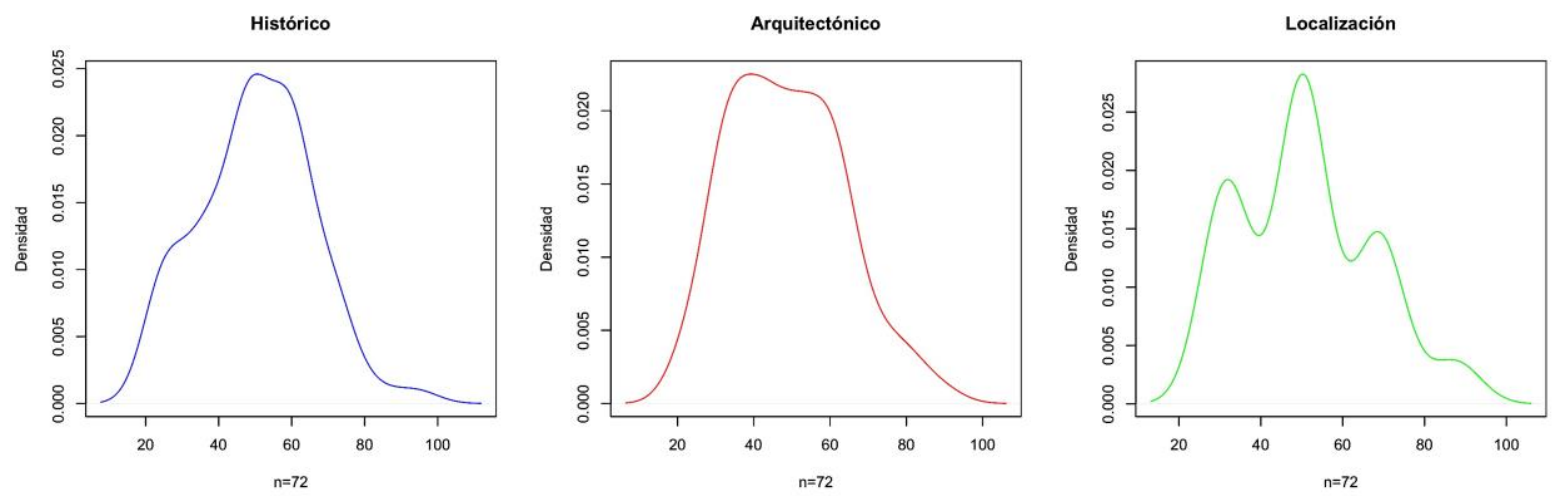

Fuente: Elaboración propia. 
Gráfico 5.16 Diagramas de cajas Pre-Test. Elementos de contenidos, experiencia de Chile, iPad

Pre-Test Chile Tratamiento Ipad. Contenidos

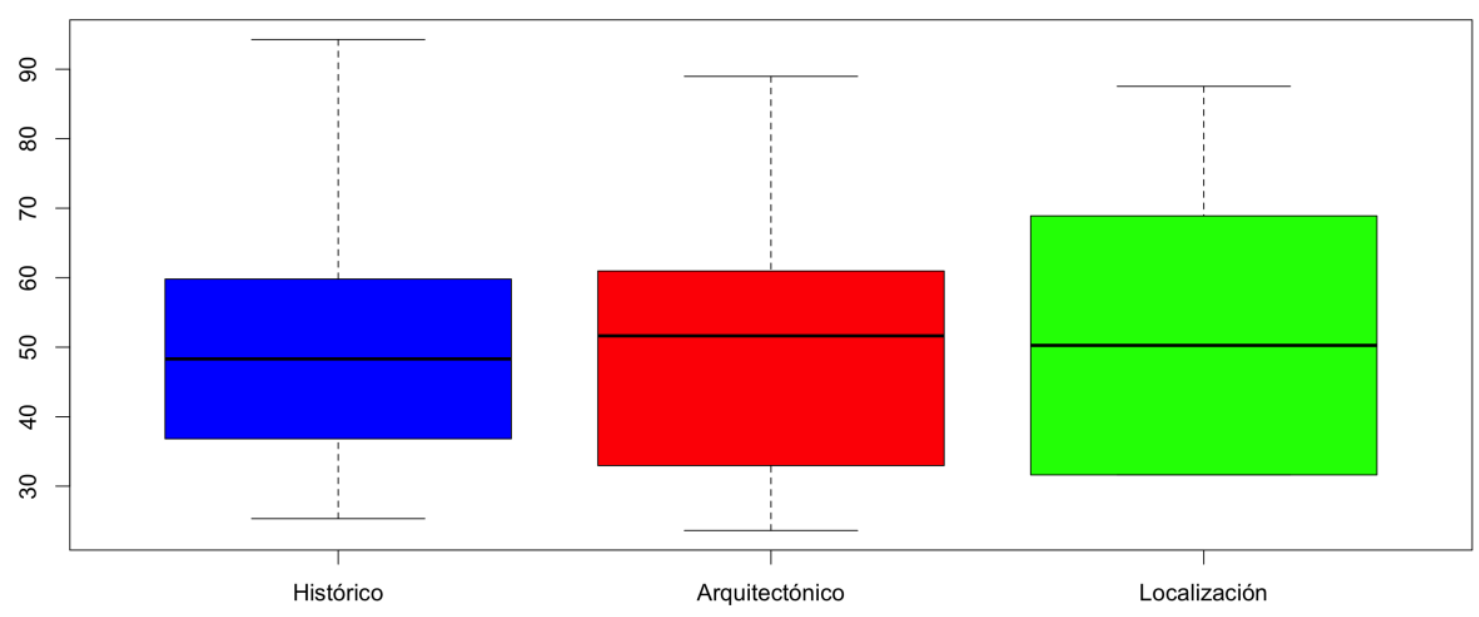

Fuente: Elaboración propia.

Desde el análisis en función del tratamiento realizado, para el caso de la experiencia educativa para Chile desarrollada con iPad (Gráfico 5.15 y Gráfico 5.16), los resultados para los ítems de contenido muestran una distribución que tiende a la normalidad, con los valores dispersos a través de todos los cuartiles con excepción del ítem de Localización. Las curvas de densidad tienen una forma leptocúrtica, a pesar que en el ítem de localización se presentan tres valores predominantes propios de distribuciones con más de una moda.

Gráfico 5.17 Función de densidad Pre-Test. Elementos de contenido, experiencia de Chile, Ordenador
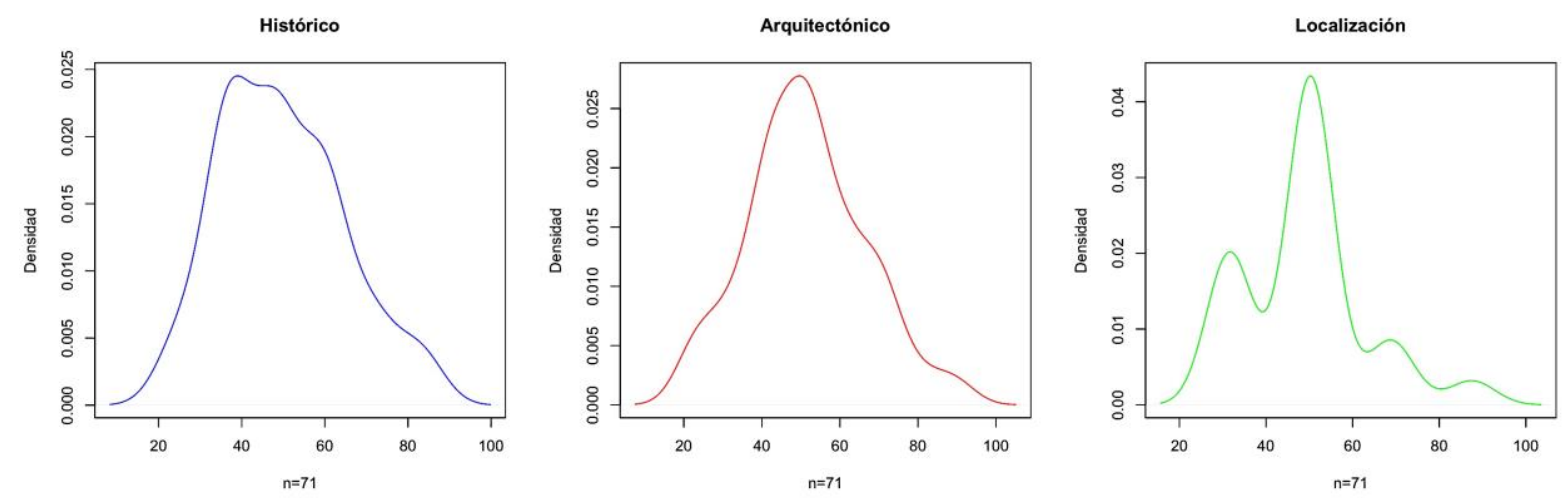

Fuente: Elaboración propia. 
Gráfico 5.18 Diagramas de cajas Pre-Test. Elementos de contenidos, experiencia de Chile, Ordenador

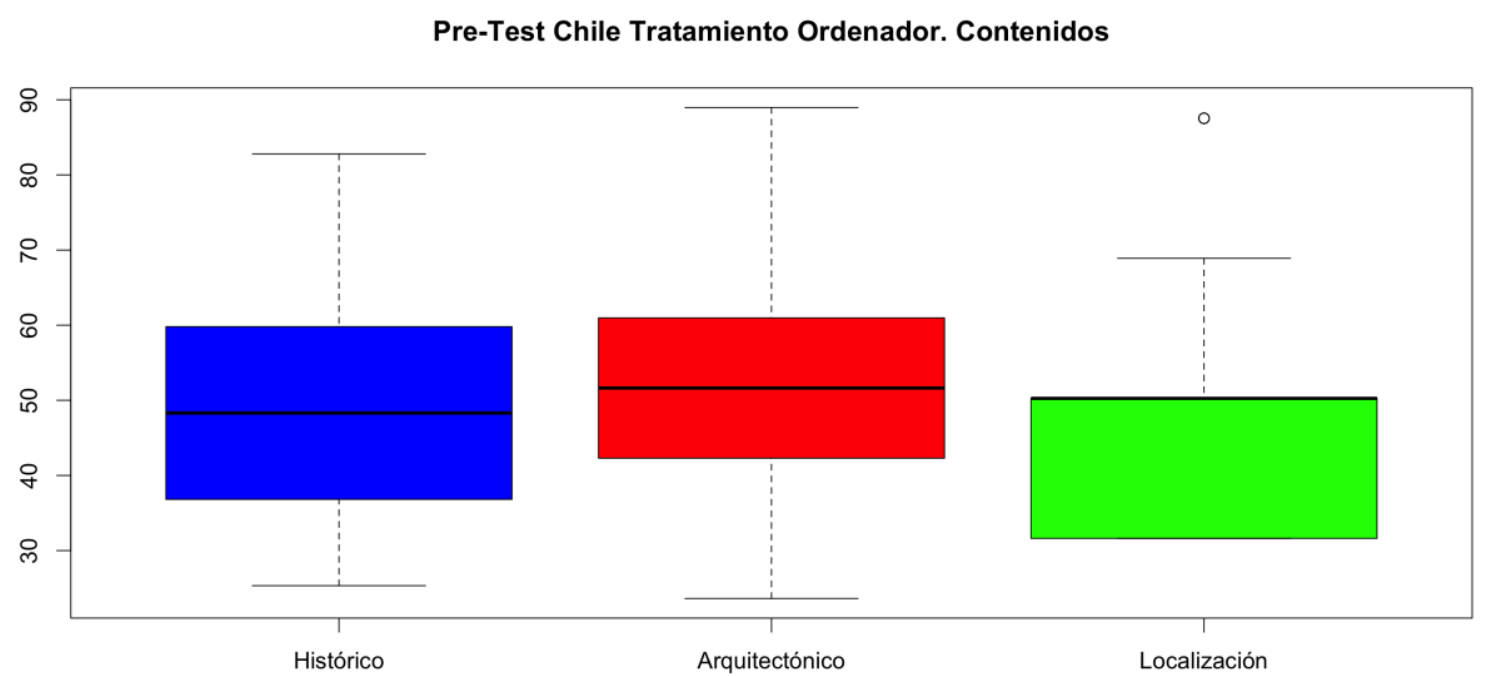

Fuente: Elaboración propia.

De manera paralela, el tratamiento realizado con ordenadores (Gráfico 5.17 y Gráfico 5.18), los resultados para los ítems Histórico y Arquitectónico muestran una distribución normal con una curva de densidad leptocúrtica. Los diagramas de cajas de dichos ítems confirman esta estructura de los datos. Por otro lado el ítem de Localización nuevamente presenta una curva de densidad que tiene más de un valor predominante y el diagrama de cajas y bigotes confirma dicha distribución de los datos.

Desde la comparación mediante los procesos (Conocimiento, Comprensión y Aplicación) evaluados en el instrumento Pre-Test, se producen comportamientos leptocúrticos de las curvas graficadas y la asimetría mantiene una tendencia positiva en los diagramas de densidad (Gráfico 5.19), con excepción del contenido de Aplicación en que la distribución de los valores tiene una tendencia negativa con tres valores punta que se destacan como elementos puntas de las distribución. En tanto los diagramas de cajas y bigotes (Gráfico 5.20), en donde los valores del proceso Conocimiento tiende a la normalidad en sus valores. Por otro lado para los procesos de Comprensión y Aplicación, los valores mínimos coinciden con valores $Q_{1}$, explicando la forma de la distribución y la estructura de datos. De la misma manera que en el caso anterior, estos comportamientos 
se explicarían por el número de ítems que componen la definición de los procesos en el instrumento aplicado

Gráfico 5.19 Función de densidad Pre-Test. Procesos, experiencia de Chile
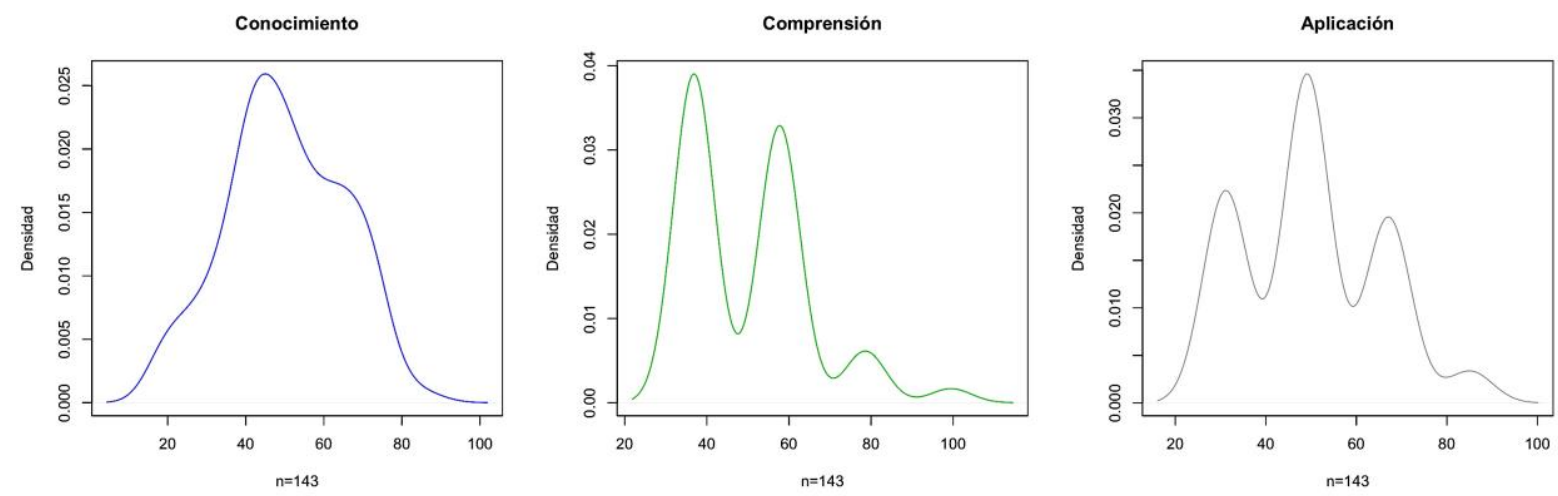

Fuente: Elaboración propia.

Gráfico 5.20 Diagramas de cajas Pre-Test. Procesos, experiencia de Chile

Pre-Test Chile. Procesos

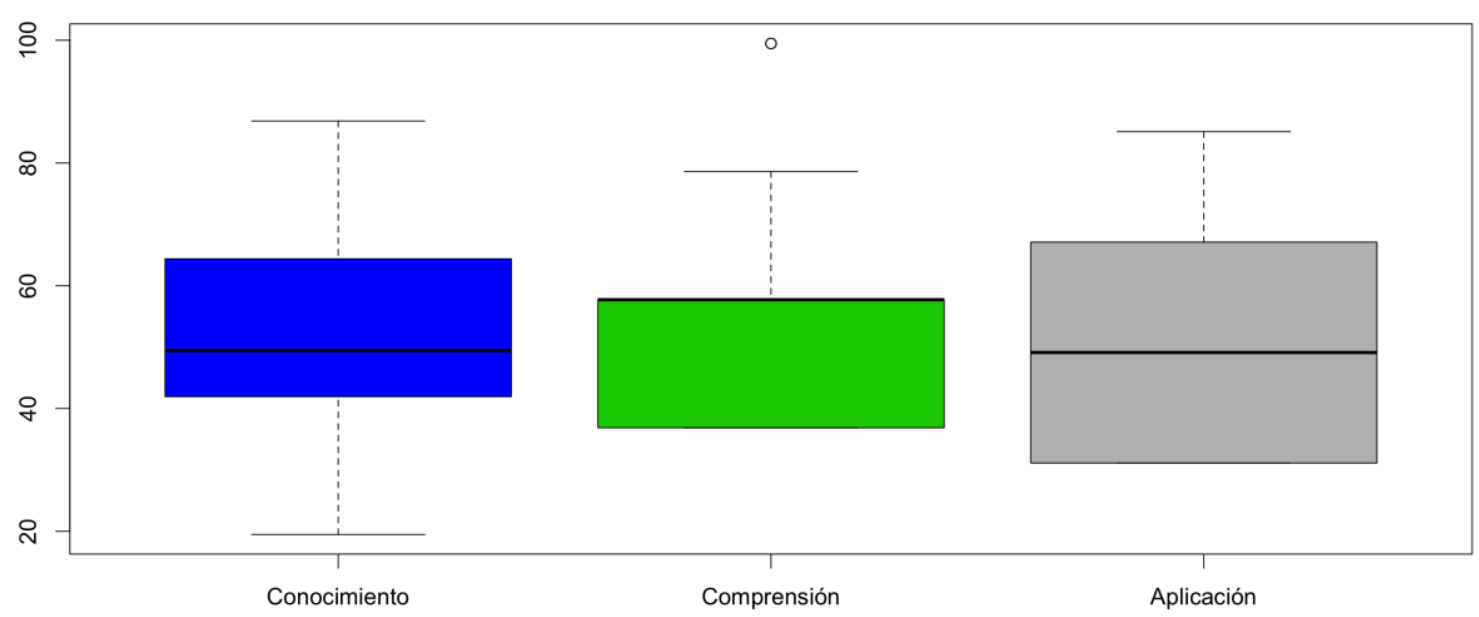

Fuente: Elaboración propia.

Los resultados representados con los gráficos de densidad y los diagramas de cajas para la distribución de los datos obtenidos para Chile (instrumento Pre-Test), presentan una serie de valores extremos que deben ser considerados con análisis posteriores, no 
pudiéndose establecer una distribución normal de manera concluyente, realizándose los contrastes de normalidad en la sección 5.3.1.6.

Gráfico 5.21 Función de densidad Pre-Test. Procesos, experiencia de Chile, iPad
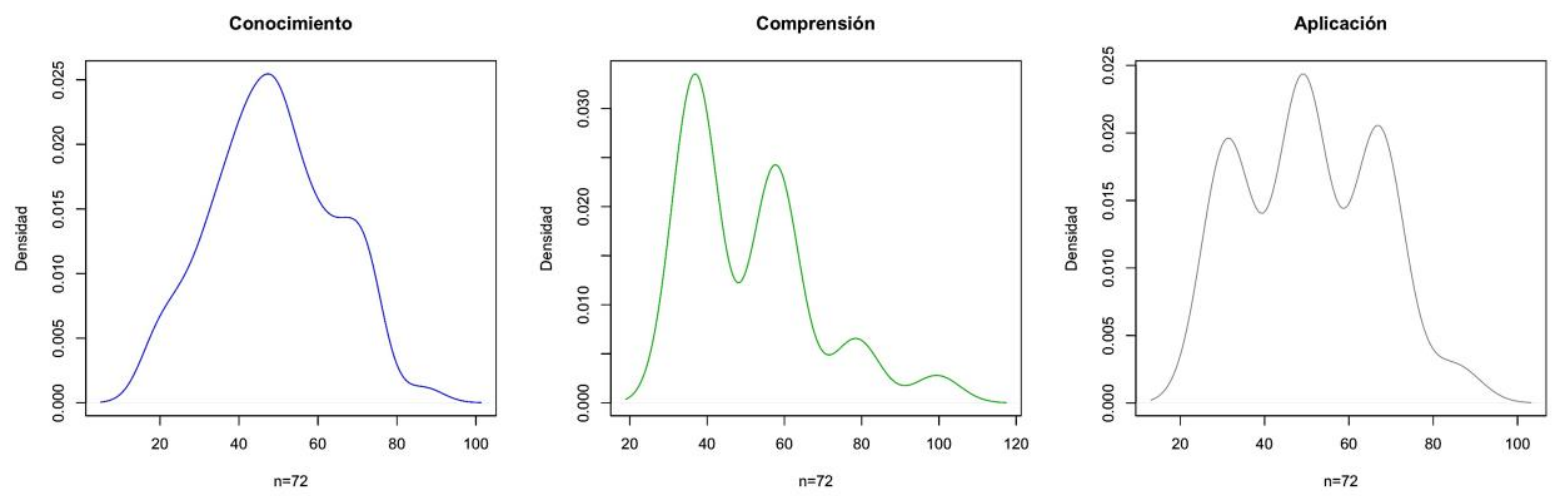

Fuente: Elaboración propia.

Gráfico 5.22 Diagramas de cajas Pre-Test. Procesos, experiencia de Chile, iPad

Pre-Test Chile Tratamiento Ipad. Procesos

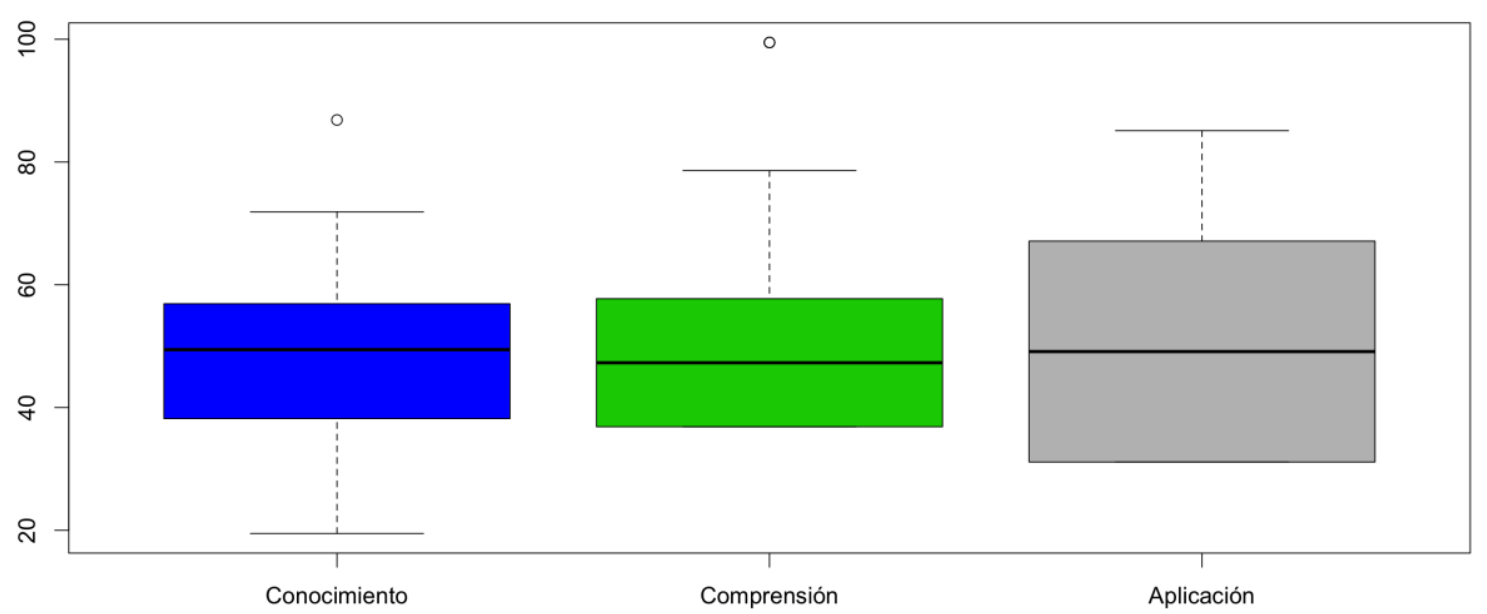

Fuente: Elaboración propia.

Para el caso de los procesos realizados con iPad (Gráfico 5.21 y Gráfico 5.22) la distribución de los datos tiende a la normalidad, aunque para los ítems de Conocimiento y Comprensión existen valores atípicos que influyen en el comportamiento de la curva. 
Los diagramas de cajas confirman la estructura de los datos y es posible establecer que la tendencia hacia una asimetría positiva.

Gráfico 5.23 Función de densidad Pre-Test. Procesos, experiencia de Chile, Ordenador
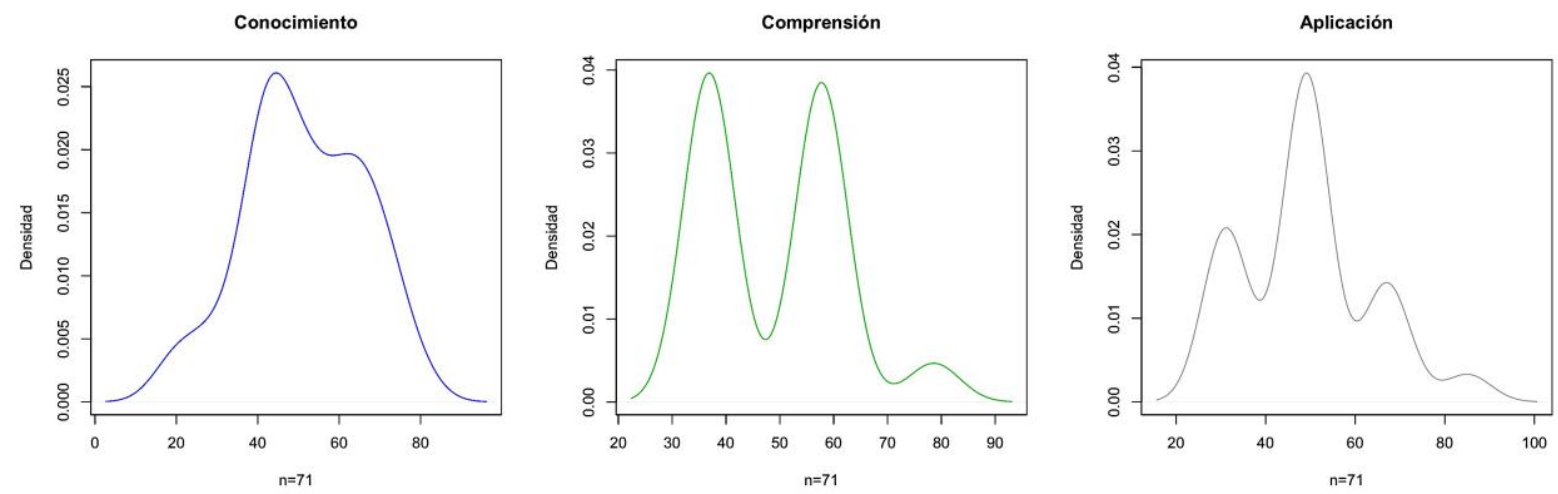

Fuente: Elaboración propia.

Gráfico 5.24 Diagramas de cajas Pre-Test. Procesos, experiencia de Chile, Ordenador

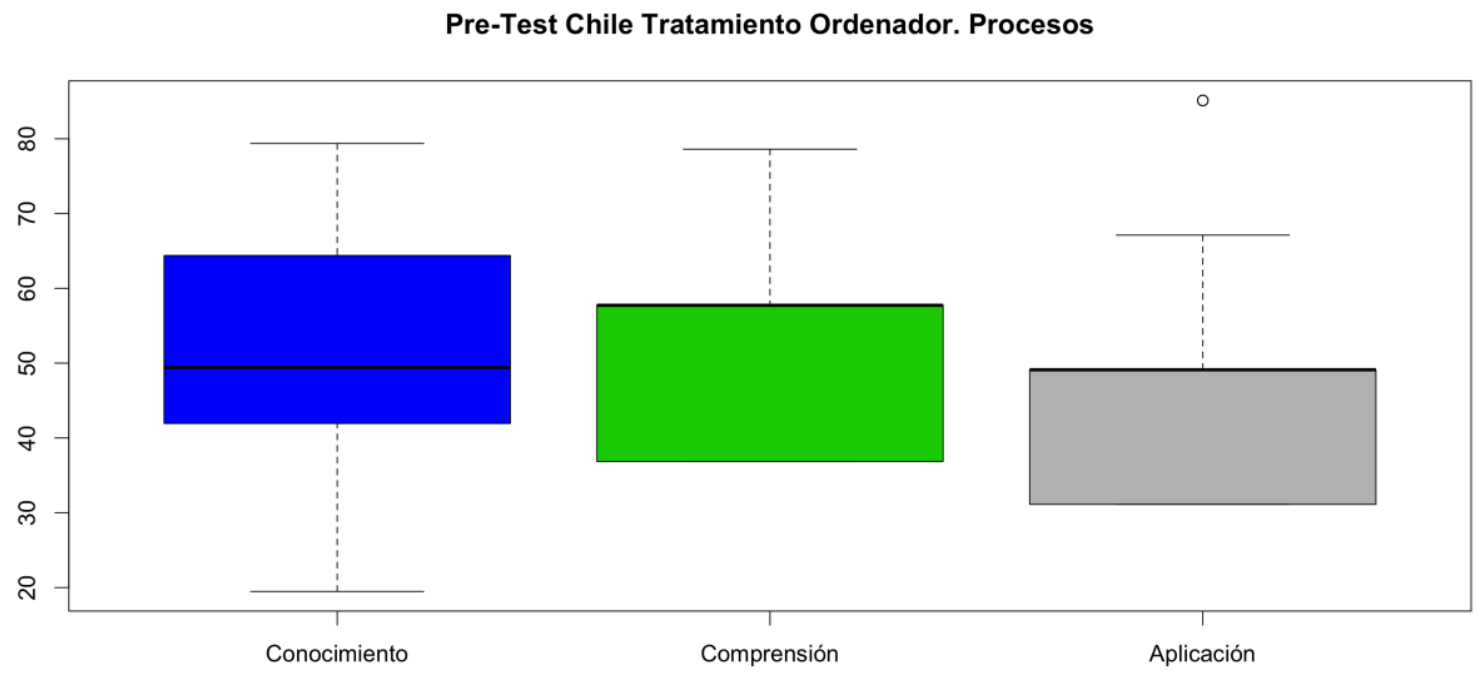

Fuente: Elaboración propia.

En el caso de los ítems de los procesos realizados con ordenador (Gráfico 5.23 y Gráfico 5.24), las curvas de los diagramas de densidad tienden a ser leptocúrticas con una asimetría positiva, aunque en los ítems de Comprensión y Aplicación las distribuciones no 
son continuas. Esto queda explicado por el número limitado de preguntas que definen estos procesos y la presencia de un valor atípico presente en los datos obtenidos. Estos resultados establecen que para la aplicación de los contrastes de hipótesis para algunos ítems se hará necesario la utilización de test no paramétricos que se ajusten adecuadamente a la distribuciones obtenidas.

\subsubsection{Pre-Test: Análisis estadístico básico y contrastes de normalidad según ítem}

Luego de un primer análisis gráfico de la distribución de los ítems agrupados en procesos y contenidos, se hace necesario aplicar un contraste paramétrico en algunos de los indicadores visualizados. De esta manera se aplicó la prueba de Kolmogorov-Smirnov con el fin de comprobar la normalidad de las distribuciones obtenidas en la investigación a través de un indicador complementario. Así, estos elementos permitirán definir la aplicación de los contraste paramétricos y no paramétricos más adecuados para el análisis en función de la estructura y dispersión de los datos.

Los estadísticos básicos en las tablas siguientes, complementan las observaciones realizadas en los gráficos de densidad y de cajas presentados, particularmente en los indicadores de asimetría, en donde se observan valores positivos a excepción del ítem Conocimiento indicadores de curtosis que tienden a formas leptocúrticas y platicúrticas (Tabla 5.11).

Tabla 5.11 Pre-test Chile. Exploración de estadísticos básicos para las puntuaciones $T$ estandarizadas $(n=144)$

\section{Asimetría}

\section{Curtosis}

\begin{tabular}{|c|c|c|c|c|c|c|}
\hline Ítem & Mediana & $\begin{array}{c}\text { Amplitud } \\
\text { Intercuartílica }\end{array}$ & Valor & Error típ. & Valor & Error típ. \\
\hline $\begin{array}{c}\text { Contenido } \\
\text { Histórico }\end{array}$ & 48,312 & 22,984 &, 283 &, 203 &,- 255 &, 403 \\
\hline $\begin{array}{c}\text { Contenido } \\
\text { Arquitectónico }\end{array}$ & 51,632 & 18,670 &, 341 &, 203 &,- 21 &, 403 \\
\hline $\begin{array}{c}\text { Contenido de } \\
\text { Localización }\end{array}$ & 50,261 & 18,638 &, 601 &, 203 &, 059 &, 403 \\
\hline $\begin{array}{c}\text { Conocimiento } \\
\text { Comprensión }\end{array}$ & 49,424 & 22,457 &,- 043 &, 203 &,- 554 &, 403 \\
\hline Aplicación & 57,735 & 20,870 & 1,036 &, 203 &, 945 &, 403 \\
\hline
\end{tabular}

Fuente: Elaboración propia. 
Tabla 5.12 Pre-test Chile. Exploración de estadísticos básicos para las puntuaciones $T$ estandarizadas, Muestra iPad $(n=72)$

\section{Asimetría}

Curtosis

\begin{tabular}{|c|c|c|c|c|c|c|}
\hline Ítem & Mediana & $\begin{array}{c}\text { Amplitud } \\
\text { Intercuartílica }\end{array}$ & Valor & Error típ. & Valor & Error típ. \\
\hline $\begin{array}{c}\text { Contenido } \\
\text { Histórico }\end{array}$ & 48,312 & 22,984 &, 127 &, 283 &,- 108 &, 559 \\
\hline $\begin{array}{c}\text { Contenido } \\
\text { Arquitectónico }\end{array}$ & 51,632 & 28,005 &, 416 &, 283 &,- 295 &, 559 \\
\hline $\begin{array}{c}\text { Contenido de } \\
\text { Localización }\end{array}$ & 50,261 & 37,277 &, 460 &, 283 &,- 449 &, 559 \\
\hline $\begin{array}{c}\text { Conocimiento } \\
\text { Comprensión }\end{array}$ & 49,424 & 20,586 &, 074 &, 283 &,- 509 &, 559 \\
\hline Aplicación & 47,300 & 20,870 & 1,133 &, 283 &, 817 &, 559 \\
\hline
\end{tabular}

Fuente: Elaboración propia.

Tabla 5.13 Pre-test Chile. Exploración de estadísticos básicos para las puntuaciones T estandarizadas, Muestra Ordenador $(n=71)$

Asimetría

Curtosis

\begin{tabular}{|c|c|c|c|c|c|c|}
\hline Ítem & Mediana & $\begin{array}{c}\text { Amplitud } \\
\text { Intercuartílica }\end{array}$ & Valor & Error típ. & Valor & Error típ. \\
\hline $\begin{array}{c}\text { Contenido } \\
\text { Histórico }\end{array}$ & 48,312 & 22,984 &, 461 &, 285 &,- 338 &, 563 \\
\hline $\begin{array}{c}\text { Contenido } \\
\text { arquitectónico }\end{array}$ & 51,632 & 18,670 &, 278 &, 285 &,- 013 &, 563 \\
\hline $\begin{array}{c}\text { Contenido de } \\
\text { Localización }\end{array}$ & 50,261 & 18,638 &, 759 &, 285 &, 942 &, 563 \\
\hline $\begin{array}{c}\text { Conocimiento } \\
\text { Comprensión }\end{array}$ & 49,424 & 22,457 &,- 153 &, 285 &,- 503 &, 563 \\
\hline Aplicación & 57,735 & 20,870 &, 504 &, 285 &,- 610 &, 563 \\
\hline
\end{tabular}

Fuente: Elaboración propia.

Cuando los datos obtenidos se dividen según tratamiento, es posible establecer que los ítems de Comprensión, Aplicación y Localización tienden hacia distribuciones normales debido a su mayor variabilidad en valores de asimetría y curtosis (Tabla 5.12 y Tabla 5.13). 
Gráfico 5.25 Q-Q normales Pre-Test Chile. Contenidos
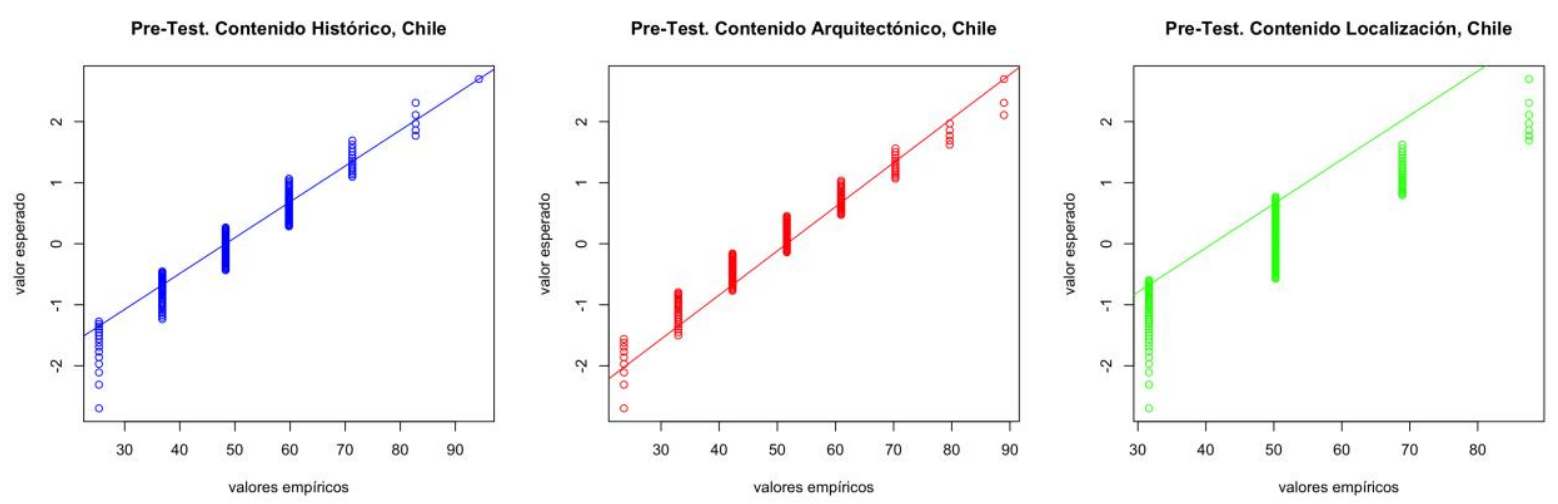

Fuente: Elaboración propia.

En cuanto a los valores que se presentan en los contenidos para el Pre-Test en Chile (Gráfico 5.25), tanto los contenidos Histórico, como Arquitectónico se ajustan a los valores esperados a una distribución normal. Sin embargo, nuevamente en el ítem de contenido Localización, los valores registrados se alejan de la distribución esperada para los datos.

Gráfico 5.26 Q-Q normales Pre-Test Chile iPad. Contenidos
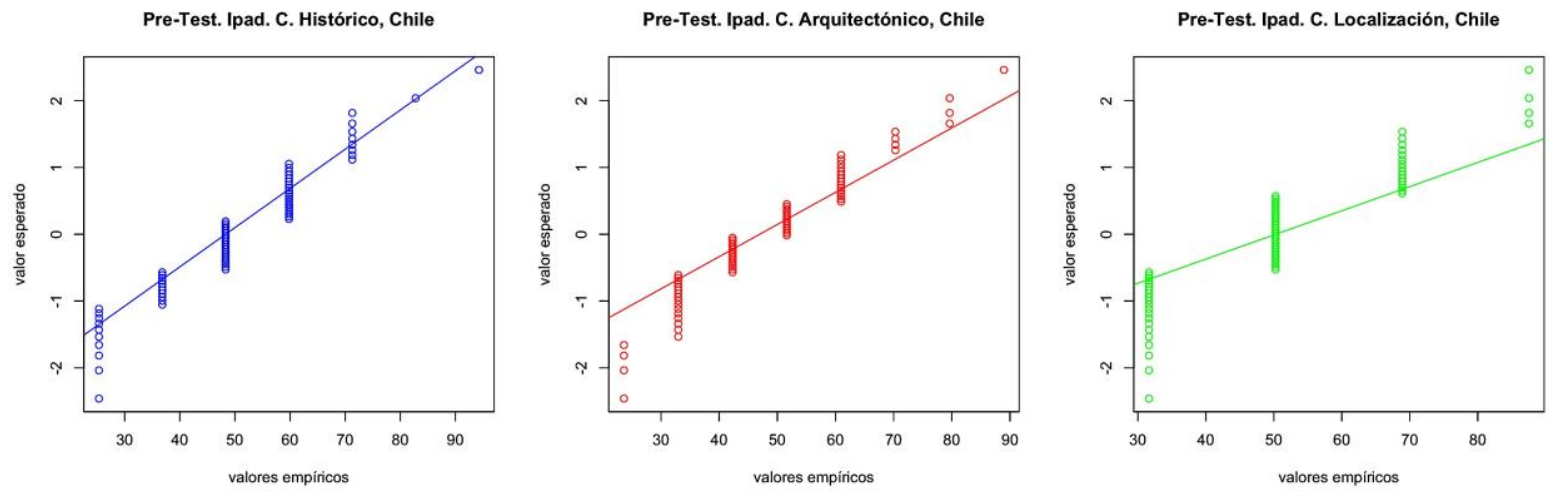

Fuente: Elaboración propia. 
Gráfico 5.27 Q-Q normales Pre-Test Chile Ordenador. Contenidos
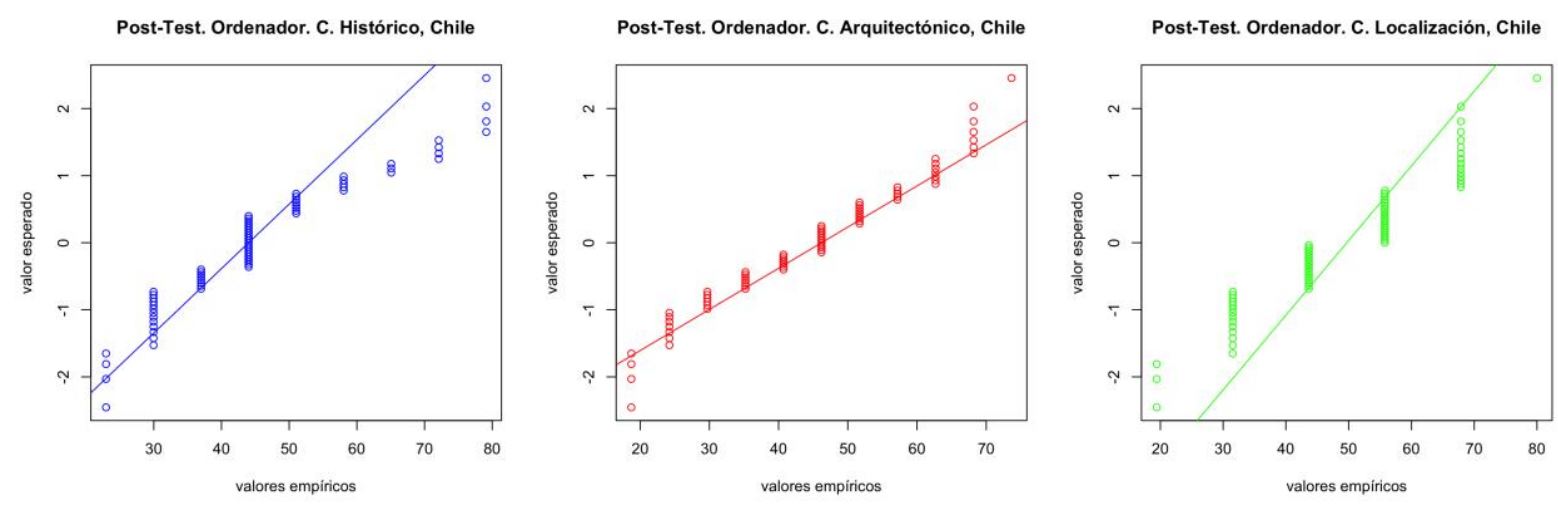

Fuente: Elaboración propia.

Cuando se dividen los datos obtenidos del Pre-Test según el tratamiento que se aplicará (Gráfico 5.26 y Gráfico 5.27), se puede observar que para el caso de la muestra iPad los valores empíricos se ajustan a la línea de los valores esperados, particularmente en los ítems de contenido Histórico y Arquitectónico. Para el caso del ítem de Localización, los valores empíricos poseen un mayor nivel de dispersión respecto al valor esperado. De manera paralela, para el caso de la muestra con Ordenadores, en el ítem de contenido Histórico, los valores obtenidos se encuentran con mayores niveles de dispersión, de la misma manera que en el ítem de Localización, presentándose en este último caso una recta de valores esperados con una mayor pendiente y con un eje de intersección $Y$ aún más negativo que en los gráficos $\mathrm{Q}-\mathrm{Q}$ de los otros ítems de contenidos, valores propios de una curva con forma platicúrtica.

En referencia a los ítems de procesos (Gráfico 5.28), Conocimiento se ajusta a la curva normal esperada, mientras que los valores de Comprensión y Aplicación presentan valores con mayor dispersión. De manera paralela, los valores esperados y su representación en las rectas presentan diferentes pendientes y valores de intersección con el eje $Y$, lo que permitiría inferir la presencia de otro tipo de distribuciones asociadas a los valores obtenidos. 
Gráfico 5.28 Q-Q normales Pre-Test Chile. Procesos
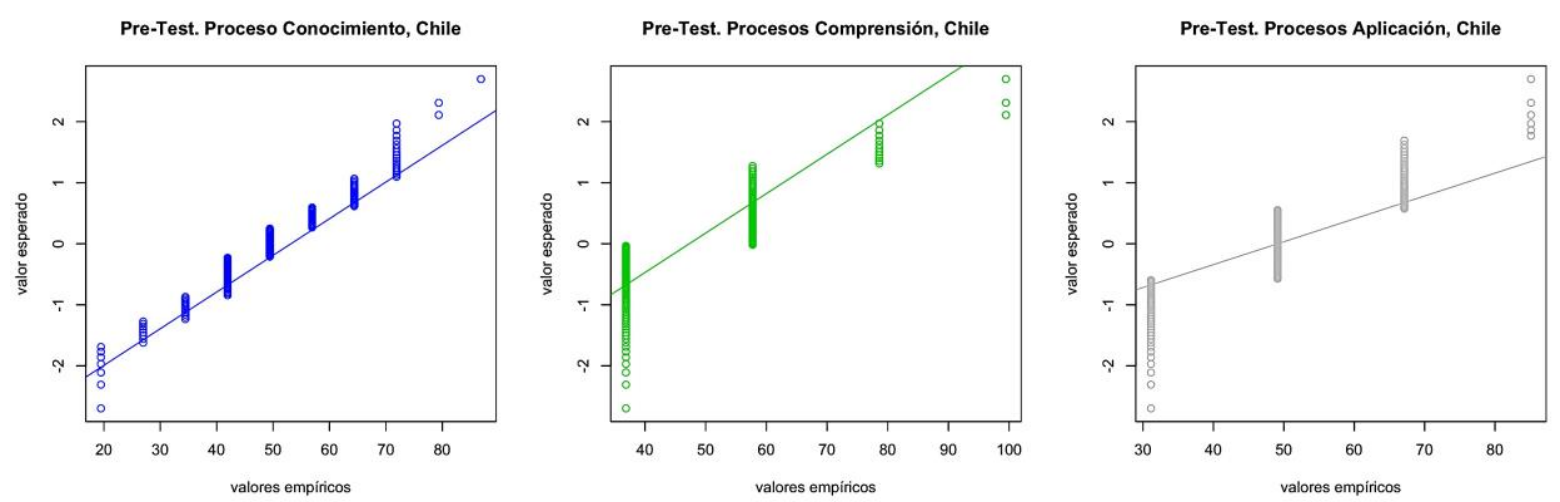

Fuente: Elaboración propia.

En cuanto a los ítems de procesos en la medición Pre-Test para el grupo iPad (Gráfico 5.29), se puede observar que las distribuciones de los valores de se ajustan a la curva normal, con la excepción de los casos atípicos extremos presentes en Comprensión y Aplicación. Dichas variables se eliminarán en los análisis posteriores para la utilización de los contrastes de hipótesis.

Gráfico 5.29 Q-Q normales Pre-Test Chile iPad. Procesos
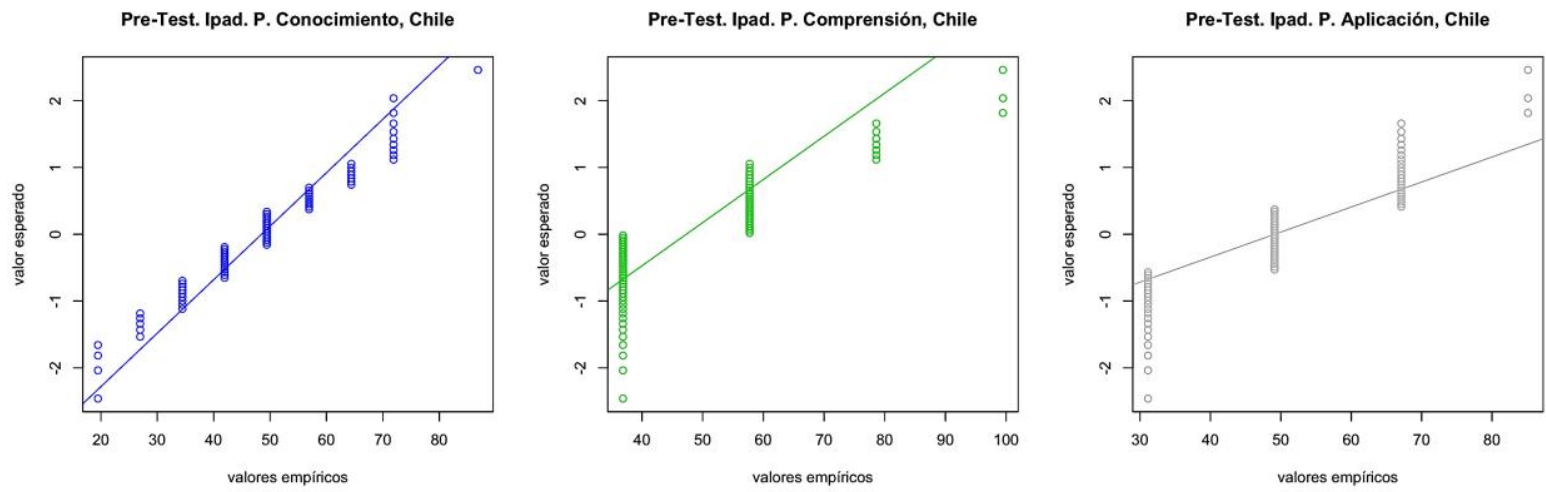

Fuente: Elaboración propia. 
Gráfico 5.30 Q-Q normales Pre-Test Chile Ordenador. Procesos
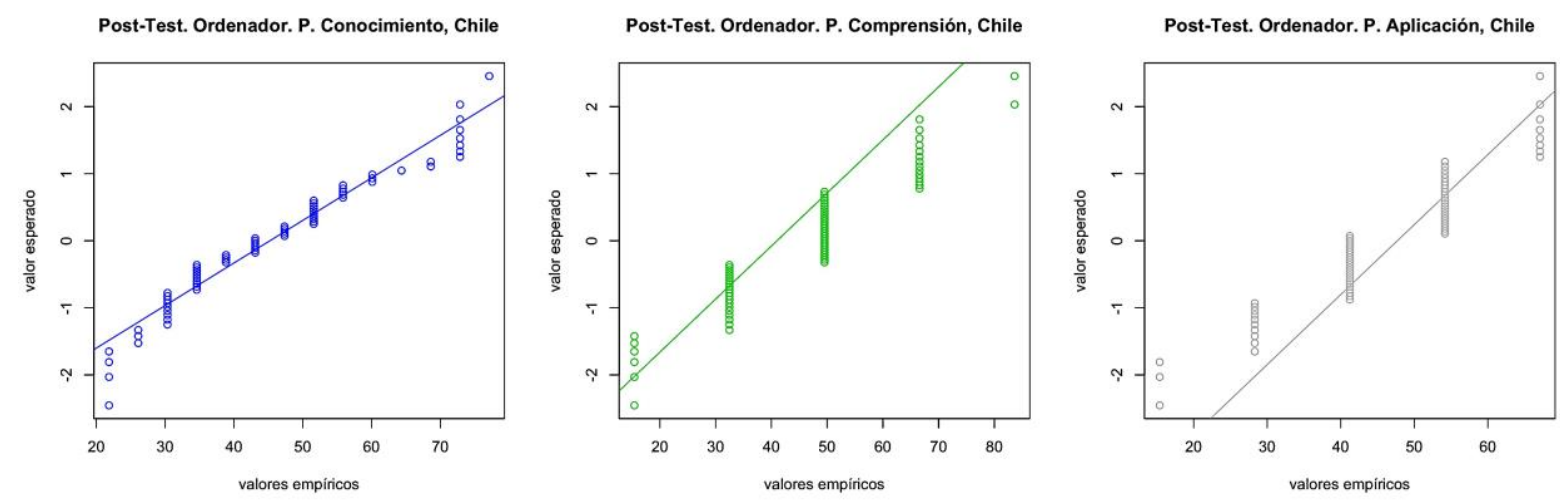

Fuente: Elaboración propia.

Los datos de los ítems de los procesos para el grupo de Ordenadores (Gráfico 5.30), son muy similares a los obtenidos con el grupo de iPad, encontrándose casos atípicos extremos presentes en Comprensión y Aplicación. Es en este último ítem donde la línea de valores esperados presenta una mayor pendiente y con un eje de intersección Y aún más negativo que los gráficos Q-Q de los otros ítems, valores propios de una curva con forma platicúrtica.

Para el análisis final de los valores de los Pre-Test obtenidos de cada experiencia, se utilizará la prueba de Kolmogorov-Smirnov, con el fin de comprobar la hipótesis de la bondad de ajuste desde las distribuciones obtenidas hacia una distribución normal.

Tabla 5.14 Test de normalidad de Kolmogorov-Smirnov Pre-Test. Caso de Chile $(n=144)$

$$
\begin{array}{llll}
\text { Ítem } & D^{104} & \text { P. } & \\
& &
\end{array}
$$

\begin{tabular}{|c|c|c|c|}
\hline $\begin{array}{c}\text { Contenido } \\
\text { Histórico }\end{array}$ & 0,153 & 1,832 &, 002 \\
\hline $\begin{array}{c}\text { Contenido } \\
\text { Arquitectónico }\end{array}$ & 0,137 & 1,636 &, 009 \\
\hline $\begin{array}{c}\text { Contenido de } \\
\text { Localización }\end{array}$ & 0,276 & 3,304 & $<, 001$ \\
\hline Conocimiento & 0,117 & 1,4 &, 040 \\
\hline Comprensión & 0,299 & 3,574 & $<, 001$ \\
\hline Aplicación & 0,237 & 2,831 & $<, 001$ \\
\hline
\end{tabular}

Fuente: Elaboración propia.

\footnotetext{
${ }^{104}$ Valor que establece la diferencia absoluta más alta entre la frecuencia acumulada teórica y la observada.

105 Los valores en rojo rechazan la $\mathrm{H}_{0}$ y determinan la no existencia de una distribución normal.
} 
Como se establece en la Tabla 5.14, los datos de los ítems obtenidos en el contexto de Pre-Test para Chile, no tienden a una distribución normal, por lo que en este caso se rechaza la hipótesis en la cual se establece que los registros tienen un comportamiento concordante con una distribución normal. Particularmente se observa que en el contenido de Localización y en los procesos de Comprensión y Contenido los rangos de valores obtenidos fueron muy limitados por el número de ítem utilizados en la prueba objetiva Pre-Test y sus valores para cada dimensión definida.

Tabla 5.15 Test de normalidad de Kolmogorov-Smirnov Pre-Test. Caso de Chile, iPad $(n=72)$

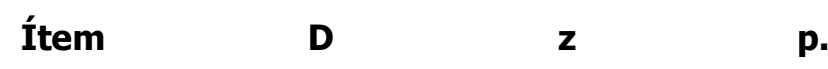

\begin{tabular}{|c|c|c|c|}
\hline $\begin{array}{c}\text { Contenido } \\
\text { Histórico }\end{array}$ & 0,159 & 1,345 &, 054 \\
\hline $\begin{array}{c}\text { Contenido } \\
\text { Arquitectónico }\end{array}$ & 0,151 & 1,280 &, 075 \\
\hline $\begin{array}{c}\text { Contenido de } \\
\text { Localización }\end{array}$ & 0,241 & 2,049 & $<, 001$ \\
\hline Conocimiento & 0,120 & 1,019 &, 251 \\
\hline Comprensión & 0,297 & 2,520 & $<, 001$ \\
\hline Aplicación & 0,197 & 1,672 &, 007 \\
\hline
\end{tabular}

Fuente: Elaboración propia.

Tabla 5.16 Test de normalidad de Kolmogorov-Smirnov Pre-Test. Caso de Chile, Ordenador $(n=71)$

\begin{tabular}{|c|c|c|c|}
\hline Ítem & D & $\mathbf{z}$ & p. \\
\hline $\begin{array}{c}\text { Contenido } \\
\text { Histórico }\end{array}$ & 0,176 & 1,48 &, 025 \\
\hline $\begin{array}{c}\text { Contenido } \\
\text { Arquitectónico }\end{array}$ & 0,169 & 1,425 & ,035 \\
\hline $\begin{array}{c}\text { Contenido de } \\
\text { Localización }\end{array}$ & 0,307 & 2,589 & $<, 001$ \\
\hline Conocimiento & 0,134 & 1,133 & 153 \\
\hline Comprensión & 0,310 & 2,615 & $<, 001$ \\
\hline Aplicación & 0,237 & 2,831 & $<, 001$ \\
\hline
\end{tabular}

Fuente: Elaboración propia. 
De manera complementaria, cuando los datos se dividen según el tratamiento que será aplicado, los ítems sufren variaciones en los indicadores, siendo para el caso de los datos iPad con los ítems de contenido Histórico, Arquitectónico y proceso de Conocimiento los que presentan una distribución normal. Por otro lado, para el caso de los sujetos Ordenador, solo el ítem Conocimiento presenta una distribución normal de los datos (Tabla 5.15 y Tabla 5.16$)$.

\subsubsection{Post-Test: Análisis gráfico de las distribuciones por ítem}

Al igual que en los resultados Pre-Test para la experiencia de Chile, se realizó los mismos análisis para los registros Post-Test, con el fin de establecer las pruebas a utilizar posteriormente en los contrastes de los datos.

Gráfico 5.31 Función de densidad Post-Test. Elementos de contenido, experiencia de Chile
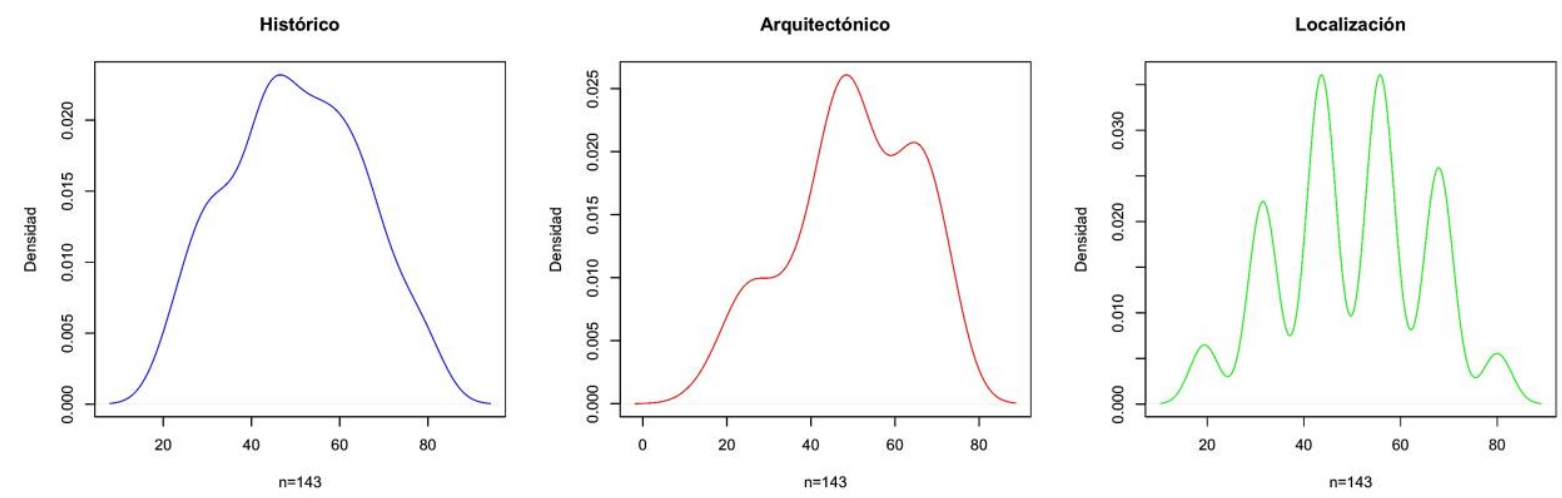

Fuente: Elaboración propia.

En el Gráfico 5.31 es posible observar que los valores presentan una distribución que tiende a la normal con una asimetría positiva en los valores de registro, aunque con formas cercanas a curvas del tipo leptocúrtica. Sin embargo, los valores referidos a la dimensión de Localización, se presenta una curva con 6 puntas indicando la presencia de otros valores en donde sus valores centrales (moda) obtienen registros importantes. Esto se relacionaría con la cantidad y valores que toman los ítems que componen el contenido de Localización. 
Gráfico 5.32 Diagramas de cajas Post-Test. Elementos de contenidos, experiencia de Chile

Post-Test Chile. Contenidos

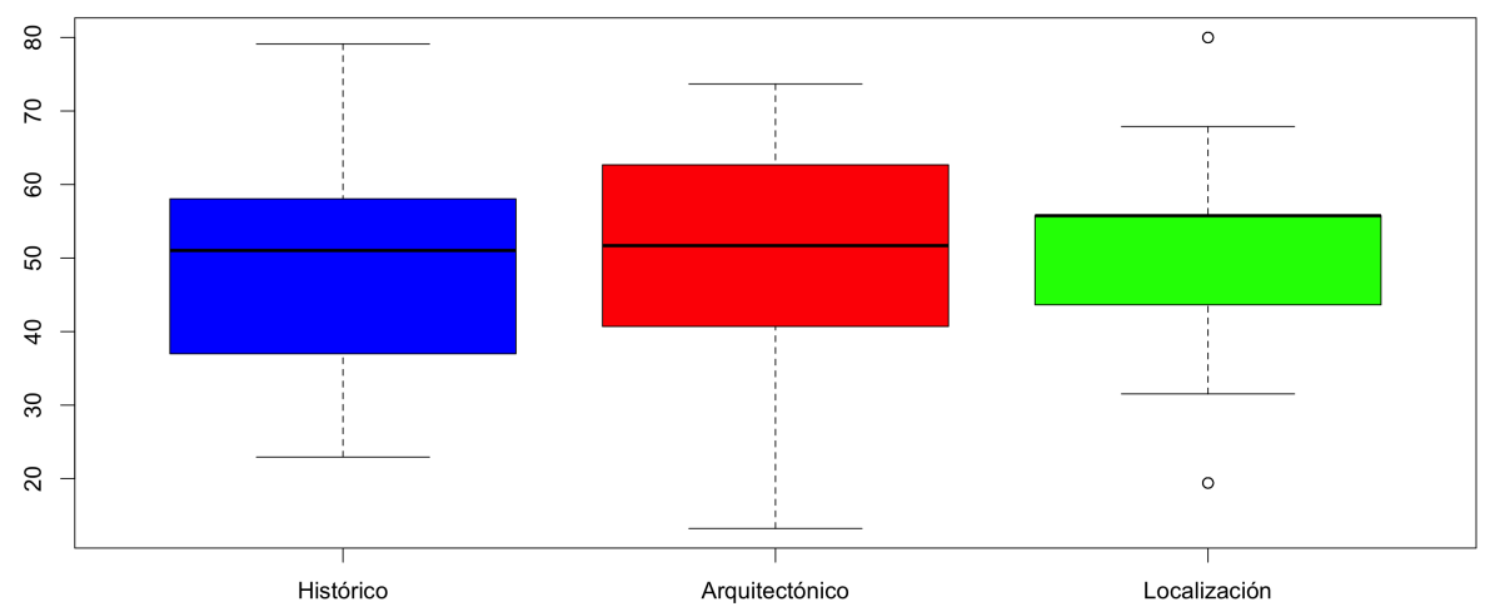

Fuente: Elaboración propia.

En los diagramas de cajas obtenidos (Gráfico 5.32) es posible visualizar que los valores obtenidos en los ítems de contenidos, presentan una distribución que tiende a la normalidad, con algunos registros que presentan un valor extremos atípicos (Localización). Además, los valores presentes en los contenidos de Localización los valores de la mediana coinciden con el $\mathrm{Q}_{3}$, estableciendo una estructura de distribución de los datos diferentes a los demás ítems analizados, graficando una asimetría negativa de la distribución de los datos. Una vez aplicado los tratamientos definidos, se procedió al análisis de las distribuciones obtenidas, en el contexto Post-Test, que permite contrastar los datos.

Gráfico 5.33 Función de densidad Post-Test. Elementos de contenido, experiencia de Chile, iPad
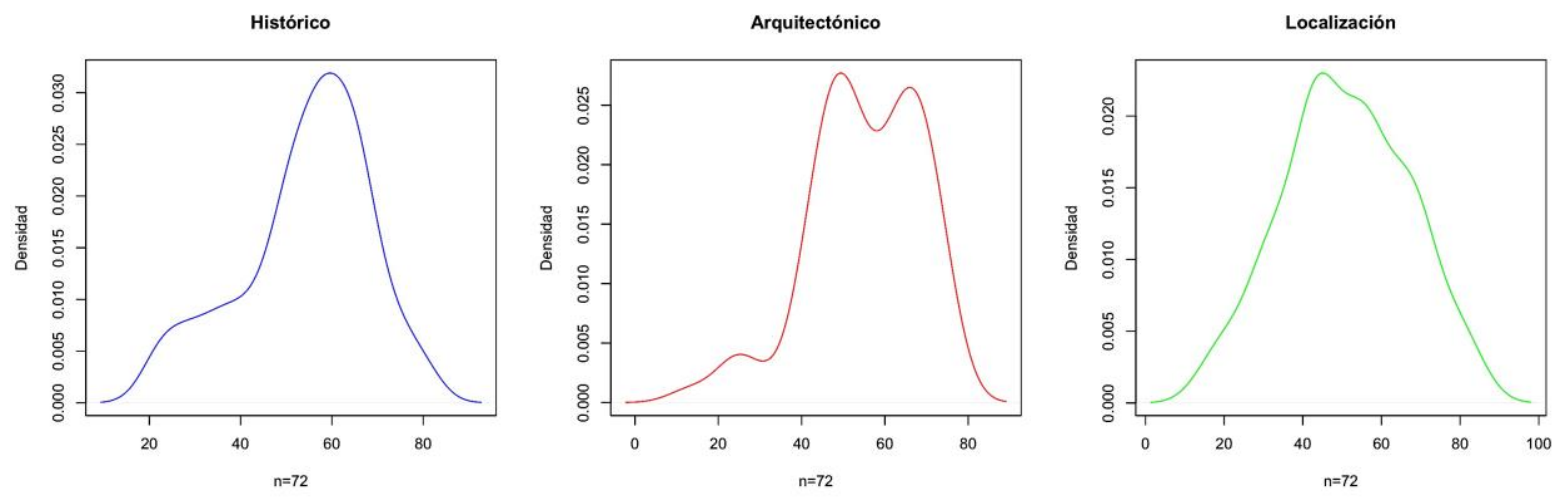

Fuente: Elaboración propia. 
Gráfico 5.34 Diagramas de cajas Post-Test. Elementos de contenidos, experiencia de Chile, iPad

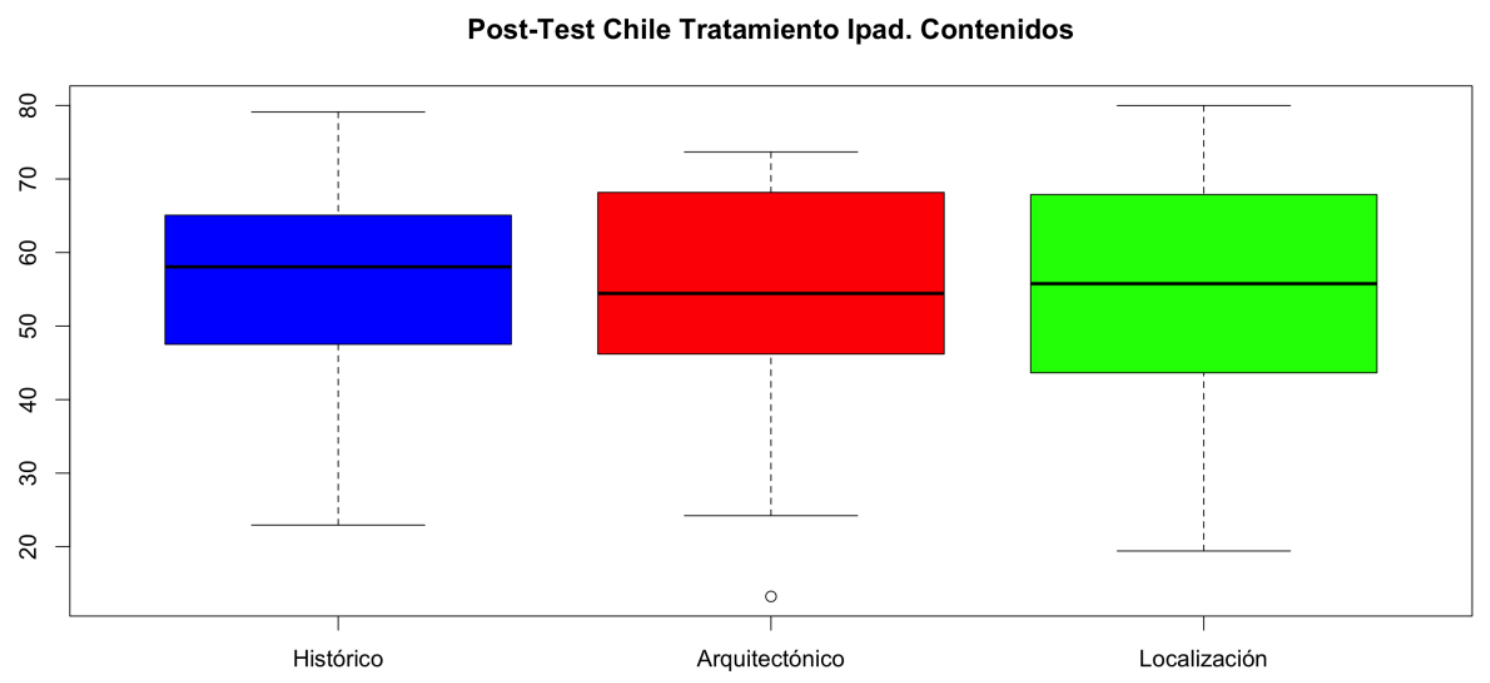

Fuente: Elaboración propia.

Para el caso de los sujetos con tratamiento con iPad (Gráfico 5.33 y Gráfico 5.34), los resultados para los ítems de contenido consultados, estos muestran que las distribuciones tienden a la normalidad. Existe un valor atípico en el ítem Arquitectónico, pero la distribución de los datos en general presenta una asimetría positiva.

Gráfico 5.35 Función de densidad Post-Test. Elementos de contenido, experiencia de Chile, Ordenador
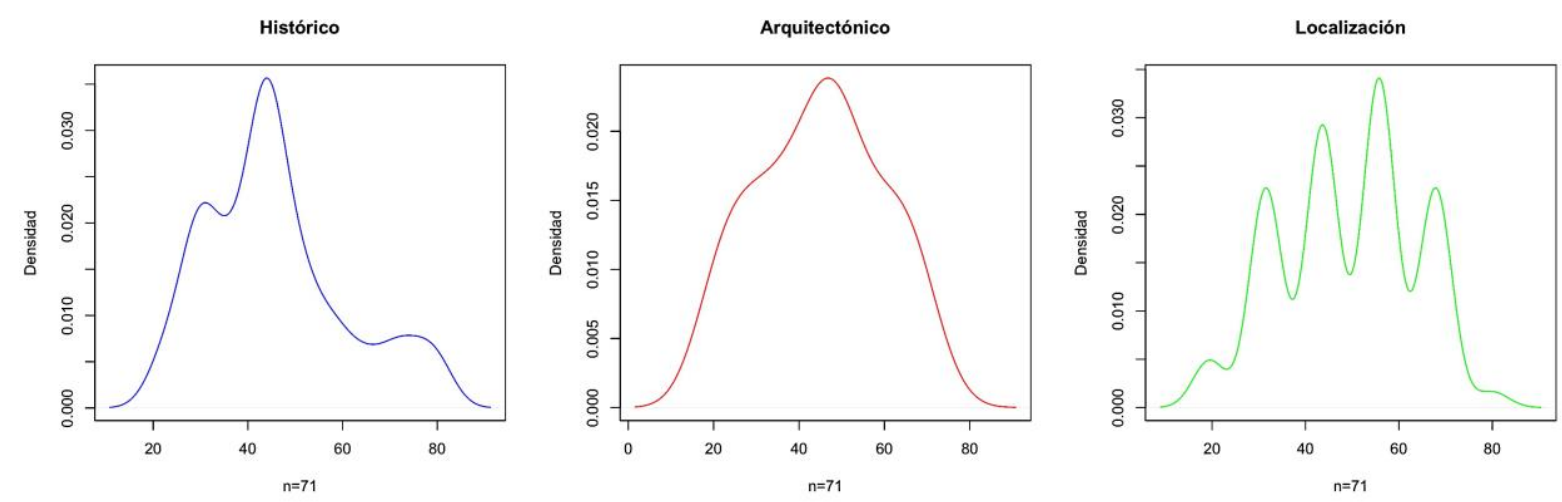

Fuente: Elaboración propia. 
Gráfico 5.36 Diagramas de cajas Post-Test. Elementos de contenidos, experiencia de Chile, Ordenador

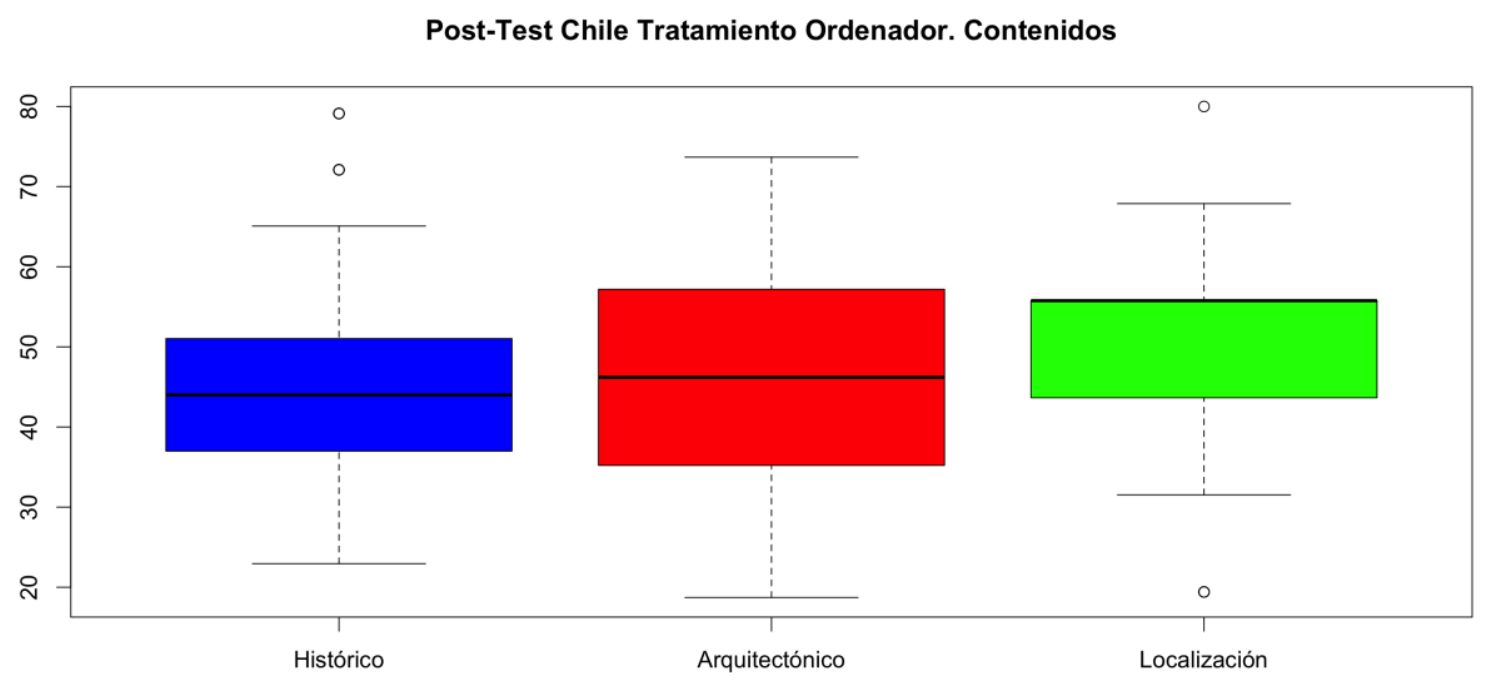

Fuente: Elaboración propia.

Para el caso de los sujetos con tratamiento con Ordenador (Gráfico 5.35 y Gráfico 5.36), los resultados para los ítems de contenido muestran que las distribuciones de los datos de contenidos tienden a la normalidad con una asimetría que levemente negativa en el ítem de Localización. Los valores atípicos se encuentran en los contenidos Histórico y de Localización, elementos que deberán ser considerados en los contrastes posteriores.

Gráfico 5.37 Función de densidad Post-Test. Procesos, experiencia de Chile
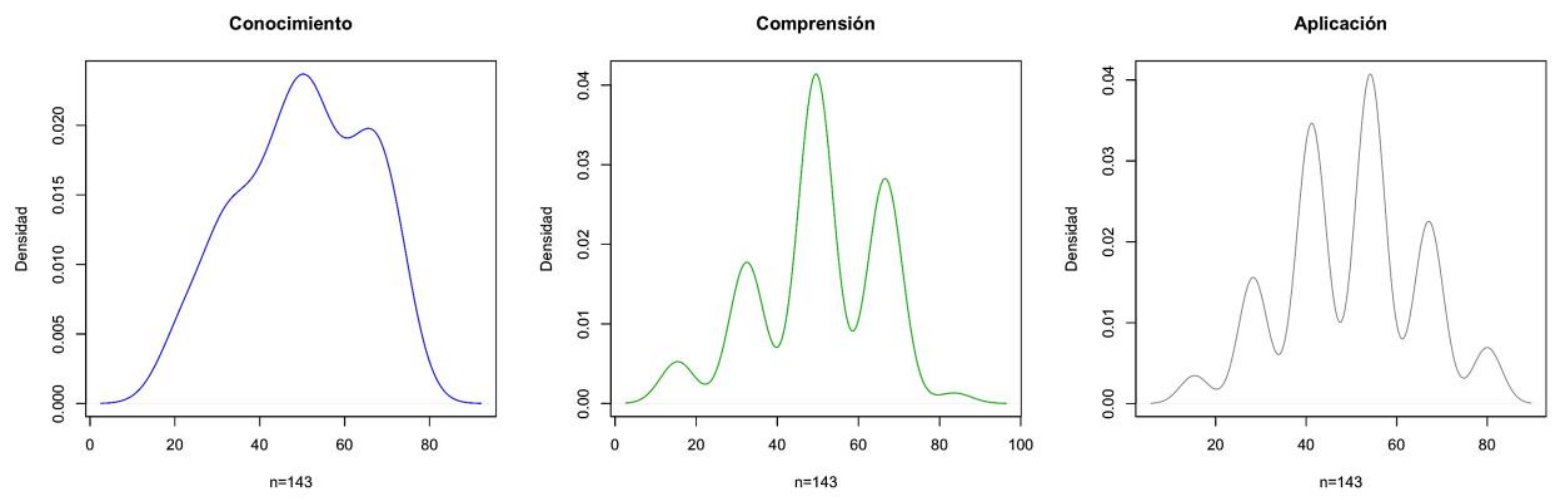

Fuente: Elaboración propia. 
En cuanto a los valores obtenidos en el ámbito de los procesos, en el instrumento Post-Test para el caso de Chile (Gráfico 5.37), se observan distribuciones no continuas en los ítems de Comprensión y Aplicación. En cuanto la distribución presente en el proceso Conocimiento, esta tiende a un comportamiento mesocúrtico con tendencia a una asimetría positiva.

Gráfico 5.38 Diagramas de cajas Post-Test. Procesos, experiencia de Chile

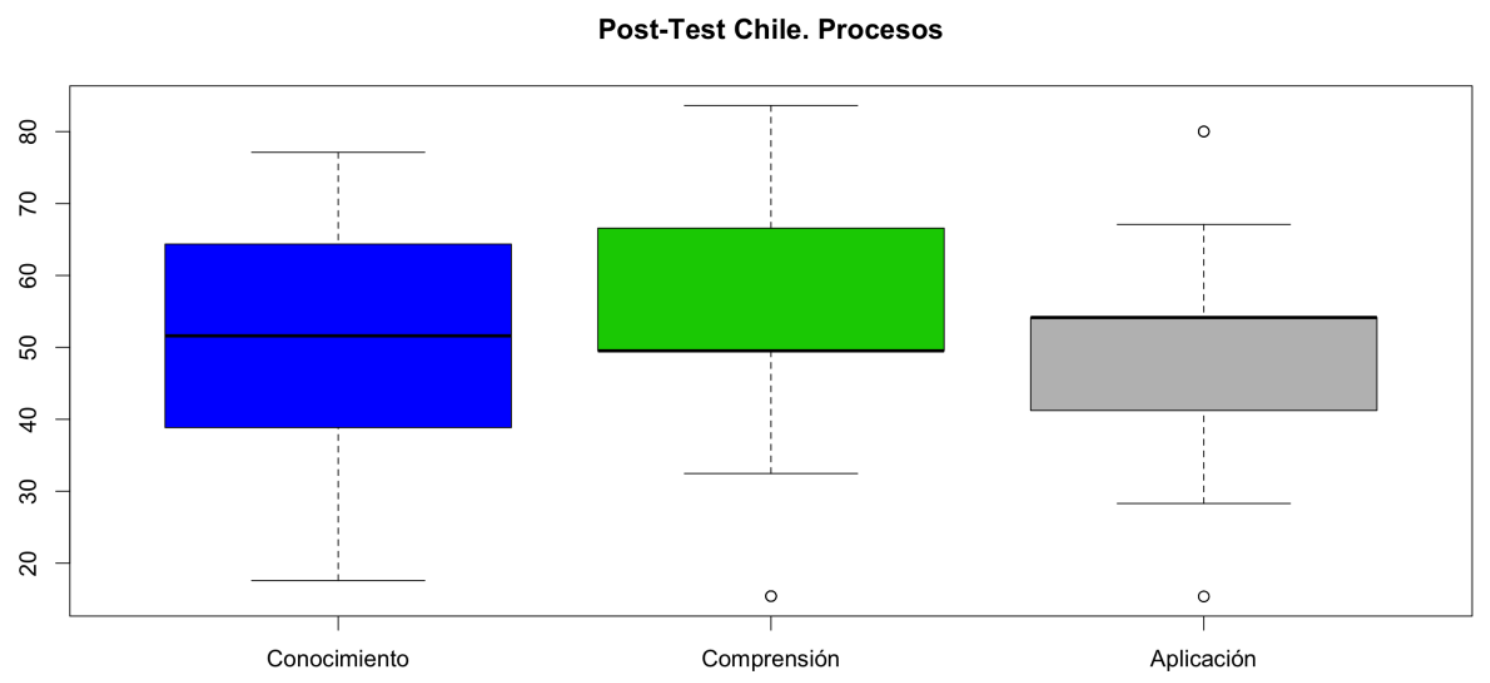

Fuente: Elaboración propia.

De manera complementaria, los diagramas de cajas para los contenidos Post-Test (Gráfico 5.38), complementan la información anterior: el ítem Conocimiento presenta una distribución con una dispersión y simetría que tendería a la normalidad. En cuanto a los ítems de Comprensión y Aplicación, las curvas presentan formas asimétricas con la existencia de valores atípicos y extremos que tienen que ser considerados en los procesos de contrastación posterior. 
Gráfico 5.39 Función de densidad Post-Test. Procesos, experiencia de Chile, iPad
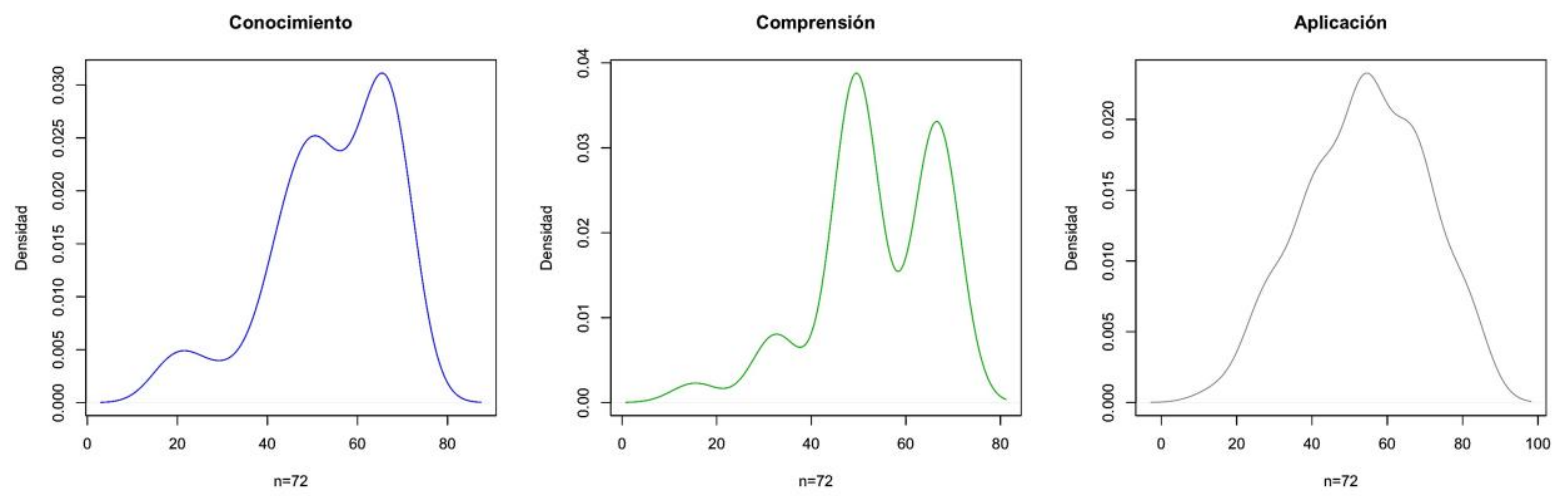

Fuente: Elaboración propia.

Gráfico 5.40 Diagramas de cajas Post-Test. Procesos, experiencia de Chile, iPad

Post-Test Chile Tratamiento Ipad. Procesos

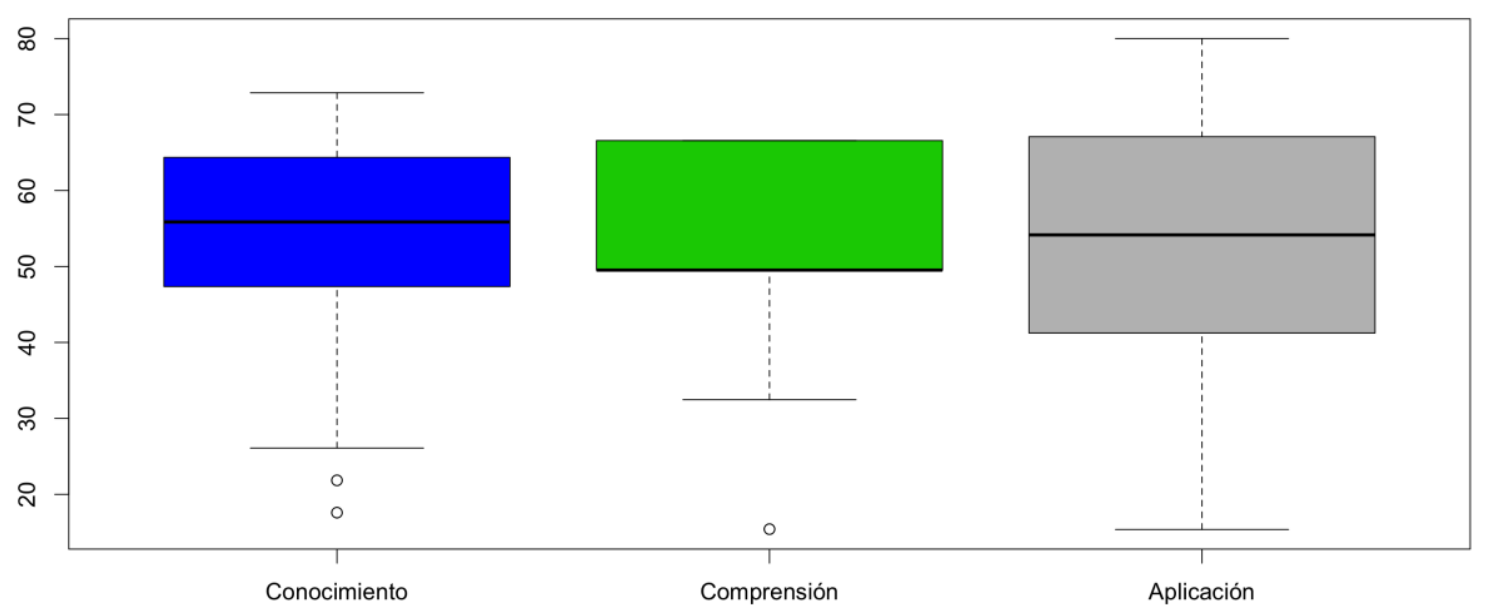

Fuente: Elaboración propia.

Para el caso de los sujetos con tratamiento con iPad (Gráfico 5.39 y Gráfico 5.40), los resultados para los ítems de proceso muestran que las distribuciones de los datos tienden a la normalidad con una asimetría que tiende ser negativa en los ítems de Conocimiento y Aplicación. El ítem de Comprensión presenta una asimetría positiva. También existen valores atípicos se encuentran en los ítems Conocimiento y Comprensión, elementos que se condicen con el tipo de asimetría que presenta los registros. 
Gráfico 5.41 Función de densidad Post-Test. Procesos, experiencia de Chile, Ordenador
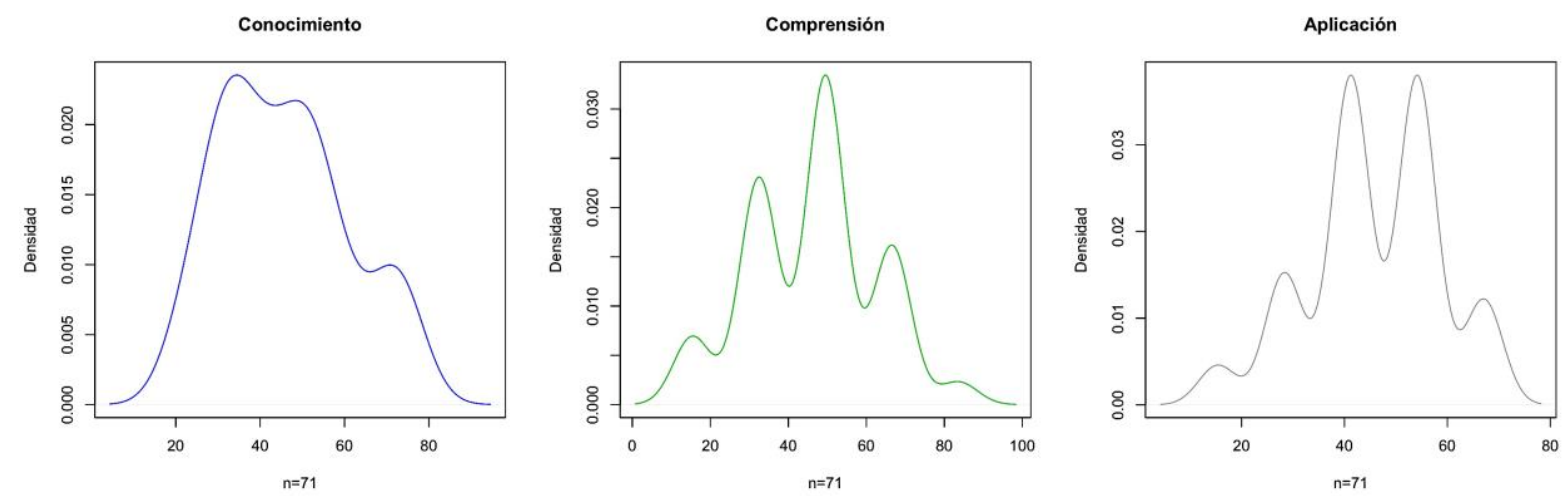

Fuente: Elaboración propia.

Gráfico 5.42 Diagramas de cajas Post-Test. Procesos, experiencia de Chile, Ordenador

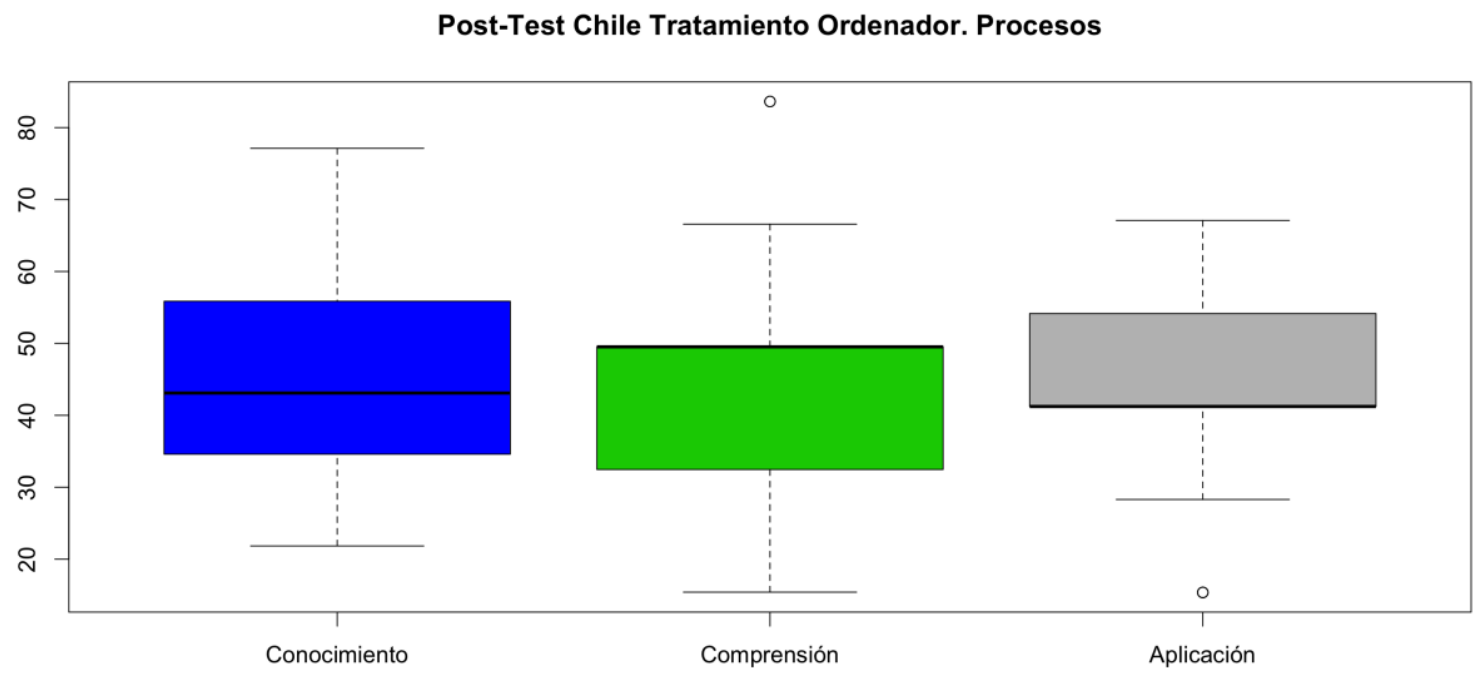

Fuente: Elaboración propia.

Para el caso de los sujetos con tratamiento con Ordenador (Gráfico 5.41 y Gráfico 5.42) los resultados para los ítems de proceso muestran que las distribuciones de los datos tienden a la normalidad, particularmente esto puede ser observador en el ítem de Conocimiento. Sin embargo, los ítems de Comprensión y Aplicación, la distribución de la curva se presenta de manera intermitente con varios puntos elevados dando cuenta de una concentración de los datos a valores determinados. Existen valores atípicos en los ítems de Comprensión y Aplicación. 
Esta evidencia gráfica entrega nuevos elementos para establecer el comportamiento de los datos, los que serán complementados con el análisis estadístico básico y el contraste de normalidad.

\subsubsection{Post-Test: Análisis estadístico básico y contrastes de normalidad según ítem}

Al igual que en los valores registrados en el instrumento Pre-Test, se realizó un análisis estadístico descriptivo y el respectivo desarrollo de los contrastes de normalidad para los datos obtenidos en los Post-Test, con el fin de establecer el comportamiento de las distribuciones y definir adecuadamente la realización de los análisis comparativos posteriores. Los resultados de los de valores se dividen en función del lugar de aplicación y en función del tratamiento (iPad u ordenador) aplicado a los sujetos de estudio.

Tabla 5.17 Post-Test Chile. Exploración de estadísticos básicos para las puntuaciones T estandarizadas $(n=144)$

\section{Asimetría Curtosis}

\begin{tabular}{|c|c|c|c|c|c|c|}
\hline Ítem & Mediana & $\begin{array}{c}\text { Amplitud } \\
\text { Intercuartílica }\end{array}$ & Valor & $\begin{array}{c}\text { Error } \\
\text { típ. }\end{array}$ & Valor & Error típ. \\
\hline $\begin{array}{c}\text { Contenido } \\
\text { Histórico }\end{array}$ & 51,031 & 21,067 &, 036 &, 203 &,- 788 &, 403 \\
\hline $\begin{array}{c}\text { Contenido } \\
\text { Arquitectónico }\end{array}$ & 51,691 & 21,976 &,- 370 &, 203 &,- 632 &, 403 \\
\hline $\begin{array}{c}\text { Contenido de } \\
\text { Localización }\end{array}$ & 55,761 & 12,116 &,- 068 &, 203 &,- 635 &, 403 \\
\hline $\begin{array}{c}\text { Conocimiento } \\
\text { Comprensión }\end{array}$ & 51,605 & 25,509 &,- 227 &, 203 &,- 879 &, 403 \\
\hline Aplicación & 54,523 & 17,051 &,- 433 &, 203 &,- 193 &, 403 \\
\hline
\end{tabular}

Fuente: Elaboración propia.

Los resultados generales para el caso de Chile establecen que todos los ítems tienen distribuciones normales en base a los valores de la curtosis (Tabla 5.18), estableciéndose excepciones en los ítems de procesos Comprensión y Aplicación, en que los valores de curtosis son menores que ,500 indicando formas platicúrtica y leptocúrticas de las curvas, y con la mayoría de los valores cercanos a la mediana. 
Tabla 5.18 Post-Test Chile. Exploración de estadísticos básicos para las puntuaciones $\mathrm{T}$ estandarizadas, muestra iPad $(n=72)$

\section{Asimetría}

Curtosis

\begin{tabular}{|c|c|c|c|c|c|c|}
\hline Ítem & Mediana & $\begin{array}{c}\text { Amplitud } \\
\text { Intercuartílica }\end{array}$ & Valor & Error típ. & Valor & Error típ. \\
\hline $\begin{array}{c}\text { Contenido } \\
\text { Histórico }\end{array}$ & 58,053 & 19,311 &,- 606 &, 283 &,- 129 &, 559 \\
\hline $\begin{array}{c}\text { Contenido } \\
\text { Arquitectónico }\end{array}$ & 54,438 & 21,976 &,- 751 &, 283 &, 556 &, 559 \\
\hline $\begin{array}{c}\text { Contenido de } \\
\text { Localización }\end{array}$ & 55,761 & 24,231 &,- 041 &, 283 &,- 574 &, 559 \\
\hline $\begin{array}{c}\text { Conocimiento } \\
\text { Comprensión }\end{array}$ & 55,857 & 17,006 &,- 926 &, 283 &, 446 &, 559 \\
\hline Aplicación & 49,523 & 17,051 &,- 864 &, 283 &, 714 &, 559 \\
\hline
\end{tabular}

Fuente: Elaboración propia.

Tabla 5.19 Post-Test Chile. Exposición de resultados estadísticos básicos para las puntuaciones T estandarizadas, muestra Ordenador $(n=71)$

Asimetría

Curtosis

\begin{tabular}{|c|c|c|c|c|c|c|}
\hline Ítem & Mediana & $\begin{array}{c}\text { Amplitud } \\
\text { Intercuartílica }\end{array}$ & Valor & Error típ. & Valor & $\begin{array}{c}\text { Error } \\
\text { típ. }\end{array}$ \\
\hline $\begin{array}{c}\text { Contenido } \\
\text { Histórico }\end{array}$ & 44,009 & 14,044 &, 692 &, 285 &,- 083 &, 563 \\
\hline $\begin{array}{c}\text { Contenido } \\
\text { Arquitectónico }\end{array}$ & 46,196 & 21,976 &,- 028 &, 285 &,- 935 &, 563 \\
\hline $\begin{array}{c}\text { Contenido de } \\
\text { Localización }\end{array}$ & 55,761 & 12,116 &,- 147 &, 285 &,- 764 &, 563 \\
\hline $\begin{array}{c}\text { Conocimiento } \\
\text { Comprensión }\end{array}$ & 43,102 & 21,258 &, 400 &, 285 &,- 752 &, 563 \\
\hline Aplicación & 49,523 & 17,051 &,- 001 &, 285 &,- 328 &, 563 \\
\hline
\end{tabular}

Fuente: Elaboración propia.

Cuando los valores de Post-Test se dividen en función del tratamiento aplicado, se puede observar que los valores tienen variaciones respecto a los resultados generales. Para el caso del tratamiento con iPad (Tabla 5.18) los ítems que tienen una curva mesocúrtica son los referentes a los contenidos Histórico y los procesos de Conocimiento, con distribuciones con asimetría negativa. Para el caso del tratamiento con ordenador (Tabla 5.19), todos los valores de curtosis son negativos, pero en función de su magnitud los ítems de contenido Histórico y de procesos de Comprensión y Aplicación las curvas son mesocúrticas. 
Todos estos datos obtenidos para cada grupo de sujetos se complementan con los gráficos Q-Q para los valores Post-Test, con el fin de permitir una mejor compresión del comportamiento de estos resultados.

Gráfico 5.43 Q-Q normales Post-Test Chile. Contenidos
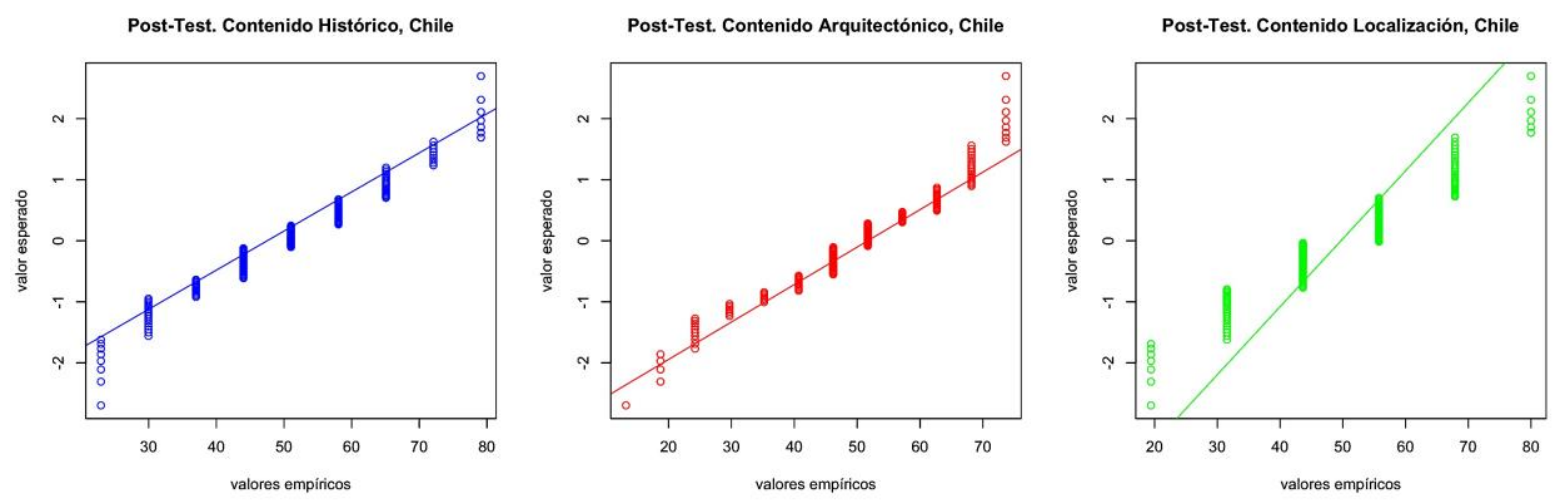

Fuente: Elaboración propia.

Los valores que se presentan en los contenidos para el Post-Test para el caso de Chile (Gráfico 5.43), tanto los ítems de contenidos Histórico y Arquitectónico se ajustan principalmente a los valores esperados a una distribución normal, aunque con la presencia de valores extremos que no se encuentran dentro de los valores esperados. De manera paralela, en el ítem de contenido Localización existen diferencias entre los valores esperados y los registrados en la distribución de los datos.

Gráfico 5.44 Q-Q normales Post-Test Chile. Contenidos, iPad

Post-Test. Ipad. C. Histórico, Chile

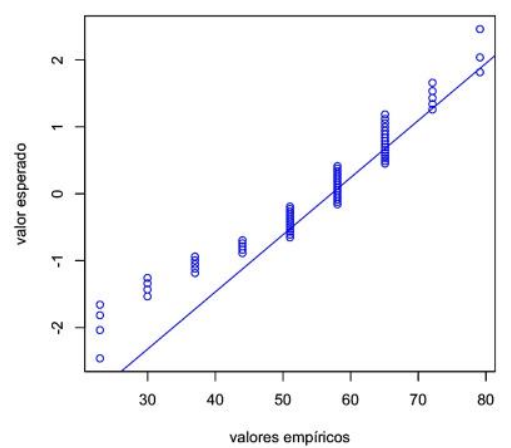

Post-Test. Ipad. C. Arquitectónico, Chile

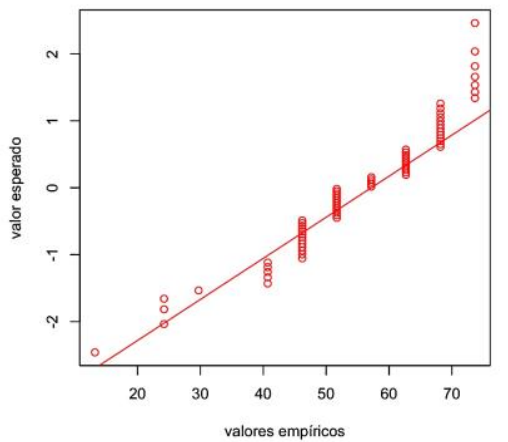

Post-Test. Ipad. C. Localización, Chile

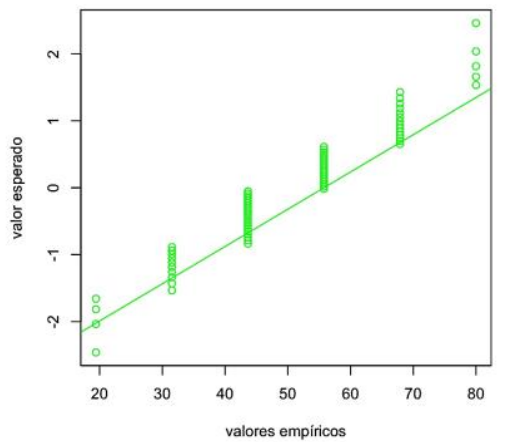

Fuente: Elaboración propia. 
De manera particular, cuando se consideran los datos en función de su tratamiento, los valores que se presentan en el grupo que utilizó el iPad para el caso de Chile (Gráfico 5.44), los ítems de contenidos se ajustan a los valores esperados a una distribución normal, aunque con la presencia de algunos valores extremos que no se encuentran dentro de los esperados, sobre todo en los extremos de los gráficos.

Gráfico 5.45 Q-Q normales Post-Test Chile. Contenidos, Ordenador
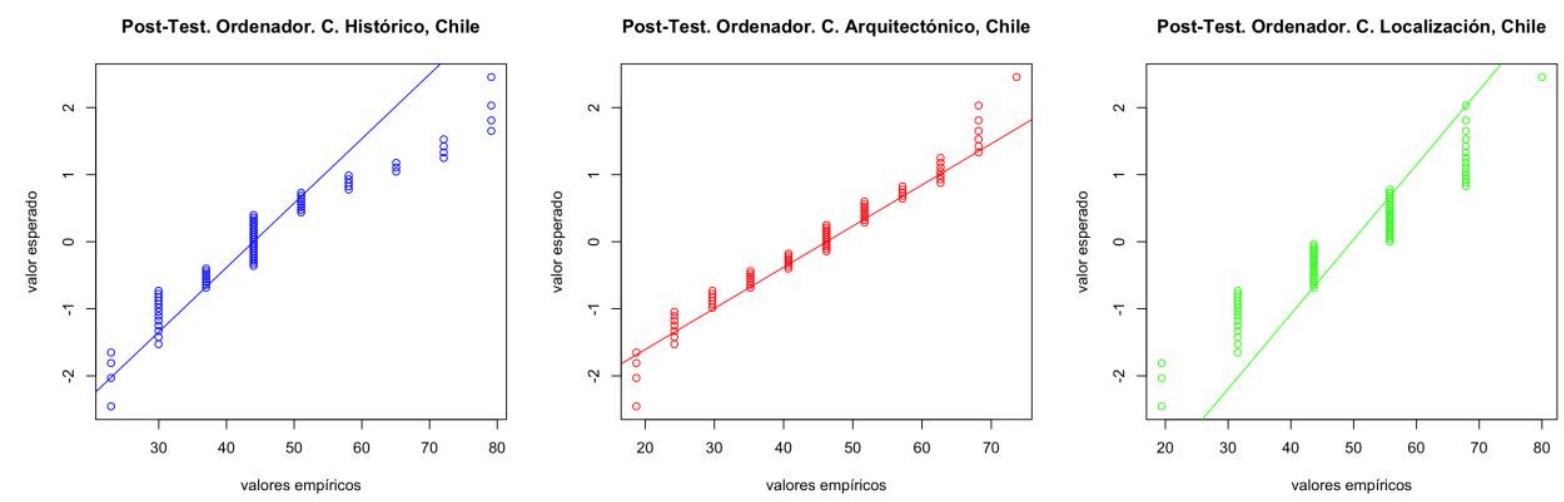

Fuente: Elaboración propia.

Por otro lado, los valores que se presentan en el grupo que utilizó ordenador como tratamiento (Gráfico 5.45), los resultados de los ítems de contenidos mayoritariamente se ajustan a los valores esperados a una distribución normal. Sin embargo, existen algunos datos empíricos que no se encuentran dentro de los valores esperados, sobre todo en los situados en los extremos de los gráficos realizados. En general estos resultados muestran muchas similitudes con el total de los valores de la muestra aplicada en Chile. 
Gráfico 5.46 Q-Q normales Post-Test Chile. Procesos
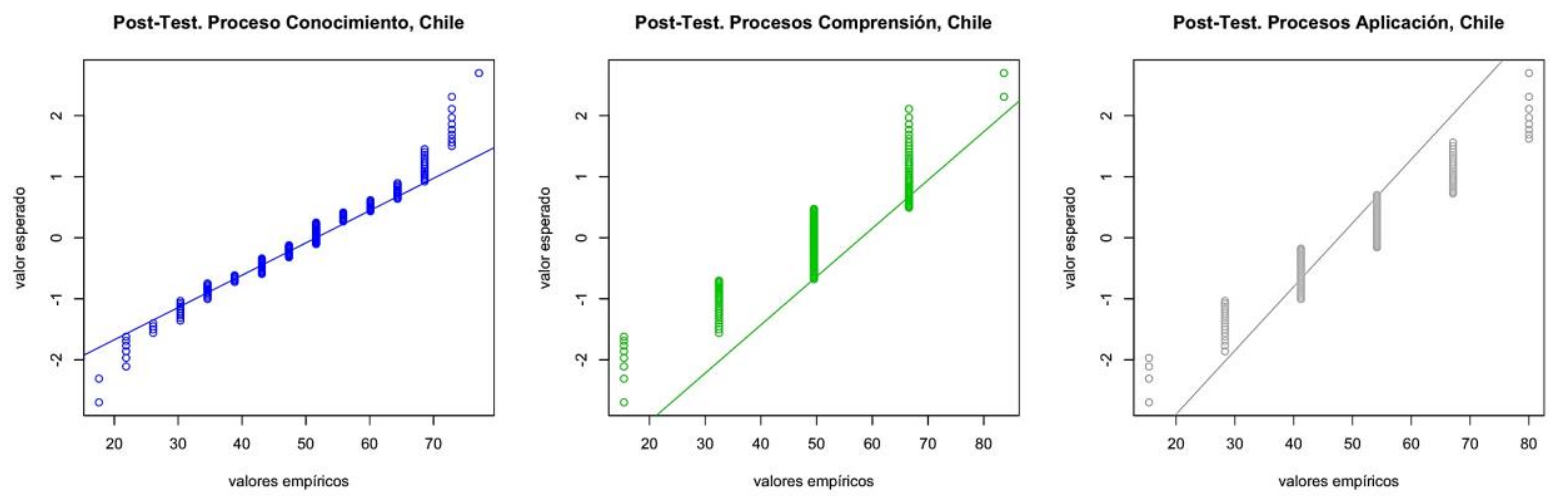

Fuente: Elaboración propia.

En referencia a los ítems de procesos, para la experiencia realizada en Chile (Gráfico 5.46), el ítem Conocimiento se ajusta a la curva normal esperada, aunque los valores extremos se alejan de los valores esperados. En cuanto a los valores de Comprensión y Aplicación se presentan valores con mayor grado dispersión, existiendo diferencias importantes entre los valores empíricos obtenidos y los valores esperados de la distribución.

Gráfico 5.47 Q-Q normales Post-Test Chile. Procesos, iPad
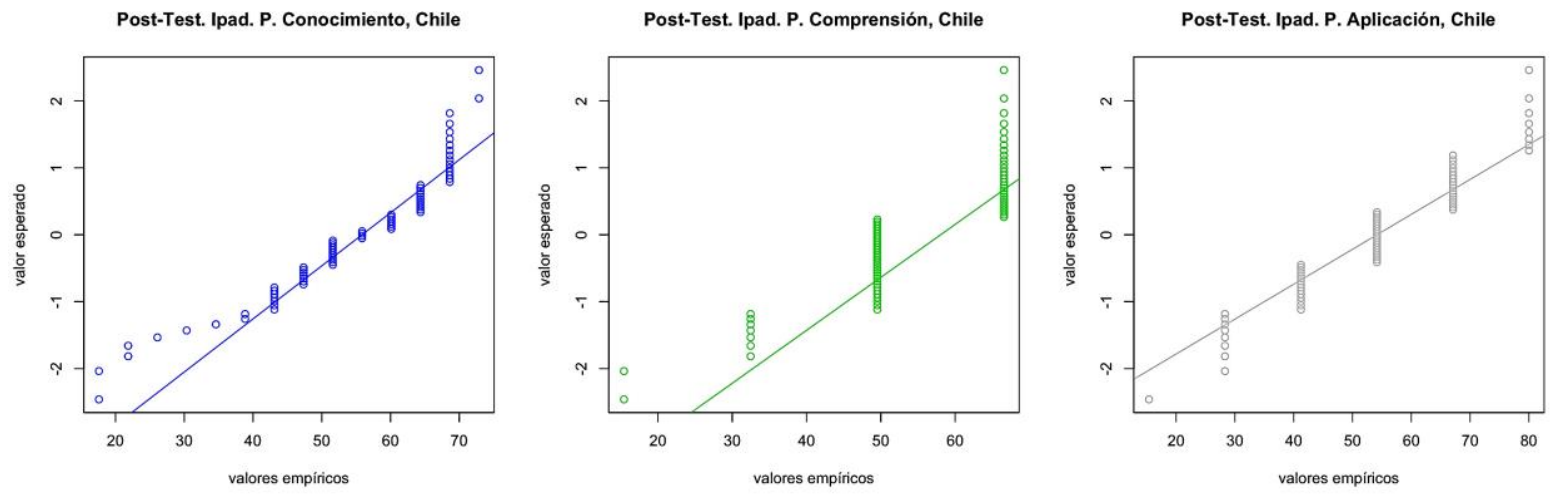

Fuente: Elaboración propia.

En cuanto a los valores de los procesos que se presentan en el grupo que utilizó iPad, y referido a los resultados posteriores al tratamiento con iPad (Gráfico 5.47), los ítems de Comprensión y Aplicación se ajustan a los valores esperados a una distribución 
normal, aunque con la presencia de algunos valores extremos que no se encuentran dentro de los esperados, sobre todo en los extremos de los gráficos. Es posible desatacar la distribución de los valores empíricos obtenidos para ítem de Conocimiento, el cual presenta una mayor dispersión de los datos extremos respecto a la los valores de la recta esperados.

Gráfico 5.48 Q-Q normales Post-Test Chile. Procesos, Ordenador
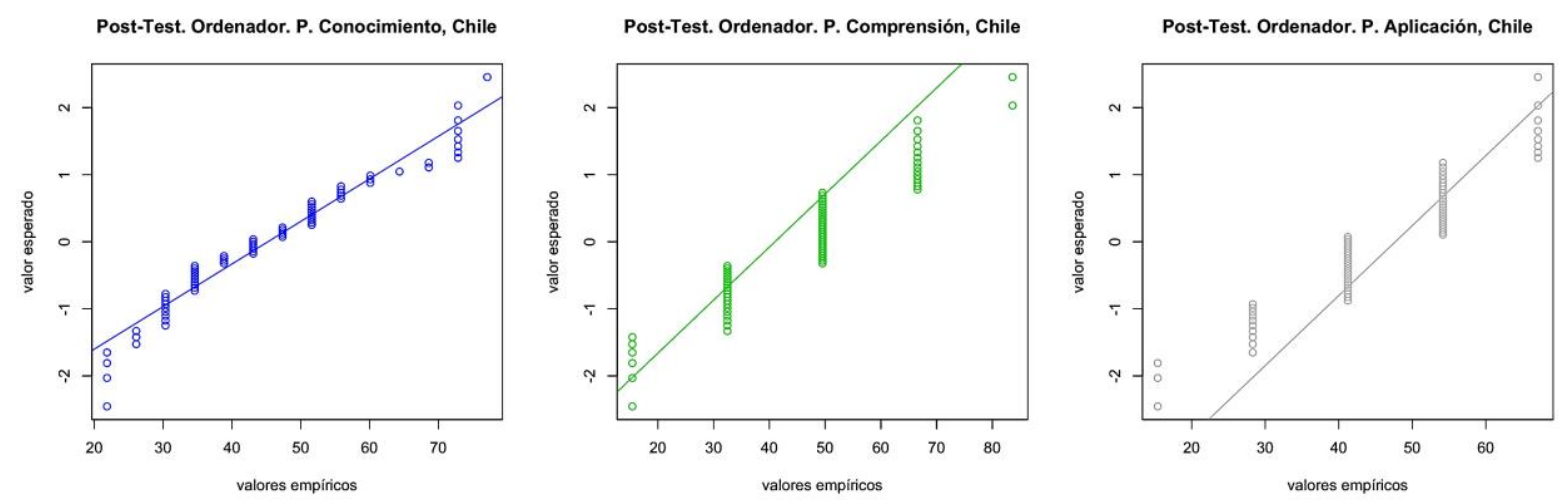

Fuente: Elaboración propia.

Por otro lado, en cuanto a los valores que se presentan en el grupo que utilizó Ordenador en torno a los procesos planteados (Gráfico 5.48), los ítems se ajustan a los valores esperados a una distribución normal, aunque con la presencia de algunos valores extremos que no se encuentran dentro de la recta graficada, sobre todo en los extremos de los gráficos.

Para complementar estos análisis y su posible normalidad, de la misma manera que en el caso de los datos Pre-Test se utilizó la prueba de Kolmogorov-Smirnov para los resultados obtenidos con la información Post-Test. Esto, con el fin de comprobar la hipótesis de la bondad de ajuste desde las distribuciones obtenidas, hacia una distribución del tipo normal. 
Tabla 5.20 Test de normalidad de Kolmogorov-Smirnov Post-Test. Caso de Chile $(n=144)$

\begin{tabular}{|c|c|c|c|}
\hline Ítem & $\mathbf{D}^{106}$ & $\mathbf{z}$ & p. \\
\hline $\begin{array}{c}\text { Contenido } \\
\text { Histórico }\end{array}$ & 0,110 & 1,312 & ,064 \\
\hline $\begin{array}{c}\text { Contenido } \\
\text { Arquitectónico }\end{array}$ & 0,116 & 1,384 & ,043 \\
\hline $\begin{array}{c}\text { Contenido de } \\
\text { Localización }\end{array}$ & 0,160 & 1,914 & ,001 \\
\hline Conocimiento & 0,097 & 1,154 & ,139 \\
\hline Comprensión & 0,243 & 2,901 & $<, 001$ \\
\hline Aplicación & 0,176 & 2,100 & $<, 001$ \\
\hline
\end{tabular}

Fuente: Elaboración propia.

Como se establece en la Tabla 5.20, sólo algunos ítems del Post-Test para Chile tienden a una distribución normal (Histórico y Conocimiento). En cuanto a los restantes ítems, se rechaza la hipótesis en la cual se establece que los registros tienen un comportamiento concordante con una distribución normal.

Tabla 5.21 Test de normalidad de Kolmogorov-Smirnov Post-Test. Caso de Chile, tratamiento iPad $(n=72)$

$\begin{array}{llll}\text { Ítem } & \text { D } & \text { p }\end{array}$

\begin{tabular}{|c|c|c|c|}
\hline $\begin{array}{c}\text { Contenido } \\
\text { Histórico }\end{array}$ & 0,176 & 1,495 &, 023 \\
\hline $\begin{array}{c}\text { Contenido } \\
\text { Arquitectónico }\end{array}$ & 0,144 & 1,222 &, 101 \\
\hline $\begin{array}{c}\text { Contenido de } \\
\text { Localización }\end{array}$ & 0,164 & 1,388 &, 042 \\
\hline Conocimiento & 0,145 & 1,231 &, 096 \\
\hline Comprensión & 0,245 & 2,083 & $<, 001$ \\
\hline Aplicación & 0,167 & 1,414 &, 037 \\
\hline
\end{tabular}

Fuente: Elaboración propia.

${ }^{106}$ Valor que establece la diferencia absoluta más alta entre la frecuencia acumulada teórica y la observada. 
De manera paralela teniendo en cuenta solo a los sujetos con el tratamiento iPad (Tabla 5.21), los ítems que presentan valores en una distribución normal son los de contenidos Arquitectónico y de proceso de Conocimiento.

Tabla 5.22 Test de normalidad de Kolmogorov-Smirnov Post-Test. Caso de Chile, tratamiento Ordenador $(\mathrm{n}=71)$

$\begin{array}{llll}\text { Ítem } & \mathrm{D} & \mathrm{z} & \end{array}$

\begin{tabular}{|c|c|c|c|}
\hline $\begin{array}{c}\text { Contenido } \\
\text { Histórico }\end{array}$ & 0,207 & 1,746 &, 005 \\
\hline $\begin{array}{c}\text { Contenido } \\
\text { Arquitectónico }\end{array}$ & 0,101 & 0,849 &, 466 \\
\hline $\begin{array}{c}\text { Contenido de } \\
\text { Localización }\end{array}$ & 0,186 & 1,569 &, 015 \\
\hline Conocimiento & 0,134 & 1,128 &, 157 \\
\hline Comprensión & 0,216 & 1,82 &, 003 \\
\hline Aplicación & 0,206 & 1,735 &, 005 \\
\hline
\end{tabular}

Fuente: Elaboración propia.

Con el tratamiento de ordenadores (Tabla 5.22) se establecen valores similares a los obtenidos para el caso con iPad, en donde los ítems de Histórico, Localización, Comprensión y Aplicación no mantienen distribuciones normales, por lo que se hará necesaria la aplicación de técnicas de contraste no paramétrico.

De esta manera, tomando como base el análisis estadístico exploratorio realizado a los datos Pre-Test y Post-Test, se aplicaron dos tipos de estadísticas de contraste, los cuales se encuentran determinados en la función de densidad y los valores de normalidad obtenidos del conjunto de datos de cada constructo e ítem. Estos estadísticos son:

A.- Análisis de varianza con medidas repetidas (ANOVA MR). Este estadístico permite analizar modelos con el efecto de uno o más factores. Los constructos e ítems que serán comparados son los referidos a los datos de Chile

B.- Prueba de los rangos con signo de Wilcoxon. Este indicador es un contraste no paramétrico para las parejas de dimensiones que no se ajustaron a la distribución normal de los datos. Los datos obtenidos para el caso de España utilizaron este medio de contraste de hipótesis. 
Esta estructura de análisis de los datos asegura la correcta interpretación de los resultados, permitiendo un mayor nivel de confianza en el estudio de los contrastes de hipótesis paramétricos y no paramétricos planteados. Adicionalmente, el uso de estadísticos complementarios permiten una interpretación con mejores niveles de fiabilidad, como son el tamaño del efecto y la potencia en cada ítem analizado.

\subsubsection{Diferencias Pre-Test y Post-Test. Aplicación de los contrastes de hipótesis}

En esta etapa se realizó un contraste de las diferencias registradas entre los valores de Pre-Test y el Post-Test para ambos países, en las variables analizadas y mediadas por el tratamiento implementado. De manera particular se tomaron las puntuaciones directas obtenidas por los sujetos en cada una de los ítems tipificados en una escala. Este análisis comienza con los resultados generales de los ítems totales, presentando los estadísticos básicos, particularmente, las medidas de tendencia central para cada grupo.

Tabla 5.23 Estadísticos básicos y diferencia de medias Pre-Test - Post-Test, constructos totales

\begin{tabular}{|c|c|c|c|c|c|c|c|c|c|}
\hline & \multicolumn{5}{|c|}{ Pre-Test } & \multicolumn{4}{|c|}{ Post-Test } \\
\hline & $\mathrm{n}$ & $\overline{\mathrm{X}}$ & $\tilde{x}$ & $S_{x}$ & $\overline{\mathrm{X}}$ & $\tilde{x}$ & $S_{x}$ & $\begin{array}{l}\overline{\mathrm{X}}_{\text {post-test }} \\
-\overline{\mathrm{X}}_{\text {pre-test }}\end{array}$ & $\begin{array}{l}\tilde{x}_{\text {post-test }} \\
-\tilde{x}_{\text {pre-test }}\end{array}$ \\
\hline $\begin{array}{l}\text { Tratamiento } \\
\text { iPad Chile }\end{array}$ & 72 & 5,040 & 5,000 & 2,388 & 13,570 & 13,000 & 3,881 & 8,530 & 8,000 \\
\hline $\begin{array}{c}\text { Tratamiento } \\
\text { Ordenador } \\
\text { Chile }\end{array}$ & 71 & 5,230 & 5,000 & 2,192 & 11,080 & 11,000 & 4,228 & 5,850 & 6,000 \\
\hline $\begin{array}{l}\text { Tratamiento } \\
\text { iPad España }\end{array}$ & 10 & 7,800 & 8,000 & 1,687 & 12,800 & 12,500 & 3,293 & 5,000 & 4,500 \\
\hline $\begin{array}{c}\text { Tratamiento } \\
\text { Ordenador } \\
\text { España }\end{array}$ & 23 & 8,170 & 8,000 & 1,557 & 14,130 & 16,000 & 4,645 & 5,960 & 8,000 \\
\hline
\end{tabular}

Fuente: Elaboración propia.

En la síntesis presentada en la Tabla 5.23, es posible visualizar que los valores Post-Test sufren importantes aumentos respecto a los estadísticos Pre-Test. 
Particularmente, las diferencias entre los valores de medias $\left(\overline{\mathrm{X}}_{\text {post-test }}-\overline{\mathrm{X}}_{\text {pre-test }}\right)$ y medianas $\left(\tilde{x}_{\text {post-test }}-\tilde{x}_{\text {pre-test }}\right)$, con valores positivos, establecen otro antecedente sobre el tratamiento aplicado y las diferencias entre los contextos en que fueron aplicados. De la misma manera, los valores de medias y medianas en el Pre-Test para cada grupo y diferenciados para cada país, tienen valores similares en sus medias e iguales en sus medianas, lo que establece que los sujetos tienen un nivel similar en conocimientos, antes de la aplicación de la experiencia educativa.

Tabla 5.24 Estadísticos básicos y diferencia de medias Pre-Test - Post-Test. Caso de Chile

\section{Pre-Test Post-Test}

\begin{tabular}{|c|c|c|c|c|c|c|c|c|c|}
\hline & $\mathrm{n}$ & $\overline{\mathrm{X}}$ & $\tilde{x}$ & $S_{x}$ & $\overline{\mathrm{X}}$ & $\tilde{x}$ & $S_{x}$ & $\begin{array}{l}\overline{\mathrm{X}}_{\text {post-test }} \\
-\overline{\mathrm{X}}_{\text {pre-test }}\end{array}$ & $\begin{array}{l}\tilde{x}_{\text {post-test }} \\
-\tilde{x}_{\text {pre-test }}\end{array}$ \\
\hline $\begin{array}{c}\text { Contenido } \\
\text { Histórico }\end{array}$ & 143 & $2,150 *$ & 2,000 & 1,310 & 4,850 & 5,000 & 2,140 & 2,700 & 3,000 \\
\hline $\begin{array}{c}\text { Contenido } \\
\text { Arquitectónico }\end{array}$ & 143 & $2,830 *$ & 3,000 & 1,610 & $7,690 *$ & 8,000 & 2,730 & 4,860 & 5,000 \\
\hline $\begin{array}{l}\text { Contenido de } \\
\text { Localización }\end{array}$ & 143 & $0,990 *$ & 1,000 & 0,810 & $2,520 *$ & 3,000 & 1,240 & 1,530 & 2,000 \\
\hline Conocimiento & 143 & $4,080 *$ & 4,000 & 2,000 & 9,620 & 10,000 & 3,530 & 5,540 & 6,000 \\
\hline Comprensión & 143 & $0,630 *$ & 1,000 & 0,720 & $2,030 *$ & 2,000 & 0,880 & 1,400 & 1,000 \\
\hline Aplicación & 143 & $1,050 *$ & 1,000 & 0,830 & $2,680 *$ & 3,000 & 1,160 & 1,630 & 2,000 \\
\hline
\end{tabular}

Para los datos obtenidos de la experiencia realizada en Chile, los estadísticos descriptivos básicos que se presenta en la Tabla 5.24 muestran como en todos ítems la puntuación lograda en el Pos-Test supera a los valores obtenidos en el Pre-Test. De esta manera, se puede afirmar que los sujetos de la muestra han tenido un mejor rendimiento en las pruebas realizadas posteriormente a la implementación de los tratamientos. 
Tabla 5.25 Estadísticos básicos y diferencia de medias Pre-Test - Post-Test. Caso de Chile, tratamiento iPad.

\begin{tabular}{|c|c|c|c|c|c|c|c|c|c|}
\hline & \multicolumn{5}{|c|}{ Pre-Test } & \multicolumn{4}{|c|}{ Post-Test } \\
\hline & $\mathrm{n}$ & $\overline{\mathrm{X}}$ & $\tilde{x}$ & $\mathrm{~S}_{\mathrm{x}}$ & $\overline{\mathrm{X}}$ & $\tilde{x}$ & $S_{x}$ & $\begin{array}{l}\overline{\mathrm{X}}_{\text {post-test }} \\
-\overline{\mathrm{X}}_{\text {pre-test }}\end{array}$ & $\begin{array}{l}\tilde{x}_{\text {post-test }} \\
-\tilde{x}_{\text {pre-test }}\end{array}$ \\
\hline $\begin{array}{l}\text { Contenido } \\
\text { Histórico }\end{array}$ & 72 & 2,170 & 2,000 & 1,332 & $5,460 *$ & 6,000 & 2,000 & 3,290 & 4,000 \\
\hline $\begin{array}{c}\text { Contenido } \\
\text { Arquitectónico }\end{array}$ & 72 & 2,680 & 3,000 & 1,600 & 8,630 & 8,500 & 2,440 & 5,950 & 5,500 \\
\hline $\begin{array}{l}\text { Contenido de } \\
\text { Localización }\end{array}$ & 72 & $1,040 *$ & 1,000 & 0,863 & $2,600 *$ & 3,000 & 1,296 & 1,560 & 2,000 \\
\hline Conocimiento & 72 & 3,900 & 4,000 & 2,057 & 10,630 & 11,000 & 3,213 & 6,730 & 7,000 \\
\hline Comprensión & 72 & $0,680 *$ & 0,500 & 0,819 & $2,250 *$ & 2,000 & 0,746 & 1,570 & 1,500 \\
\hline Aplicación & 72 & $1,100 *$ & 1,000 & 0,875 & $3,000 *$ & 3,000 & 1,222 & 1,900 & 2,000 \\
\hline
\end{tabular}

* Valor tomado de un ítem no ajustado a la curva normal.

Fuente: Elaboración propia.

Tabla 5.26 Estadísticos básicos y diferencia de medias Pre-Test - Post-Test. Caso de Chile, tratamiento Ordenador.

Pre-Test

Post-Test

\begin{tabular}{|c|c|c|c|c|c|c|c|c|c|}
\hline & $\mathrm{n}$ & $\overline{\mathrm{X}}$ & $\tilde{x}$ & $\mathrm{~S}$ & $\overline{\mathrm{x}}$ & $\tilde{x}$ & $\mathrm{~S}_{\mathrm{x}}$ & $\begin{array}{l}\overline{\mathrm{X}}_{\text {post-test }} \\
-\overline{\mathrm{X}}_{\text {pre-test }}\end{array}$ & $\begin{array}{l}\tilde{x}_{\text {post-test }} \\
-\tilde{x}_{\text {pre-test }}\end{array}$ \\
\hline $\begin{array}{c}\text { Contenido } \\
\text { Histórico }\end{array}$ & 71 & $2,130^{*}$ & 2,000 & 1,287 & $4,240 *$ & 4,000 & 2,108 & 2,110 & 2,000 \\
\hline $\begin{array}{c}\text { Contenido } \\
\text { Arquitectónico }\end{array}$ & 71 & $2,970^{*}$ & 3,000 & 1,612 & 6,750 & 7,000 & 2,698 & 3,780 & 4,000 \\
\hline $\begin{array}{c}\text { Contenido de } \\
\text { Localización }\end{array}$ & 71 & $0,930^{*}$ & 1,000 & 0,743 & $2,450 *$ & 3,000 & 1,181 & 1,520 & 2,000 \\
\hline \begin{tabular}{c} 
Conocimiento \\
\hline Comprensión
\end{tabular} & 71 & 4,250 & 4,000 & 1,947 & 8,610 & 8,000 & 3,564 & 4,360 & 4,000 \\
\hline Aplicación & 71 & $1,000 *$ & 1,000 & 0,793 & $2,350 *$ & 2,000 & 1,001 & 1,350 & 1,000 \\
\hline
\end{tabular}

* Valor tomado de un ítem no ajustado a la curva normal.

Fuente: Elaboración propia.

Cuando se dividen los datos en función del tratamiento aplicado (Tabla 5.25 y Tabla 5.26), se observan los mismos resultados, aunque los valores parecen mayores en el tratamiento con iPad. 
Tabla 5.27 Estadísticos básicos y diferencia de medias Pre-Test - Post-Test. Caso de España

\begin{tabular}{|c|c|c|c|c|c|c|c|c|c|}
\hline & \multicolumn{4}{|c|}{ Pre-Test } & \multicolumn{3}{|c|}{ Post-Test } & & \\
\hline & $\mathrm{n}$ & $\overline{\mathrm{X}}$ & $\tilde{x}$ & $S_{x}$ & $\overline{\mathrm{X}}$ & $\tilde{x}$ & $S_{x}$ & $\begin{array}{l}\overline{\mathrm{X}}_{\text {post-test }} \\
-\overline{\mathrm{X}}_{\text {pre-test }}\end{array}$ & $\begin{array}{l}\tilde{x}_{\text {post-test }} \\
-\tilde{x}_{\text {pre-test }}\end{array}$ \\
\hline $\begin{array}{l}\text { Contenido } \\
\text { Histórico }\end{array}$ & 33 & 3,880 & 4,000 & 1,270 & 6,520 & 7,000 & 2,030 & 2,640 & 3,000 \\
\hline $\begin{array}{c}\text { Contenido } \\
\text { Arquitectónico }\end{array}$ & 33 & 6,550 & 7,000 & 1,540 & 9,670 & 10,000 & 3,280 & 3,120 & 3,000 \\
\hline $\begin{array}{l}\text { Contenido de } \\
\text { Localización }\end{array}$ & 33 & $1,480 *$ & 1,000 & 0,870 & 1,970 & 2,000 & 0,770 & 0,490 & 1,000 \\
\hline Conocimiento & 33 & 6,700 & 6,000 & 1,550 & 11,120 & 12,000 & 3,960 & 4,420 & 6,000 \\
\hline Comprensión & 33 & $0,850 *$ & 1,000 & 0,710 & 1,940 & 2,000 & 1,000 & 1,090 & 1,000 \\
\hline Aplicación & 33 & $1,730 *$ & 2,000 & 0,720 & 2,910 & 3,000 & 0,770 & 1,180 & 1,000 \\
\hline
\end{tabular}

Fuente: Elaboración propia.

Para los datos obtenidos de la experiencia realizada en España, los estadísticos descriptivos básicos que se presenta en la Tabla 5.27 muestran como en todos ítems, la puntuación lograda en el Pos-Test supera a los valores obtenidos en el Pre-Test. Así, es posible afirmar también que los sujetos de la muestra han tenido un mejor rendimiento en las pruebas realizadas posteriormente a la implementación de los tratamientos. 
Tabla 5.28 Estadísticos básicos y diferencia de medias Pre-Test - Post-Test. Caso de España, tratamiento iPad

\section{Pre-Test Post-Test}

\begin{tabular}{|c|c|c|c|c|c|c|c|c|c|}
\hline & $\mathrm{n}$ & $\overline{\mathrm{X}}$ & $\tilde{x}$ & $\mathrm{~S}$ & $\overline{\mathrm{X}}$ & $\tilde{x}$ & $\mathrm{~S}_{\mathrm{x}}$ & $\begin{array}{l}\overline{\mathrm{X}}_{\text {post-test }} \\
-\overline{\mathrm{X}}_{\text {pre-test }}\end{array}$ & $\begin{array}{l}\tilde{x}_{\text {post-test }} \\
-\tilde{x}_{\text {pre-test }}\end{array}$ \\
\hline $\begin{array}{c}\text { Contenido } \\
\text { Histórico }\end{array}$ & 10 & 3,900 & 4,000 & 1,37 & 6,300 & 6,000 & 2,263 & 2,400 & 2,000 \\
\hline $\begin{array}{c}\text { Contenido } \\
\text { Arquitectónico }\end{array}$ & 10 & 6,200 & 6,500 & 1,476 & 9,500 & 9,500 & 2,506 & 3,300 & 3,000 \\
\hline $\begin{array}{c}\text { Contenido de } \\
\text { Localización }\end{array}$ & 10 & 1,000 & 1,000 & 0,667 & 2,200 & 2,000 & 0,789 & 1,200 & 1,000 \\
\hline \begin{tabular}{c} 
Conocimiento \\
\hline Comprensión
\end{tabular} & 10 & 6,700 & 6,500 & 1,767 & 10,400 & 9,500 & 3,406 & 3,700 & 3,000 \\
\hline Aplicación & 10 & 1,400 & 1,000 & 0,516 & 3,100 & 3,000 & 0,738 & 1,700 & 2,000 \\
\hline
\end{tabular}

Fuente: Elaboración propia.

Tabla 5.29 Estadísticos básicos y diferencia de medias Pre-Test - Post-Test. Caso de España, tratamiento Ordenador

Pre-Test

Post-Test

\begin{tabular}{|c|c|c|c|c|c|c|c|c|c|}
\hline & $\mathrm{n}$ & $\overline{\mathrm{X}}$ & $\tilde{x}$ & $\mathrm{~S}$ & $\overline{\mathrm{X}}$ & $\tilde{x}$ & $\mathrm{~S}_{\mathrm{x}}$ & $\begin{array}{l}\overline{\mathrm{X}}_{\text {post-test }} \\
-\overline{\mathrm{X}}_{\text {pre-test }}\end{array}$ & $\begin{array}{l}\tilde{x}_{\text {post-test }} \\
-\tilde{x}_{\text {pre-test }}\end{array}$ \\
\hline $\begin{array}{c}\text { Contenido } \\
\text { Histórico }\end{array}$ & 23 & 3,870 & 4,000 & 1,254 & 6,610 & 7,000 & 1,971 & 2,740 & 3,000 \\
\hline $\begin{array}{c}\text { Contenido } \\
\text { Arquitectónico }\end{array}$ & 23 & 6,700 & 7,000 & 1,579 & 9,740 & 10,000 & 3,608 & 3,040 & 3,000 \\
\hline $\begin{array}{c}\text { Contenido de } \\
\text { Localización }\end{array}$ & 23 & 1,700 & 2,000 & 0,876 & 1,870 & 2,000 & 0,757 & 0,170 & 0,000 \\
\hline $\begin{array}{c}\text { Conocimiento } \\
\text { Comprensión }\end{array}$ & 23 & 6,700 & 6,000 & 1,49 & 11,430 & 13,000 & 4,208 & 4,730 & 7,000 \\
\hline Aplicación & 23 & 1,870 & 2,000 & 0,757 & 2,830 & 3,000 & 0,778 & 0,960 & 1,000 \\
\hline
\end{tabular}

Fuente: Elaboración propia.

Para este caso, cuando los datos se dividen en función del tratamiento aplicado (Tabla 5.28 y Tabla 5.29), los resultados para España tienen resultados similares a los datos del caso de Chile. De la misma manera, los valores de cada ítem son mayores en el tratamiento con iPad, destacando el caso del ítem de contenidos de localización para el tratamiento en ordenador, en donde las diferencias entre medias son mínimas y las diferencias entre medianas son nulas. 
Desde este estudio descriptivo de los datos, se da inicio al análisis del real impacto que tienen estas herramientas para los grupos participantes, traduciéndose en distintos tipos de resultados en las diferencias obtenidas una vez aplicado el tratamiento correspondiente, entregando evidencia de la efectividad y las diferencias desde el punto de vista del aprendizaje.

\subsubsection{Resultados de los contrastes de hipótesis para Chile}

Teniendo estos antecedentes descriptivos, un elemento adicional que se hace necesario para el estudio de estos datos, corresponde a establecer si el tratamiento aplicado con las herramientas establecidas y sus implementaciones (iPad u Ordenador) mejoran los procesos y contenidos de aprendizaje propuesto en lo tocante a contenidos patrimoniales. Para ello se utilizarán los contrastes de hipótesis planteados en la metodología, siendo para el caso de Chile en su constructo total la aplicación del modelo de análisis de varianza (ANOVA) con medidas repetidas (MR) con el fin de estudiar el efecto del factor de tratamiento al grupo de sujetos considerados en el estudio. Las condiciones previas de los datos antes de la aplicación de los contrastes respectivos, establecen que existe una distribución normal de los datos. De esta manera el primer contraste realizado (puntuaciones en el Pre-Test en los grupos iPad y Ordenador) produjo valores de $t=-, 479$ y $p=, 633$, por lo que se acepta $H_{0}$ estableciendo que los niveles de estos grupos son similares en sus puntuaciones previo a la aplicación del tratamiento.

En la Tabla 5.30 se presentan las diferencias obtenidas en el contraste utilizado para el constructo general del resultado en Chile, teniendo como condiciones previas valores en la prueba $M$ de Box igual a 2,464 y significancia de ,489 posibilitando la aplicación de la ANOVA-RM. Así se pudo establecer que existen variaciones significativas entre el rendimiento de los sujetos en la situación Pre-Test /Post-Test, en función del tratamiento aplicado. Puesto que el nivel crítico (Sig.) asociado al contraste es menor que ,050, es posible rechazar la hipótesis nula de igualdad de medias estableciendo que los niveles de rendimiento generales son diferentes en cada tratamiento aplicado. 
Tabla 5.30 Contraste de hipótesis. Diferencia de medias-medianas Pre-Test/Post-Test para Chile

\begin{tabular}{cccccc} 
& & Fig & Sig. & $\begin{array}{c}\text { Eta Cuadrado } \\
\text { parcial }\end{array}$ & $\begin{array}{c}\text { Potencia de } \\
\text { la prueba }\end{array}$ \\
\hline \multirow{2}{*}{$\begin{array}{c}\text { Total } \\
\text { constructo }\end{array}$} & Efecto Principal & 328,647 & $<, 001$ &, 700 & $100,00 \%$ \\
\cline { 2 - 6 } & Interacción & 11,308 &, 001 &, 074 & $91,60 \%$ \\
\hline
\end{tabular}

Fuente: Elaboración propia.

En torno al efecto principal, el valor obtenido por el tratamiento es bastante grande $\left(\eta^{2}=, 700\right)$, valor que queda confirmado por los valores de media obtenidos según el tratamiento realizado a los sujetos (Tabla 5.23). Estos resultados confirman que, mientras ambos grupos aumentan sus niveles de aprendizaje tras los tratamientos realizados, el grupo que ha trabajado con iPads lo ha hecho de manera más significativa. Para el caso de los efectos de interacción entre grupos, se realizará un análisis por separado.

Así, con estos indicadores obtenidos, se confirma la diferencia significativa entre los tratamientos y procesos (iPad/Ordenador) aplicados a los alumnos. De manera paralela, se ha realizado un análisis comparativo gráfico con el fin de establecer cómo se comportan estas variables en su conjunto y a través del proceso de cambio desde las etapas de Pre-Test hacia el Post-Test.

107 La significación referida al factor de esfericidad no aparece en esta tabla resumen ya que con dos niveles no es posible hablar de esfericidad ya que se presenta sólo una covarianza que es igual a sí misma. 
Gráfico 5.49 Diferencias Pre-Test/Post-Test según tratamiento. Caso de Chile

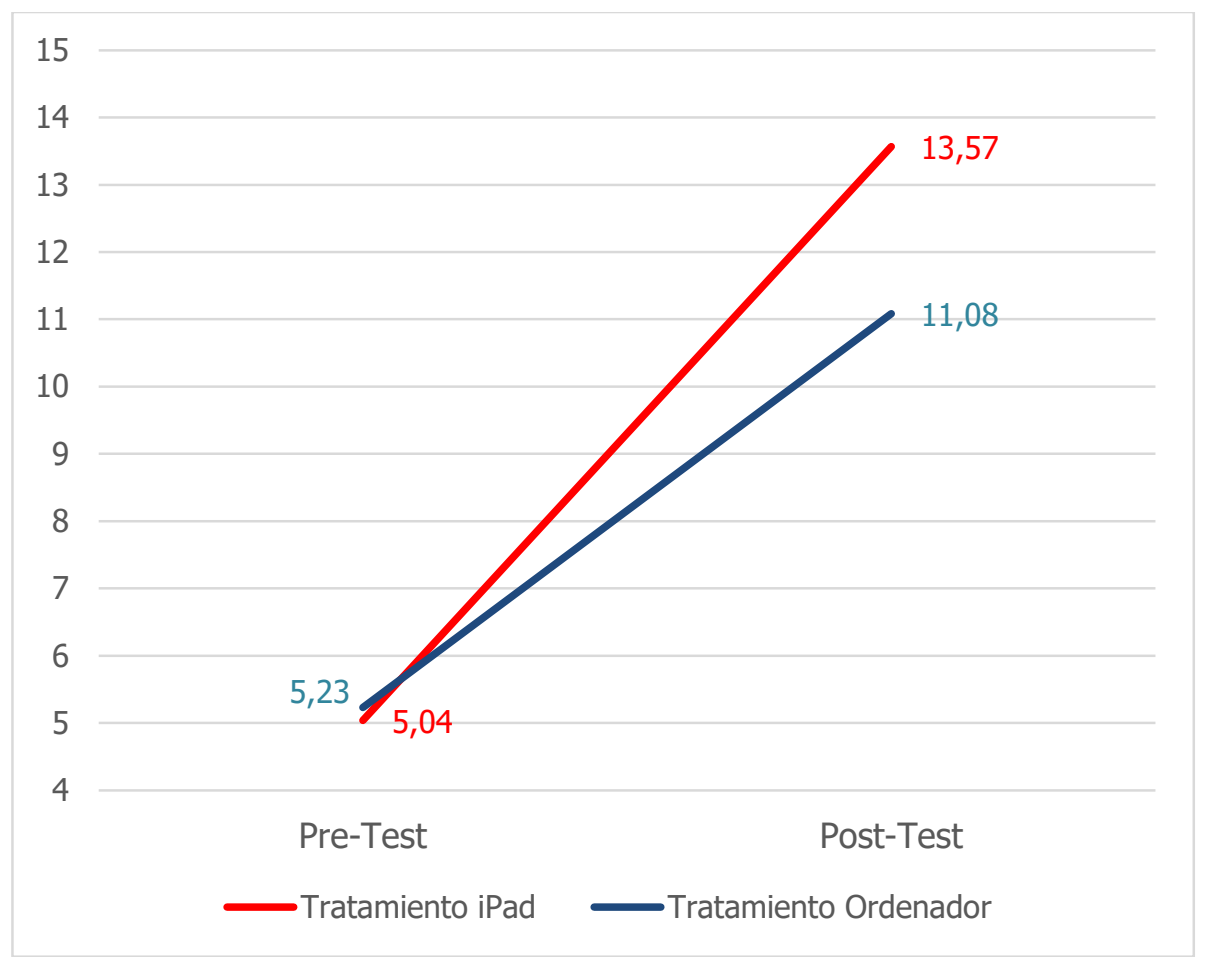

Fuente: Elaboración propia.

En un primer lugar y desde el contexto visual (Gráfico 5.49), los valores de las medidas Pre-Test no presentan diferencias significativas entre la media del grupo experimental -iPad- y la media del grupo de control -Ordenador-, es decir, los grupos tienen el mismo nivel sobre los temas patrimoniales que serán abordados en los tratamientos respectivos. Tras el desarrollo de la actividad educativa con las herramientas informáticas (tratamiento), ambos grupos han mejorado notablemente su rendimiento, pero el grupo con la aplicación móvil obtiene una media mayor respecto al grupo de ordenador de escritorio, lo que establece que la herramienta iPad tiene una mayor efectividad en el proceso de aprendizaje respecto al ordenador.

Tras estos datos iniciales, se lleva a cabos los contrastes de hipótesis particulares según dimensión y tratamiento (Tabla 5.31). 
Tabla 5.31 Prueba de Wilcoxon. Diferencia de medianas Pre-Test/Post-Test según elementos y procesos para Chile

Tamaño Efecto

\begin{tabular}{|c|c|c|c|c|c|c|}
\hline Grupo & $\mathbf{n}$ & $\mathbf{Z}$ & Sig. & $\mathbf{r}$ & $\mathbf{P S}_{\text {dep }}$ & $\begin{array}{l}\text { Potencia } \\
\text { de la } \\
\text { prueba }\end{array}$ \\
\hline $\begin{array}{l}\text { Contenido Histórico } \\
\text { (Pre/Post-Test) }\end{array}$ & 143 & $-9,097$ & $<, 001$ & 609 & 867 & $100,00 \%$ \\
\hline $\begin{array}{l}\text { Contenido Arquitectónico } \\
\text { (Pre/Post-Test) }\end{array}$ & 143 & $-9,905$ & $<, 001$ & 737 & ,920 & $100,00 \%$ \\
\hline $\begin{array}{c}\text { Contenido de } \\
\text { Localización (Pre/Post- } \\
\text { Test) }\end{array}$ & 143 & $-8,466$ & $<, 001$ & ,594 & 850 & $100,00 \%$ \\
\hline $\begin{array}{l}\text { Proceso de Conocimiento } \\
\text { (Pre/Post-Test) }\end{array}$ & 143 & $-9,787$ & $<, 001$ & 696 & ,888 & $100,00 \%$ \\
\hline $\begin{array}{l}\text { Proceso de Comprensión } \\
\text { (Pre/Post-Test) }\end{array}$ & 143 & $-9,189$ & $<, 001$ & 658 & 871 & $100,00 \%$ \\
\hline $\begin{array}{l}\text { Proceso de Aplicación } \\
\text { (Pre/Post-Test) }\end{array}$ & 143 & $-9,064$ & $<, 001$ & 629 & ,853 & $100,00 \%$ \\
\hline
\end{tabular}

Fuente: Elaboración propia.

Los contrastes de hipótesis particulares para los resultados según elementos y procesos para el caso de Chile (Tabla 5.31) entrega valores críticos de significancia menor a 0.05 (Sig. $=<, 001$ ) para todos los casos, rechazando la hipótesis nula sobre la igualdad de los valores de medianas. Estos resultados confirman, de manera disgregada por elementos y procesos, que los alumnos aumentan su nivel de aprendizaje respecto a su estado inicial, y que esta situación se hace de forma significativa.

En cuanto a los valores de tamaño del efecto obtenidos, indican que los tratamientos aplicados son altamente efectivos con valores superiores a $\mathrm{PS}_{\text {dep }} \approx>, 850 \mathrm{y} \mathrm{r}$ $\approx>, 550$. En lo referente a la potencia de cada prueba, todos los ítems marcan valores iguales a $100 \%$ evitando la posibilidad de encontrar un error del tipo II. 
Gráfico 5.50 Diferencias Pre-Test/Post-Test según contenido y proceso. Caso de Chile

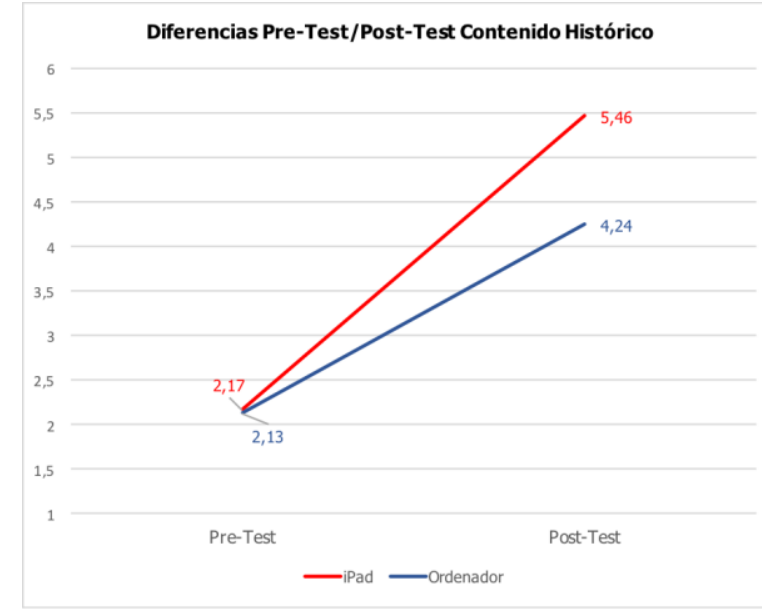

Diferencias Pre-Test/Post-Test, Contenido Arquitectónico

Diferencias Pre-Test/Post-Test, Contenido de Localización
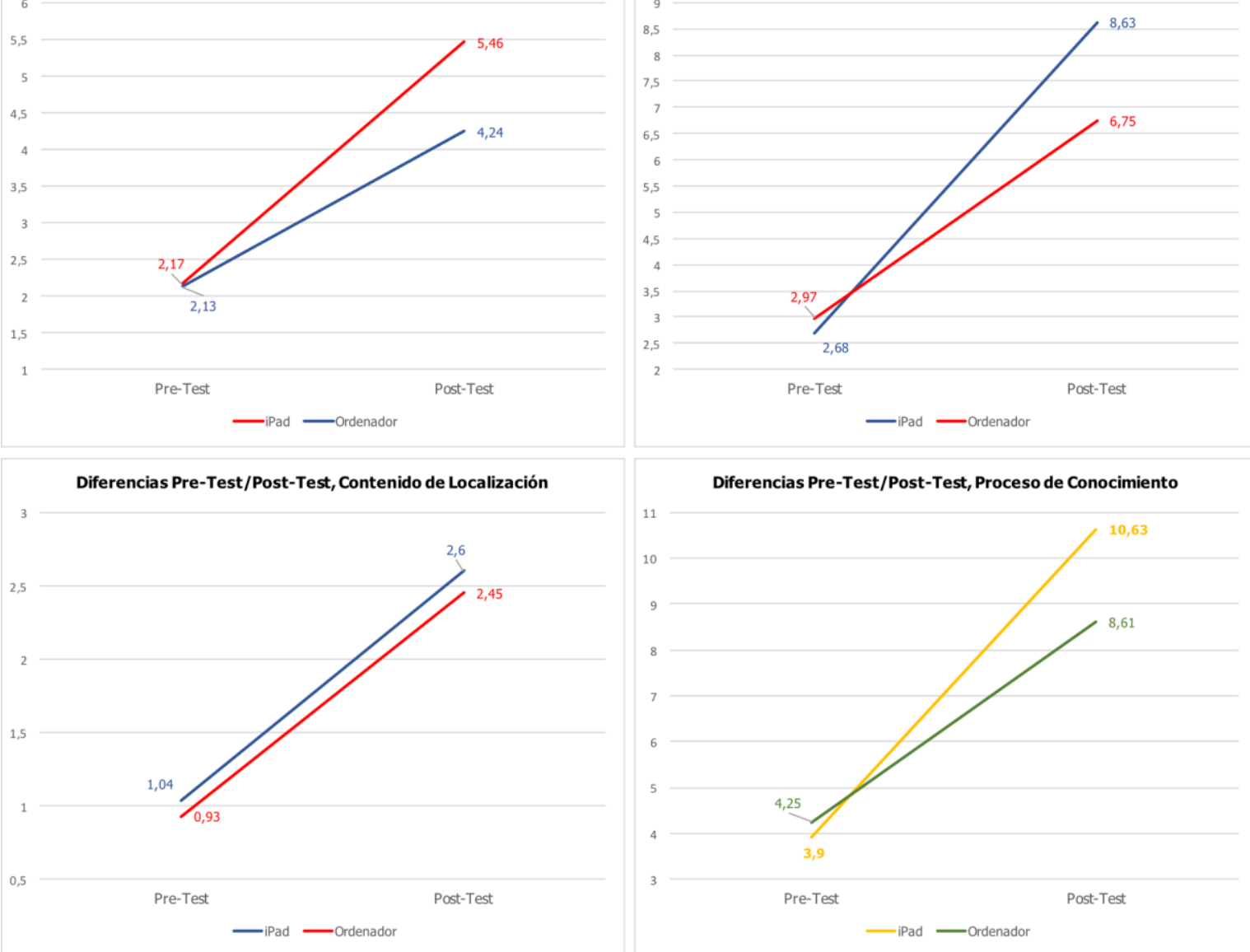

Diferencias Pre-Test/Post-Test, Proceso de Conocimiento

Diferencias Pre-Test/Post-Test, Proceso de Comprensión
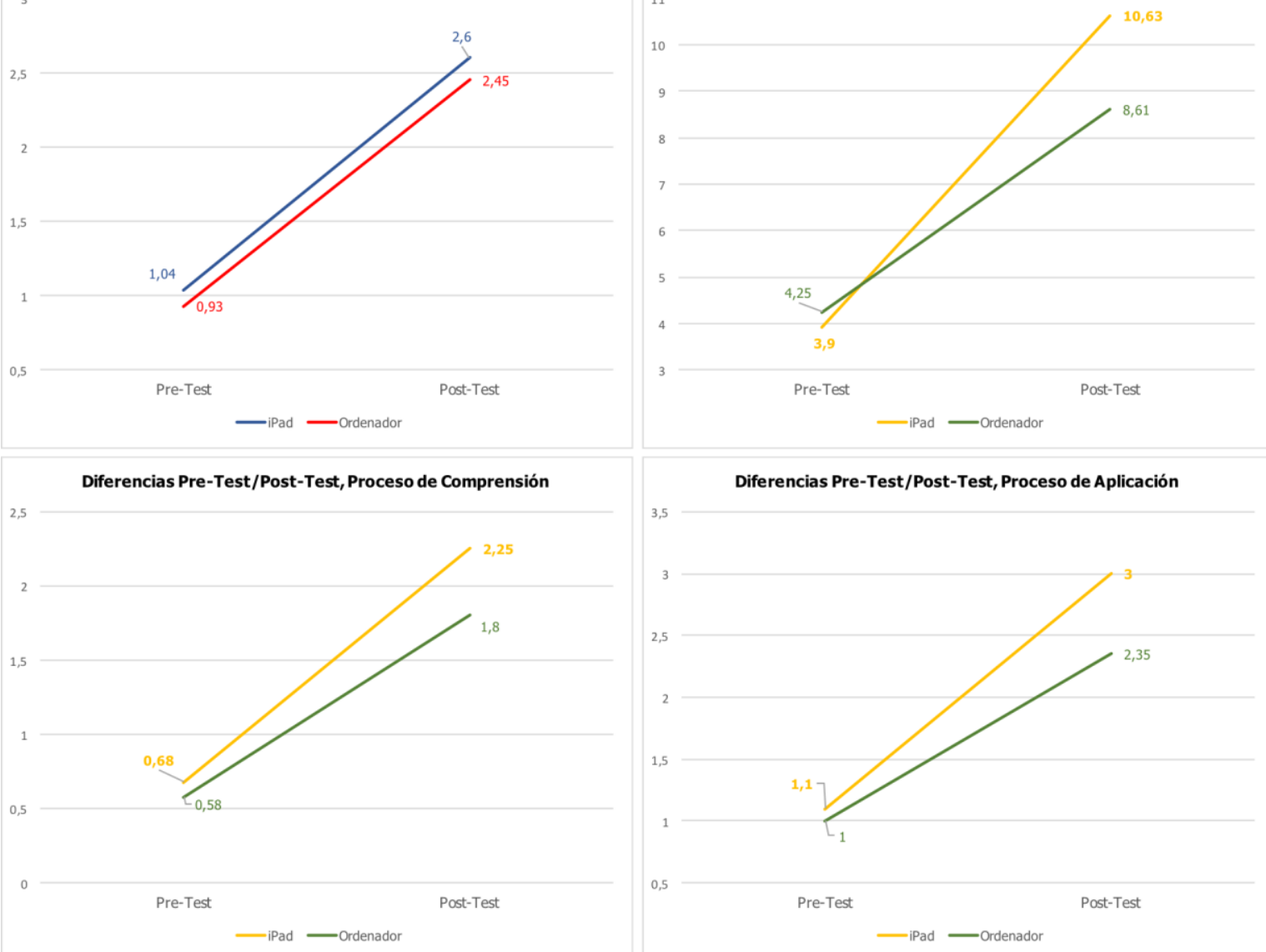

Diferencias Pre-Test/Post-Test, Proceso de Aplicación

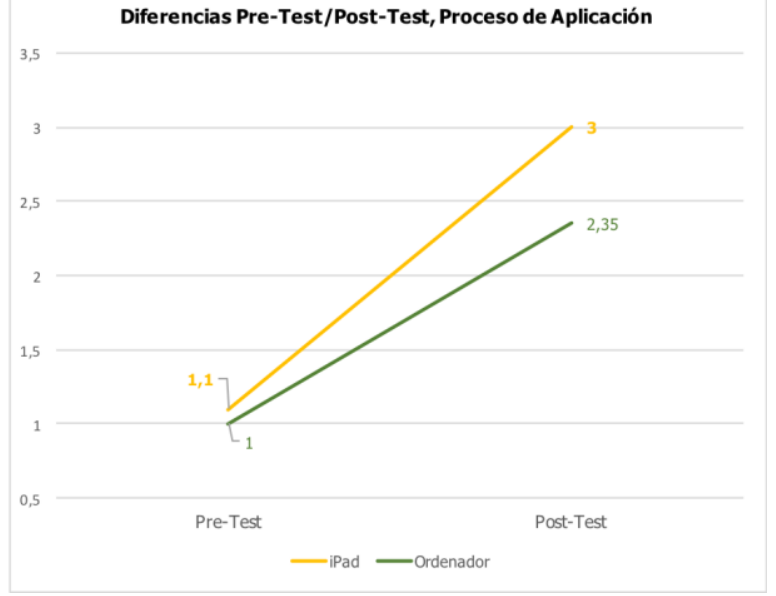

Fuente: Elaboración propia.

Analizando gráficamente los resultados (Gráfico 5.50), cada contenido y proceso tiene un valor en el Pre-Test diferente debido a la cantidad de ítems que lo conformaba en la prueba objetiva aplicada, lo cual explica los diferentes puntos de comienzo de cada 
recta. Sin embargo, ya con el valor Post-Test incorporado, es posible ver el incremento de todas las dimensiones, algunas con una mayor pendiente en el tratamiento iPad respecto al de Ordenador, presentándose una diferencia en el proceso de Localización en la cual ambas rectas se mantienen de manera paralela, es decir, la proporción de los puntajes obtenidos son constante en los individuos.

Cuando se hace se realiza el análisis estadístico en función del tratamiento aplicado (iPad u Ordenador) en todos los grupos Pre/Post-Test el nivel crítico de significancia es menor que ,05 (Tabla 5.33), indicando que hay diferencias significativas entre la primera medición y la segunda, las que son debidas a la aplicación del tratamiento respectivo. De esta manera, en el contexto general de las intervenciones educativas, es posible establecer que existe un aumento de las puntuaciones de los alumnos. Queda por establecer si existen diferencias entre el tipo de tratamiento utilizado para cada experiencia. 
Tabla 5.32 Prueba W-Wilcoxon. Diferencia de medianas Pre-Test/Post-Test según tratamiento para Chile

\begin{tabular}{|c|c|c|c|c|c|c|}
\hline \multirow[b]{2}{*}{ Grupo } & \multirow[b]{2}{*}{$\mathbf{n}$} & \multirow[b]{2}{*}{$\mathbf{z}$} & \multirow[b]{2}{*}{ p. } & \multicolumn{2}{|c|}{$\begin{array}{l}\text { Tamaño del } \\
\text { efecto }\end{array}$} & \multirow[b]{2}{*}{$\begin{array}{c}\text { Potencia } \\
\text { de la } \\
\text { prueba }\end{array}$} \\
\hline & & & & $\mathbf{r}$ & $\mathbf{P S}_{\text {dep }}$ & \\
\hline $\begin{array}{l}\text { Constructo (Pre/Post- } \\
\text { Test iPad) }\end{array}$ & 72 & $-7,236$ & $<, 001$ & 800 & ,958 & $100,00 \%$ \\
\hline $\begin{array}{l}\text { Contenido Histórico } \\
\text { (tratamiento iPad) }\end{array}$ & 72 & $-6,925$ & $<, 001$ & 698 & ,896 & $100,00 \%$ \\
\hline $\begin{array}{l}\text { Contenido Arquitectónico } \\
\text { (tratamiento iPad) }\end{array}$ & 72 & $-7,256$ & $<, 001$ & 823 & ,944 & $100,00 \%$ \\
\hline $\begin{array}{l}\text { Contenido de } \\
\text { Localización (tratamiento } \\
\text { iPad) }\end{array}$ & 72 & $-5,86$ & $<, 001$ & ,580 & ,826 & $100,00 \%$ \\
\hline $\begin{array}{l}\text { Conocimiento } \\
\text { (tratamiento iPad) }\end{array}$ & 72 & $-7,142$ & $<, 001$ & ,782 & ,938 & $100,00 \%$ \\
\hline $\begin{array}{l}\text { Comprensión } \\
\text { (tratamiento iPad) }\end{array}$ & 72 & $-6,746$ & $<, 001$ & 710 & ,896 & $100,00 \%$ \\
\hline $\begin{array}{l}\text { Aplicación (tratamiento } \\
\text { iPad) }\end{array}$ & 72 & $-6,505$ & $<, 001$ & 670 &, 861 & $100,00 \%$ \\
\hline $\begin{array}{l}\text { Constructo (tratamiento } \\
\text { Ordenador) }\end{array}$ & 71 & $-6,811$ & $<, 001$ & 659 & ,859 & $100,00 \%$ \\
\hline $\begin{array}{l}\text { Contenido Histórico } \\
\text { (tratamiento Ordenador) }\end{array}$ & 71 & $-5,83$ & $<, 001$ &, 520 & ,838 & $100,00 \%$ \\
\hline $\begin{array}{l}\text { Contenido Arquitectónico } \\
\text { (tratamiento Ordenador) }\end{array}$ & 71 & $-6,752$ & $<, 001$ & 650 & ,894 & $100,00 \%$ \\
\hline $\begin{array}{l}\text { Contenido de } \\
\text { Localización (tratamiento }\end{array}$ & 71 & $-6,139$ & $<, 001$ & 613 & ,873 & $100,00 \%$ \\
\hline $\begin{array}{l}\text { Conocimiento } \\
\text { (tratamiento Ordenador) }\end{array}$ & 71 & $-6,674$ & $<, 001$ & 607 & ,838 & $100,00 \%$ \\
\hline $\begin{array}{l}\text { Comprensión } \\
\text { (tratamiento Ordenador) }\end{array}$ & 71 & $-6,236$ & $<, 001$ & 613 &, 845 & $100,00 \%$ \\
\hline $\begin{array}{l}\text { Aplicación (tratamiento } \\
\text { Ordenador) }\end{array}$ & 71 & $-6,32$ & $<, 001$ & 602 & ,845 & $100,00 \%$ \\
\hline
\end{tabular}

Fuente: Elaboración propia.

En cuanto a los tamaños del efecto para el caso de Chile y a partir de los valores $\mathrm{PS}_{\text {dep }}$ y $r$, los resultados obtenidos establecen el tamaño de efecto en niveles medios con valores $\mathrm{PS}_{\mathrm{dep}} \approx>, 630$ y de $\mathrm{r} \approx>, 300$, estableciendo la efectividad de los tratamientos utilizados.

En lo referente a la potencia de cada prueba, la totalidad de los ítems presentan valores iguales al 100\%, evitando la probabilidad de cometer un error del tipo II. Estos valores se explican por la cantidad de sujetos participantes en el muestreo, la poca 
variabilidad de los datos, sobre todo en los valores de Post-Test y los niveles grandes presentes en el tamaño del efecto obtenido para cada contraste.

Otro elemento incorporado en el análisis, fue el punto en que se encontraban los grupos iPad/Ordenador antes de la aplicación del tratamiento (Tabla 5.33). Los resultados establecen que ambos grupos no presentan diferencias significativas antes del desarrollo de la actividad educativa (Sig. > ,05), aceptándose la hipótesis nula sobre la igualdad de los valores de medianas. Todos los valores de los grupos en comparación, desde el constructo general Pre-Test, hasta los elementos y procesos presentan los mismos niveles, no habiendo diferencia entre los valores de partida para la medición de la experiencia. Desde los valores de tamaño de los efectos se puede establecer que la magnitud de la diferencia de los puntajes entre grupos son pequeños $(r \approx>0,1)$, lo que confirma que ambos grupos comienzan con el mismo nivel, datos explicados por la estructura metodológica: se comparan los alumnos presentes en el mismo grado y establecimientos educacionales. En cuanto a los valores de la potencia de los test aplicados, estos son bajos (> 30\%) y se encuentran condicionados a los datos obtenidos en el tamaño del efecto, en donde los resultados del Pre-Test son homogéneos entre los grupos, pero presentan una baja variabilidad inicial (ver $S_{x}$ en Tabla 5.24).

Tabla 5.33 Prueba U de Mann-Whitney, contenidos y procesos en Pre-Test, Chile

\begin{tabular}{|l|c|c|c|c|c|}
\hline \multicolumn{1}{|c|}{ Grupo } & $\mathbf{n}$ & $\mathbf{Z}$ & Sig. & $\mathbf{r}$ & $\begin{array}{c}\text { Potencia } \\
\text { de la } \\
\text { prueba }\end{array}$ \\
\hline $\begin{array}{l}\text { Pre-Test } \\
\text { (iPad/Ordenador) }\end{array}$ & 143 & $-0,477$ &, 633 &, 040 & $12,24 \%$ \\
\hline $\begin{array}{l}\text { Contenido Histórico } \\
\text { (iPad/Ordenador) }\end{array}$ & 143 & $-0,402$ &, 688 &,- 015 & $7,11 \%$ \\
\hline $\begin{array}{l}\text { Contenido } \\
\text { Arquitectónicos }\end{array}$ & 143 & $-1,128$ &, 259 &, 091 & $27,59 \%$ \\
\hline $\begin{array}{l}\text { Contenido de } \\
\text { Localización } \\
\text { (iPad/Ordenador) }\end{array}$ & 143 & $-0,746$ &, 455 &,- 070 & $19,75 \%$ \\
\hline $\begin{array}{l}\text { Proceso de Conocimiento } \\
\text { (iPad/Ordenador) }\end{array}$ & 143 & $-1,05$ &, 294 &, 088 & $26,47 \%$ \\
\hline $\begin{array}{l}\text { Proceso de Comprensión } \\
\text { (iPad/Ordenador) }\end{array}$ & 143 & $-0,291$ &, 771 &,- 072 & $20,17 \%$ \\
\hline $\begin{array}{l}\text { Proceso de Aplicación } \\
\text { (iPad/Ordenador) }\end{array}$ & 143 & $-0,718$ &, 473 &,- 059 & $17,14 \%$ \\
\hline
\end{tabular}

Fuente: Elaboración propia. 
Desde la comparación de los resultados Post-Test (Tabla 5.34), los grupos iPad/Ordenador presentan diferencias significativas en casi todas las dimensiones comparadas (Sig. < ,05), con excepción del ítem de elementos de Localización (Sig. = ,535), lo cual establece lo anteriormente planteado en las diferencias Pre-Test/Post-Test: los grupos presentan diferencias significativas en su aprendizaje antes y después de realizada la actividad educativa, y, además, existen diferencias significativas en los resultados, según el tratamiento utilizado. Como se ha dicho anteriormente, los valores del ítem Localización no presenta diferencia entre los grupos, resultado que podría estar condicionado al número de preguntas que componen dicho ítem. Desde los valores de tamaño de los efectos se puede establecer que la magnitud de la diferencia de los puntajes entre grupos aumenta en el contexto del Post-Test $(r \approx>, 100)$. De la misma manera los valores de la Potencia de la prueba aumenta en casi todos los ítems (>90,00\%) a excepción del ítem de Localización (17,32\%), condicionados por el aumento en el tamaño del efecto y la variabilidad de los datos.

Tabla 5.34 Prueba U de Mann-Whitney, contenidos y procesos en Post-Test, Chile

\begin{tabular}{|c|c|c|c|c|c|}
\hline Grupo & $\mathbf{n}$ & $\mathbf{Z}$ & Sig. & $\mathbf{r}$ & $\begin{array}{l}\text { Potencia } \\
\text { de la } \\
\text { prueba }\end{array}$ \\
\hline $\begin{array}{l}\text { Post-Test } \\
\text { (iPad/Ordenador) }\end{array}$ & 143 & $-3,471$ & ,001 &,- 295 & $95,89 \%$ \\
\hline $\begin{array}{l}\text { Contenido Histórico } \\
\text { (iPad/Ordenador) }\end{array}$ & 143 & $-3,813$ & $<, 001$ &,- 286 & $97,27 \%$ \\
\hline $\begin{array}{l}\text { Contenido } \\
\text { Arquitectónicos }\end{array}$ & 143 & $-4,145$ & $<, 001$ &,- 345 & $96,46 \%$ \\
\hline $\begin{array}{l}\text { Conténidó de } \\
\text { Localización } \\
\text { (iPad/Ordenador) }\end{array}$ & 143 & $-0,62$ & ,535 &,- 059 & $99,54 \%$ \\
\hline $\begin{array}{l}\text { Proceso de Conocimiento } \\
\text { (iPad/Ordenador) }\end{array}$ & 143 & $-3,503$ & $<, 001$ &,- 287 & $17,32 \%$ \\
\hline $\begin{array}{l}\text { Proceso de Comprensión } \\
\text { (iPad/Ordenador) }\end{array}$ & 143 & $-3,171$ & ,002 &,- 255 & $96,53 \%$ \\
\hline $\begin{array}{l}\text { Proceso de Aplicación } \\
\text { (iPad/Ordenador) }\end{array}$ & 143 & $-3,245$ &, 001 &,- 280 & $92,19 \%$ \\
\hline
\end{tabular}

Fuente: Elaboración propia. 


\subsubsection{Resultados de los contrastes de hipótesis para España}

Comenzando con la visualización gráfica de los resultados (Gráfico 5.51), los datos muestran que existen diferencias entre las etapas Pre-Test y Post-Test tanto en el los grupo iPad como Ordenador. Dichas diferencias se repiten cuando se analiza específicamente los valores desde los contenidos y procesos definidos, por lo que se puede establecer que los tratamientos aplicados tienen un efecto sobre los alumnos que han participado en la experiencia educativa.

Gráfico 5.51 Diferencias Pre-Test/Post-Test según tratamiento. Caso de España

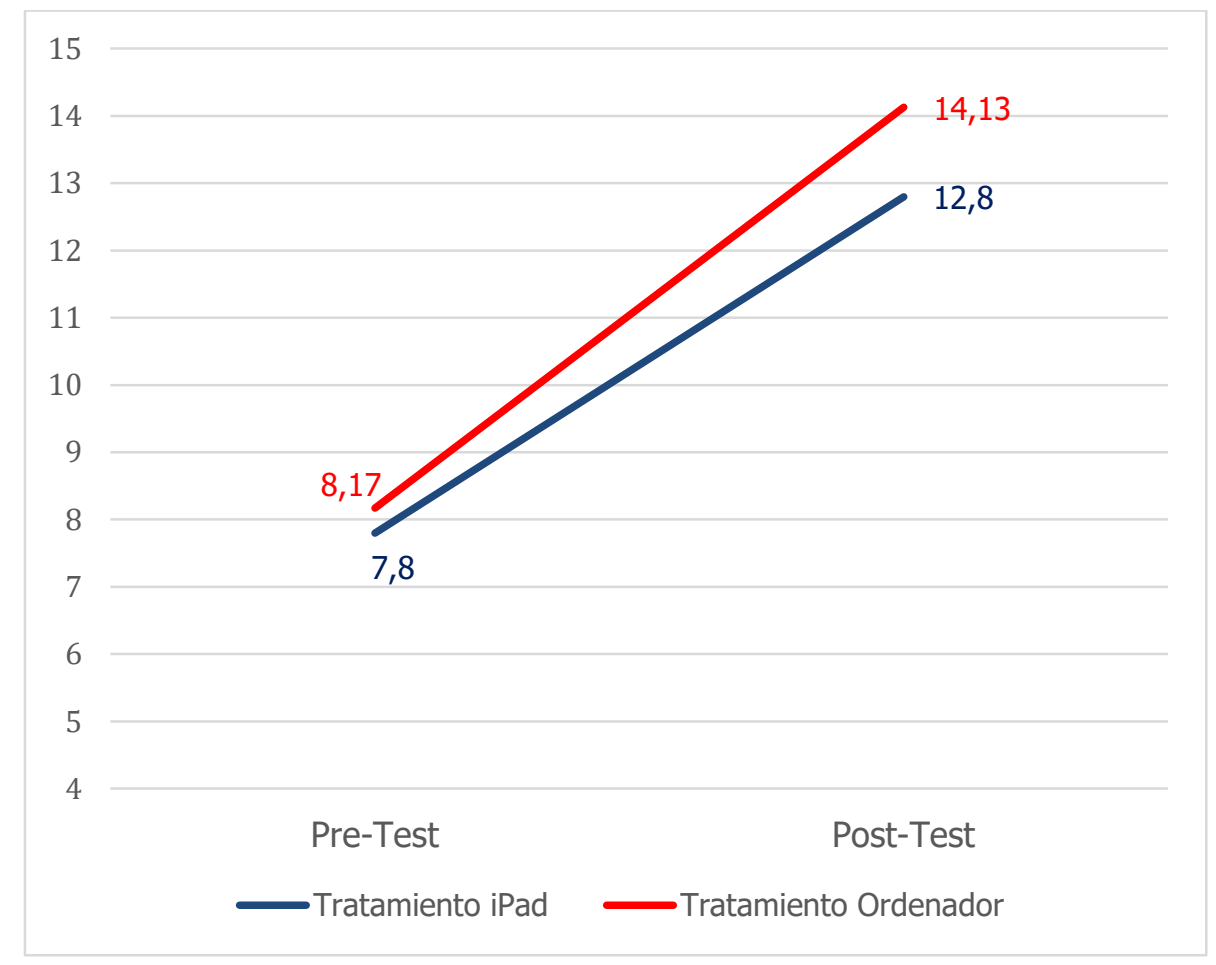

Fuente: Elaboración propia.

Dentro de este mismo análisis según el tratamiento aplicado (Gráfico 5.52), los sujetos que utilizaron el ordenador tienen mejores resultados en los contenidos Históricos, Arquitectónicos y en los procesos de Conocimiento. Sin embargo, es posible notar una situación particular en el contenido de Localización y Aplicación, en donde los alumnos que utilizan ordenador comienzan con mejores puntuaciones, las cuales tienen un leve incremento luego del tratamiento, pero que son superadas por las puntaciones de los alumnos que utilizaron iPad. 
Gráfico 5.52 Diferencias Pre-Test/Post-Test según contenido y proceso. Caso de España

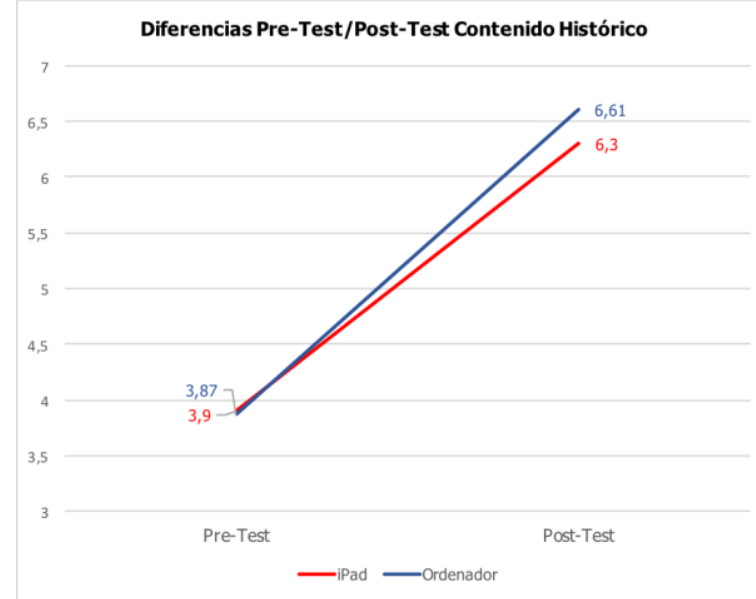

Diferencias Pre-Test/Post-Test Contenido Arquitectónico

Diferencias Pre-Test/Post-Test Contenido de Localización
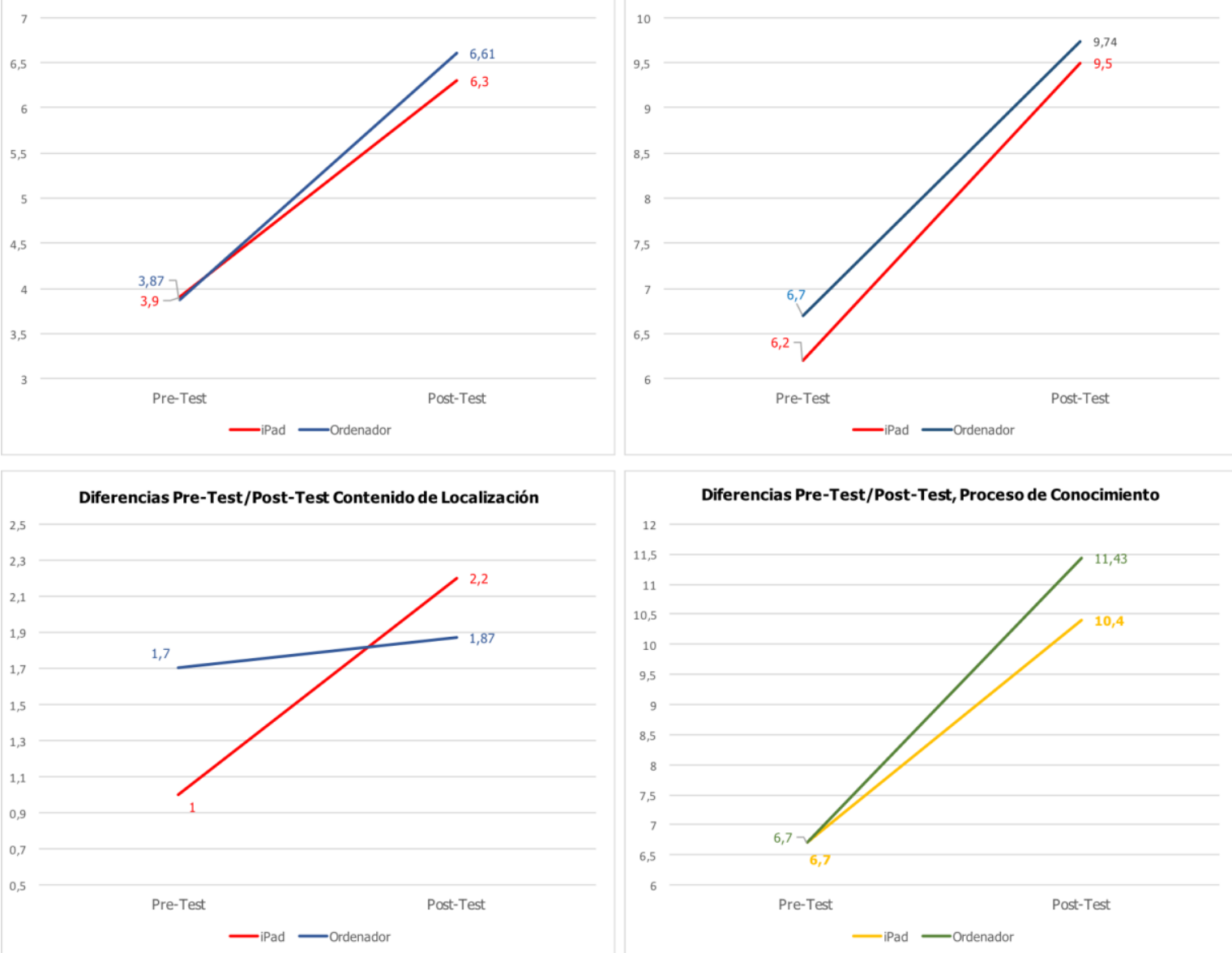

Diferencias Pre-Test/Post-Test, Proceso de Comprensión

Diferencias Pre-Test/Post-Test, Proceso de Conocimiento

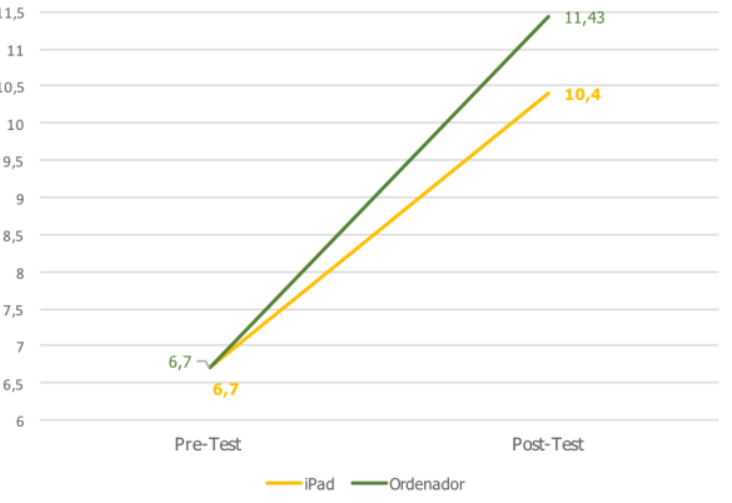

Diferencias Pre-Test/Post-Test, Proceso de Aplicación
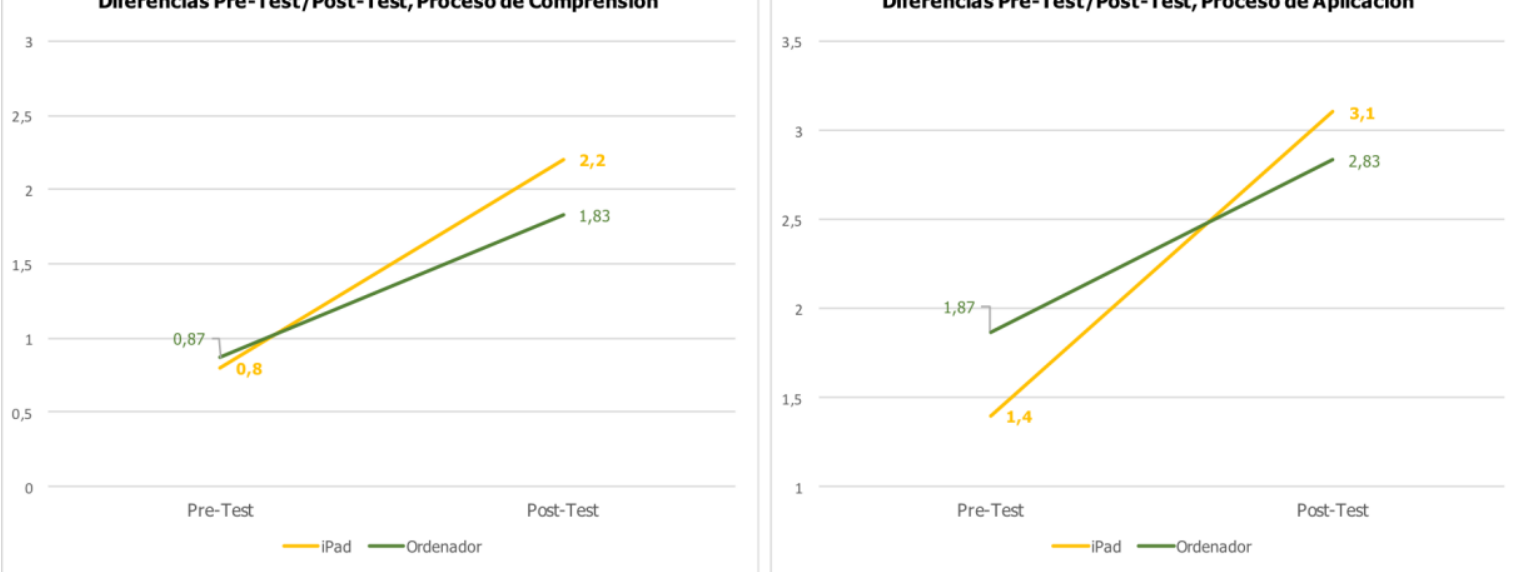

Fuente: Elaboración propia. 
Para confirmar los resultados gráficos, se realizó una serie de contrastes de hipótesis de los rangos con signo de Wilcoxon (Tabla 5.35). Así, el nivel crítico (Sig.) asociado a la mayoría de los ítems contrastados, es menor a ,05, rechazando la hipótesis nula en la igualdad de los valores de medianas. Con esto se establece que los niveles de rendimiento son diferentes en la mayoría de los casos en función del tratamiento aplicado (iPad/Ordenador).

Tabla 5.35 Rangos con signo de Wilcoxon. Diferencia de medianas Pre-Test/Post-Test para España

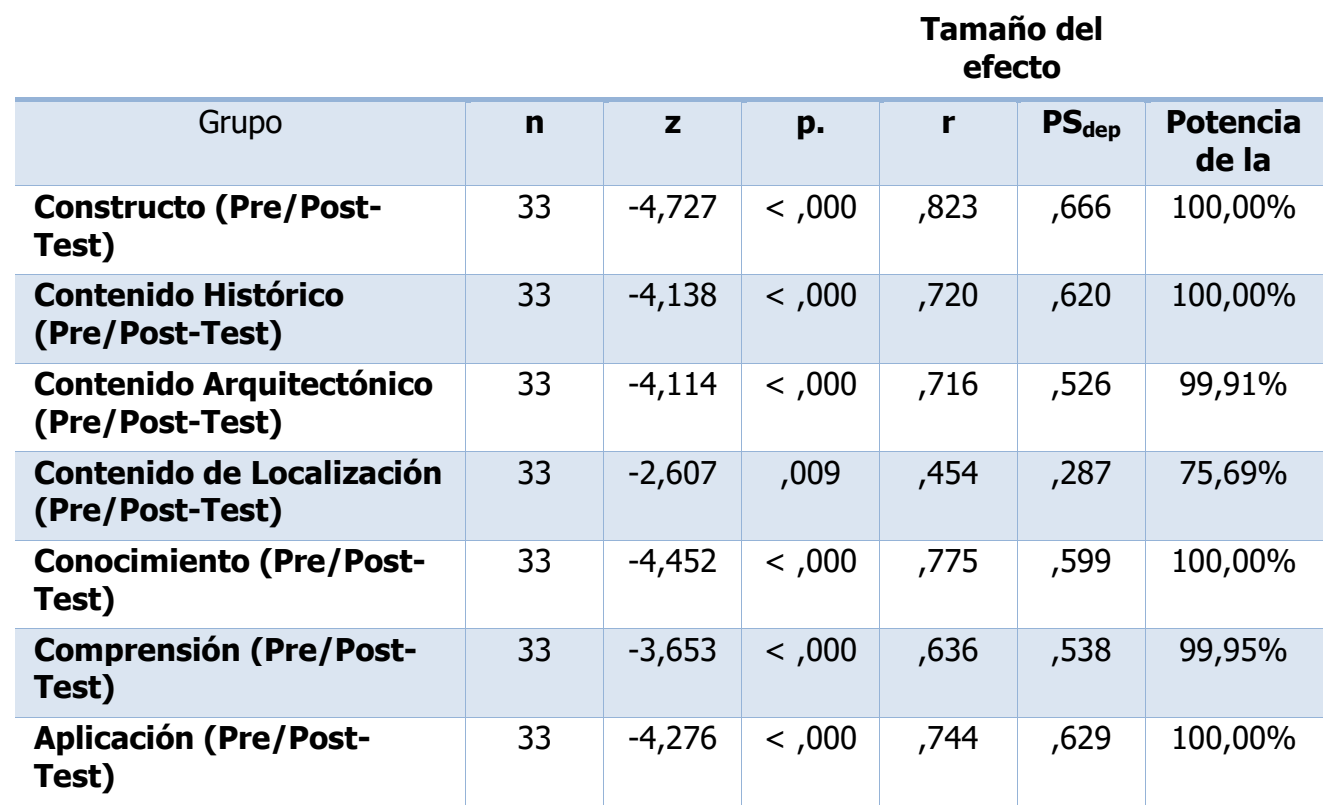

Fuente: Elaboración propia.

En cuanto a los tamaños del efecto y a partir de los valores PS $_{\text {dep }}$ y $r$, los resultados obtenidos establecen en que el tamaño del efecto se encuentra en niveles medios $\left(\mathrm{PS}_{\mathrm{dep}} \approx>, 630 ; \mathrm{r} \approx>, 300\right)$. Esto implica que el tratamiento aplicado ha sido lo suficientemente efectivo para establecer grados de diferencias entre los grupos comparados. En lo referente a la potencia de cada prueba, la mayoría de los ítems presentan valores aceptables (>95\%). Sin embargo, existen valores en que los ítems se 
encuentran alrededor del 75\% (Localización) lo que implica la posibilidad de encontrar un error del tipo II en la interpretación de estos resultados ${ }^{108}$.

Cuando se hace se realiza el análisis estadístico en función del tratamiento aplicado (iPad u Ordenador) en casi todos los grupos Pre/Post-Test el nivel crítico de significancia es menor a ,050 (Tabla 5.36), indicando que hay diferencias significativas entre la primera medición y la segunda, las que son debidas a la aplicación del tratamiento respectivo. Sin embargo, para el grupo Localización (tratamiento Ordenador) el valor de contraste obtenido no es significativo, indicando que no hay un efecto real en la aplicación del tratamiento asignado (experiencia educativa en el ordenador) en los sujetos participantes (Sig. = ,334). Queda entonces el establecimiento de las diferencias intrasujetos para los grupos iPad y Ordenador para el caso de España.

${ }^{108}$ Es importante mencionar que la eficiencia/potencia de la prueba en los contrastes no paramétricos es aproximadamente, en muestras pequeñas, del $95 \%$ de la potencia lograda en la aplicación del contraste paramétrico para las mismas variables y tamaños de muestra (Mood, 1954; Siegel \& Castellan, 2009). 
Tabla 5.36 Rangos con signo de Wilcoxon. Diferencia de medianas Pre-Test/Post-Test según tratamiento para España

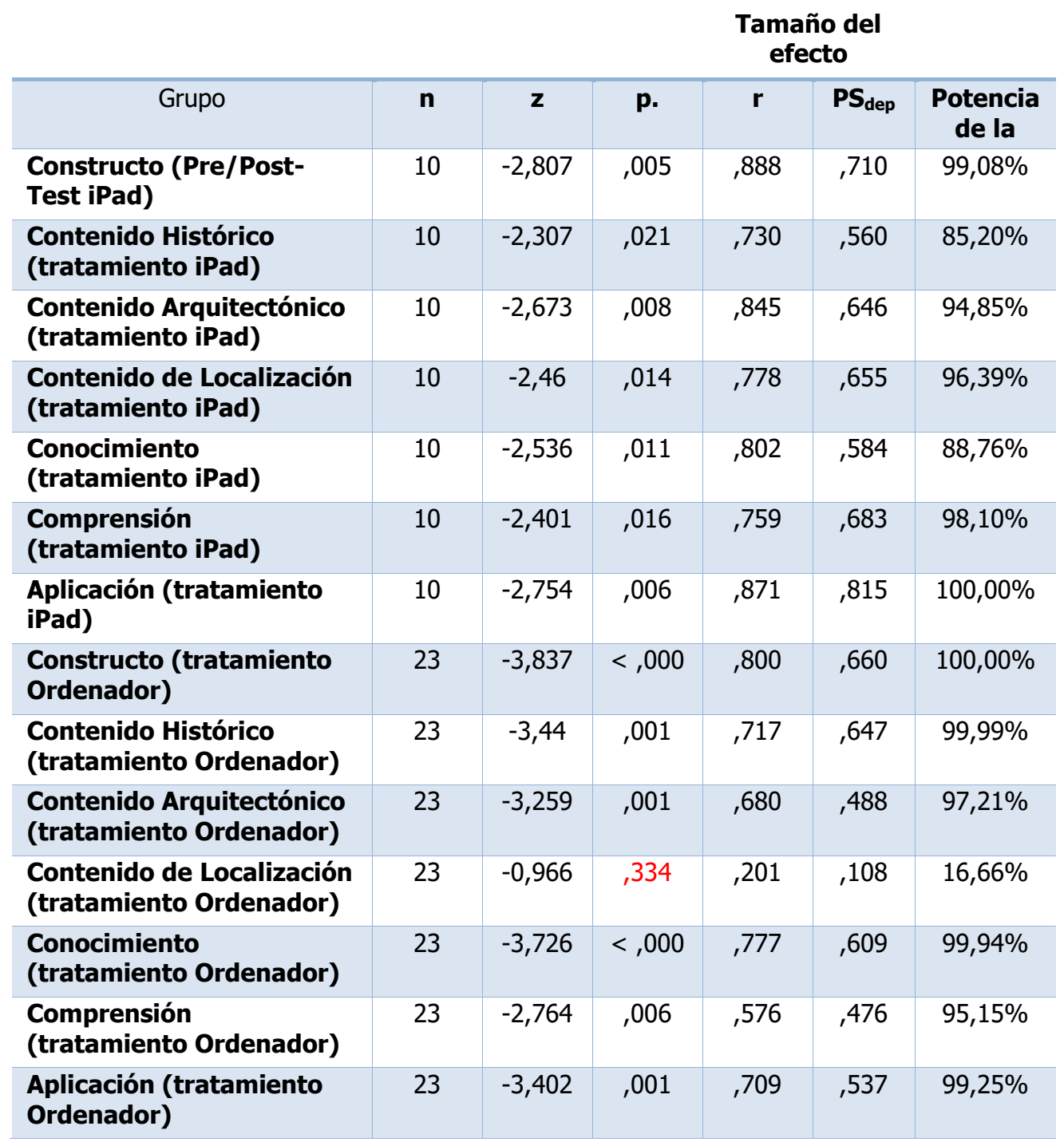

Fuente: Elaboración propia.

En cuanto a los tamaños del efecto para el caso de España y a partir de los valores $\mathrm{PS}_{\text {dep }}$ y $\mathrm{r}$, los resultados obtenidos establecen el tamaño de efecto en niveles medios con valores $\mathrm{PS}_{\mathrm{dep}} \approx>$,630 y de $\mathrm{r} \approx>$,300. La excepción se encuentra nuevamente en el grupo de contraste de Localización (tratamiento de ordenador), en donde el valor del tamaño del efecto es bajo ( $P S_{\text {dep }} \approx>, 200 ; r \approx>, 100$ ), indicando que existe un menor nivel de mejora intrasujetos. 
En lo referente a la potencia de cada prueba, nuevamente, la mayoría de los ítems presentan valores aceptables ( $>80 \%$ ). Sin embargo, existen valores en que los ítems se encuentran alrededor del $17 \%$ (Localización) lo que implica la posibilidad de encontrar un error del tipo II en la interpretación de estos resultados.

También se realizó el análisis en los grupos iPad/Ordenador antes de la aplicación del tratamiento (Tabla 5.37). Los resultados establecen que ambos grupos no presentan diferencias significativas antes del desarrollo de la actividad educativa (Sig. > ,05), aceptándose la hipótesis nula sobre la igualdad de los valores de medianas, con excepción de los elemento de Localización, en donde los grupos presentan diferencias en los puntajes obtenidos. Desde los valores de tamaño de los efectos se puede establecer que la magnitud de la diferencia de los puntajes entre grupos son mayoritariamente pequeños ( $r$ $\approx>0,1)$, a excepción nuevamente de Localización. En el contexto general de los resultados se confirma que ambos grupos comienzan con el mismo nivel, datos explicados por la estructura metodológica: se comparan los alumnos presentes en el mismo grado y establecimientos educacionales. En cuanto a los valores de la potencia de los test aplicados, estos son mayoritariamente bajos (> 30\%), aunque nuevamente Localización y Aplicación presentan valores relativamente altos (73,27\% y $57,29 \%)$ y se encuentran condicionados a los datos obtenidos en el tamaño del efecto, en donde los resultados del Pre-Test son homogéneos entre los grupos, y el número de sujetos que se compara en cada grupo $\left(n_{\text {ipad }}=10\right.$ y nordenador $\left.=23\right)$.

Tabla 5.37 Prueba U de Mann-Whitney en contenidos y procesos en Pre-Test, España

\begin{tabular}{|c|c|c|c|c|c|}
\hline Grupo & $\mathbf{n}$ & $\mathbf{Z}$ & Sig. & $\mathbf{r}$ & $\begin{array}{c}\text { Potencia } \\
\text { de la } \\
\text { prueba }\end{array}$ \\
\hline $\begin{array}{l}\text { Pre-Test } \\
\text { (iPad/Ordenador) }\end{array}$ & 33 & $-0,442$ & 658 & 110 & $14,23 \%$ \\
\hline $\begin{array}{l}\text { Contenido Histórico } \\
\text { (iPad/Ordenador) }\end{array}$ & 33 & $-0,121$ & ,904 &,- 011 & $5,62 \%$ \\
\hline $\begin{array}{l}\text { Contenido Arquitectónico } \\
\text { (iPad/Ordenador) }\end{array}$ & 33 & $-0,619$ & ,536 & 150 & $20,61 \%$ \\
\hline $\begin{array}{l}\text { Contenido de Localización } \\
\text { (iPad/Ordenador) }\end{array}$ & 33 & $-2,067$ & ,039 & ,373 & $73,27 \%$ \\
\hline $\begin{array}{l}\text { Proceso de Conocimiento } \\
\text { (iPad/Ordenador) }\end{array}$ & 33 & $-0,263$ & ,792 &,- 001 & $5,00 \%$ \\
\hline $\begin{array}{l}\text { Proceso de Comprensión } \\
\text { (iPad/Ordenador) }\end{array}$ & 33 & $-0,192$ & 848 & ,046 & $8,20 \%$ \\
\hline $\begin{array}{l}\text { Proceso de Aplicación } \\
\text { (iPad/Ordenador) }\end{array}$ & 33 & $-1,662$ & ,096 & ,305 & $57,29 \%$ \\
\hline
\end{tabular}

Fuente: Elaboración propia. 
Cuando se realizan los contrastes entre el tipo de tratamiento realizado y los resultados en el Post-Test (Tabla 5.38), los valores generales obtenidos establecen la ausencia de significancia (se rechaza $\mathrm{H}_{0}$ ), lo que en síntesis establece que no hay mayores diferencias entre los sujetos que emplearon iPad en la experiencia y aquellos que utilizaron el ordenador como medio de aprendizaje. En los datos del tamaño del efecto, los valores que se presentan son bajos ( $r \approx>0,1)$, estableciendo que existen menores niveles de diferencia respecto al tratamiento utilizado.

En todos los contraste realizados entre el tipo de tratamiento (iPad/Ordenador) la potencia de la prueba aplicada se encuentran valores inferiores al 30\%. En estos casos la posibilidad de establecer un falso negativo es muy elevada, por lo que se debe tener cautela en la interpretación de estos resultados.

Tabla 5.38 Prueba U de Mann-Whitney en contenidos y procesos en Post-Test, España

\begin{tabular}{|c|c|c|c|c|c|}
\hline Grupo & $\mathbf{n}$ & $\mathbf{Z}$ & Sig. & $\mathbf{r}$ & $\begin{array}{c}\text { Potencia } \\
\text { de la } \\
\text { prueba }\end{array}$ \\
\hline $\begin{array}{l}\text { Post-Test } \\
\text { (iPad/Ordenador) }\end{array}$ & 33 & $-0,907$ & ,364 & , 145 & $20,84 \%$ \\
\hline $\begin{array}{l}\text { Contenido Histórico } \\
\text { (iPad/Ordenador) }\end{array}$ & 33 & $-0,42$ &, 674 & ,071 & $10,09 \%$ \\
\hline $\begin{array}{l}\text { Contenido Arquitectónico } \\
\text { (iPad/Ordenador) }\end{array}$ & 33 & $-0,256$ & ,798 &, 034 & $7,35 \%$ \\
\hline $\begin{array}{l}\text { Contenido de Localización } \\
\text { (iPad/Ordenador) }\end{array}$ & 33 & $-1,13$ & ,259 &,- 200 & $28,47 \%$ \\
\hline $\begin{array}{l}\text { Proceso de Conocimiento } \\
\text { (iPad/Ordenador) }\end{array}$ & 33 & $-0,806$ &, 420 & ,122 & $16,69 \%$ \\
\hline $\begin{array}{l}\text { Proceso de Comprensión } \\
\text { (iPad/Ordenador) }\end{array}$ & 33 & $-0,945$ & ,345 &,- 175 & $24,55 \%$ \\
\hline $\begin{array}{l}\text { Proceso de Aplicación } \\
\text { (iPad/Ordenador) }\end{array}$ & 33 & $-0,964$ & ,335 &,- 167 & $22,75 \%$ \\
\hline
\end{tabular}

Fuente: Elaboración propia.

Como síntesis de los resultados obtenidos para la experiencia aplicada para el caso de España, se puede establecer que los tratamientos tienen un efecto en los procesos de aprendizaje. Sin embargo, los resultados también muestran que no hay mayores diferencias en las puntuaciones finales y el uso particular entre un tipo de tratamiento $u$ otro (Ordenador o iPad). Sin embargo, estos resultados deben interpretarse con cuidado 
ya que, mientras el contraste de hipótesis intrasujetos presenta valores de de potencias aceptables, los valores intersujetos son relativamente bajos debido a la cantidad de alumnos participantes en la experiencia.

\subsubsection{Diferencias Pre-Test/Post. Análisis gráfico}

Se ha llevado a cabo un análisis grafico particular efectuando la comparación entre elementos y procesos definidos en el instrumento de evaluación, y en los momentos PreTest y Post-Test de cada medición. Este análisis se ha llevado a cabo utilizando diagramas de $3 D$ de densidad y gráficos de frecuencias, con el fin de interpretar los resultados obtenidos en los contrastes anteriormente realizados.

Gráfico 5.53 Resultados Pre-Test/Post-Test, tratamiento iPad Chile
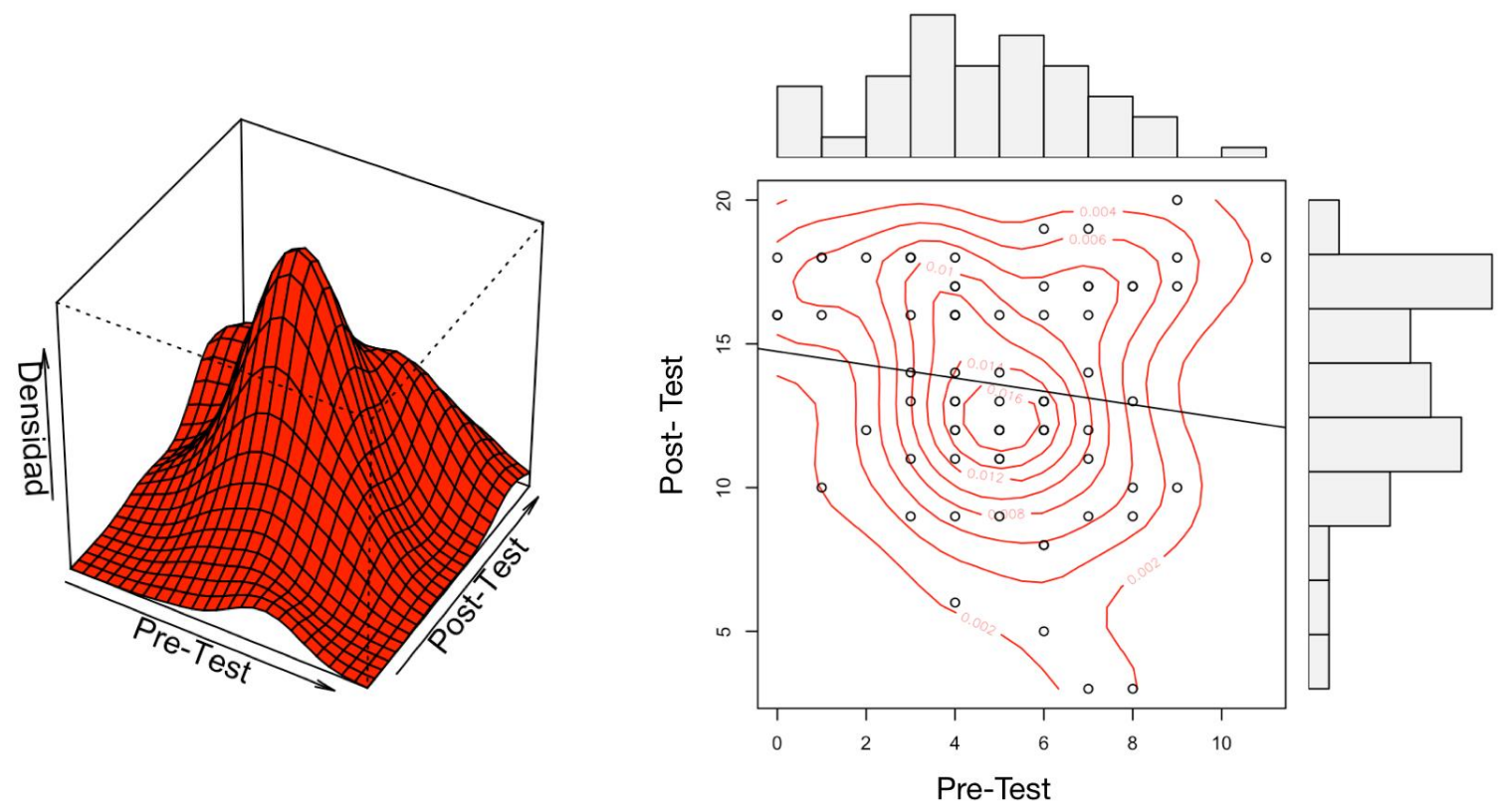

Fuente: Elaboración propia.

En el primer análisis con el Gráfico 5.53 es posible visualizar la existencia de una tendencia menor en la variabilidad de los valores Pre-Test respecto a los datos obtenidos del Post-Test, lo cual indica que los sujetos, tras la aplicación del tratamiento, aumentan sus puntuaciones y con ello el rango de valores obtenidos se amplía. Otro punto 
interesante es que los sujetos que tuvieron un menor resultado en el Pre-Test, aumentan sus valores en los resultados Post-Test, configurando la tendencia de la recta graficada.

Gráfico 5.54 Funciones de densidad conjuntas, ítems de contenidos iPad Chile
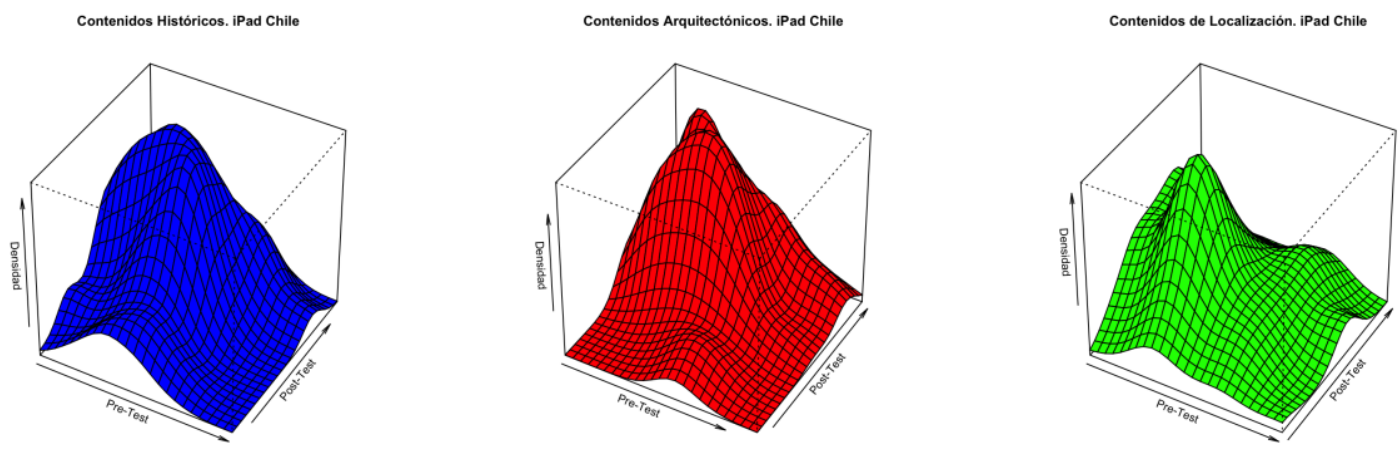

Fuente: Elaboración propia.

Gráfico 5.55 Diagramas de dispersión e histograma de variables bidimensionales, ítems de contenidos iPad Chile
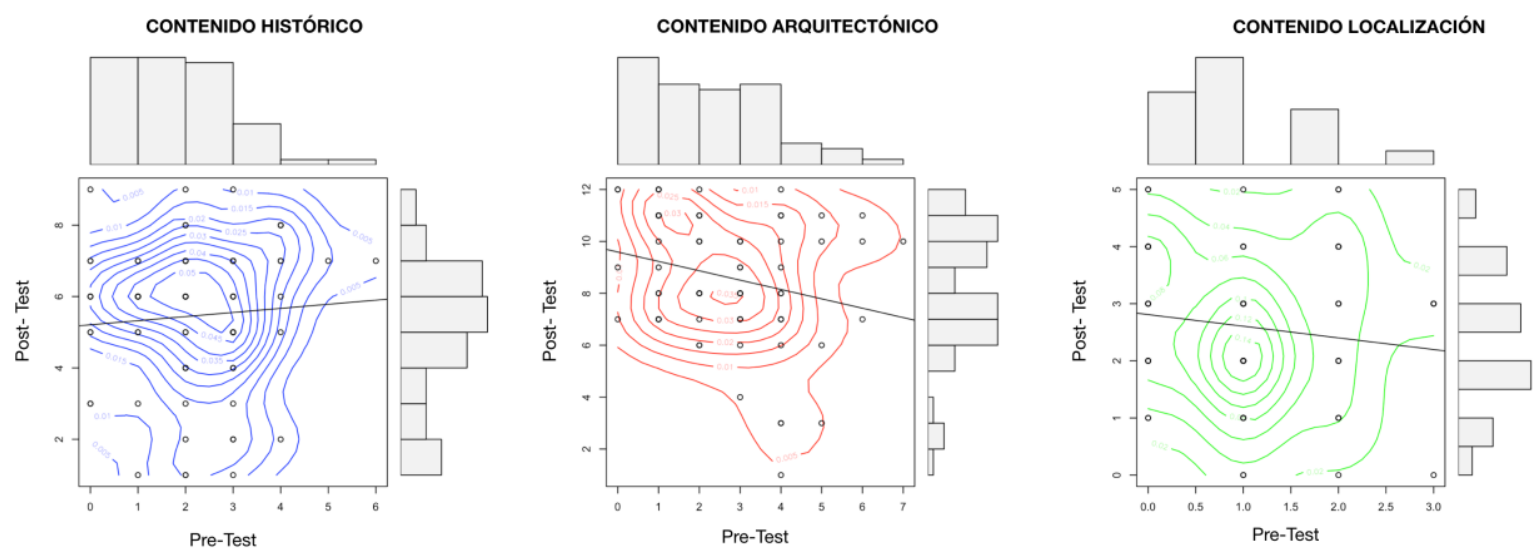

Fuente: Elaboración propia.

En lo referente al tratamiento con iPad para el caso de Chile (Gráfico 5.54 y Gráfico 5.55), al igual que en los contrastes anteriores, las curvas de nivel tienden a una menor variabilidad en los valores Pre-Test, existiendo para el caso del Post-Test, un aumento de las puntuaciones, y, de manera paralela, la variabilidad de los valores obtenidos. Para el caso de los contenidos Arquitectónico y de Localización las puntuaciones bajas en el PreTest, aumentan en los resultados Post-Test, configurando la forma de la recta interpolada. 
Sin embargo, es importante destacar que ambas dimensiones tienen un número acotado de ítems que los definen, condicionando los gráficos de frecuencia y las interpolaciones obtenidas.

Gráfico 5.56 Funciones de densidad conjuntas, ítems de procesos iPad Chile
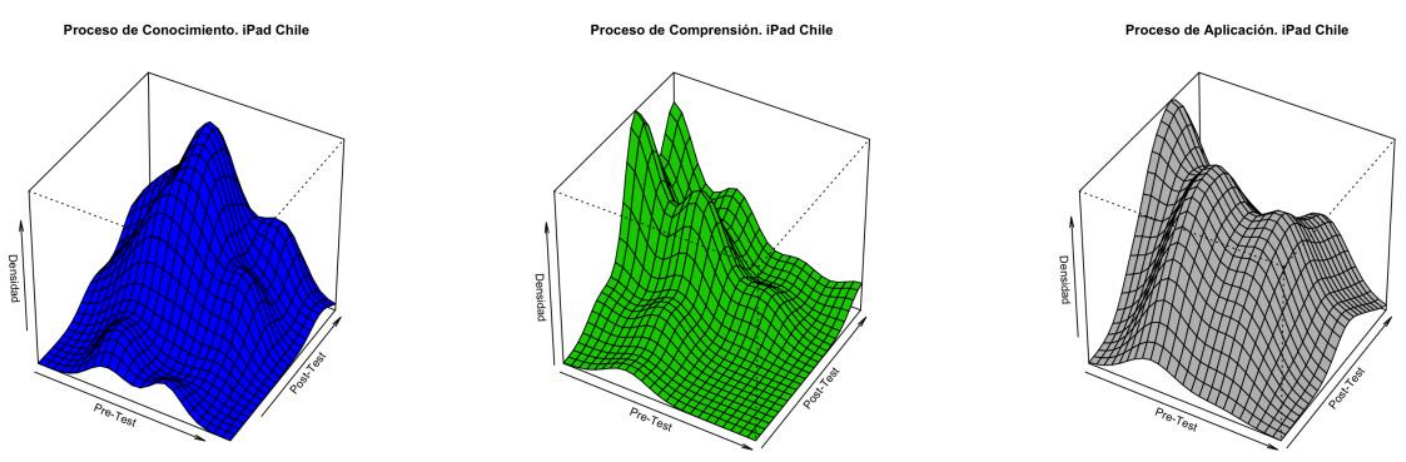

Fuente: Elaboración propia.

Gráfico 5.57 Diagramas de dispersión e histograma de variables bidimensionales, ítems de procesos iPad Chile
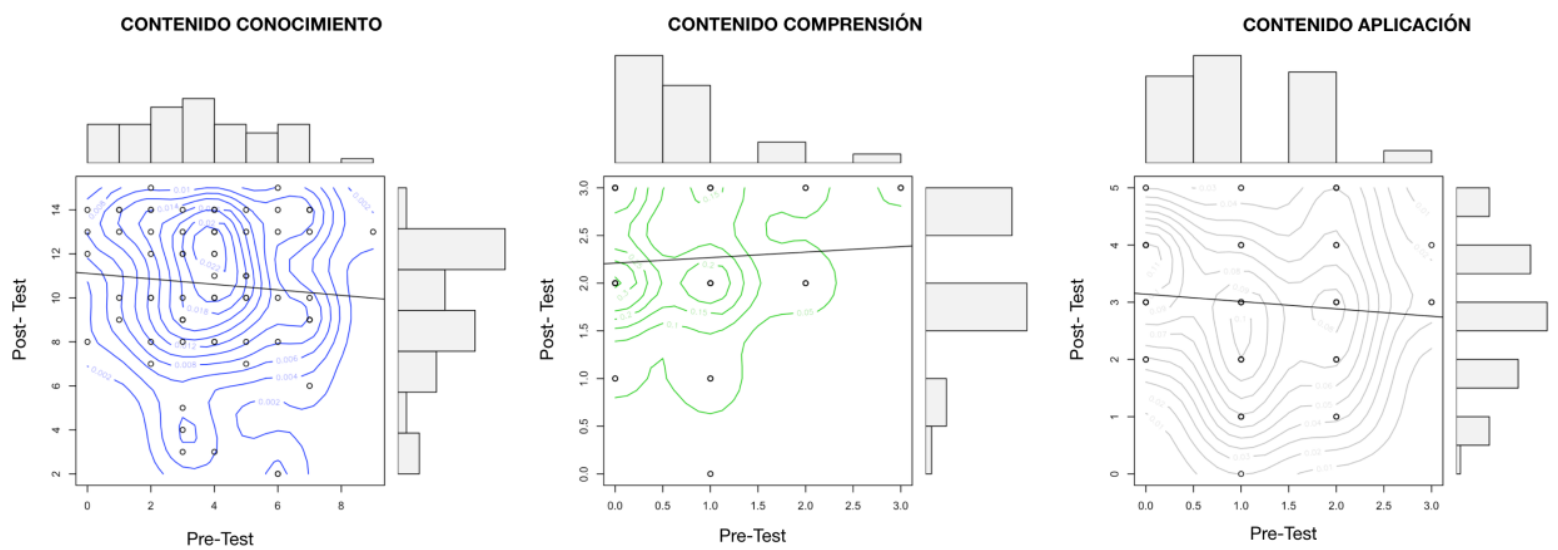

Fuente: Elaboración propia.

Desde el análisis de los procesos (Gráfico 5.56 y Gráfico 5.57), es posible observar el incremento de los valores hacia los sectores Post-Test, y de manera paralela, una mayor dispersión de los valores respecto a los registros Pre-Test de los sujetos que han utilizado iPad. La configuración de la recta y la presentación de la interpolación de las curvas de nivel, indican un aumento similar en las puntuaciones de los sujetos. Por otro lado, para 
el caso del contenido de Comprensión, el número de registro condiciona la frecuencia de valores presentes dentro del gráfico y la configuración del diagrama de densidad.

Gráfico 5.58 Resultados Pre-Test/Post-Test, tratamiento Ordenador Chile
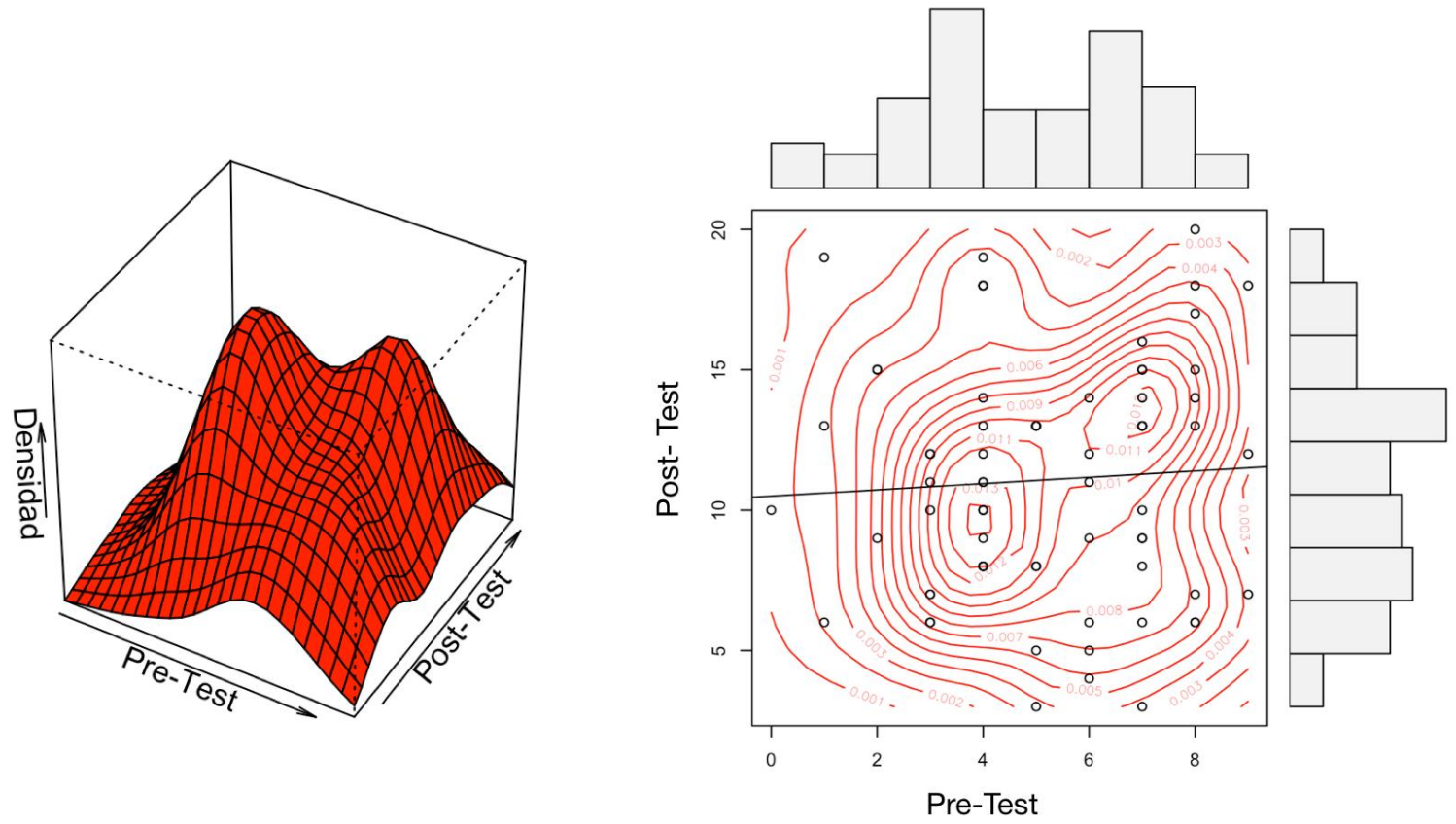

Fuente: Elaboración propia.

En el ámbito del tratamiento con Ordenador para el caso de Chile (Gráfico 5.58), la comparativa entre los valores generales Pre-Test y Pos-Test complementa los datos entregados en los valores de contraste de hipótesis realizados en la Tabla 5.33. También es posible ver que en el diagrama de densidad se observar dos valores máximos que definen la distribución de las curvas de nivel y la recta de valores esperados. 
Gráfico 5.59 Funciones de densidad conjuntas, ítems de contenidos Ordenador Chile
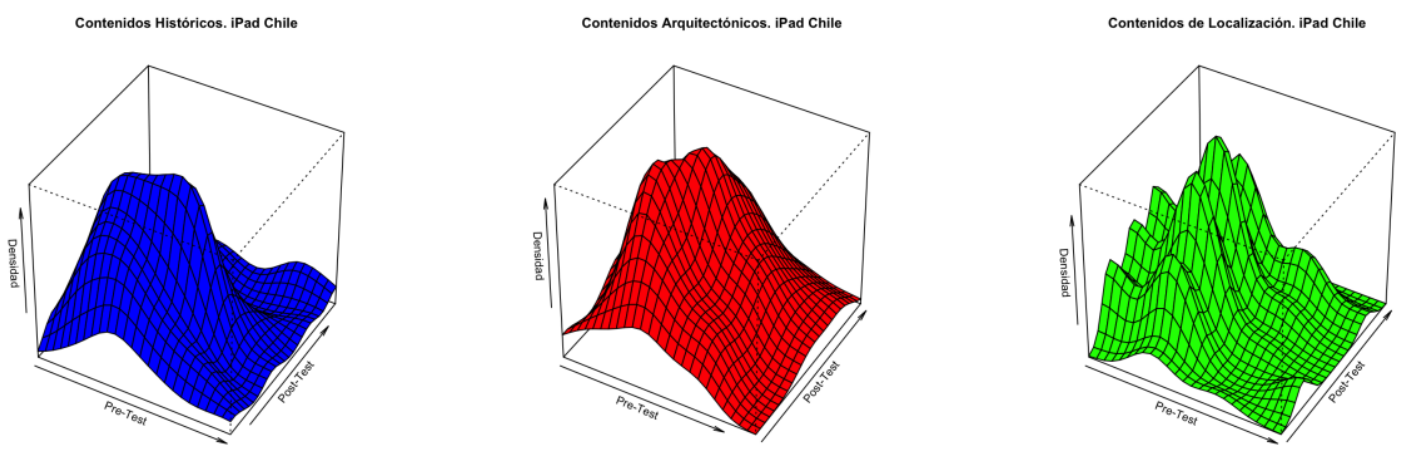

Fuente: Elaboración propia.

Gráfico 5.60 Diagramas de dispersión e histograma de variables bidimensionales, ítems de contenidos Ordenador Chile
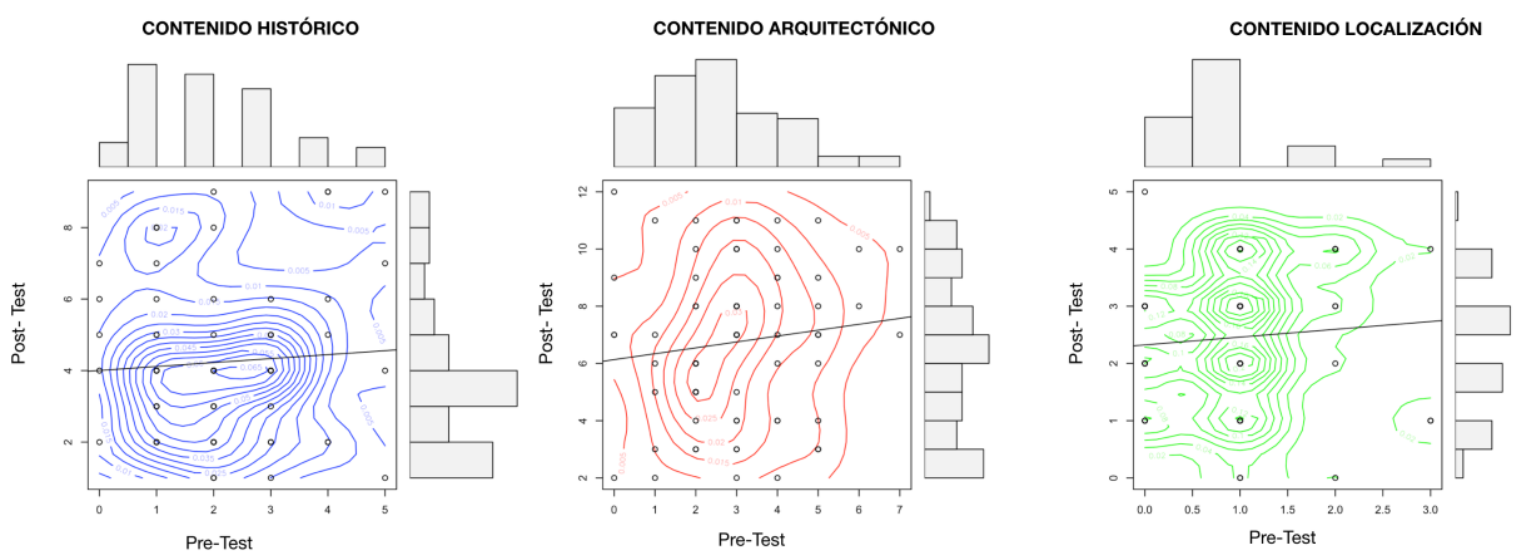

Fuente: Elaboración propia.

En el análisis particular de los contenidos con el tratamiento con Ordenador (Gráfico 5.59 y Gráfico 5.60), es posible observar que los valores de la recta tienden a ser positivos, aunque en los ítems de contenido Arquitectónico y de Localización, los valores registrados se encuentren altamente dispersos. Para este último caso, el número limitado de ítems condiciona la estructura de los valores representados tanto en el diagrama de densidad como en el de curvas de nivel, presentándose más de tres valores punta en su visualización. 
Gráfico 5.61 Funciones de densidad conjuntas, ítems de procesos Ordenador Chile
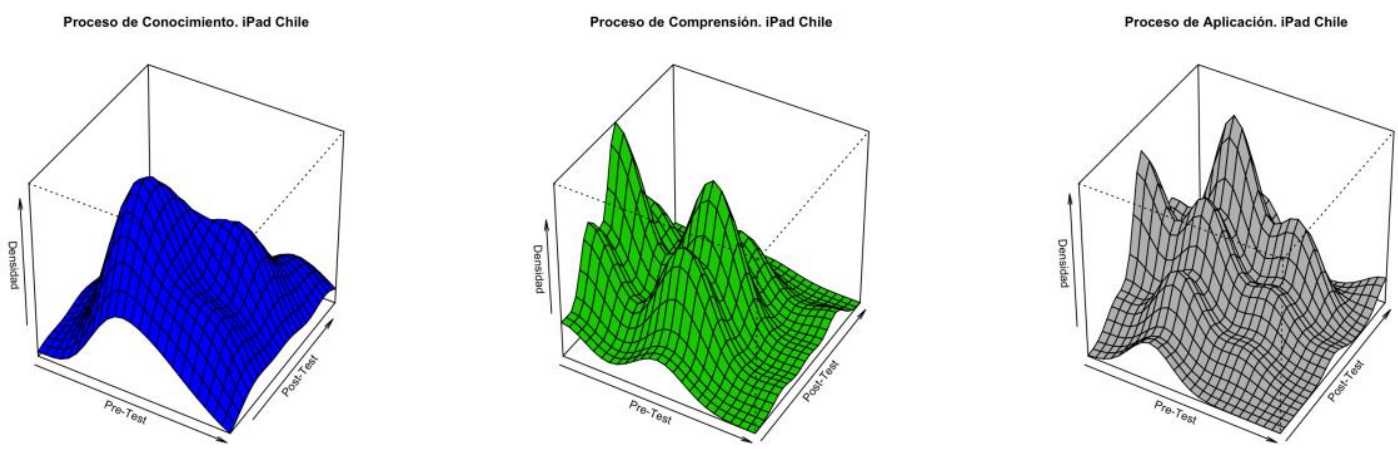

Fuente: Elaboración propia.

Gráfico 5.62 Diagramas de dispersión e histograma de variables bidimensionales, ítems de procesos Ordenador Chile
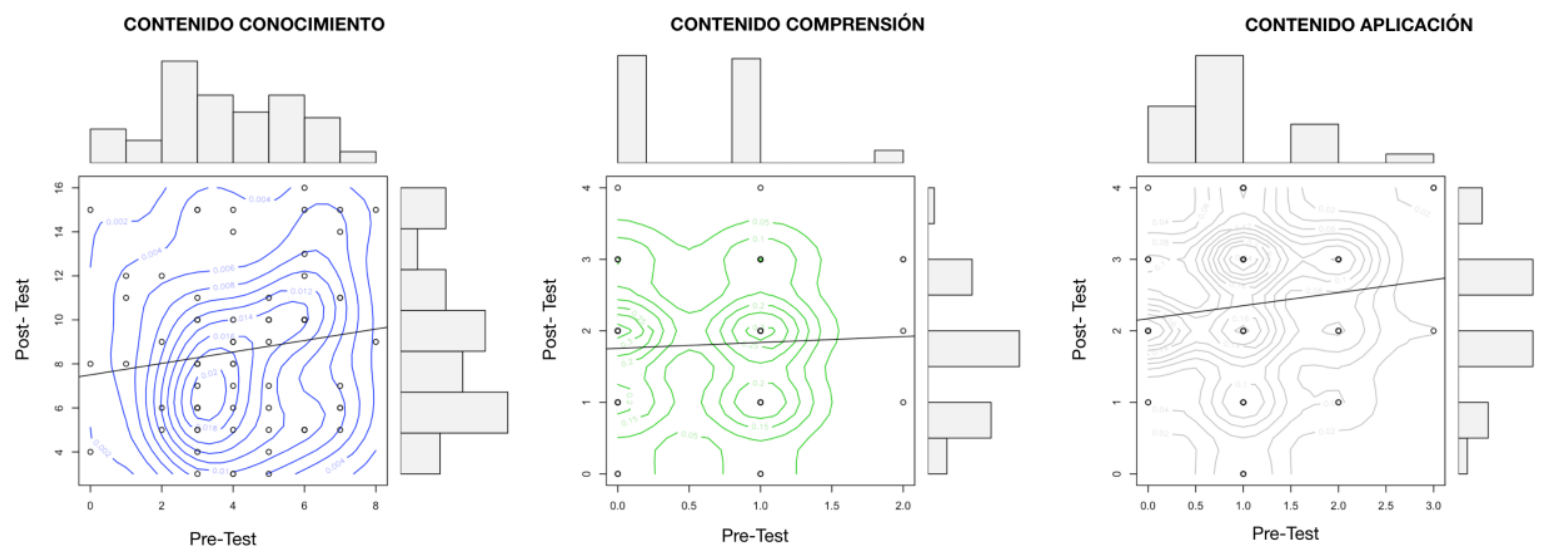

Fuente: Elaboración propia.

En el ámbito de los procesos para el tratamiento Ordenador (Gráfico 5.61 y Gráfico 5.62), los diagramas obtenidos son muy similares a los presentados en los contenidos. Particularmente, en el caso de ítem de Conocimiento, los valores presentan un aumento de los valores y es posible visualizar cómo las curvas de nivel tienden a un desplazamiento hacia los valores altos. En cuanto a las representaciones obtenidas entre los ítems de Comprensión y Aplicación, la distribución de los valores es homogénea, derivado del número limitado de preguntas componentes de dichas dimensiones.

Dentro del contexto de España, los valores generales obtenidos en el Pre-Test y Post-Test (Tabla 5.36) muestran diferencias una vez que se aplica el tratamiento definido para ambos grupos. Sin embargo, las pruebas de hipótesis y los valores obtenidos entre los tratamientos, confirman los datos obtenidos ya que no existen diferencias significativas 
entre grupos de tratamiento. De esta manera, el análisis grafico que se realiza a continuación entrega algunos detalles del comportamiento de estos resultados según elemento y proceso en situación de Pre-Test o Post-Test.

Gráfico 5.63 Resultados Pre-Test/Post-Test, tratamiento Ordenador España
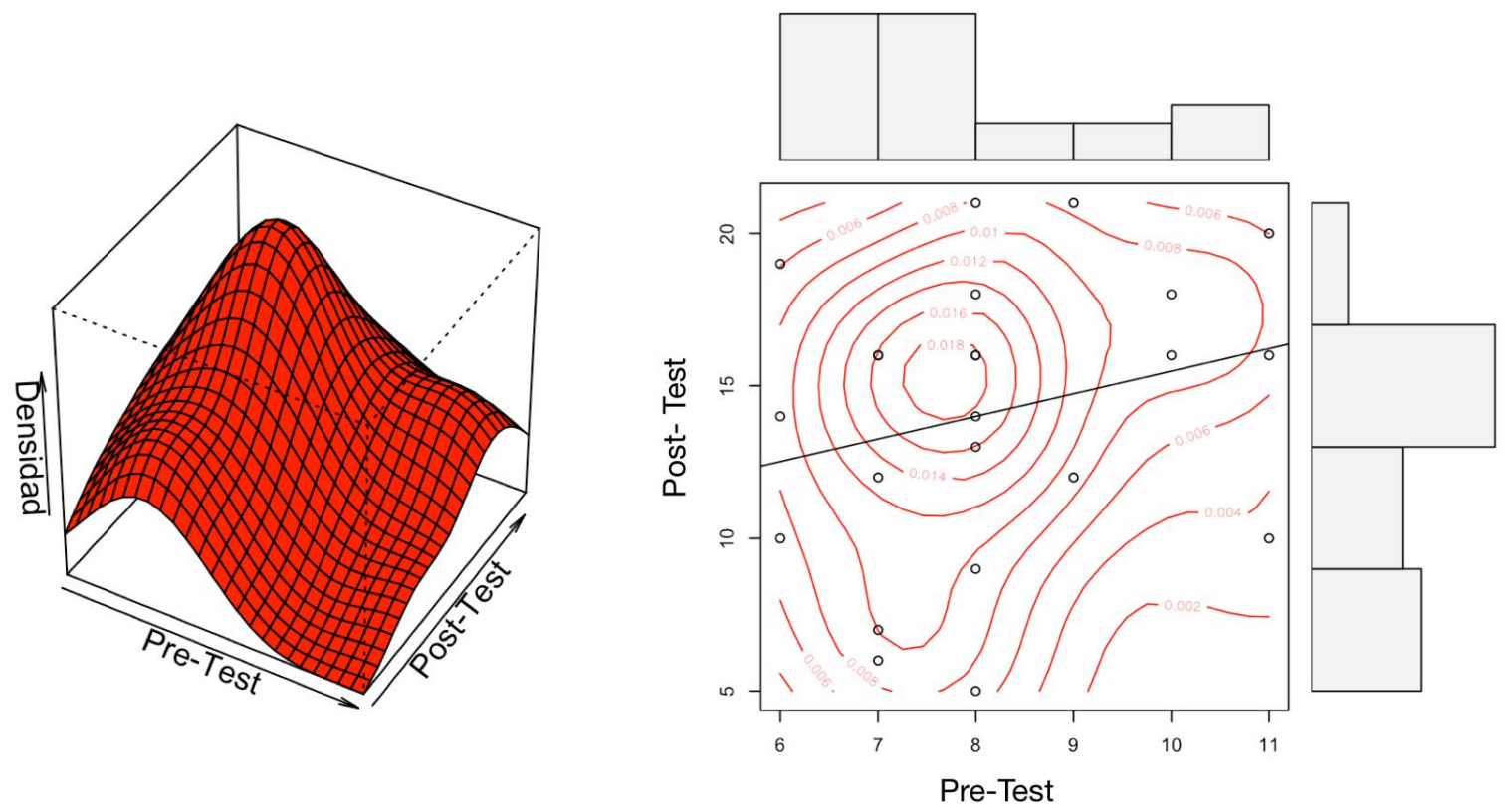

Fuente: Elaboración propia.

Para el caso de constructo para la experiencia de ordenador (Gráfico 5.63), es posible que observar que los datos presentes en el Pre-Test muestran un mayor nivel de dispersión de los valores, lo que puede visualizarse en el número de frecuencias generadas. En cuanto a los valores Post-Test, la dispersión de los valores tiende a disminuir, estableciéndose en puntuaciones altas. De esta manera, es posible notar, desde el contexto gráfico, que existe un aumento en las puntuaciones, destacando un punto caliente, en donde los sujetos que tuvieron un valor cercano a 8 en el Pre-Test, en el PostTest se transforman a valores cercanos a 15. 

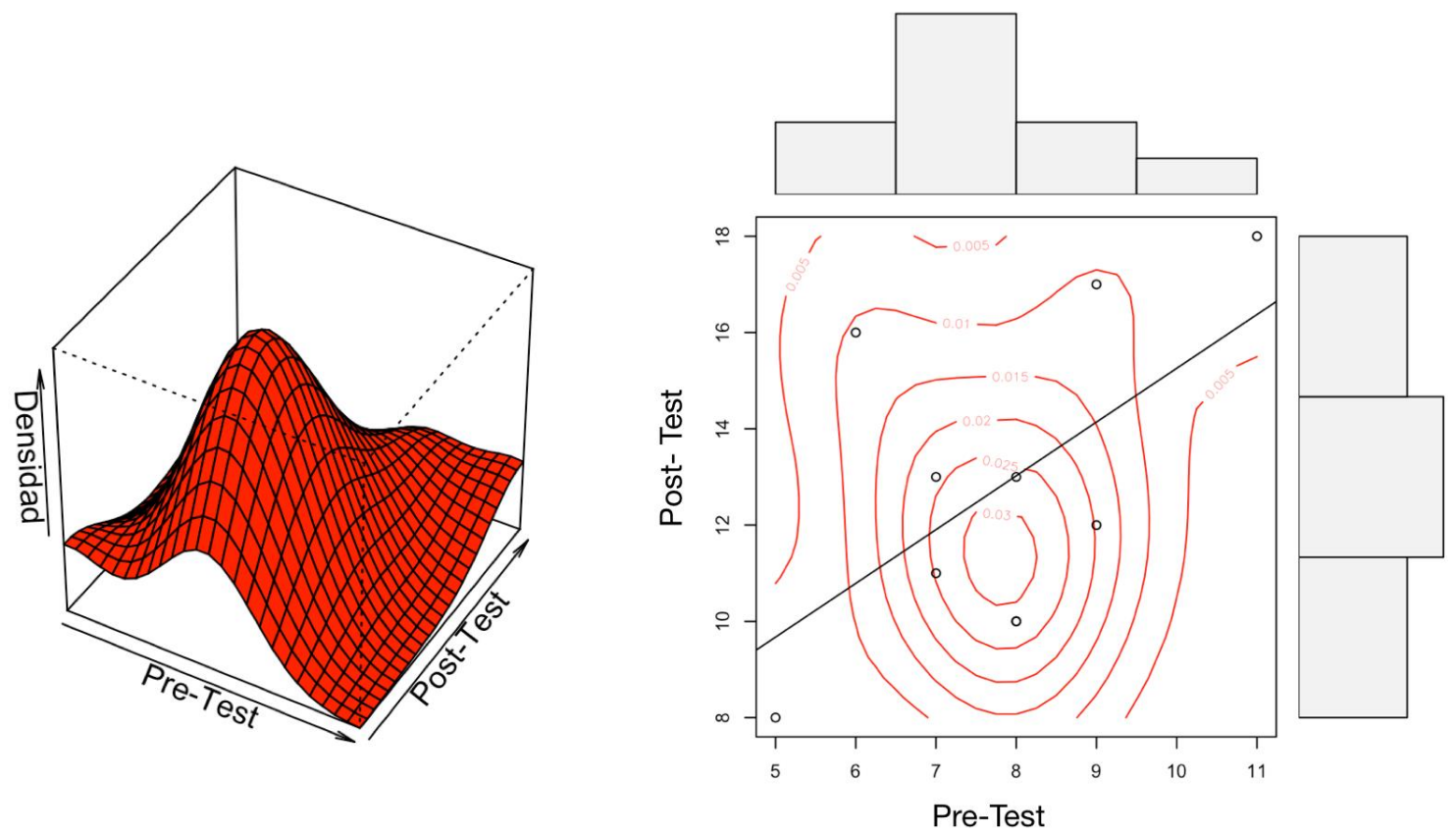

Fuente: Elaboración propia.

Cuando los datos se analizan según tratamiento, para el caso de los resultados con iPad (Gráfico 5.64), es posible apreciar que los valores Pre-test se encuentran concentrados en una zona delimitada (en torno a los valores $X=8$ e $Y=11$ ) estableciendo un sector alto en la representación gráfica. En los valores Post-Test, las curvas de nivel tienden a tener mayores puntuaciones y una mayor dispersión de los registros condicionando la forma del modelo obtenido y de la recta de comparación graficada.

Gráfico 5.65 Funciones de densidad conjuntas, ítems de contenidos iPad España
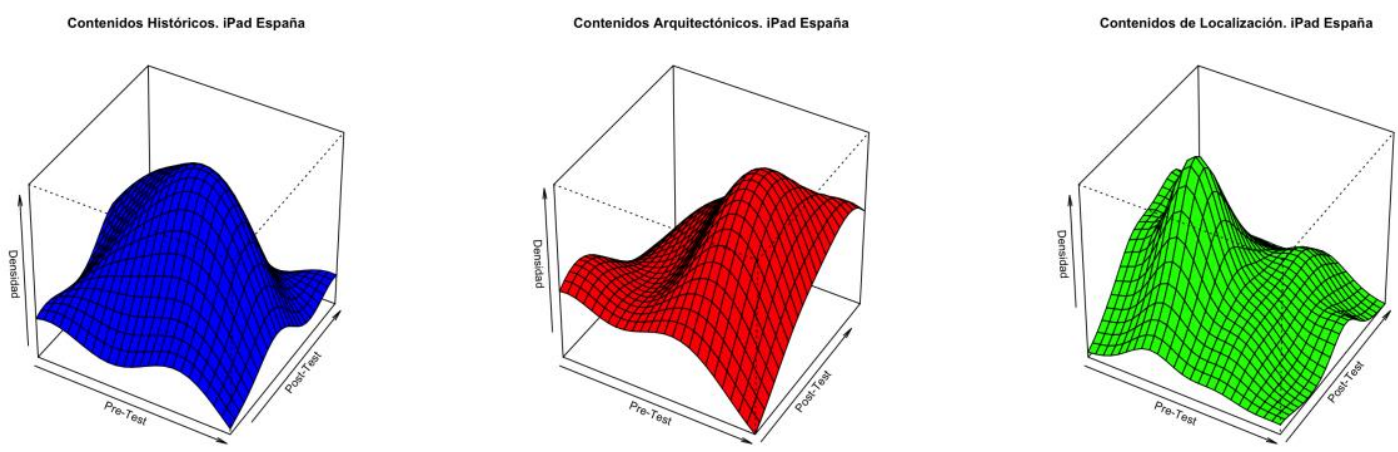
Fuente: Elaboración propia.

Gráfico 5.66 Diagramas de dispersión e histograma de variables bidimensionales, ítems de contenidos iPad España
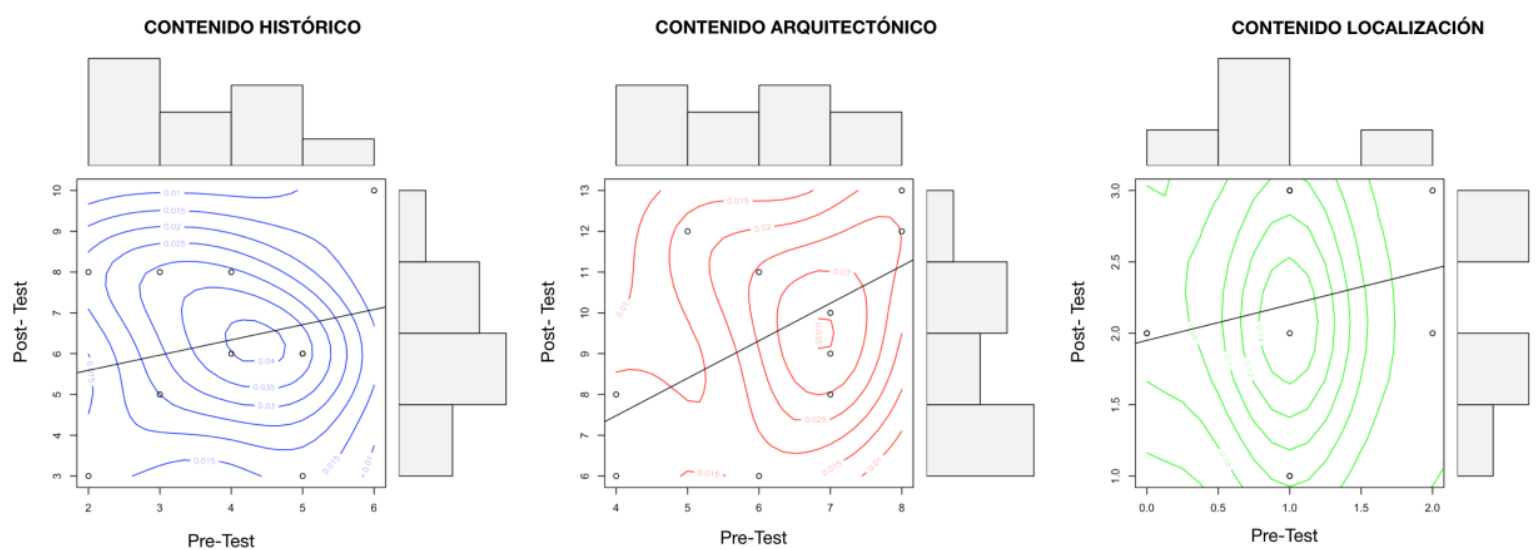

Fuente: Elaboración propia.

En el ámbito de los contenidos para el grupo con tratamiento iPad (Gráfico 5.65 y Gráfico 5.66), tanto las distribuciones en las curvas de nivel como en los diagramas 3D se presentan con una alta variabilidad, elemento explicado por la cantidad de sujetos, los valores obtenidos en el Pre-Test y en el Post-Test y la definición de cada ítem. Todos los contenidos analizados muestran un valor central en donde se agrupan la mayoría de los datos obtenidos, pero que con los registros Post-Test tienen un desplazamiento significativo.

Gráfico 5.67 Funciones de densidad conjuntas, ítems de procesos iPad España
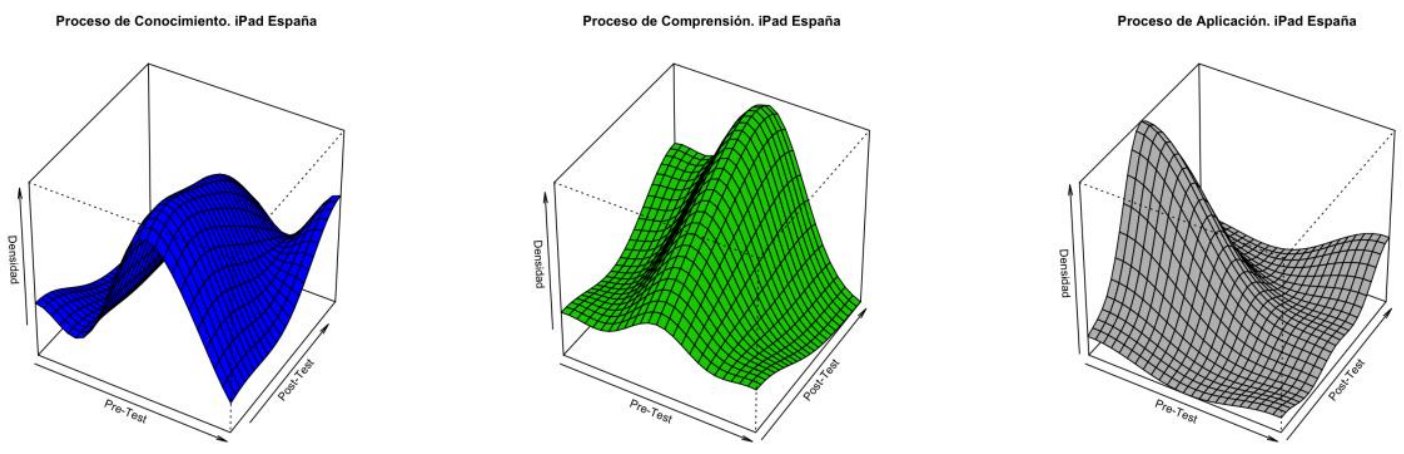

Fuente: Elaboración propia. 
Gráfico 5.68 Diagramas de dispersión e histograma de variables bidimensionales, ítems de procesos iPad España
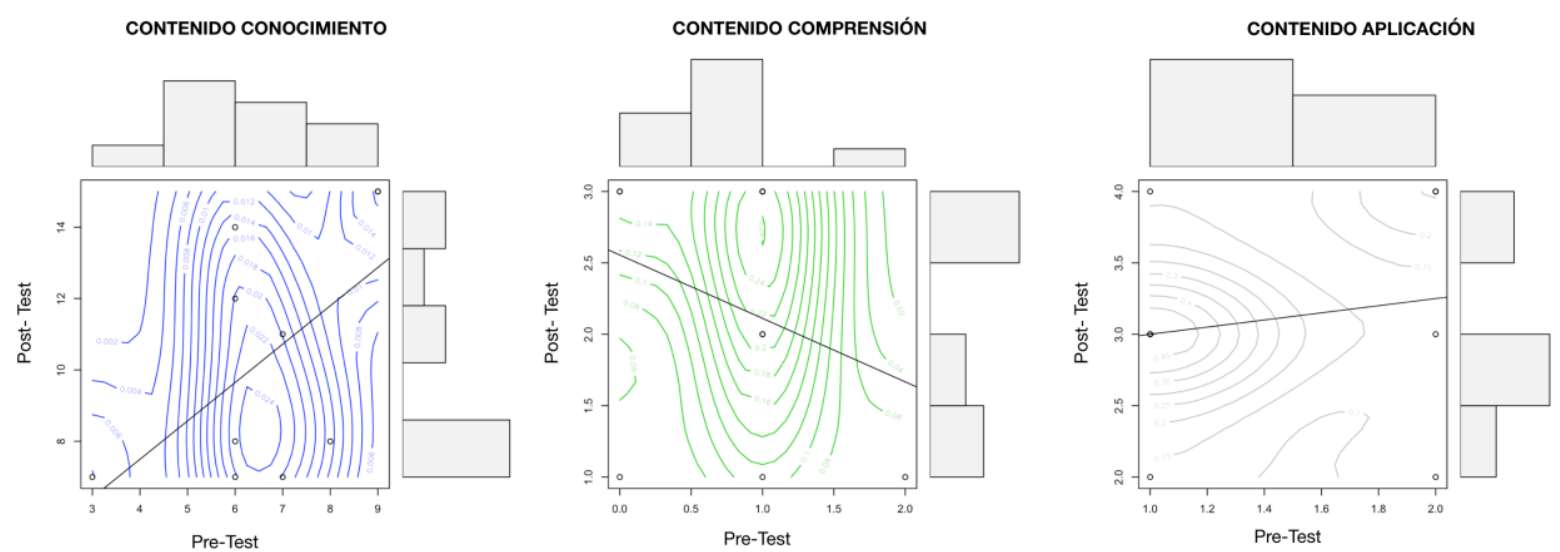

Fuente: Elaboración propia.

Para los procesos en el grupo con tratamiento iPad (Gráfico 5.67 y Gráfico 5.68), todos los contenidos analizados muestran un valor central en donde se agrupan la mayoría de los datos representados, pero que con los registros Post-Test tienen un desplazamiento significativo. Para el caso particular del ítem Comprensión los valores bajos en el Pre-Test tienen una mejora significativa en la aplicación del tratamiento, lo que lleva a la forma que adquiere la recta en el diagrama de dispersión.

Gráfico 5.69 Funciones de densidad conjuntas, ítems de contenidos iPad España
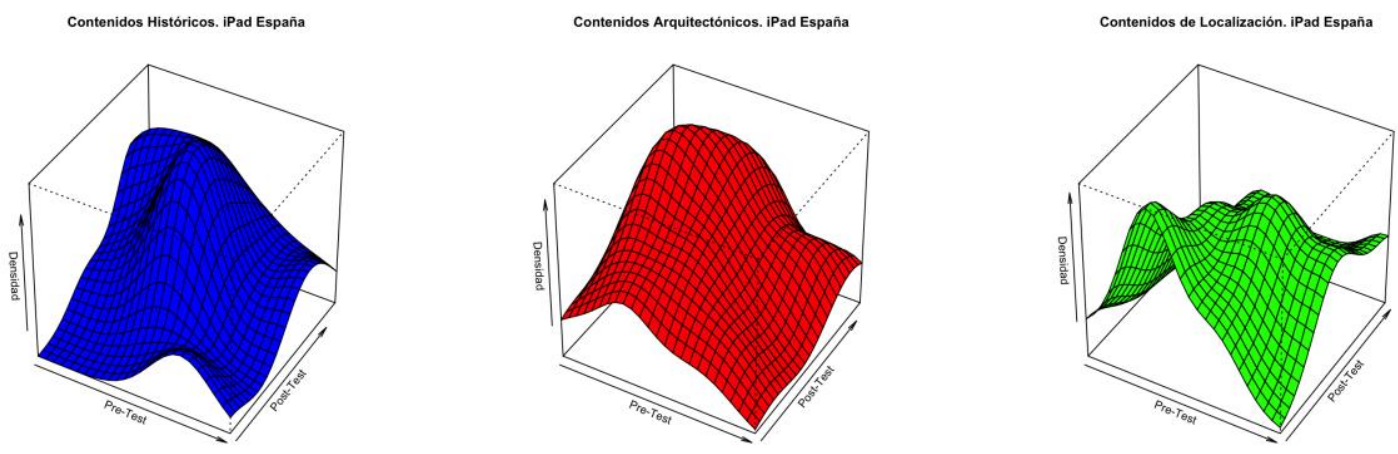

Fuente: Elaboración propia. 
Gráfico 5.70 Diagramas de dispersión e histograma de variables bidimensionales, ítems de contenidos Ordenador España
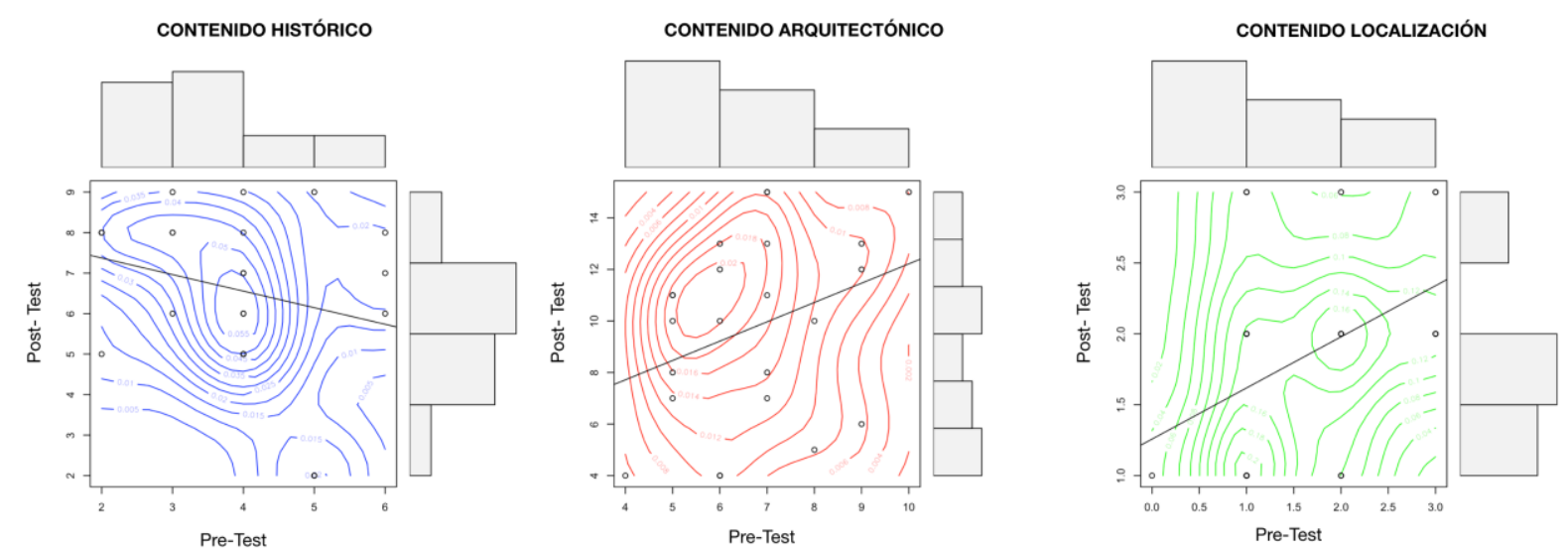

Fuente: Elaboración propia.

En el ámbito de los contenidos para el grupo con tratamiento Ordenador (Gráfico 5.69 y Gráfico 5.70), tanto las distribuciones en las curvas de nivel como en los diagramas 3D se presentan con una alta variabilidad de los datos. Todos los contenidos analizados muestran un valor central en donde se agrupan la mayoría de los datos obtenidos, pero que con los registros Post-Test tienen un desplazamiento significativo hacia valores más altos. Destaca el ítem de contenido Histórico en donde los valores bajos en el Pre-Test tienden a ser significativamente mayores una vez aplicado el tratamiento con ordenadores.

Gráfico 5.71 Funciones de densidad conjuntas, ítems de procesos Ordenador España
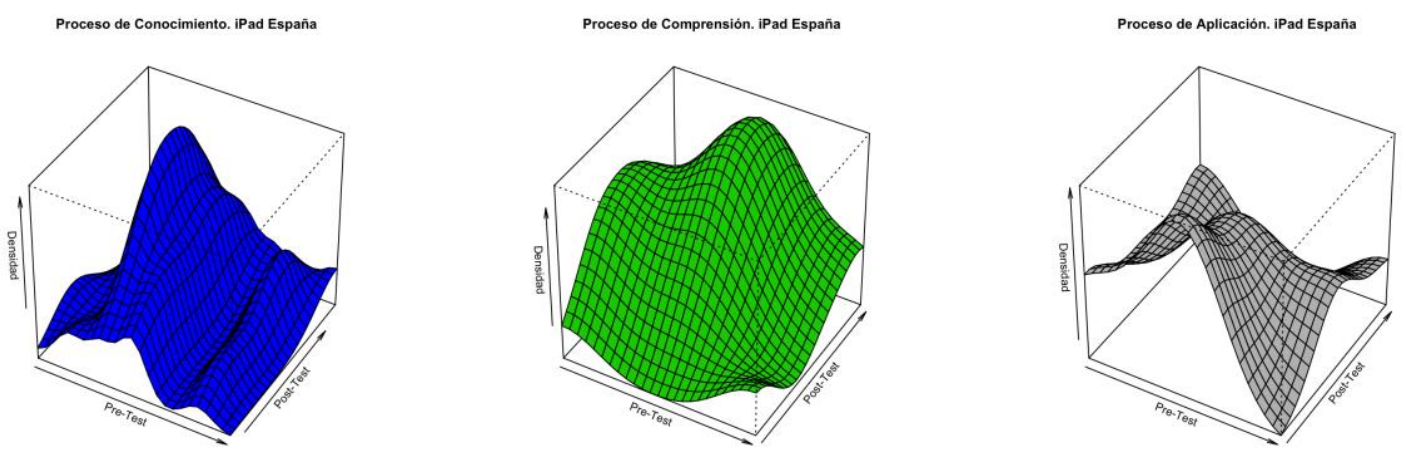

Fuente: Elaboración propia. 
Gráfico 5.72 Diagramas de dispersión e histograma de variables bidimensionales, ítems de procesos Ordenador España
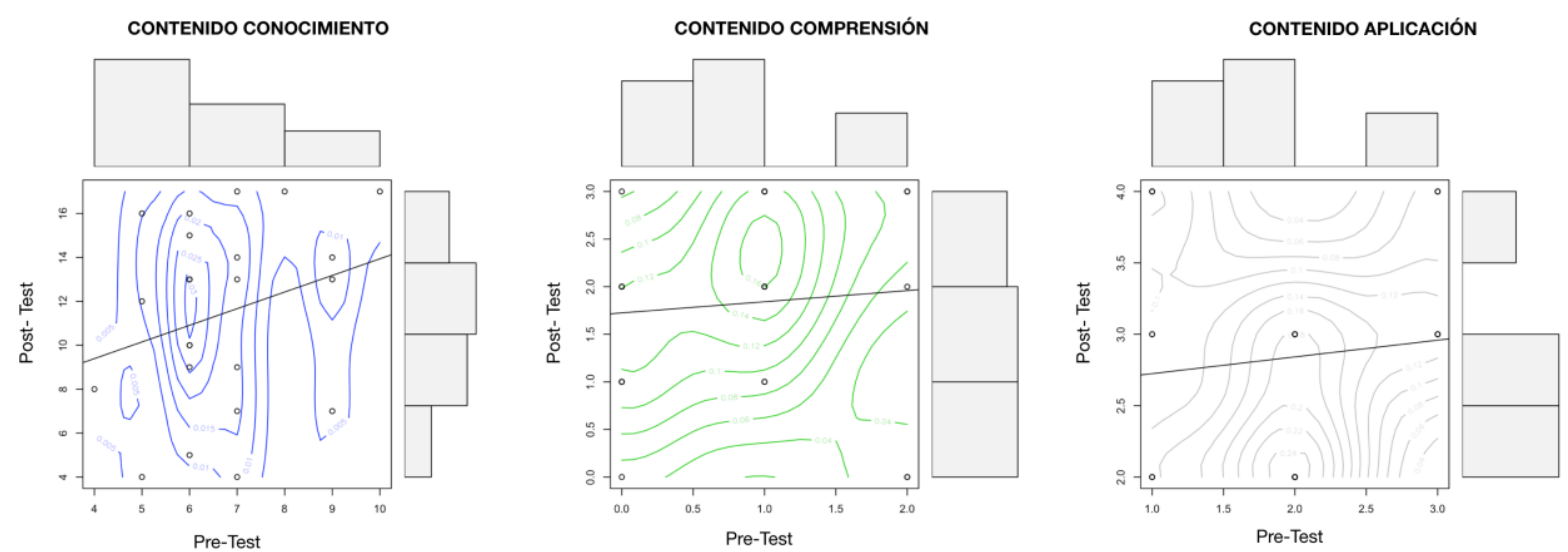

Fuente: Elaboración propia.

En el ámbito de los procesos para el tratamiento Ordenador (Gráfico 5.71 y Gráfico 5.72), los diagramas obtenidos son muy similares a los presentados en los ítems de contenidos. Particularmente, en el caso de ítem de Conocimiento, los valores presentan un aumento de los valores Post-Test, siendo posible visualizar una estructura de curvas de nivel dispuestas hacia valores centrales.

\subsubsection{Escala de satisfacción de las experiencias educativas}

Adicionalmente, a los alumnos participantes de cada experiencia, les fue aplicado un instrumento para determinar el grado de satisfacción de la actividad educativa en conjunto con los recursos propuestos y la metodología TIC implementada en la actividad. Como ya se ha señalado, la escala de satisfacción consistió en 10 ítems en una escala de tipo Likert con valores que van del 1 (muy en desacuerdo) al 5 (muy de acuerdo). La fiabilidad de este instrumento, mediante el coeficiente Alfa de Cronbach toma un valor de 0,69 lo que para la valoración de algunos autores parece ser suficiente para un análisis exploratorio estándar (Loewnthal, 1996; Nunnally, 1978), aunque un valor de validación entregado por el Alfa de Cronbach Ordinal, entrega un coeficiente igual a 0,765 indicando una buena consistencia interna de los datos (Dominguez Lara, 2012). Adicionalmente, al constituir y utilizar el mismo instrumento para ambos países, los resultados sólo se han dividido según el tipo de tratamiento de los participantes, cuyos datos pueden visualizarse en la Tabla 5.39 y Tabla 5.40: 
Tabla 5.39 Descriptivos básicos ítems de satisfacción experiencia con iPads

\begin{tabular}{|c|c|c|c|c|c|c|c|c|c|}
\hline ÍTEM & $\mathbf{n}$ & $1(\%)$ & $2(\%)$ & $3(\%)$ & $4(\%)$ & $5(\%)$ & $\overline{\mathbf{x}}$ & Sx & cV \\
\hline $\begin{array}{l}\text { Aplicación - } \\
\text { Implementación } \\
\text { [ITEM_3] }\end{array}$ & 82 & $8,54 \%$ & $2,44 \%$ & $3,66 \%$ & $32,93 \%$ & $52,44 \%$ & 4,18 & 1,19 & $28,39 \%$ \\
\hline $\begin{array}{l}\text { Aplicación - } \\
\text { Implementación } \\
\text { [ITEM_8] }\end{array}$ & 82 & $4,88 \%$ & $7,32 \%$ & $9,76 \%$ & $24,39 \%$ & $53,66 \%$ & 4,15 & 1,17 & $28,14 \%$ \\
\hline $\begin{array}{l}\text { Aplicación - } \\
\text { Contenidos } \\
\text { [ITEM_10] }\end{array}$ & 82 & $6,10 \%$ & $7,32 \%$ & $3,66 \%$ & $36,59 \%$ & $46,34 \%$ & 4,10 & 1,16 & $28,34 \%$ \\
\hline $\begin{array}{l}\text { Aplicación - } \\
\text { Implementación } \\
\text { [ITEM_9] }\end{array}$ & 82 & $9,76 \%$ & $2,44 \%$ & $10,98 \%$ & $36,59 \%$ & $40,24 \%$ & 3,95 & 1,23 & $31,04 \%$ \\
\hline $\begin{array}{l}\text { Aplicación - } \\
\text { Contenidos } \\
\text { [ITEM_5] }\end{array}$ & 81 & $12,20 \%$ & $2,44 \%$ & $7,32 \%$ & $32,93 \%$ & $43,90 \%$ & 3,95 & 1,32 & $33,46 \%$ \\
\hline $\begin{array}{l}\text { Hardware } \\
\text { [ITEM_2] }\end{array}$ & 82 & $9,76 \%$ & $2,44 \%$ & $9,76 \%$ & $37,80 \%$ & $39,02 \%$ & 3,95 & 1,22 & $30,98 \%$ \\
\hline $\begin{array}{l}\text { Aplicación - } \\
\text { Contenidos - } \\
\text { Implementación } \\
\text { [ITEM_6] }\end{array}$ & 80 & $13,41 \%$ & $1,22 \%$ & $13,41 \%$ & $20,73 \%$ & $48,78 \%$ & 3,93 & 1,39 & $35,52 \%$ \\
\hline $\begin{array}{l}\text { Aplicación - } \\
\text { Implementación } \\
\text { [ITEM_1] }\end{array}$ & 82 & $15,85 \%$ & $9,76 \%$ & $10,98 \%$ & $13,41 \%$ & $50,00 \%$ & 3,72 & 1,54 & $41,45 \%$ \\
\hline $\begin{array}{l}\text { Aplicación - } \\
\text { Implementación } \\
\text { [ITEM_7] }\end{array}$ & 82 & $9,76 \%$ & $18,29 \%$ & $13,41 \%$ & $24,39 \%$ & $34,15 \%$ & 3,55 & 1,38 & $38,89 \%$ \\
\hline $\begin{array}{l}\text { Aplicación - } \\
\text { Contenidos } \\
\text { [ITEM_4] }\end{array}$ & 82 & $9,76 \%$ & $17,07 \%$ & $29,27 \%$ & $19,51 \%$ & $24,39 \%$ & 3,32 & 1,29 & $38,74 \%$ \\
\hline
\end{tabular}

Fuente: Elaboración propia.

Es posible observar que el ítem que presenta una mayor aceptación entre los sujetos participantes, corresponde al no 3 ("Es fácil navegar dentro de la aplicación utilizada"), el cual está referido a la facilidad de navegación dentro de la aplicación creada. Esto es seguido por el ítem 8 ("Es fácil usar la aplicación"), lo que entrega indicios sobre la usabilidad del dispositivo y del programa en un ambiente móvil. Los ítems con menores puntuaciones (ítems 7 y 4 ) se encuentran referidos a los recursos gráficos de los contenidos, aunque los valores obtenidos no indican una desaprobación, sino más bien, a un sentido de indiferencia en los elementos de despliegue de la aplicación móvil. 
Tabla 5.40 Descriptivos básicos ítems de satisfacción experiencia con Ordenadores

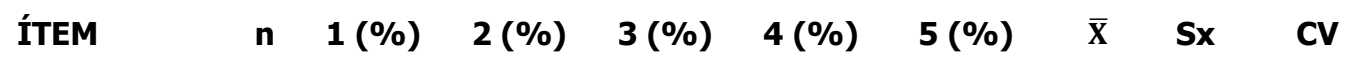

\begin{tabular}{|c|c|c|c|c|c|c|c|c|c|}
\hline $\begin{array}{l}\text { Aplicación - } \\
\text { Contenidos - } \\
\text { Implementación } \\
\text { [ITEM_6] }\end{array}$ & 87 & $6,82 \%$ & $2,27 \%$ & $10,23 \%$ & $32,95 \%$ & $46,59 \%$ & 4,11 & 1,14 & $27,59 \%$ \\
\hline $\begin{array}{l}\text { Aplicación - } \\
\text { Implementación } \\
\text { [ITEM_3] }\end{array}$ & 88 & $5,68 \%$ & $6,82 \%$ & $9,09 \%$ & $30,68 \%$ & $47,73 \%$ & 4,08 & 1,17 & $28,60 \%$ \\
\hline $\begin{array}{l}\text { Aplicación - } \\
\text { Implementación } \\
\text { [ITEM_8] }\end{array}$ & 94 & $4,55 \%$ & $6,82 \%$ & $15,91 \%$ & $28,41 \%$ & $51,14 \%$ & 4,07 & 1,13 & $27,70 \%$ \\
\hline $\begin{array}{l}\text { Aplicación - } \\
\text { Contenidos } \\
\text { [ITEM_5] }\end{array}$ & 88 & $6,82 \%$ & $4,55 \%$ & $10,23 \%$ & $34,09 \%$ & $44,32 \%$ & 4,05 & 1,16 & $28,77 \%$ \\
\hline $\begin{array}{l}\text { Aplicación - } \\
\text { Implementación } \\
\text { [ITEM_9] }\end{array}$ & 87 & $9,09 \%$ & $3,41 \%$ & $10,23 \%$ & $28,41 \%$ & $47,73 \%$ & 4,03 & 1,25 & $31,04 \%$ \\
\hline $\begin{array}{l}\text { Aplicación - } \\
\text { Contenidos } \\
\text { [ITEM_10] }\end{array}$ & 88 & $9,09 \%$ & $5,68 \%$ & $14,77 \%$ & $27,27 \%$ & $43,18 \%$ & 3,90 & 1,28 & $32,79 \%$ \\
\hline $\begin{array}{l}\text { Aplicación - } \\
\text { Implementación } \\
\text { [ITEM_1] }\end{array}$ & 88 & $7,95 \%$ & $10,23 \%$ & $15,91 \%$ & $28,41 \%$ & $37,50 \%$ & 3,77 & 1,28 & $33,80 \%$ \\
\hline $\begin{array}{l}\text { Hardware } \\
\text { [ITEM_2] }\end{array}$ & 88 & $10,23 \%$ & $5,68 \%$ & $22,73 \%$ & $35,23 \%$ & $26,14 \%$ & 3,61 & 1,23 & $33,94 \%$ \\
\hline $\begin{array}{l}\text { Aplicación - } \\
\text { Contenidos } \\
\text { [ITEM_4] }\end{array}$ & 94 & $3,41 \%$ & $19,32 \%$ & $34,09 \%$ & $28,41 \%$ & $21,59 \%$ & 3,43 & 1,10 & $32,18 \%$ \\
\hline $\begin{array}{l}\text { Aplicación - } \\
\text { Implementación } \\
\text { [ITEM_7] }\end{array}$ & 94 & $10,23 \%$ & $17,05 \%$ & $30,68 \%$ & $27,27 \%$ & $21,59 \%$ & 3,31 & 1,24 & $37,36 \%$ \\
\hline
\end{tabular}

Fuente: Elaboración propia.

Cuando se evalúan los niveles de satisfacción con la experiencia Ordenadores, el ítem que presenta un mejor rendimiento corresponde al $n^{\circ} 6$, muy relacionado con el proceso conjunto de la implementación educativa realizada ("La aplicación me ha entregado información importante para mi aprendizaje'). También el ítem 3 mantiene valores altos al igual que los datos obtenidos en la experiencia de iPad, aunque el contexto de interfaz de usuario referida a la plataforma implementada para un ambiente estático difiere de uno móvil.

Los ítems con menores puntuaciones (ítems 4 y 7) se encuentran referidos a los recursos gráficos de los contenidos entregados en la aplicación de escritorio, así como la precisión de los datos espaciales, lo que podría relacionarse por la implementación del 
contexto virtual y estacional de contenidos patrimoniales en un ordenador de escritorio, intentando realizar representaciones territoriales (Gráfico 5.73).

Gráfico 5.73 Resultados encuesta de satisfacción según tratamiento

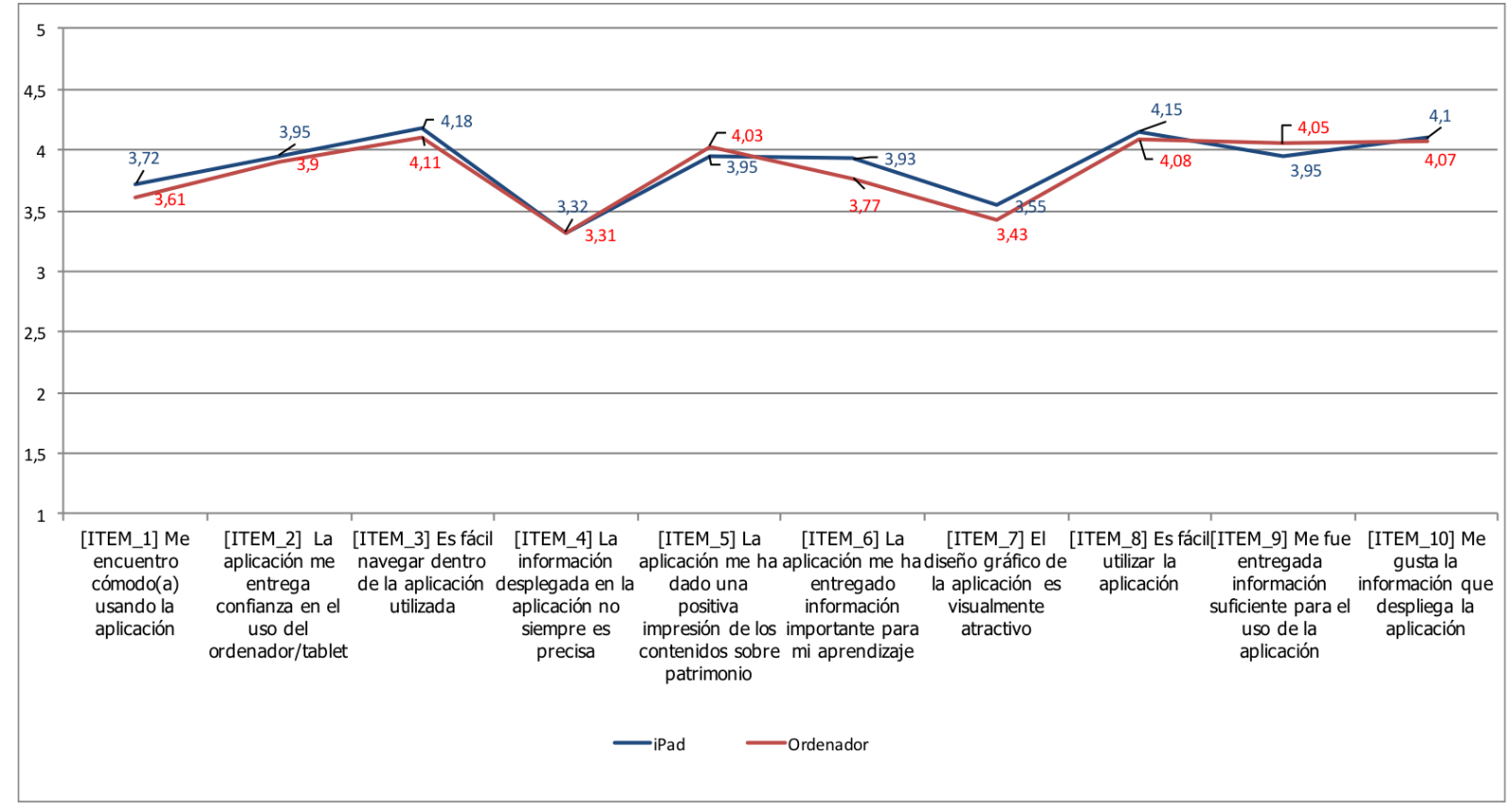

Fuente: Elaboración propia.

Gráfico 5.74 Resultados encuesta de satisfacción según país

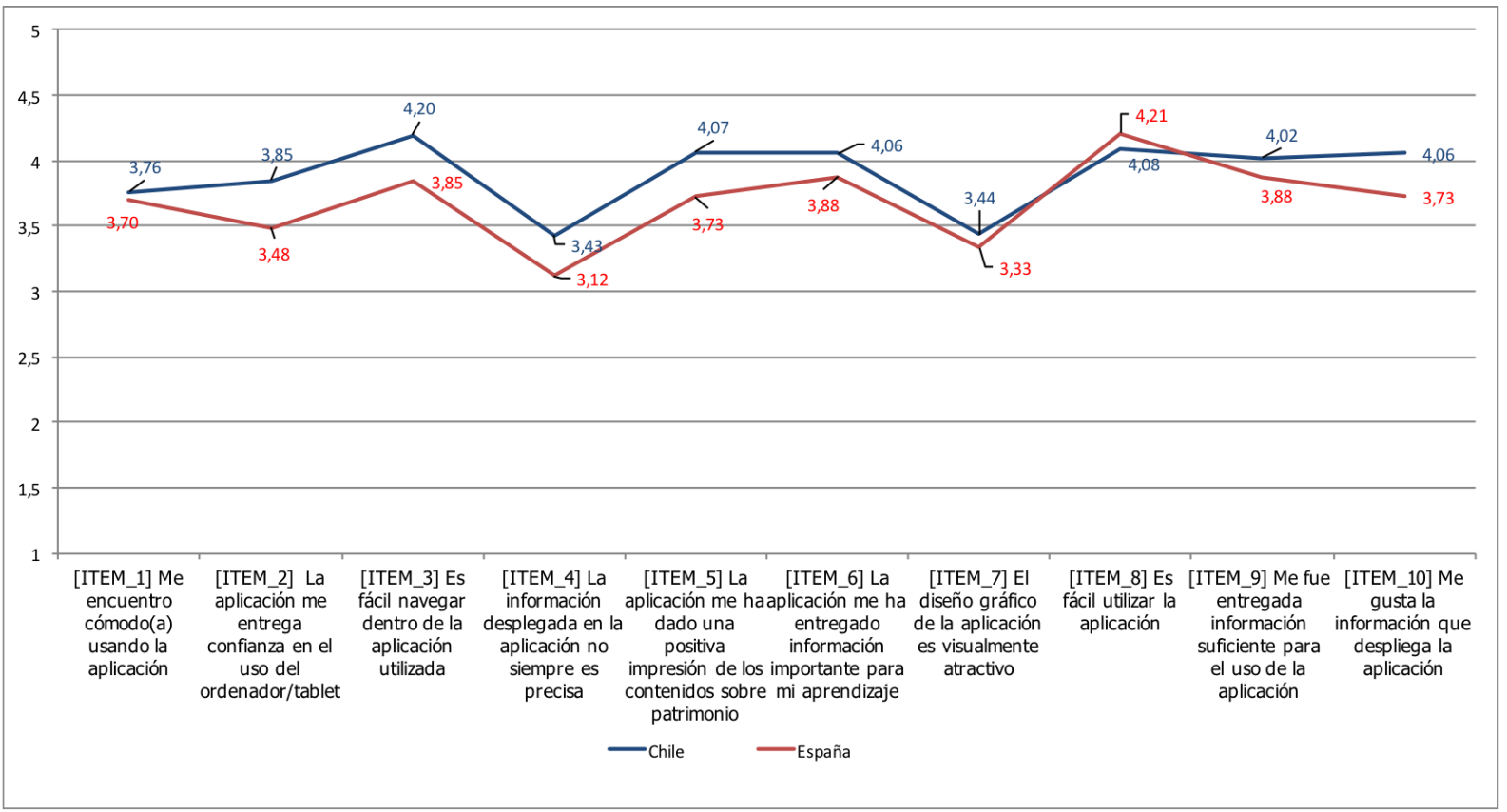

Fuente: Elaboración propia. 
Cuando se realiza una comparación en función del país de cada alumno que participó en alguna de las actividades educativas (Gráfico 5.74), se puede observar que los alumnos de Chile tienen mayores puntaciones positivas en torno a los recursos y contenidos utilizados en las experiencias. El único ítem en donde se observa diferencias en estas tendencias corresponde al $n^{\circ} 7$, lo que se podría explicar por el grado de penetración que tienen estas tecnologías en cada país, siendo para el caso de España, tecnología de uso cotidiano, y para el caso chileno, implementaciones novedosas e innovadoras lo cual se expresa en los resultados que se generan.

Para complementar los análisis, se ha realizado la prueba t para dos muestras independientes utilizando los valores totales para cada ítem de la escala109, con el fin de obtener información relevante sobre dos aspectos:

- Si existen diferencias significativas en la percepción de las herramientas, según tipo de experiencia educativa realizada (iPad u Ordenador), y

- Si existen diferencias significativas en la percepción de la actividad educativa implementada, según país en que fue desarrollada.

Para el primer caso, en los valores de la prueba de Levene se cumple el requisito de homocedasticidad de los datos $(F=, 054: p=, 817)$, teniendo como resultado la aceptación de la hipótesis nula en la prueba de $\mathrm{t}(\mathrm{t}=, 230 ; \mathrm{p}=, 818)$. Esto que implica que no existen diferencias significativas en las percepciones del grupo iPad versus los de tratamiento con Ordenador. Ambos tratamientos implementados presentan la misma percepción de los alumnos como actividad educativa. En lo referente a la diferencia según país, los valores de homocedasticidad de la prueba de Levene se cumplen ( $F=1,014: p$ $=, 326)$, con lo cual, los resultados de la prueba $t(t=1,695 ; p=, 092)$ establecen como resultado la aceptación de la hipótesis nula. Esto se traduce que en que no hay diferencias en los resultados de percepción obtenidos y el país en donde fue realizado cada experiencia educativa.

\footnotetext{
109109 Aplicando la prueba de Kolmogorov-Smirnov a la muestra, la significancia obtenida de los datos es igual a 0,1 , con una media de 38,622 y una desviación típica de 6,42, lo cual implica una distribución normal de los valores presentes.
} 


\subsection{Contexto cualitativo de las experiencias educativas realizadas}

\subsubsection{Análisis de los datos obtenidos de los docentes}

Desde los datos obtenidos de los docentes participantes en cada experiencia educativa implementada, se realizaron las entrevistas en donde los datos consultados se centraron en la experiencia con TIC y la actividad con los recursos informáticos propuestos. De esta manera los cuatro docentes participantes estuvieron en algunas de las intervenciones educativas con los tratamientos desarrollados (iPad u ordenador) para la investigación en los ámbitos escolares (Tabla 5.41). Además, se les consultó por los datos sociodemográficos generales y su experiencia profesional educativa (todos los entrevistados son maestros y maestras de Historia, y Geografía), además de su autopercepción en el nivel de utilización de las TIC.

Al igual que en el caso con los alumnos, el análisis pretendió identificar los factores de las variables (códigos), el refinamiento y expresión del contenido por parte de los docentes, el establecimiento de relaciones entre los códigos y la constitución general de la red de significados en torno a las TIC y particularmente a las experiencias realizadas.

Tabla 5.41 Antecedentes sociodemográficos de los docentes

\begin{tabular}{|c|c|c|c|c|c|}
\hline Nombre* & Genero & Edad & $\begin{array}{c}\text { Años de } \\
\text { experiencia } \\
\text { docente }\end{array}$ & $\begin{array}{l}\text { Colegio de la } \\
\text { experiencia }\end{array}$ & $\begin{array}{c}\text { Nivel de } \\
\text { utilización } \\
\text { de TIC }\end{array}$ \\
\hline Cristina & $F$ & 27 & 3 & Colegio 1 (Chile) & Medio \\
\hline Pedro & M & 30 & 2 & Colegio 1 (Chile) & Alto \\
\hline Andrea & $\mathrm{F}$ & 28 & 4 & Colegio 2 (Chile) & Medio \\
\hline Sebastián & M & 29 & 1 & Colegio 3 (España) & Medio \\
\hline
\end{tabular}

La codificación inicial establecía la constitución de cuatro grandes dimensiones en la que se presentaban 17 variables preestablecidas con el fin de determinar la real influencia de las actividades realizadas desde la visión de los docentes participantes. De 
manera adicional, se incorporaron variables que fueron introducidas en el contexto general de la dimensión cualitativa, con el fin de tener un completo contexto de las percepciones desde el análisis inductivo. Con la flexibilidad de estos hallazgos, se pudieron incorporar nuevas dimensiones (Significado) y nuevos códigos enriqueciendo la estructura general del análisis (10 variables).

Tabla 5.42 Dimensiones, variables y episodio narrativo representativo de los docentes: antecedentes generales en el uso de las TIC

Categoría

(1) Antecedentes sociales-particulares.

Elementos sociodemográficos de los docentes
Código ${ }^{110}$

$\bullet 1.1$ Contexto Social
Educativo

Episodio narrativo

Desde cuando yo cursaba $3^{\circ}$ medio (2005), porque tuve cursos básicos en el colegio, donde nos enseñaron a enviar correos, todo lo que sea de MS-Office

..si, mis padres, porque el ordenador que ocupaba

- 1.2 Contexto cuando era chico lo compraron ellos, el ordenador era de la casa. De hecho, en el colegio era limitadísimo... a ver, cuando pasé a primero medio en el liceo, en el 2000, ahí tenían ordenadores, pero en la escuela básica no.

Visitar páginas web con fuentes para nuestra temática, analizar diferentes documentos: imágenes, noticias y textos, utilización de diferentes tipos de vídeos para - 3.5 Estrategias apoyar la explicación, presentaciones por parte de los alumnos, presentación de esquemas, apuntes, actividades de indagación... educativas con TIC

Los chicos están demasiado acostumbrados a tener un profesor cerca para guiar el trabajo, para resolver todas las dudas que tengan, ya sea de lenguaje o preguntas de contenido o del contexto donde estaba el edificio...

(D) Aspectos negativos en el uso de las TIC
- 3.6 Interacción con los alumnos eso no aparecía en la aplicación y cuando dejaban de lado la aplicación y trataban de comparar lo que estaba ahí con lo que estaban viendo les surgían muchas dudas de lo que tenía al lado este edificio... y eso no estaba en la aplicación, entonces tiene que haber alguien ahí para que se los vaya diciendo, para que integren los contenidos.

Dentro de lo negativo, que es lo que más tengo fresco, fue la inestabilidad de algunos modelos, eso fue un

- Limitaciones en el punto muy negativo porque cuando los tratamos de uso de las TIC ocupar en el momento, hubieron algunas tablets en que simplemente no funcionó entonces eso definitivamente marca un quiebre.

Fuente: Elaboración propia.

110 Los códigos definidos previamente se encuentran numerados en función a la dimensión a la cual pertenecen. Las variables o códigos que fueron definidos durante el análisis están sin numeración. 
En las primeras categorías (Tabla 5.42) se toman las variables personales que los docentes tienen en torno a las TIC, enfocándose particularmente en la relación particular con las herramientas, primero en un contexto familiar y propio, y luego, como una herramienta en su actividad profesional. Dentro de los aspectos negativos se encuentran los hallazgos que se hacen dentro del ámbito profesional docente, de las actividades educativas planteadas en la investigación y en la relación que hay entre alumnos y tecnología dentro de su proceso formativo.

Tabla 5.43 Dimensión Evaluación de la Experiencia: variables y episodio narrativo representativo de los docentes

Categoría Código Episodio narrativo

\begin{tabular}{|c|c|c|}
\hline \multirow{4}{*}{$\begin{array}{l}\otimes \text { Evaluación de la } \\
\text { experiencia educativa } \\
\text { con RA-NPM }\end{array}$} & $\begin{array}{l}3.4 \text { Adaptación de } \\
\text { los recursos TIC }\end{array}$ & $\begin{array}{l}\text { Una actividad sólo en el aula no sería igual, porque la } \\
\text { libertad que tienen en el terreno, en la sala de clases no } \\
\text { sabrían cómo utilizarla. En el terreno se sienten en un } \\
\text { ambiente distinto, más libres de expresarse, de } \\
\text { investigar... y en la sala esperan que las cosas se las den } \\
\text { y es decirles paso a paso lo que tienen que hacer. }\end{array}$ \\
\hline & $\begin{array}{l}\text { - } 4.1 \text { Percepción de } \\
\text { la actividad de trabajo } \\
\text { de campo para el } \\
\text { aprendizaje }\end{array}$ & $\begin{array}{l}\text { Obviamente es mucho más simpático, mucho más } \\
\text { entretenido verlo desde una Tablet y si eso se puede } \\
\text { acompañar con una experiencia en terreno es mucho } \\
\text { mejor. De hecho, como complemento de una actividad } \\
\text { en terreno a mí me parece fantástico. Ahora, dentro de } \\
\text { mi contexto como profe de historia, creo que incluso } \\
\text { más que la clase, más que los libros, más que la Tablet, } \\
\text { la actividad en terreno por si sola es lo que termina } \\
\text { siendo lo más rescatable dentro del contexto del } \\
\text { conocimiento patrimonial }\end{array}$ \\
\hline & $\begin{array}{l}4.2 \text { Percepción } \\
\text { educativa de los } \\
\text { mapas digitales y la } \\
\text { NPM }\end{array}$ & $\begin{array}{l}\text { Yo como usuario lo comprendía, pero me imagino un } \\
\text { poco por mi formación como profe de historia y además } \\
\text { de geografía yo ya estaba familiarizado con el uso de } \\
\text { mapas y también por mi uso cotidiano con esas } \\
\text { herramientas. En el caso particular de los chicos, me di } \\
\text { cuenta de que el uso del mapa no estaba tan } \\
\text { desarrollado, pero ahí también creo que es gran parte de } \\
\text { responsabilidad del programa educativo que tiende a no } \\
\text { concentrarse en estos elementos actualmente y eso lo } \\
\text { puedo ver igual en cabros más grandes, en tercero, en } \\
\text { cuarto medio que actualmente todavía tienen problemas } \\
\text { para leer mapas. }\end{array}$ \\
\hline & $\begin{array}{l}\text { - } 4.3 \text { Percepción } \\
\text { educativa de la RA }\end{array}$ & $\begin{array}{l}\text { No lo había usado tampoco y la primera vez que lo fue } \\
\text { como: "iha, esto era. Me gusta!" Llama la atención. En } \\
\text { eso creo que tuve la misma impresión que los niños. lo } \\
\text { puedo ver de acá y creo que fue perspectiva distinta que } \\
\text { enriqueció el terreno y enriqueció también el }\end{array}$ \\
\hline
\end{tabular}


conocimiento que lograron tener, así que eso es algo que valoro además de las fotografías que tenía.

- 4.5 Limitaciones de los recursos usados en las experiencias
Dentro de lo negativo, que es lo que más tengo fresco, fue la inestabilidad de algunos modelos, eso fue un punto muy negativo porque cuando los tratamos de ocupar en el momento, hubieron algunas tablets en que simplemente no funcionó entonces eso definitivamente marca un quiebre.

$\mathrm{mmm}$, creo que ambas funcionan bien (las experiencias). Pero habría que hacer una transposición

- 4.6 Sentimiento en torno a estas experiencias (tabletas/ordenador de escritorio) un poco más básica respecto de ciertos conceptos que pueden resultar complicados para que una persona que no está del todo enterada, que no ha estudiado puntualmente el tema de patrimonio y mucho menos el lugar en particular pueda entenderlo más fácil, saber de qué se está hablando. En particular estoy pensando en las cuestiones de arquitectura.

Me pareció un buen material didáctico, ya que los alumnos pueden en primer lugar localizar el patrimonio, observar "in situ" los diferentes conjuntos artísticos, identificar sus características, aprender curiosidades,

- Aplicación Realidad Aumentada-NPM apreciar cómo eran antiguamente estos edificios (fotos antiguas), características de su construcción, vistas aéreas (realidad aumentada). Siempre que su funcionamiento sea correcto, las posibilidades que presenta para el alumnado y profesorado son múltiples.

Siento que es un recurso súper bueno para usarlo, porque lo que hace es dejar la duda. Deja una duda y luego que los alumnos solos la resuelvan. Ahora claro, el alumno, el profesor después puede guiar: "oye pero

- Aprendizaje Autónomo busquen esto, busquen esto otro, revisen la aplicación, fijense la información que da, fijense en esto o en esto otro" más que en dar informaciones, siento que a veces o es una o es la otra y se generó esa curiosidad en la sala súper rápida y ellos altiro comenzaron a buscar.

...eeeh, a mí me gusta más la de la tablet, porque es más interactivo, yo estoy viendo información, pero a la vez la estoy viendo en la realidad. Y a mí me pareció que la actividad en la sala de computación también habría dejado más tiempo a los chiquillos anduvieran solos, porque se produjo algo súper entretenido en la sala de computación, porque se hizo la prueba y los chicos quedaron con muchas dudas y me decían "es que no sé nada profe" entonces a ellos ya se pusieron a buscar en Wikipedia por ejemplo, algo más de contenido. Entonces a mí me hubiera gustado que ese salto lo hicieran solitos, porque yo siento que no es necesario estar explicando, porque está la información ahí y ellos como que aaah, se pusieron a leer y quedaron con la duda... aaah, esto era lo que preguntaban, entonces, esta era la respuesta, no me equivoqué.

Claro... y respecto de lo mismo, para volver al tema de que tan guiado pueda ser el trabajo de campo. Esos elementos de lenguaje fue lo primero por lo que los alumnos - 'pensando en un contexto autoguiadochocaron. Ahí recurrieron inmediatamente a mi preguntándome: "oye que significa eso" entonces esa es 
una posibilidad que la herramienta, la aplicación por sí sola no les podía responder. Entonces decirles en el momento: "mira, eso significa tal cosa y lo puedes ver ahi, ahí y ahi", eso fue parte también de la necesidad del apoyo docente para eso.

\begin{tabular}{ll}
\hline El contexto no acompaña mucho, porque los chiquillos \\
parece que para ellos el ordenador está más asociado a \\
la entretención entonces yo, hay veces en que si los \\
llevo a la sala de computación ellos se ponen a hacer \\
otras cosas. Entonces, está muy acompañado del tema \\
de la autonomía. \\
Sí, la volvería a realizar. Puede ser una aplicación muy \\
útil para un primer acercamiento al patrimonio histórico \\
de nuestra ciudad, y también, puede ser una aplicación \\
que nos permita profundizar ya en cursos superiores, \\
centrándonos en un determinado estilo artístico o para \\
comparar diferentes estilos. Su uso en el aula, en \\
algunas asignaturas y ajustándose la aplicación al \\
temario puede permitirnos múltiples posibilidades y esto \\
es lo más positivo. \\
Los chicos están demasiado acostumbrados a tener un \\
profesor cerca para guiar el trabajo, para resolver todas \\
las dudas que tengan, ya sea de lenguaje o preguntas \\
de contenido o del contexto donde estaba el edificio... \\
eso no aparecía en la aplicación y cuando dejaban de \\
lado la aplicación y trataban de comparar lo que estaba \\
ahí con lo que estaban viendo les surgían muchas dudas \\
de lo que tenía al lado este edificio... y eso no estaba en \\
la aplicación, entonces tiene que haber alguien ahí para \\
que se los vaya diciendo, para que integren los \\
contenidos.
\end{tabular}

Fuente: Elaboración propia.

La evaluación de las experiencias educativas -tratamiento con iPad u Ordenadores- (Tabla 5.43) corresponde a la categoría con el mayor número de variables e interrelaciones con otros ámbitos y niveles de análisis. Desde esta dimensión, emergieron nuevas variables que entregaron una mejor perspectiva de la eficacia de las herramientas propuestas (Formación previa, Limitaciones en el uso de las TIC, Replicabilidad de la experiencia TIC), y del rol de los docentes en este planteamiento educativo (Aprendizaje autónomo, Rol docente). 
Tabla 5.44 Dimensión Uso de la tecnología en el contexto educativo, variables y episodio narrativo representativo de los docentes

\section{Categoría Código Episodio narrativo}

(D) Uso de la tecnología en el contexto educativo.

Actitudes y

funcionalidades que otorgan a las TIC en el ámbito docente.
Hace las clases más entretenidas y logras llamarles la atención, que queden enganchados en la clase y a la vez
- 3.1 Percepción Tecnológica en Contextos Educativos Formales enseñarles cómo deberían aprovechar las herramientas que hay, porque la mayoría de los niños, aunque vive pegados al teléfono y en la tarde llegan a quedarse cerca del ordenador, no lo saben ocupar; solamente escriben en el Facebook y en los juegos, no lo usan para trabajo o algo académico. Yo lo tiendo a usar para acercarlos y enseñarles esa forma.

...una vez trate de usar el teléfono móvil en un curso, resultó, pero me costó, porque están demasiado acostumbrados a que si tienen el teléfono móvil cerca, a
- 3.2 Utilización de TIC en las actividades educativas. Práctica docente con TIC. su alcance, ellos lo van a ocupar para otra cosa y no para lo que uno quiere usarlo, que es para el ámbito académico. Así que traté una vez, lo repetí en tres cursos y no fue lo mejor.

con tablets, jamás en mi vida.

Aplicadas a la enseñanza yo creo que son algo completamente necesario actualmente, porque la mayor parte de los alumnos con los que estamos lidiando en estos momentos son nativos digitales que incluso si tiene un uso limitado de la tecnología o si no tienen el contexto para poder sacarle el provecho pedagógico, docente a las cosas que ocupan de manera cotidiana,
- 3.3 Obtención de objetivos educativos son chicos que están acostumbrados a trabajar por ejemplo con un teléfono inteligente, entonces, si yo no adapto mis clases a ese contexto, a esa realidad que para ellos es mucho más de interacción constante y multitarea, no voy captar su atención... Y de hecho, las veces en que he utilizado herramientas TIC de manera más intensiva es cuando he tenido mejores resultados, porque los niños se sienten más cómodos en un contexto que para ellos es mucho más familiar.

Fuente: Elaboración propia.

Desde la dimensión Uso de la tecnología en el contexto educativo (Tabla 5.44) los entrevistados expresan su grado, sentimiento y opinión de, en un primer lugar, el uso educativo de las TIC, y, de manera particular, de las herramientas propuestas en los tratamientos de la presente investigación. Aquí emergen testimonios cercanos, tanto positivos como negativos, de la utilización de la tecnología, y de manera particular, la inclusión a un nuevo nivel enmarcado por el m-learning. Sin embargo, también existe 
evidencia de elementos tradicionales en la formación que se realiza, con la enseñanza directa y guiada que se realiza en los centros educativos donde imparten sus labores.

Tabla 5.45 Dimensión Uso personal de la tecnología, variables y episodio narrativo representativo de los docentes

\begin{tabular}{ll} 
Categoría & Episodio norrativo \\
\hline & Intento aprovechar las oportunidades que nos ofrece el \\
mundo de Internet: proyección de vídeos, noticias y & recursos didácticos relacionados con nuestra materia. \\
Además de trabajar con diferentes programas para la \\
presentación de apuntes y esquemas relacionados con \\
la temática (expuestos a través del proyector).
\end{tabular}

- 2.1 Experiencia con

la Tecnología.

Uso personal de la tecnología. Actitudes y funcionalidad que otorgan a la tecnología en su vida personal
De todo lo que sea funcionamiento básico del ordenador, lo que sea aprovechar todas las cosas como comunes y corrientes, como el Office, el internet para poder comunicarse eso lo sé y es para mí lo básico que me enseñaron en el colegio y de ahí es casi lo mismo lo que he mantenido.
Si, debo decir que sí. Hace las clases más entretenidas y logras llamarles la atención, que queden enganchados en la clase y a la vez enseñarles cómo deberían aprovechar las herramientas que hay, porque la mayoría de los niños, aunque vive pegados al teléfono y en la tarde llegan a quedarse cerca del ordenador, no lo saben ocupar; solamente escriben en el Facebook y en los juegos, no lo usan para trabajo o algo académico. Yo lo tiendo a usar para acercarlos y enseñarles esa forma.

Fuente: Elaboración propia.

En cuanto a la dimensión Uso Personal de la tecnología (Tabla 5.45), los entrevistados presentan sus experiencias y actitudes personales frente la inclusión de la tecnología, desde el ámbito particular hasta niveles en donde los recursos tecnológicos se socializan y participan del contexto educativo que realizan. También se presenta un intento constante de construir una estructura educativa con medios que no son explícitos para la formación (Facebook, móvil), pero que al dirigirlos hacia una funcionabilidad hacia el aprendizaje, toman nuevos sentidos (aumento de la didáctica, clases más "entretenidas"). 
Tabla 5.46 Dimensión Significado, variables y episodio narrativo representativo de los docentes

\begin{tabular}{|c|c|c|}
\hline Categoría & Código & Episodio narrativo \\
\hline \multirow{2}{*}{ (8) Significado } & $\begin{array}{l}\text { - Limitaciones en el } \\
\text { uso de las TIC }\end{array}$ & $\begin{array}{l}\text { En el colegio, ahí, como no está la posibilidad de hacer } \\
\text { un uso intensivo de las TIC es una limitante, porque los } \\
\text { niños tienden a distraerse mucho con el uso de sus } \\
\text { teléfonos; ahora, dentro de otros contextos, eso mismo } \\
\text { lo podría utilizar para pedirles a ellos que busquen } \\
\text { información... Para ayudarles y enseñarles a ocupar su } \\
\text { teléfono no solo estar metidos en Facebook o en } \\
\text { WhatsApp, sino también utilizarlo para hacer } \\
\text { actividades docentes; en ese sentido, que todos lo } \\
\text { tengan, y todos lo ocupen y lo sepan utilizar es } \\
\text { fantástico. Insisto, muchas veces lo que puedes o no } \\
\text { puedes hacer y que tan útil sea o que tan limitante sea, } \\
\text { depende del contexto que te dan el colegio. }\end{array}$ \\
\hline & - Sentido de las TIC & $\begin{array}{l}\text { Sí, en la medida en que uno vaya enseñándoles a } \\
\text { utilizar la tecnología, por ejemplo algo tan sencillo como } \\
\text { que todos tienen teléfono móvil, pero por ejemplo, no } \\
\text { anotan las fechas de las pruebas en el teléfono móvil, } \\
\text { cosa que ellos podrían usarlo, por ejemplo, ellos poner } \\
\text { en su teléfono móvil y yo les diría: "Ya chiquillos, } \\
\text { saquen sus teléfonos móviles y anotan la fecha de las } \\
\text { pruebas". Tan sencillo como eso, entonces yo creo que } \\
\text { en la medida que uno les enseñe a hacer un uso } \\
\text { correcto (quizás no correcto sino útil) útil en otro } \\
\text { sentido, no solo de jugar con la tecnología, yo creo que } \\
\text { ellos sí podrían. El tema es que uno a veces lo limita un } \\
\text { poco, porque ellos cuando sacan el teléfono móvil no lo } \\
\text { sacan para trabajar, lo sacan para jugar. }\end{array}$ \\
\hline
\end{tabular}

Fuente: Elaboración propia.

La última dimensión Significado (

Tabla 5.46), se genera dentro de los hallazgos derivados del análisis de las entrevistas, al igual que los códigos que la componen. En ella se encuentran los elementos personales particulares y que están definidos por la experiencia cotidiana de los entrevistados, su contexto laboral y profesional (entregando testimonio de las limitaciones en el uso de estos recursos) y la propia experiencia con el uso de las TIC, siendo el ejemplo la contextualización: entregar un significado más complejo a la utilización de las herramientas: más que correcto, dar un sentido útil que va más allá del ámbito cotidiano con que usan la tecnología los alumnos.

Todas estas dimensiones y variables se encuentran relacionadas directa o indirectamente, estableciendo una estructura que compone el discurso docente, que va desde la propia apreciación de las TIC (contexto general) hasta el desarrollo de la actividad 
educativa propuesta con las tablets (contexto especifico del uso de las TIC en el marco del m-learning), pasando por la fase y construcción intermedia del uso de herramientas tecnológicas en su ámbito profesional-educativo (Figura 5.11).

Figura 5.11 Relaciones entre categorías y códigos. Docentes

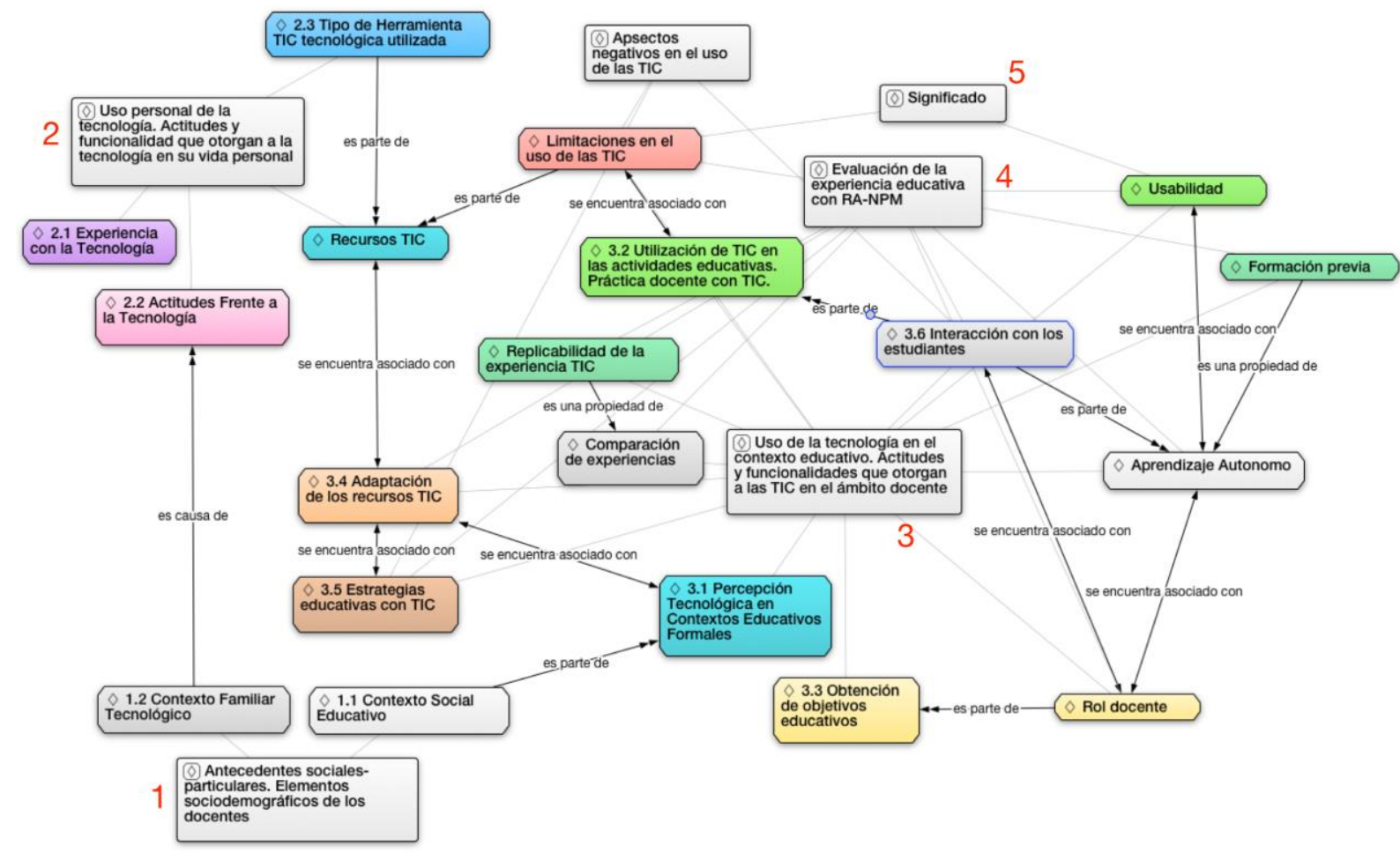

Fuente: Elaboración propia.

De esta manera, las variables que tienen una mayor interacción con otras ya establecidas y se presentan como nodos de los testimonios analizados son la adaptación de los recursos TIC, el aprendizaje autónomo y las limitaciones en uso de las TIC, elementos que giran principalmente en torno a las del uso de la tecnología en el contexto educativo y la evaluación de la experiencia educativa. Dentro de las 5 categorías generales utilizadas se dan relaciones como "es parte de", "se encuentra asociado con", "es una propiedad de" las que establecen los lazos entre variables y del cómo se estructuran los enlaces dispuestos en las entrevistas. Así, de manera específica, uno de los temas que salió a la luz dentro de la información consultada fue las posibilidad de replicar esta experiencia TIC en otros contenidos de enseñanza. De la misma manera y relacionado con el código anterior, es la adaptación de los recursos TIC, preocupación mostrada por los 
entrevistados y refiriéndose a los posibles logros en el aprendizaje de los alumnos, la posibilidad de incorporar estas metodologías en ambientes donde los recursos son limitados y la real efectividad de estas herramientas frente a la clases presenciales y derivados en variables como el aprendizaje autónomo y el rol docente.

Cuando se analiza la nube de palabras creada (Figura 5.12), con los conceptos que mayor frecuencia se presentan en el discurso de los docentes, los términos que destacan se encuentran referidos al contexto instrumental de las experiencias (ordenador, iPad, sala, tablet, tecnología, terreno'11, RA, móvil, computación, herramientas). De manera paralela, dentro de los aspectos procedimentales se encuentran referidos con conceptos como enseñanza, explorar, autonomía, comparar, entender, explicación, por mencionar algunos, lo que genera el conceptualización general de unas actividades (intervenciones TIC, tratamiento) que se relacionan con habilidades propias de un proceso de aprendizaje.

111 Trabajo de campo. 
Figura 5.12 Nube de palabras, entrevistas con los docentes

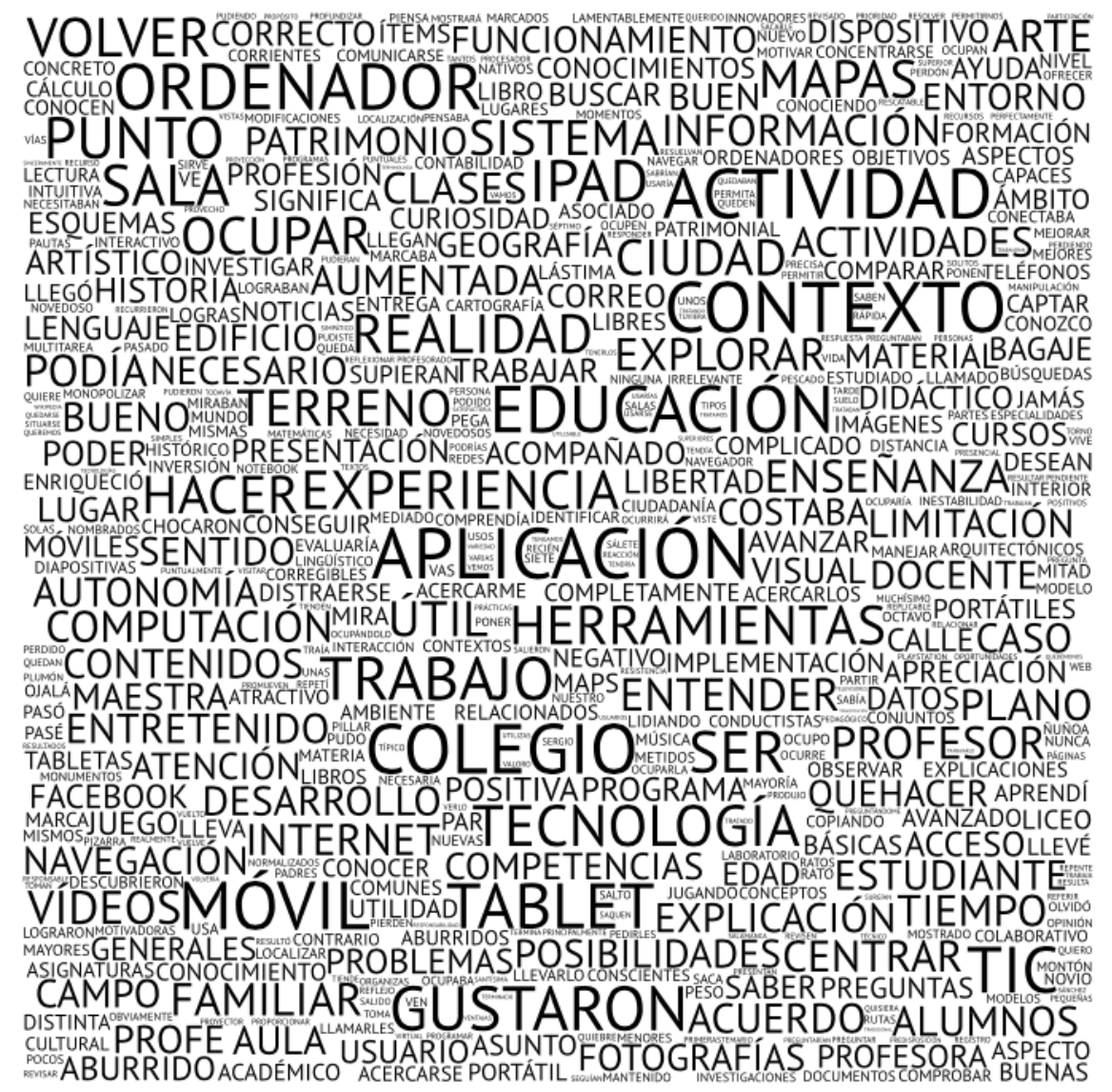

Fuente: Elaboración propia.

También es posible observar palabras sobre las cualidades y percepciones frente a las actividades desarrolladas. Dentro de una dimensión positiva se encuentran gustaron, acuerdo, buenas (buen), libertad, enriqueció, y utilidad. Dentro del ámbito negativo, es posible visualizar conceptos como aburrido, complicado y distraerse. La cantidad de conceptos y las magnitudes que toman en las entrevistas analizadas entregan nuevos aspectos en la consideración, desde el punto de vista docente, del rol de los recursos y actividades planteados.

Otro elemento importante se presentó en el rol que toman los docentes, particularmente en el desarrollo de una actividad con iPad (Tabla 5.47). Las opiniones de los participantes se encuentran divididas en torno al rol que debe tener el profesor en la actividad (particularmente en el tratamiento con iPad), en donde se encontraron dos tipos 
de percepciones: los docentes que apuestan por un rol mediador y los que apuestan por la autonomía de los alumnos.

Tabla 5.47 Forma de realización del aprendizaje con la actividad TIC

\begin{tabular}{|c|c|c|}
\hline Nombre* & $\begin{array}{l}\text { Forma en que } \\
\text { debería realizarse el } \\
\text { aprendizaje }\end{array}$ & Episodio narrativo \\
\hline Cristina & $\begin{array}{l}\text { Rol docente como } \\
\text { mediador }\end{array}$ & $\begin{array}{l}\text { Los chicos están demasiado acostumbrados a } \\
\text { tener un profesor cerca para guiar el trabajo, } \\
\text { para resolver todas las dudas que tengan, ya } \\
\text { sea de lenguaje o preguntas de contenido o del } \\
\text { contexto donde estaba el edificio... }\end{array}$ \\
\hline Pedro & $\begin{array}{l}\text { Aprendizaje autónomo } \\
\text { de los alumnos }\end{array}$ & $\begin{array}{l}\text { Si, si ... entonces yo pensaba que ellos, como } \\
\text { que captaron mucho, al final captaron el uso de } \\
\text { la Tablet y yo sentí que no era necesario que se } \\
\text { les diera mayor explicación, porque estaba la } \\
\text { información ahí. }\end{array}$ \\
\hline Andrea & $\begin{array}{l}\text { Aprendizaje autónomo } \\
\text { de los alumnos }\end{array}$ & $\begin{array}{l}\text { Entonces a mí me hubiera gustado que ese salto } \\
\text { lo hicieran solitos, porque yo siento que no es } \\
\text { necesario estar explicando, porque está la } \\
\text { información ahí y ellos como que aaah, se } \\
\text { pusieron a leer y quedaron con la duda... aaah, } \\
\text { esto era lo que preguntaban, entonces, esta era } \\
\text { la respuesta, no me equivoqué. }\end{array}$ \\
\hline
\end{tabular}

Soy de la opinión que el profesor en este caso

$\begin{array}{lll}\text { Sebastián } & \text { Rol docente como } & \begin{array}{l}\text { no debe monopolizar dicha actividad, se debe } \\ \text { centrar en ofrecer unas pautas (pequeñas } \\ \text { explicaciones) y en comprobar junto a los } \\ \text { alumnos si se han conseguido los objetivos. }\end{array}\end{array}$

* Los nombre reales fueron reemplazados por seudónimos

Fuente: Elaboración propia.

Un último elemento que fue la referencia estructural de las entrevistas fue acerca de las actividades realizadas con RA-NPM en el contexto de e-learning y m-learning (Tabla 5.48), en donde de manera general, los docentes tuvieron una percepción positiva acerca de estas herramientas, con matices en torno a elementos específicos derivados de su experiencia personal (aplicación desde los contenidos formales, implementación tecnológica, rol docente). Estos hallazgos son el complemento a la información presentada en la Tabla 5.48. 
Tabla 5.48 Percepción sobre los recursos de RA-NPM en e-learning y m-learning

\begin{tabular}{|c|c|c|}
\hline Nombre* & $\begin{array}{l}\text { Percepción de la } \\
\text { actividad }\end{array}$ & Episodio narrativo \\
\hline Cristina & Positiva & $\begin{array}{l}\text { A ver, el contenido me gusta, siento que es algo } \\
\text { que se trabaja muy poco en el currículo y } \\
\text { llevarlos a terreno y tener la aplicación en la } \\
\text { Tablet como ayuda me gustó porque los chicos } \\
\text { tienen a la mano un material que en papel, en } \\
\text { una guía se queda perdido y no lo hubiesen } \\
\text { revisado, así que en eso me gustó la aplicación. }\end{array}$ \\
\hline Pedro & Positiva & $\begin{array}{l}\text { Creo que es especialmente útil en el caso de } \\
\text { personas que están conociendo un entorno } \\
\text { completamente nuevo, porque te da la } \\
\text { posibilidad de conocer cosas de una manera } \\
\text { autoguiada y dentro de ese contexto es además } \\
\text { una aplicación bastante intuitiva y descontando } \\
\text { uno que otro fallo con el mapa (que son errores } \\
\text { puntuales perfectamente corregibles) en general } \\
\text { tendía a ser bastante precisa respecto de las } \\
\text { rutas que había que desarrollar. }\end{array}$ \\
\hline Andrea & Positiva & $\begin{array}{l}\text { La aplicación estaba buena para que ellos } \\
\text { trabajaran solos y sentí que estuvo muy bueno } \\
\text { eso, porque ellos comenzaron a explorar, a ver... } \\
\text { a veces se salieron un poco del patrimonio, pero } \\
\text { descubrieron que podían ocupar maps y que eso } \\
\text { quizás ayudó a que vieran que podía ocupar de } \\
\text { otra forma la tecnología que no conocían. }\end{array}$ \\
\hline
\end{tabular}

Me pareció un buen material didáctico, ya que los alumnos pueden en primer lugar localizar el patrimonio, observar "in situ" los diferentes conjuntos artísticos, identificar sus

Sebastián Positiva características, aprender curiosidades, apreciar cómo eran antiguamente estos edificios (fotos antiguas), características de su construcción, vistas aéreas (realidad aumentada). Siempre que su funcionamiento sea correcto, las posibilidades que presenta para el alumnado y profesorado son múltiples.

\footnotetext{
* Los nombre reales fueron reemplazados por seudónimos
}

Fuente: Elaboración propia. 


\subsubsection{Análisis de los datos obtenidos de los alumnos}

De manera paralela a las entrevistas realizadas a los docentes, se realizó una serie de consultas a los alumnos que participaron en la actividad de campo con iPad, tratando de determinar su percepción acerca de los recursos implementados en un contexto educativo formal. Como se presenta en la Tabla 5.49, 2 alumnos corresponden a hombres y 5 a mujeres, cuyas edades fluctúan entre los 13 y 15 años, en diferentes niveles y centros educativos. De la mimas manera, se les consultó sobre su autopercepción en el manejo de TIC, siendo el valor que más se repitió el nivel medio.

Tabla 5.49 Antecedentes sociodemográficos de los alumnos

$\begin{array}{lllll}\text { Nombre* Genero Edad } & \begin{array}{c}\text { Nivel } \\ \text { educativo }\end{array} & \begin{array}{l}\text { Colegio de la } \\ \text { experiencia }\end{array} & \begin{array}{l}\text { Nivel de } \\ \text { utilización } \\ \text { de TIC }\end{array}\end{array}$

\begin{tabular}{|l|c|c|c|l|l|}
\hline Ana & F & 15 & $\begin{array}{c}10 \text { Educación } \\
\text { Secundaria }\end{array}$ & Colegio 2 (Chile) & Medio \\
\hline Cristián & M & 16 & $\begin{array}{r}1^{\circ} \text { Educación } \\
\text { Secundaria }\end{array}$ & Colegio 2 (Chile) & Medio \\
\hline Camilo & M & 14 & $\begin{array}{r}1^{\circ} \text { Educación } \\
\text { Secundaria }\end{array}$ & Colegio 2 (Chile) & Alto \\
\hline Bernarda & F & 13 & 7 EGB & Colegio 1 (Chile) & Bajo \\
\hline Katerine & F & 15 & 7 EGB & Colegio 1 (Chile) & Bajo \\
\hline Susana & F & 16 & $2^{\circ}$ ESO & Colegio 3 (España) & Medio \\
\hline Angélica & $\mathrm{F}$ & 16 & $2^{\circ}$ ESO & Colegio 3 (España) & Medio \\
\hline * Los nombre reales fueron reemplazados por seudónimos & & \\
\hline
\end{tabular}

Fuente: Elaboración propia.

Dentro de las primeras categorías definidas para las entrevistas de los alumnos (Tabla 5.50) se consulta sobre las variables personales que los jóvenes tienen en torno a las TIC, enfocándose particularmente en la relación particular con las herramientas tecnológicas, primero en un contexto familiar y propio, y luego, como una herramienta que es parte de su formación tradicional. Los testimonios recogidos de las entrevistas, muestran que son alumnos que se encuentran en contacto permanente con la tecnología, la cual se sitúa en diferentes ámbitos de su vida (entretenimiento, educación, comunicación, información). 
Tabla 5.50 Dimensiones, variables y episodio narrativo representativo de los alumnos: antecedentes generales en el uso de las TIC

Categoría

Código

(1) Antecedentes sociales-particulares. Elementos sociodemográficos de los alumnos

\section{Episodio narrativo}

Bueno, cuando... él es más mayor y cuando él, por así decirlo, era de la gente que sí, le gustaba jugar a la Play y demás, pero ahora ya, no la usa. Y bueno, también utiliza el móvil, la Tablet y el portátil.

- ¿Y tus padres?

Mi madre solo el teléfono y mi padre, pues también el ordenador y él móvil. Más mi padre y algunas veces mi hermano.

Si, somos bastante (cómo se podría decir)... amantes de

- 1.2 Contexto la tecnología, porque tenemos televisión, computador, la Familiar Tecnológico Tablet ahora que también me voy a ganar, eem y teléfonos también.

- 2.1 Experiencia con

la tecnología

Eso más, lo hago a través del móvil, pero para, por ejemplo, utilizo más el ordenador para meterme a la plataforma del colegio o sino, para buscar información de trabajos y cosas así.

Normalmente, pues la usamos pero no con tanta frecuencia como se debería. Porque como ahora

$\nabla$ Uso personal de la tecnología. Actitudes y funcionalidades que otorgan a la tecnología en su vida personal.

\section{- 2.2. Aptitudes}

frente a la tecnología estamos más metidos en el mundo de las tecnologías, creo que los libros ya no son tan necesarios, entonces, cuanto más estemos en contacto con la tecnología, pues, aprendemos como más fácilmente, porque luego ya cuando somos mayores, por ejemplo nuestros abuelos, si quieren aprender, les cuestan más, pero si empiezas desde pequeños es más sencillo. Entonces, yo creo que se debería empezar con esto desde pequeños.

- ¿Los profesores o los maestros utilizan algún tipo de tecnologías en las clases?

Sí, suelen utilizar más el ordenador.

- ¿Con el proyector?

Sí.

- 2.3 Tipología en el - Y aparte de eso, ¿Ningún otro?

uso de las herramientas tecnológicas
Hay veces que también se traen la Tablet o el iPad. Es que, a través del móvil no sueles ponernos nada, más bien es el ordenador o tableta.

- ¿Te acuerdas de alguna tarea que hayas hecho del colegio con ayuda de internet del móvil o la Tablet?

La última que hemos hecho con la Tablet ha sido una presentación para Religión.

- ¿En qué consistía?

Creo que era keynote y bueno hacer una presentación para varios escritos.

Fuente: Elaboración propia. 
Para los alumnos, la tecnología con sus diversas cualidades y aspectos, no representa algo desconocido, ni inmanejable (Tabla 5.51), sino que corresponde a un elemento que es parte de su vida cotidiana y que queda representada en ámbitos tan diferentes como su vida familiar (padres con móviles, hermanos con videojuegos), vida social (amigos en redes sociales) y vida escolar (profesores que usan la tecnología en sus clases).

Tabla 5.51 Dimensión uso personal de la tecnología por parte de los alumnos

\section{Categoría}

\section{Código}

\section{Episodio narrativo}

- ¿Tienes conexión a internet?

Si (risas) el modem que traía el cosito

- ¿y tus padres saben manejar esta cosa de la tecnología? ¿Saben ocupar internet, correo electrónico?

No, mis papás no, pero mi hermano si

- Bueno, tú tienes computador-pero itienes por ejemplo una Tablet?

No.

- 2.1 Experiencia con la tecnología
(8) Uso personal de la tecnología. Actitudes y funcionalidades que otorgan a la tecnología en su vida personal

- ¿nunca habías usado antes una Tablet?

O sea sí, pero la de mi sobrino... pero mi Tablet... yo antes tenía, pero

- ¿pero qué le pasó? O sea, ¿sabías como ocupar una Tablet?

Un poco.

- ¿Celulares no tienes?

No.

- Claro, porque te quería preguntar si tenías consola de videojuegos, PlayStation o cosas así

No.

- ¿Entonces tú te sientes cómoda con el uso de la tecnología?

- 2.2. Aptitudes frente a la tecnología

Yo sí, porque ayuda a poder conectarse más con los demás, porque en caso de emergencia, o al saber otras cosas

- ¿usas internet para qué cosas?

- 2.3 Tipología en el uso de las herramientas tecnológicas
Eeeh, me conecto a Facebook, WhatsApp y hago tareas ¿qué páginas usas para ver, para hacer las tareas?

Wikipedia (risas).

- ya, ¿y te conectas todos los días? ¿y te conectas a las redes sociales?

Sí.

Fuente: Elaboración propia. 
Cuando a los entrevistados se les consulto sobre el rol educativo formal de las TIC en sus procesos de formación (Tabla 5.52), la tendencia general es que la tecnología es un elemento fundamental dentro de su formación, la que se utiliza de manera cotidiana en las clases y actividades que los jóvenes tienen en sus centros. La percepción general es positiva, aunque no resulta de manera homogénea en todas las disciplinas, ni con todos los recursos posibles existentes en educación. Algunos elementos que se generan en la formación tradicional -como el aprendizaje cooperativo- se replican en la utilización de las herramientas utilizadas. Sin embargo, queda la sensación de una falta de intensidad en el uso de estos recursos TIC por parte de los alumnos (código 3.1), y que serían importantes en el contexto social y "mundial tecnológico". Puntos paralelos a las ideas base que se proponían como códigos a explorar, fueron otros temas como el $m$-learning, el rol docente y los inconvenientes y las limitaciones que tiene la tecnología en su sentido de formación. Particularmente, la actividad educativa formal debe contener un rol docente guiador presente que vaya guiando el uso de la tecnología y de los contenidos.

Tabla 5.52 Dimensión uso personal de la tecnología por parte de los alumnos

\section{Categoría Código Episodio narrativo}

Normalmente, pues la usamos (la tecnología) pero no con tanta frecuencia como se debería. Porque como ahora estamos más metidos en el mundo de las

- 3.1 Percepción tecnológica en contextos educativos formales

(D) Uso de la tecnología en el contexto educativo. Actitudes y funcionalidades que otorgan a la tecnología en el ámbito profesional docente tecnologías, creo que los libros ya no son tan necesarios, entonces, cuanto más estemos en contacto con la tecnología, pues, aprendemos como más fácilmente, porque luego ya cuando somos mayores, por ejemplo nuestros abuelos, si quieren aprender, les cuestan más, pero si empiezas desde pequeños es más sencillo. Entonces, yo creo que se debería empezar con esto desde pequeños.

- ¿Y te gusta más una clase con tecnología o sin tecnología? ¿Con el profesor en la pizarra o que usen videos, que usen data?

A mí me gusta que lo usen... que usen más el data para... para hacer más dinámica la clase, porque todo el rato de escribir ahí, se pone uno así como ...pfff... como

- 3.2 Utilización TIC en las actividades educativas formales mosca así escribiendo y luego uno no entiende cómo estudiar después... a mí me ha pasado que yo de repente escribo mucho y después yo no entiendo cómo estudiarlo después... no... no sé cómo estudiarlo después. Yo hago resúmenes después y con eso yo me quedo... con eso puedo estudiar... con lo otro... con lo otro no porque creo que es mucha información... después yo me enredo y no se... no me acuerdo que va 
primero, que va después, que va al final... noo. me enredo mucho.

- ¿Aquí en el colegio, los profesores utilizan tecnología?

- 3.3 Estrategias para el aprendizaje con TIC
Por lo que yo he visto, la mayoría ocupa tablets que se le hace más fácil que el computador, porque tienen todo sus proyecciones de la clase ahi, y entonces las conectan al data y proyectan la clase.

\section{- Sobre la experiencia RA-NPM}

No era tan complicado, porque trabaje con otras - 3.4 Interacción personas también.

entre alumnos mediante TIC

- ¿pudiste intercambiar ideas con otros? ¿o hablaban de otras cosas?

No po, si era... del tema que hablábamos, de eso hablábamos.

- ¿Tú crees que esta actividad hubiera funcionado pero sin el trabajo de campo? Es decir, trabajar en el aula pero con las Tablet ¿Hubiera sido lo mismo?

- Comparación de tratamientos

No, yo creo que no. Es más, si vas allí como que lo estás viendo, ¿No? Entonces como que captas más la atención, pero estando aquí, pues, no sé, estás como más distraído. Allí como que estás interactuando más con las tabletas y lo estás viendo también.

Yo no sé si por mi cuenta lo haría, porque igual creo que puede ser peligroso andar sola... Si, me gustaría hacer lo del código porque se ve bastante bonito... iría por eso, para ver si se ve realmente como en la imagen.

- Inconvenientes limitaciones

O sea, se podría aplicar en todos los ramos

- Interoperabilidad de los recursos educativos digitales (asignaturas), pero hay personas diferentes con esa enseñanza que se puede realizar con la tecnología. Por ejemplo, tengo amigos que no entienden mucho de tecnología, pero igual la manejan... Los datas y todo eso.

Me parece muy completo, porque en un libro ves la información pero no tienes fotos antiguas como habían,

- m-learning representado en el uso de la tablet o móvil no te iba siguiendo con las chinchetas donde vas yendo, no sé, es muy completo, te dice el lugar, estás allí viéndolo, te da la información, te aporta fotos. Además, se lleva mucho lo de la tecnología, no cualquiera sale con un libro a ver los patrimonios. Sin embargo, vas con la Tablet, lo vas viendo.

Yo creía que iba a ser como que ibas a ir explicando y los íbamos viendo en los IPads, pero era más todo centrarlo en el iPad pero como que me faltó eso, que explicaras mientras lo íbamos viendo.

Fuente: Elaboración propia. 
Cuando a los alumnos se les consulta de manera particular por la actividad RANPM realizada (Tabla 5.53), las opiniones y comentarios generales son positivos, destacando el sentido didáctico de la actividad, mediante lo que es la interactividad con el dispositivo y el contexto de trabajo de campo presentado. Adicionalmente aparece la opinión sobre la forma de medir el proceso (prueba objetiva), la cual fue mencionada por una de las entrevistadas con elementos muy positivos en su valoración.

Tabla 5.53 Dimensión evaluación de la experiencia RA-NPM por parte de los alumnos

\section{Categoría}

Código

4.1 Percepción sobre el aprendizaje con mapas y NPM

\section{Episodio narrativo}

Al principio no entendía mucho, porque había que apretar como muchas partes para que te diera otra $y$ otra, pero si me gustó, porque cuando uno iba caminando se iba marcando el recorrido, entonces era como más fácil llegar, y también salían las imágenes antiguas de ... por ejemplo, una iglesia y yo ni siquiera sabía cómo eran antes, y entonces en lugar de darse la flojera de buscar en google la imagen antigua, estaban ahí.

- 4.2 Percepción
sobre el aprendizaje
con RA

A mí me gustó mucho esa donde uno ponía el código de barras, o sea, el código... no sé cómo se dice, y se veía la imagen porque se veía muy real, parecía un holograma y se veía muy bonito

Hee... o sea... no, no lo encontré tan largo, lo encontré como más... más, así como más... así como más... entretenido para mí, no lo encontré tan largo, lo encontré más divertido hacerlo afuera en vez de estar encerrado en el colegio, entre cuatro paredes haciendo una clase... que fome, latero (aburrido), qué se yo... más que latero ahí el profesor habla, el resto habla y no se entiende la idea, hay ideas que se enredan y queda la idea ... como se llama... toda enredada, no se entiende $y$ luego desenredar la idea cuesta mucho. sobre el aprendizaje con tablets

Me pareció bastante buena porque a pesar de los lugares que siempre están ahí, nosotros no teníamos idea de cuál era su historia, por qué estaban ahí y que hacían ahí y... el uso de las tecnologías fue bueno porque no sabíamos que tenía también esas aplicaciones que nos ayudaron a conocer más sitios de nuestro país.

4.4 Sentimiento torno a la experiencia de trabajo

Me gustó que nos hicieras una especie de examen al principio y luego al final por qué, no sé, no nos lo habian

- Evaluación de la hecho nunca, ha sido algo nuevo y como que te das experiencia cuenta de lo que sabes al principio, de lo que no sabes y luego al final te das cuenta de que has estado reteniendo cosas y te has dado cuenta de cosas.

Fuente: Elaboración propia. 
Todas estas dimensiones y variables definidas se encuentran representadas en relaciones de diverso tipo (Figura 5.13), en las que destacan la asociación, la pertenencia o la condición. De esta manera, se establece una estructura que compone el discurso desde los alumnos, que va desde la propia apreciación de las TIC (contexto generalpersonal) hasta el desarrollo de la actividad educativa AR-NPM, con sus valoraciones e impresiones. También se incluyen los contextos de antecedentes particulares y el uso de la tecnología en contextos educativos formales, los cuales se encuentran relacionados con las otras variables de manera directa o indirecta.

Figura 5.13 Relaciones entre categorías y códigos. Alumnos

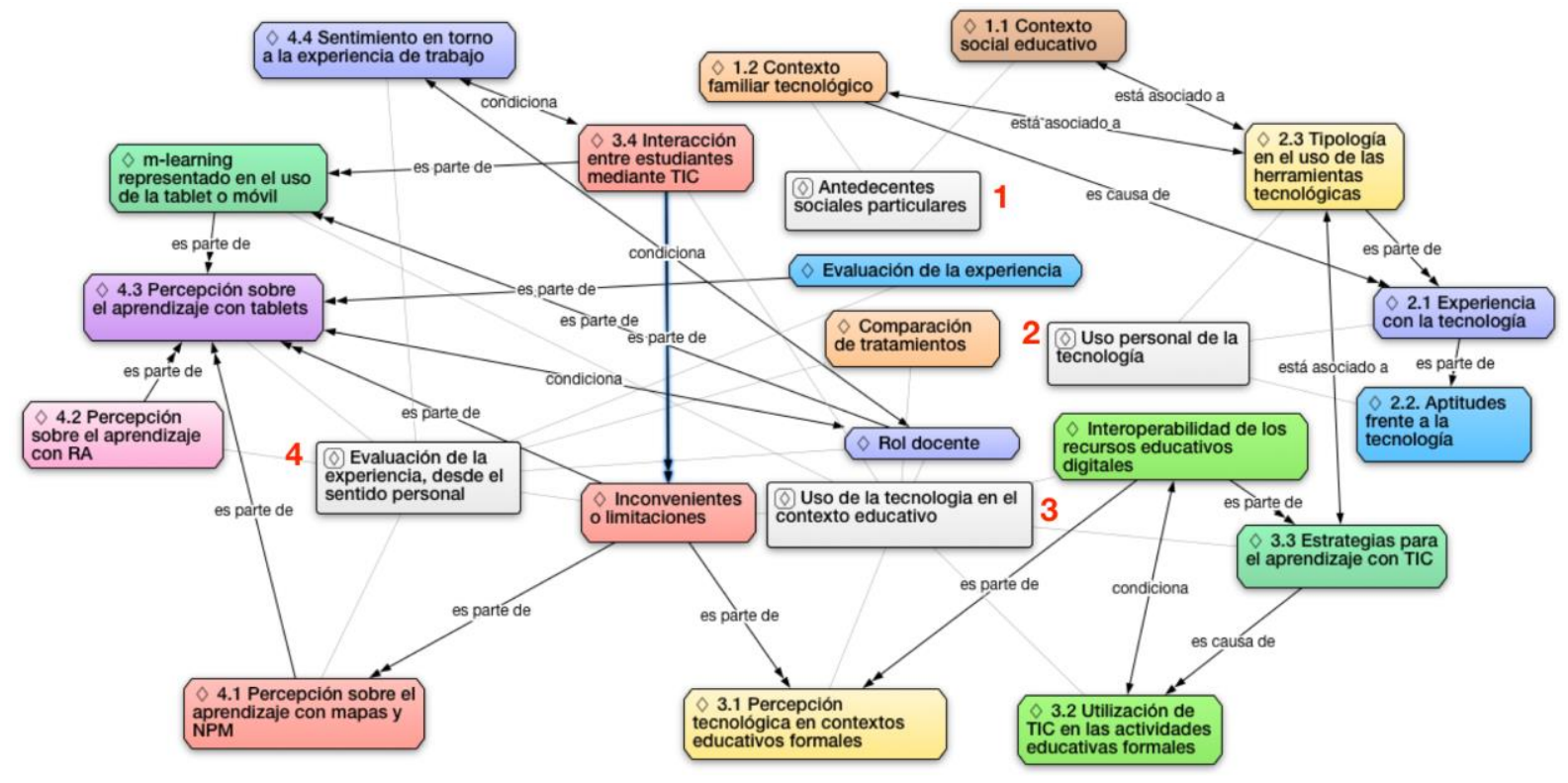

Fuente: Elaboración propia.

Así, las variables que tienen una mayor dinámica dentro del contexto cualitativo son m-learning y la percepción del aprendizaje con tablets, elementos que se articulan con una cantidad importante de otros códigos. Es importante mencionar que el aspecto de Inconvenientes o limitaciones se presenta como un punto central el cual se relaciona con elementos como la forma de aprendizaje con las herramientas propuestas y la interacción entre alumnos y TIC.

Cuando se analiza la nube de palabras creada con el discurso de los alumnos (Figura 5.14), los términos que destacan se encuentran referidos a diversos aspectos de la experiencia educativa de la que forman parte (interactuando, instrucciones, 
computador, completo, estaban, aplicaciones, entender, información, conectarse, herramientas). Aunque no es posible establecer patrones en los conceptos y su preponderancia en las entrevistas realizadas. Sin embargo, es posible notar que la cantidad de palabras con connotaciones negativas (miedo, aburre, problema, deslocalizaba) emergen visualmente y son parte de la estructura del discurso en torno a estas herramientas. También es importante destacar que a diferencia del discurso de los docentes, los relatos son dispersos con menos puntos en concordancia, lo cual explica la forma y distribución de la nube de palabras obtenida.

Figura 5.14 Nube de palabras, entrevistas con los alumnos

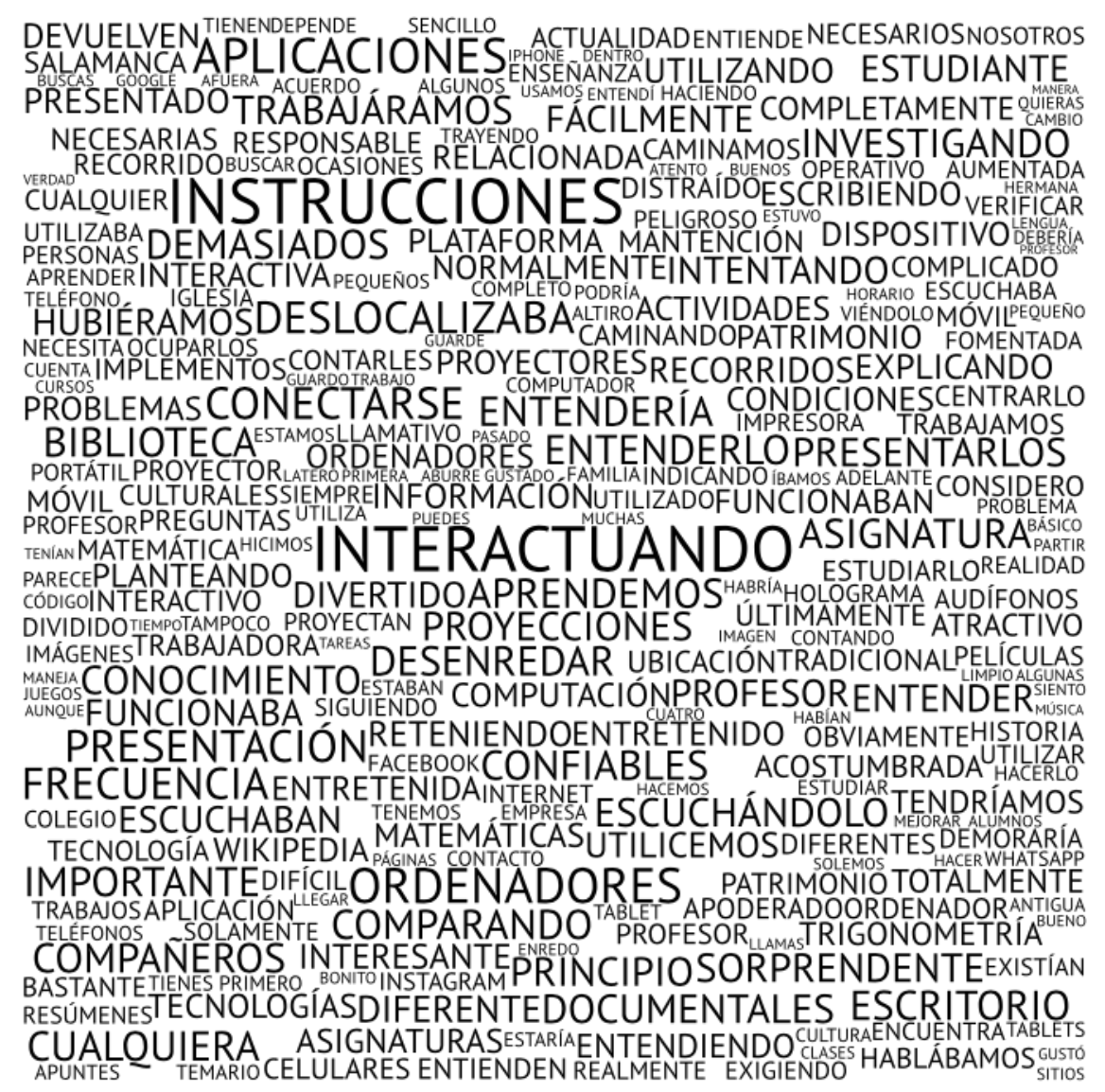

Fuente: Elaboración propia.

Desde los resultados de los relatos obtenidos de los profesores y alumnos, es posible encontrar algunos puntos de concordancia, particularmente en lo referido a la innovación establecida de la herramienta (aplicación RA-NPM) dentro de los contenidos sobre patrimonio. Este núcleo general se encuentra presente en las entrevistas con la 
presencia de su codificación y en las nubes de palabras en donde conceptos como "aplicación" e "interactuando" emergen como términos que salen a la luz de sus testimonios. Las relaciones que se generan en las conceptualizaciones presentadas en las categorías "uso de la tecnología en el contexto educativo" y "evaluación de la experiencia educativa con $R A-N P M^{\prime \prime}$, tanto en profesores como en alumnos, son las que tienen más interacciones con otros códigos y categorías, siendo elementos tangenciales de los relatos en general, posiblemente, debido al tipo de ejercicio educativo que se estaba proponiendo. Por otro lado, las mayores diferencias en los testimonios se presentan en el tema sobre el rol que tiene la tecnología: mientras los profesores abordan dicha dimensión desde una perspectiva propia de su práctica docente-profesional, y en donde emergen códigos como "rol docente", "recursos TIC", "limitaciones", "formación previa", los cuales entregan señales de cuál es el significado de las herramientas utilizadas en la experiencia educativa. En cuanto a los alumnos, el significado particular de las herramientas utilizadas se encuentra asociado al ámbito formal educativo con la definición de códigos como "percepción del aprendizaje", "rol docente", "interacción entre alumnos" y "sentimiento en torno a la experiencia de trabajo". Este resultado podría estar condicionado contexto formal en que se realiza la actividad, la cual mediante las pruebas objetivas, fue evaluada, proceso similar al que ocurre con otros procesos de enseñanza-aprendizaje en escuelas e institutos.

\subsection{Resumen}

El presente capítulo de la tesis ha expuesto los resultados y la evaluación de los datos generales del estudio, considerando las diferentes dimensiones y metodologías propuestas, las que van desde el ámbito de la tecnología y el desarrollo informático, pasando por el análisis territorial, hasta llegar a los elementos educativos que envuelven el contenido de la investigación.

De esta manera, se comienza con una exposición de los resultados a los análisis territoriales realizados para las dos experiencias educativas a implementar, que, desde el ámbito patrimonial y teniendo un contexto territorial de características urbanas, es posible de modelar y situar con el fin de obtener algunos elementos espaciales que sirvan de contexto al entorno educativo que se propone. 
Además, se expone el contexto tecnológico el cual se encuentra enmarcado por el desarrollo informático móvil, considerando los aspectos esenciales en torno a la implementación de la herramienta base que se quiere evaluar desde el contexto mlearning y u-learning. Esta etapa de desarrollo, al igual que todas los elementos de esta tesis, se realizó teniendo en cuenta los casos de estudio a generar (Santiago de Chile y Salamanca, España), y, adicionalmente, considerando los avances en los aspectos de programación móvil implementados recientemente con la utilización de Objective-C y Swift para la elaboración de las aplicaciones.

La sección educativa del capítulo se encuentra enmarcada en la utilización de metodologías cuantitativas y cualitativas, que entregan las valoraciones respectivas al diseño e implementación de las herramientas utilizadas. En el primer caso, se hace una análisis profundo en un contexto cuasiexperimental de los resultados del aprendizaje de los participantes, con la determinación del comportamiento de la normalidad de los datos, la contrastación de hipótesis correspondiente y la determinación de los efectos y potencia de las pruebas aplicadas. Así, desde un contexto general, los resultados muestran cómo los tratamientos aplicados han tenido efectos positivos en los alumnos, con un aumento en las puntuaciones finales obtenidas en el Post-Test, sinónimo de que existe una mejora en el aprendizaje derivado de la utilización de estas herramientas. Desde los elementos particulares, tanto contenidos como procesos presentan variaciones positivas, sin embargo, el contenido de Localización los resultados obtenidos difieren de los otros contenidos y procesos, siendo uno de los menores rendimientos de la prueba objetiva aplicada. La explicación de esta situación, se presenta en la entrevista a los profesores, quienes establecían la necesidad de una formación previa en conceptos de representación territorial y espacial (lectura de mapas, puntos de referencia, puntos cardinales) para mejorar el rendimiento en este tipo de contenidos. A pesar que los resultados entre países no se pudieron comparar, por la diferencia en las estructuras de las pruebas objetivas utilizadas, es posible establecer que, para el caso de Chile, el aprendizaje realizado con iPad ( $m$-learning) tiene un mejor rendimiento respecto al tratamiento con Ordenador ( $e$ learning). Para el caso de España, estas diferencias en los tratamientos no se encuentran bien definidas. A pesar que desde los valores generales hay un aumento en las puntuaciones de los alumnos después de realizada las actividades educativas, cuando se analizan los ítems de manera disgregada existen leves diferencias entre los tratamientos: para los contenidos Históricosy Arquitectónico y el proceso de Conocimiento se presentan mejores rendimientos para el tratamiento con Ordenador, y en los ámbitos de Localización, 
Comprensión y Aplicación las mayores puntuaciones relativas se dan con el tratamiento iPad.

Adicionalmente se realiza un análisis a la escala de satisfacción a los alumnos participantes, entregando evidencias hacia una valoración positiva de la actividad, y que permite complementar los resultados del Pre-test/Post-Test. En términos generales no hay diferencias significativas entre la percepción de los alumnos y el tratamiento utilizado, así como tampoco hay diferencias importantes entre la nacionalidad y la actividad educativa realizada (iPad u Ordenador).

Desde el ámbito cualitativo, se realizó un análisis de las entrevistas, realizando la codificación y estructurando su presentación a través de redes gráficas y nubes de palabras. De esta manera se recogió información de los testimonios de los profesores participantes de la experiencia, siendo algunos de los elementos a comunes a destacar: la posibilidad de replicar la actividad a otros contenidos de sus disciplinas y la incorporación de nuevos recursos tecnológicos para el desarrollo de las actividades educativas. Por otro lado, los elementos que emergieron de los relatos con diferentes percepciones, se encuentra el rol que debe tener el docente en la utilización de estas herramientas: el cual para algunos el docente debe ser un activo protagonista, guía del proceso educativo que se está realizando. Para otros entrevistados, este rol solo debe situarse como mediador, permitiendo a los alumnos realizar su aprendizaje mediante la exploración y el descubrimiento.

De la misma manera, las percepciones y opiniones de los alumnos entrevistados entregan, de manera general, valoraciones positivas de la actividad y de las herramientas, las que pueden deberse a la asociación lúdica que hay entre este tipo de tecnología y su utilización cotidiana por parte de los entrevistados. En cuanto a los aspectos específicos en donde existen diferencias de opinión y percepción de los alumnos, nuevamente se encuentra el rol del profesor como guía de la actividad, la implementación adecuada de los recursos multimedia (incluido los mapas y la RA).

Así, estos resultados entregan valiosa información sobre los procesos, sus diferencias, las herramientas utilizadas, sus dimensiones y los participantes, entregando validez a los procesos de m-learning y acercándose a la contextualización que propone una práctica educativa con u-learning. 
Capítulo VI

Discusión de los resultados 



\section{DISCUSIÓN DE LOS RESULTADOS}

\subsection{Discusión en torno al marco teórico}

En el desarrollo del marco teórico de la investigación se ha definido en profundidad el contexto y el contenido de las herramientas que enmarcan el estudio propuesto, situándolo dentro de un gran escenario teórico como es la Sociedad del Conocimiento, abordado desde los aspectos de la evolución de las innovaciones y las estructuras teóricas educativas que se encuentran presentes.

En un primer lugar, se establece que desde estos contextos se desarrollan nuevas formas de aprendizaje, relacionados con nuevas metodologías, formas y artefactos, los cuales se despliegan en conjunto desde un contexto multitemático, sumamente flexible y adaptable a los contextos sociales particulares de cada lugar. Sin embargo, hay elementos fundamentales de estos procesos de implementación tecnológica que continúan hacia el campo educativo, como son la experiencia y la realidad en el marco del contexto cotidiano (ubicuidad ${ }^{112}$ ), los cuales siempre han estado presentes en el desarrollo de las personas, pero que en la actualidad se potencian con la existencia de la información estructurada y diseminada con compleja tecnología en un contexto de movilidad.

La implementación de toda herramienta o artefacto tecnológico conlleva un aspecto social que puede masificarse y evolucionar, superando la intención inicial para la cual fue creada. Para el caso de los mapas, este instrumento tuvo un papel fundamental en la época de los descubrimientos (siglos XV al XVII), llevando a su desarrollo como disciplina y más particularmente como arte y lenguaje. Ya entrado en el siglo XX, los mapas se transformaron en una herramienta sumamente compleja sobre la representación de la Tierra, siendo ya en el siglo XXI, en un contexto digital con la masificación y almacenamiento de datos, una herramienta de análisis y modelación de patrones. Una situación similar ha ocurrido con la realidad aumentada, que en poco más de medio siglo ha sufrido importantes variaciones en su forma de implementación y uso: como desarrollo tecnológico nace con fines académicos, encontrando prontamente utilidad en el campo militar. En la actualidad se utiliza de manera cotidiana con móviles y tabletas en áreas como la publicidad, medicina o el entretenimiento. Quizás una evolución mucho más

\footnotetext{
112 La Real Academia de la Lengua Española define el término "ubicuo" como "Dicho de una persona: Que todo lo quiere presenciar y vive en continuo movimiento." (En http://dle.rae.es/?id=b0TGxUs. Consultado el 9 de mayo de 2016).
} 
dinámica se ha generado en el área de la informática en el contexto de movilidad. En menos de 15 años las capacidades de procesamiento de datos y las innovaciones técnicas de los dispositivos han crecido de forma casi exponencial, permitiendo la portabilidad en diferentes contextos y tipos, con implementaciones diversas que van desde los smartphones y tablets hasta los smartwatches, y con una evolución que continúa en proceso.

Ahora, el aspecto social que se ha analizado en esta Tesis corresponde al contexto educativo, en donde estas herramientas toman perspectivas particulares para la formación, desde la visualización, interpretación y comprensión de una parte de la realidad que se abstrae dentro una temática particular como lo puede ser el patrimonio en su representación dentro del territorio.

\subsubsection{Realidad aumentada: más que una extensión visual de la realidad}

Desde la construcción teórica del concepto, la RA puede entenderse como parte de un paradigma tecnológico en donde la información presente en el mundo real se relaciona con los datos generados mediante ordenador en un ámbito donde se hace la utilización de las 3 dimensiones espaciales (Amin \& Govilkar, 2015; C.-H. Chen et al., 2016; Kipper \& Rampolla, 2012; Martin-Gutierrez, Garcia-Dominguez, Gonzalez, \& Corredeguas, 2013). Dicho paradigma se encuentra constituido por lo que Milgram y Kishino (1994; 1995) establecieron como el Continuo Virtual, en donde la RA sería una fase intermedia entre lo que es la realidad absoluta, sin la intervención de medios informáticos, hasta lo que se conoce como Realidad Virtual, en donde todo el concepto de contexto espacial se encuentra modelado por información digital generada por ordenador. Como tecnología que tiene un avance propio la RA pasa a tener elementos que lo comienzan a caracterizar y clasificar, generando tipologías y taxonomías en torno a estas herramientas (Aurelia et al., 2014; Kipper \& Rampolla, 2012; Minguell et al., 2012), que van desde los tipos de reconocimientos que realizan de su entorno $(\mathrm{QR}$, imágenes, objetos, localización), pasando por aspectos como la forma de interacción con los elementos visuales, hasta el contexto de hardware en que se despliega (RA móvil).

Desde el aporte teórico de la tesis en el ámbito de la RA, se hace necesaria la conformación de un concepto mayor como sistema, en donde se establece la reunión de elementos orientados para el manejo y administración de información en un contexto digital, los 
cuales se encuentran organizados para su uso. Esto se deriva hacia lo que es un Sistema de Información en donde los componentes básicos propuestos para la implementación de un Sistema de RA son:

- Hardware: en RA, de manera paralela a lo que es el almacenamiento y el procesamiento de la información (elementos propios de los ordenadores), se encuentran dos aspectos que son fundamentales para su funcionamiento, como son la captura visual de datos, mediante una cámara y el despliegue de la información gráfica a través de una pantalla (Yoo \& Lee, 2015). En un contexto de movilidad todos estos aspectos se encuentran situados en un solo dispositivo como los teléfonos móviles inteligentes o las tabletas (S. Lee, Suh, \& Park, 2015).

- Software: este componente corresponde a la arista lógica del sistema de RA. En este aspecto se encontrarían no sólo las aplicaciones de despliegue de la información, sino también la administración de los datos digitales y los sistemas operativos involucrados como plataformas base (Cubillo Arribas, 2014; Jamali et al., 2014).

- Datos: es la información digital que es desplegada visualmente y que puede ser consultada y transferida por la acción conjunta del software, el hardware y las personas (Martín Gutiérrez \& Meneses Fernández, 2014). El próximo nivel que debería alcanzar el estado de los datos en RA es el procesamiento, transformación y la captura de la información del entorno, con el almacenamiento de su forma espacial y el contexto de la información que le rodea (por ejemplo: la posición, el tiempo). Con ello se realiza la interoperabilidad de la información hacia otras plataformas o sistemas de datos que no necesariamente tienen como objetivo la RA.

- Personas: dentro de la estructura de este sistema, corresponde a los que realizan la interacción con los modelos generados por ordenador, mediante su creación o su utilización.

La incorporación de estas características tiene como fin proponer una definición tendente a un enfoque funcionalista, en donde todos los elementos toman parte fundamental en la constitución de una estructura operativa e integradora con otros 
aspectos de la implementación de la RA, superando el exclusivo despliegue y visualización de datos.

Desde el ámbito educativo, la RA toma su rol como medio de transferencia de información. Dicha transferencia tiene una mayor potencia respecto a otras formas de comunicación como son el lenguaje escrito o el matemático, aunque la interpretación o la transformación de la información en conocimiento queda condicionada a parámetros que guíen y ayuden al observador:

"Es más fácil de aceptar la teoría de que hablar y entender es un proceso sintético que la idea de que la visión es sintetizada, porque nos damos menos cuenta de que estamos viendo activamente que de que estamos hablando. Nadie cree que necesita aprender a "ver". Pero si se acepta esa idea resultan explicables muchas más cosas que con la antigua y más difundida noción de que una "realidad" uniforme y estable es registrada por su sistema receptor visual pasivo, que hace que para todas las personas sea igual lo visto y que por ende pueda utilizarse como un punto de referencia universal" (Hall, 2003, p. 88).

De esta manera, la RA asume un potencial de comunicación visual, en el cual es posible guiar la visualización: ayudando a ver en el contexto de complementariedad frente a los elementos que se presentan en los escenarios reales.

A diferencia de la Realidad Virtual, la RA simplifica el despliegue de información digital en elementos visuales que son complementarios, permitiendo interactuar con una cantidad importante de fenómenos reales, lo que hace que sea un sistema ideal para la situación de información de todo tipo, con gran potencial para contextualizarlo en ambientes educativos. Las experiencias de RA en educación se inician con la implementación de libros aumentados, dando paso a otros recursos como son la RA portable y móvil, aplicándose a diferentes disciplinas (Billinghurst et al., 2001; Santos et al., 2013; Squire \& Klopfer, 2007). Así, desde dos escenarios educativos con el uso de tecnología (e-learning y m-learning), se planteó un proceso de formación en donde los elementos de la realidad presente estaban complementados con información gráfica sobre historia, patrimonio y elementos territoriales de un lugar determinado. 
La RA como recurso educativo, al igual que las otras estructuras informáticas utilizadas en esta tesis, se plantean desde los paradigmas presentes en la formación con tecnología. En un primer lugar, se encuentra el e-learning, ya en su versión 2.0, en donde se integran las funcionalidades propias de la web 2.0 (Berlanga, García Peñalvo, \& Sloep, 2010), y en donde la noción inicial de formación con herramientas digitales ha derivado a otros contextos y metodologías de aprendizajes específicos. Uno de estos corresponde al $m$-learning, caracterizado por la movilidad que permite la tecnología en un contexto de aprendizaje, en donde se presentan tres componentes esenciales: hardware, interface y el diseño pedagógico (Petrova \& Li, 2009). Sin embargo, muchos de los estudios y experiencias en torno al $m$-learning se establecen desde el ámbito informal de los procesos educativos, siendo esta una de las limitaciones hacia la incorporación en las experiencias formales de enseñanza-aprendizaje de las personas (Sánchez Prieto et al., 2014; Traxler, 2009). También es importante mencionar que el $m$-learning es una etapa previa antes del u-learning, en donde las personas, mediante la tecnología móvil, pueden aprender desde el contexto en que se encuentren situadas, de acuerdo a sus requerimientos e intereses (Conde et al., 2008; Schmalstieg et al., 2011). En este contexto, la RA y los dispositivos móviles, tipología más específicamente conocida como RA móvil, toma un rol importante para la interacción entre los espacios físicos y sus características y la información virtualizada, entregando un valor adicional a los procesos educativos. Así, desde esta dimensión educacional, la tendencia del uso de RA y la tecnología móvil tiende a la estabilización y alcanza un proceso de maduración, incorporando estas herramientas en escenarios formativos establecidos y guiados, incluso superando el aprendizaje autónomo.

También, dentro de este contexto educativo, el próximo paso es la incorporación de la tecnología de Realidad Virtual -una evolución natural de la RA-, superando los aspectos lúdicos en que se ha implementado, y situarlo en los procesos formativos (Bonenberger \& Harris, 2013; Passig, Tzuriel, \& Eshel-Kedmi, 2016). Sin embargo, esta tecnología no debería sustituir a la RA debido a los diferentes alcances, interacciones y contextos en que se desenvuelven desde la interacción y la presentación de la información digital.

\subsubsection{Geotecnología en la escala local con contenidos personalizables}

Al igual que la RA móvil, las herramientas informáticas se han visto condicionadas por el uso de los datos en función de su localización, que es parte del sentido de ubicuidad 
y la nueva forma de aprendizaje, sobrepasando el simple sentido de movilidad. La implementación de este contexto móvil con datos sobre el espacio físico, ha tenido su origen en la implementación de otras herramientas tan antiguas como la civilización, como son los mapas, la brújula, los globos terráqueos o los sistemas de coordenadas (Branch, 2011). El ser humano siempre ha tenido la necesidad de emular los contextos territoriales para lograr una mejor comprensión de estos, mediante una representación simplificada con algunos elementos o propiedades de un sistema territorial que sea comprensible y fácil de leer (Errázuriz, 1988; Joly, 1988).

Para obtener una simplificación y un modelo de la realidad del espacio físico se hace necesario considerar aspectos que la definen y diferencian como son: la cantidad y los tipos de entidades por las que se encuentra conformada y que pueden ser caracterizadas y definidas, además de ser contextualizados en un modelo abstracto; las variaciones y magnitudes que tienen estas entidades a nivel físico-espacial; y la forma en que se modela y almacena este tipo de información (actualmente en un contexto digital), en la cual se incluyen identificadores, propiedades y relaciones, las cuales son sólo una simplificación de la verdadera magnitud de estos fenómenos (Burrough \& McDonnell, 1998). Así, la representación final de esta realidad se realiza mediante estructuras matemáticas (principalmente geométricas) en donde las entidades se representan mediante puntos, líneas y polígonos. Todo esto ha generado un lenguaje para la interpretación espacial de la información territorial, la que con el advenimiento de la informática se ha constituido con elementos propios y que se encuentra presente en diversos niveles y tipos de herramientas para el almacenamiento, análisis y despliegue de este tipo de información: si en un primer momento fueron los mapas, cartas y planos, con la incorporación de la informática adquirió un aspecto digital con modelos en pixeles y $C A D^{113}$. Es entonces pertinente desde este punto hablar de cartografía inteligente, en la que a diferencia de la cartografía tradicional, los datos son sumamente dinámicos y contextualizados en función de la localización del usuario, es posible aplicar metodologías para generar nueva información sobre el territorio y permite su adaptabilidad en relación con objetivos específicos.

Otra nueva etapa surge con el advenimiento de Internet a mediados de los 90, que ha permitido la masificación de estas herramientas hacia el usuario común, con la

\footnotetext{
113 Computer-aided design, es el diseño asistido por ordenador.
} 
incorporación de los servidores de mapas y los globos terráqueos virtuales, comenzando una nueva fase en el siglo XXI, con la masificación de la telefonía y los datos móviles, la incorporación de aplicaciones portátiles y los servicios basados en localización (Abbas et al., 2014; Riera et al., 2014). La masificación de la cartografía en un contexto de portabilidad, ha permitido la creación de nuevas formas de información espacial, como son la navegación peatonal móvil, la presentación gráfica de los mapas o las funciones de proximidad, muy relacionadas con las nuevas características de los aparatos derivados de los sensores incorporados (aGPS, brújula, cámaras, giroscopios, acelerómetros), además de las condiciones derivadas del tamaño de las pantallas para el adecuado uso y rendimiento (Degbelo et al., 2016; Reichenbacher, 2005).

Desde la particularidad que ofrece la movilidad en este contexto, existen algunas dificultades en torno a la utilización de estas herramientas (G. Bertrand et al., 2006; Tapiador, 2006), que van desde la fiabilidad de los datos representados, pasando por las limitaciones técnicas derivadas del almacenamiento, la conexión y el procesamiento de datos, hasta los elevados costos para la implementación de este tipo de tecnología y los cuestionamientos éticos derivados de la falta de privacidad y la mala utilización de la información generada. Sin embargo, creemos que este tipo de cuestionamientos son generalizables para todo tipo de información que se genera y distribuye desde los contextos digitales, por sobre el ámbito relacionado con la temática territorial, situación que en la actualidad se encuentra en constante evolución ${ }^{114}$ y que se resuelve de manera reactiva por las sociedades que se ven afectadas.

Desde el plano educativo, los cuestionamientos se producen por la pérdida de capacidades o competencias en torno a la lectura de la cartografía tradicional, ya que ésta se presenta como una forma de lenguaje propia, una técnica particular derivada de la geometría y una expresión de diseño gráfico, con elementos propios y que sería necesario conocer como cualquier otra disciplina (Heap, 2015), con el fin de abstraer y construir una realidad sobre el espacio desde la observación y comprensión de los elementos que la

\footnotetext{
114 En la fecha de creación de esta tesis, han ocurrido algunos hechos de ámbito público que han puesto de manifiesto el debate que se está presentando en las sociedades para el manejo este tipo de situaciones y que implican aspectos jurídicos que superan el desarrollo de esta investigación. Así, cada país actúa de una manera particular frente a estos dilemas, en función de su estructura jurídica y legislativa, la que no necesariamente puede ser replicada o adoptada de manera universal. Algunos de estos hechos son: el desbloqueo de un móvil iPhone de un atacante terrorista por parte del FBI (Hola, 2016), o "el derecho al olvido" sentenciado por el Tribunal de Justica de la Unión Europea y que la compañía Google debió implementar en sus servicios (Rodríguez Álvarez, 2014).
} 
constituyen. Sin embargo, es posible argumentar que estas competencias, que se sintetizan en lo que se conoce como inteligencia espacial y se caracterizan por estar compuestas por la comprensión de las relaciones espaciales, la visualización en un contexto espacial y la propia orientación de los sujetos en un contexto físico-espacial, no desaparecen en la utilización de un escenario tecnológico enmarcado en la movilidad (Newcombe \& Frick, 2010). Sólo se adaptan a las condiciones que proponen estos dispositivos (tamaño de pantalla, sensores, conectividad), por lo que el usuario debe adquirir similares niveles de competencias -incluso competencias digitales- para la lectura, comprensión y utilización de la información territorial. Desde este concepto de inteligencia espacial se deriva lo que es la navegación, siendo una de las capacidades propias de todos los seres humanos, la cual permite el desplazamiento sobre los entornos, con su correspondiente interacción, comprensión y aprendizaje (Brunyé et al., 2014). De esta manera, en un proceso de navegación asistida, se cumplen los mismos elementos que son complementados con algún medio tecnológico, pero en donde el aprendizaje y el contexto cognitivo siguen siendo indispensables para lograr una real comprensión del entorno desde el nivel del desplazamiento.

En un contexto general más allá de la navegación, el aprendizaje con las herramientas que utilizan el contexto espacial para la educación, abarca una serie de dimensiones que tradicionalmente se encuentran presentes en la enseñanza de contenidos sobre el territorio:

- Conocimiento y comprensión del territorio y su organización (De Miguel González, 2014)

- Técnicas de representación del territorio (Artvinli, 2010)

- Destrezas para la obtención de información territorial (Rød et al., 2010).

\subsubsection{Dimensión social y educativa en torno a estas herramientas}

Un último aspecto que se intenta abordar es cómo estas herramientas tecnológicas -más allá de los contextos de las TIC que se presentan de manera general- se presentan en esta nueva etapa histórica y social en que se sitúa la humanidad. De esta manera, la complejidad que están adquiriendo los procesos sociales a nivel global y a escalas locales, 
en donde ambos niveles se entremezclan, se superponen y configuran, en el ámbito particular que entrega la información, en todas las dimensiones, escalas y tipos, se traduce en lo que primeramente fue la Sociedad de la Información (Castells, 2010; CEPAL, 2003). Ya que la información hace referencia al dato duro, obtenido desde la fuente, sin algún proceso o método que le diera funcionalidad, se dio luz al siguiente paso en donde una "Sociedad del Conocimiento", mediante la transformación de la información, puede generar crecimiento económico, capital y trabajo, permitiendo la creación de productos con un alto valor agregado (Krüger, 2006), que muchas veces son intangibles (por ejemplo, un programa informático) y que reestructuran diversos aspectos sociales como son la economía, la política y la educación.

Es para este último caso en donde esta Sociedad del Conocimiento tiene un gran impacto, en donde los niveles de educación, formal e informal, han pasado a ser permanentes (López i Amat, 2010) debido al dinamismo que toma el conocimiento derivado del auge constante de los datos. Dentro de las precauciones que se deben tener en este contexto, las más significativas y que se hacen presentes son:

- La acumulación de datos no es conocimiento. Y el simple conocimiento no es sabiduría.

- Los datos iniciales no necesariamente representan la idea sobre la realidad, y la ciencia, encargada de procesar dichos datos, no hace más fácil la comprensión de dichos fenómenos en torno a los datos (Krüger, 2006).

- La cantidad y densidad de la información existente en la actualidad es inabarcable para un ser humano. Esto atenta contra la idea de comprensión de la información y su posterior traspaso a conocimiento (Heidenreich, 2003).

- Las casi infinitas y complejas interacciones entre la tecnología y los contextos humanos en donde los datos se generan a cada instante en todos los lugares. Esto hace imposible que muchos de estos elementos actúen como cajas negras en donde solo podemos apreciar sus resultados sin mediar en la comprensión de los pasos intermedios y de los resultados obtenidos (Innerarity, 2009).

Todo este conjunto de situaciones en torno a la información y el conocimiento ha dado paso a una serie de estructuras que se desarrollan y actúan, como parte de la 
resiliencia que tiene la sociedad en general, sobre todo ante dificultades que le afectan. Para este caso, esta avalancha de datos e información se ha abordado de manera multisistémica, con la creación de lazos entre disciplinas y metodologías, con el fin de evitar la atomización del conocimiento y la hiperespecialización de los contenidos. Lo anterior se plantea como Complejidad (Morin, 1984, 1999, 2002), en donde contenidos de diversa índole hacen un todo superando la particularidad de sus partes y de su todo, desde lo que es la multidimensionalidad de los fenómenos.

Desde una conformación estructural y social más amplia, es posible entender que todos los avances tecnológicos tengan una respuesta en la constitución de las sociedades, sobre todo desde la segunda mitad del siglo XX. Desde la historia, la modernidad que se presenta con la revolución industrial es reemplazada por el postmodernismo con importantes cambios en los ámbitos políticos, económicos, culturales y sociales del mundo entero (Harvey, 1998; Lyotard, 1987). Desde lo que es el conocimiento, este se encuentra en un estado de legitimación constante debido a los procesos permanentes de innovación y la transformación continua que tienen todos los aspectos sociales. Sin embargo, lo postmoderno no parece ser un concepto bien delimitado para abarcar e interpretar el conjunto de situaciones que están ocurriendo. De esta manera la sociedad se encuentra en una "Modernidad Liquida", la que es una extensión importante del postmodernismo, mejor caracterizado y complejo, en donde el conocimiento deja de estar en un estado sólido, estático y único, para transformarse en algo dinámico, relativo y con elevados niveles de incertidumbre (Bauman, 2004, 2013, 2015), en donde la formación constante toma un protagonismo importante, frente a las clásicas e inflexibles estructuras educativas de tiempos de la modernidad sólida.

El Postmodernismo, la Complejidad y la Modernidad Liquida, tienen subprocesos que han condicionado los aspectos del cómo el conocimiento (transformado en algún tipo de innovación que hace frente a la sociedad) se genera, se desarrolla y masifica en la actualidad. Entre algunas de las teorías que tratan de explicar estos procesos, se encuentran la Teoría de la Difusión de las Innovaciones (Rogers, 2003) y los Ciclos de Sobreexpetación (Gartner, 2015), en las cuales, las innovaciones derivadas del conocimiento toman diversos estadios o fases desde su creación o nacimiento, hasta su posible masificación o maduración. La importancia de estos modelos de innovación, radica en que permiten estimar los alcances que pueda tener una tecnología o técnica dentro del contexto global y, particularmente, dentro del contexto de esta tesis, establecer la posible correlación entre las etapas de la innovaciones tecnológicas analizadas (RA y 
geotecnologías) con su situación en el campo educativo, por sobre el contexto económico sobre la demanda de innovaciones informáticas.

Particularmente desde el ámbito de la educación, estos cambios se han traducido en dos aspectos que es necesario abordar (Jaeger, 2001): la realidad no es un fenómeno inmutable y el orden del mundo no es concreto e inflexible; y las leyes que rigen la interacción humana pueden cambiar, dejando de ser inmutables, sufriendo anomalías y reestructurando los paradigmas establecidos (Kuhn, 1979). Con esto, la cultura y el conocimiento son elementos que presentan fuertes dinamismos, muy cambiantes y a veces efímeros, requiriendo nuevas formas de aprendizaje, de adquisición de competencias y metodologías.

Uno de los aspectos diferenciadores que se proponen dentro de estas nuevas estructuras en la educación, corresponde a la experiencia, que, como referente personal, es un estado único y le otorga un valor agregado al conocimiento general masivo, haciéndolo un proceso particular en un contexto de contenido multidimensional. Estos planteamientos no son nuevos, y se basan en la idea de John Dewey sobre una educación experiencial que supera a la simple acción de entregar contenidos en un entorno estricto e inflexible (Dewey, 1943, 1989; Wheeler, 2015). De esta manera, se requieren nuevos procesos educativos que intenten reunir lo que son los contenidos, la experiencia como valor especial y la tecnología, superando los estándares educativos y tecnológicos inflexibles y descontextualizados. Así, dos modelos que sirven de ejemplo para crear, adaptar, implementar y difundir el proceso educativo presente en esta tesis, se encuentran referidos al TPACK y los Objetos de Aprendizaje. Para el primer modelo, se hace hincapié en los conocimientos (o contenido temático), los cuales se deben dominar para la correcta incorporación de las herramientas TIC en los procesos de enseñanza planteados (Edwards \& Nuttall, 2015; Koh et al., 2015; Mishra \& Koehler, 2006). Dicho modelo ya se ha implementado de manera particular en disciplinas y contenidos como en la enseñanza de la Geografía (Doering, Scharber, et al., 2009) o la Ingeniería (Fonseca, Redondo, Villagrasa, \& Canaleta, 2015). Desde este modelo, los contenidos sobre patrimonio e historia local fueron los referentes para su implementación en un contexto tecnológico, con recursos y sistemas apropiados a las temáticas que se quieren enseñar, teniendo en cuenta las particularidades locales como son los aspectos históricos, la funcionalidad educativa de los recorridos, los recursos gráficos a desplegar y los contenidos que deben ser incorporados. Desde el modelo de los Objetos de Aprendizaje se propone la adaptabilidad y reutilización de las herramientas y recursos digitales creados para ser 
incorporados en otras temáticas educativas con otro tipo de procesos y situaciones (Morales Morgado, 2007). Funcionalmente, la aplicación RA-NPM presenta las siguientes características propias de un Objeto de Aprendizaje:

- Cada material creado es abordado de manera independiente en el contexto de un dispositivo móvil, mediante las escenas y subescenas de la aplicación.

- Los elementos presentes son utilizados y adaptados en diferentes contextos educativos, en lo que se conoce como reutilización. Para este caso particular, la reutilización se realizó entre las ciudades de Santiago de Chile y Salamanca, España.

- Derivado de los aspectos propios de la Programación Orientada a Objetos, la aplicación fue estructurada con el fin de cumplir los objetivos de aprendizaje.

De manera paralela, es importante mencionar que existe la ausencia de algunos elementos para hablar realmente de un Objeto de Aprendizaje, como es la implementación de la interoperabilidad de recursos y contenidos, además del desarrollo y la definición de los metadatos que permitan su real masificación.

\subsection{Discusión de los resultados}

Dentro de la discusión de los resultados se ha realizado una división según los datos obtenidos en cada sección que compone la estructura de la investigación propuesta, desde el ámbito patrimonial y territorial, hasta la discusión de las evidencias desde un plano cualitativo, permitiendo una visión particular de cada proceso con sus características, posibilidades y limitaciones.

\subsubsection{Contexto patrimonial y territorial}

Uno de los aspectos particulares en torno al contenido temático desarrollado por esta tesis, se corresponde con la incorporación de elementos patrimoniales, históricos y culturales dentro de una estructura territorial con sus propias características, influencias y contextos, situación que otorga un sello propio a cada escenario físico-espacial que es 
analizado, sintetizado y modelado en una estructura digital, que en su desarrollo es abstracta, pero que para el usuario final, es una simplificación de la riqueza de estos contenidos. La utilización de las TIC en la enseñanza de estos contenidos ha tenido un reciente auge con la inclusión de nuevas herramientas de despliegue gráfico y de contenidos in situ, pasando de la simple digitalización de los temáticas patrimoniales, a situarlos en escenarios en donde adquieren un valor agregado, superando la simple presentación de estos recursos, permitiendo ir un paso adelante en el análisis y replicabilidad de estos fenómenos invaluables, sin alterar su constitución original evitando el posible daño y deterioro (Rodríguez Silgo, 2016).

Así, las ciudades de Santiago de Chile y Salamanca en España cumplen con los requisitos en torno a su contenido patrimonial, el cual se encuentra inserto dentro de un contexto territorial que tiene una funcionalidad propia, superando las características geométricas como son las distancias y longitudes, siendo representadas y abstraídas en modelos digitales que permiten su comprensión y aprendizaje, primero, desde sus particularidades y elementos aislados, para, posteriormente, situarlos como un gran sistema que se desenvuelve en conjunto. La aplicación de una metodología de análisis espacial permite abordar algunos de estos aspectos más allá de la situación de la localización de estos contenidos, encontrando nuevas formas de representación y comprensión de este tipo de realidad. La idea de transmitir a los usuarios contenidos complejos, que son multidimensionales desde su temática (el patrimonio se encuentra relacionado con la historia, economía, arquitectura, arte, por mencionar algunas disciplinas) es una tarea sumamente difícil, por lo que algunas herramientas visuales permiten una adecuada síntesis de estos contenidos. El cerebro humano, en un alto porcentaje, trabaja con el componente visual (Owens, 2007), lo cual puede relacionarse y adaptarse con los recursos gráficos existentes como son los mapas, modelos 3D, imágenes y video, todos presentes en el ámbito digital y móvil (Gaffney et al., 2013).

Desde este punto de partida, se establece que ambas ciudades contienen elementos patrimoniales, los cuales, sin embargo, difieren en aspectos y magnitudes (no solamente en lo referido a su tamaño, sino también a la magnitud de su significado social y cultural) y que también deben ser considerados como parte esencial de este tipo de implementaciones: la evolución del bien patrimonial a lo largo de la historia, los diferentes contextos culturales en que se han establecido y su situación presente, la cual no siempre es la adecuada para un recurso patrimonial. 
Es desde esta perspectiva multidimensional, que se plantea la posibilidad de replicar esta metodología, no sólo en otros escenarios patrimoniales y urbanos, o en diferentes escalas y espacios, sino también en otros contextos temáticos para la enseñanza como es el medio ambiente (tan multidisciplinar como el patrimonio, pero con disciplinas como la biología, la ecología, la climatología, botánica, geología, por mencionar algunas) o la enseñanza de las ciencias (química, física y matemáticas), permitiendo generar escenarios personalizables de aprendizaje y en donde la ubicuidad entregue un valor agregado a los procesos de formación.

\subsubsection{Desarrollo informático}

Los últimos avances en materia de tecnología móvil y en elementos de desarrollo programático han permitido aumentar, hasta niveles nunca antes vistos, las funcionalidades y operaciones que presentan estos aparatos. En el desarrollo de esta tesis, se han abordado tres de estos componentes para situarlos, en su conjunto, en un contexto de movilidad que otorgan las tabletas, particularmente en lo referido a tecnología iPad. Un primer componente y que se plantea como base del sistema de la aplicación móvil desarrollada, se encuentra referido al conjunto de frameworks conocido como Cocoa Touch, el cual permite la operabilidad de los datos, la implementación de la interface del usuario y a la interacción de otros componentes que son implementados en la aplicación. Los siguientes frameworks componentes del sistema elaborado -MapKity CoreLocationpermiten la interacción físico-espacial del dispositivo, entregando información de localización e informando visualmente por medio de un mapa, de estos datos, permitiendo la interactividad entre sensores de posición, usuario e interfaz gráfica. Además, mediante esta herramienta, la implementación del sistema de navegación en función de los datos y recursos patrimoniales previamente obtenidos, en conjunto con la interacción de los otros elementos informáticos del sistema, permitió la adecuada interacción entre presentación y despliegue de resultados dentro del contexto educativo formal. Un último módulo fue la inclusión de los recursos de RA, el cual fue implementado mediante el framework Metaio, debido a su facilidad de implementación (lenguaje iOS Objective-C), la capacidad de leer objetos 3D desde formatos gráficos genéricos (modelos .DAE y .SKP) y su metodología de reconocimiento óptico que supera la lectura de imágenes o códigos $\mathrm{QR}$, para realizar el proceso mediante el reconocimiento de formas o con información geolocalizada. Desde la perspectiva propia del desarrollo, la aplicación creada ha presentado diversos cambios y 
actualizaciones, siendo una de las derivaciones propias de la situación en torno al avance informático, cada vez más vertiginoso y rápido, pero con implementaciones que enriquecen los productos que se plantean. El cambio más significativo fue en torno al uso del lenguaje de desarrollo, que en un primer momento se planteó en Objective-C, con todas las funcionalidades de la programación orientada a objetos y lingua franca de la estructura general de los productos Apple (Bennett et al., 2010; Hillegass, 2011; Hillegass \& Conway, 2013). El cambio radical, que se hizo también presente en el desarrollo de la aplicación, fue la aparición de un nuevo lenguaje de implementación propuesto por Apple, Swift 1.0, multiparadigma y con programación funcional, lo que permitió la flexibilización del código utilizado, la reducción del número de clases y objetos, y el desarrollo del primer paso para un concepto de interoperabilidad real de los datos con la lectura de archivos externos para la definición de los contenidos. Sin embargo, se hace necesario el establecimiento de la normalización estructural de la información implementada con la incorporación de elementos y formatos establecidos, como son los estándares de datos para RA y para la información espacial digital (Enviroment Research System Investigation, 2008; Open Geospatial Consortium, 2006, 2013). Esta estandarización se encuentra en una estructura XML de datos, lo que facilitaría la interoperabilidad entre plataformas, la creación de recursos digitales y su almacenamiento.

\subsubsection{Dimensión cuantitativa}

Desde el ámbito cuantitativo educativo de la presente investigación, se apuntó a la evaluación de la aplicación creada estableciendo la eficacia de recursos tecnológicos como RA y la NPM, sobre los procesos de adquisición de conocimiento en un contexto de m-learning/u-learning con tecnología móvil (tabletas) en comparación con otras metodologías similares, pero aplicadas en contextos diferentes (e-learning). Para la comprobación de esta afirmación se ha desarrollado un proceso metodológico desde una perspectiva científica, con la valoración de cada una de las etapas de diseño, desde la selección de contenidos patrimoniales que serán enseñados, hasta una profunda revisión de las pruebas objetivas aplicadas.

Es importante destacar que para poder realizar un análisis detallado de la eficacia de estas herramientas, el contexto de aprendizaje de contenidos propuesto en la prueba escrita, fue subdivido en dimensiones funcionales con contenidos Históricos, Arquitectónicos y de Localización, y procesos de Conocimiento, Comprensión y Aplicación 
con el fin de facilitar la evaluación de las mismas. Sin embargo, es importante entender que estas dimensiones conforman un sistema conceptual integrado (aprendizaje), el cual, independiente de sus resultados particulares, debe visualizarse como un todo dentro de este proceso evaluativo. Así, desde este nivel general y unificado, los resultados globales son positivos, pudiéndose afirmar que estas herramientas han mejorado significativamente el nivel de aprendizaje de los alumnos en temáticas sobre patrimonio local. Es debido a este contexto temático propuesto para cada país, que desde un contexto general puede ser similar y replicable (contenidos y procesos), pero desde la particularidad de las escalas locales y temporales de cada ciudad, la diferencias se hacen explicitas y se desvelan finalmente en la estructura del instrumento de evaluación, con fenómenos, temporalidad y magnitudes diversas y diferentes. Por esta razón, los resultados entre países no son comparables a pesar que ambas experiencias propuestas fueron establecidas con el mismo rigor metodológico, aunque en la prueba objetiva las diferencias de contenidos no puedan permitir el contraste correspondiente de estos resultados.

Desde un segundo nivel, con los resultados divididos en función del tipo de tratamiento que se utilizó para cada experiencia educativa, se puede establecer que para el caso de Chile existen diferencias significativas de aprendizaje entre los alumnos que utilizaron iPad con respecto a los que trabajaron con Ordenador. A pesar que ambos grupos presentan aumentos importantes en sus puntuaciones finales después de las actividades desarrolladas, los alumnos que se desenvolvieron en un contexto m-learning tuvieron un mejor rendimiento respecto a los alumnos que sólo trabajaron en una situación e-learning. Estas diferencias se dieron de manera explícita en aspectos como los contenidos Histórico, Arquitectónico, y en procesos de Conocimiento, Comprensión y Aplicación, en donde el trabajo de campo más la incorporación de la aplicación móvil, con sus elementos de RA, mapas y recursos multimedia, permitió una optimización del proceso de aprendizaje, confirmando los resultados de otras investigaciones que van por esta línea (Al-Qahtani \& Higgins, 2013; Friess, Oliver, Quak, \& Lau, 2016; Furió, Juan, Seguí, \& Vivó, 2014). De manera particular, en el contexto de los contenidos de Localización, aunque hay un incremento de las puntaciones finales, no existen diferencias significativas entre los grupos según tipo de herramienta utilizada, situación que podría explicarse desde varias situaciones, que van, desde el cómo se realizó el planteamiento de la metodología educativa y el número de ítems de la prueba objetiva, hasta problemas informáticos derivados de la conectividad y el uso de hardware, entre otros. Otra posible explicación de esta situación fue planteada en las entrevistas con los docentes participantes 
(profesores Pedro y Cristina), quienes establecían la falta de habilidades de los alumnos para interpretar mapas e información espacial (conceptos de referencia como norte, latitud, escala), derivado de la ausencia de estos contenidos en los planes y programas educativos presentes en la formación escolar, situación que es corroborada con algunos autores que establecen que para la correcta lectura y comprensión de la información digital espacial es necesario el conocimiento previo de los significados y contextos como se produce en cualquier otro tipo de técnica (Medyńska-Gulij, 2014; Yilmaz, Kemec, SebnemDuzgun, \& Cakir, 2014).

Para el caso de España, los resultados del contraste por contenidos y procesos son disímiles entre sí, en donde los contenidos Históricos y Arquitectónicos y el proceso de Conocimiento los alumnos que realizaron al experiencia con Ordenador presentan leves niveles superiores a los de iPad, aunque estadísticamente no son significativos. El caso contrario radica en los procesos de Aplicación y Comprensión, en donde los alumnos con iPad presentan mejores rendimientos respecto al tratamiento de Ordenador, aunque igualmente no se encuentran diferencias significativas. Nuevamente el contenido de Localización se presenta como un elemento particular de todos estos análisis, ya que las diferencias entre grupos sí son significativas, desde la medición Pre-Test hasta los resultados de sus puntuaciones finales en el Post-Test, siendo el grupo con iPad el que tiene un mejor rendimiento, debido al aumento considerable en sus resultados finales, los cuales superan al grupo de ordenador. Estos resultados van en la línea de otros estudios (Jacob, Mooney, \& Winstanley, 2011; Rovelo et al., 2015; Szymczak, Magnusson, \& Rassmus-Gröhn, 2012), en donde una navegación asistida mejora la comprensión espacial de los usuarios. Es importante mencionar que los resultados para España deben leerse con un mayor cuidado por la pequeña cantidad de alumnos participantes para cada experiencia, lo cual podría influir sobre los resultados obtenidos, al no definirse totalmente las tendencias de las puntuaciones.

Un último aspecto de esta dimensión cuantitativa está referido a la encuesta de satisfacción. Desde el plano general, los valores obtenidos establecen que las implementaciones informáticas tuvieron una alta aceptación entre los alumnos, no existiendo diferencias significativas entre los alumnos de Chile y España, aunque es posible percibir que las diferencias existentes podrían ser debidas al nivel socioeconómico de los participantes, a la penetración tecnológica presente en cada país y la accesibilidad a los recursos tecnológicos. Desde estos posibles factores, los alumnos de Chile presentan un mayor nivel de satisfacción en el uso de las herramientas informáticas implementadas, 
percibiéndolas como herramientas innovadoras y originales contextualizadas en una actividad educativa, superando el uso informal y cotidiano con que se les relaciona. De la misma manera, no se presentaron diferencias significativas en el nivel de satisfacción de los alumnos que realizaron la experiencia desde un iPad respecto a los de Ordenador, ya que los mismos recursos (particularmente en lo referido a la RA), se presentaron en ambas implementaciones, siendo el punto diferenciador el contexto situado mediante el trabajo de campo.

Desde los aspectos particulares de estos resultados, los elementos que tuvieron una menor valoración fueron los referidos a la precisión de la información desplegada y al diseño gráfico de las aplicaciones implementadas, aunque estos resultados se situaban cerca del valor "indiferente" ("Ni de acuerdo" - "ni en desacuerdo"). Por otro lado, los ítems que tienen mejores percepciones se encuentran referidos a la usabilidad de los programas (ítem 8) y la facilidad de la navegación dentro de los contenidos (ítem 3). En síntesis, la percepción general de los alumnos participantes se encuentra en torno a un valor nominal "de acuerdo" a todas las afirmaciones planteadas en el instrumento, traduciéndose en un resultado positivo desde el ámbito de la satisfacción por la actividad, por encima de los indicadores de aprendizaje obtenidos en etapas anteriores.

De esta manera, una limitación de este apartado se relaciona con la determinación de otros factores que afectan a los resultados obtenidos, más allá de la implicación de los tratamientos realizados. Desde el nivel de los participantes, factores como nivel socioeconómico de los alumnos, la edad, el género o el rendimiento académico son algunas posibles variables que necesariamente deben incluirse en trabajos futuros para tener una visión más clara de cómo se está produciendo el aprendizaje. Desde el nivel de los centros educativos, elementos como los planes y programas de estudios y las políticas internas en torno a la incorporación TIC, son aspectos que ayudarían en una mejor comprensión de estos resultados.

\subsubsection{Dimensión cualitativa}

Lo resultados de la dimensión cualitativa de la experiencia educativa se presentaron y analizaron desde dos contextos, el de los profesores como sujetos que definen los procesos de enseñanza y aprendizaje desde un contexto predefinido y con herramientas y métodos que utilizan para ese fin, y el de los alumnos, quienes incorporan 
ese aprendizaje con diferentes formas y percepciones. Como se ha establecido anteriormente, la tesis propone un ejercicio complejo, desde el ámbito establecido por Morín (2002), en donde el contenido de patrimonio se sintetiza en dimensiones tan diversas que van desde la historia hasta el uso de iPads u Ordenadores. De manera paralela, la experiencia como elemento educativo planteado por Dewey (1943), entrega un valor agregado a este proceso de aprendizaje. De esta manera, desde el contexto personal de los profesores se establece que son usuarios que utilizan de manera constante la tecnología, aunque las funcionalidades que realizan son las cotidianas (redes sociales, escuchar música, chatear), y que desde al ámbito educativo la utilización de TIC se enmarca en el contexto tradicional con la utilización de herramientas como proyectores o la consulta de información en la web. Para el caso de Chile, el contexto profesional en donde se desenvuelven, según el testimonio de los propios protagonistas, es complejo para la incorporación profunda de las TIC debido a la falta de recursos y el escenario escolar en que están situados los alumnos. De esta manera, queda condicionada la aceptación de estas herramientas: mientras algunos plantean su incorporación profunda debido a que son herramientas transversales y de uso cotidiano, también se apuesta por la autosuficiencia en el aprendizaje, entendiendo que los alumnos son nativos digitales (Prensky, 2001) y que deben comprender que estas herramientas tienen un uso que supera su simple utilización lúdica. Por otro lado, existen profesores que plantean desde su percepción que estas herramientas, particularmente las que se implementaron en las experiencias realizadas, deben utilizarse en un contexto mediado, donde el rol del docente como guía debe seguir siendo indispensable sobre todo en lo que se refiere a una enseñanza formal y estructurada, como especialista en los contenidos y en las herramientas que se encuentran utilizando como medio didáctico.

Desde el ámbito de los alumnos, es posible ver que son personas inmersas en la tecnología, con varios tipos de dispositivos en algunos casos, y con la participación constante en redes sociales. Desde el ámbito formal, los entrevistados utilizan las herramientas TIC para sus labores escolares (Word, Excel, Wikipedia, Google).

De manera particular, referido hacia la actividad educativa realizada y los procesos formativos, las opiniones expresadas establecen de modo general, que las herramientas TIC son indispensables para su formación y que su utilización se realiza de manera cotidiana, aunque condicionada por los planteamientos metodológicos del profesor. En el contexto de la actividad educativa realizada y la aplicación RA-NPM utilizada, la percepción general es positiva, valorando la interactividad de la herramienta y el contexto de trabajo 
de campo (m-learning y u-learning), aunque en los aspectos negativos como el uso del mapa son elementos que salieron de los testimonios de los alumnos. De la misma manera que en los docentes, algunos alumnos planteaban la posibilidad de la autonomía en el desarrollo de la actividad, utilizando de manera personal los recursos y definiendo los intereses de los contenidos. Por otro lado, algunos alumnos planteaban la necesidad de la mediación constante del profesor, por medio de instrucciones o explicaciones de los hitos patrimoniales, ya que percibían la actividad como un proceso educativo formal en donde el rol docente es indispensable.

Las limitaciones referentes a esta ámbito cualitativo (enriquecimiento de percepciones, determinación de actitudes) podrían ser subsanadas con la aplicación de otros métodos complementarios a las entrevistas, como son la observación participante, aplicada a los alumnos en el ejercicio de la actividad propuesta por un lado, y a la creación, junto con los docentes del planteamiento educativo en un contexto de investigación-acción estableciendo las identidades para la construcción de la teoría en torno a la significación de esta herramienta propuesta. 
Capítulo VII

Conclusiones 



\section{CONCLUSIONES}

Desde la mirada general de la presente tesis, ésta se ha querido plantear como un ejercicio multidisciplinar complejo, exhaustivo, metódico y riguroso, elementos propios que se presentan en una Sociedad del Conocimiento, manteniendo una estructura científica, evidenciando los logros y dificultades durante todo el proceso investigativo. De alguna manera, disciplinas tan diversas como la Informática, la Educación, el Patrimonio, la Geografía y la Estadística confluyeron en este ejercicio, tratando de aportar, desde un contexto general, un pequeño grano de arena en la construcción de lo que se entiende como conocimiento. Así, en esta última sección, se realiza una síntesis de los resultados obtenidos y las debilidades encontradas con el fin de evidenciar que esta pequeña investigación es un proceso perfectible, con posibles y continuas mejoras en los planteamientos, métodos y contextos que se utilizan, y que, desde estas características, se transforman en la generación de nuevas líneas de investigación, además de la consolidación y maduración de otros lineamientos investigativos relacionados con la formación en contextos de movilidad.

\subsection{Conclusiones desde los aspectos teóricos y empíricos}

Abordándose tres aspectos esenciales que constituyen las bases teóricas de la investigación, es posible obtener una serie de conclusiones generales. En un primer lugar referido a los aspectos tecnológicos que se ha abordado:

- La RA es un nuevo nivel de visualización de datos, en donde, mediante la utilización de una interfaz gráfica derivada de un ordenador, los elementos presentes en la realidad, adquieren valores añadidos derivados de un contexto digital. Esta tecnología, que en un principio nace para satisfacer necesidades militares y académicas, se encuentra en la actualidad en un proceso de maduración gracias a las capacidades tecnológicas de los dispositivos móviles, llevándose a áreas como la enseñanza, el entretenimiento, la medicina o la publicidad entre otras

- Dentro de los procesos educativos, la RA ofrece características que no se presentan en otras herramientas tecnológicas, como son la observación de contenidos que no son apreciables de otra manera, la creación de múltiples perspectivas de 
visualización superando los límites impuestos por la realidad, y la adaptación de los contenidos al contexto temático que se está desarrollando.

- Los información geoespacial móvil, que queda representada de manera particular en lo que son los mapas digitales y la NPM, corresponde a una evolución natural de técnicas tan antiguas como la humanidad (la cartografía, la brújula y los sistemas de coordenadas), pero que desde su contexto informático (web 2.0 y web 3.0), adquieren un valor importante, en donde el dato digital tiene una posición descriptible en el espacio físico. De la misma manera, esta información entrega nuevos aspectos y funcionalidades que pueden ser utilizados en procesos educativos, dando lugar a una cartografía inteligente, la cual se adapta a los contextos territoriales y a las necesidades de los usuarios.

- Desde la perspectiva educativa, el desarrollo de la inteligencia espacial (el cómo las personas perciben y construyen su realidad desde la apreciación de los elementos que constituyen el espacio físico), puede verse favorecida con la implementación de estas tecnologías en un contexto móvil, permitiendo fortalecer el sentido de las relaciones espaciales, la visualización y la orientación. Este desarrollo de la inteligencia espacial fortalecería el razonamiento visual, permitiendo la comprensión de información en otros contextos (geométrico, gráfico).

- El aprendizaje electrónico (e-learning) se ha extendido y derivado, desde una nueva dimensión tecnológica en donde la portabilidad se encuentra presente, en lo que es conocido como aprendizaje móvil (m-learning), y en donde las metodologías y experiencias educativas se relacionan con nuevos recursos tecnológicos para lograr el aprendizaje. Además, llevado al contexto de la particularidad de los procesos educativos, se establece el aprendizaje situado ( $u$ learning), en donde se tienen en consideración los contextos particulares de la enseñanza y el aprendizaje, propios de la experiencia de los sujetos. De manera particular, existen estándares y modelos metodológicos que tratan de abordar estas formas de aprendizaje, como son Technological PedAgogical Content Knowledge (TPACK) y los Objetos de Aprendizaje, adaptando contextos tecnológicos y educativos, los cuales pueden ser de interés para la relación de 
contenidos territoriales, tecnología móvil y su inclusión en procesos de enseñanza y aprendizaje.

- En la actualidad, los constantes avances tecnológicos hacen que se generen importantes flujos de contenidos, datos e información, elementos que se han transformado en uno de los pilares de la economía actual con productos de elevada complejidad y transacciones de bienes que son intangibles. De esta manera, se ha pasado de una "Sociedad de la Información" en donde los datos se crean y esparcen a nivel global, a una "Sociedad del Conocimiento" en donde hay una transformación de los datos en su estado puro para convertirlos en bienes como servicios y productos.

- La actual Sociedad del Conocimiento requiere nuevas formas de pensar e implementar los procesos educativos teniendo en cuenta elementos como los volúmenes de información generada, la dificultad para comprender fenómenos que son sumamente complejos y las interacciones que se generan entre los elementos tecnológicos, los sociales y la realidad. De esta manera, se apuesta por la transformación de la información en estado puro a un nivel de "saber" el cual tiene significado y contexto para la enseñanza y el aprendizaje.

- En la Sociedad del Conocimiento, los procesos de especialización de los contenidos y las disciplinas, deben ser abordados desde un contexto de Complejidad que va más allá de la unión sistémica de las partes, conformando un todo en donde se encuentran la unidad y la multiplicidad de saberes.

- En una época en donde las grandes y clásicas estructuras del conocimiento comenzaron a reestructurarse por los cambios de paradigmas, desde la Sociedad del Conocimiento se genera la conceptualización de la Modernidad Liquida, en donde el caos y la incertidumbre social son influencias para una reconfiguración constante, rol que debe asumir la educación, adaptando a las personas para que puedan hacer frente a tal grado de dinamismo. Particularmente, esta Modernidad Liquida se hace patente en dos modelos teóricos sobre el desarrollo tecnológico: la Teoría de la Difusión de las Innovaciones y los Ciclos de Exceso de Expectativas, los cuales tienen su eco en la implementación de sistemas como la RA y el $m$ learning. 
- Un valor diferencial y agregado que se puede entregar en este contexto casi totalizador de la Sociedad del Conocimiento que envuelve los procesos educativos, es el rol que debe tener la experiencia personal, entrelazando contenidos y métodos con la vivencia personal de cada persona, transformando el aprendizaje en una forma activa y más significativa. Desde este contexto, el entorno, enmarcado por el territorio es un punto de partida para lograr un aprendizaje experiencial el que puede tener una mayor incidencia como proceso en un mundo sumamente dinámico.

Desde el contexto de los resultados empíricos, la implementación temática y territorial en el contexto del desarrollo informático es posible establecer las siguientes conclusiones:

- Desde el marco territorial modelizado para cada ciudad, ambos ejercicios metodológicos se sitúan como ejemplos adecuados para la espacialización de contenidos temáticos en escenarios territoriales, por la cantidad de recursos patrimoniales presentes y los elementos urbanos que configuran la situación de dichos recursos. Estos elementos pueden ser implementados hacia el contexto educativo desde la dimensión físico-espacial, estableciendo las aptitudes adecuadas para la incorporación final en la actividad educativa. De esta manera, las zonas definidas para las ciudades de Santiago y Salamanca (zonas E y A), corresponden a sectores con una mejor accesibilidad y una mayor cantidad de recursos patrimoniales, tanto en lo referido a la cantidad de hitos como a la importancia educativa de estos, permitiendo una mejor configuración del proceso de enseñanza-aprendizaje en un contexto m-learning. Estos mismos modelos territoriales, desde un escenario e-learning, sirvieron de insumo para la implementación de los recursos en el aula, mediante al interoperabilidad de los datos en plataformas web.

- En el desarrollo de la aplicación móvil, se han integrado tres grandes herramientas que confluyen en un contexto de movilidad: la RA, mapas y localización, e interfaz gráfica. En la actualidad existen muchas opciones para cada una de estas herramientas y su implementación en contextos móviles, con diversas características, costos, opciones y plataformas, decidiéndose en un pequeño 
estudio evaluativo, las herramientas que generan una mejor interacción entre el sistema operativo móvil y los otros componentes, el hardware utilizado, la interoperabilidad con datos de otras fuentes, particularmente en lo referido a modelos e información territorial, y su costo económico.

- En las dos experiencias implementadas en las ciudades respectivas, se utilizaron diferentes lenguajes de desarrollo, aunque ambos dentro de lo que es el entorno iOS. En el caso de Santiago, el lenguaje utilizado (Objective-C) permitió erigir las bases del sistema general de la aplicación móvil planteada con la definición de las funcionalidades y clases para cada zona, hito y recurso multimedia asociado. En una fase posterior, se realizó una versión 2.0 asociada con la ciudad de Salamanca, siendo el lenguaje utilizado Swift 2.2, el cual permitió una mayor flexibilidad entre frameworks, una mayor síntesis de clases y la facilidad de implementar. Sin embargo, como todo proceso actual en informática, el mantenimiento de la aplicación será constante y condicionado a los errores imprevistos y a las actualizaciones correspondientes de lenguaje o alguno de sus frameworks.

En lo referente a las conclusiones que se obtienen del estudio cuantitativo de los aspectos educativos, se puede señalar lo siguiente:

- Tanto desde un contexto m-learning como e-learning, es posible desarrollar un diseño e implementación de una experiencia educativa sobre contenidos patrimoniales en el territorio, con amplios resultados positivos. La incorporación de recursos como la RA y los mapas digitales en herramientas como iPads y Ordenadores ha demostrado ser eficaz en procesos generales de aprendizaje de contenidos y elementos patrimoniales locales.

- La particularidad local de cada temática patrimonial, hizo que los resultados de las pruebas objetivas entre países no fueran comparables entre sí. Sin embargo, de manera particular, los resultados son los siguientes:

- Para el caso de Chile, los alumnos que trabajaron con iPads respecto a Ordenadores en sala de clases, tuvieron mejores puntuaciones en casi todos los elementos de contenidos y procesos, estableciéndose que las 
actividades m-learning tiene una mayor efectividad respecto al contexto tradicional e-learning. Sin embargo, desde la dimensión de la espacialidad y la localización, no existen diferencias significativas entre los grupos-

- Para el caso de España, los resultados sugieren que los alumnos en general, aumentan sus puntuaciones finales con la utilización de estas herramientas y contextos m-learning y e-learning. Sin embargo no se observan diferencias significativas entre los grupos, aunque hay pequeñas variaciones en los contenidos Histórico y Arquitectónico y el proceso de Conocimiento en donde el grupo Ordenador tuvo leves mejores resultados. Por otro lado en el contenido de Localización y procesos de Comprensión y Aplicación los leves aumentos de puntuaciones los tiene el grupo de iPad. Destacan los resultados del contenido de Localización, en donde los incrementos del grupo iPad son significativos, los cuales pueden ser derivados del sistema de navegación implementado en las tabletas y el contexto u-learning que se propone con el trabajo de campo.

- Desde el contexto de la opinión de los alumnos y el nivel de satisfacción personal frente al trabajo realizado, se establece que existen altos niveles de satisfacción en la utilización de este tipo de herramientas para el aprendizaje de contenidos patrimoniales. De manera particular, no existen diferencias significativas entre el grado de satisfacción expresado por los alumnos y el tratamiento utilizado para el desarrollo de la experiencia educativa (iPad u Ordenador). De la misma manera, al comparase los resultados obtenidos según país, tampoco existen diferencias significativas, estableciéndose altos niveles de satisfacción en general. Es importante destacar que los aspectos que tuvieron una menor satisfacción se encuentran referidos a la precisión de la información desplegada y en lo referente al diseño gráfico de los programas (aplicación móvil y de escritorio), elementos que serán tomados en cuenta en una futura actualización.

Desde la dimensión cualitativa de los aspectos del estudio educativo, los resultados son los siguientes:

- En torno a la percepción de los profesores participantes en las actividades educativas propuestas, sus testimonios plantean que es una forma novedosa de 
entregar contenidos con el uso de tecnología, particularmente en contenidos sobre el área de Historia y Ciencias Sociales, la cual se encuentra un poco más lejana en la utilización de TIC, que se resume en el trabajo con metodologías y herramientas tradicionales (uso de proyector, navegación y búsqueda de información en la red). La mayoría de los docentes están dispuestos a replicar la experiencia utilizando otras herramientas como los móviles inteligentes, y proponerlos en otras temáticas y contenidos.

- La mitad de los profesores entrevistados, cree que el uso de la tecnología en un contexto formal educativo debe estar acompañado por el docente que guíe la actividad desde el plano tecnológico (como se usan las herramientas) y desde la dimensión de los contenidos (el profesor debe complementar la información temática presente en los recursos informáticos). El otro grupo de docentes establece que estas herramientas deberían proponer el aprendizaje autoguiado de los alumnos, siendo el rol del profesor el proponer y elaborar los contextos temáticos generales, pero que el aprendizaje se realice en un contexto de descubrimiento y autoenseñanza.

- Desde la percepción de los alumnos, las opiniones destacadas y que se presentan de manera general, establecen que la actividad educativa fue interesante y positiva para su aprendizaje, aunque estas herramientas se asocian principalmente a contextos lúdicos y de ocio, más que a procesos formativos, sobre todo desde un ámbito formal.

- Desde el ámbito patrimonial, los alumnos entrevistados establecen que fue una nueva forma de abordar conceptos y elementos desde el lugar en donde se encontraban, reconociendo procesos y características históricas mediante el uso de iPad. Sin embargo también se planteó la necesidad de una mayor moderación por parte de los docentes, guiando la actividad y entregando antecedentes y explicaciones sobre el tema. Es decir, la percepción en torno a estas herramientas en un contexto formal educativo debe estar mediado por un docente, más allá de una posible autoenseñanza. 


\subsection{Aspectos perfectibles de la investigación}

La presente tesis intentó abordar un problema del ámbito tecnológico-educativo desde diferentes dimensiones, las cuales estaban relacionadas entre sí mediante lo que es el pilar de los procesos m-learning con recursos como la RA y NPM. Desde este marco general, al acercarse a aspectos particulares de cada dimensión se han ido encontrado ciertos puntos débiles, los cuales se han tratado de corregir en la medida de lo posible. También se han sucedido una serie de inconvenientes que no se han podido subsanar correctamente debido a las limitaciones en los recursos (incluido el tiempo), la aparición situaciones excepcionales, o asuntos del ámbito personal del investigador (formación, tipo de competencias necesarias para el desarrollo informático, para el análisis cuantitativo y cualitativo).

Desde el ámbito temático territorial y patrimonial, la escasez de recursos fotográficos y archivísticos sobre algunos de los monumentos y conceptos, condicionó la estructura de las aplicaciones planteadas en un principio, y con ello la implementación de las actividades educativas. Así mismo, desde este ámbito de los datos originales, los modelos territoriales generados necesitan información específica que no se contó (volúmenes de desplazamiento peatonal y vehicular, dimensiones de edificaciones, por mencionar algunos), lo que hubiera aumentado la calidad de los datos obtenidos.

Desde el ámbito del desarrollo de la aplicación, se plantea como una serie de mejoras futuras, la utilización de estándares informáticos en el ámbito de la RA (XML), en la información geoespacial (GeoJSON o KML) o de los datos internos (SQLite). De la misma manera se pretende establecer el contexto de Objeto de Aprendizaje Móvil con contenidos y elementos adaptables para cada escenario educativo (este último punto se establece también como una línea de investigación futura).

El instrumento de evaluación Pre-Test y Post-Test se estableció sólo como una prueba de alternativas midiendo dimensiones en torno a los contenidos y procesos definidos. Un instrumento más complejo, con otras opciones de evaluación, hubiera enriquecido los resultados, sobre todo en aspectos como son la evaluación del proceso de Localización. De la misma manera, una tarea compleja pero no imposible, es equiparar las pruebas (medir los mismos ítems) sobre la temática patrimonial para cada país. Este problema surge por diversas aristas: desde la cantidad de elementos patrimoniales existentes en área de estudio (con diferentes magnitudes espaciales e históricas), el tiempo cronológico que abarca cada ciudad, hasta aspectos administrativos como los planes y programas educativos que se proponen en cada país, lo que finalmente 
condiciona la elaboración del instrumento final. De la misma manera, se hace necesario fortalecer el instrumento que mide el grado de satisfacción de los alumnos sobre la actividad realizada. Este instrumento debería poder medir, además, otros elementos como el contexto sociodemográfico desde la perspectiva que tienen los alumnos de las TIC. Con esta información adicional sería posible establecer las posibles relaciones existentes entre los resultados de la prueba objetiva, los grados de satisfacción presentados y los contextos sociales y académicos de los alumnos.

Desde el ámbito cualitativo, las posibles mejoras pasan por la utilización de otras metodologías que también son adecuadas para la evaluación de este tipo de experiencias, como son la observación participante y la investigación acción (desde la estructuración de la teoría fundamentada o la etnografía digital), participando de manera directa en las experiencias propuestas, con lo que se obtendrían resultados que podrían abarcar un nuevo campo de implicaciones y sentidos.

\subsection{Líneas de investigación futuras}

El contexto general planteado en esta tesis doctoral y particularmente en el desarrollo de las conclusiones y las limitaciones presentadas, pone de manifiesto algunas líneas futuras de investigación, las que pueden ya estar trabajándose por la comunidad científica o son espacios de investigación para explorar y proponer dentro del contexto educativo que ofrecen estas herramientas tecnológicas. Estos planteamientos se pueden considerar, primero, como una mejora al ejercicio investigativo realizado, y segundo, como la posibilidad de incorporar nuevos lineamientos y aspectos en torno a la visualización físico-espacial mediante la portabilidad. De esta manera, las líneas que se proponen son:

- Desde la vertiginosa dinámica que existe en torno a los datos, se hace necesario realizar un análisis en profundidad de los modelos de innovación y adquisición tecnológica que tiene la RA (y sus derivaciones) y los dispositivos móviles, teniendo como factores base su utilización en la educación formal, permitiendo establecer las tendencias futuras, los contextos en que son utilizados y las innovaciones en las que se están trabajando.

- El desarrollo de estudios que permitan establecer el sentido de la percepción (particularmente en el aspecto del Affordance) desde la dimensión del espacio 
físico, mediante la tecnología portátil y cómo estos elementos influyen en los procesos de aprendizaje y el desarrollo de la inteligencia espacial.

- La replicabilidad de esta investigación (con la utilización de la RA-NPM en una experiencia educativa concreta) en otros contextos temáticos, asociados a otras disciplinas como son las Ciencias, Tecnología, Ingeniería y Matemáticas (STEM por sus siglas en inglés), permitiendo conocer la forma en que interactúan los alumnos en un contexto de u-learning. También se hace necesario la replicabilidad en otros niveles como son la educación terciaria o contextos de educación informal.

- Desde el desarrollo informático, se plantea la posibilidad de trabajar con los datos generados por los usuarios a modo de big data, estudiando no solo la interacción con la posición geográfica y los elementos de la aplicación, sino también hacia otro tipo de herramientas como las redes sociales, midiendo su interacción e influencia en el contexto educativo.

- Evaluar la posibilidad de implementar la información en servidores propios con estructuras de datos como son servidores web y de mapas, permitiendo una mayor personalización de los contenidos desde una estructura enteramente situada en un contexto cliente-servidor.

\subsection{Publicaciones vinculadas a la Tesis Doctoral}

Durante el desarrollo de la tesis doctoral se han ido generando una serie de resultados que han sido publicados parcialmente a través de diversas fuentes que van desde publicaciones científicas, hasta la participación en congresos.

\subsubsection{Artículos en revistas científicas}

Joo Nagata, J., Martínez Abad, F., \& García-Bermejo Giner, J. R. (aceptado en prensa). Augmented Reality and Mobile Pedestrian Navigation in m-Learning: educational assessment of an implementation in Chile. International Journal of Engineering Education. 
Joo Nagata, J., García-Bermejo Giner, J. R., \& Martínez Abad, F. (2016). Virtual Heritage of the Territory: Design and Implementation of Educational Resources in Augmented Reality and Mobile Pedestrian Navigation. Tecnologías Del Aprendizaje, IEEE Revista Iberoamericana del Aprendizaje, 11(1), 41-46. http://doi.org/10.1109/RITA.2016.2518460

Joo Nagata, J., García-Bermejo Giner, J. R., \& Martínez Abad, F. (2015). Patrimonio Virtual del Territorio: Diseño e implementación de Recursos Educativos en Realidad Aumentada y Navegación Peatonal Móvil. VAEP-RITA, 3(1), 46-51.

Joo Nagata, J., García-Bermejo, R., \& Muñoz Rodríguez, J. (2015). Herramientas Geomáticas utilizadas en Educación: situación actual y su relación con procesos educativos. Enseñanza \& Teaching Revista Interuniversitaria de Didáctica, 33(1), 25-56. http://dx.doi.org/10.14201/et20153312556

\subsubsection{Capítulo de libro en obras colectivas}

Joo Nagata, J., García-Bermejo Giner, J. R., \& Martínez Abad, F. (2016). Virtual Territorial Heritage in Education through mLearning resources: Cities of Salamanca Spain and Santiago of Chile. In L. Briz-Ponce, F. J. García-Peñalvo, \& J. A. JuanesMéndez (Eds.), Handbook of Research on Mobile Devices and Applications in Higher Education Settings (p. 450). IGI Global. En http://www.igiglobal.com/book/handbook-research-mobile-devices-applications/143640

\subsubsection{Contribuciones en congresos}

Joo Nagata, J., García-Bermejo Giner, J., \& Martínez Abad, F. (2015). Virtual Heritage Territories: Augmented Reality and Pedestrian Navigation Through Educational Implementation. En Proceedings of the 3rd International Conference on Technological Ecosystems for Enhancing Multiculturality (pp. 105-110). New York, NY, USA: ACM. http://doi.org/10.1145/2808580.2808597

Joo Nagata, J., García-Bermejo Giner, J. R., \& Martínez Abad, F. (2015). Territorios Patrimoniales Virtuales: Realidad Aumentada y Navegación Peatonal de la 
ciudad de Salamanca y su implementación educativa. Presentado en CIMIE 15 Foruth Multidisciplinary International Congress of Educational Research, Valencia.

Joo Nagata, J., \& Martínez Abad, F. (2015). Patrimonio territorial virtual en educación: recursos en mlearning sobre la ciudad de Salamanca. In Investigar con y para la sociedad (Vol. 3, pp. 1681-1692). Cádiz, España: Bubok. En http://aidipe2015.aidipe.org

Joo Nagata, J., \& García-Bermejo Giner, J. R. (2014a). Model of Augmented Reality and Pedestrian Navigation About the Territorial Heritage: Design, Implementation and Evaluation. In Proceedings of the Second International Conference on Technological Ecosystems for Enhancing Multiculturality (pp. 633-637). New York, NY, USA: ACM. http://doi.org/10.1145/2669711.2669966

Joo Nagata, J., \& García-Bermejo Giner, J. R. (2014b). Unidades de Realidad Aumentada y Navegación Peatonal del Patrimonio Territorial: su implementación educativa. In VI Congreso Internacional sobre Aplicación de Tecnologías de la Información y Comunicaciones Avanzadas (pp. 465-472). Alcalá de Henares.

Joo Nagata, J., Ramos, P. H., González, M. Á. C., García-Bermejo, J. R., \& García Peñalvo, F. J. (2014). Comparison of the Use of Personal Learning Environments (PLE) Between Students from Chile and Ecuador: An Approach. In Proceedings of the Second International Conference on Technological Ecosystems for Enhancing Multiculturality (pp. 75-80). New York, NY, USA: ACM. http://doi.org/10.1145/2669711.2669882

Joo Nagata, J. (2013). Geomatics tools and education: status, integration and perception. In Proceedings TEEM (Vol. 1, pp. 501-506). Salamanca, España. http://doi.org/10.1145/2536536.2536613 
Bibliografía 



\section{BIBLIOGRAFIA}

Abad, F. J., Olea, J., Ponsoda, V., \& García, C. (2011). Medición en ciencias sociales y de la salud (1. ${ }^{\mathrm{a}}$ ed.). Madrid: Sintesis.

Abbas, R., Michael, K., \& Michael, M. (2014). The regulatory considerations and ethical dilemmas of location-based services (LBS). Information Technology \& People, 2オ1), 2-20. http://doi.org/10.1108/ITP-12-2012-0156

Adams, M. (2005). The 10 most important emerging technologies for humanity. Truth Publishing International. Recuperado a partir de http://www.naturalnews.com/SpecialReports/EmergingTechnologies.pdf

Ai-Lim Lee, E., \& Wong, K. W. (2014). Learning with desktop virtual reality: Low spatial ability learners are more positively affected. Computers \& Education, 79, 4958. http://doi.org/10.1016/j.compedu.2014.07.010

Albert Gómez, M. J. (2006). La investigación educativa: claves teóricas. Madrid: McGrawHill.

Allan, A. (2012). Geolocation in IOS. O'Reilly Media, Inc.

Al-Qahtani, A. A. Y., \& Higgins, S. e. (2013). Effects of traditional, blended and elearning on students' achievement in higher education. Journal of Computer Assisted Learning, 29(3), 220-234. http://doi.org/10.1111/j.13652729.2012.00490.x

Amin, D., \& Govilkar, S. (2015). Comparative study of augmented reality SDK's. International Journal on Computational Sciences \& Applications (IJCSA), $5(1), 11-26$.

Amirian, P., Basiri, A., Gales, G., Winstanley, A., \& McDonald, J. (2015). The Next Generation of Navigational Services Using OpenStreetMap Data: The Integration of Augmented Reality and Graph Databases. En J. J. Arsanjani, A. Zipf, P. Mooney, \& M. Helbich (Eds.), OpenStreetMap in GIScience (pp. 211228). Springer International Publishing. Recuperado a partir de http://link.springer.com/chapter/10.1007/978-3-319-14280-7_11

Andujar, J. M., Mejías, A., \& Marquez, M. A. (2011). Augmented reality for the 
improvement of remote laboratories: an augmented remote laboratory. Education, IEEE Transactions on, 54(3), 492-500.

Apple Inc. (2009, julio 6). The Objective-C 2.0 Programming Language: Introduction to The Objective-C 2.0 Programming Language. Recuperado 25 de enero de 2016, a partir de http://web.archive.org/web/20090706113224/http://developer.apple.com/do cumentation/Cocoa/Conceptual/ObjectiveC/Introduction/introObjectiveC.html

Apple Inc. (2011, mayo 9). Xcode Project. Recuperado 4 de mayo de 2016, a partir de https://developer.apple.com/library/ios/featuredarticles/XcodeConcepts/Conc ept-Projects.html

Apple Inc. (2014). The Swift Programming Language (Swift 2.1). Cupertino, California: Apple. Recuperado a partir de https://itunes.apple.com/book/swiftprogramming-language/id881256329?mt=11

Apple Inc. (2016). About Swift. Recuperado 3 de marzo de 2016, a partir de https://swift.org/

Aranda, J. (2006, octubre 22). Cheap shots at the Gartner Hype Curve. Recuperado a partir de https://catenary.wordpress.com/2006/10/22/cheap-shots-at-thegartner-hype-curve/

Arce, R. A. (2013). Mobile learning: aprendizaje móvil como complemento de una estrategia de trabajo colaborativo con herramientas Web 2 y entorno virtual de aprendizaje WebUNLP en modalidad de blended learning. Presentado en I Jornadas Nacionales de TIC e Innovación en el Aula. Recuperado a partir de http://hdl.handle.net/10915/26538

Armstrong, T., Gardner, H., \& Diéguez, R. (2006). Inteligencias múltiples en el aula: guía práctica para educadores (1a. ed., 4a. reimp). Barcelona: Paidós.

Arnal, J., Rincón, D. del, \& Latorre, A. (1992). Investigación educativa: fundamentos y metodologías. Editorial Labor.

Arnau, J. (1995). Diseños longitudinales aplicados a las ciencias sociales y del comportamiento. Editorial Limusa. 
Arribas, J. C., Gutiérrez, S. M., Gil, M. C., \& Santos, A. C. (2014). Recursos digitales autónomos mediante Realidad Aumentada. RIED. Revista Iberoamericana de Educación a Distancia, 172). Recuperado a partir de http://espacio.uned.es/revistasuned/index.php/ried/article/view/12686

Artvinli, E. (2010). The Contribution of Geographic Information Systems (GIS) to Geography Education and Secondary School Students' Attitudes Related to GIS. Educational Sciences: Theory and Practice, 10(3), 1277-1292.

Aurelia, S., Raj, M. D., \& Saleh, O. (2014). Mobile Augmented Reality and Location Based Service. Advances in Information Science and Applications, 2, 551558.

Awange, J. L., \& Kiema, J. B. K. (2013). Geodata and Geoinformatics. En Environmental Geoinformatics (pp. 17-27). Springer Berlin Heidelberg. Recuperado a partir de http://link.springer.com/chapter/10.1007/978-3-642-34085-7_2

Aydin, B., Gensel, J., Genoud, P., Calabretto, S., \& Tellez, B. (2013). Extending Augmented Reality Mobile Application with Structured Knowledge from the LOD Cloud. En T. Delot, S. Geisler, S. Ilarri, \& C. Quix (Eds.), Proceedings of the 3rd International Workshop on Information Management for Mobile Applications, Riva del Garda, Italy, August 26, 2013 (Vol. 1075, pp. 21-27). CEUR-WS.org. Recuperado a partir de http://ceur-ws.org/Vol-1075/03.pdf

Azuma, R. (1997). A survey of augmented reality. Presence, 6(4), 355-385.

Azuma, R., Baillot, Y., Behringer, R., Feiner, S., Julier, S., \& MacIntyre, B. (2001). Recent advances in augmented reality. IEEE Computer Graphics and Applications, 21(6), 34-47. http://doi.org/10.1109/38.963459

Baranovskiy, N., \& Zharikova, M. (2014). A Web-Oriented Geoinformation System Application for Forest Fire Danger Prediction in Typical Forests of the Ukraine. En T. Bandrova, M. Konecny, \& S. Zlatanova (Eds.), Thematic Cartography for the Society (pp. 13-22). Springer International Publishing. Recuperado a partir de http://link.springer.com/chapter/10.1007/978-3-31908180-9_2

Bauman, Z. (2004). Modernidad líquida (3. ${ }^{\mathrm{a}}$ ed.). Buenos Aires: Fondo de Cultura 
Económica.

Bauman, Z. (2013). Vida Líquida. (A. S. Mosquera, Trad.). Barcelona: Planeta.

Bauman, Z. (2015). Los Retos De La Educación En La Modernidad Líquida. Barcelona: GEDISA.

Beck, R. J. (2010, noviembre 23). What Are Learning Objects? Recuperado 23 de noviembre de 2015, a partir de http://www4.uwm.edu/cie/learning_objects.cfm?gid=56

Bell, D. (2001). El advenimiento de la sociedad post-industrial: un intento de prognosis social (6. ${ }^{\text {a }}$ ed.). Madrid: Alianza Editorial.

Bellisario, A. (2001). Territorio y economía: La teoría de la especialización flexible. Revista de Geografía Norte Grande, (28), 43-56.

Bennett, G., Fisher, M., \& Lees, B. (2010). Objective-C for Absolute Beginners: iPhone, iPad and Mac Programming Made Easy (1 edition). Apress.

Berggren, J. L. (2000). Ptolemy's Geography: An Annotated Translation of the Theoretical Chapters. Princeton University Press.

Berlanga, A. J., García Peñalvo, F., \& Sloep, P. B. (2010). Towards eLearning 2.0 University. Interactive Learning Environments, 18(3), 199-201. http://doi.org/10.1080/10494820.2010.500498

Berlanga Silvente, V., \& Rubio Hurtado, M. J. (2012). Clasificación de pruebas no paramétricas. Cómo aplicarlas en SPSS. Reire. Revista d'Innovació i Recerca en Educació, 5(2), 101-113. http://doi.org/10.1344/reire2012.5.2528

Berners-Lee, T., Hendler, J., \& Lassila, O. (2001, mayo). The Semantic Web. Recuperado 6 de abril de 2015, a partir de http://www.scientificamerican.com/article/thesemantic-web/

Bertrand, C., Bertrand, G., \& Rodríguez Martínez, F. (2007). Geografía del medio ambiente: el sistema GTP: geosistema, territorio y paisaje. Granada: Editorial Universidad de Granada.

Bertrand, G., Lindón, A., \& Hiernaux, D. (2006). Tratado de geografía humana. 
Anthropos Editorial.

Biebrach, T. (2007). What impact has GIS had on geographical education in secondary schools? Geographical Association UK. Recuperado a partir de www.geography.org.uk/download/GA_PRSSBiebrach.doc

Bienk, S., Kattenbeck, M., Ludwig, B., Müller, M., \& Ohm, C. (2013). I Want to View It My Way: Interfaces to Mobile Maps Should Adapt to the User's Orientation Skills. En Proceedings of the 12th International Conference on Mobile and Ubiquitous Multimedia (pp. 34:1-34:9). New York, NY, USA: ACM. http://doi.org/10.1145/2541831.2541841

Biggs, J. (2012). An interview with McGraw-Hill Higher Education President, Brian Kibby, about the future of ebooks. Recuperado a partir de http://techcrunch.com/2012/05/09/an-interview-with-mcgraw-hill-highereducation-president-brian-kibby-about-the-future-of-ebooks-tctv/

Billinghurst, M. (2002). Augmented Reality in Education. Recuperado 22 de julio de 2014, a partir de http://www.it.civil.aau.dk/it/education/reports/ar_edu.pdf

Billinghurst, M., Kato, H., \& Poupyrev, I. (2001). The MagicBook: a transitional AR interface. Computers \& Graphics, 25(5), 745-753.

Black, J. (2008). A Revolution in Military Cartography?: Europe 1650-1815. The Journal of Military History, 73(1), 49-68. http://doi.org/10.1353/jmh.0.0160

Bloom, B. S., Hastings, J. T., \& Madaus, G. F. (1985). Evaluación del aprendizaje. Vol. 1 (4a. ed, Vol. 1). Buenos Aires: Troquel.

Boix, G., \& Olivella, R. (2007). Los Sistemas de Información Geográfica (SIG) aplicados a la educación. El proyecto PESIG (Portal Educativo en SIG). En M. Marrón Gaite, J. Salom Carrasco, \& X. M. Souto (Eds.), Las competencias geográficas para la educación ciudadana (pp. 23-32). Valencia: Edicions Culturals Valencianes. Recuperado a partir de http://www.agedidacticageografia.es/docs/Publicaciones/2007_comp_ecogeo.pdf

Bonenberger, D. J., \& Harris, T. M. (2013). Placing Virtual Heritage: Reconciling virtual and cultural heritage with the Spatial Turn. En Digital Heritage International 
Congress (DigitalHeritage), 2013 (Vol. 2, pp. 601-604).

http://doi.org/10.1109/DigitalHeritage.2013.6744827

Borges del Rosal, A., Cañadas Osinski, I., \& Sánchez Bruno, A. (2000). El contraste de medias recortadas ante la violación de los supuestos paramétricos.

Psicothema, 12(2), 506-508.

Branch, J. (2011). Mapping the Sovereign State: Technology, Authority, and Systemic Change. International Organization, 65(01), 1-36. http://doi.org/10.1017/S0020818310000299

Brey, A. (2009). La sociedad de la ignorancia. Una reflexión sobre la relación del individuo con el conocimiento en el mundo hiperconectado. En La Sociedad de la Ignorancia y otros ensayos (pp. 17-42). Barcelona: Infonomia.

Brinkmann, S. (2014). Unstructured and Semi-Structured Interviewing. En P. Leavy (Ed.), The Oxford handbook of qualitative research (pp. 277-299). New York: Oxford University Press.

Brodkin, J. (2007, septiembre 21). Gartner touts Web 2.0, scoffs at sequel. Recuperado 6 de abril de 2015, a partir de http://www.networkworld.com/article/2285911/software/gartner-touts-web2-0--scoffs-at-sequel.html

Brovelli, M. A., Minghini, M., \& Zamboni, G. (2015). Public participation in GIS via mobile applications. ISPRS Journal of Photogrammetry and Remote Sensing. http://doi.org/10.1016/j.isprsjprs.2015.04.002

Browning, R. C., Baker, E. A., Herron, J. A., \& Kram, R. (2006). Effects of obesity and sex on the energetic cost and preferred speed of walking. Journal of Applied Physiology, 100(2), 390-398. http://doi.org/10.1152/japplphysiol.00767.2005

Brunyé, T. T., Gagnon, S. A., Gardony, A. L., Gopal, N., Holmes, A., Taylor, H. A., \& Tenbrink, T. (2014). Where did it come from, where do you go? Direction sources influence navigation decisions during spatial uncertainty. The Quarterly Journal of Experimental Psychology, o(0), 1-23. http://doi.org/10.1080/17470218.2014.963131 
Burbules, N. (2010). Meanings of «Ubiquitous Learning». En B. Cope \& M. Kalantzis (Eds.), Ubiquitous Learning (pp. 15-20). University of Illinois Press.

Burbules, N. C. (2012). El aprendizaje ubicuo y el futuro de la enseñanza. Encounters on education/Encuentros sobre educación/Recontres sur l'éducation, (13), 3-14.

Burrough, P. A., \& McDonnell, R. A. (1998). Principles of Geographical Information Systems. Londres: Oxford University Press.

Buzai, G. (2011). La geotecnología: ¿Nuevo paradigma de la geografía o paradigma geográfico de la ciencia? Revista Catalana de Geografía, XVI(42). Recuperado a partir de http://www.rcg.cat/articles.php?id=187

Buzai, G., \& Baxendale, C. (2006). Análisis socioespacial con Sistemas de Información Geográfica. Lugar.

Buzai, G., Baxendale, C., Cacace, G., Humacata, L., Caloni, N., \& del Rosario Cruz, M. (2012). Geografía y Sistemas de Información Geográfica (SIG) en la escuela secundaria. Reflexiones y propuestas para el trabajo en las aulas de la República Argentina. Revista Geográfica, (152), 63-82.

Cadillo León, J. (2013). Nuestra experiencia con la Realidad Aumentada. Recuperado a partir de https://conocimientoysistemas.wordpress.com/category/realidadaumentada/nuestra-experiencia-con-la-realidad-aumentada/

Cadillo León, J. (2015). Uso de la Realidad Aumentada. Recuperado 25 de febrero de 2015, a partir de http://docentesinnovadores.net/Contenidos/Ver/4500

Caldeiro, G., \& Schwartzman, G. (2013). Aprendizaje ubicuo. Entre lo disperso, lo efímero y lo importante: nuevas perspectivas para la educación en línea. En $I$ Jornadas Nacionales y III Jornadas de Experiencias e Investigación en Educación a Distancia y Tecnología Educativa (PROED) (pp. 1-13). Córdoba. Recuperado a partir de http://www.pent.org.ar/institucional/publicaciones/aprendizaje-ubicuo-entrelo-disperso-lo-efimero-lo-importante-nuevas-per

Calvo, M. (2011). Geo-conceptualización y modelado del espacio geográfico. Madrid: Editorial Academica Espanola. Recuperado a partir de https://www.eae- 
publishing.com/catalog/details/store/es/book/978-3-8465-6367-0/geoconceptualizaci\%C3\%B3n-y-modelado-del-espacio-geogr\%C3\%A1fico

Camacho, M., \& Lara, T. (Eds.). (2011). M-Learning, en España, Portugal y América Latina (Observatorio de la Formación en Red). Salamanca, España: Universidad de Salamanca. Recuperado a partir de http://scopeo.usal.es/wpcontent/uploads/2013/04/scopeom003.pdf

Camargo Vega, J. J., Joyanes Aguilar, L., \& Camargo Ortega, J. F. (2015). Conociendo Big Data. Revista Facultad de Ingeniería (Fac. Ing.), 24(38), 63-77.

Campani, M., \& Vaglio, R. (2015). A simple interpretation of the growth of scientific/technological research impact leading to hype-type evolution curves. Scientometrics, 103(1), 75-83. http://doi.org/10.1007/s11192-0151533-6

Campbell, D. T., \& Stanley, J. C. (1973). Diseños experimentales y cuasiexperimentales en la investigación social (1a. ed., 2a. reimp). Buenos Aires: Amorrortu.

Campbell, D. T., \& Stanley, J. C. (1993). Diseños experimentales y cuasiexperimentales en la investigación social (1a. ed., 6a. reimp.). Buenos Aires: Amorrortu.

Campbell, T. (1987). Portolan Charts from the Late Thirteenth Century to 1500. En J. B. Harley \& D. Woodward (Eds.), The History of Cartography (74. ${ }^{\text {a }}$ ed., Vol. 1). Chicago: University of Chicago Press. Recuperado a partir de http://www.press.uchicago.edu/books/HOC/index.html

Capel, H. (2009). La enseñanza digital, los campus virtuales y la geografía. Recuperado 23 de enero de 2013, a partir de http://www.ub.edu/geocrit/aracne/aracne125.htm

Cárdenas Castro, M., \& Arancibia Martini, H. (2014). Potencia estadística y cálculo del tamaño del efecto en G*Power: complementos a las pruebas de significación estadística y su aplicación en psicología. Salud \& Sociedad, 5(2), 210-224.

Caspa, E. R., de la Cruz, L. Q., \& Yarnold, C. M. (2011). Realidad aumentada e inteligencias múltiples en el aprendizaje de matemáticas. Concurso de Proyectos Feria Tecnológica IEEE INTERCON. Recuperado a partir de 
http://www.usmp.edu.pe/publicaciones/boletin/fia/info80/otros/aprendizaje. pdf

Castells, M. (2010). The rise of the network society ( $2^{\circ}$ ed.). Chichester; Malden: WileyBlackwell.

CEPAL. (2003). Los caminos hacia una sociedad de la información en América Latina y el Caribe (Vol. 72). Santiago, Chile: Naciones Unidas.

Cerf, V. G. (2013). Augmented Intelligence. IEEE Internet Computing, 1入5), 96-96.

Chan, T., Sharples, M., Vavoula, G., \& Lonsdale, P. (2004). Educational metadata for mobile learning. En The 2nd IEEE International Workshop on Wireless and Mobile Technologies in Education, 2004. Proceedings (pp. 197-198). http://doi.org/10.1109/WMTE.2004.1281386

Chen, C.-H., Chou, Y.-Y., \& Huang, C.-Y. (2016). An Augmented-Reality-Based Concept Map to Support Mobile Learning for Science. The Asia-Pacific Education Researcher, 1-12. http://doi.org/10.1007/s40299-016-0284-3

Cheng, K.-H., \& Tsai, C.-C. (2012). Affordances of Augmented Reality in Science Learning: Suggestions for Future Research. Journal of Science Education and Technology, 22(4), 449-462. http://doi.org/10.1007/s10956-012-9405-9

Chen, G., \& Kotz, D. (2000). A survey of context-aware mobile computing research (Technical Report) (p. 16). NH. USA: Dept. of Computer Science, Dartmouth College.

Churches, A. (2009). Taxonomía de Bloom para la Era Digital. Recuperado 16 de abril de 2013, a partir de http://www.eduteka.org/TaxonomiaBloomDigital.php

Chuvieco Salinero, E. (1996). Fundamentos de teledetección espacial (3. ${ }^{\text {a ed. }) . ~ M a d r i d: ~}$ Ediciones Rialp.

CNNExpansion. (2015, mayo 29). Apple compra Metaio, firma dedicada a la realidad aumentada. Recuperado 25 de enero de 2016, a partir de http://www.cnnexpansion.com/negocios/2015/05/29/apple-compra-metaiofirma-dedicada-a-la-realidad-aumentada 
Colás Bravo, P., \& Casanova Correa, J. (2010). Variables docentes y de centro que generan buenas prácticas Con TIC. Teoría de la Educación. Educación y Cultura en la Sociedad de la Información, 11(1), 121-147.

Colls, C. S., \& Colls, K. (2013). Reconstructing a Painful Past: A Non-Invasive Approach to Reconstructing Lager Norderney in Alderney, the Channel Islands. En E. Ch'ng, V. Gaffney, \& H. Chapman (Eds.), Visual Heritage in the Digital Age (pp. 119-146). Springer London. Recuperado a partir de http://link.springer.com/chapter/10.1007/978-1-4471-5535-5_7

Conde, M., Muñoz, C., \& García, F. J. (2008). mLearning, the first step in the learning process revolution. International Journal of Interactive Mobile Technologies (iJIM), 2(4), 61-63.

Consejo de Monumentos Nacionales de Chile. (2015a). Monumentos en Google Earth (Archivo KMZ). Recuperado 21 de enero de 2015, a partir de http://www.monumentos.cl/consejo/606/w3-article-45367.html

Consejo de Monumentos Nacionales de Chile. (2015b, marzo 5). Nómina oficial de monumentos nacionales declarados por decreto. CMN. Recuperado a partir de http://www.monumentos.cl/catalogo/625/articles-22591_doc_xls.xlsx

Corbin, J., \& Strauss, A. (2014). Basics of Qualitative Research: Techniques and Procedures for Developing Grounded Theory (4. ${ }^{a}$ ed.). Londres: SAGE Publications. Recuperado a partir de https://books.google.es/books?hl=es\&lr=\&id=MaKWBQAAQBAJ\&oi=fnd\&pg $=P P 1 \& d q=$ Basics + of + qualitative + research: + Techniques + and + procedures $+f$ or+developing+Grounded+Theory\&ots=QrFctP6V_\&sig=oCaQY9ZEKX21hwe9NtPhl8811ZY\&redir_esc $=y \# v=$ onepage\&q=Basi cs\%20of\%20qualitative\%20research\%3A\%20Techniques\%20and\%20proce dures\%20for\%20developing\%20Grounded\%20Theory\&f=false

Corder, G. W., \& Foreman, D. I. (2009). Nonparametric Statistics for Non-Statisticians: $A$ Step-by-Step Approach (1. ${ }^{\text {a }}$ ed.). Hoboken, N.J: Wiley.

Covington, R. (2007, junio). The Third Dimension. Aramco World, 58(3), 17-21.

Cox, B. J., \& Novobilski, A. J. (1993). Programacion orientada a objetos/Object-Oriented 


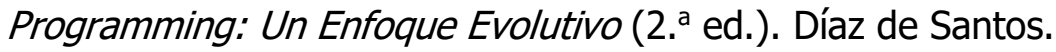

Crane, N. (2003). Mercator: the man who mapped the planet. London: Phoenix.

Creswell, J. W. (2008). Educational research: planning, conducting, and evaluating quantitative and qualitative research (3. ${ }^{\text {a }}$ ed.). Upper Saddle River, N.J.: Pearson/Merrill Prentice Hall.

Cubillo Arribas, J. (2014). ARLE: una herramienta de autor para entornos de aprendizaje de realidad aumentada (Tesis doctoral). Universidad Nacional de Educación a Distancia, Valladolid, España. Recuperado a partir de http://espacio.uned.es/fez/eserv.php?pid=tesisuned:IngIndJcubillo\&dsID=Documento.pdf

Cuendet, S., Bonnard, Q., Do-Lenh, S., \& Dillenbourg, P. (2013). Designing augmented reality for the classroom. Computers \& Education, 68, 557-569. http://doi.org/10.1016/j.compedu.2013.02.015

Dacey, M. F. (1971). Linguistic Aspects of Maps and Geographic Information (Final Report) (p. 33). Illinois: Departament of Geography, Northwestern University.

Dangermond, J. (2004). Keynote address to ESRI User Conference. En ESRI User Conference. San Diego. Recuperado a partir de http://www.esri.com

Davis, C. M. (2006). Patient Practitioner Interaction: An Experiential Manual for Developing the Art of Health Care. SLACK Incorporated.

Davis, N. (2016, enero 28). Augmented Reality SDK Comparison [SocialCompare Collaborative comparison engine]. Recuperado 20 de enero de 2015, a partir de http://socialcompare.com/en/comparison/augmented-reality-sdks

Deagostini Routin, D., \& Murillo Forero, J. A. (1978). Introducción a la Fotogrametría (Centro Interamericano de Fotointerpretación). Bogotá, Colombia: Centro Interamericano de Fotointerpretación, Ministerio de Obras Públicas.

Dede, C. (2009). Immersive Interfaces for Engagement and Learning. Science, 323(5910), 66-69. http://doi.org/10.1126/science.1167311 
Degbelo, A., Granell, C., Trilles, S., Bhattacharya, D., Casteleyn, S., \& Kray, C. (2016). Opening up Smart Cities: Citizen-Centric Challenges and Opportunities from GIScience. ISPRS International Journal of Geo-Information, 5(2), 16. http://doi.org/10.3390/ijgi5020016

De Jong, A. (2015). Using Facebook as a Space for Storytelling in Geographical Research. Geographical Research, n/a-n/a. http://doi.org/10.1111/17455871.12095

de Lázaro y Torres, M. L., de Miguel González, R., \& González González, M. J. (2015). Impulsar las competencias geoespaciales a través de mapas web y la enseñanza inversa en las aulas universitarias. En Á. Fidalgo Blanco, M. L. Sein-Echaluce Lacleta, \& F. García Peñalvo (Eds.), La Sociedad del Aprendizaje (pp. 84-89). Madrid: Fundación General de la Universidad Politécnica de Madrid.

Del Bosque, I., Fernández, C., Martín-Forero, L., \& Pérez, E. (2012). Los Sistemas de Información Geográfica y la Investigación en Ciencias Humanas y Sociales. Madrid. Recuperado a partir de http://digital.csic.es/bitstream/10261/64940/1/Los\%20SIG\%20y\%20la\%20I nvestigacion\%20en\%20Ciencias\%20Humanas\%20y\%20Sociales.pdf

Del Grande, J. (1990). Spatial Sense. Arithmetic teacher, 376), 14-20.

De Miguel González, R. (2014). Aprendizaje por descubrimiento, enseñanza activa y geoinformación: hacia una didáctica de la Geografía innovadora. Didáctica Geográfica, (14), 17-36.

de Pablos Pons, J., Colás Bravo, P., \& González Ramírez, T. (2010). Factores facilitadores de la innovación con TIC en los centros escolares. Un análisis comparativo entre diferentes políticas educativas autonómicas. Revista de Educación, 352, 23-51.

de Paiva Guimarães, M., \& Farinazzo Martins, V. (2014). Desafios a serem superados para o uso de Realidade Virtual e Aumentada no cotidiano do ensino. Revista de Informática Aplicada/Journal of Applied Computing, 9(1), 1-10.

De Ramón, A. (1992). Santiago de Chile (1541-1991): historia de una sociedad urbana. 
Madrid: Editorial MAPFRE.

de Smith, M., Goodchild, M. F., \& Longley, P. A. (2015). Geospatial Analysis - a comprehensive guide. (5. ${ }^{\mathrm{a}}$ ed.). Winchelsea: The Winchelsea Press. Recuperado a partir de http://www.spatialanalysisonline.com

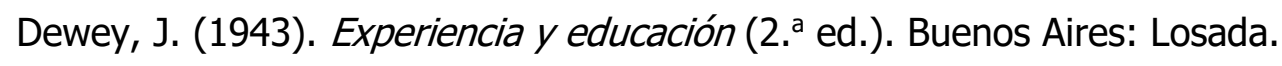

Dewey, J. (1989). Cómo pensamos: nueva exposición de la relación entre pensamiento y proceso educativo (1. ${ }^{\mathrm{a}}$ ed.). Barcelona [etc.]: Paidós.

Dey, A. K. (2001). Understanding and Using Context. Personal and Ubiquitous Computing, 5, 4-7.

Diego Obregón, R. (2014). Realidad Aumentada en documentos e imágenes. Revista Aula de innovación educativa, 230, 65-66.

Doering, A., Koseoglu, S., Scharber, C., Henrickson, J., \& Lanegran, D. (2014). Technology Integration in K-12 Geography Education Using TPACK as a Conceptual Model. Journal of Geography, 113(6), 223-237. http://doi.org/10.1080/00221341.2014.896393

Doering, A., Scharber, C., Miller, C., Veletsianos, G., Doering, A., Scharber, C., ... Veletsianos, G. (2009). GeoThentic: Designing and Assessing with Technological Pedagogical Content Knowledge. Contemporary Issues in Technology and Teacher Education, 9(3), 316-336.

Doering, A., Veletsianos, G., Scharber, C., \& Miller, C. (2009). Using the Technological, Pedagogical, and Content Knowledge Framework to Design Online Learning Environments and Professional Development. Journal of Educational Computing Research, 41(3), 319-346. http://doi.org/10.2190/EC.41.3.d

Doering, A., Veletsianos, G., \& Sharber, C. (2008). Coming of Age. Research and Pedagogy on Geospatial Technologies within K-12 Social Studies Education. En A. J. Milson \& M. Alibrandi (Eds.), Digital Geography: Geospatial Technologies in the Social Studies Classroom (pp. 213-226). Information Age Publishing.

Dominguez Lara, S. (2012). Propuesta para el cálculo de Alfa Ordinal y Theta de Armor. 
Revista de Investigación en Psicología, 15(1), 213-217.

Doswell, J. T. (2006). Augmented Learning: Context-Aware Mobile Augmented Reality Architecture for Learning. En Proceedings of the Sixth IEEE International Conference on Advanced Learning Technologies (pp. 1182-1183). Washington, DC, USA: IEEE Computer Society. Recuperado a partir de http://dl.acm.org/citation.cfm?id=1156068.1156186

Dumova, T., \& Fiordo, R. (Eds.). (2010). Handbook of Research on Social Interaction Technologies and Collaboration Software: Concepts and Trends. IGI Global. Recuperado a partir de http://services.igiglobal.com/resolvedoi/resolve.aspx?doi=10.4018/978-1-60566-368-5

Dündar, H., \& Akçayır, M. (2014). Implementing tablet PCs in schools: Students' attitudes and opinions. Computers in Human Behavior, 32, 40-46. http://doi.org/10.1016/j.chb.2013.11.020

Dünser, A., Walker, L., Horner, H., \& Bentall, D. (2012). Creating Interactive Physics Education Books with Augmented Reality. En Proceedings of the 24th Australian Computer-Human Interaction Conference (pp. 107-114). New York, NY, USA: ACM. http://doi.org/10.1145/2414536.2414554

Edilux. (2002). Salamanca de cerca: guía ilustrada de Salamanca. Granada: Edilux. EducAR. (2014). Argentina Virtual. Recuperado 25 de febrero de 2015, a partir de http://argentinavirtual.educ.ar/localhost/index.html

Edwards, S., \& Nuttall, J. (2015). Teachers, technologies and the concept of integration. Asia-Pacific Journal of Teacher Education, 43(5), 375-377. http://doi.org/10.1080/1359866X.2015.1074817

Ehlers, M. (2008). Geoinformatics and digital earth initiatives: a German perspective. International Journal of Digital Earth, 1(1), 17-30. http://doi.org/10.1080/17538940701781975

Elias, T. (2011). Universal instructional design principles for mobile learning. The International Review of Research in Open and Distributed Learning, 12(2), $143-156$. 
Elliott, G. (2004). Global Business Information Technology: An Integrated Systems Approach. Essex, Inglaterra: Pearson Education.

Empresa de Transporte de Pasajeros Metro S.A. (2015). Metro de Santiago Oficial (Versión 2.0) [IOS]. Santiago de Chile: Empresa de Transporte de Pasajeros Metro S.A.

Engelbart, D. (1962). Augmenting Human Intellect: A Conceptual Framework. Recuperado 1 de julio de 2014, a partir de http://www.dougengelbart.org/pubs/augment-3906.html\#4d

Enviroment Research System Investigation. (2008). The Multipatch Geometry Type. ESRI Press.

Enviroment Research System Investigation. (2016). ArcGIS Network Analyst (Versión 10.3.1) [Windows]. New York: ESRI. Recuperado a partir de http://www.esri.com/software/arcgis/extensions/networkanalyst/keyfeatures

Errázuriz, A. M. (1988). Cartografía temática. Santiago, Chile: Ediciones Universidad Católica de Chile.

Errázuriz, A. M., \& González, J. I. (1992). Proyecciones cartográficas: manejo y uso (1a. edición). Santiago, Chile: Universidad Católica de Chile, Instituto de Geografía.

Errázuriz, A. M., \& González, J. I. (1993). Cartografía topográfica. Santiago, Chile Pontificia Universidad Católica de Chile, Vicerrectoría Académica, Fondo de Desarrollo de la Docencia.

European Space Agency. (2009). 50 years of Earth Observation. Recuperado 5 de mayo de 2015, a partir de http://www.esa.int/About_Us/Welcome_to_ESA/ESA_history/50_years_of_Ea rth_Observation

Faulkner, J. (2012, septiembre 24). MiniDisc, the forgotten format. The Guardian. Recuperado a partir de http://www.theguardian.com/music/musicblog/2012/sep/24/sony-minidisc- 
20-years

Favier, T. T., \& van der Schee, J. A. (2012). Exploring the characteristics of an optimal design for inquiry-based geography education with Geographic Information Systems. Computers \& Education, 58(1), 666-677.

http://doi.org/10.1016/j.compedu.2011.09.007

Favier, T. T., \& van der Schee, J. A. (2014). The effects of geography lessons with geospatial technologies on the development of high school students' relational thinking. Computers \& Education, 76, 225-236.

http://doi.org/10.1016/j.compedu.2014.04.004

Fernández Campos, A., González Mendizábal, I., \& Pérez Gómez, M. del M. (2012). Callejeros literarios: una propuesta para la educación literaria. Revista Iberoamericana de educación, (59), 157-167.

Fernández García, F. (2000). Introducción a la fotointerpretación (1. a ed.). Barcelona: Ariel.

Fischer, F. (2014). Everyday Geomedia use and the appropriation of space. En E. Sanchez, I. Gryl, \& T. Jekel (Eds.), Learning and Teaching with Geomedia (pp. 10-21). Newcastle, UK: Cambridge Scholars Publishing.

FitzGerald, E., Adams, A., Ferguson, R., Gaved, M., Mor, Y., \& Thomas, R. (2012). Augmented reality and mobile learning: the state of the art. En CEUR Workshop Proceedings (Vol. 955, pp. 62-69). Helsinki, Finland. Recuperado a partir de http://ceur-ws.org/Vol-955/papers/paper_49.pdf

Flanagin, A. J., \& Metzger, M. J. (2008). The credibility of volunteered geographic information. GeoJournal, 72(3-4), 137-148. http://doi.org/10.1007/s10708008-9188-y

Flick, U. (2007). Introducción a la investigación cualitativa (2. ${ }^{a}$ ed.). Madrid, A Coruña: Morata; Fundación Paideia Galiza.

Flores Rodríguez, V. G. (2014). Los Sistemas de Información Geográfica (SIG) en la enseñanza de la geografía desde nivel básico hasta universitario. Una nueva experiencia educativa en México. En Congreso Virtual sobre Tecnología, 
Educación y Sociedad (Vol. 1, pp. 1-18). México. Recuperado a partir de http://cenid.org.mx/ctes_2015/memorias/index.php/ctes/article/download/12 $8 / 127$

Fombona Cadavieco, J. (2014). La interactividad de los dispositivos móviles geolocalizados, una nueva relación entre personas y cosas. Historia y Comunicación Social, 18(0), 777-788. http://doi.org/10.5209/rev_HICS.2013.v18.44007

Fonseca, D., Redondo, E., Villagrasa, S., \& Canaleta, X. (2015). Assessment of Augmented Visualization Methods in Multimedia Engineering Education. International Journal of Engineering Education, 31(3), 736-750. http://doi.org/EN

Foo, P., Warren, W. H., Duchon, A., \& Tarr, M. J. (2005). Do Humans Integrate Routes Into a Cognitive Map? Map- Versus Landmark-Based Navigation of Novel Shortcuts. Journal of Experimental Psychology: Learning, Memory, and Cognition, 31(2), 195-215. http://doi.org/10.1037/0278-7393.31.2.195

Franklin, T. (2011). Mobile Learning: At the Tipping Point. Turkish Online Journal of Educational Technology - TOJET, 10(4), 261-275.

Freund, J., Geiger, C., Grafe, M., \& Kleinjohann, B. (2001). The augmented reality personal digital assistant. En Proceedings of the Second International Symposium on Mixed Reality (pp. 85-94).

Friess, D. A., Oliver, G. J. H., Quak, M. S. Y., \& Lau, A. Y. A. (2016). Incorporating «virtual» and «real world» field trips into introductory geography modules. Journal of Geography in Higher Education, Q(0), 1-19. http://doi.org/10.1080/03098265.2016.1174818

Fu, P., \& Sun, J. (2011). Web GIS: principles and applications.

Furió, D., Juan, M.-C., Seguí, I., \& Vivó, R. (2014). Mobile learning vs. traditional classroom lessons: a comparative study. Journal of Computer Assisted Learning, n/a-n/a. http://doi.org/10.1111/jcal.12071

Fuxin, Y. (2012). Mobile/Smartphone Use in Higher Education. Proceedings of the 2012 
Southwest Decision Sciences Institute, 831-839.

Gaffney, V. L., Sears, G., Gaffney, C., Schmidt, A., Goodchild, H., Lobb, M., ... Barabrić, V. (2013). Visualising Space and Movement: A Multidisciplinary Approach to the Palace of Diocletian, Split. En E. Ch'ng, V. Gaffney, \& H. Chapman (Eds.), Visual Heritage in the Digital Age (pp. 93-117). Springer London. Recuperado a partir de http://link.springer.com/chapter/10.1007/978-1-4471-5535-5_6

Galani, A., Mazel, A., Maxwell, D., \& Sharpe, K. (2013). Situating Cultural Technologies Outdoors: Empathy in the Design of Mobile Interpretation of Rock Art in Rural Britain. En E. Ch'ng, V. Gaffney, \& H. Chapman (Eds.), Visual Heritage in the Digital Age (pp. 183-204). Springer London. Recuperado a partir de http://link.springer.com/chapter/10.1007/978-1-4471-5535-5_10

Garagorri, X. (2007). Propuestas curriculares basadas en competencias en el ámbito europeo. Aula de innovación educativa, 161, 56-59.

García-Bermejo Giner, J. R. (2014, septiembre). Programación avanzada III: ciclo vital del desarrollo de software. Clase presentado en Programación Avanzada III, Salamanca, España.

García González, J. A. (2013). El lenguaje visual y cartográfico en las enseñanzas humanísticas. Planos de Metro de Albacete. Cartografías utópicas. Ensayos: Revista de la Facultad de Educación de Albacete, (28), 101-115.

García Rojas, I. B. (2008). El estudio histórico de la cartografía. Takwá. Revista de historia, 13, 11-32.

Gardner, H. (1999). Inteligencias múltiples: la teoría en la práctica (6a. ed). Barcelona [etc.]: Paidós.

Gardner, H. (2006). Multiple Intelligences: New Horizons. New York: Basic Books.

Garfield, S. (2013). En el mapa: de cómo el mundo adquirió su aspecto. [Madrid: Taurus.

Garnica Berrocal, R., \& Galvis Causil, S. (2014). Análisis geográfico del turismo desde la perspectiva espacial de los equipamientos y sitios de interés turísticos en Montería, una ciudad ribereña al norte de Colombia. Revista Geográfica de 
América Central, 1(52), 117-138.

Garrido, M. (2005). El Espacio por aprender, el mismo que enseñar: las urgencias de la educación geográfica. Cadernos CEDES. Campinas, 25(66), 137-163.

Gartner. (2015). Gartner Hype Cycle. Recuperado 29 de octubre de 2015, a partir de http://www.gartner.com/technology/research/methodologies/hype-cycle.jsp

Gibbs, G. (1988). Learning by Doing, A Guide to Teaching and Learning Methods (2013. ${ }^{\mathrm{a}}$ ed.). Oxford Brookes University. Recuperado a partir de brookes.ac.uk/services/ocsld

GIS Wiki. (2012). GIS Wiki | The GIS Encyclopedia. Recuperado 2 de abril de 2013, a partir de http://wiki.gis.com/wiki/index.php/Main_Page

Gobierno Regional Metropolitano. (2013). [Datos Planta Urbana de Santiago]. Servidor de mapas, Santiago de Chile. Recuperado a partir de http://www.gobiernosantiago.cl/servidor-de-mapas\#

Goel, S., \& Bhardawaj, A. (2014). A Critical Analysis of Augmented Learning by Applicability of IT Tools. International Journal of Information and Computation Technology, 4(4), 425-430.

Golledge, R., \& Stimson, R. (1997). Spatial Behavior: A Geographic Perspective. New York: Guilford Press.

Gómez Delgado, M., \& Barredo Cano, J. I. (2005). Sistemas de información geográfica y evaluación multicriterio: en la ordenación del territorio. Madrid: Ra-Ma.

González, C., Martín-Gutiérrez, J., \& Domínguez, M. (2013). Improving Spatial Skills: An Orienteering Experience in Real and Virtual Environments With First Year Engineering Students. 2013 International Conference on Virtual and Augmented Reality in Education. Recuperado a partir de http://udv.ull.es/vare/data/vare2013_ID_73_FULL\%20PAPER.pdf

González García, M. (1982). Salamanca en la Baja Edad Media. Universidad de Salamanca.

González, Ó. (2013, marzo). Educación aumentada. Boletín del Centro del Conocimiento. 
Recuperado a partir de

http://bibliotecaescolardigital.es/comunidad/BibliotecaEscolarDigital/recurso/ boletin-19-articulos-de-oscar-gonzalez-y-jose-maia/e7f51ef6-be56-4d70b8ca-51922e622732

González, T., \& de Celis, J. L. (1998). Salamanca: patrimonio de la humanidad. Guía artística. Salamanca: Colegio de España.

Gonzálvez Vallés, J. E. (2011). La web 2.0 y 3.0 en su relación con el EEES. Madrid: Vision Libros.

Goodchild, M. F. (2007). Citizens as sensors: the world of volunteered geography. GeoJournal, 69(4), 211-221. http://doi.org/10.1007/s10708-007-9111-y

Goodchild, M. F. (2008). Assertion and Authority: The Science of User- Generated Geographic Content. En Assertion and Authority: The Science of UserGenerated Geographic Content (Universidad de California, pp. 1-18). Santa Barbara.

Goodchild, M. F. (2009). NeoGeography and the nature of geographic expertise. Journal of Location Based Services, 3(2), 82-96. http://doi.org/10.1080/17489720902950374

Goodchild, M. F. (2011). Formalizing Place in Geographic Information Systems. En L. M. Burton, S. A. Matthews, M. Leung, S. P. Kemp, \& D. T. Takeuchi (Eds.), Communities, Neighborhoods, and Health (pp. 21-33). New York, NY: Springer New York. Recuperado a partir de http://link.springer.com/10.1007/978-1-4419-7482-2_2

Graham, M. (2010). Neogeography and the Palimpsests of Place: Web 2.0 and the Construction of a Virtual Earth. Tijdschrift Voor Economische En Sociale Geografie, 101(4), 422-436. http://doi.org/10.1111/j.14679663.2009.00563.x

Graham, R., \& Read, R. (1986). Manual of aerial photography. London; Boston: Focal Press.

Grissom, R. J., \& Kim, J. J. (2011). Effect sizes for research: univariate and multivariate 
applications. (2. ${ }^{\text {a }}$ ed.). Routledge.

Grønfeldt Winther, R. (2015). Mapping kinds in GIS and Cartography. En C. Kendig (Ed.), Natural kinds and classification in scientific practice (pp. 1-20). Routledge.

Gros Salvat, B., \& Forés Miravalles, A. (2013). El uso de la geolocalización en educación secundaria para la mejora del aprendizaje situado: Análisis de dos estudios de caso. RELATEC: Revista Latinoamericana de Tecnología Educativa, 12(2), 41-53.

Guerra, M., \& Jordán, V. (2010). Políticas públicas de sociedad de la información en América Latina: ¿una misma visión? Santiago, Chile: Comisión Económica para América Latina y el Caribe (CEPAL).

Gutiérrez, A. (1991). Procesos y habilidades en visualización espacial. En Memorias del 3er Congreso Internacional sobre Investigación en Educ. Mat., Valencia, España (pp. 44-59). Recuperado a partir de http://cmapspublic.ihmc.us/rid=1NGRW4M0Z-BZQ2WQFV/imaginaci\%C3\%B3n\%20espacial.pdf

Guven, S., \& Feiner, S. (2003). Authoring 3D hypermedia for wearable augmented and virtual reality. En Seventh IEEE International Symposium on Wearable Computers, 2003. Proceedings (pp. 118-126). http://doi.org/10.1109/ISWC.2003.1241401

Hall, E. T. (2003). La dimensión oculta (21. ${ }^{\text {a ed. }) . ~ M e ́ x i c o: ~ S i g l o ~ v e i n t i u n o ~ e d i t o r e s . ~}$

Hanchard, M. (2013, marzo 2). Towards a Digital Sociology of Cartography. Recuperado a partir de https://matthewhanchard.wordpress.com/tag/digital-sociology/

Han Rebekah Wong, S. (2012). Which platform do our users prefer: website or mobile app? Reference Services Review, 40(1), 103-115.

Harbort, J. R. (2014, agosto 3). Rohto Digi-Eye Feat. Hatsune Miku AR App Now Activated on iOS and Android. Recuperado a partir de http://www.mikufan.com/rohto-digi-eye-feat-hatsune-miku-ar-app-nowactivated-on-ios-and-android/

Harvey, D. (1998). La condición de la posmodernidad: investigación sobre los orígenes 
del cambio cultural. Buenos Aires: Amorrortu.

Heap, T. H. (2015, mayo 4). 5 razones para usar mapas tradicionales en lugar del GPS. Recuperado 16 de mayo de 2016, a partir de http://www.bbc.com/mundo/noticias/2015/05/150502_tecnologia_mapas_m ejor_que_navegacion_satelite_bd

Heidenreich, M. (2003). Die Debate um die Wissensgesellschaft. En S. Böschen \& I. Schultz-Schaeffer (Eds.), Wissenschaft in der Wissensgesellschaft. Opladen: Westdeutscher.

Heiskanen, W. A., \& Moritz, H. (1985). Geodesia Física. Madrid: Instituto Geográfico Nacional, Instituto de Astronomía y Geodesia.

Henderson, S., \& Yeow, J. (2012). iPad in Education: A Case Study of iPad Adoption and Use in a Primary School. En 2012 45th Hawaii International Conference on System Science (HICSS) (pp. 78-87). http://doi.org/10.1109/HICSS.2012.390

Henríquez, C., \& Quense, J. (2009). Evaluación Multicriterio/Multiobjetivo aplicada a los usos y coberturas de suelo en la cuenca de Chillán. Tiempo y Espacio, Universidad del Bio-Bío, (25), 21-39.

Hernández, R., Fernández, C., \& Baptista, P. (2010). Metodología de la investigación (5. ${ }^{\text {a }}$ ed.). México: McGraw Hill.

Hilbert, M., Bustos, S., \& Ferraz, J. C. (2015). Estrategias nacionales para la sociedad de la información en América Latina y el Caribe (Documentos de Proyectos No. 17) (p. 82). Santiago de Chile: Comisión Económica para América Latina y el Caribe (CEPAL). Recuperado a partir de http://www.cepal.org/es/publicaciones/4087-estrategias-nacionales-para-lasociedad-de-la-informacion-en-america-latina-y-el

Hillegass, A. (2011). Objective-C programming: the Big Nerd Ranch guide. Atlanta, GA: Big Nerd Ranch.

Hillegass, A., \& Conway, J. (2013). iOS programming: the Big Nerd Ranch guide.

Hofmann, S., \& Mosemghvdlishvili, L. (2014). Perceiving spaces through digital augmentation: An exploratory study of navigational augmented reality apps. 
Mobile Media \& Communication, 2(3), 265-280.

http://doi.org/10.1177/2050157914530700

Hola, C. (2016, marzo 29). ¿Cómo logró el FBI desbloquear el iPhone del atacante de San Bernardino y de paso frustrar a Apple? Recuperado 15 de mayo de 2016, a partir de http://www.bbc.com/mundo/noticias/2016/03/160329_tecnologia_fbi_como_ desbloqueo_iphone_san_bernardino_apple_ch

Hollemans, M. (2015). The iOS Apprentice (Fourth Edition): Beginning iOS Development with Swift 2 (4. ${ }^{\text {a }}$ ed.). USA: Razeware LLC.

Höllerer, T., \& Feiner, S. (2004). Mobile Augmented Reality. En Telegeoinformatics: Location-Based Computing and Services (1. ${ }^{a}$ ed., p. 392). CRC Press.

Honan, M. (2007, enero 9). Apple unveils iPhone. Recuperado 16 de febrero de 2015, a partir de http://www.macworld.com/article/1054769/iphone.html

Hori, M., Ono, S., Kobayashi, S., Yamaji, K., Kita, T., \& Yamada, T. (2016). Fusion of ETextbooks, Learning Management Systems, and Social Networking Sites: A Mash-Up Development. En T. T. Zin, J. C.-W. Lin, J.-S. Pan, P. Tin, \& M. Yokota (Eds.), Genetic and Evolutionary Computing (Vol. 388, pp. 377-386). Cham: Springer International Publishing. Recuperado a partir de http://link.springer.com/10.1007/978-3-319-23207-2_38

Huang, H., Schmidt, M., \& Gartner, G. (2012). Spatial Knowledge Acquisition with Mobile Maps, Augmented Reality and Voice in the Context of GPS-based Pedestrian Navigation: Results from a Field Test. Cartography and Geographic Information Science, 39(2), 107-116. http://doi.org/10.1559/15230406392107

Huberman, A. M., \& Miles, M. B. (1994). Data management and analysis methods. En N. K. Denzin \& Y. S. Lincoln (Eds.), Handbook of qualitative research (pp. 428444). Thousand Oaks, CA, US: Sage Publications, Inc.

Huisman, O., \& de By, R. A. (Eds.). (2009). Principles of Geographic Information Systems. An introductory textbook. Países Bajos: The International Institute for Geo-Information Science and Earth Observation (ITC). 
Hwang, G.-J., Tsai, C.-C., \& Yang, S. J. (2008). Criteria, Strategies and Research Issues of Context-Aware Ubiquitous Learning. Educational Technology \& Society, $11(2), 81-91$.

Ibarra Marinas, D., Martínez Hernández, C., Rubio Iborra, J., Pérez Resina, J. P., \& Figueres Cuesta, C. (2015). Aplicación de Web Map Services en la elaboración de un bloque temático de la materia de Biología y Geología de $4^{\circ}$ de ESO. Edutec. Revista Electrónica de Tecnología Educativa, O(51), 1-10.

IEEE Learning Tecnnologies Standards Committee. (2005). IEEE Standard for Learning Technology-Extensible Markup Language (XML) Schema Definition Language Binding for Learning Object Metadata - 1484.12.3. IEEE Standarts.

Ifenthaler, D., \& Schweinbenz, V. (2013). The acceptance of Tablet-PCs in classroom instruction: The teachers' perspectives. Computers in Human Behavior, 29(3), 525-534. http://doi.org/10.1016/j.chb.2012.11.004

IHE. (2016). International Conference on the use of iPads in Higher Education. Recuperado 4 de marzo de 2016, a partir de http://ipadsinhe.org

Innerarity, D. (2009). La sociedad del desconocimiento. En La Sociedad de la Ignorancia y otros ensayos (pp. 17-42). Barcelona: Infonomia.

Innerarity, D. (2011). La democracia del conocimiento: por una sociedad inteligente. Barcelona: Paidós.

Innerarity, D. (2016). Ciudadanía digital. La necesidad de revisar algunos conceptos básicos. TELOS Revista de Pensamiento sobre Comunicación, Tecnología y Sociedad, 102, 13-24.

Instituto de Tecnologías Educativas. (2011). Indicadores y datos de las tecnologías de la información y comunicación en la educación en Europa y España (p. 39). España: Instituto de Tecnologías Educativas, Departamento de Proyectos Europeos. Recuperado a partir de http://www.ite.educacion.es

Instituto Geográfico Nacional. (1946). Salamanca. Fotografía área, Madrid, España. Recuperado a partir de http://fototeca.cnig.es

Instituto Geográfico Nacional (IGN). (2015). Mosaico MA 1:50.000 PNOA hoja 0478. 
Ortofotografía, Salamanca, España: IGN.

Jacob, R., Mooney, P., \& Winstanley, A. C. (2011). Guided by Touch: Tactile Pedestrian Navigation. En Proceedings of the 1st International Workshop on Mobile Location-based Service (pp. 11-20). New York, NY, USA: ACM. http://doi.org/10.1145/2025876.2025881

Jaeger, W. (2001). Paideia: Los Ideales de la Cultura Griega (15. a ed.). México: Fondo de Cultura Económica. Recuperado a partir de https://detemasytemas. files.wordpress.com/2012/05/32726025-wernerjaeger-paideia-los-ideales-de-la-cultura-griega-iii.pdf

Jamali, S. S., Shiratuddin, M. F., \& Wong, K. W. (2014). A review of augmented reality (AR) and mobile-augmented reality (mAR) technology: Learning in tertiary education. International Journal of Learning in Higher Education, 20(2), 3754.

Jan, M., \& Squire, K. (2007). Mad City Mystery: Developing Scientific Argumentation Skills with a Place-based Augmented Reality Game on Handheld Computers. Journal of Science Education and Technology, 16(1), 5-29. http://doi.org/10.1007/s10956-006-9037-z

Jara, I., Claro, M., Hinostroza, J. E., San Martín, E., Rodríguez, P., Cabello, T., ... Labbé, C. (2015). Understanding factors related to Chilean students' digital skills: A mixed methods analysis. Computers \& Education, 88, 387-398. http://doi.org/10.1016/j.compedu.2015.07.016

Jara, I., \& Toledo, C. (2009). Portales educativos. En Las Tecnologías de la Información y la Comunicación en el aula. Plan CEIBAL - MEC (pp. 30-33). Uruguay: Ministerio de Educación y Cultura (MEC). Recuperado a partir de http://educacion.mec.gub.uy/boletin1309/2.\%20Portales\%20Educativos.pdf

Johnson, J. (2012). «The Master Key»: L. Frank Baum envisions augmented reality glasses in 1901. Recuperado 11 de julio de 2014, a partir de https://archive.today/4jTOk

Johnson, L., Smith, R., Willis, H., Levine, A., \& Haywood, K. (2011). The horizon report 2011 ed. Austin, TX; Boulder, CO: The New Media Consortium; EDUCAUSE 
Learning Initiative. Recuperado a partir de http://www.nmc.org/pdf/2011Horizon-Report.pdf

Johnson, R. B., \& Onwuegbuzie, A. J. (2004). Mixed Methods Research: A Research Paradigm Whose Time Has Come. Educational Researcher, 33(7), 14-26. http://doi.org/10.3102/0013189X033007014

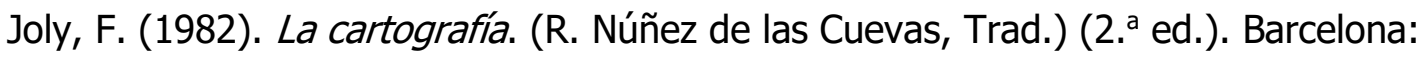
Ariel.

Joly, F. (1985). La cartografía (3. a ed.). Barcelona: Ariel.

Joly, F. (1988). La cartografía. (D. de Bas, Trad.). Vilassar de Mar, Barcelona: Oikos-Tau. Joo, K. H., Park, N. H., \& Choi, J. T. (2014). An Adaptive Teaching and Learning System for Efficient Ubiquitous Learning. En Y.-S. Jeong, Y.-H. Park, C.-H. Hsu, \& J. J. Park (Eds.), Ubiquitous Information Technologies and Applications (Vol. 280, pp. 659-666). Berlin, Heidelberg: Springer Berlin Heidelberg. Recuperado a partir de http://link.springer.com/10.1007/978-3-642-416712_84

Joo Nagata, J. (2013). Geomatics tools and education: status, integration and perception. En Proceedings TEEM(Vol. 1, pp. 501-506). Salamanca, España. http://doi.org/10.1145/2536536.2536613

Joo Nagata, J., García-Bermejo Giner, J. R., \& Martínez Abad, F. (2015). Patrimonio Virtual del Territorio: Diseño e implementación de Recursos Educativos en Realidad Aumentada y Navegación Peatonal Móvil. VAEP-RITA, 3(1), 46-51.

Joo Nagata, J., García-Bermejo Giner, J. R., \& Muñoz Rodríguez, J. (2015). Herramientas Geomáticas utilizadas en Educación: situación actual y su relación con procesos educativos. Enseñanza \& Teaching Revista interuniversitaria de didáctica, 33(1), 25-56. http://doi.org/http://dx.doi.org/10.14201/et20153312556

Joo Nagata, J., \& Valdés Durán, Y. (2011). Google Earth como recurso de aprendizaje en la Formación Inicial Docente en las Áreas de Historia y Geografía. UMCE. Recuperado a partir de http://www.umce.cl/index.php/item-transparencia- 
activa/transparencia-activa-solicitud-informacion/48-facultades/facultad-dehistoria-geografia-y-letras/d-historia

Jover, G., \& Fernández, A. G. (2015). Relectura de la educación por competencias desde el pragmatismo de John Dewey. Education in the Knowledge Society (EKS), $16(1), 32-43$.

Joyanes Aguilar, L. (1997). Cibersociedad. Los retos sociales ante un nuevo mundo digital. Madrid: McGraw Hill.

Joyanes Aguilar, L. (2008). Fundamentos de programación: algoritmos, estructura de datos y objetos (4. ${ }^{\text {a ed. }) . ~ M a d r i d: ~ M c G r a w-H i l l . ~}$

Joyanes Aguilar, L. (2014). Big data: análisis de grandes volúmenes de datos en organizaciones. Barcelona: Marcombo.

Junta de Castilla y León. (2010). Ficha del Catálogo de Bienes Protegidos de la Dirección General de Patrimonio Cultural de la Junta de Castilla y León. Recuperado 21 de octubre de 2013, a partir de http://servicios.jcyl.es/pweb/datos.do?numero=10089\&tipo=inmueble\&ruta=

Kalkush, M., Lidy, T., Knapp, M., Reitmayr, G., Kaufmann, H., \& Scmalstieg, D. (2002). Structured Visual Markers for Indoor Pathfinding. Presentado en Proceedings of the First IEEE International Workshop on ARToolKit, IEEE Computer Society. Recuperado a partir de https://www.ims.tuwien.ac.at/publications/tuw-137073.pdf

Kerski, J. J. (2003). The Implementation and Effectiveness of Geographic Information Systems Technology and Methods in Secondary Education. Journal of Geography, 102(3), 128-137. http://doi.org/10.1080/00221340308978534

Kipper, G., \& Rampolla, J. (2012). Augmented Reality: An Emerging Technologies Guide to $A R$. Elsevier.

Kirk, R. E. (1995). Experimental design. En Experimental Design: Procedures for the Behavioral Sciences (3. ${ }^{\text {a }}$ ed., pp. 23-45). California: Wadsworth Inc Fulfillment.

Knowles, A. K., \& Hillier, A. (2008). Placing History: How Maps, Spatial Data and GIS are 
Changing Historical Scholarship (Edición: Pap/Cdr). Redlands, Calif: ESRI Press.

Koehler, M. (2012). Using the TPACK Image. Recuperado a partir de http://www.tpack.org

Koh, J. H. L., Chai, C. S., \& Lee, M.-H. (2015). Technological Pedagogical Content Knowledge (TPACK) for Pedagogical Improvement: Editorial for Special Issue on TPACK. The Asia-Pacific Education Researcher, 24(3), 459-462. http://doi.org/10.1007/s40299-015-0241-6

Kokalj, Ž., Pehani, P., Goodchild, H., Gaffney, V., \& Oštir, K. (2013). Crossing Borders: A Multi-Layer GIS Mapping Framework for the Cultural Management of the Mundo Maya Region. En E. Ch'ng, V. Gaffney, \& H. Chapman (Eds.), Visual Heritage in the Digital Age (pp. 169-182). Springer London. Recuperado a partir de http://link.springer.com/chapter/10.1007/978-1-4471-5535-5_9

Komorowski, M. (2014, septiembre 3). A history of storage cost (update). Recuperado 25 de noviembre de 2015, a partir de http://www.mkomo.com/cost-pergigabyte-update

Korte, W. B., \& Hüsing, T. (2006). Benchmarking access and use of ICT in European schools 2006: Results from head teacher and a classroom teacher surveys in 27 European countries. isbon Strategy and Policies for the Information Society. European Commision. Recuperado a partir de http://www.awt.be/contenu/tel/dem/final_report_3.pdf

Krüger, K. (2006). El concepto de «Sociedad del Conocimiento». Biblio 3W, Revista Bibliográfica de Geografía y Ciencias Sociales, Universidad de Barcelona, XI(683). Recuperado a partir de http://www.ub.es/geocrit/b3w-683.htm

Kuhn, T. S. (1979). La estructura de las revoluciones científicas (1a ed., 4a. reimp.). México: Fondo de Cultura Económica.

Kurilovas, E., Kubilinskiene, S., \& Dagiene, V. (2014). Web 3.0 - Based personalisation of learning objects in virtual learning environments. Computers in Human Behavior, 30, 654-662. http://doi.org/10.1016/j.chb.2013.07.039 
Kvale, S. (2011). Las entrevistas en investigación cualitativa. (Vol. 2). España: Morata.

Lankshear, C., Peters, M., \& Knobel, M. (2000). Information, Knowledge and learning: Some Issues Facing Epistemology and Education in a Digital Age. The Journal of the Philosophy of Education Society of Great Britain, 34(1), 17-39.

Laru, J., \& Järvelä, S. (2013). Using Gartner's Hype Curve as a basis to analyze research on the educational use of ubiquitous computing (CSCL 2013) (Vol. 1, pp. 280-287). Presentado en The Computer Supported Collaborative Learning (CSCL) Conference 2013, Madison. Recuperado a partir de https://www.academia.edu/3773533/Using_Gartner_s_Hype_Curve_as_a_ba sis_to_analyze_research_on_the_educational_use_of_ubiquitous_computing _CSCL_2013_

Laru, J., Naykki, P., \& Järvelä, S. (2015). Four Stages of Research on the Educational Use of Ubiquitous Computing. IEEE Transactions on Learning Technologies, 8(1), 69-82. http://doi.org/10.1109/TLT.2014.2360862

Lave, J., \& Wenger, E. (1991). Situated Learning: Legitimate Peripheral Participation. Cambridge University Press.

Law, M., \& Collins, A. K. (2015). Getting to Know ArcGIS (4. ${ }^{\text {a }}$ ed.). Estados Unidos: Esri Press.

Lee, K. (2012). Augmented reality in education and training. TechTrends, 56(2), 13-21.

Lee, S.-G., Trimi, S., Byun, W. K., \& Kang, M. (2011). Innovation and imitation effects in Metaverse service adoption. Service Business, 5(2), 155-172. http://doi.org/10.1007/s11628-011-0108-8

Lee, S., Suh, J., \& Park, H.-D. (2015). BoreholeAR: A mobile tablet application for effective borehole database visualization using an augmented reality technology. Computers \& Geosciences, 76, 41-49. http://doi.org/10.1016/j.cageo.2014.12.005

Lesemann, F. (2014). Sociedad del conocimiento: los cambios en el mundo del trabajo y las nuevas competencias de los trabajadores. En G. Valenti \& M. Casalet (Eds.), Instituciones, sociedad del conocimiento y mundo del trabajo (pp. 97- 
142). México: FLACSO. Recuperado a partir de http://www.jstor.org/stable/j.ctt16f8csq.7

Lingel, J., \& Bishop, B. W. (2014). The GeoWeb and everyday life: An analysis of spatial tactics and volunteered geographic information. First Monday, 19(7). http://doi.org/http://dx.doi.org/10.5210/fm.v19i7.5316

Llobet, C. (2011). Enseñar y aprender Historia del Arte. En A. Santisteban \& J. Pagès (Eds.), Didáctica del Conocimiento Social y Cultural en la Educación Primaria: Ciencias Sociales para comprender, pensar y actuar (pp. 269-294). Madrid: Síntesis.

Loewnthal, K. M. (1996). An introduction to psychological tests and scales. Londres: UCL Press.

López, G. B. (2012). Geolocalización y Redes Sociales. Madrid: Bubok.

López i Amat, J. (2010). De la Sociedad de la información a la(s) Sociedad(es) del Conocimiento. Vasos comunicantes en el cambio de milenio. 1960-2010. (Trabajo de Investigación - D.E.A.). Universidad Complutense de Madrid, Madrid, España. Recuperado a partir de https://ia902501.us.archive.org/11/items/SociedadInformacionSociedadConocimiento/De\%20la\%20Sociedad\%20de\%20la\%20Información \%20a\%20la\%20Sociedad\%20del\%20Conocimiento\%20\%20\%20Jordi\%20LOPEZ\%20AMAT-\%20CC.pdf

Lyotard, J.-F. (1987). La condición postmoderna: informe sobre el saber (3. a ed.). Madrid: Cátedra.

Mahapatra, L. (2013, noviembre 11). Android Vs. iOS: What's The Most Popular Mobile Operating System In Your Country? [Electronic newspaper]. Recuperado 16 de febrero de 2015, a partir de http://www.ibtimes.com/android-vs-ioswhats-most-popular-mobile-operating-system-your-country-1464892

Maliene, V., Grigonis, V., Palevičius, V., \& Griffiths, S. (2011). Geographic information system: Old principles with new capabilities. Urban Design International, 16(1), 1-6. http://doi.org/10.1057/udi.2010.25 
Mann, S. (2012). Eye Am a Camera: Surveillance and Sousveillance in the Glassage.

Time. Recuperado a partir de http://techland.time.com/2012/11/02/eye-ama-camera-surveillance-and-sousveillance-in-the-glassage/

Marc, S. (2014, febrero 27). Google Maps, Nokia Here y Apple Maps a prueba en nuestro reto. Recuperado 22 de julio de 2014, a partir de http://articulos.softonic.com/google-maps-nokia-here-apple-maps-a-pruebareto?utm_source=all_win\&utm_medium=email\&utm_campaign=ES

Martí, C., Feliu, J., \& Varga, D. (2014). Geographic Information Technology and Innovative Teaching: Keys to Geography Degree Curriculum Reform. Journal of Geography, 113(3), 118-128. http://doi.org/10.1080/00221341.2013.835855

Martínez Abad, F. (2013). Evaluación y Formación en Competencias Informacionales en la Educación Secundaria Obligatoria. Universidad de Salamanca, Salamanca, España. Recuperado a partir de http://www.europeana.eu/portal/record/2022701/oai_gredos_usal_es_10366 _121869.html

Martínez, A. M., Navarro, J. G. C., \& Sánchez, J. A. R. (2012). Aprendizaje basado en competencias: Una propuesta para la autoevaluación del docente. Profesorado. Revista de Currículum y Formación de Profesorado, 16(2), 325338.

Martínez Clares, P., \& Echeverría Samanes, B. (2009). Formación basada en competencias. Revista de Investigación Educativa, 2Л1), 125-147.

Martínez Landa, H. (2015). Problems Analysis and Solutions for the Establishment of Augmented Reality Technology in Maintenance and Education. Tampere University of Technology, Tampere, Finlandia.

Martin-Gutierrez, J., Garcia-Dominguez, M., Gonzalez, C. R., \& Corredeguas, M. C. M. (2013). Using different methodologies and technologies to training spatial skill in Engineering Graphic subjects. En 2013 IEEE Frontiers in Education Conference (pp. 362-368). http://doi.org/10.1109/FIE.2013.6684848

Martín Gutiérrez, J., Luís Saorín, J., Contero, M., Alcañiz, M., Pérez López, D. C., \& 
Ortega, M. (2010). Design and validation of an augmented book for spatial abilities development in engineering students. Computers \& Graphics, 34(1), 77-91. http://doi.org/10.1016/j.cag.2009.11.003

Martín Gutiérrez, J., \& Meneses Fernández, M. (2014). Applying Augmented Reality in Engineering Education to Improve Academic Performance \& Student Motivation. International Journal of Engineering Education, 30(3), 1-11.

Martín Izard, J. F. (2011). Técnicas de encuesta: cuestionario y entrevista. En S. Nieto Martín (Ed.), Principios, métodos y técnicas esenciales para la investigación

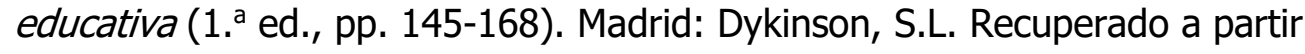
de http://books.google.es/books?id=jJrFZwEACAAJ

Marzal, M. Á., \& Pedrazzi, S. (2015). Educational potential of topic maps and learning objects for m-learning in the knowledge society. Transinformação, 273), 229-244. http://doi.org/10.1590/0103-37862015000300005

Mastache, A. (2007). Formar personas competentes: desarrollo de competencias tecnológicas y psicosociales. Buenos Aires: Novedades Educativas.

Mathias, M., \& Gallagher, J. (2015). Swift Programming: The Big Nerd Ranch Guide. Estados Unidos: Big Nerd Ranch Guides.

Mayr, S., Buchner, A., Erdfelder, E., \& Faul, F. (2007). A short tutorial of GPower. Tutorials in Quantitative Methods for Psychology, 3(2), 51-59.

McPherson, P. (2016). Tablets. Tips and Trends/Instructional Technologies Committee, $1-6$.

Medyńska-Gulij, B. (2014). Cartographic sign as a core of multimedia map prepared by non-cartographers in free map services. Geodesy and Cartography, 63(1), 55-64. http://doi.org/10.2478/geocart-2014-0004

Meece, S. (2006). A bird's eye view - of a leopard's spots. The Çatalhöyük 'map' and the development of cartographic representation in prehistory. Anatolian Studies, $56,1-16$.

Mertens, D. M. (2010). Research and evaluation in education and psychology: integrating diversity with quantitative, qualitative, and mixed methods (3. ${ }^{a}$ 
ed.). Thousand Oaks, California: Sage Publications.

Milgram, P., \& Kishino, F. (1994). A taxonomy of mixed reality visual displays. IEICE TRANSACTIONS on Information and Systems, 77(12), 1321-1329.

Milgram, P., Takemura, H., Utsumi, A., \& Kishino, F. (1995). Augmented reality: A class of displays on the reality-virtuality continuum. En Photonics for Industrial Applications (pp. 282-292). International Society for Optics and Photonics.

Miller, R., \& Constine, J. (2015, mayo 28). Apple Acquires Augmented Reality Company Metaio. Recuperado a partir de http://social.techcrunch.com/2015/05/28/apple-metaio/

Millwood, R. (2013, abril 30). Learning Theory v6 [Mapa Mental]. Recuperado 11 de octubre de 2015, a partir de http://cmapspublic3.inmc.us/rid=1LGVGJY66CCD5CZ-12G3/Learning\%20Theory.cmap

Milson, A. J. (2011). SIG en la nube: WebSIG para la enseñanza de la Geografía. Didáctica Geográfica, O(12), 111-124.

Minguell, M. E., Font, J. F., Cornellas, P., \& Regás, D. C. (2012). Realidad aumentada y códigos QR en educación. En J. Hernández Ortega, M. Pennesi Fruscio, D. Sobrino López, \& A. Vázquez Gutierrez (Eds.), Tendencias emergentes en Educación con TIC (pp. 135-157). Barcelona: Espiral. Recuperado a partir de http://dialnet.unirioja.es/servlet/articulo;jsessionid=4A1750EAD741F8AB384 451D143729D12.dialnet02?codigo $=4230624$

Ministerio de Educación Chile. (2015, agosto 21). Estadísticas de la Educación 2014. MINEDUC. Recuperado a partir de http://centroestudios. mineduc. $\mathrm{cl} /$ index.php?t=96\& $\mathrm{i}=2 \& \mathrm{cc}=2036 \& \mathrm{tm}=2$

Ministerio de Educación, Cultura y Deporte España. (2015). Instituto de Tecnologías Educativas y de Formación del Profesorado. Objetivos. Recuperado 26 de noviembre de 2015, a partir de http://www.ite.educacion.es/es/intef

Mishra, P., \& Koehler, M. (2006). Technological Pedagogical Content Knowledge: A Framework for Teacher Knowledge. Teachers College Record, 108(6), 10171054. 
Mitchell, T. (2005). Web mapping illustrated. California: O’Reilly.

Miyajima, K. (1998). Projection Methods in Chinese, Korean and Japanese Star Maps. En J. Andersen (Ed.), Highlights of Astronomy (pp. 712-715). Dordrecht:

Springer Netherlands. Recuperado a partir de http://link.springer.com/10.1007/978-94-011-4778-1_33

Mohler, B. J., Thompson, W. B., Creem-Regehr, S. H., Pick, H. L., \& Warren, W. H. (2007). Visual flow influences gait transition speed and preferred walking speed. Experimental Brain Research, 181(2), 221-228. http://doi.org/10.1007/s00221-007-0917-0

Möhring, M., Lessig, C., \& Bimber, O. (2004). Video see-through ar on consumer cellphones. En Proceedings of the 3rd IEEE/ACM International Symposium on Mixed and Augmented Reality (pp. 252-253). IEEE Computer Society. Recuperado a partir de http://dl.acm.org/citation.cfm?id=1033722

Montello, D. (2005). Navigation. En P. Shah \& A. Miyake (Eds.), The Cambridge Handbook of Visuospatial Thinking (pp. 257-294). Cambridge.: Cambridge University Press.

Montilva, J., Arapé, N., \& Colmenares, J. (2003). Desarrollo de software basado en componentes. En CAC-2003 (pp. 1-9). Mérida, Venezuela. Recuperado a partir de http://juancol.me/rsrc/sw-basado-en-comp-CAC2003.pdf

Mood, A. M. (1954). On the Asymptotic Efficiency of Certain Nonparametric Two-Sample Tests. The Annals of Mathematical Statistics, 25(3), 514-522.

Mora, J. A. (1995). Evolución histórica de las teorías y medidas sobre la inteligencia. Revista de Historia de la Psicología, 16(3-4), 3-16.

Moralejo, L., Sanz, C. V., Pesado, P., \& Baldassarri, S. (2014). Avances en el diseño de una herramienta de autor para la creación de actividades educativas basadas en realidad aumentada. Revista Iberoamericana de Educación en Tecnología y Tecnología en Educación, 12, 8-14.

Morales Morgado, E. (2007). Gestión del conocimiento en sistemas E-Learning, basado en objetos de aprendizaje, cualitativa y pedagógicamente definidos. 
Universidad de Salamanca, Salamanca, España. Recuperado a partir de http://dialnet.unirioja.es/servlet/tesis?codigo=18457

Morales, P., \& Landa, V. (2004). Aprendizaje basado en problemas. Theoria, 13(1), 145157.

Morales Vallejo, P. (2012). Tamaño necesario de la muestra: ¿Cuántos sujetos necesitamos? Estadística aplicada a las ciencias sociales. Madrid, España: Facultad de Humanidades. Universidad Pontificia Comillas. Recuperado a partir de

http://web.upcomillas.es/personal/peter/investigacion/Tama\%F1oMuestra.pd $f$

Morin, E. (1984). Ciencia con consciencia. Barcelona: Anthropos.

Morin, E. (1999). Los siete saberes necesarios para la educación del futuro. Paris: Organización de las Naciones Unidas para la Educación, la Ciencia y la Cultura. Recuperado a partir de http://www.edgarmorin.org/descarga-librolos-7-saberes.html

Morin, E. (2002). La cabeza bien puesta: Repensar la reforma. Reformar el pensamiento (1. ${ }^{a}$ ed.). Buenos Aires: Nueva Visión.

Muñiz, J. (2010). Las teorías de los tests: Teoría Clásica y Teoría de Respuesta a los Ítems. Papeles del Psicólogo, 31(1), 57-66.

Muñoz, A. (2015, abril 23). Décimo aniversario del primer vídeo de YouTube. El Mundo. Madrid. Recuperado a partir de http://www.elmundo.es/espana/2015/04/23/5537e4dc22601d97368b457a.ht $\mathrm{ml}$

Muñoz Cristóbal, J. A., Martínez Monés, A., Asensio Pérez, J. I., Villagrá Sobrino, S. L., Hoyos Torio, J. E., \& Dimitriadis, Y. (2014). City Ads: Embedding Virtual Worlds and Augmented Reality in Everyday Educational Practice. Journal of Universal Computer Science, 20(12), 1670-1689.

NASA Landsat Program. (2003, octubre 26). Escena p233r084_7k199991226_z19_nn61. Landsat TM, Sioux Falls: USGS. Recuperado a partir de 
http://glcf.umd.edu/data/landsat/

National Aeronautics and Space Administration. (2015). Landsat Program. Recuperado 5 de mayo de 2015, a partir de http://landsat.gsfc.nasa.gov/

Navia Bueno, F., Joo Nagata, J., \& Guerra Pinto, K. (2014). El patrimonio en la Web 2.0: Atlas virtual del Campus Macul Universidad Metropolitana de Ciencias de la Educación (UMCE). Santiago de Chile: Ediciones UMCE.

Nelles, C., Lee, G. A., Billinghurst, M., \& Kim, G. (2004). Immersive authoring of tangible augmented reality applications. En Third IEEE and ACM International Symposium on Mixed and Augmented Reality, 2004. ISMAR 2004 (pp. 172181). Washington, DC, USA: IEEE Computer Society. http://doi.org/10.1109/ISMAR.2004.34

Newcombe, N. S., \& Frick, A. (2010). Early education for spatial intelligence: Why, what, and how. Mind, Brain, and Education, 4(3), 102-111.

Nieto Martín, S. (2011). Medidas de tendencia central y variabilidad. En S. Nieto Martín (Ed.), Principios, métodos y técnicas esenciales para la investigación educativa (1. ${ }^{\text {a }}$ ed., pp. 145-168). Madrid: Dykinson, S.L. Recuperado a partir de http://books.google.es/books?id=jJrFZwEACAAJ

Niu, E. (2015, noviembre 16). How Many iOS Devices Has Apple Sold? -. Recuperado 4 de marzo de 2016, a partir de http://www.fool.com/investing/general/2015/11/16/ios-devices-sold.aspx

Noriega Biggio, M., Maris Vázquez, S., \& Maris García, S. (2011). Componentes de la competencia espacial. Exploración en ingresantes a la Facultad de Arquitectura, Diseño y Urbanismo. Revista de Orientación Educacional, 25(47), 95-112.

Norman, D. (2013). The Design of Everyday Things: Revised and Expanded Edition. New York: Basic Books. Recuperado a partir de https://books.google.es/books?id=nVQPAAAAQBAJ\&pg=PT18\&redir_esc=y\# $\mathrm{v}=$ onepage $\& q \& \mathrm{f}=\mathrm{false}$

Norman, H., Din, R., \& Nordin, N. (2011). A preliminary study of an authentic ubiquitous 
learning environment for higher education. Recent Researches in E-Activities, $3(4), 89-94$.

Nuchera, A. H., Idoipe, A. V., \& Torres, M. (2008). Los factores clave de la innovación tecnológica: claves de la competitividad empresarial. Dirección y Organización, a(36), 5-22.

Nunnally, J. C. (1978). Psychometric theory (2. ${ }^{a}$ ed.). New York: McGraw-Hill.

Núñez, P. (2001). Salamanca: guía de arquitectura. Salamanca: Colegio Oficial de Arquitectos de León, Delegación de Salamanca.

OECD. (2001). OECD Science, Technology and Industry Scoreboard - Towards a knowledge-based economy. Recuperado a partir de http://www.oecdilibrary.org/docserver/download/9201041e.pdf?expires=1452515458\&id=id\& accname $=$ guest $\&$ checksum $=7$ EE2D8DA4B8542A83F6EEAC278EABDB8

Okuku Oloo, J., \& Van der Krapf, J. (2015). Spatial data infrastructure and voluntary geographic information. Journal of Multidisciplinary Engineering Science and Technology (JMEST), 2(1), 39-45.

O'Malley, C., Vavoula, G., Glew, J., Taylor, J., Sharples, M., Lefrere, P., ... Waycott, J. (2005). Guidelines for learning/teaching/tutoring in a mobile environment. Recuperado a partir de https://hal.archives-ouvertes.fr/hal-00696244/

Onsrud, H. J., \& Pinto, J. K. (1991). Diffusion of geographic information innovations. International Journal of Geographical Information Systems, 5(4), 447-467. http://doi.org/10.1080/02693799108927868

Open Geospatial Consortium. (2006). Web Map Service. Recuperado 3 de enero de 2016, a partir de http://www.opengeospatial.org/standards/wms

Open Geospatial Consortium. (2013, febrero 11). OGC Augmented Reality Markup Language 2.0 (ARML 2.0). TBD. Recuperado a partir de http://www.opengis.net/doc/arml2x0/2.0

Open Street Map. (2015). Salamanca, Castilla y León. Mapa de calles y referencias. Recuperado a partir de https://www.openstreetmap.org/\#map=16/40.9634/-5.6631 
Open Street Map. (2016, enero 7). OSM Apple iOS. Recuperado 29 de febrero de 2016, a partir de http://wiki.openstreetmap.org/wiki/Apple_iOS

O'Reilly, T. (2005, septiembre 30). What Is Web 2.0. Recuperado 6 de abril de 2015, a partir de http://www.oreilly.com/pub/a/web2/archive/what-is-web-20.html

O'Reilly, T. (2006). Qué es Web 2.0. Patrones del diseño y modelos del negocio para la siguiente generación del software. Fundación Telefónica, 1-13.

Organización para la Cooperación y Desarrollo Económico. (2015). Key ICT Indicators. Recuperado 26 de noviembre de 2015, a partir de http://www.oecd.org/internet/broadband/oecdkeyictindicators.htm

Ortiz Morales, M. D., Joyanes Aguilar, L., \& Giraldo Marín, L. M. (2015). Los desafíos del marketing en la era del big data. e-Ciencias de la Información, 6(1), 1. http://doi.org/10.15517/eci.v6i1.19005

Owens, J. B. (2007). What Historians Want from GIS. Recuperado 18 de mayo de 2016, a partir de http://www.esri.com/news/arcnews/summer07articles/whathistorians-want.html

Palma Herrera, J. L. (2013). Sistemas de Información Geográfica (SIG) y metodologías de evaluación multicriterio (EMC) en la búsqueda de escenarios alternativos para el mejoramiento socioespacial de las áreas urbanas populares de la ciudad de Comayagua. Geografía y Sistemas de Información Geográfica. (GESIG-UNLU, Luján), 5(5), 180-193.

Pardo Merino, A. (2002). SPSS 11: guía para el análisis de datos. España: McGraw-Hill.

Passig, D., Tzuriel, D., \& Eshel-Kedmi, G. (2016). Improving children's cognitive modifiability by dynamic assessment in 3D Immersive Virtual Reality environments. Computers \& Education, 95, 296-308. http://doi.org/10.1016/j.compedu.2016.01.009

Pastor, J. (2007, septiembre 19). Gordon Moore: «Mi ley dejará de cumplirse dentro de 10 o 15 años». Recuperado 24 de noviembre de 2015, a partir de http://www.theinquirer.es/2007/09/19/gordon_moore_mi_ley_dejara_de_cu mplirse_dentro_de_10_o_15_anos.html 
Patterson, T. C. (2007). Google Earth as a (Not Just) Geography Education Tool. Journal of Geography, 106(4), 145-152. http://doi.org/10.1080/00221340701678032

Pei, L.-S., Cai, S., \& Shi, P.-F. (2013). Mobile Campus Touring System based on AR and GPS: a Case Study of Campus Cultural Activity. En Proceedings of the 21st International Conference on Computers in Education (pp. 518-526). Denpasar, Indonesia.

Peñalvo García, F., Zangrando, V., Seoane Pardo, M. A., García Holgado, A., Szczecinska, J., Baldner, J. M., ... Crivellari, C. (2012). Multicultural Interdisciplinary Handbook: tools for learning history and geography in a multicultural perspective. España: GRIAL. Recuperado a partir de http://repositorio.grial.eu/handle/grial/173

Perera, C., Zaslavsky, A., Christen, P., \& Georgakopoulos, D. (2014). Context Aware Computing for The Internet of Things: A Survey. IEEE Communications Surveys Tutorials, 16(1), 414-454. http://doi.org/10.1109/SURV.2013.042313.00197

Pérez Serrano, G. (1994). Investigación cualitativa: retos e interrogantes. Madrid: La Muralla.

Perpetua, M. (2011, enero 6). Vinyl Sales Increase Despite Industry Slump. Recuperado 26 de octubre de 2015, a partir de http://www.rollingstone.com/music/news/vinyl-sales-increase-despiteindustry-slump-20110106

Perrenoud, P. (2008). Construir competencias desde la escuela. (M. Lorca, Trad.) (2. ${ }^{a}$ ed.). Santiago de Chile: J.C. Sáez editor.

Petrova, K., \& Li, C. (2009). Focus and setting in mobile learning research: A review of the literature. Recuperado a partir de http://aut.researchgateway.ac.nz/handle/10292/2527

Pomés, J., \& Argüelles, B. (1991). Análisis de ítems de opción múltiple. Zaragoza: Universidad de Zaragoza.

Prendes Espinosa, C. (2015). Realidad Aumentada y Educación: Análisis de Experiencias 
Prácticas. Píxel-Bit. Revista de Medios y Educación., 46, 187-203.

http://doi.org/http://dx.doi.org/10.12795/pixelbit.2015.i46.12

Prensky, M. (2001). Digital natives, digital inmigrants. On the Horizon, 9(5), 1-6.

Prieto, G., \& Delgado, A. R. (2010). Fiabilidad y validez. Papeles del Psicólogo, 31(1), 6774.

Quinn, C. (2000). mLearning: Mobile, wireless, in-your-pocket learning. Recuperado 22 de enero de 2105, a partir de http://www.linezine.com/2.1/features/cqmmwiyp.htm

Rahimi, M., \& Malek, M. R. (2015). Context-aware abstraction and generalization of street networks: two cognitively engineered user-oriented approaches using network Voronoi diagrams. Geocarto International, 30(5), 560-579. http://doi.org/10.1080/10106049.2014.985742

Ramirez, V., \& Cassinerio, S. (2014). Realidad Aumentada-trabajo cooperativo; Nivel Inicial. (pp. 1-21). Presentado en Congreso Iberoamericano de Ciencia, Tecnología, Innovación y Educación, Buenos Aires. Recuperado a partir de http://www.oei.es/congreso2014/memoriactei/1669.pdf

Ramsey, E. (2013). Urban Scrawl: Reconstructing Urban Landscapes Using Documentary Sources. En E. Ch'ng, V. Gaffney, \& H. Chapman (Eds.), Visual Heritage in the Digital Age (pp. 147-167). Springer London. Recuperado a partir de http://link.springer.com/chapter/10.1007/978-1-4471-5535-5_8

Raskar, R., Welch, G., \& Fuchs, H. (1998). Spatially augmented reality. En First IEEE Workshop on Augmented Reality (IWAR'98) (pp. 11-20). Recuperado a partir de http://masters.donntu.edu.ua/2012/fknt/sobolev/library/article7.pdf

Reichenbacher, T. (2005). Adaptative egocentric maps for mobile users. En L. Meng, T. Reichenbacher, \& A. Zipf (Eds.), Map-based Mobile Services. Theories, Methods and Implementations. (pp. 141-158). Berlin/Heidelberg: SpringerVerlag. Recuperado a partir de http://link.springer.com/10.1007/b138407

Reichenbacher, T., \& Meng, L. (2005). Map-based Mobile Services. En L. Meng, T. Reichenbacher, \& A. Zipf (Eds.), Map-based Mobile Services. Theories, 
Methods and Implementations. (pp. 1-8). Berlin/Heidelberg: Springer-Verlag. Recuperado a partir de http://link.springer.com/10.1007/b138407

Reich, R. B. (1992). The Work of Nations: Preparing Ourselves for 21st Century Capitalism. New York: Vintage.

Reinoso, R. (2012). Posibilidad de la Realidad Aumentada en Educación. En J. Hernández, D. Pennesi, D. Sobrino, \& A. Vázquez (Eds.), Tendencias emergentes en Educación con TIC (pp. 175-196). Barcelona: Espiral.

Riera, A. S., Redondo, E., \& Fonseca, D. (2014). Geo-located teaching using handheld augmented reality: good practices to improve the motivation and qualifications of architecture students. Universal Access in the Information Society, 14(3), 363-374. http://doi.org/10.1007/s10209-014-0362-3

Ritter, M. (2014, marzo 28). How Many Man-Made Satellites Are Currently Orbiting Earth? Recuperado 5 de mayo de 2015, a partir de http://talkingpointsmemo.com/idealab/satellites-earth-orbit

Riyad, E. (2008, abril). Music on the Move. MiniDisc. Recuperado 26 de octubre de 2015, a partir de http://www.trustedreviews.com/opinions/music-on-themove_Page-4

Rocha Salamanca, L. Á., \& Díaz Vega, N. A. (2010). Las Geotecnologías como herramientas importantes en la educación de la geografía. UD Y La Geomática, (4), 44-52.

Rød, J. K., Larsen, W., \& Nilsen, E. (2010). Learning geography with GIS: Integrating GIS into upper secondary school geography curricula. Norsk Geografisk Tidsskrift - Norwegian Journal of Geography, 64(1), 21-35. http://doi.org/10.1080/00291950903561250

Rodríguez Álvarez, J. L. (2014, mayo 30). Google ya permite solicitar el «derecho al olvido» [Periodico]. Recuperado 15 de mayo de 2016, a partir de http://www.abc.es/tecnologia/redes/20140530/abci-google-derecho-olvido201405301014.html

Rodríguez Conde, M. J. (2011). Test y otras pruebas escritas u orales. En S. Nieto Martín 
(Ed.), Principios, métodos y técnicas esenciales para la investigación educativa (1. a ed., pp. 191-219). Madrid: Editorial Dykinson, S.L. Recuperado a partir de http://books.google.es/books?id=jJrFZwEACAAJ

Rodríguez Silgo, A. (2016). Digitalización y virtualización del patrimonio cultural. Hacia un nuevo horizonte en la conservación-restauración. TELOS Revista de Pensamiento sobre Comunicación, Tecnología y Sociedad, 102, 67-76.

Rodríguez Zoya, L., \& Aguirre, J. L. (2011). Teorías de la complejidad y Ciencias Sociales. Nuevas Estrategias Epsitemológicas y Metodológicas. Nómadas. Revista Crítica de Ciencias Sociales y jurídicas, 30(2), 1-20.

Rogers, E. M. (2003). Diffusion of innovations (5th ed). New York [etc.]: Free Press.

Rohs, C. (2012). Die erweiterte Realität: Einsatzgebiete und Potential von Augmented Reality (Auflage: 1., Aufl.). Hamburg: Bachelor + Master Publishing.

Roopesh, kevin, Sunkur, A., Panchoo, N., \& Kirtee, B. (2016). Augmented reality, the future of contextual mobile learning. Interactive Technology and Smart Education, 13, 12-15.

Rosenberg, L. B. (1993). Virtual fixtures as tools to enhance operator performance in telepresence environments (Vol. 2057, pp. 10-21). http://doi.org/10.1117/12.164901

Rovelo, G., Abad, F., Juan, M. C., \& Camahort, E. (2015). Studying the User Experience with a Multimodal Pedestrian Navigation Assistant (pp. 1-8). Presentado en Computer Graphics Theory and Applications (GRAPP) 2015, Berlin. Recuperado a partir de https://doclib.uhasselt.be/dspace/handle/1942/18335

Rubino, D. (2009, enero 3). GPS vs. aGPS: A Quick Tutorial. Recuperado 3 de marzo de 2016, a partir de http://www.windowscentral.com/gps-vs-agps-quick-tutorial

Ruiz Olabuénaga, J. I. (2012). Metodología de la investigación cualitativa (1a. reimp. de la 5a. ed). Bilbao: Universidad de Deusto.

Ruiz Torres, D. (2013). La realidad aumentada y su aplicación en el patrimonio cultural. Gijón: Trea. 
Rychen, D., \& Salganik, L. H. (2006). Las competencias clave para el bienestar personal, económico y social. (J. M. Pomares Olivares, Trad.). Granada; Archidona, Málaga: Aljibe.

Sagan, C. (1982). Cosmos. Barcelona: Planeta.

Sánchez Cabana, A. (2011). Ponencia La realidad aumentada. Una experiencia real. Recuperado a partir de https://www.youtube.com/watch?v=XojvqauJyNg\&feature=youtube_gdata_ player

Sánchez Prieto, J. C., Olmos Migueláñez, S., \& García Peñalvo, F. (2013). Mobile Learning: Tendencies and Lines of Research. En Proceedings of the First International Conference on Technological Ecosystem for Enhancing Multiculturality (pp. 473-480). New York, NY, USA: ACM. http://doi.org/10.1145/2536536.2536609

Sánchez Prieto, J. C., Olmos Migueláñez, S., \& García Peñalvo, F. (2014). Understanding mobile learning: devices, pedagogical implications and research lines. Teoría de la Educación: Educación y Cultura en la Sociedad de la Información, 15(1), 20-42.

Sandelowski, M., Voils, C. I., \& Barroso, J. (2006). Defining and Designing Mixed Research Synthesis Studies. Research in the schools : a nationally refereed journal sponsored by the Mid-South Educational Research Association and the University of Alabama, 13(1), 29.

Santisteban, A., \& Pagès, J. (2011a). Enseñar y Aprender Ciencias Sociales. En A. Santisteban \& J. Pagès (Eds.), Didáctica del Conocimiento Social y Cultural en la Educación Primaria: Ciencias Sociales para comprender, pensar y actuar (pp. 23-39). Madrid: Síntesis.

Santisteban, A., \& Pagès, J. (2011b). Enseñar y aprender el tiempo histórico. En A. Santisteban \& J. Pagès (Eds.), Didáctica del Conocimiento Social y Cultural en la Educación Primaria: Ciencias Sociales para comprender, pensar y actuar (pp. 229-245). Madrid: Síntesis.

Santos, M. E. C., Chen, A., Terawaki, M., Yamamoto, G., Taketomi, T., Miyazaki, J., \& 
Kato, H. (2013). Augmented Reality X-Ray Interaction in K-12 Education: Theory, Student Perception and Teacher Evaluation. En 2013 IEEE 13th International Conference on Advanced Learning Technologies (ICALT) (pp. 141-145). http://doi.org/10.1109/ICALT.2013.45

Santos Preciado, J. M. (2012). La enseñanza virtual de los sistemas de información geográfica (SIG) en la Universidad Nacional de Educación a Distancia (UNED). Acomodación al marco del espacio europeo de educación superior (EEES). Espacio Tiempo y Forma., Serie VI(4-5), 83-100. http://doi.org/http://dx.doi.org/10.5944/etfvi.4-5.2011.13724

Sarjakoski, T., \& Nivala, A.-M. (2005). Adaptation to context - A way to improve the usability of mobile maps. En L. Meng, T. Reichenbacher, \& A. Zipf (Eds.), Map-based Mobile Services. Theories, Methods and Implementations. (pp. 107-123). Berlin/Heidelberg: Springer-Verlag. Recuperado a partir de http://link.springer.com/10.1007/b138407

Scharl, A. (2007). Towards the Geospatial Web: Media Platforms for Managing Geotagged Knowledge Repositories. En K. Tochtermann \& A. Scharl (Eds.), The Geospatial Web: How Geobrowsers, Social Software and the Web 2.0 are Shaping the Network Society (pp. 3-14). Londres: Springer.

Schmalstieg, D., Langlotz, T., \& Billinghurst, M. (2011). Augmented Reality 2.0. En G. Brunnett, S. Coquillart, \& G. Welch (Eds.), Virtual Realities (pp. 13-37). Springer Vienna. Recuperado a partir de http://link.springer.com/chapter/10.1007/978-3-211-99178-7_2

Secretaría de Planificación de Transporte. (2012). Ortofotomosaico Gran Santiago.

Ortofotografía, Santiago de Chile. Recuperado a partir de http://www.sectra.gob.cl/datos_informacion_espacial/metropolitana/santiago 01.htm

Sengupta, S. (2007). Geographical Information System Concepts And Business Opportunities. Concept Publishing Company.

Sessano, P., \& Corbetta, S. (2015). Educación Ambiental y TIC. Orientaciones para la enseñanza. Buenos Aires: Programa Nacional Conectar Igualdad- ANSES. Recuperado a partir de 
http://www.fundacionluminis.org.ar/biblioteca/educacion-ambiental-y-ticorientaciones-para-la-ensenanza

Sevtsuk, A., \& Mekonnen, M. (2012). Urban network analysis. A new toolbox for ArcGIS. Revue Internationale de Géomatique, 222(2), 287-305.

Sharples, M., Corlett, D., \& Westmancott, O. (2002). The Design and Implementation of a Mobile Learning Resource. Personal and Ubiquitous Computing, 6(3), 220234. http://doi.org/10.1007/s007790200021

She, B., Zhu, X., Ye, X., Guo, W., Su, K., \& Lee, J. (2015). Weighted network Voronoi Diagrams for local spatial analysis. Computers, Environment and Urban Systems, 52, 70-80. http://doi.org/10.1016/j.compenvurbsys.2015.03.005

Shekhar, S., Feiner, S., \& Aref, W. (2016). Spatial computing. Magazine Communications of the ACM, 59(1), 72-81. http://doi.org/10.1145/2756547

Shelton, B. E., \& Stevens, R. R. (2004). Using Coordination Classes to Interpret Conceptual Change in Astronomical Thinking. En Proceedings of the 6th International Conference on Learning Sciences (pp. 634-634). Santa Monica, California: International Society of the Learning Sciences. Recuperado a partir de http://dl.acm.org/citation.cfm?id=1149126.1149258

Sherman, W. R., \& Craig, A. B. (2002). Understanding Virtual Reality: Interface, Application, and Design (Edición: Revised, Update.). Amsterdam; Boston: Morgan Kaufmann.

Shulman, L. S. (1986). Those Who Understand: Knowledge Growth in Teaching. Educational Researcher, 15(2), 4-14. http://doi.org/10.3102/0013189X015002004

Sicilia, M.-A., \& Garcia, E. (2003). On the Concepts of Usability and Reusability of Learning Objects. The International Review of Research in Open and Distributed Learning, 4(2). Recuperado a partir de http://www.irrodl.org/index.php/irrodl/article/view/155

Siegel, S., \& Castellan, J. (2009). Estadística no paramétrica: aplicada a las ciencias de la conducta (4. ${ }^{\mathrm{a}}$ ed.). México: Trillas. 
Smith, C. (2013, septiembre 5). Google+ Is The Fourth Most-Used Smartphone App.

Recuperado 29 de febrero de 2016, a partir de

http://www.businessinsider.com/google-smartphone-app-popularity-2013-9

Squire, K., \& Klopfer, E. (2007). Augmented Reality Simulations on Handheld Computers. Journal of the Learning Sciences, 16(3), 371-413.

http://doi.org/10.1080/10508400701413435

Stobbing, C. (2015, septiembre 29). The New Apple Maps vs. Google Maps: Which is Right For You? Recuperado 29 de febrero de 2016, a partir de http://www.howtogeek.com/229945/the-new-apple-maps-vs.-google-mapswhich-is-right-for-you/

Stošić, L., \& Stošić, I. (2015). Perceptions of teachers regarding the implementation of the internet in education. Computers in Human Behavior, 53, 462-468. http://doi.org/10.1016/j.chb.2015.07.027

Strahler, A. N., \& Strahler, A. H. (2000). Geografía física (3a ed., 3a. reimp). Barcelona: Omega.

Strobl, J. (2014). Technological Foundations for the GISociety. En E. Sanchez, I. Gryl, \& T. Jekel (Eds.), Learning and Teaching with Geomedia (pp. 1-9). Newcastle, UK: Cambridge Scholars Publishing.

Sturm, C. (2012, agosto 6). Visita la primera página web del mundo, creada hace más de 20 años [blog de tecnología]. Recuperado 27 de octubre de 2015, a partir de https://www.fayerwayer.com/2012/08/visita-la-primera-pagina-web-delmundo-creada-hace-mas-de-20-anos/

Suazo, A. (2008). Realidad aumentada sobre web y vídeo en tiempo real: Plataforma de trabajo colaborativo para asistir al diseño arquitectónico. En Congreso SIGraDI (Vol. 14). La Habana. Recuperado a partir de http://cumincades.scix.net/data/works/att/sigradi2008_161.content.pdf

Suchman, L. (2006). Human-Machine Reconfigurations: Plans and Situated Actions (2 edition). Cambridge; New York: Cambridge University Press.

Summerfield, J. (2012). Mobile Website vs Mobile App (Application): Which is Best for 
Your Organization. Recuperado 16 de febrero de 2016, a partir de http://www.hswsolutions.com/services/mobile-web-development/mobilewebsite-vs-apps/

Sunkel, G., Trucco, D., \& Espejo, Á. (2013). La integración de las tecnologías digitales en las escuelas de América Latina y el Caribe: una mirada multidimensional. Santiago de Chile: Comisión Económica para América Latina y el Caribe (CEPAL).

Surry, D. W., \& Ely, D. P. (2001). Adoption, diffusion, implementation, and institutionalization of educational innovations. Trends \& issues in instructional design and technology, 183-193.

Sutherland, I. E. (1968). A head-mounted three dimensional display. En Proceedings of the December 9-11, 1968, fall joint computer conference, part I (pp. 757764). ACM. Recuperado a partir de http://dl.acm.org/citation.cfm?id=1476686

Szymczak, D., Magnusson, C., \& Rassmus-Gröhn, K. (2012). Guiding Tourists through Haptic Interaction: Vibration Feedback in the Lund Time Machine. En P. Isokoski \& J. Springare (Eds.), Haptics: Perception, Devices, Mobility, and Communication (pp. 157-162). Springer Berlin Heidelberg. Recuperado a partir de http://link.springer.com/chapter/10.1007/978-3-642-31404-9_27

Tapiador, F. (2006). Las Tecnologías de Información Geográfica: Criticando al Crítico. Una respuesta a Horacio Capel. Revista Bibliográfica de Geografía y Ciencias Sociales, 10646). Recuperado a partir de http://www.ub.es/geocrit/b3w646.htm

Tavera Momphotez, E. D. (2013, octubre 21). Desarrollo del producto multimedial como apoyo a la enseñanza a través de un módulo básico sobre sistemas de información geográfica -SIG-. Recuperado a partir de http://ridum.umanizales.edu.co:8080/xmlui/handle/6789/431

Taylor, D. R. F. (2005). The theory and practice of cybercartography: An introduction. En D. R. F. Taylor (Ed.), Modern Cartography Series (Vol. 4, pp. 1-13). Academic Press. Recuperado a partir de http://www.sciencedirect.com/science/article/pii/S1363081405800048 
Taylor, D. R. F., \& Caquard, S. (2006). Cybercartography: Maps and Mapping in the Information Era. Cartographica: The International Journal for Geographic Information and Geovisualization, 41(1), 1-6. http://doi.org/10.3138/U63137K3-3NL6-4136

Taylor, S., \& Procter, T. (2014). iPads as collaborative tools to enhance biological identification skills in the lab and field. En N. Souleles \& C. Pillar (Eds.), iPad use in fieldwork: Proceedings of the 1st International Conference on the use of iPads in higher education (ihe2014) (pp. 24-30). Cambridge Scholars Publishing. Recuperado a partir de http://centaur.reading.ac.uk/38078/

Thomas, B., Close, B., Donoghue, J., Squires, J., De Bondi, P., Morris, M., \& Piekarski, W. (2000). ARQuake: An Outdoor/Indoor Augmented Reality First Person Application (pp. 139-146). Presentado en 4th International Symposium on Wearable Computers, Atlanta, GA. Recuperado a partir de http://www.tinmith.net/papers/thomas-iswc-2000.pdf

Thrower, N. J. W. (1996). Longitude in the Context of Cartography. En W. J. H. Andrewes (Ed.), The Quest for Longitude: The Proceedings of the Longitude Symposium, Harvard University, Cambridge, Massachusetts, November 4-6, 1993 (pp. 50-62). Collection of Historical Scientific Instruments, Harvard University.

Thrower, N. J. W. (2002). Mapas y civilización: historia de la cartografía en su contexto cultural y social. Barcelona: Ediciones del Serbal.

Tobón, S., Pimienta, J. H., \& García, J. A. (2010). Secuencias didácticas: aprendizaje y evaluación de competencias. México: Pearson Educación de México.

Tomlinson, R. (2008). Pensando en el SIG: Planificación del Sistema de Información Geográfica dirigida a Gerentes. Redlands (California): Esri Pr.

Traxler, J. (2009). Current state of mobile learning. En M. Ally (Ed.), Mobile Learning: Transforming the Delivery of Education and Training (pp. 9-25). Edmonton: Athabasca University Press.

Trinder, J. (2015). Characteristics of New Generation of Digital Aerial Cameras. Recuperado 5 de mayo de 2015, a partir de 
http://geospatialworld.net/Paper/Technology/ArticleView.aspx?aid=2238

Trullier, O., Wiener, S., Berthoz, A., \& Meyer, J. (1997). Biological-based artificial navigation sytems: Review and prospects. Progress in Neurobiology, 51(5), 483-544. http://doi.org/10.1016/S0301-0082(96)00060-3

UNESCO Institute for Information Technologies in Education. (2000). Internet in education. Support materials for educators. Moscú: Organización de las Naciones Unidas para la Educación, la Ciencia y la Cultura (UNESCO). Recuperado a partir de http://iite.unesco.org/pics/publications../en/files/3214612.pdf

United States Geological Service. (2013). [Región Metropolitana, Santiago de Chile. Shuttle Radar Topography Mission]. archivo. bil. Recuperado a partir de https://ta.cr.usgs.gov/SRTM2

United States Geological Service. (2014). [Castilla y Léon, Salamanca. Shuttle Radar Topography Mission]. archivo. bil. Recuperado a partir de https://lta.cr.usgs.gov/SRTM2

Valle, J. (2011). Acciones de la Unión Europea en materia de innovación educativa. En Ministerio de Educación España (Ed.), Estudio sobre la innovación educativa en España (Vol. 17, pp. 419-470). España: Ministerio de Educación.

Van der Merwe, P. (Ed.). (2012). Royal Observatory Greenwich Souvenir Guide (2. a ed.). Londres: Royal Museums Greenwich, NMM Enterprises Ltd. Recuperado a partir de http://www.alibris.com/search/books/isbn/9781906367510

Van Schaik, L. (2008). Spatial Intelligence: New Futures for Architecture. West Sussex: Wiley. Recuperado a partir de http://eu.wiley.com/WileyCDA/WileyTitle/productCd-047072322X.html

Vargas Jiménez, I. (2012). La entrevista en la investigación cualitativa: nuevas tendencias y retos. Revista Calidad en la Educación Superior, 3(1), 119-139.

Vela Peón, F. (2001). Un acto metodológico básico de la investigación social: la entrevista cualitativa. En M. L. Tarrés (Ed.), Observar, escuchar y comprender sobre la tradición cualitativa en la investigación social (pp. 63- 
94). México: El colegio de México, FLACSO.

Velazco Flórez, S. Y. (2013). Interoperabilidad entre plataformas heterogéneas GIS: identidad de un modelo y servicios web en la georreferenciación (Tesis doctoral). Pontificia Universidad de Salamanca, Madrid, España. Recuperado a partir de http://dialnet.unirioja.es/servlet/articulo?codigo $=4646562$

Veryard, R. (2005, septiembre 16). Demanding Change: Technology Hype Curve. Recuperado a partir de http://demandingchange.blogspot.com.es/2005/09/technology-hypecurve.html

Vignola, J., Pardo Mellado, F., \& Peris Garcia, P. (2011). Influencia de las TIC en la educación (p. 25). Valencia: SFE-Grupo de Filosofía. Recuperado a partir de http://users.dsic.upv.es/ pperis/tic.pdf

Wen, J., Deneka, A., Helton, W. S., Dünser, A., \& Billinghurst, M. (2014). Fighting Technology Dumb Down: Our Cognitive Capacity for Effortful AR Navigation Tools. En M. Kurosu (Ed.), Human-Computer Interaction. Applications and Services (Vol. 8512, pp. 525-536). Cham: Springer International Publishing. Recuperado a partir de http://link.springer.com/10.1007/978-3-319-072272_50

Whalley, B. W., France, D., Park, J. R., Mauchline, A. L., Powell, V., \& Welsch, K. (2014). iPad use in fieldwork: formal and informal use to enhance pedagogical practice in a bring your own technology world. En N. Souleles \& C. Pillar (Eds.), iPad use in fieldwork: Proceedings of the 1st International Conference on the use of iPads in higher education (ihe2014) (pp. 110-125). Cambridge Scholars Publishing. Recuperado a partir de http://centaur.reading.ac.uk/38078/

Wheeler, S. (2015, febrero 16). The Pedagogy Of John Dewey: A Summary. Recuperado 3 de noviembre de 2015, a partir de http://www.teachthought.com/learning/pedagogy-john-dewey-summary/

White, S. (2008). Diffusion of innovations theory. Framing IT and GIS Adoption. En A. J. Milson \& M. Alibrandi (Eds.), Digital Geography: Geospatial Technologies in the Social Studies Classroom (pp. 169-195). Estados Unidos: Information 
Age Publishing.

Whitten, J., \& Bentley, L. (2007). Systems Analysis and Design Methods (7. ${ }^{a}$ ed.). Boston: McGraw-Hill/Irwin.

Wiley, D. A. (2000). Connecting learning objects to instructional design theory: A definition, a metaphor, and a taxonomy. Recuperado a partir de http://reusability.org/read/chapters/wiley.doc

Winters, N. (2007). What is mobile learning. Big issues in mobile learning, 7-11.

Wood, D. (1960). Test Construction: Development and Interpretation of Achievement Tests. Ohio, Columbus: C.E. Merrill Pub. Co.

Woodward, D. (1987). Medieval Mappaemundi. En J. B. Harley \& D. Woodward (Eds.), The History of Cartography (Vol. 1). Chicago: University of Chicago Press. Recuperado a partir de http://www.press.uchicago.edu/books/HOC/index.html

Woodward, D. (1989). The Image of the Spherical Earth. Perspecta, 25, 2-15.

Yang, L. (2013). El Concepto y el Proceso de Apropiación de una Tecnología Móvil aplicada a la Práctica a la Práctica Formativa: Estudio de Caso en el CEO Miguel Delibes en Salamanca. Universidad de Salamanca, Salamanca.

Yilmaz, A., Kemec, S., SebnemDuzgun, H., \& Cakir, M. P. (2014). Cognitive Aspects of Geovisualisation: A Case Study of Active and Passive Exploration in a Virtual Environment. En T. Bandrova, M. Konecny, \& S. Zlatanova (Eds.), Thematic Cartography for the Society (pp. 157-170). Springer International Publishing. Recuperado a partir de http://link.springer.com/chapter/10.1007/978-3-31908180-9_13

Yin, R. K. (1994). Case study research: design and methods. Thousand Oaks: Sage Publications.

Yoo, H., \& Lee, J. (2015). Mobile Augmented Reality Authoring System with 3D Modeling and Lighting Estimation. Appl. Math, 9(2L), 553-562.

Zhao, X., Wan, X., \& Okamoto, T. (2010). Adaptive content delivery in ubiquitous 
learning environment. En Wireless, Mobile and Ubiquitous Technologies in Education (WMUTE), 2010 6th IEEE International Conference on (pp. 1926). IEEE. Recuperado a partir de http://ieeexplore.ieee.org/xpls/abs_all.jsp?arnumber=5476533

Zinger, J. (2014). Navegando el Hype Cycle: El Futuro de 5 Tácticas de Marketing Online. Recuperado a partir de http://www.genwords.com/blog/navegandoel-hype-cycle-el-futuro-de-5-tcticas-de-marketing-online/ 
Anexos 


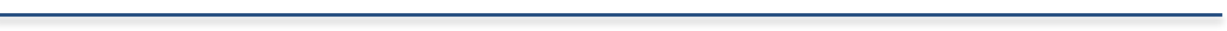




\section{ANEXOS}

Anexo 01

Anexo 02

Anexo 03

Anexo 04

Anexo 05

Anexo 06

Anexo 07

Anexo 08

Anexo 09

Anexo 10

Anexo 11

Anexo 12

Anexo 13

Anexo 14

Anexo 15
Datos de Patrimonio en Santiago de Chile

Datos de Patrimonio en Salamanca España

Comparación de SDK de Realidad Aumentada

Comparación de servicios de mapas en línea

Instrumento de Evaluación: Prueba Objetiva

Instrumento para medir el grado de satisfacción de los estudiantes.

Matriz de evaluación de la prueba objetiva de Chile, por especialistas expertos.

Matriz de evaluación de la prueba objetiva de España, por especialistas expertos.

Entrevistas a Alumnos participantes en la experiencia educativa

Entrevistas a Profesores participantes en la experiencia educativa

Registro de valores de posición, dispositivos iPad (Síntesis)

Análisis gráfico y estadístico para los valores obtenidos en la experiencia de España

Matriz de datos resultados Pre-Test/Post-Test, Chile

Matriz de datos resultados Pre-Test/Post-Test, España

Matriz de datos encuesta de satisfacción de la intervención educativa. Chile y España. 